\title{
The Beginnings of
}

\section{Embryonic Development}



DR. JOHN W. SAUNDERS.JR.

DEPARTMENT OF BYOLOGY

MARQUETTE UNIVERSITY

MILWAUKEE 3, WISCONSIN

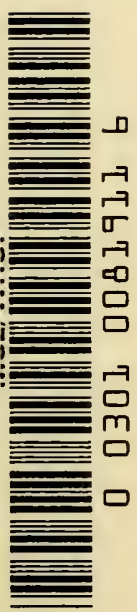





\section{The Beginnings of Embryonic Development}

A symposium organized by the Section on Zoological Sciences of the American Association for the Advancement of Science, cosponsored by the American Society of Zoologists and the Association of Southeastern Biologists, and presented at the Atlanta Meeting, December 27, 1955

\section{Edited by}

Albert Tyler, R. C. von Borstel, and Charles B. Metz

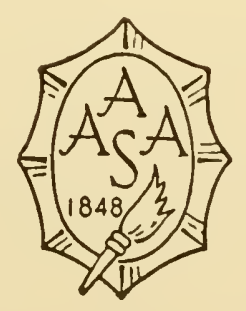

Publication No. 48 of the AMERICAN ASSOCIATION FOR THE ADVANCEMENT OF SCIENCE Washington, D. C., 1957 
(C) 1957

The American Association for the Advancement of Science

Library of Congress Catalog Card Number 57-11246

Printed in the United States of America 


\section{PREFACE}

A symposium on "Formation and Early Development of the Embryo," held December 27, 1955, at the Second Atlanta Meeting of the AAAS, served as the basis for the present volume. The symposium emphasized problems of early development and of the initiation of development. However, in selecting this general area for discussion the organizing committee did not intend to imply that the problems are considered to be fundamentally different from those encountered in later development. In fact, many of the contributions presented here indicate the generality of the problems of developmental change at any stage along with the special nature of the particular events studied. It may also be said that an understanding of early, as well as later, development depends largely on knowledge of the manner of formation of the egg, that is, of the processes that endow the oocyte, in contrast to other tissue cells, with the capacity to form a new individual. The first paper deals with one aspect of this subject which is also partly considered in some of the others. The next five papers treat principally with the initiation of development, and the remaining seven center primarily about subsequent events as related to nuclear and cytoplasmic factors.

As with most symposia the general purpose of this one was to bring together a group of individuals working in related fields so that there would be opportunity for participants and audience to profit directly from exchange of knowledge and ideas. It was also decided that the presentations be made available to others in published form.

Since the symposium was planned for a one day session, the number of speakers was correspondingly restricted. However, for the purpose of the present volume it was considered desirable that the coverage of the general field be expanded somewhat. This has been done by the inclusion of articles requested from some additional investigators, in this country and abroad, whose work pertains to the subjects under consideration. 
It will be readily recognized that the present volume comprises a selected sample, rather than a more comprehensive coverage of investigations into problems of the initial developmental changes undergone by the egg and early embryo. The investigations presented in the various communications cover both descriptive and experimental work on the biological and chemical levels. Many of the articles contain results of previously umpublished researches as well as general reviews of the particular subject.

No special attempt was made to force the contributions into a preconceived plan, or to develop an overall general concept. The interrelationships of the individual topics assured a reasonable amount of unity to the work. In addition, there was exchange of articles among some of the contributors, besides the verbal discussions at the symposium, that provided opportunity for further integration and for elimination of unnecessary repetition. The instances of overlapping that remain were considered desirable, especially where there were differences in outlook and interpretation. Although such differences reflect, in part, variations in point of view and judgment of the individual contributors, they serve mainly to emphasize the lack of critical information concerning the particular problem under discussion. In fact we consider much of the value of a work such as this to reside in the extent to which it brings to the attention of students and investigators these regions of uncertainty and indicates the kinds of problems that are in urgent need of solution, along with the modern methods by which answers may be sought.

Apart from their intrinsic interest and the measure of progress that they provide, the specific discoveries and analyses presented in this book serve, then, to exemplify various approaches toward our understanding of the manner in which sperm and egg contrive to produce a new individual.

Albert Tyler 


\section{CONTRIBUTORS}

C. R. Austin, Division of Experimental Biology, National Institute for Medical Research, Mill Hill, London, England

M. W. H. Bishop, Division of Experimental Biology, National Institute for Medical Research, Mill Hill, London, England R. C. von Bonstel, Biology Division, Oak Ridge National Laboratory, Oak Ridge, Tennessee

M. C. Chang, The Worcester Foundation for Experimental Biology, Shrewsbury, and Department of Biology, Boston University, Boston, Massachusetts

Arthur L. Colwin, Department of Biology, Queens College, Flushing, New York

Laura Hunter Colivin, Department of Biology, Queens College, Flushing, New York

John R. GregG, Department of Zoology, Columbia University, New York City, New York

H. E. Lehman, Department of Zoology, University of North Carolina, Chapel Hill, North Carolina

Charles B. Metz, Oceanographic Institute, The Florida State University, Tallahassee, Florida

Alberto Monroy, Istituto di Anatomia Comparata, Università di Palermo, Palermo, Italy

Silvio Ranzi, Istituto di Zoologia dell'Università, Milan, Italy

G. Reverberi, Istituto di Zoologia, Università di Palermo, Palermo, Italy

John R. Shaver, Department of Zoology, Michigan State University of Agriculture and Applied Science, East Lansing, Michigan

Albert Tyler, Division of Biology, California Institute of Technology, Pasadena, California

W. S. Vincent, Department of Anatomy, College of Medicine, State University of New York, Syracuse, New York 



\section{CONTENTS}

Some Studies on Differentiation and Development of the

Oocyte

W. S. Vincent

Specific Egg and Sperm Substances and Activation of the Egg

Charles B. Metz

Preliminaries to Fertilization in Mammals

C. R. Austin and M. W. H. Bishop

Some Aspects of Mammalian Fertilization

M. C. Chang

Morphology of Fertilization: Acrosome Filament Formation and Sperm Entry

Arthur L. Coliwin and laura Hunter Colwin

Studies of Proteins of Sea Urchin Egg and of Their Changes

Following Fertilization

Alberto Monroy

Nucleocytoplasmic Relations in Early Insect Development

R. C. von Bonstel

Nuclear Transplantation, a Tool for the Study of Nuclear Differentiation

H. E. Lehman

Morphogenesis and Metabolism of Gastrula-Arrested Embryos in the Hybrid Rana pipiens of $\mathrm{x}$ Rana sylvatica of

John R. GregG

Some Observations on Cytoplasmic Particles in Early

Echinoderm Development

John R. Shaver .

263

Early Determination in Development under Normal and Experimental Conditions

Silvio Ranzi 
viii CONTENTS

The Role of Some Enzymes in the Development of Ascidians

G. Reverberi

Immunological Studies of Early Development Albert Tyler Index 


\title{
SOME STUDIES ON DIFFERENTIATION AND DEVELOPMENT OF THE OOCYTE *
}

\author{
W. S. VINCENT: UPSTATE MEdCAL CENTER, \\ STATE UNIVERSITY OF NEW YORK, \\ SYRACUSE, NEWV YORK
}

When one considers the development of the oocyte, it becomes apparent that there are two general problems to be studied. One of these is the problem of the origin of the egg cell; the other, that of its later development.

The study of the origin of the primary germ cell, from which the oocyte is derived, has provoked wide interest and considerable controversy. Out of this has arisen the following questions: Is there a separate germinal plasm which gives rise to the primordial germ cells, these in turn migrating to the gonad and there forming definitive gonia; or do some or all of the definitive germ cells arise from somatic cells of the germinal epithelium? In some invertebrates it is readily observed that the functional germ cells are derived from a line of cells set apart very early in development, although in the coelenterates and annelids this early setting apart is still questionable (Berrill and Liu, 1948; Wilson, 1928). In vertebrates, and especially mammals, the evidence for the origin of the definitive germ cell from a primary cell type is far from being conclusive. Although there is general agreement that a primordial germ cell type is found, there is disagreement as to whether these cells migrate into the gonad and there eventually differentiate into mature oocytes, or whether they degen-

- Part of the work reported here was done during the tenure of a Fulbright Fellowship to Belgium. Some of the work was done at the Marine Biological Laboratory, Woods Hole, during the tenure of a Lalor Foundation Fellowship, and in addition, while supported by funds from the Atomic Energy Commission, grant AT(30-1) 1343. 
erate completely before any definitive cells are formed. In the latter case the oocyte would arise from the germinal epithelium. Some recent studies on this problem include those of Vincent and Dornfeld (1948), Everett (1945), and Jones (1949). An excellent review of the problem of germ cell origin is given by Nelsen (1953).

The other aspect of the general problem of the development of the oocyte is that of its differentiation and growth into the mature egg. For the purposes of this discussion, it is convenient to define three general areas of influence on the developing oocyte. Two of these might be called external, namely, the contributions to the developing egg cell by the surrounding circulatory fluids and the contributions to the oocyte by surrounding cells. The third area is the effects of the oocyte nucleus on the development of its own cytoplasm.

Considerable information is now available regarding the contributions of the circulatory media to the developing egg. Classically, the yolk in avian eggs has been considered to be derived from large molecules carried in the circulation (Romanoff and Romanoff, 1949). Probably the most clear-cut demonstration of the transfer of blood proteins to the egg is that of Telfer (1954). He found an albumin-like, antigenic protein present in very high quantities in the blood of female Cecropia during the pupal stage. He was then able to demonstrate conclusively that this protein was transferred to the yolk of developing egg cells. Immunological similarities between the yolk and adult blood proteins have been detected in vertebrates (Nace, 1953), and this suggests that in toto transfer of protein (or at least of specific combining sites) occurs in these forms as well. In his general review of the development of immumological properties, Tyler (1955) pointed out that there is evidence that similarities exist between blood proteins and both the ground substance and the formed elements of the egg cytoplasm. Considerable importance must be attached therefore to the contributions of the circulatory fluids to the development of the oocyte.

The effects of the surrounding cells on the oocyte are varied. 
Apparently, they must provide some of the differentiating influences that allow the presumptive oocyte to form an egg, since egg cells are not known to differentiate outside the ovary. A discussion of some of these inducing influences is given by Vincent and Dornfeld (1948). The follicle cells which surround the oocyte are usually considered to function in some positive manner during the growth of the oocyte-either by direct transfer and/or fusion of all or part of the follicle cell to the developing egg, or by acting as a transferring system for substances provided by the blood stream.

In the cases in which the accessory cells contribute directly to the substance of the oocytes, the accessory cells are known as nurse cells. At times, the egg cell and its associated nurse cells can be shown to have been the offspring of a single parent cell (see discussion in Wilson). Often the transfer of not only cytoplasm but also nuclear material is observed in the oocyte-nurse cell relationship. (For recent histochemical studies of such relationships see Schrader and Leuchtenberger, 1952.) It seems reasonable to assume that the "excess" amount of deoxyribonucleic acid found in the cytoplasm of oocytes may arise from such nuclear transfer (Zeuthen and Hoff-Jørgenson, 1952; Marshak, 1953). The nature of the cytoplasmic materials that are transferred to the egg is discussed by Schrader and Leuchtenberger. Where direct transfer of large cellular fragments is concerned, it is obvious that there does exist a mechanism for considerable modification of oocyte development by its cellular enviromment.

The existence of transferral mechanisms ascribed to the follicle cells is based primarily on inference. Inasmuch as this cellular layer is interposed between the blood stream and the egg, it has generally been assumed that the follicle cell functions in the transfer of materials to the oocyte cytoplasm. Little experimental evidence is available to confirm or deny the validity of such an assumption.

The third area of influence, that of the effects of the oocyte nucleus on its own cytoplasm, has been widely studied. The nuclear changes which accompany the growth of the oocyte are so 
striking that they have long been correlated with the cytoplasmic changes which occur. The tremendous enlargement of the nucleus, specialized modifications of chromosomal structure, and the formation of very large or very many nucleoli, have been interpreted as a reflection of nuclear intervention in cytoplasmic differentiation and growth. The many morphological studies of oocyte development have generally led to the conclusion that the nucleoli and the nucleic acid content of the nucleus play a major role in the oocyte. These studies include those of Montgomery (1898), Brachet $(1950,1955)$, Painter and Taylor (1942), Panijel (1951), and Wittek (1952).

My own cytochemical and biochiemical studies on the role of nucleoli and nucleic acids in the development of the egg are primarily concerned with ribonucleic acid (RNA). RNA has been assumed to be related to the synthetic activity of cells since the pioneering studies of Caspersson and co-workers and, independently, Brachet, in the late nineteen thirties (Brachet, 1950; Caspersson, 1950). Both of these workers believed that nuclear RNA was somehow involved in the cytoplasmic expression of genetic activity. This concept has attained new importance in a more specific way in that RNA has been repeatedly suggested as an agent which could receive genetic specificity residing in nuclear deoxyribonucleic acid and transfer this specificity to synthetic centers in the cytoplasm (Dounce, 1953; Rich and Watson, 1954; Goldstein and Plaut, 1955; Lockingen and DeBusk, 1955; Gamow and Y̌̌as, 1955).

In the experiments reviewed below, the starfish oocyte has been used in the study of nuclear RNA. These oocytes can be obtained readily in all stages of development, and in large quantities. They have a large nucleus and nucleolus, the latter of which can be isolated in considerable quantity. In addition, the nucleolus of the starfish oocyte appears to contain all the RNA of the nucleus (Vincent, 1952). By combining qualitative and quantitative histochemistry with direct chemical analyses of isolated nucleoli, it has been possible to study certain aspects of RNA metabolism in the starfish oocyte as it relates to the functional activities of this cell. 


\section{Growth of the Starfish Oocyte}

In order to relate some of the chemical changes observed in the nucleolus to oocyte growth, it was necessary to determine the size relationships of the nucleolus, nucleus, and cytoplasm of the starfish oocyte. The relationship between nucleus and cytoplasm in the starfish oocyte follows a rigid pattern during growth.

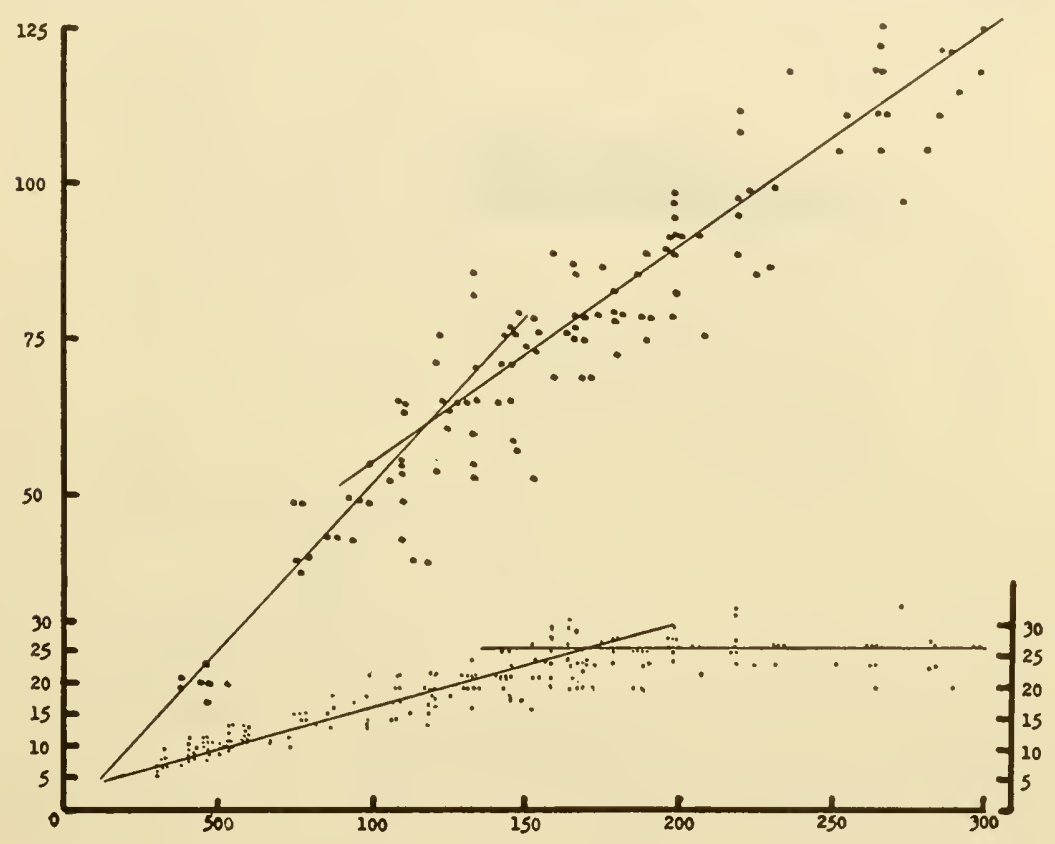

Fig. 1. Diameter of Asterias rubens nuclei (large dots) and nucleoli (small dots) plotted against oocyte diameter. Ordinate: diameter of nucleolus or nucleus; abscissa: oocyte diameter in microns.

Since I have been unable to determine an exact time scale for the growth of the oocyte, changes in size of the nucleus and nucleolus are plotted against oocyte diameter (Fig. 1). The relationship shown here seems to be a general one for oocytes, as similar growth curves are found in amphibians (Gall, 1955) and in rats (Vincent, unpublished data). The volume of nucleus and cytoplasm increases proportionately until the oocyte reaches about one-half its mature size (Fig. 2). At this time the rate of cyto- 


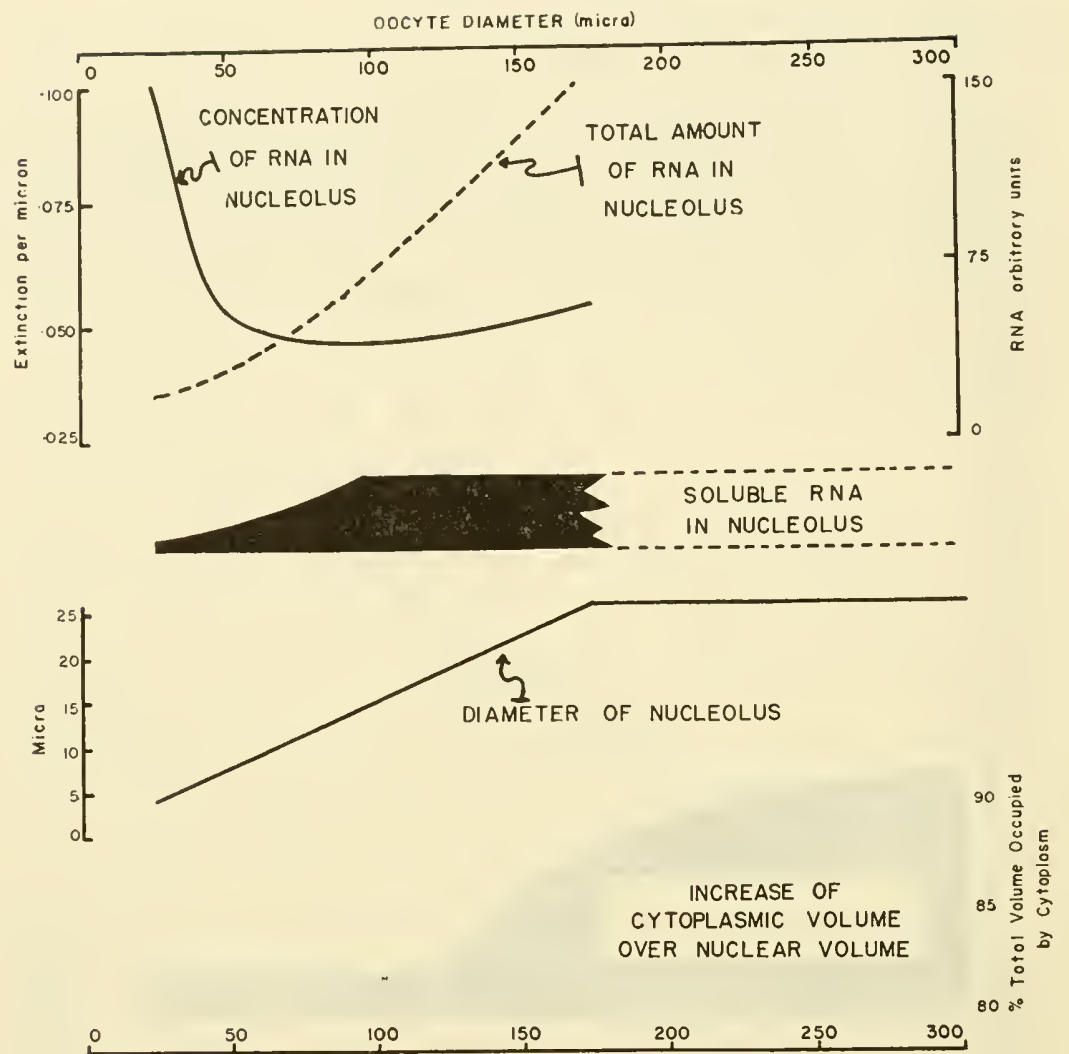

OOCYTE DIAMETER (micra)

Fig. 2. A comparison of some of the changes in nucleolar RNA and the growth of the oocyte. (Data from Figs. 1 and 3.)

plasmic contribution to cell size increases markedly. This is indicated by the break in the slope of the curve for the nucleus in Fig. 1. The diameters of the nucleolus and the oocyte increase proportionately until the latter attains about one-half its mature size, when all growth ceases (curve for the nucleolus in Fig. 1).

\section{RNA Content of Individual Nucleoli}

Some measurements on the RNA content and concentration of individual nucleoli are pertinent in this regard. The ultraviolet absorption of nucleoli isolated in clistilled water was compared 
with the absorption of nucleoli which had been fixed in formalin prior to measurement. The RNA was then removed with hot perchloric acid and the absorption of nucleoli was remeasured. The latter value was taken as the nonspecific absorption and was subtracted from the total absorption of the nucleolus; the difference was considered to be due to the RNA present. The results are shown in Fig. 3 in which the upper curve indicates the amount of RNA in formalin fixed nucleoli and the lower curve, the values

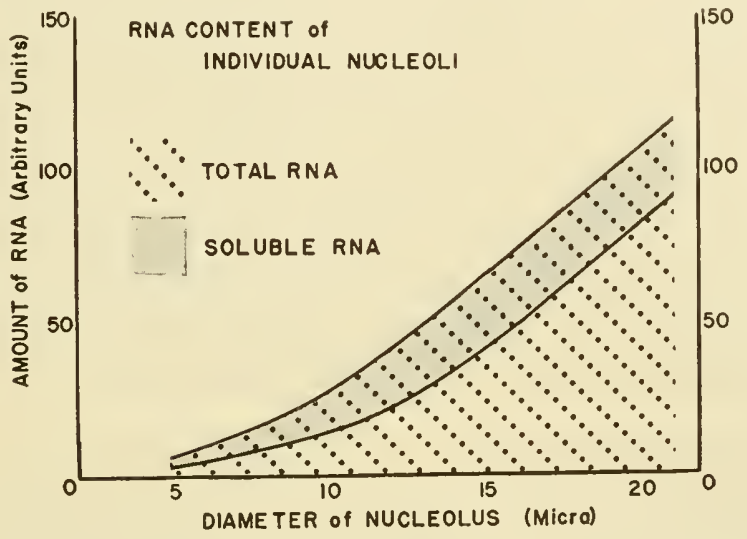

Fig. 3. RNA content of individual Asterias rubens nucleoli fixed in formalin (dotted and shaded area) and nucleoli isolated in distilled water (dotted area only). Measurements were made with a microphotometer after Lison (1950) employing Beck reflecting objective and condenser N.A. $0.65,10 \times$ quartz ocular. Light source: 2537 A. line of low pressure mercury lamp.

obtained from nucleoli isolated in distilled water. The difference between the two curves (shaded in the figure) is of interest. First, it indicates that there is less RNA in isolated nucleoli than in fixed nucleoli of the same size. Second, the pattern of difference in RNA content is proportional to the total amount present until the diameter of the nucleolus reaches about 12 microns. Beyond this, the difference between the two remains a constant value. A possible interpretation of this change will be discussed below. The differences in RNA content found in this experiment complement the radiophosphorus studies, suggesting again that starfish 


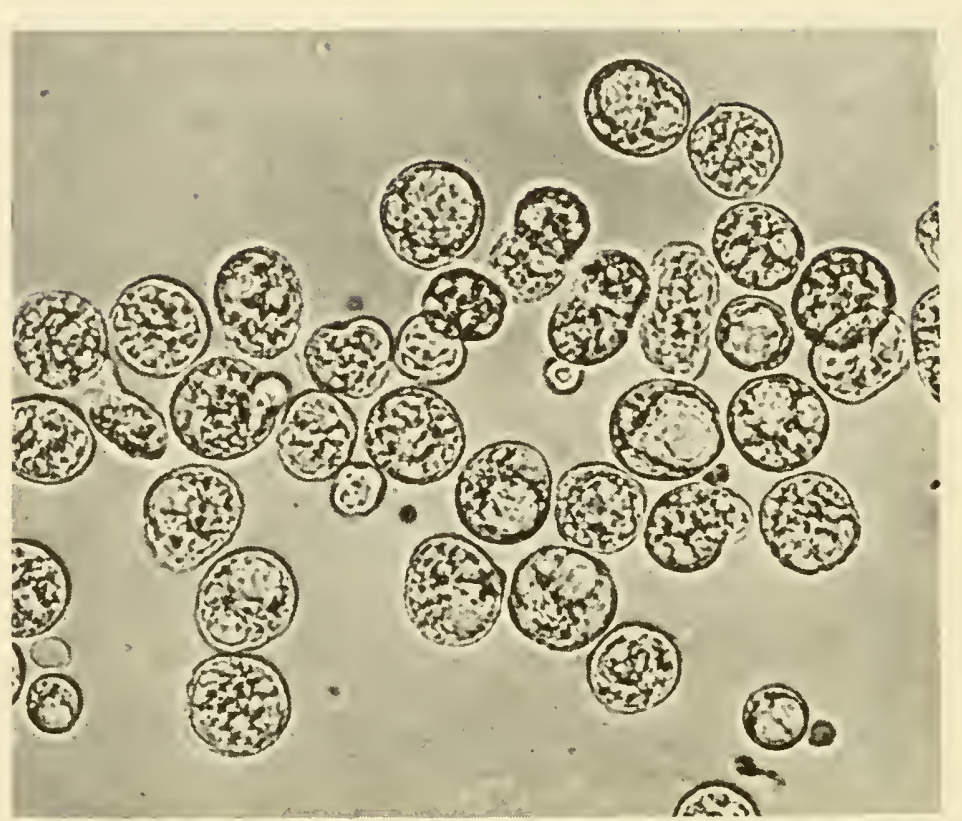

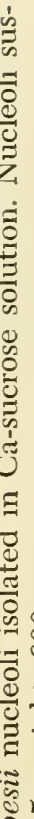
(3) -

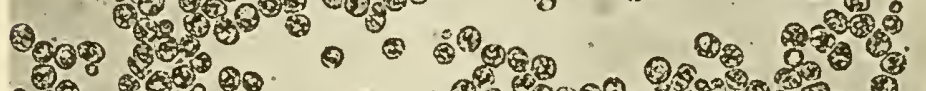
- .8 60.

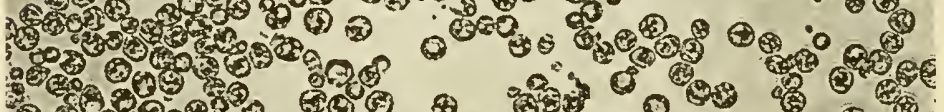
1. 2003

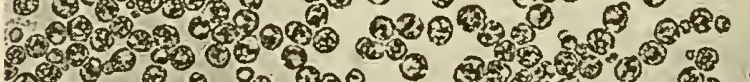$$
\text { 西 }
$$
3. 3.

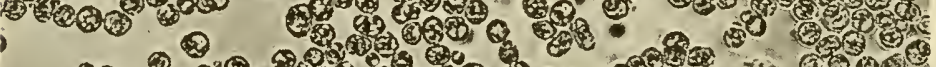

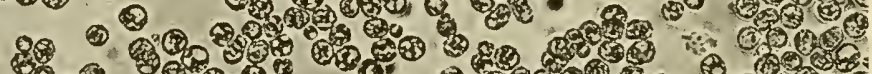

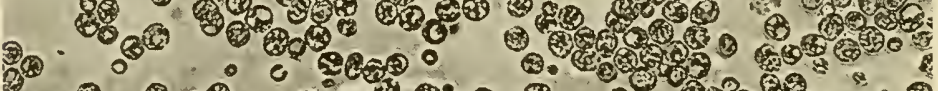

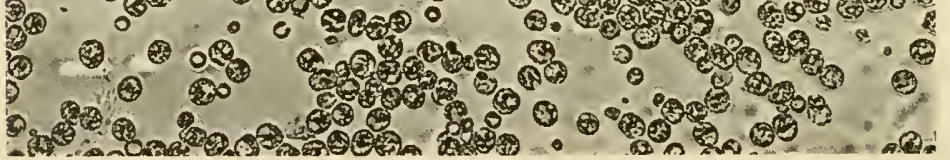
인 $+5$ 马े 니 물 $\rightarrow$ ․ㅛ पै. हี 독

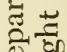
Di: $4 \frac{0}{0}$ ह $\pi$ कo ठำ है क 군 के ○ म․ xio 我 
nucleoli possess a RNA fraction which is readily soluble in distilled water.

A summary of some of the data on nucleolar RNA is given in Fig. 2. Here the data are plotted against oocyte diameter and related to the changes in cytoplasmic volume which are shown on the lower part of the figure. In general, one finds that the oocyte enters a new phase of activity at about 100 microns, with the onset of rapid cytoplasmic growth. This can be attributed to the synthesis of yolk proteins. This new phase of activity is reflected also in a drop in cytoplasmic RNA concentration not shown here, but readily apparent on slides stained with basic dyes. Such a cytoplasmic picture is typical of oocytes (Vincent and Dornfeld, 1948; Brachet, 1950; Panijel, 1951; Dalcq and Van Egmond, 1953). The nucleolar changes which precede cytoplasmic synthesis are of considerable interest (Fig. 2). In general one finds a shifting from curvilinear to linear relationships. RNA concentration drops very rapidly during early growth of the oocyte, but with the onset of the production of constant amounts of soluble RNA, maintains a constant concentration, although the nucleolus continues to grow. The nucleolus stops growing shortly after the onset of yolk deposition.

\section{RNA Metabolism in Starfish Oocytes}

By studying isolated nucleoli it has been possible to obtain some information about the metabolism of RNA in the oocyte nucleus. The advantages of working with pure preparations of isolated cell organelles are well known, and therefore a technique was developed whereby nucleoli could be isolated in quantity from starfish oocytes (Vincent, 1952). Distilled water was used as an isolation medium. Baltus (1954) reported that a modified technique in which sugar solutions of high density were used gave greater biochemical integrity than the distilled water medium. The technique was tedious and the yield low, however. The results and interpretations reported below are based primarily on studies carried out on nucleoli isolated in a Ca-sucrose medium. This process was developed when it became apparent that RNA was lost from the nucleoli into the distilled water iso- 
lation medium. This isolation procedure was modified from the technique of Hogeboom et al. (1952) for the isolation of mammalian cell fractions. I am indebted to Dr. Alfred Marshak for his suggestion to use this medium in the isolation of oocyte nucleoli. The nature of these preparations is indicated in Fig. 4.

Chemical Properties of Nucleoli. Some of the gross chemical properties of the starfish nucleolus are given in Table I.

TABLE I. Chemical Properties of Isolated Nucleoli

\begin{tabular}{|c|c|c|c|}
\hline \multicolumn{2}{|c|}{ Constituent, \% } & \multicolumn{2}{|l|}{ Enzymatic activity } \\
\hline $\mathrm{RNA}$ & $2.2-4.6^{a}$ & Guanase & -6 \\
\hline & $5^{b}$ & Adenosine deaminase & $-b$ \\
\hline & $3.15-5.6^{c}$ & Nucleoside phosphorylase & $+t^{b}$ \\
\hline Adenylic acid (5) & Trace $a . b$ & DPN synthetase & $t+b$ \\
\hline $\mathrm{DNA}$ & Undetectable $^{a, b, c}$ & Dipepticlase & $-a$ \\
\hline \multirow{2}{*}{ Phosphorus } & $1.1^{a}$ & DPN reductase & $-a$ \\
\hline & $0.6-1.3^{c}$ & Alkaline phosphatase & $-^{a}$ \\
\hline Nitrogen & $16-20^{a}$ & Acid phosphatase & $? ?^{a}$ \\
\hline Calcium & Absent ${ }^{d}$ & Ribonuclease & $-d$ \\
\hline Dry matter & $40-90^{e}$ & & \\
\hline
\end{tabular}

${ }^{a}$ Vincent, 1952 .

${ }^{d}$ Vineent, $1955 \mathrm{a}$.

${ }^{b}$ Baltus, 1954 .

e Vincent and Huxley, 1954.

c Present communication.

RNA Content of Nucleoli. The RNA concentration of nucleoli from two species of starfish, Asterias forbesii and A. rubens, appears to be about the same, averaging about $4 \%$ in each case. Baltus (1954) found about 5\% RNA in sucrose isolated nucleoli of $A$. rubens where the author had found an average of $3.6 \%$ in the same species when isolated in distilled water. As shown below, no significant differences were found in the concentration of RNA in A. forbesii nucleoli isolated in either distilled water or the modified sucrose medium presented above. Changes of concentration and total content of RNA of individual A. rubens nucleoli during growth of the oocyte are presented in Figs. 2 and 3. The base content of the RNA of nucleoli and cytoplasmic granules from A. rubens is shown in Fig. 5 (data recalculated from Vincent, 1952). Significant differences are found in both guanine 
and uracil content between nucleolus and cytoplasm. Of interest here is the fact that the purine-pyrimidine ratio of the cytoplasmic RNA is $1: 1$, while the nucleolar RNA varies considerably from this ratio. The cytoplasmic RNA of animals generally seems to follow the pattern found in the starfish of high guanine and cytosine values, and a purine-pyrimidine relationship of unity. Nuclear RNA's, on the other hand, depart from this relationship (Elson and Chargaff, 1954).

Raclioisotope Studies on Nuclear RNA. Numerous reports of

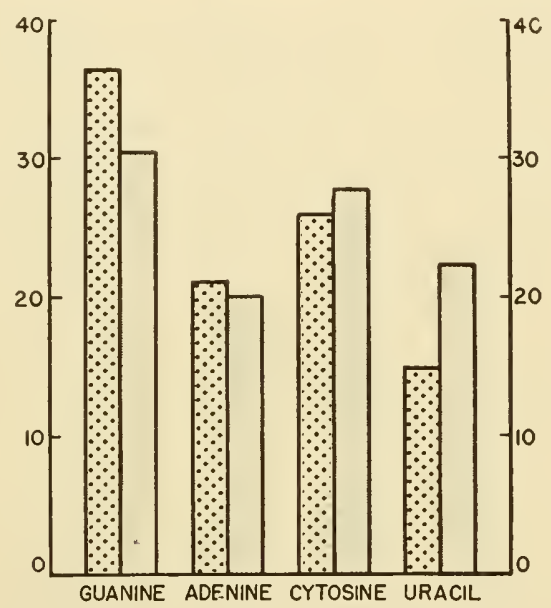

Fig. 5. Moles of nitrogenous base per 100 moles of phosphorus in RNA isolated from Asterias rubens nucleoli (dotted) and cytoplasmic granules (shaded). (Recalculated from Vincent, 1952.)

rapid synthesis of RNA by nuclei have appeared in the last few years (see Smellie, 1955, for review). I have carried out a series of studies on the metabolism of RNA in the starfish oocyte in which radiophosphorus was used as the tracer element. The ovaries of the starfish are removed, the gonoducts are tied off and then placed in filtered sea water containing inorganic $\mathrm{P}^{32}$ at appropriate levels. The usual dosage has been about 0.25 microcurie of $\mathrm{P}^{32}$ per milliliter of sea water. After exposure for appropriate intervals, the ovaries are removed, washed thoroughly in filtered sea water, and the nucleoli and other fractions are isolated. Some 
preliminary reports of these experiments have appeared (Vincent, 1954, 1955a,b).

When ovaries of $A$. forbesii were exposed to $\mathrm{P}^{32}$ at the dose indicated above for periods up to 8 hours at $23^{\circ} \mathrm{C}$. and the nucleoli were isolated by the distilled water technique, the uptake of radiophosphorus was linear with time (see Fig. 6). As well, $\mathrm{P}^{32}$ was incorporated into nucleolar RNA at about the same, or at a lower, relative rate than it was incorporated into the cytoplasmic RNA. This relation changes little during the time intervals studied (Fig. 7A).

The radioautographic studies of Taylor (1953) and Ficq (1953) appeared just after the experiments in Figs. 6 and 7 were completed. These workers found that the nucleolus incorporated radioisotope into RNA up to 100 times more rapidly than the cytoplasm. In the light of these reports, the experiment described above was repeated in conjunction with a radioautographic control as follows. Ovaries were exposed for 6 hours to sea water containing 0.25 microcurie of $\mathrm{P}^{32}$ per milliliter. At the end of this time the ovaries were washed thoroughly, a small piece of tissue was fixed in formalin and processed for radioautography, and the nucleoli were isolated from the remainder of the tissue by the distilled water technique. The relative specific activity of the RNA extracted from the isolated nucleoli and cytoplasm was found to be near unity; this is in agreement with the previous experiments. However, the radioautographs prepared from the fixed tissue indicated a much more rapid uptake of $\mathrm{P}^{32}$ by nucleolar RNA, in agreement with the results of the other workers. This experiment indicated that considerable radioactivity incorporated into RNA was lost during isolation. Further demonstration of loss of radioactivity from the nucleoli during isolation was obtained by smearing the homogenates of the oocytes on nuclear track plates (Kodak NTB-1) at various steps of the isolation procedure. The nucleoli present in the fresh homogenates gave intense blackening of the plate, whereas only a few dozen reduced silver grains were found under the isolated nucleoli. These results indicated a considerable loss of radioactivity from nucleoli during isolation in the distilled water medium. 
The sucrose procedure mentioned above was then developed in an attempt to maintain a higher integrity in the isolated nucleoli. The results of the experiments after isolation in sucrose media are compared with the results obtained in pure water isolation in Figs. 6 and 7. The results obtained from these studies compare favorably with those obtained by Ficq $(1953,1955)$ in radioautographic studies of starfish nucleoli. Ficq, using a value of $10 \%$ RNA for cytoplasm, calculated a relative specific activity of nucleolar RNA of $100 \times$ that of the cytoplasm. This value, taken

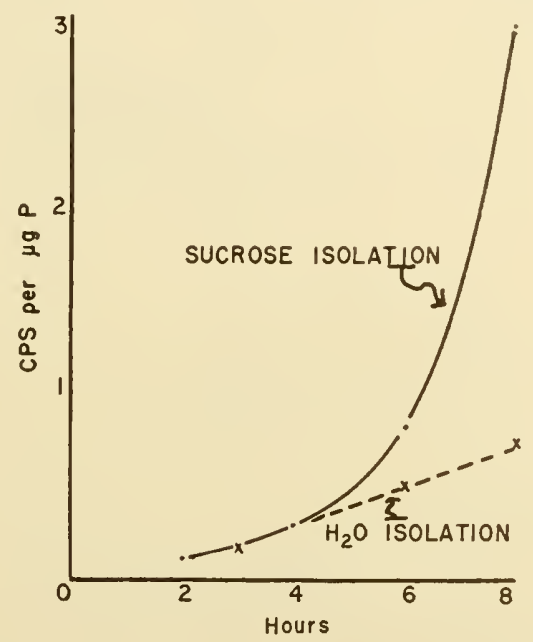

Fig. 6. Specific activity of nucleolar phosphorus after isolation in distilled water and in $\mathrm{Ca}$-sucrose solutions.

from Vincent (1952), was for the mixed mitochondrial-microsome granules of the oocyte cytoplasm. Actual values found for RNA concentration of acetone-dried starfish cytoplasm average $1.7 \%$ (range $1.1 \%-2.5 \%$ ). Ficq's value of $100 \times$ should thus be reduced by a factor of at least 5 , which brings the values found by radioautography into reasonable agreement with those found by direct analyses of isolated nucleoli.

These data are in agreement with the findings of other workers that nuclear RNA appears to accumulate radiophosphorus more rapidly than cytoplasmic RNA. If one examines the distribution 
of recovered isotope within the nucleolus and cytoplasm a more striking picture appears. As shown in Fig. 7B, at 2 hours, $75 \%$ of the total radiophosphorus present in the nucleolus is in the RNA fraction. A more extensive analysis of the time distribution of radiophosphorus in nucleoli is in progress, but the very high proportion of radiophosphorus present in the RNA fraction at the
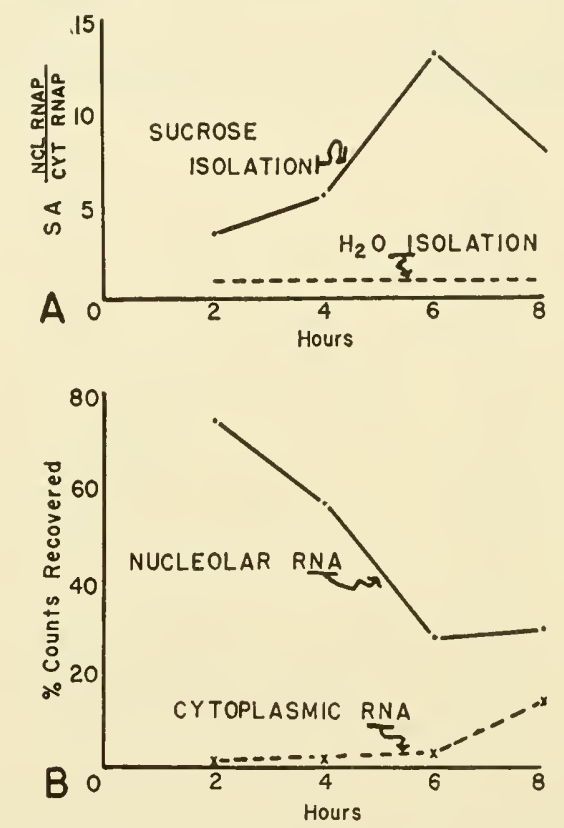

Fig. 7. A. Comparison of relative specific activities of nucleolar and cytoplasmic RNA when nucleoli were isolated in Ca-sucrose (solid line) and in distilled water (dashed line). B. Per cent of total counts recovered from nucleoli and from cytoplasm which was found in the RNA fraction.

short time interval strongly suggests that RNA synthesis occurs in, or immediately adjacent to, the nucleolus.

Another fact which has emerged from these studies on isolated nucleoli is that the RNA concentration ( $3.6 \%$ for $\mathrm{H}_{2} \mathrm{O}, 3.9 \%$ for sucrose, range identical) is not significantly different in the nucleoli isolated by the two clifferent techniques, although very significant differences in radioactivity of RNA in the two different preparations are apparent. 
The possibility exists that the higher isotope content of nucleolar RNA is due to contamination by a small fraction of highly active material other than RNA. Although such a possibility has not been totally eliminated, the procedure used for extraction of RNA (Vincent, 1952) has been highly satisfactory in giving very good separation of this compound. Ultraviolet absorption measurements and direct phosphorus determination have been made in every case. The two types of preparations are handled in identical fashion, but agreement between the two has been found to be within the limits of experimental error. This procedure includes thorough washing in cold $0.1 \mathrm{~N} \mathrm{HCl}$ and 60 minutes refluxing in boiling alcohol-ether prior to extraction of RNA in hot $N$ acid. On the basis of these considerations it seems likely that the increased activity present in sucrose nucleoli must be present in a small fraction of the RNA. This fraction is apparently lost in the distilled water media.

Structural and Soluble RNA. The data given here are interpreted as follows. The nucleolus of the starfish oocyte contains at least two types of RNA. One type is bound to the nucleolar structure and has been characterized thus: it is most of the RNA present in the nucleolus; it is resistant to removal by water solutions; its base ratio differs from the cytoplasmic RNA in guanine and uracil content; it is metabolically relatively inactive. This is called structural RNA. The other RNA is characterized primarily from inference. It appears to be soluble in distilled water; to be produced in amounts related to cytoplasmic synthetic activities; and to be synthesized at a rapid rate, in that it contains nearly all the label in isotope experiments. Its base composition is as yet unknown. This RNA fraction has been designated soluble RNA. (See Vincent, 1955a, for a more extensive discussion of nucleolar RNA.)

\section{Functions of Nuclear RNA}

I should like to suggest some possible functions for these RNA fractions. The nucleolus contains the highest concentration of dry matter (predominantly protein) of any cell structure (Vincent, 1955a). A suggested role for the structural RNA is that it precip- 
itates nuclear proteins, and aids in bringing about this very dehydrated state. The soluble RNA, produced at a rapid rate and being quite soluble, is apparently passed to the cytoplasm. Its appearance and amount suggest that it is intimately associated with protein synthesis. These qualities are those required of a material which could transfer genetic specificity to the cytoplasm.

The data given here will not distinguish between the two alternatives, (a) RNA is synthesized within the nucleolus, and (b) RNA is synthesized elsewhere in the nucleus and specifically accumulated by the nucleolus. The paper of Taylor et al. (1955) offers a possible answer to this problem, at least in the material which they used (Drosophila). They found that with high resolution radioautographs $\mathrm{P}^{32}$ appeared to be localized initially ( 1 hour after feeding of the isotope) immediately adjacent to the nucleolus, possibly associated with the chromosomes. This suggests that the RNA was initially synthesized adjacent to or on the surface of the nucleolus. Within two hours, the label appeared to be evenly distributed in the nucleolus. They found no apparent localization of activity about a single region, as would be expected if the nucleolus organizer region were the sole site of synthesis of nucleolar materials. (For a discussion of the origin of nucleolar materials, see Vincent, 1955a.)

The work of Goldstein and Plaut (1955) also supports the contention that RNA is actually synthesized in the nucleus. Their results appear to demonstrate the passage of the label on RNA from the nucleus of the amoeba to the cytoplasm, but no reverse passage appears to occur. Such data seem to be best interpreted by concluding that RNA is synthesized in the nucleus and passes to the cytoplasm. On the other hand, cytoplasmic RNA does not appear to move in the reverse direction.

A further question arises in considering the role of the nucleolus in RNA relationships between nucleus and cytoplasm. Is the nucleolus at all necessary in a system of specificity transfer such as has been suggested? If specificity residing in DNA is transferred to RNA structure by a template mechanism of synthesis (Dounce, 1953; Lockingen and DeBusk, 1955), the RNA product could then diffuse directly to the cytoplasm and there impart to 
the synthesis of new material genetic guidance. As it has been shown that the synthesis of both RNA and specific protein will occur in the absence of the nucleus, although at a diminished rate (Brachet, 1955), one can question the necessity of the nuclear contribution to synthetic activities. The intimate correlation of nucleolar activities with cytoplasmic synthesis however (see above, also Vincent, 1955a) necessitates the presumption of some sort of relationship between nuclear, nucleolar, and cytoplasmic activities. The finding of Baltus that nucleoli possess high concentrations (although less than $10 \%$ of the cellular activity) of nucleoside phosphorylase and DPN synthetase certainly suggests that the nucleolus can be involved in nucleotide synthesis. The autoradiographic results mentioned above, and the data reported in this paper strongly suggest that RNA synthesis itself occurs in the nucleolus.

The data on the RNA of nucleolus and cytoplasm raise another problem in that the base content of the two regions differs widely. Such a difference is found in the starfish (in Fig. 3). This is not in agreement with the hypothesis that nuclear or nucleolar synthesis is the sole source of cytoplasmic RNA. The experiments presented above, however, strongly indicate the presence of at least two metabolically quite different RNA fractions in the nucleolus. Further characterization of these fractions may help to resolve this apparent disagreement.

We are then faced with the conclusion that the chromosomes, the nucleolus, and the cytoplasm are all able to carry out de novo synthesis of RNA. Accepting the contention that specificity is conferred on RNA from a DNA template and that this RNA passes to the cytoplasm, we know that this specificity is maintained for some time in the cytoplasm (Hämmerling, 1953). Whether or not the cytoplasm is able to reduplicate specific RNA molecules (i.e., the plasmagene hypothesis of Spiegelman and Kamen, 1946), has not yet been adequately determined. Enucleation experiments suggest that if the cytoplasm is able to perform this function, reduplication is not able to keep up with destruction, and therefore the system eventually runs down.

We have mentioned two possibilities for RNA synthesis in the 
nucleus: one, by specificity being imparted from the gene itself (i.e., DNA structure) to RNA structure through a template mechanism, the other by nucleolar enzymes. If one considers a simple case, that of a cell synthesizing a single specific protein molecule at a rapid rate, the question of template yield becomes significant. That is, can a single genetic locus or "master template" (such as would limit the rate of production of any end product) produce secondary templates rapidly enough to keep up with inactivation which seems to occur during cytoplasmic synthesis? If not, we can suggest the following as a plausible role for the nucleolus which is at least not contradictory to any evidence presently available and seems to offer possibilities for experimental analysis.

The nucleolus might be considered to be analogous to a duplicating machine with the gene providing the stencil, in that the mucleolus could be assumed to have a specialized mechanism for the rapid synthesis of many new RNA molecules from the specific structure provided by a genetic locus. In this way, identical specific molecules of RNA in large numbers could be manufactured for transfer to the cytoplasm.

This general pattern of chromosomal, nucleolar, and cytoplasmic relationships is essentially that advanced by Caspersson and co-workers in 1940 (Caspersson, 1950, pp. $101 \mathrm{ff}$.) except that Caspersson's group did not have the advantage of the recent discoveries regarding the porosity of the nuclear membrane and the actual transfer of RNA to the cytoplasm. Caspersson's group therefore tended to emphasize the participation of basic proteins in the role which is ascribed to RNA in the preceding paragraph.

\section{Summary}

In this review of some of the many aspects of the origin and development of the oocyte, I have considered in detail only one of the problems which were mentioned in the introduction. In the study of the role of the nucleus in oocyte development reviewed above, evidence has been presented that indicates that the RNA of the nucleus is intimately involved in the transfer of genetic specificity to the cytoplasm. The muclear RNA of the 
starfish oocyte is shown to be metabolically heterogeneous in that a small fraction of the RNA possesses different solubility characteristics and is metabolically very active; the rest of the RNA is relatively inert according to these criteria. The correlation between chromosomal, nucleolar, and cytoplasmic events, particularly with respect to RNA, has led to a hypothesis of the role of RNA and the nucleolus in the transfer of genetically determined specificity to the cytoplasm. The RNA is considered to be a carrier of structural specificity imparted by genetic loci, and the nucleolus is suggested as a site of multiplication of these specific RNA molecules which are then transferred to the cytoplasm.

\section{ACKNOWhengment}

Gratitude is expressed for the help of Dr. Jean Brachet and members of his staff in providing laboratory space and for many stimulating conversations at the Laboratory of Experimental Morphology, University of Brussels, Belgium. The assistance of Dr. Maurice Erreril is also acknowledged in making the measurements for Fig. 3.

\section{REFERENCES}

Baltus, E. 1954. Observations sur le rôle biochimique du nucléole. Biochim. et Biophys. Acta, 15, 263-67.

Berrill, N. J., and C. K. Liu. 1948. Germplasm, Weismann, and Hydrozoa. Quart. Rev. Biol., 23, 124-49.

Brachet, J. 1950. Chemical Embryology. Interscience Publishers, New York-London.

Brachet, J. 1955. The biological role of the pentose nucleic acids. In E. Chargaff and J. N. Davidson (eds.) The Nucleic Acids, Vol. II, pp. 475-519. Academic Press, New York.

Caspersson, T. O. 1950. Cell Growth and Cell Function. W. W. Norton and Co., New York.

Dalcq, A., and M. Van Egmond. 1953. Effects de la centrifugation sur l'oocyte de trois mammifères. Arch. Biol. (Liége), 64, 311-97.

Dounce, A. L. 1953. Duplicating mechanism for peptide chain and nucleic acid synthesis. Enzymologia, 15, 251-58. 
Elson, D., and E. Chargaff. 1954. Regularities in the composition of pentose nucleic acids. Nature, 173, 1037-38.

Everett, N. B. 1945. The present status of the germ cell problem in vertebrates. Biol. Revs., Cambridge Phil. Soc., 20, 45-55.

Ficq, A. 1953. Incorporation in vitro de glycocolle-1-14C dans les oocytes d'Astéries. Experientia, 9, 377-79.

Ficq, A. 1955. Etude autoradiographique du métabolisme de l'oocyte d'Asterias rubens au cours de las croissance. Arch. Biol. (Liége), 66, 509-24.

Flickinger, R. A., and G. W. Nace. 1952. An investigation of proteins during the development of the amphibian embryo. Exptl. Cell Research, 3, 393-405.

Gall, J. 1955. Problems of structure and function in the amphibian oocyte nucleus. Symposia Soc. Exptl. Biol., 9, 358-70.

Gamow, G., and M. Yčas. 1955. Statistical correlation of protein and ribonucleic acid composition. Proc. Natl. Acad. Sci., 41, 1011-1019.

Goldstein, L., and W. Plaut. 1955. Direct evidence for nuclear synthesis of cytoplasmic ribose nucleic acid. Proc. Natl. Acad. Sci. U. S., 41, 874-80.

Hämmerling, J. 1953. Nucleo-cytoplasmic relationships in the development of Acetabularia. Intern. Rev. Cytol., 2, 475-98.

Hogeboom, G. H., W. C. Schneider, and M. S. Striebach. 1952. Cytochemical studies. V. On the isolation and biochemical properties of liver cell nuclei. J. Biol. Chem., 196, 111-20.

Jones, R. M. 1949. The use of vital staining in the study of the origin of germ cells in the female rat. J. Morphol., 84, 293-333.

Lison, L. 1950. Étude et realisation d'un photomètre à l'usage histologique. Acta Anat., 10, 333-47.

Lockingen, L. S., and A. G. DeBusk. 1955. A model for intracellular transfer of DNA (gene) specificity. Proc. Natl. Acad. Sci. U. S., 41, 925-34.

Marshak, A., and C. Marshak. 1953. Desoxyribonucleic acid in Arbacia eggs. Exptl. Cell Research, 5, 288-300.

Montgomery, T. H. 1898. Comparative cytological studies, with especial reference to the morphology of the nucleolus. J. Morphol., 15, 265-582.

Nace, G. W. 1953. Serological studies of the blood of the developing chick embryo. J. Exptl. Zool., 122, 423-28.

Needham, J. 1942. Biochemistry and Morphogenesis. University Press, Cambridge, England. 
Nelsen, O. E. 1953. Comparative Embryology of the Vertebrates. Blakiston Co., New York.

Painter, T. S., and A. N. Taylor. 1942. Nucleic acid storage in the toads egg. Proc. Natl. Acad. Sci. U. S., 28, 311-16.

Panijel, J. 1951. Métabolisme des nucléoprotéines dans la gamétogénèse ct la fécondation. Hermann and Cie., Paris.

Rich, A., and J. D. Watson. 1954. Some relations between DNA and RNA. Proc. Natl. Acad. Sci. U. S., 40, 759-64.

Romanoff, A. L., and A. J. Romanoff. 1949. The Avian Egg. John Wiley and Sons, New York.

Schrader, F., and C. Leuchtenberger. 1952. The origin of certain nutritive substances in the eggs of Hemiptera. Exptl. Cell Research, 3, 136-46.

Smellie, R. M. S. 1955. The metabolism of nucleic acids. In E. Chargaff and J. N. Davidson (eds.), The Nucleic Acids. Vol. II. pp. 393-434. Academic Press, New York.

Spiegelman, S., and M. D. Kamen. 1946. Genes and nucleoproteins in the synthesis of enzymes. Science, 104, 581-84.

Taylor, J. H. 1953. Intracellular localization of labelled nucleic acid determined by autoradiographs. Science, 118, 555-57.

Taylor, J. H., R. D. McMaster, and M. F. Calya. 1955. Autoradiographic study of incorporation of $\mathrm{P}^{32}$ into ribonucleic acid at the intracellular level. Exptl. Cell Research, 9, 460-73.

Telfer, W. H. 1954. Immunological studies of insect metamorphosis. II. The role of a sex-limited blood protein in egg formation by the Cecropia silkworm. J. Gen. Physiol., 37, 539-58.

Tyler, A. 1955. Ontogeny of immunological properties. In B. H. Willier, P. A. Weiss, and V. Hamburger (eds.), Analysis of Development. W. B. Saunders Company, Philadelphia.

Vincent, W. S. 1952. The isolation and chemical properties of the nucleoli of starfish oocytes. Proc. Natl. Acad. Sci. U. S., 38, 139-45.

Vincent, W. S. 1954. P32 incorporation in starfish oocyte nucleoli. Biol. Bull., 107, 326.

Vincent, W. S. 1955a. Structure and chemistry of nucleoli. Intern. Rev. Cytol., 4, 269-98.

Vincent, W. S. 1955b. Phosphate metabolism of starfish oocyte nucleoli. Biol. Bull., 109, 353.

Vincent, W. S., and E. J. Dornfeld. 1948. Localization and role of nucleic acids in the developing rat ovary. Am. J. Anat., 83, 437-70. 
Vincent, W. S., and A. H. Huxley. 1954. The dry matter content of starfish oocyte nucleoli. Biol. Bull., 107, 290-91.

Wilson, E. B. 1928. The Cell in Development and Heredity. Macmillan, New York.

Wittek, M. 1952. La vitellogénèse chez les Amphibiens. Arch. Biol., 63, 133-98.

Zeuthen, E., and E. Hoff-Jørgenson, 1952. Evidence for cytoplasmic desoxyribosides in the frog's eggs. Nature, 169, 245-46. 


\title{
SPECIFIC EGG AND SPERM SUBSTANCES AND ACTIVATION OF THE EGG
}

\author{
CHARLES B. METZ* : OCEANOGRAPHIC INSTITUTE, \\ FLORIDA STATE UNIVERSITY, TALLAHASSEE
}

At fertilization the egg undergoes a complex series of morphological, physiological, biochemical and, in many cases, morphogenetic changes that ultimately lead to the differentiation of the new individual. These initial changes constitute the activation of the egg. Under favorable conditions they proceed in an orderly sequence, and the precision of this sequence suggests that the activation changes are interrelated and that they all follow from a few or even a single reaction between the egg and the sperm. Many consider this problem of the activation initiating mechanism the central problem of fertilization, but it should be borne in mind that fertilization involves other problems as well. Thus fertilization is characterized by a high order of specificity. This reaches its ultimate expression in those hermaphroditic organisms that exhibit self sterility. Finally the sperm must approach the egg, penetrate any extraneous egg membranes, attach to and penetrate the egg surface.

These problems of fertilization may be attacked experimentally in several ways and of these the one most likely to provide solutions would appear at present to be the study of the role of specific egg and sperm substances in fertilization. The literature of fertilization recounts many attempts to extract a "fertilizing substance" from sperm or to activate eggs with dead sperm. However, none of these efforts appears to have stood the test of critical examination in spite of initial claims of success. Even the most

- These studies have been supported in part by grants from the National Institutes of Health, the American Cancer Society, and the National Science Foundation. 
recent of these (Felix, 1955) may meet a similar fate. Nevertheless, it should be recalled that paramecia killed by various agents including formalin will specifically activate paramecia of opposite mating type (Metz, 1947, 1954a). Therefore this direct approach to the problem may still hold promise even for the more orthodox material.

Although these efforts with metazoa appear to have failed in their primary objective, they and related studies have shown that a number of interesting substances may be obtained from both eggs and sperm. Certain of these agents clearly perform a necessary role in fertilization and the nature of some others suggests that they too may eventually be assigned a definite if not essential function in fertilization.

Serious study of such agents began with Frank R. Lillie's investigation of the sperm isoagglutinin, fertilizin, which he obtained from the eggs of the sea urchin Arbacia and the annelid Nereis. Lillie's (1912, 1913b, 1914, 1919) studies produced the only comprehensive, though now outmoded, theory of fertilization, namely the Fertilizin Theory. Publication of the Fertilizin Theory stimulated a very considerable series of studies during the following decade. Interest then lagged until the late nineteen thirties when it was revived largely by Hartmann and his associates in Germany and by Tyler in America. This interest has steadily increased but with it has come much conflicting data and many divergent statements, owing in part at least to differences in experimental material. Unfortunately, several of these areas of disagreement have not been resolved satisfactorily in the literature. These will receive particular attention here. Some of the well-established aspects of the subject will be treated in less detail for they have been discussed in several reviews (Bielig and von Medem, 1949; Tyler, 1948a, 1949, 1955; Runnström, 1949a,b, 1952; Rothschild, 1951a,b).

\section{Classification of Sex Substances}

Fertilization presupposes a ripening of the parent animals and an appropriate release of the gametes. These processes have been found to be controlled in many instances by environmental con- 
ditions, by sex substances, hormones, etc., or a combination of these factors. These interesting preliminaries to fertilization are beyond the scope of this review. Only those substances derived from and directly affecting the gametes themselves will be considered here.

The more spectacular and more readily investigated sex substances of this sort appear in the natural fluids containing the gametes. Their presence in such fluids indicates that they are available under natural conditions and their action upon gametes, especially those of the opposite sex, constitutes strong evidence that they function in fertilization. In the demonstrable absence of sex substances in natural fluids, the interaction of gametes at fertilization may again be attributed to more or less specific sex substances, but in this case the agents must be insoluble in the fluid medium, firmly bound to the gametes or both. The sex substances of Paramecium are exclusively of this type (Metz, 1954a), but comparable agents have not been examined extensively in other organisms. Upon proper analysis such insoluble or bound sex substances may be found to occur widely, and an analysis of their role in fertilization may contribute much to our understanding of the physiology of fertilization.

Aside from the agents that appear in the media surrounding the gametes, agents of various sorts may be obtained by more or less elaborate extraction of gametes. A number of such agents have definite action upon gametes of the same or opposite sex, but the question of their role in fertilization is not so readily settled for the agents may not be available under natural physiological conditions. Indeed they may be artificial products of the extraction procedures. The basic proteins (protamines, histones) obtained by acid extraction of sperm are notable recent examples of this.

\section{Agents from Eggs}

The simplest preparation from eggs is the supernatant water in which eggs have been suspended. Such egg water may be expected to be charged with soluble and readily diffusible agents from the eggs. The most thoroughly studied of these agents is 
the glycoprotein fertilizin, which specifically agglutinates sperm. However, egg water has been reported to have a variety of other effects on sperm as well. In some instances these effects have also been attributed to fertilizin, but the possibility of action by other agents has not always been eliminated. The effects of egg water on sperm will be considered briefly before discussing fertilizin and the antifertilizin from eggs.

\section{Effects of Egg Water on Sperm}

Chemotaxis and the Approach of the Sperm. When eggs are inseminated, the sperm are frequently observed to accumulate in the vicinity of the egg. This effect is particularly striking in species whose eggs have a gelatinous coat, and it has led several investigators (Lillie, 1913b; Hartmann, Kuhn, Schartau, and Wallenfels, 1939; Vasseur and Hagström, 1946) to the view that diffusible agents (including echinochrome) from the eggs have chemotactic action upon the sperm. Action of this kind appears to be well established in certain mosses and ferns (see Rothschild, 1951a, 1952, for recent account), but this effect has yet to be demonstrated convincingly in metazoa. Sperm can be shown to accumulate in capillary tubes containing egg water or in drops of egg water injected into sperm suspensions. However, as several investigators (Morgan, 1927; Rothschild, 1951a,b, 1952; Tyler, 1948a, 1955) have emphasized, the possibility of a trap action on the sperm has not been eliminated in these experiments. Such trap action could result from agglutination of the sperm or a combination of factors affecting sperm motility (see Rothschild, 1951b, for detailed discussion). In the absence of independent evidence it must be concluded that chemotaxis of metazoan sperm has not been demonstrated and that the sperm probably approach the egg by random motion. Accumulation of sperm about eggs is explained by an adhesion (trapping) of sperm in the jelly or at the egg surface following chance contact.

Effect of Egg Water on Sperm Motility and Respiration. Spermatozoa of the sea urchin become intensely active in the vicinity of eggs. This observation suggests that some product diffusing from the egg activates the sperm. Lillie (1913b) confirmed this 
view by demonstrating that specific egg water increases the motility of Arbacia sperm. This sperm activating action of egg water has been confirmed in a number of forms including Megathura (Tyler, 1940a) and other molluses (von Medem, 1945), the annelid Nereis (Lillie, 1913b), and several sea urchins. However, it does not appear to be a universal property of egg water for Metz (1945) found no sperm activating action of starfish egg water in spite of Loeb's (1915) claims to the contrary.

The nature of the sperm activating agent in sea urchin egg water has been the subject of some dispute. Loeb (1915) believed that this agent differed from fertilizin since egg water prepared from fertilizin-free eggs still activated sperm and because calcium ion was required for the agglutination but not the activating action of egg water.

In studies that aroused much interest at one time Hartmann, Kuhn, Schartau, and Wallenfels (1939) reported that crystalline preparations of the substituted naphthaquinone, echinochrome, in sea water solution activated the sperm of Arbacia. Echinochrome occurs in the form of granules in eggs of the genus Arbacia. Tyler (1939a) and Cornman (1941), however, were unable to confirm this action of echinochrome on sperm of Strongylocentrotus purpuratus and Arbacia punctulata respectively. Both of these investigators used crystalline preparations. Cornman (1941) suggested that Hartmann's results may have resulted from failure to control the $\mathrm{pH}$ of the solutions. Bielig and Dohrn (1950) found no sperm activating action of echinochrome in buffered systems. It would appear, then, that there is no confirmatory evidence to support the view that echinochrome activates sperm.

Volatile or dialyzable sperm activating agents have been reported from egg waters by several investigators (Clowes and Bachman, 1921; Cornman, 1941; Vasseur and Hagström, 1946). Tyler and Fox $(1939,1940)$, however, found that sperm activating action remained with fertilizin through precipitation and dialysis. Tyler (1955) concluded that the activating action of egg water is associated with the fertilizin but that the fertilizin may be split to yield volatile or dialyzable fractions with sperm activating properties. 
In view of its stimulatory action on sperm motility it might be expected that egg water would also increase sperm respiration. This is indeed the case in the sea urchins Echinus esculentus (Gray, 1928; Carter, 1930, 1931; Vasseur, 1949b), Strongylocentrotus droebachiensis (Vasseur, 1949b), and the gastropod Megathura (Tyler, 1948a; Krauss, 1950a). However, in some other forms, notably Arbacia punctulata (Hayashi, 1946), S. purpuratus (Tyler, 1948a; Spikes, 1949a), Echinus (Psammechinus) miliaris (Gray, 1928; Carter, 1930, 1931), Lytechinus variegatus (Greenberg, unpublished), and L. pictus (Spikes, 1949a), egg water fails to increase sperm respiration. Indeed egg water treatment may actually reduce the rate of oxygen uptake of the sperm of some sea urchins (e.g., Lytechinus, Spikes, 1949a; Arbacia, Hayashi, 1946). Or the egg water may simply delay the usual rapid fall in respiratory rate characteristic of sea water suspensions of sperm (e.g., P. miliaris, Gray, 1928; Carter, 1931). Finally starfish egg water has no effect upon either sperm motility or respiration (Metz, 1945; Metz and Birky, umpublished).

The agent in egg water which affects the respiration of sperm is usually assumed to be fertilizin. This view is supported by experiments (Spikes, 1949a) showing that the agglutinating action and respiratory effects (in this case a lowering of oxygen uptake) of sea urchin egg water are destroyed simultaneously by ultraviolet irradiation. On the other hand, heating at $126^{\circ} \mathrm{C}$. destroys the sperm agglutinating action but actually enhances the respiration increasing action of $E$. esculentus egg water. Egg water autoclaved in acid ( $\mathrm{pH} 0.5$ ) failed to increase the oxygen uptake of the sperm (Vasseur, 1949b; see also Bielig and Dohrn, 1950).

The discovery (Tyler and Rothschild, 1951; Tyler, 1953; Rothschild and Tyler, 1954) that metal binding or chelating agents increase the motility of sperm may explain the motility increasing action of egg water. As suggested by Tyler and Metz (1955), sea urchin fertilizins may possess metal binding action. Low molecular weight substances in egg water and split products of fertilizin may also be found to have this effect. Finally, appreciation of the possibility of this mode of action should materially aid in a further identification of the active agent or agents in egg water. 
The situation with respect to increase in respiration appears to be somewhat more complicated. In some forms metal binding agents fail to increase the oxygen uptake but do increase anaerobic metabolism of sperm (e.g., Lytechinus pictus, Tyler and Rothschild, 1951). In the starfish, however, similar agents clearly increase oxygen uptake of sperm (e.g., Asterias forbesii, Metz and Birky, 1955). Irrespective of whether the agents increase aerobic or anaerobic energy yielding systems, egg water and metal binding agents should have similar action on sperm respiration if their mechanisms of action are the same. In some forms such parallel action has been reported, but in others conflicting data prevent a clear decision. It is evident from the available clata (Table I) that the problem requires further investigation.

Effect of Egg Water on Sperm Morphology. Studies (reviewed by Colwin and Colwin, this volume, Dan, 1956, and Metz, 1956) have shown that the sperm acrosome of a variety of forms (24 species in 4 phyla) undergoes a striking change under certain conditions. The change, known as the acrosome reaction, involves the conversion of the normally compact acrosome into a filament.

This discovery has contributed substantially to our understanding of the morphology of fertilization. Specifically it has provided a satisfactory explanation for the filaments that extend between the egg surface and the sperm in the early stages of fertilization of some forms (see Colwin and Colwin, this volume; Dan, 1954a, 1956).

The acrosome reaction has been reported to result under a variety of conditions. These include contact of the sperm with a surface such as glass or the egg, exposure to alkaline sea water, or low temperature and treatment with excess calcium or egg water (Dan, 1952, 1954a,b; Dan and Wada, 1955; Wada, Collier, and Dan, 1956; A. L. Colwin and L. H. Colwin, 1955; L. H. Colwin and A. L. Colwin, 1955a,b; Metz and Morrill, 1955). In fact the reaction sometimes occurs in a high proportion of sperm after dilution with sea water (Rothschild and Tyler, 1955). Of these conditions the treatment with egg water is of special interest, for it suggests the possibility that the acrosome reaction 
TABLE I. Effect of Egg Water and Metal Binding Agents on

Oxygen Uptake of Sea Urchin Sperm

\begin{tabular}{|c|c|c|}
\hline Species & Reaction & Reference \\
\hline Echinus esculentus & $\begin{array}{l}\text { + Egg water } \\
+ \text { B (thyroxine, desiodo- } \\
\text { thyroxine, diiodotyrosine, } \\
\text { tyrosine? tryptophane?) } \\
\text { - B (versene) }\end{array}$ & $\begin{array}{l}\text { Gray, 1928; Carter, } 1930 \text {, } \\
1931 \text {; Vasseur, 1949b } \\
\text { Carter, } 1931 \\
\text { Rothschild and Tyler, } 1954\end{array}$ \\
\hline $\begin{array}{l}\text { Psammechinus } \\
\text { mitiaris }\end{array}$ & $\begin{array}{l}\text { - Egg water (maintains } \\
\text { but does not increase } \mathrm{QO}_{2} \text { ) } \\
+\mathrm{Egg} \text { water } \\
\text { - } \mathrm{B} \text { (thyroxine maintains } \\
\text { but does not increase } \mathrm{QO}_{2} \text { ) } \\
+\mathrm{B} \text { (albumen, trypsin, } \\
\text { amino acids) }\end{array}$ & $\begin{array}{l}\text { Gray, 1928; Carter, 1930, } \\
1931 \\
\text { Vasseur, 1949b; Vasseur, } \\
\text { Wicklund and Runnström, } \\
1950 \\
\text { Carter, } 1931 \\
\text { Wicklund, 1954c; Vasseur, } \\
\text { Wicklund and Runnström, } \\
1950\end{array}$ \\
\hline Lytechinus pictus & $\begin{array}{l}\text { - Egg water } \\
\text { - B (amino acids) }\end{array}$ & $\begin{array}{l}\text { Spikes, } 1949 \mathrm{a} \\
\text { Tyler and Rothschild, } 1951\end{array}$ \\
\hline $\begin{array}{l}\text { Lytechinus } \\
\text { variegatus }\end{array}$ & $\begin{array}{l}\text { - Egg water } \\
\text { - B (alanine) }\end{array}$ & $\begin{array}{l}\text { Greenberg, unpublished } \\
\text { Greenberg, unpublished }\end{array}$ \\
\hline $\begin{array}{l}\text { Strongylocentrotus } \\
\text { purpuratus }\end{array}$ & - Egg water & Tyler, 1948a; Spikes, 1949a \\
\hline Arbacia punctulata & $\begin{array}{l}\text { - Egg water } \\
\text { - B (seminal plasma) }\end{array}$ & $\begin{array}{l}\text { Hayashi, } 1946 \\
\text { Hayashi, } 1946\end{array}$ \\
\hline
\end{tabular}

+ increase in oxygen uptake.

- no substantial increase.

B agents which probably bind metals.

can be a specific response to an agent from eggs of the species. So far no specificity studies have been carried out with respect to this action of egg water. Furthermore, no substantial attempt has yet been made to determine the active agent in egg water. Its identity with or separation from the sperm isoagglutinin, fertilizin, is a problem of special interest. The only data available indicate that egg water can agglutinate sea urchin sperm under conditions (absence of calcium) which do not permit formation 
of filaments (Dan, 1954b). On the other hand, a high incidence of filament formation is associated with a strong agglutinating action of egg water in Asterias and Nereis (Metz and Morrill, 1955). In fact in Asterias the two effects are related to the extent that egg water fails to have either action in the absence of a metal binding agent.

Egg water treatment also results in a "loosening" and displacement of the echinoderm sperm midpiece (Dan, 1954a; Popa, 1927; Rothschild and Tyler, 1955; Tyler, 1952). It is suggested (Tyler, 1952) that this effect may be related to the normal separation of these parts that occurs during fertilization.

\section{Fertilizin Agglutination of Sperm}

The sperm agglutinating action of egg water was reported by several early investigators (see Morgan, 1927, for review) but it was not until Lillie's (1913a,b, 1919) classical studies on Arbacia and Nereis that a possible relation between this effect and the fertilization of the egg was fully appreciated. Lillie termed the agglutinating agent of egg water fertilizin. Subsequently others have employed a variety of terms for the same agent. $^{*}$

Lillie (1913b) showed that fertilizin agglutination of sperm was characterized by a high order of specificity, and this has been confirmed on a wide scale (e.g., Metz, 1945; Tyler, 1949; Vasseur, 1951). Lillie (1913b) also found that the agglutinin was used up or absorbed in the agglutination reaction (see also Tyler, 1941; Metz, 1945; Monroy et al., 1954), and he first employed an analogy with antigen-antibody reactions to explain the agglutination of sperm. More recently this analogy has been developed further, particularly by Tyler and his students (see especially Tyler, 1941, 1948a, 1955; Spikes, 1949b; Metz, 1945).

Mechanism of Agglutination. In keeping with modern immunological theory agglutination is considered to result from a chemical reaction between two substances, antifertilizin on the sperm surface and the fertilizin dissolved in egg water. The reac-

* Fertilizin (Lillie, 1913a,b; Tyler, 1948a) = Gynogamone II (Hartmann et al., 1940) = jelly coat substance (Runnström, 1949a). 
tion between fertilizin and antifertilizin is further consiclered to result from interaction of specific reactive groups or sites of fertilizin with other reactive groups on the sperm surface (antifertilizin). The reactive groups of fertilizin and antifertilizin are endowed with a high order of configurational complementariness and the specificity of fertilizin agglutination resides in the specific "lock and key" nature of this complementary relationship. Finally,
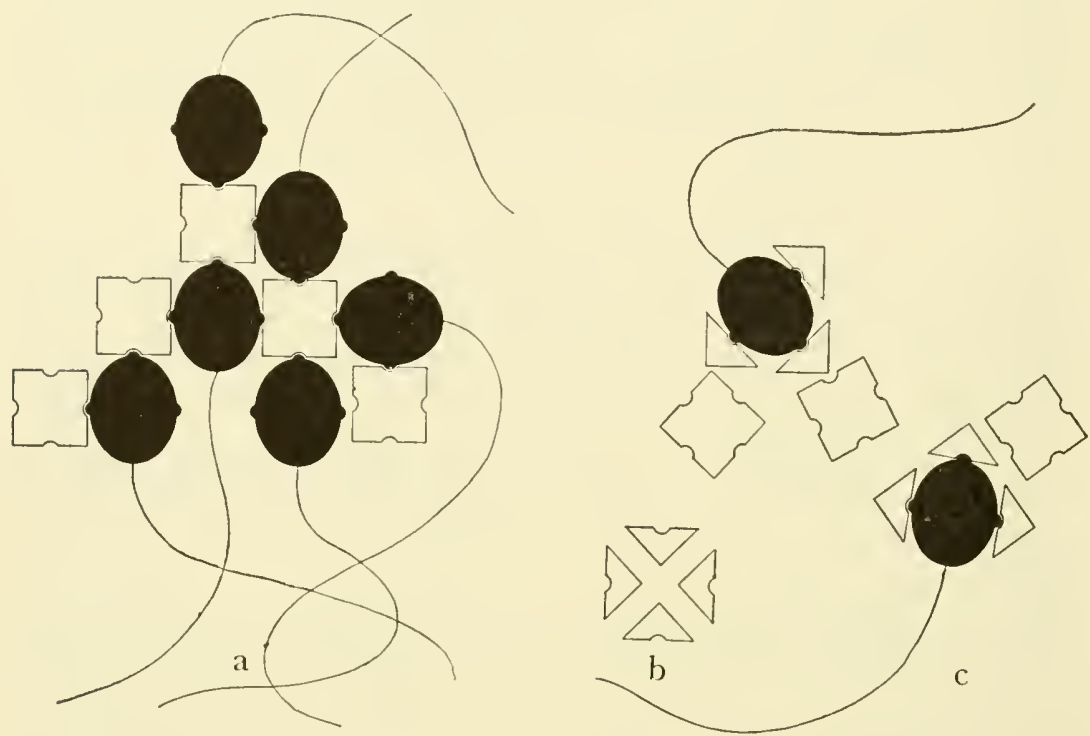

Fig. 1. (a) Agglutination of sperm by interaction of multivalent fertilizin with antifertilizin of sperm surface. (b) Multivalent fertilizin split into univalent fragments. (c) Failure of sperm to agglutinate with multivalent fertilizin following saturation with univalent fertilizin. (From Rothschild, 1951b.)

the agglutinating fertilizin molecule is considered to be multivalent with respect to its specific reactive groups. Agglutination results when several sperms are linked together by fertilizin molecules. These relations are illustrated schematically in Fig. 1.

In most groups of organisms where it has been reported, fertilizin agglutination presents an orthodox antigen-antibody type reaction. In the echinoderms, however, certain interesting exceptional features have been reported. These include spontaneous 
reversal of agglutination in the echinoids and the necessity of an "adjuvant" or second factor in asteroids.

Spontaneous Reversal of Agglutination. Lillie (1913b) observed that upon mixing Arbacia sperm and egg water the sperm clumped together forming microscopically visible agglutinates, but within a few minutes these clumps broke down, releasing the individual sperms. Similar spontaneous reversal of agglutination has been reported in most of the echinoids so far examined. Lillie (1913b) showed that following such reversal of agglutination the sperm could not be reagglutinated by further addition of egg water. Evidently then, the sperm surface is altered in the course of agglutination and reversal. Tyler (1941) considered several possible explanations for this spontaneous reversal and failure of reagglutination and he concluded that the fertilizin molecule was probably split by action of the sperm into fragments each possessing only a single reactive group. Such univalent fragments should remain in combination with and saturate the antifertilizin groups of the sperm surface without causing agglutination. Furthermore, the univalent fragments should protect or block the sperm antifertilizin from reaction with the normal, multivalent, agglutinating fertilizin (see Fig. 1 for schematic illustration). In support of this view Tyler (1941) and Metz (1942a, 1954c) have shown that a number of agents (heating, proteolytic enzymes, x-radiation or ultraviolet radiation, $\mathrm{H}_{2} \mathrm{O}_{2}$ oxidation) will convert fertilizin to the univalent form. Such fertilizin will not agglutinate sperm but it will combine with sperm and render it unagglutinable by untreated fertilizin. As a final parallel with antigen-antibody systems Tyler (1945) showed that rabbit antibody could also be converted to a nonagglutinating, univalent form.

Fertilizin Agglutination of Starfish Sperm. Some early investigators (Glaser, 1914; Woodward, 1918) reported direct agglutination of starfish sperm by specific egg water, but others (Just, 1930; Loeb, 1914; Tyler, 1941; Metz, 1945, 1954b; Metz and Donovan, 1950; Dan, 1954a) have been unable to confirm this result in the same and other species. Conditions in the starfish were clarified by the discovery (Metz, 1944, 1945) that strong agglutination results when sperm are mixed with specific egg 

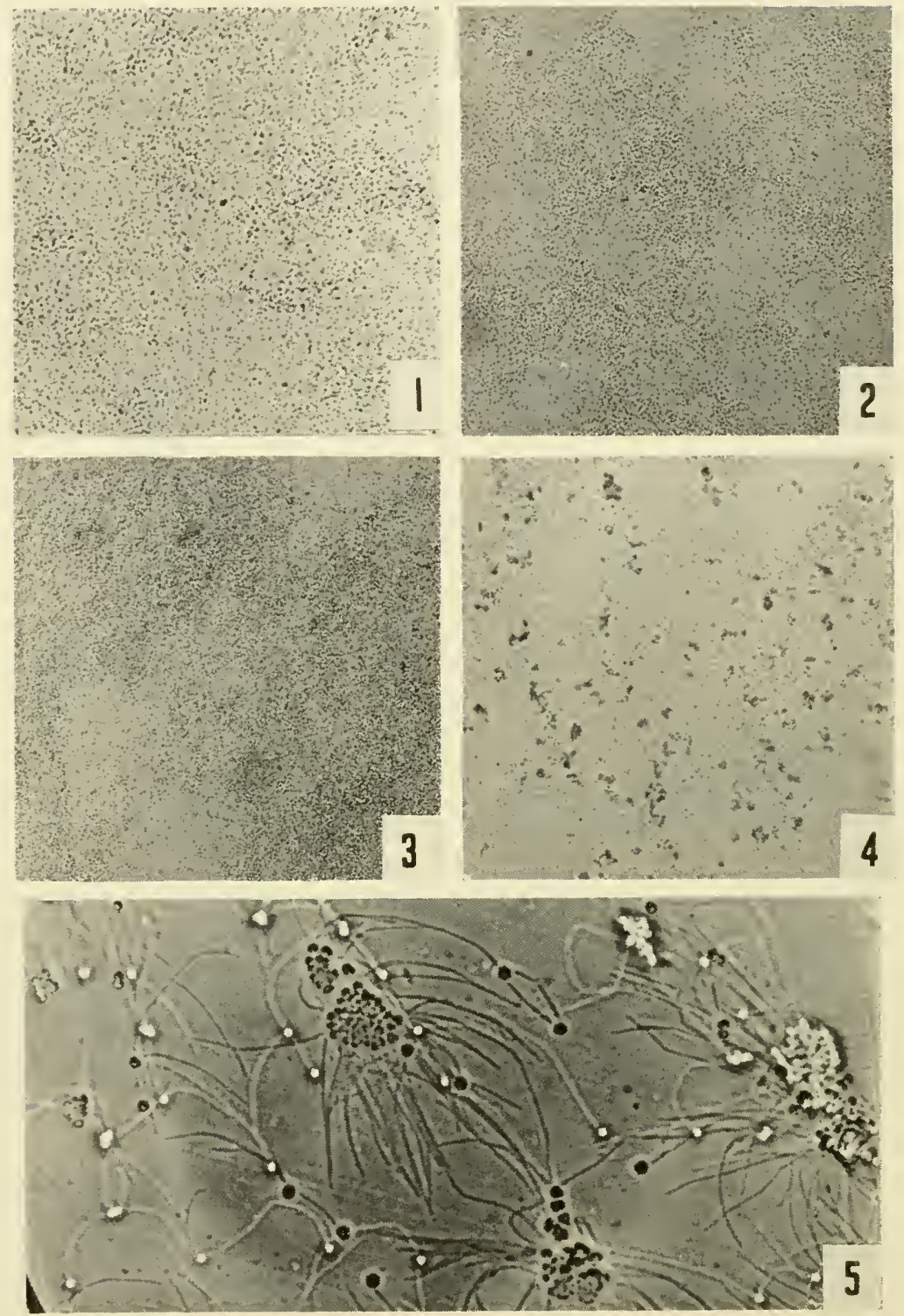

Plate I. Agglutination of Luidia clathrata sperm by versene-egg water. 1 , Sperm in sea water. 2, Sperm in $0.0025 M$ versene, $\mathrm{pH}$ 8.1. 3, Sperm in egg water. 4, Sperm in versene (0.0025M, pH 8.1)-egg water. 5, Sperm in versene-egg water. Agglutination appears to be strictly head to head. (Phase contrast optics, $1-4$, approximately $100 \times$; 5 , approximately $430 \times$.) 
water and an "adjuvant" (Plate I). This fertilizin-adjuvant agglutination has been reported in ten species of starfish (Metz, 1945, 1954b; Metz and Donovan, 1950; Dan, 1954a). In this reaction the fertilizin is species specific; the adjuvant is not specific. The first adjuvants found were poorly defined materials (animal sera, hen's egg white), but subsequent study (Metz and Donovan, 1950; Metz, 1954b) revealed that alkali, amino acids, peptides, SH containing substances, versene, and other metal binding or chelating agents were effective adjuvants. Since metal binding is a common property of these diverse agents and since the adjuvant action is inhibited by addition of metal cations (Metz, 1954b), it appears that the essential function of the adjuvant is a removal of metal ions. This view explains certain earlier observations. Among these is the report (Metz, 1945) that denaturation by heating or ultraviolet radiation increases the adjuvant action of egg white. This enhanced action probably results from exposure of additional SH groups (Mirsky and Anson, 1934).

The adjuvant apparently acts upon the sperm, not upon the fertilizin in the fertilizin-adjuvant agglutination reaction. This follows from the fact that sperm, after removal from the adjuvant, can agglutinate on addition of fertilizin. In one experiment (Metz, 1945) sperm were washed free of adjuvant (hen's egg white) with sea water. In another (unpublished) the alkali used as the adjuvant was neutralized with acid. This experiment is summarized in Table II. In both of these experiments the sperm reverted rather rapidly to the nonagglutinable condition. This is explained by the addition of metal ions (sea water) in the first experiment. The action of alkali in the second experiment is assumed to involve binding metal ions as insoluble or un-ionized hydroxides. Upon addition of acid these hydroxides would be neutralized and thus free the metal cations. Presumably the sperm would remain agglutinable if the adjuvant (and bound metals) were washed away with salt solutions lacking the offending metal ions.

These experiments show that the adjuvants act primarily upon the sperm. Accordingly the fertilizin must be multivalent. This view is supported to the extent that starfish fertilizin can be con- 
Table II. Effect of $\mathrm{pH}$ on Fertilizin Agglutination of Patiria Sperm ${ }^{a}$

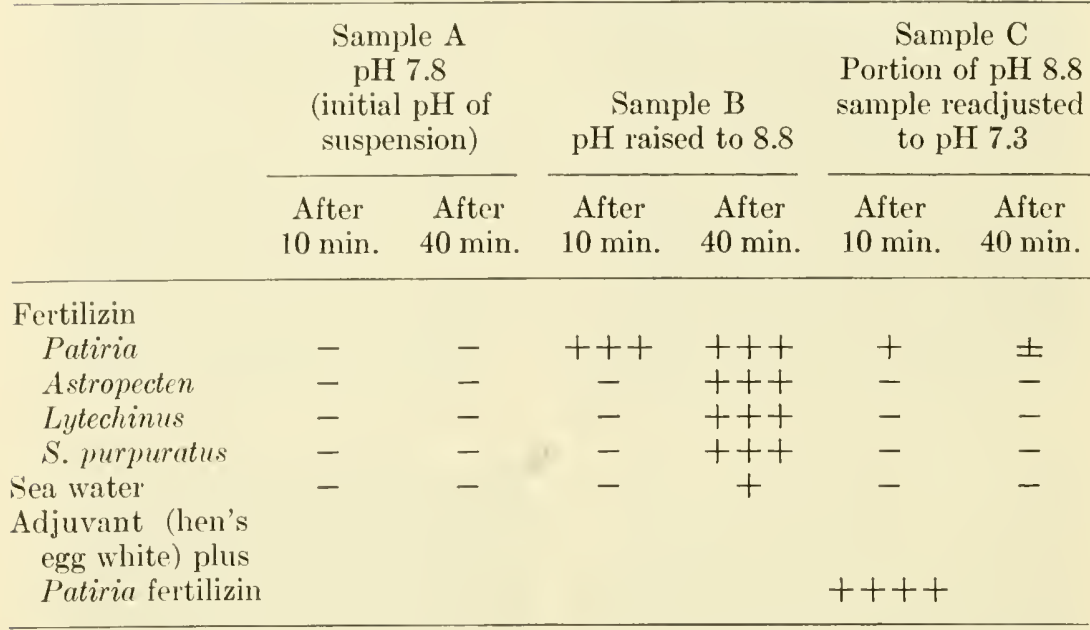

${ }^{a}$ Of three samples from a Patiria miniata sperm suspension $\mathrm{A}$ served as a control ( $\mathrm{pH} 7.8$ ), B was raised to $\mathrm{pH} 8.8$ with $0.1 \mathrm{~N} \mathrm{NaOH}$, and $\mathrm{C}$ was raised to $\mathrm{pH} 8.8$ and then lowered to $\mathrm{pH} 7.3$. Ten and 40 minutes after final $\mathrm{pH}$ adjustments the suspensions were tested for agglutination with homologous and heterologous fertilizins. Sample A failed to agglutinate. Sample B agglutinated specifieally at 10 minutes, but gave nonspecific reactions at 40 minutes. Sample C agglutinated weakly, but specifically at 10 minutes, very weakly, if at all, at 40 minutes.

verted to the nonagglutinating, univalent form by ultraviolet radiation (Metz, 1945).

The experiments cited, then, show that the metal ions affect the ability of starfish sperm to agglutinate with multivalent fertilizin. The metals probably combine with and block the reactive sites of most of the sperm surface antifertilizin. Such action implies that strong anionic groups, $\mathrm{SH}$ groups, amino acid, or other groups with a strong affinity for metal ions are essential constituents of the "active sites" of starfish antifertilizin, and that these groups must be free to combine with appropriate groups of fertilizin. Evidence for such blocking action was obtained in a series of absorption experiments. These showed that untreated starfish sperm can bind fertilizin to a limited extent but that this fertilizin 
binding capacity is increased by a factor of at least 128 in the presence of an adjuvant (Metz, 1945).

\section{Role of Fertilizin in Fertilization}

The highly specific and dramatic sperm agglutinating action of fertilizin suggests that this agent may play an important if not essential role in fertilization. The effect of egg water on sperm motility, respiration, and the sperm acrosome (see effects of egg water) may result from action of fertilizin. These effects may be aids to or essential for fertilization.

Evidence concerning a more direct role of fertilizin in fertilization and especially a direct role in the activation of the egg has centered about the following considerations: $(a)$ the universality of occurrence of fertilizin among metazoa, $(b)$ the source of fertilizin, $(c)$ the effect of removal and addition of fertilizin on the fertilizability of the egg, and $(d)$ the effect of fertilizin on the fertilizing capacity of sperm.

The evidence with regard to these points has been reviewed in detail by Tyler (1941, 1948a, 1955). Therefore it will suffice here to summarize this information and emphasize the most recent work.

Occurrence of Fertilizin. If fertilizin has a fundamental role in fertilization, it might be expected to occur widely if not universally. Lillie (1919) and Just (1930) believed this to be the true, although they demonstrated agghutination of sperm by egg water in only a limited number of forms. Subsequently, others have added to the list (Tyler, 1948a; Bielig and von Medem, 1949) so that positive cases are now known in four of the major phyla (molluses, annelids, echinoderms, chordates). However, the fact remains that the number of species included is small.

Nevertheless, the list is being extended. This extension involves both the discovery of orthodox egg water agglutination of sperm as new species are examined and the development of special methods for detecting fertilizin in egg waters that ordinarily fail to agglutinate homologous sperm. Two such methods have been employed successfully. The first is based on the premise that fer- 
tilizin should combine with sperm even though it fails to agglutinate. Tyler (1941) detected such combination in Urechis caupo and Patiria miniata by the inhibiting action of fertilizin on the fertilizing power of the sperm. Mactra (Spisula) solidissima fertilizin was first detected by the same method (Metz and Donovan, 1949). The second method involves the conversion of the normally nonagglutinating system to an agglutinating one by the addition of an adjuvant. The presence of fertilizin in Patiria egg water, originally demonstrated by the first method, was subsequently confirmed by this second method. Later studies employing the adjuvant technique have demonstrated agghtinating fertilizins in egg waters of nine other asteroids (see section on starfish agglutination). Finally calcium appears to be necessary for agglutination in some (Loeb, 1915; Vasseur, 1949a) but not all (Dan, 1954b) species. Fortification of the system with an excess of this ion may enhance agglutination (Vasseur, 1949a) or even induce agglutination in nonggglutinating systems. In a number of forms (see effects on sperm morphology, above) egg water has been shown to induce the sperm acrosome reaction. Although it is premature to conclude that fertilizin is the responsible agent in this effect, it is possible that such may prove to be the case and that the acrosome reaction can be developed into a sensitive test for fertilizin.

As suggested by the above account, failure to obtain agglutination may result from several causes. In some cases this may be due to a high calcium requirement. In the starfish, metal ions prevent agglutination by blocking most of the antifertilizin groups of the sperm. In some species fertilizin may exist mainly or entirely in the univalent form (Tyler, 1941, 1948a). Finally, fertilizin or fertilizin-like material may occur in an insoluble form, firmly bound to or built into the egg surface. The mating type substances of Paramecium are of this nature (Metz, 1954a). Likewise sea urchin eggs appear to retain a bound layer of fertilizin at their surfaces after the outer gelatinous coat has been removed by acid treatment or enzymatic digestion (Tyler, 1941; Tyler and Metz, 1955). As Tyler (1948a) suggests, the normally jellyless 
eggs of many forms may prove to be comparable to jelly-free sea urchin eggs with respect to fertilizin.

It should be evident from the foregoing discussion that fertilizin may exist in several forms and that any one of a variety of methods may be required to demonstrate it. Clearly then, the possibility that fertilizin, in one form or another, occurs widely or universally among eggs cannot yet be rejected.

Source of Fertilizin. Lillie (1914) believed that fertilizin was produced continuously by Arbacia eggs. Loeb (1914, 1915), however, found that after dissolving the gelatinous coat in acidified sea water no fertilizin could be obtained from sea urchin eggs. This has been confirmed repeatedly (Tyler and Fox, 1939, 1940; Tyler, 1940a; Hartmann, Schartau, and Wallenfels, 1940; see also Runnström, 1949a; Tyler, 1948a). In fact fertilizin appears to be the sole component of the jelly for Tyler (1949) and Rumnström, Tiselius, and Vasseur (1942) found that solutions of the coat are homogeneous upon electrophoretic or ultacentrifugal analysis.

Although identification of fertilizin with the jelly layer of sea urchin eggs is well established, the cellular origin of the jelly is disputed. For example, on the basis of histological studies Jenkinson (1911) believed that the jelly is layed down by the follicle cells of the ovary, whereas Lindahl (1932) concluded that the egg itself produces the jelly. Later Vasseur (1951) obtained fertilizin from the ovaries of spent sea urchins. Since these ovaries lacked eggs, Vasseur concluded that the fertilizin was produced by ovarian tissue, not by eggs. However, fertilizin from eggs may have remained in the ovary after the eggs were shed.

In this connection it is of interest that Mellita quinquiesperforata egg suspensions obtained by the $\mathrm{KCl}$ injection method frequently contain jellies which do not enclose eggs. Indeed, over $90 \%$ of jellies from some females are empty (Metz, umpublished). These empty jellies may have been laid down independently by ovarian tissue in the absence of eggs, or the eggs may have escaped from the jellies. The former possibility seems more likely since the suspensions do not contain proportionate numbers of naked eggs. Nevertheless, in the writer's opinion definite con- 
clusions concerning the cellular origin of the echinoid egg jelly must await further study. Perhaps an investigation of the cellular origin of the echinochrome bodies in sanddollar egg jellies might be rewarding in this regard.

Although the jelly surrounding the sea urchin egg is clearly the main source of fertilizin, studies indicate that fertilizin or fertilizin like material may also be obtained from less superficial regions of the egg. Thus Motomura (1950a) reported extraction of a sperm agglutinin from unfertilized, jellyless S. pulcherrimus eggs by prolonged standing in sea water, by boiling, and by shaking jellyless, fertilized eggs to break the fertilization membranes. On the basis of these experiments Motomura concluded that the sea urchin egg produces a second sperm agglutinin, cytofertilizin. Following certain objections to these experiments (Byers, 1951) Motomura (1953a,b) extended his studies. He found that the surrounding sea water becomes charged with sperm agglutinin upon hatching of blastulae from jellyless eggs. Furthermore, jellyless eggs treated with NaSCN to remove the vitelline membrane charge the sea water with agglutinin during the first ten minutes after fertilization. Finally Temnopleurus hardewickii eggs normally fail to produce a satisfactory agglutinating egg water, but after removal of the jelly and membranes fertilized eggs, blastulae or gastrulae of this species charge the sea water with sperm agglutinin. The exact source of Motomura's cytofertilizin has yet to be established, but the hyaline layer material of the egg is one likely possibility (Tyler, Monroy, and Metz, 1956). This view is supported by cytochemical studies at least to the extent that the egg jelly, the hyaline layer material and the cortical granules give positive tests for acid polysaccharides (Monné and Slautterback, 1950; Monné and Harde, 1951).

According to Motomura's experiments the egg jelly fertilizin and cytofertilizin have different $\mathrm{pH}$ optima for extraction. This suggests that they may be chemically different, although it may only reflect differences in bonding of the same agent. In any event a comparison of the biological properties of the two agents should be made. Information on the specificity of cytofertilizin agglutination and the effect of cytofertilizin on sperm that have 
reversed after agglutination with normal fertilizin will be awaited with particular interest.

The source of fertilizin has been examined seriously in only two forms other than the sea urchin, namely the gastropod, Megathura, and the amnelid, Nereis. Megathura (Tyler, 1940a) is similar to the sea urchin. The unfertilized egg is surrounded by a gelatinous coat. When this coat is removed, no further fertilizin can be obtained from the egg.

Conditions in Nereis are more complex. The unfertilized egg has no substantial gelatinous coat (Lillie, 1911). However, upon activation of the egg a thick jelly is extruded. The mechanism of this release of jelly has been investigated most recently by Costello (1949). He has shown that the jelly arises by a transformation of certain granules released from the egg cortex. The egg water of unfertilized Nereis eggs contains fertilizin (Lillie, 1913b). Therefore release of some fertilizin does not depend upon visible extrusion of the jelly. However, solutions of the jelly, obtained by treating eggs with alkaline sea water (method of Novikoff, 1939; Costello, 1945) give higher sperm agglutination titers than normal egg water controls (Tyler, 1948b). This suggests that the jelly material of the Nereis egg may be the fertilizin. To account for the fertilizin in normal egg water Tyler suggests that some of the jelly material may diffuse from the normal, unfertilized egg. In any event these experiments are evidence that the fertilizin of Nereis is produced by the egg itself, not by follicle cells of the ovary.

Effect of Removal and Addition of Fertilisin on Fertilizability of the Egg. If fertilizin is essential for fertilization, fertilizin-free eggs should fail to fertilize and fertilizability should be restored upon addition of fertilizin. This test for the essentiality of fertilizin has been attempted by a number of workers (see Tyler, 1948a for thorough review of this work). Fertilizin camnot be demonstrated in washings from acid-treated, jellyless eggs. Nevertheless such eggs can be fertilized. Clearly then, fertilizin is not essential for fertilization or the extraction procedure fails to remove all the fertilizin. In support of the latter view Frank (1939) and Tyler (1941) have shown that jellyless eggs agglutinate when 
treated with antifertilizin from sperm. This result indicates that some fertilizin remains bound to the egg surface.

Similar results have been obtained following treatment of Arbacia eggs with crystalline trypsin and chymotrypsin (Tyler and Metz, 1955). The digestion removes the egg jellies, but these eggs fertilize when inseminated. Interpretation of the action of the enzymes is complicated by the fact that the treated eggs fail to elevate fertilization membranes upon fertilization. This suggests that the enzymes digest not only the jelly but also the vitelline membrane of the egg and any fertilizin bound to it, including that remaining after acid sea water treatment. Even though the vitelline membrane may be removed and in spite of the fact that such eggs show a greater receptivity to foreign sperm (Hultin, 1948a,b; Bohus Jensen, 1953a,b; Tyler and Metz, 1955), they still agglutinate on addition of antifertilizin (Tyler and Metz, 1955). If it is assumed that antifertilizin suffers no loss in specificity upon extraction from the sperm, it must be concluded that some fertilizin, possible cytofertilizin, resists the action of trypsin for some time.

Evidently, then, an unequivocal test of the fertilizability of the fertilizin-free egg has yet to be devised. Nevertheless, removal of the jelly by acid or enzymes lowers the fertilizability of eggs to the extent that more sperm are required to obtain a given percentage of fertilized eggs. Furthermore, the fertilizability and antifertilizin agglutinability decrease in parallel fashion upon prolonged treatment with trypsin (Tyler and Metz, 1955). Finally, antifertilizin treatment greatly reduces the fertilizability of both control and jellyless eggs (Tyler, 1941; Tyler and Metz, 1955). These experiments, then, show quite clearly that fertilizin in the form of the jelly layer aids fertilization. Furthermore, they strongly suggest that fertilizin at the egg surface is essential for fertilization.

If fertilizin is an aid to or essential for fertilization, addition of more fertilizin to eggs, especially jellyless eggs, might be expected to improve fertilization. However, as Tyler (1941) points out, no way has yet been found to cause added fertilizin to assume its normal relationship (a jelly layer) to the egg. Furthermore, Mon- 
roy et al. (1954) have shown that fertilizin in solution and in the gel form have somewhat different chemical as well as physical properties. Finally, fertilizin in concentrated solution can act upon and saturate the sperm while the latter is still distant from the egg (see below). In view of these considerations it is not surprising that addition of fertilizin fails to increase the fertilizability of eggs, even jellyless eggs (Tyler, 1941).

Effect of Fertilizin on the Fertilizing Capacity of Sperm. In the sea urchin, sperm agglutination spontaneously reverses. If the sperm is initially treated with an excess of fertilizin, the "reversed" sperm fail to reagglutinate on further addition of fertilizin. This indicates that the surface antifertilizin of the sperm is bound or blocked by univalent fertilizin (Fig. 1). Such saturation of the surface might be expected to have a profound effect upon the fertilizing capacity of the sperm. However, it should be noted at the outset that tests of the fertilizability of reversed sperm are critical only if the sperm surface antifertilizin is completely blocked or unless an elaborate quantitative measurement of sperm fertilizability is performed. With this factor controlled Tyler (1941) found a marked reduction in fertilizing capacity of reversed S. purpuratus sperm. Similarly, reduction in fertilizing power has been reported in some other sea urchins (e.g., Dan, $1954 \mathrm{~b}$ ). On the other hand, a number of investigators have obtained no significant reduction in fertilizing capacity of fertilizintreated sperm of other species (e.g., Fuchs, 1914, 1915; Hagström, 1956; Runnström, 1949a). Most of these reports failed to take into account the degree of saturation of the sperm with fertilizin. Finally, in studies of several forms (Metz, 1942b; Metz and Donovan, 1949; Tyler and Metz, 1955), species differences were found. In Mactra (Spisula) solidissima, and S. purpuratus, fertilizin treatment markedly reduced the fertilizing capacity of the sperm, but it failed to do so in Arbacia punctulata and Mellita quinquiesperforata. However, these species differences appear to be relative, not absolute, for Tyler and Metz (1955) did find a reduction in fertilizing capacity when the reversed sperm of

* Lillie (1913b) reported reduction of fertilizing capacity of Arbacia sperm after fertilizin treatment. 
Arbacia and Mellita were tested for their ability to fertilize jellyless (trypsin-treated) eggs. Evidently jellyless eggs provide a more sensitive system for testing the effect of fertilizin on sperm, and use of this system may resolve the conflicting data of the past.

The experimental results reviewed in this section, then, show that fertilizin at the egg surface facilitates fertilization whereas the same agent in solution, by virtue of its combination with sperm, acts as a barrier to fertilization. The apparent inconsistency of these observations is resolved (Tyler, 1941, 1948a, 1955; Tyler and Metz, 1955) in terms of an essential role of fertilizin in linking the sperm to the egg surface. According to this concept, fertilizin molecules attached to or built into the egg surface combine with antifertilizin groups of the sperm to effect the linkage. Thus if the free fertilizin groups at the egg surface are reduced in number by acid extraction, enzymatic digestion or blockage with antifertilizin, the fertilizability of the egg is reduced. Likewise, blocking the antifertilizin groups of the sperm with univalent fertilizin (e.g., "reversed" sperm) or univalent antisera (Tyler, 1946a) reduces the number of such groups available for combination with the egg surface fertilizin and correspondingly lowers the fertilizing capacity of the sperm.

It might be expected that the sperm surface would be saturated by fertilizin during its passage through the egg jelly and before the sperm reaches the egg surface fertilizin. In considering this possibility Tyler (1948a) suggests that the specific reactive groups of fertilizin in the gel form may be bound by cross linkages. Such linked groups would not be freely available to combine with the sperm. Differences in the metachromatic staining properties of fertilizin in the gel form and in sea water solution (Monroy et al., 1954) are in keeping with this view.

\section{Chemistry of Fertilizin}

The chemistry of fertilizin has been reviewed on several occasions (Tyler, 1948a, 1949, 1955; Runnström, 1949a, 1952; Vasseur, $1952 \mathrm{a})$. Therefore the present treatment will be confined largely to recent work. 
Chemical studies have been restricted mainly to the fertilizins from sea urchins. Sea urchin fertilizin (egg jelly or jelly coat subsiance) can be prepared in rather pure form by brief extraction of washed eggs in acid solution (see Tyler 1949, for method). Such preparations give a single component on ultracentrifugal and electrophoretic examination. These purified fertilizins have been employed in the analytical studies. They are found to be glycoproteins which, on hydrolysis, yield a number of amino acids, one or a few monosaccharides and considerable sulfate. The amino acid composition of several species has been examined. In S. purpuratus chromatographic analyses (Tyler, 1948c, 1949, $1955)$ have revealed fifteen amino acid spots identified as glycine, alanine, serine, threonine, valine, leucine, isoleucine, aspartic, glutamic, arginine, lysine, phenylalanine, tyrosine, tryptophane, and proline. In Echinus esculentus, Paracentrotus lividus, and Strongylocentrotus droebachiensis nine (lysine, arginine, histidine, valine, isoleucine, threonine, phenylalanine, tyrosine, and proline) were demonstrated by microbiological assay (Vasseur, 1948, 1952a). Aspartic and glutamic acids were also found in these fertilizins by chromatography (Vasseur, 1948). Thus a considerable number of amino acids are present in sea urchin fertilizin. The proportions of the amino acids showed little variation among the above three species studied by Vasseur. However, Echinocardium cordatum fertilizin was low in lysine and valine.

The monosaccharides found in hydrolyzates of several species are listed in Table III. In contradistinction to the amino acids, the number of different monosaccharides in any species is small. The galactose of E. esculentus occurs mainly in the "unnatural" or L-form (Vasseur, 1950).

Sulfate has been found to the extent of about $25 \%$ in most fertilizins (e.g., S. drocbachiensis, Vasseur, 1947; S. purpuratus, Tyler, 1949). Brissopsis lyrifera fertilizin, on the other hand, is low in sulfate (about $4 \%$ ). This, correlated with the fact that B. lyrifera fertilizin does not agglutinate sperm (Vasseur, 1952a; Vasseur and Carlsen, 1948; Vasseur and Hagström, 1946), suggests that sulfate groups are essential for helping endow the molecule with agglutinative properties (see below). 
TABLE III. Monosaccharides Identified in Hydrolyzates of Sea Urchin Fertilizins

\begin{tabular}{|c|c|c|c|c|c|}
\hline \multirow[b]{2}{*}{ Species } & \multicolumn{4}{|c|}{ Monosaccharide } & \multirow[b]{2}{*}{ Reference } \\
\hline & Fucose & $\begin{array}{c}\text { Galac- } \\
\text { tose }\end{array}$ & $\begin{array}{l}\text { Glu- } \\
\text { cose }\end{array}$ & $\begin{array}{l}\text { Frue- } \\
\text { tose }\end{array}$ & \\
\hline $\begin{array}{l}\text { Echinocardium cordatum } \\
\text { Strongylocentrotus }\end{array}$ & $\mathrm{x}$ & & & & Vasseur, 1952a \\
\hline $\begin{array}{l}\text { droebachiensis } \\
\text { Strongylocentrotus }\end{array}$ & $\mathrm{x}$ & $\mathrm{x}$ & & & Vasseur, 1952a \\
\hline purpuratus & $\mathrm{x}$ & $\mathrm{x}$ & & & Tyler, 1955 \\
\hline Arbacia lixula & $\mathrm{x}$ & $\mathrm{x}$ & & & $\begin{array}{l}\text { Minganti, cited by } \\
\text { Monroy et al., } 1954\end{array}$ \\
\hline Paracentrotus lividus & $\mathrm{x}$ & & $\mathrm{x}$ & & Vasseur, $1952 \mathrm{a}$ \\
\hline Echinus esculentus & & $\mathrm{x}$ & & & Vasseur, $1952 \mathrm{a}$ \\
\hline Echinorachnius parma & & & & $\mathrm{x}$ & Bishop \& Metz, 1952 \\
\hline
\end{tabular}

So far fertilizin has not been separated into polysaccharide and protein moieties, at least under mild conditions. Upon oxidation of Echinocardium fertilizin with periodate, Vasseur (1952b) obtained a precipitate. Analysis of the precipitate and supernatant revealed nitrogen in both fractions. Vasseur concluded that the nitrogen in the latter was not fertilizin nitrogen. The carbohychate was largely confined to the supernatant. Since both the supernatant and precipitate fractions were nondialyzable, Vasseur concluded that he had achieved a separation into protein and carbohydrate components. However, it appears that the evidence for separate protein and carbohydrate moieties in the fertilizin molecule is incomplete.

The sulfate is probably esterified to the carbohydrate. Only half of the fucose of Echinocardium cordatum fertilizin is readily attacked by periodate. From this Vasseur (1952b) suggests that the carbohydrate portion consists of a branching fucose sulfate chain. Each fucose sulfate of the "backbone" is linked "laterally" to a single fucose sulfate side group. Only the latter have $\alpha$-glycol groups free to react with the periodate. Tyler (1948c, 1949) offered another explanation for the failure to readily obtain a separation into protein and polysaccharide components, namely, that fertilizin may not be a conjugated protein in the usual sense, 
but that the sugars and amino acids are interlinked. In any event such interlinking is probably not a simple alternation of amino acids and sugars since fertilizin contains peptide linkages as indicated by a positive biuret reaction and inactivation by proteolytic enzymes (Tyler and Fox, 1940).

As might be expected from their high sulfate content fertilizins are strongly acidic proteins. Even near $\mathrm{pH} 2$ they migrate rapidly to the anode during electrophoresis (Rumnström, Tiselius, and Vasseur, 1942; Tyler, 1949; Tyler, Burbank, and Tyler, 1954b).

Values for the molecular weight of fertilizin have been calculated from ultracentrifugation data. Earlier values [e.g., 82,000 for S. purpuratus fertilizin (Tyler, 1949)] were based on the assumption of a spherical molecule. However, the fertilizin molecule is clearly not spherical for the substance forms gels, precipitates as fibrils (Monroy, 1955), exhibits flow birefringence, and gives sedimentation values that vary with concentration. Accordingly, revised estimates of the molecular weight and axial ratios have been made from more recent sedimentation and diffusion data. These give for Arbacia punctulata fertilizin a molecular weight of 300,000 and an axial ratio of 28:1 (Tyler, Burbank, and Tyler, 1954a; Tyler, 1956). When corrected for water of hydration, this axial ratio becomes 20:1 (Tyler, 1956).

Apparently no detailed study of the chemistry of univalent sea urchin fertilizin has yet been made. Univalent fertilizin, like the multivalent agent, is nondialyzable (Tyler, 1941) and gives the mucin-clot reaction, indicating that the univalent fragments are relatively large stable subunits of fertilizin (Krauss, 1949). Production of the univalent agent by proteolytic enzymes indicates that peptide bonds may form one type of linkage between such units.

Clear understanding of the chemistry of the "reactive groups" of fertilizin has yet to be obtained. Studies of Arbacia punctulata fertilizin with a series of "protein group reagents" (Metz, 1954c; Runnström, 1935) showed that free S-S, SH, phenolic and amino groups are not essential constituents of the receptor groups of fertilizin. Strong oxidizing agents $\left(\mathrm{H}_{2} \mathrm{O}_{2}\right)$ destroy the sperm agglutinating action by conversion to the univalent form. They fail 
to inactivate the receptors. Reducing agents do not destroy the agglutinating activity.

Periodate oxidation destroys not only the agglutinating action (Immers and Vasseur, 1949) but also the receptors as shown by inhibition tests (Metz, 1954c). This action suggests that adjacent hydroxyl groups of carbohydrate may be essential, but the action of periodate is rather drastic, at least on long exposure (Vasseur, 1952b) and may involve configurational changes in the molecule which are largely responsible for the inactivation. Coupling with diazo salts also inactivates the receptor groups (Metz, 1954c), but diazo compounds react with such a variety of groups that further study will be required to understand the inactivating action of this agent.

Several investigators (e.g., Vasseur, 1948; Monroy et al., 1954) have suggested that sulfate groups are directly involved in the combination of fertilizin with sperm antifertilizin. Several lines of evidence support this view. Fertilizins low in sulfate (Brissopsis lyrifera) fail to agglutinate sperm (Vasseur, 1948; Vasseur and Carlsen, 1948). Sulfate groups are hydrolyzed from fertilizin at pH's that inactivate fertilizin (Vasseur, 1952a), but such inactive fertilizin apparently has not been tested for univalence, and blocking the basic groups of the sperm surface prevents agglutination (Metz and Donovan, 1951) by fertilizin." Finally, fertilizin is adsorbed to positively charged resins (Monroy et al., 1954). It is also adsorbed to calcium carbonate, aluminum oxide, charcoal, and kaolin (Tyler and Fox, 1940).

A final observation that requires clarification concerns the role of calcium in agglutination. In some forms this ion aids or is required for agglutination (Loeb, 1915; Vasseur, 1949a,b), but in some others it is not essential (Dan, 1954b).

* These experiments have been cited by Monroy et al. (1954) in support of the above view. They involved the use of sperm killed with Bouin's fixative. Such sperm will agglutinate with homologous (Arbacia) fertilizin but not with fertilizins from other species. This was originally interpreted to mean that the fixation did not alter the sperm surface antifertilizin. However, subsequent study (Metz, unpublished) revealed that Arbacia fertilizin will agglutinate Bouin's fixative-killed sperm of many species quite nonspecifically. 
Although sea urchin fertilizins have been examined most thoroughly, some information on the chemistry of a few other fertilizins and egg jellies is available. The invertebrates include Megathura and Nereis. Megathura fertilizin (Tyler and Fox, 1940), like sea urchin fertilizin, is nondialyzable, precipitates with protein precipitants, and gives color tests for proteins. Similarly the nitrogen content ( 4 to $5 \%$ ) of both is low. Megathura fertilizin is more stable to heat, acid, and proteolytic enzymes than sea urchin fertilizins. Possibly this is related to the fact that the Megathura sperm agglutination does not reverse spontaneously (Tyler, 1940a). Tests for univalent Megathura fertilizin following inactivation have not been reported. Nereis egg jelly has been examined by Ferry (cited by Costello, 1949) and Tyler (1938b). According to the former, the material contains less than $1 \%$ nitrogen, at least $75 \%$ carbohydrate, part or all of which may be uronic acid, and considerable bound inorganic material. Tyler found that the jelly contained about 5\% nitrogen and at least $18 \%$ reducing sugar. The fertilizins and egg jellies of some vertebrates have been examined chemically. The forms include the trout (Hartmann et al., 1947) and amphibian (Minganti, 1955).

\section{Antifertilizin from Eggs}

Lillie (1914) observed that egg water from cytolyzed sea urchin eggs failed to agglutinate sperm strongly. From this Lillie concluded that an agent, antifertilizin, was released from within the egg upon cytolysis and that the agent combined with and neutralized the fertilizin. Later the agent was obtained in active form by freeze-thawing jellyless eggs (Tyler, 1940b). Solutions of the agent form precipitates with and inactivate the sperm agglutinating action of fertilizin. They also precipitate egg jellies and agglutinate eggs.

The antifertilizin is not highly specific, for Tyler (1948a) obtained cross reactions between related echinoids. Extracts of Arbacia lixula and Paracentrotus lividus eggs give an unexpected specificity pattern when tested in the presence of electrolytes (Runnström and Monroy, 1950). Arbacia extract was relatively specific whereas Paracentrotus extract was strongly active only 
on Arbacia eggs. In sucrose solution, however, these and other cross tests revealed no specificity (Hagström and Hagström, 1955). Egg antifertilizin specificity has not been tested in forms other than echinoids.

The agent is evidently a protein since it is insoluble in protein precipitants and is inactivated by proteolytic enzymes (Tyler, 1940b, 1948a). According to Tyler (1948a) and Runnström, Wicklund, and Löw (1954) egg antifertilizin is quite heat labile. The latter workers find that Arbacia lixula egg antifertilizin is inactivated at $57^{\circ} \mathrm{C}$ in 45 minutes (Hagström and Hagström, 1955, report that the same antifertilizin is not inactive after 30 minutes at $100^{\circ} \mathrm{C}$ ).

The antifertilizin activity is associated with pigment containing granules (Monroy and Runnström, 1952; Wicklund, 1954a) of the egg cytoplasm. These granules failed to sediment at $25,000 \mathrm{~g}$ in 45 minutes, but did form a precipitate in 45 minutes at 155,$000 \mathrm{~g}$. Ultracentrifugal and electrophoretic analysis revealed two components. In the ultracentrifuge only one of these was pigmented. The component with antifertilizin activity has not been identified. Since treatment with ribonuclease appears to enhance the antifertilizin activity of the granular fraction (Rumnström, Hagström, and Löw, 1955), it is likely that the active agent is bound to RNA granules.

Egg antifertilizin may have a role in fertilization but as yet this remains to be demonstrated. The agent can be extracted from both fertilized and unfertilized eggs (Monroy and Runnström, 1952 ). It seems unlikely, then, that much, if any, of the antifertilizin is bound during or participates in the activation changes of the egg.

Antifertilizin-treated eggs do not fertilize readily (Tyler, 1940b, 1948a), as might be expected, since the agent precipitates the jelly of the egg in the form of a membrane. As Tyler (1940b) has shown, the membrane acts as a mechanical barrier to the sperm; likewise fertilizability of jellyless eggs is inhibited. This effect has been cited in the case of sperm antifertilizin in support of an essential role of fertilizin in fertilization (Tyler and Metz, 1955 ). The argument applies equally well for egg antifertilizin. 
Apparently, in dilute solution, egg antifertilizin can aid fertilization to the extent that the "fertilization rate" of both normal and jellyless eggs is increased (Hagström and Hagström, 1955). This action was most pronounced when fertilization was performed in the solution. This and the fact that the action was cluplicated by albumen suggests that the effect may have been upon the sperm. It is probably due to a metal binding action of the egg extract. Antifertilizin evidently facilitates the parthenogenetic action of hypertonic sea water (Runnström, Wicklund, and Löw, 1954).

In several recent reports (Motomura, 1950b; Monroy and Rumnström, 1950, 1952; Wicklund, 1954b; Runnström, Wicklund, and Löw, 1954) agents from eggs which thicken, toughen, or facilitate elevation of the fertilization membrane have been described, and a possible relation of the active agent or agents to egg antifertilizin has been suggested. Evidently the membrane elevating factor differs from antifertilizin since the two effects are associated with separate fractions in the ultracentrifuge and have different heat labilities (Runnström, Wicklund, and Löw, 1954). With regard to this effect it should be noted that metal binding agents act on sperm to facilitate membrane elevation (Tyler, 1953).

The membrane toughening action appears to be associated with pigment granules of the egg (Monroy and Runnström, 1952; Wicklund, 1954a). An agent with similar action is extractable from fertilized eggs with weak ( $\mathrm{pH}$ 4.5) acid (Motomura, 1950b). The membrane toughening and egg jelly precipitating effects have not been separated. These may be different manifestations of antifertilizin action.

Upon treatment of eggs with iodosobenzoic acid (Monroy and Runnström, 1952) or anisotonic sea water (Runnström and Monroy, 1950; Wicklund, 1954a) varying degrees of cytolysis of fertilized eggs are induced. Such cytolysis is associated with a release of pigment from the egg, a thickening of the fertilization membrane and sometimes a partial precipitation of the egg jelly outside the fertilization membrane. These observations indicate a release of the agent(s) responsible for membrane toughening and jelly precipitation. They also suggest (Motomura, 
1950b; Runnström, Wicklund, and Löw, 1954) the possibility of release of the responsible agent $(s)$ at fertilization under normal conditions. However, the situation is complicated by cytofertilizin which, according to Motomura (1950a, 1953a,b) is also released by the egg at fertilization. Antifertilizin and cytofertilizin might be expected to interact with mutual neutralization. The two agents would not be expected to exist together in active form. Even if they were released separately they should interact in the perivitelline space, and only the agent in excess should be detectable. In view of this apparent inconsistency, the release of antifertilizin and cytofertilizin must be re-examined with a strict accounting of both agents.

\section{Agents from Sperm}

Several agents have been obtained from sperm which may function in fertilization. These include the antifertilizin from sperm, egg membrane lysins, and preparations which affect the physiological activity of sperm. Before considering these it should be emphasized again that agents in sperm extracts which act upon gametes may be products of the method of preparation. Such agents may not exist in an active form and function in fertilization under physiological conditions.

\section{Antifertilizin from Sperm}

Agglutination of sperm by fertilizin implies the existence of a specific receptor on the sperm surface (Fig. 1). The agent, antifertilizin," should have biological properties similar to those of the antifertilizin from eggs. It should occur in appreciable amounts on the sperm surface. In solution it should neutralize fertilizin, precipitate egg jellies and agglutinate eggs. Preparations with such properties have been obtained from sea urchin sperm by heating (Frank, 1939), freeze thawing (Tyler, 1939b), extraction with weak acid (Tyler and O'Melveny, 1941), or by

* Sperm antifertilizin (Tyler and O’Melveny, 1941) = Sperm receptor (Lillie, 1913a, 1914) = Androgamone II (Hartmann et al., 1940) = Jelly precipitating factor from sperm, abbreviated JePpF (S) (Hultin et al., 1952). 
centrifuging sperm (Southwick, 1939; see also Tyler, 1948a, for further details). The active agent in these preparations is considered by most investigators to be antifertilizin, the sperm surface receptor substance that combines with fertilizin at agglutination. According to the analysis of Tyler and of Rumnström, Tiselius, and Vasseur (see Tyler, 1948a, for review), the active agent gives the usual protein tests, is relatively heat stable, contains about $16 \%$ nitrogen, and can be prepared in electrophoretically homogeneous form. It is inactivated by proteolytic enzymes. Ultracentrifugation, electrophoretic mobility, and isoelectric precipitation studies indicate a molecule with an acid isoelectric point and a molecular weight under 10,000.

Unfortunately, this agent has been confused, as a result of experiments of Hultin (1947b, 1949), with the basic proteins (protamines, histones) from sperm. Solutions of basic proteins are readily prepared by acidifying a sperm suspension to $\mathrm{pH} 1$ or lower, separating the insoluble nucleic acid from the dissolved basic protein by centrifugation and neutralizing the basic protein containing supernate. Basic proteins characteristically combine with a wide variety of substances and cells, precipitating the former and agglutinating the latter. It is not suprising, therefore, that sea urchin sperm basic protein agglutinates both the sperm and the eggs of the homologous species (Metz, 1942b, 1949; Hultin, 1947a) as well as a variety of unrelated forms (see Metz, Foley, and Donovan, 1949, concerning specificity). Because of the agglutinating action on sea urchin eggs and certain other considerations, Hultin (1947b) concluded that the egg agglutinins prepared by freeze thawing, heating, or mild acid extraction of sperm are also basic protein, not the specific receptor substance (antifertilizin) of the sperm surface. However, the latter preparations agglutinate only eggs, whereas the basic proteins agglutinate both sperm and eggs. Furthermore, the egg agglutinating action of antifertilizin is destroyed by the basic protein extraction procedure ( $\mathrm{pH} 1$ or lower), and mixture of the two extracts results in mutual neutralization (Metz, 1949). In view of these observations and the acid isoelectric point of antifertilizin (Tyler, 1949; Runnström, Tiselius, and Vasseur, 
1942), it is evident that the egg agglutinating action is not due to basic protein. Hultin (1949) also ascribed the egg agglutinating action of antifertilizin preparations to the nucleoprotein sometimes present in such solutions. However, the main activity of antifertilizin solutions cannot be attributed to nucleoprotein (Metz and Tyler, independent unpublished studies) because the nucleic acid content is not related to the biological activity of antifertilizin preparations. Thus one extract prepared by freezethawing Arbacia sperm (egg agglutinin titer 16) gave positive reactions with Schiff's reagent, both before and after hydrolysis, no color with diphenylamine (Dische test), and no absorption maximum at $260 \mathrm{~m} \mu$ when diluted to $1 / 10$. Two other preparations gave absorption peaks at $260 \mathrm{~m} \mu$ when diluted beyond the range of biological activity. Clearly, then, the egg agglutinating action of antifertilizin is not dependent upon nucleoprotein.

In other studies Motomura (1954, 1955) has prepared acid extracts of acetone-precipitated echinoid sperm. The extracts agglutinated eggs and sperm and precipitated with hen's egg white. It seems most probable that Motomura's agent is also basic protein. The writer has repeated Motomura's procedure and obtained an agent which appears to be identical with the basic protein extracted from sperm by less elaborate methods.

Evidently, two agglutinins may be obtained from sperm. One of these is a basic protein(s) of histone type (Hamer, 1955). It agglutinates both eggs and sperm. The other is an acidic protein containing very little if any nucleic acid. It agglutinates only eggs.

Although the egg agglutinating agent is not a nucleoprotein or basic protein, the question may be raised whether it actually is the sperm receptor substance, antifertilizin. Information on this point might be obtained by consideration of the agent's source and specificity. Extraction of the egg agglutinin with weak acid $(\mathrm{pH} 3)^{2}$ results in swelling and partial dissolution of the sperm head surface between the acrosome and midpiece (Tyler, 1949). This indicates that the agent may have been removed from this region of the sperm surface. The specificity has been examined 
by several workers (Frank, 1939; Tyler, 1940b, 1948a; Hartmann et al., 1940; Hultin, 1947b, 1949; Runnström et al., 1942, 1944) all of whom have reported cross reactions. Some of these reactions were between distantly related forms clearly beyond the bounds of fertilizin agglutination specificity. However, as Tyler (1948a) pointed out, cross agglutination of eggs by sperm extracts may result from action of natural heteroagglutinins, not from antifertilizin cross reactions. Natural heteroagglutinins for sperm, eggs, and red cells occur widely in invertebrate bloods and seminal fluids (Tyler and Metz, 1945; Tyler, 1946b; Metz, 1949). Another possibility is that the specificity of antifertilizin is altered upon extraction from the sperm. Such loss of specificity could result from alteration of the specific receptor groups or from exposure of other less specific groups that are normally bound. Evidently, the question of identity of the sperm surface antifertilizin with the egg agglutinating agent cannot be settled by the available specificity data. A thorough test of antifertilizin specificity, taking the above factors into consideration, should be performed.

Role in Fertilization. If fertilizin is essential for fertilization by virtue of a specific interaction with the sperm, then antifertilizin must also be essential. However, the role of fertilizin in fertilization is uncertain. Therefore, independent evidence for the role of antifertilizin has been sought. Thus blocking the sperm surface antifertilizin with fertilizin (Tyler, 1941; Tyler and Metz, $1955)$ or with univalent antibodies prepared from rabbits immunized with purified antifertilizin (Tyler, 1946a) reduces the fertilizing capacity of sperm. Likewise partial removal of antifertilizin from the sperm surface renders these cells less effective in fertilization (Tyler and O'Melveny, 1941). Finally, treatment of normal or jellyless eggs with antifertilizin solution (Tyler and Metz, 1955) lowers fertilizability of eggs. This action on normal eggs is evidently due to the precipitation of the egg jelly in the form of a membrane. impermeable to the sperm (Tyler and O'Melveny, 1941). Sperm penetration of normal egg membranes is considered below. 
These experiments indicate that antifertilizin at the sperm surface is an aid to fertilization and render likely the possibility that the agent is essential for fertilization.

\section{Sperm Paralyzing Agents}

Several workers (e.g., Southwick, 1939; Hartmann, Schartau, and Wallenfels, 1940; Vasseur and Hagström, 1946; Rumnström, Lindvall, and Tiselius, 1944; Rothschild, 1948) have found that seminal fluid or sperm extracts, mainly from sea urchins, inhibit sperm motility. Hartmann et al. (1940) attributed the action to an agent, androgamone I. Other investigators working on other forms have failed to find comparable action. In certain cases the paralyzing effect is evidently due to $\mathrm{O}_{2}$ lack. Only in the case of the salmon is it probable that the agent is normally functional (Rothschild, 1951b). Tyler (1948a), Runnström (1949a), and Rothschild (1951b) have reviewed these studies in detail.

\section{Egg Membrane and Surface Lysins from Sperm}

In many forms the egg is surrounded by extraneous jelly layers, membranes, cell layers, or a combination of these. Such membranes are mechanical barriers to the fertilizing sperm. These and the egg surface itself must be penetrated for the sperm to enter the egg cytoplasm. Such penetration is evidently achieved, in some forms at least, through the action of egg membrane lysins carried by the sperm. Indeed, of the various "sex substances" that have been obtained from gametes only these membrane lysins have well-understood action in fertilization. The most thoroughly studied of these agents are the membrane lysins from the sperm of molluses and hyaluronidase in mammals. Since the role of hyaluronidase in mammalian fertilization is discussed elsewhere (Chang, this volume), it will be omitted here. Among molluscs the limpet, Megathura crenulata and the mussel, Mytilus edulis, have been examined in most detail.

Freshly shed Megathura eggs are surrounded by a jelly layer and a rather thick membrane. The latter is closely applied to the egg but gradually rises as the egg stands in sea water. Upon heavy insemination, the membrane disappears. The responsible 
agent is weakly bound to the sperm surface since, on standing, sperm suspensions gradually charge the sea water with membrane lysin (Tyler, 1939b; Krauss, 1950a). The lysin can be extracted with alkali (Krauss, 1950a) or by freeze thawing (Tyler, 1939b). The lytic agent and the Megathura antifertilizin also present in frozen-thawed extracts are distinct since the two agents have different heat stabilities [the lytic agent is rapidly destroyed at $60^{\circ} \mathrm{C}$; antifertilizin remains active for some time at $100^{\circ} \mathrm{C}$ (Tyler, 1939b; Krauss, 1950a)], and they can be extracted separately [the lysin with alkali; antifertilizin with acid (Krauss, 1950a) ]. The Megathura egg membrane lysin is evidently a labile protein (Tyler, 1939b); Krauss, 1950a). Release of the lysin by alkali is associated with dissolution of the sperm acrosome (Tyler, 1949). Krauss (1950a) suggests that the lysin may act by rechucing disulfide linkages since cysteine and other sulfhydryl reagents dissolved the membrane. However, he was unable to demonstrate free SH groups in the native extract or block the action of the lysin with iodoacetate.

Unfertilized Mytilus edulis eggs are surrounded by a thin, tight vitelline membrane. This membrane is lysed by frozen-thawed or acid extracts of Mytilus sperm (Berg, 1949, 1950). Furthermore, if eggs are permitted to cleave in these extracts, the resulting blastomeres are very loosely joined. The intercellular cement is evidently attacked by the extract. The two effects may result from separate agents, for the membrane lysin is more readily destroyed by heat than the cement lysin. Furthermore, only the latter action is inhibited in concentrated sperm extracts. Both agents appear to be proteins (Berg, 1950). Lytic agents comparable to those from Megathura and Mytilus sperm have been demonstrated in sperm extracts of several other molluses (Tyler, 1939b; von Medem, 1942, 1945) and the amphibian, Discoglossus pictus (Hibbard, 1928). Concentrated sperm suspensions have similar action on the egg membrane of the annelid Pomatoceros triquester (Monroy, 1948). In fact, it is reasonable to assume some such agent for species with eggs that are surrounded by heavy membranes, even when the lysin is not found in sperm extracts [e.g., Cerebratulus (Metz, unpublished)]. 
These lytic agents not only permit penetration of the egg membranes by the sperm, but they may also contribute a specificity factor in fertilization. Thus the lysins and eggs of Haliotus and Megathura do not cross react (Tyler, 1939b). Mytilus californianus extracts dissolved both the egg membrane and intercellular cement of $M$. edulis but cross reaction did not occur in the reverse combination. Extracts from neither species acted on eggs of more distantly related forms. Likewise, sperm extracts from such foreign species did not act on Mytilus eggs (Berg, 1950). In other molluses the lytic action is also largely specific (von Medem, 1942, 1945). Krauss (1950b), however, reported an interesting heterologous reaction, namely lysis of the Megathura membrane by a heat-labile agent from sea urchin sperm.

Although the cases described above are well established, the situation in the sea urchin has been disputed. In sea urchins a special lytic agent may not be required for penetration of the sperm through the jelly. In most species the jelly is not highly viscous and is readily soluble in weak acid. The $\mathrm{CO}_{2}$ procluced by the penetrating sperm may be sufficient to dissolve a path to the egg surface. Claims that the sea urchin egg jelly is dissolved by depolymerases from the sperm have not been substantiated (Krauss, 1950c; Monroy and Tosi, 1952; Monroy et al., 1954).

Aside from action on the egg jelly, extracts have been prepared from sperm which act upon the egg surface. Rumnström, Lindvall, and Tiselius (1944) found that the methanol extracts of sea urchin sperm caused eggs to shrink without wrinkling in hypertonic sea water. This and other tests led to the view that the methanol extracts partially lysed or liquefied the egg surface. This egg surface lysin (androgamone III) was found to be heat stable and dialyzable. These and other properties, including duplication of the action by detergents, led to the view that the agent is a low-molecular-weight, surface-active agent of fatty acid nature (Rumnström, Tiselius, and Lindvall, 1945; Runnström and Lindvall, 1946; Rumnström, 1947, 1949a). Sperm supernatants have the same action as methanol extracts. Therefore the agent may be available and function under physiological conditions. 
The agent inhibits the sperm agghtinating action of fertilizin (presumably in the absence of antifertilizin) and fertilization. The latter action is reversible to the extent that eggs washed free of the extract will fertilize although development is abnormal (Runnström, 1947). Runnström and co-workers suggest a number of possible functions for the agent in fertilization. However, judgment as to the function of the agent should be withheld pending further study.

\section{Summary}

It is evident from the account given here that fertilization and especially the activation of the egg cannot as yet be described completely in terms of the interaction of known specific egg and sperm substances. However, it is equally clear that agents are known which have specific action upon gametes of the opposite sex. Of these the egg membrane lysins from sperm perform a definite, and essential, though secondary, function in fertilization, namely, removal of mechanical barriers between the approaching sperm and the egg surface. Agents from eggs would also appear to facilitate fertilization by physiological action on sperm. Increase in sperm motility is one of the more obvious of these effects. Fertilizin and antifertilizin on the surfaces of the respective gametes may well be the receptor agents by which sperm and eggs make initial union. Furthermore, the presence of these substances on the gametes and not on other tissues can account for the tissue specificity of fertilization. Likewise, the species specificity of fertilization may be attributed largely, if not entirely, to these agents, since action of fertilizin on sperm parallels roughly the species specificity of fertilization. Positive evidence for a direct and essential role of known substances in the primary activation reactions is wanting. On the other hand, the possibility of such action, especially for fertilizin and antifertilizin is not exchuded by the available evidence. It remains to discover the role that known agents (especially fertilizin and antifertilizin) play in the activation of the egg and perhaps to discover other agents which are as yet unknown and unsuspected. 


\section{REFERENCES}

Berg, W. E. 1949. Some effects of sperm extracts on the eggs of Mytilus. An. Naturalist, 83, 221-26.

Berg, W. E. 1950. Lytic effects of sperm extracts on the eggs of Mytilus edulis. Biol. Bull., 98, 128-38.

Bielig, H. J., and F. G. von Medem. 1949. Wirkstoffe der tierischen Befruchtung. Experientia, 5, 11-30.

Bielig, H. J., and P. Dohrn. 1950. Zur Frage der Wirkung von Echinochrom A und Gallerthullensubstanz auf die Spermatozoen des Seeigels Arbacia lixula (A. pustulosa). Z. Naturforsch, 5b, 316-38.

Bishop, D. W., and C. B. Metz. 1952. Fructose as a carbohydrate constituent of fertilizin from the sand-dollar, Echinarachnius parma. Nature, 169, 548.

Bohus Jensen, A. 1953a. Some observations on the action of trypsin on sea urchin eggs. Exptl. Cell Research, 4, 60-68.

Bohus Jensen, A. 1953b. The effect of trypsin on the cross fertilizability of sea urchin eggs. Exptl. Cell Research, 5, 325-28.

Byers, H. L. 1951. Failure to obtain "cytofertilizin" from Arbacia eggs. Biol. Bull., 101, 218 (abstract).

Carter, G. S. 1930. Thyroxine and the oxygen consumption of the spermatozoa of Echinus miliaris. J. Exptl. Biol., 7, 41-48.

Carter, G. S. 1931. Iodine compounds and fertilization. II. The oxygen consumption of suspensions of sperm of Echinus esculentus and Echinus miliaris. J. Exptl. Biol., 8, 176-93.

Clowes, G. H. A., and E. Bachman. 1921. A volatile, sperm-stimulating substance derived from marine eggs. J. Biol. Chem., 46, xxxi-xxxii (abstract).

Colwin, A. L., and L. H. Colwin. 1955. Concerning the spermatozoon and fertilization in the egg of Sabellaria vulgaris. Biol. Bull., 109, 357 (abstract).

Colwin, L. H., and A. L. Colwin. 1955a. Some factors related to sperm entry in two species of Asterias. Biol. Bull., 109, 357 (abstract).

Colwin, L H., and A. L. Colwin. 1955b. The spermatozoon and sperm entry in the egg of the holothurian, Thyone briareus. Biol. Bull., 109, 357-58 (abstract).

Cornman, I. 1941. Sperm activation by Arbacia egg extracts, with special reference to echinochrome. Biol. Bull., 80, 202-7. 
Costello, D. P. 1945. Experimental studies of germinal localization in Nereis. I. The development of isolated blastomeres. J. Exptl. Zool., 100, 19-66.

Costello, D. P. 1949. The relations of the plasma membrane, vitelline membrane, and jelly in the egg of Nereis limbata. J. Gen. Physiol., $32,351-66$.

Dan, J. C. 1952. Studies on the acrosome. I. Reaction to egg-water and other stimuli. Biol. Bull., 103, 54-66.

Dan, J. C. 1954a. Studies on the acrosome. II. Acrosome reaction in starfish spermatozoa. Biol. Bull., 107, 203-18.

Dan, J. C. 1954b. Studies on the acrosome. III. Effect of calcium deficiency. Biol. Bull., 107, 335-49.

Dan, J. C. 1956. The acrosome reaction. Intern. Rev. Cytol., 5, 365-93.

Dan, J. C., and S. K. Wacka. 195.5. Studies on the acrosome. IV. The acrosome reaction in some bivalve spermatozoa. Biol. Bull., 109, 4055.

Felix, K. 1955. Protamines, nucleoproteins, and nuclei. Am. Scientist, $43,431-49$.

Frank, J. A. 1939. Some properties of sperm extracts and their relationship to the fertilization reaction in Arbacia punctulata. Biol. Bull., 76, 190-216.

Fuchs, H. M. 1914. The action of egg-secretions on the fertilizing power of sperm. Arch. Entw.-mechan., 40, 205-52.

Fuchs, H. M. 1915. Studies in the physiology of fertilization. J. Genetics, 4, 215-301.

Glaser, O. 1914. A qualitative analysis of the egg-secretions and extracts of Arbacia and Asterias. Biol. Bull., 26, 367-86.

Gray, J. 1928. The effect of egg-secretions on the activity of spermatozoa. J. Exptl. Biol., 5, 362-65.

Hagström, B., and B. E. Hagström. 1955. The action of a jelly precipitating factor on the fertilization in sea urchins. Arkiv Zool., ser. 2, 7, 579-85.

Hagström, B. E. 1956. Studies on the fertilization of jelly-free sea urchin eggs. Exptl. Cell Research, 10, 24-28.

Hamer, D. 195.5. The composition of the basic proteins of echinoderm sperm. Biol. Bull., 108, 35-39.

Hartmann, M., F. G. von Medem, R. Kuhn, and H. J. Bielig. 1947. Untersuchungen uber die Befruchtungsstoffe der Regenbogenforelle. Z. Naturforsch. 2b, 330-49. 
Hartmann, M., R. Kuhn, O. Schartau, and K. Wallenfels. 1939. Uber die Sexualstoffe der Seeigel. Naturwissenschaften, 27, 433.

Hartmann, M., O. Schartau, and K. Wallenfels. 1940. Untersuchungen uber die Befruchtungsstoffe der Seeigel. II. Biol. Zentr., 60, 398-23. Hayashi, T. 1946. Dilution medium and survival of the spermatozoa of Arbacia punctulata. 1I. Effect of the medium on respiration. Biol. Bull., 90, 177-87.

Hibbard, H. 1928. Contribution a l'étude de l'ovogenese, de la fécundation, et de l'histogenèse chez Discoglossus pictus otth. Arch. Biol., $38,251-326$.

Hultin, E., G. Kriszat, S. Lindvall, G. Lundblad, H. Low, J. Runnström, E. Vasseur, and E. Wicklund. 1952. On the interaction between the gametes of the sea urchin at fertilization. Arkiv Kemi, 5, 83-87. Hultin, T. 1947a. Some physiological effects of basic sperm proteins. Arkio Kemi, 24B, No. 12, 1-6.

Hultin, T. 1947b. On the question of sperm antifertilizin. Pubbl. staz. zool. Napoli, 21, 153-63.

Hultin, T. 1948a. Species specificity in fertilization reaction. I. The role of the vitelline membrane of sea-urchin eggs in species specificity. Arkiv Zool., 40A, No. 12, 1-9.

Hultin, T. 1948b. Species specificity in fertilization reaction. 1I. Influence of certain factors on the cross-fertilization capacity of Arbacia lixula (L.). Arkiv Zool., 40A, No. 20, 1-S.

Hultin, T. 1949. Agglutination of sea urchin eggs by nucleoproteins. Arkiv Kemi, 1, 419-23.

Immers, J., and E. Vasseur. 1949. Comparative studies on the coagulation process with heparin and sea-urchin fertilizin. Experientia, 5, 124-25.

Jenkinson, J. W. 1911. On the origin of the polar and bilateral structure of the egg of the sea-urchin. Arch. Entw.-mechan., 32, 699-716. Just, E. E. 1930. The present status of the fertilizin theory of fertilization. Protoplasma, 10, 300-42.

Krauss, M. 1949. A mucin clot reaction with sea-urchin fertilizin. Biol. Bull., 96, 74-89.

Krauss, M. 1950a. Lytic agents of the sperm of some marine animals.

I. The egg membrane lysin from sperm of the giant keyhole limpet, Megathura crenulata. J. Exptl. Zool., 114, 239-78.

Krauss, M. 1950b. Lytic agents of the sperm of some marine animals. II. Extraction of a hetero-egg membrane lysin from sea-urchin sperm. J. Exptl. Zool., 114, 279-91. 
Krauss, M. 1950c. On the question of hyaluronidase in sea-urchin spermatozoa. Science, 112, 759.

Lillie, F. R. 1911. Studies of fertilization in Nereis. I. The cortical changes in the egg: II. Partial fertilization. J. Morph., 22, 361-90.

Lillie, F. R. 1912. The production of sperm iso-agglutinins by ova. Science, 36, 527-30.

Lillie, F. R. 1913a. The mechanism of fertilization. Science, 38, 524-2S.

Lillie, F. R. 1913b. Studies of fertilization. V. The behavior of the spermatozoa of Nereis and Arbacia with special reference to eggextractives. J. Exptl. Zool., 14, 515-74.

Lillie, F. R. 1914. Studies of fertilization. VI. The mechanism of fertilization in Arbacia. J. Exptl. Zool., 16, 523-90.

Lillie, F. R. 1919. Problems of Fertilization. University of Chicago Press, Chicago, Illinois.

Lindahl, P. E. 1932. Zur Kenntnis des Ovarialeies bei dem Seeigel. Arch. Entw.-mechan., 126, 373-90.

Loeb, J. 1914. Cluster formation of spermatozoa caused by specific substances from eggs. J. Exptl. Zool., 17, 123-40.

Loeb, J. 1915. On the nature of the conditions which determine or prevent the entrance of the spermatozoan into the egg. Am. Naturalist, 49, 257-85.

von Medem, F. G. 1942. Beiträge zur Frage der Befruchtungsstoffe bei marinen Mollusken. Biol. Zentral., 62, 431-46.

von Medem, F. G. 1945. Untersuchungen uber die Ei- und Spermawirkstoffe bei marinen Mollusken. Zool. Jalıb., 61, 5 .

Metz, C. B. 1942a. The inactivation of fertilizin and its conversion to the "univalent" form by x-rays and ultraviolet light. Biol. Bull., 82, 446-54.

Metz, C. B. 1942b. Doctoral thesis, California Institute of Technology, Pasadena, Calif.

Metz, C. B. 1944. Agglutination of starfish sperm by homologous egg water. Anat. Record, 89(4), 559 (abstract).

Metz, C. B. 1945. The agglutination of starfish sperm by fertilizin. Biol. Bull., 89, 84-94.

Metz, C. B. 1947. Induction of "pseudo-selfing" and meiosis in Paramecium aurelia by formalin killed animals of opposite mating type. J. Exptl. Zool., 105, 115-39.

Metz, C. B. 1949. Agglutination of sea urchin eggs and sperm by basic proteins. Proc. Soc. Exptl. Biol. Med., 70, 422-24.

Metz, C. B. 1954a. Mating substances and the physiology of fertiliza- 
tion in ciliates, in Sex in Microorganisms, O. H. Wenrich, editor. American Association for the Advancement of Science, Washington, D. C.

Metz, C. B. 1954b. The adjuvant action of chelating agents in fertilizin agglutination of starfish sperm. Biol. Bull., 107, 317 (abstract).

Metz, C. B. 1954c. The effect of some protein group reagents on the sperm agglutinating action of Arbacia fertilizin. Anat. Record, 120, 713-14 (abstract).

Metz, C. B. 1956. Mechanisms in fertilization, in Physiological Triggers, T. H. Bullock, editor. American Physiological Society. In press. Metz, C. B., and C. W. Birky, Jr. 1955. The action of some metal ions and metal chelating agents on the motility and respiration of starfish sperm. Biol. Bull., 109, 365-66 (abstract).

Metz, C. B., and J. E. Donovan. 1949. Fertilizin from the eggs of the clam, Mactra solidissima. Biol. Bull., 97, 257 (abstract).

Metz, C. B., and J. E. Donovan. 1950. Adjuvant action of amino acids and peptides in fertilizin agglutination of starfish sperm. Science, $112,755-56$.

Metz, C. B., and J. E. Donovan. 1951. Specific fertilizin agglutination of dead sperm. Biol. Bull., 101, 202 (abstract).

Metz, C. B., M. T. Foley, and J. E. Donovan. 1949. Evidence for structural specificity in basic proteins. Anat. Record, 105, 492 (ab)stract).

Metz, C. B., and J. B. Morrill, Jr. 1955. Formation of acrosome filaments in response to treatment of sperm with fertilizin in Asterias and Nereis. Biol. Bull., 109, 349 (abstract).

Minganti, A. 1955. Chemical investigations on amphibian egg jellies. Exptl. Cell Research, Suppl. 3, 248.

Mirsky, A. E., and M. L. Anson. 1934. Sulfhydryl and disulfide groups of proteins. I. Methods of estimation. J. Gen. Physiol., 18, 307-23.

Monné, L., and S. Harde. 1951. On the cortical granules of the sea urchin egg. Arkiv Zool., ser. 2, 1, 487-98.

Monné, L., and D. B. Slautterback. 1950. Differential staining of various polysaccharides in sea urchin eggs. Exptl. Cell Rescarch, 1, 47791.

Monroy, A. 1948. A preliminary approach to the physiology of fertilization in Pomatoceros triquester L., Arkiv Zool., 40A, No. 21, 1-7.

Monroy, A. 1955. Optical properties of the fibrils obtained from the jelly coat substance of the sea urchin egg. Exptl. Cell Research, Suppl. 3, 252-54. 
Monroy, A., and J. Runnström. 1950. Further studies on the action of a cytoplasmic component on jelly coat and membrane formation in Arbacia punctulata. Biol. Bull., 99, 339 (abstract).

Monroy, A., and J. Runnström. 1952. A cytoplasmic fraction acting on the surface layers of the Arbacia punctulata eggs. Exptl. Cell Research, 3, 10-18.

Monroy, A., and L. Tosi. 1952. A note on the jelly-coat-sperm interaction in sea-urchin. Experientia, 8, 393-94.

Monroy, A., L. Tosi, G. Giardina, and R. Maggio. 1954. Further investigations on the interaction between sperm and jelly-coat in the fertilization of the sea urchin egg. Biol. Bull., 106, 169-77.

Morgan, T. H. 1927. Experimental Embryology, Columbia Univ. Press, New York.

Motomura, I. 1950a. Secretion of fertilizin in the eggs of a sea urchin, S. pulcherrimus. Sci. Repts. Tôhoku Univ., ser. 4, 18, 554-60.

Motomura, I. 1950b. On a new factor for the toughening of the fertilization membranes of sea-urchins. Sci. Repts. Tôhoku Univ., ser. $4,18,561-70$.

Motomura, I. 1953a. Secretion of sperm agglutinin in the fertilized eggs of the sea urchins. Exptl. Cell Research, 5, 187-90.

Motomura, I. 1953b. Secretion of the sperm agglutinin in the fertilized and denuded eggs of the sea urchin, Strongylocentrotus nudus. Sci. Repts. Tôhoku Univ., ser. 4, 20, 93-97.

Motomura, I. 1954. On the autoagglutination in the sperm of the sanddollar, Dendraster excentricus. Sci. Repts. Tôhoku Univ., ser. 4, 10, 323-28.

Motomura, I. 1955. On the irreversible agglutination of the sperm caused by the sperm extracts in the sea urchins. Exptl. Cell Research, Suppl. 3, 255-61.

Novikoff, A. B. 1939. Changes at the surface of Nereis limbata eggs after insemination. J. Exptl. Biol., 16, 403-8.

Popa, G. T. 1927. The distribution of substances in the spermatozoon (Arbacia and Nereis). Biol. Bull., 52, 238-57.

Rothschild, Lord. 1948. The physiology of sea-urchin spermatozoa. Lack of movement in semen. J. Exptl. Biol., 25, 344-52.

Rothschild, Lord. 1951a. Sperm-egg interacting substances and metabolic changes associated with fertilization. Biochem. Soc. Symposia (Cambridge, Eng.), 7, 40-51.

Rothschild, Lord. 1951b. Sea-urchin spermatozoa. Biol. Revs., 26, $1-27$. 
Rothschild, Lord. 1952. Spermatozoa. Science Progr., 40, 1-10.

Rothschild, Lord, and A. Tyler. 1954. The physiology of sea-urchin spermatozoa. Action of versene. J. Exptl. Biol., 31, 252-59.

Rothschild, Lord, and A. Tyler. 1955. Acrosomal filaments in spermatozoa. Exptl. Cell Research, Suppl. 3, 304-11.

Runnström, J. 1935. Influence of iodoacetate on activation and development of the eggs of Arbacia punctulata. Biol. Bull., 69, 351-55.

Runnström, J. 1947. Further studies on the formation of the fertilization membrane in the sea urchin egg. Arkiv Zool., 40A, No. 1, 1-9.

Runnström, J. 1949a. The mechanism of fertilization in metazoa. Advances in Enzymol., 9, 241-327.

Runnström, J. 1949b. Some results and views concerning the mechanism of initiation of development in the sea urchin egg. Pubbl. staz. zool. Napoli, 21, 9-21.

Runnström, J. 1952. The cell surface in relation to fertilization. Symp. Soc. Exptl. Biol., 6, 39-88.

Runnström, J., B. Hagström, and H. Löw. 1955. On the effect of ribonuclease on a jelly precipitating factor from the egg of the sea urchin, Psammechinus miliaris. Exptl. Cell Research, 8, 235-39.

Runnström, J., and S. Lindvall. 1946. The effect of some agents upon the reaction of Echinocardium spermatozoa toward egg water. Arkiv Zool., 38A, No. 10, 1-9.

Runnström, J., S. Lindvall, and A. Tiselius. 1944. Gamones of the sperm of the sea urchin and salmon. Nature, 153, 285-86.

Runnström, J., and A. Monroy. 1950. The effect of egg extract on the surface of the sea urchin eggs and spermatozoa. Arkiv Kemi, 2, 40516.

Runnström, J., A. Tiselius, and A. Lindvall. 1945. The action of androgamone III on the sea urchin egg. Arkiv Zool., 36A, No. 22, 1-25.

Runnström, J., A. Tiselius, and E. Vasseur. 1942. Zur kenntnis der Gamonwirkungen bei Psammechinus miliaris und Echinocardium cordatum. Arkiv Kemi, 15A, No. 16, 1-18.

Runnström, J., E. Wicklund, and H. Löw. 1954. The fertilization and development of the sea urchin egg, Arbacia lixula, under the influence of fractions of egg homogenate. Exptl. Cell Research, 6, 45978.

Southwick, W. E. 1939. Activity-preventing and egg-sea-water neutralizing substances from spermatozoa of Echinometra subangularis. Biol. Bull., 77, 147-56. 
Spikes, J. D. 1949a. Metabolism of sea urchin sperm. Am. Naturalist, 83, 285-301.

Spikes, J. D. 1949b. The prezone phenomenon in sperm agglutination. Biol. Bull., 97, 95-99.

Tyler, A. 1939a. Crystalline echinochrome and spinochrome: Their failure to stimulate the respiration of eggs and of sperm of Strongylocentrotus. Proc. Natl. Acad. Sci. U. S., 25, 523-28.

Tyler, A. 1939b. Extraction of an egg membrane lysin from sperm of the giant keyhole limpet (Megathura crenulata). Proc. Natl. Acad. Sci. U. S., 25, 317-23.

Tyler, A. 1940a. Sperm agglutination in the keyhole limpet, Megathura crenulata. Biol. Bull., 78, 159-78.

Tyler, A. 1940b. Agglutination of sea-urchin eggs by means of a substance extracted from the eggs. Proc. Natl. Acad. Sci. U. S., 26, 249 56.

Tyler, A. 1941. The role of fertilizin in the fertilization of eggs of the sea-urchin and other animals. Biol. Bull., 81, 190-204.

Tyler, A. 1945. Conversion of agglutinins and precipitins into "univalent" (non-agglutinating or non-precipitating) antibodies by photodynamic irradiation of rabbit-antisera vs. pneumococci, sheep-redcells and sea-urchin sperm. J. Immunol., 51, 157-72.

Tyler, A. 1946a. Loss of fertilizing power of sea-urchin and Urechis sperm treated with "univalent" antibodies vs. antifertilizin. Proc. Soc. Exptl. Biol. Med., 62, 197-99.

Tyler, A. 1946b. Natural heteroagglutinins in the body-fluids and seminal fluids of various invertebrates. Biol. Bull., 90, 213-19.

Tyler, A. 1948a. Fertilization and immunity. Physiol. Revs., 28, 180219.

Tyler, A. 1948b. Fertilizin of Nereis limbata. Biol. Bull., 95(2), 271 (abstract).

Tyler, A. 1948c. On the chemistry of the fertilizin of the sea-urchin Strongylocentrotus purpuratus. Anat. Record, 101, 658-59 (abstract).

Tyler, A. 1949. Properties of fertilizin and related substances of eggs and sperm of marine animals. Am. Naturalist, 83, 195-219.

Tyler, A. 1952. Further investigations on fertilizins of eggs of seaurchins. Anat. Record, 113, 525-26 (abstract).

Tyler, A. 1953. Prolongation of life-span of sea urchin spermatozoa, and improvement of the fertilization-reaction, by treatment of sper- 
matozoa and eggs with metal-chelating agents (amino acids, versene, DEDTC, oxine, cupron). Biol. Bull., 104, 224-39.

Tyler, A. 1955. Gametogenesis, fertilization and parthenogenesis. Sec. V, Chap. 1 in Analysis of Development, B. H. Willier, P. A. Weiss, V. Hamburger, editors. W. B. Saunders Co., Philadelphia, Pa.

Tyler, A. 1956. Physico-chemical properties of the fertilizins of the sea-urchin, Arbacia punctulata and the sand-dollar Echinarachnius parma. Exptl. Cell Research, 10, 377-86.

Tyler, A., A. Burbank, and J. S. Tyler. 1954a. Sedimentation constants, viscosity, and diffusion of the fertilizins of Arbacia and Echinarachnins. Biol. Bull., 107, 303 (abstract).

Tyler, A., A. Burbank, J. S. Tyler. 1954b. The electrophoretic mobilities of the fertilizins of Arbacia and Echinarachnius. Biol. Bull., 107, 304 (abstract).

Tyler, A., and S. W. Fox. 1939. Sperm agglutination in the keyhole limpet and the sea-urchin. Science, 90, 516-17.

Tyler, A., and S. W. Fox. 1940. Evidence for the protein nature of the sperm agglutinins of the keyhole limpet and the sea-urchin. Biol. Bull., 79, 153-65.

Tyler, A., and C. B. Metz. 1945. Natural heteroagglutinins in the serum of the spiny lobster, Panulirus interruptus. I. Taxonomic range of activity, electrophoretic and immunizing properties. $J$. Exptl. Zool., 100, 387-406.

Tyler, A., and C. B. Metz. 1955. Effects of fertilizin-treatment of sperm and trypsin-treatment of eggs on homologous and crossfertilization in sea-urchins. Pubbl. staz. zool. Napoli, 27, 128-45.

Tyler, A., A. Monroy, and C. B. Metz. 1956. Fertilization of fertilized sea urchin eggs. Biol. Bull., 110, 184-95.

Tyler, A, and K. O’Melveny. 1941. The role of antifertilizin in the fertilization of sea-urchin eggs. Biol. Bull., 81, 364-74.

Tyler, A., and Lord Rothschild. 1951. Metabolism of sea urchin spermatozoa and induced anaerobic motility in solutions of amino acids. Proc. Soc. Exptl. Biol. Med., 76, 52-58.

Vasseur, E. 1947. The sulfuric acid content of the egg coat of the sea urchin Strongylocentrotus droebachiensis Mull. Arkiv Kemi, 25B, $1-2$.

Vasseur, E. 1948. Chemical studies on the jelly coat of the sea-urchin egg. Acta Chem. Scand., 2, 900-13.

Vasseur, E. 1949a. Effect of calcium ions on the agglutination in Strongylocentrotus droebachiensis Mull. Arkiv Kemi, 1, 105-16. 
Vasseur, E. 1949b. Effect of sea urchin egg jelly coat solution and calcium ions on the oxygen uptake of sea urchin sperm. Arkiv Kemi, 1, 393-99.

Vasseur, E. 1950. L-Galactose in the jelly coat of Echinus esculentus eggs. Acta Chem. Scand., 4, 1144-45.

Vasseur, E. 1951. Strongylocentrotus pallidus (G. O. Sars) and S. droebachiensis (O. F. Muller) distinguished by means of spermagglutination with egg-water and ordinary morphological characters. Acta Borelia, A. Scientia, No. 2, 1-16.

Vasseur, E. 1952a. The chemistry and physiology of the jelly coat of the sea urchin egg. Independent publication, Kihlströmstryck, A. B. Stockholm.

Vasseur, E. 1952b. Periodate oxidation of the jelly coat substance of Echinocardium cordatum. Acta Chem. Scand., 6, 376-84.

Vasseur, E., and I. Carlsen. 1946. Sexual maturity of the sea-urchin Brissopsis lyrifera (Forbes) in the Gullmar Fjord. Arkiv Zool., 41A, No. 16, 1-10.

Vasseur, E., and B. Hagström. 1946. On the gamones of some seaurchins from the Swedish west coast. Arkiv Zool., 37A, No. 17, 1-17.

Vasseur, E., E. Wicklund, and J. Runnström. 1950. Respiration and fertilizing capacity of sea urchin sperm in presence of serum albumin and jelly coat solution. Biol. Bull., 99, 324-25 (abstract).

Wada, S. K., J. R. Collier, and J. C. Dan. 1956. Studies on the acrosome. V. An egg-membrane lysin from the acrosomes of Mytilus edulis spermatozoa. Exptl. Cell Research, 10, 168-80.

Wicklund, E. 1954a. Release of pigment in fertilized eggs of Arbacia lixula upon transfer to hypertonic medium. Arkiv Zool., ser. 2, 7, 113-16.

Wicklund, E. 1954b. Formation of the fertilization membrane in centrifuged eggs of Arbacia lixula. Arkiv Zool., ser. 2, 7, 109-12.

Wicklund, E. 1954c. Effect of albumin and trypsin on the oxygen uptake and the fertilizing activity of sea urchin spermatozoa. Arkiv Zool., ser. 2, 7, 117-24.

Woodward, A. E. 1918. Studies on the physiological significance of certain precipitates from the egg secretions of Arbacia and Asterias. J. Exptl. Zool., 26, 459-501. 



\title{
PRELIMINARIES TO FERTILIZATION \\ IN MAMMALS
}

\author{
C. R. AUSTIN AND M. W. H. BISHOP: \\ NATIONAL INSTITUTE FOR MEDICAL RESEARCH,
}

MILL HILL, LONDON

Since von Baer described the mammalian primary oocyte and Barry observed spermatozoa within the rabbit egg, work on fertilization in mammals has been directed chiefly toward the elucidation of cytological problems. In recent years, however, increasingly more attention has been paid to the events occurring between coitus and the arrival of the spermatozoon in the egg cytoplasm. As a result, it is becoming evident that the preliminaries to fertilization are of a highly complex nature and further that, in large measure, they determine the successful union of the gametes and the normal outcome of syngamy.

Among many invertebrates and lower vertebrates the gametes are released into the surrounding aqueous medium, which constitutes their environment of fertilization. As the spermatozoa approach the eggs they experience the influence of chemical substances associated with the eggs, and on their part the spermatozoa arouse reactions in the eggs during the course of penetration, so that interaction between egg and spermatozoon becomes a feature of the environment of fertilization.

With the occurrence of ovulation and ejaculation the mammalian gametes are projected into their environment of fertilization, which thus consists of the accessory secretions of the male and the entire genital tract of the female. From the moment of their release into the female tract, the spermatozoa come under the manifold influences of this environment, all of which may affect the incidence or course of fertilization. A contribution is also made by the egg to the environment of the spermatozoon, al- 
though it may not be as generous as that of the externally fertilized egg. Since the mammalian egg has yet to pass through the genital tract it is possible that certain substances reaching the lumen of the tract in the liquor folliculi or in the secretions of the mucosa correspond to those actually carried by externally fertilized eggs.

The numerous interactions in which the gametes participate with the environment of fertilization and with each other, together with the mechanisms that permit the spermatozoon to reach and enter the egg, may thus be held to be the preliminaries to fertilization. It is the purpose of this review to describe the current trends of research on these events and processes, in the hope of revealing some possibilities for advance in knowledge in the near future.

\section{Dilution and Activation of Spermatozoa}

At ejaculation the spermatozoa are mingled with fluids from the accessory glands, principally the seminal vesicles and the prostate, and this fluid forms the bulk of the seminal plasma. The degree of dilution of spermatozoa varies considerably between species: in the semen of the ram the spermatozoa constitute about 25 per cent of the total volume, whereas in the semen of the boar this proportion is only about 1 per cent. The total number of spermatozoa, the volume of the ejaculate, and the composition of the accessory fluids also vary widely. Despite the fact that much is known about the nature of the seminal plasma (Mann, 1954), its precise role is far from clear. Certainly it functions as a vehicle for the spermatozoa, but it by no means provides an ideal medium for their survival. Moreover, the larger the proportion of seminal plasma in the ejaculate the more unfavorable it is as a medium (Gunn, 1936). Spermatozoa can be stored in vitro in artificial diluents that are quite unlike seminal plasma much more successfully than in the natural diluent itself. The fertility of spermatozoa, also, is not dependent upon their admixture with the accessory secretions (Ivanov, 1926; Hammond, 1930; Walton, 1930). When epididymal spermatozoa were 
used for inseminating cows, the resulting incidence of conception was approximately the same as that which had previously been obtained with ejaculated spermatozoa from the same bulls (Lardy and Ghosh, 1952). The fact that the spermatozoa in the epididymis and vas deferens are almost motionless but become vigorously active when they make contact with the accessory secretions, much as sea urchin spermatozoa do when shed into sea water, suggests that activation of spermatozoa is the only important function of seminal plasma, other than the carriage of the spermatozoa from male to female tracts.

The mechanism of activation is little understood, but it is evidently not of a specific nature. It may be due in part, at least, to the dilution of an inhibitory substance (Bishop and Salisbury, $1955 \mathrm{a}, \mathrm{b}$ ) similar in its action to that of potassium in trout and salmon semen (Rothschild, 1951a), or of zinc in echinoderm semen (Fujii, Utida, and Mizuno, 1955). Lardy and his associates, on the other hand, claim that the respiration and aerobic glycolysis of bovine spermatozoa are stimulated at ejaculation by a specific activator, believed to be a sulfite or sulfhydryl compound, that has the effect of reducing the metabolic efficiency of these cells as measured by the Meyerhof oxidation quotient (Lardy, Ghosh, and Plaut, 1949; Lardy, 1953). Gunn (1936) noted activation of epididymal spermatozoa upon dilution and aeration. Bishop and Matthews (1952) report that quiescence of spermatozoa in the vas deferens is associated with very low oxygen tensions and a deficiency of glycolyzable substrate, but not with narcotic accumulations of lactic acid or carbon dioxide. They conclude that oxygen is the principal activating factor, an observation in agreement with Rothschild's (1948) findings on the activation of sea urchin spermatozoa. Electrolytes are also known to stimulate spermatozoon motility (Milovanov, 1934a,b), and they probably play an important part in the activation phenomenon.

Both in mammalian and echinoderm spermatozoa increased dilution leads to increased physical and metabolic activity, but to decreased survival of the spermatozoa (Gray, 1928; Salisbury, 
Beck, Cupps, and Elliott, 1943; Chang, 1946a,b; Emmens and Swyer, 1948; Cheng, Casida, and Barrett, 1949; Rothschild, 1951b; Willett, 1953; Bishop, 1954). Excessive dilution in vitro is invariably harmful, probably because of the irreparable decay of enzyme systems in the actively metabolizing cells resulting from the stimulating effect of dilution, and because of loss of substances from the cell surface (Emmens and Swyer, 1948). In particular, it is known that electrolytes remove phospholipid material from cell membranes (Milovanov, 1934a,b; Lovelock, 1954, 1955; Dallam and Thomas, 1952). The efficiency of removal varies with the electrolyte, according to the lyotropic series of ions (Anderson, 1945). It seems probable that the functions of the osmotically active organic constituents of the seminal plasma, such as fructose, lactic acid, citric acid, amino acids, urea, and inositol, include maintenance of a suitable osmotic environment with a low electrolyte to nonelectrolyte ratio. Kampschmidt, Mayer, and Herman (1953) and Kok (1953) have found that the survival of spermatozoa in vitro is prolonged when the electrolyte to nonelectrolyte ratio of the diluents is reduced by the addition of metabolizable sugars, and Roy and Bishop (1954) have obtained similar results by replacing electrolytes with glycine. Although other explanations can be offered, it is likely that the beneficial effect of the sugars and glycine was due to reduction of the stimulating and destructive action of the electrolytes. With sea urchin spermatozoa, on the other hand, glycine provides protection chiefly by chelating heavy metals (Tyler and Rothschild, 1951; Tyler, 1953). Substances such as lecithin, albumin, mucin, and egg yolk also help to protect the spermatozoon membranes from the deleterious effects of dilution: constituents of the seminal plasma and of the female genital secretions presumably have a similar function.

It would seem, therefore, that the genital secretions, both of male and female but chiefly the former, have the function of activating the spermatozoa in a controlled manner, the stimulating property being appropriately balanced by the property that mitigates the deleterious effect of electrolytes. 


\section{Transport and Distribution of Spermatozoa}

Motility is an almost universal characteristic of male gametes throughout the animal kingdom and it undoubtedly facilitates the meeting of egg and spermatozoon. However, the available evidence, particularly that relating to rate of transport of spermatozoa in the female tract, indicates that during their passage from the site of deposition to the site of fertilization the spermatozoa play a passive role in most species and transport depends little upon their active swimming.

The importance of muscular activity of the female tract in the transport of spermatozoa has been appreciated for a long time. Heape (1898) imputed this significance to the activity of the dog uterus which he found to be increased by stimulation of the external genitalia. Westman (1926) observed augmented contractions of the Fallopian tubes of female rabbits when in the presence of the male, and Krehbiel and Carstens (1939) found that fluids placed in the rabbit vagina were carried throughout the uterus when the vulva was artificially stimulated. Increased uterine activity in the rabbit following mating was noted by Reynolds (1930), and Van Demark and Hays (1951, 1952, 1953) have shown that strong uterine contractions in the cow are induced by various mating stimuli, including the sight of the male, although coitus was the most effective. Hays and Van Demark (1952) claim that rapid spermatozoon transport occurs in the perfused, excised cow uterus, provided that oxytocin is present in the perfusate. It has been shown in the mare (Millar, 1952) that the orgasm of coitus produces a negative pressure within the uterus which would have the effect of rapidly drawing the semen into the uterine lumen.

Both the act of ejaculation and the physical and chemical properties of the seminal plasma may also assist transport. In the rodents, the sow, and the mare, the spermatozoa are not deposited in the vagina but passed directly through the cervix. Gelation of the semen of the boar and stallion presumably plays an important role in retaining the large ejaculate in the uterus. 
A similar function may reasonably be imputed to the vaginal plugs formed in many rodents, some bats and insectivores, and the chimpanzee. In the opossum a similar plug is apparently formed by coagulation of female secretions by the seminal fluid. The human seminal gel evidently has a different significance for it soon liquefies under the action of a proteolytic enzyme present in the semen (Huggins and Neal, 1942; Huggins and Vail, 1943). Seminal gels may also have the function of stimulating the female tract by mechanical action, and seminal plasma as a whole by virtue of its physiologically active constituents, such as choline and adrenaline (see Mann, 1954). It has been claimed, notably by Russian workers, that spermatozoa penetrate into the wall of the female tract and exert a stimulating influence upon its functions ( see Kushner, 1954).

For many species the recorded time interval between coitus and the arrival of spermatozoa in the ampulla of the Fallopian tube is surprisingly short: intervals of 15 minutes or less have been noted in the sheep (Starke, 1949), cow (Van Demark and Moeller, 1951), mouse (Lewis and Wright, 1935), rat (Blandau and Money, 1944), and bitch (Whitney, cited by Evans, 1933). By contrast, spermatozoon transport in the rabbit seems to take about 3 or 4 hours (Heape, 1905; Parker, 1931; Florey and Walton, 1932; Braden, 1953; Adams, 1956), although it may occasionally take only one hour (Chang, 1952a). It is possible that the slower rate in the rabbit may be associated with the absence of copious uterine fluid; Warren (1938), however, found that removal of the uterine fluid from the rat uterus delayed transport by only a few minutes. It is possible that rabbit spermatozoa depend, much more than those of the other species mentioned, upon their own motility to reach their goal. The rabbit, it would seem, does not require rapid spermatozoon transport because it exhibits copulatory ovulation. The biological advantage of rapid transport to animals showing spontaneous ovulation is presumably that it increases the period during which coitus can result in normal fertilization-it would be especially important when coitus occurs close to or soon after ovulation. Experimentally delayed coitus or insemination often results in a large increase 
in the incidence of abnormal fertilization in rats (Blandau, 1952) and rabbits (Chang, 1952b) and of polyspermic fertilization in rats and rabbits (Austin and Braden, 1953a,b) and mice (Braden and Austin, 1954b), an increase in the incidence of abnormal pregnancy, and reduction in the number of normal young born in the guinea pig (Blandau and Young, 1939), rat (Soderwall and Blandau, 1941; Blandau and Jordan, 1941), rabbit (Hammond, 1934), sheep (Quinlan, Mare, and Roux, 1932), sow (Lewis, 1911), and cow (Trimberger, 1948).

Both mechanical and physical attributes of the female genital tract also reduce greatly the numbers of spermatozoa passing to the site of fertilization (Braden, 1953). The chief agents in this process of reduction are the cervix (in species having intravaginal ejaculation), utero-tubal junction, and tubal isthmus by virtue of their narrow lumen, and the uterus, by virtue of its large internal surface area (rabbit) or voluminous fluid content (rodents especially). Leonard and Perlman (1949) found that, in the rat, only vigorously motile spermatozoa could pass the uterotubal junction. Furthermore, not only were inert particles and immotile spermatozoa unable to pass the junction, but active spermatozoa of other species (bull, mouse, and guinea pig) were similarly unable to enter the Fallopian tube, even when mixed with active rat spermatozoa. By contrast, in the cow, dead spermatozoa were transported as rapidly as living ones (Van Demark and Moeller, 1951), and rat spermatozoa were found to be capable of passing into the Fallopian tube of the ewe (Phillips and Andrews, 1937). Consistently, the pressure required to force fluids from the uterus to the tubes is very high in the rat (Alden, 1943) and low in the sheep and cow (Andersen, 1928). Andersen's paper contains descriptions of the morphology of the uterotubal junction in 25 mammals belonging to 10 different orders, which indicate that the restrictive power of the region must differ widely among these species. She noted, too, that fluid could not be forced from the uterus to the tube in the cat and rabbit, and that passage was difficult in the sow at the time when eggs are in the tubes. The comparative freedom of passage through the utero-tubal junction of the cow is illustrated by Rowson's (1955) 
observations on the passage of radio-opaque fluids. It may also be relevant that hybrids seem to be more common in ungulates than they are among rodents (Gray, 1954). These data suggest that the exclusion of foreign spermatozoa is a mechanical function of the utero-tubal junction, but reactions of an immunological nature may also be involved.

Within the environment of fertilization there is an ecological niche of special significance which is more clearly defined in mammals than in species having external fertilization. This is the "site of fertilization" and it is characterized not merely by anatomical position but by the fact that here the conditions are presumably optimal for ensuring the penetration of the spermatozoon into the egg-they may not necessarily be the best for maintaining the viability of the gametes or of the zygote. In most mammals the site of fertilization is the ampulla of the Fallopian tube; in some species spermatozoon penetration may occur in the peri-ovarian sac or bursa which can thus be regarded as an extension of the Fallopian tube, physiologically as well as anatomically ( see Braden and Austin, 1954a). A notable exception to the general rule is provided by the tenrecs, in which penetration apparently occurs while the egg is still in the ovarian follicle (Bluntschli, 1938; Strauss, 1938, 1950). That fertilization within the follicle may occasionally take place in other species also is shown by the fact that ovarian pregnancies have long been known in man (Mahfouz, 1949). The number of spermatozoa that have been observed at the site of fertilization is surprisingly small, especially when compared with the many millions deposited at coitus: rat, mean number of 43 spermatozoa per Fallopian tube (Austin, 1948b), mean of 12 spermatozoa (Blandau and Odor, 1949); mouse, mean of 17 spermatozoa (Braden and Austin, 1954a); rabbit, less than 1000 spermatozoa (Austin, 1948b; Chang, 1951b), mean of 500 spermatozoa (Braden, 1953); sheep, mean of 340 spermatozoa (Braden and Austin, 1954a).

In view of the known influence of ovarian function upon the spontaneous muscular activity of the uterus (Reynolds, 1949; Wislocki and Guttmacher, 1924; Cupps and Asdell, 1944; Evans and Miller, 1936) and on the nature of secretions of the repro- 
ductive tract, notably the cervical mucus (Pommerenke and Viergiver, 1946; Glover and Scott Blair, 1953) it would be unexpected to find that spermatozoon transport occurred with equal rapidity at all phases of the estrous cycle. However, Green and Winters (1935), Schott and Phillips (1941), and Starke (1949) all consider that the speed of transport in the sheep is independent of ovarian activity. Rowson (1955), on the other hand, expresses doubt that this is so in the cow, and Warbritton, McKenzie, Berliner, and Andrews (1937) suggest that conditions for spermatozoon transport in the ewe are optimal 10 to 12 hours after the beginning of estrus. In the rat the passage of spermatozoa occurs more readily late in estrus (Braden and Austin, 1954a). During pseudopregnancy in the rabbit, conditions do not favor the fertilization of eggs (Wislocki and Snyder, 1931, 1933; Murphree, Warwick, Casida, and McShan, 1947; Boyarsky, Baylies, Casida, and Meyer, 1947) and fewer spermatozoa reach the uterus and tubes than during estrus (Austin, 1949). Unfavorable conditions obtaining in the tract at other times than estrus may constitute a defense against the possibility of fertilization in pregnancy, an occurrence that could lead to superfetation. That superfetation can arise has been shown experimentally in the rat (Canivenc, Doruvillé, and Mayer, 1953).

From what has been said it appears that the mechanical and physical attributes of the environment of fertilization tend to exert opposing effects upon the spermatozoa. The specialized movements of the tract, accompanied in certain instances by pressure gradients, have the effect of quickly and efficiently transporting spermatozoa to the site of fertilization. On the other hand, attributes such as the narrow Iumen of certain regions, the accumulations of fluid, and the large mucosal surface areas exert a diluting influence and greatly diminish the number and density of spermatozoa approaching the site of fertilization.

\section{Maintenance of Spermatozoa in the Female Tract}

Immediately following ejaculation, the spermatozoa, already suspended in the male accessory secretions, are further diluted by admixture with the secretions of the female tract. The propor- 
tionate contribution made by the seminal plasma to this environment varies widely in different species. The environment afforded by the female tract is presumably ideal for the preparation of the spermatozoa for the task of reaching and entering the eggs. This implies in most animals the existence of conditions favoring vigorous activity. The female environment is not necessarily the best for the survival of the spermatozoa, and it is well known that the life of the spermatozoon is much shorter in the female tract than in the male (see Hartman, 1939). It would indeed be of little advantage for the spermatozoa long to outlive the eggs. Nevertheless, the circumstances may occasionally favor longevity. Relatively favorable conditions may exist in the cervical canal, and it has been suggested that this region may act as a reservoir of spermatozoa from which they are steadily released into the uterus (Quinlan, Mare, and Roux, 1932, 1933; Starke, 1949), a situation somewhat analogous to that of the "sperm nests" found in the uterus of the domestic fowl (Van Drimmelen, 1949, 1951). However, the most remarkable instances of spermatozoon survival are to be found among the bats, wherein the spermatozoa may retain their fertility in the female tract for as long as five months (Redenz, 1929; Wimsatt, 1942, 1944). During this period they remain embedded in high concentrations in the thick uterine mucus, motionless but capable of exhibiting active motility upon dilution. Clearly, conditions within the bat uterus are highly specialized, for not only is the capacity of the spermatozoa for motility retained but also the capacity for fertilization and for initiating the development of normal individuals. Spermatozoa in the genital tracts of most other mammals soon enter a state of senescence when these capacities are lost. The losses occur at different times - the ability to form a viable embryo is lost before the ability to fertilize eggs, and fertilizing capacity is lost before motility (Van Drimmelen and Oettlé, 1949). In the fowl malformed, nonviable embryos resulted when the eggs were fertilized with aged spermatozoa (Crew, 1926; Nalbandov and Card, 1943; Dharmarajan, 1950 ). There is evidence of similar changes in mammalian spermatozoa. Young (1931) found that the incidence of nonviable embryos in the guinea pig could be increased from 3.6 to 20 per 
cent by retaining spermatozoa in the epididymis for 20 to 25 days. The observations of Salisbury, Bratton, and Foote (1952) suggest that the incidence of embryonic mortality in cattle increases with the age of the spermatozoa.

It is now well known that mammalian spermatozoa in vitro, unlike sea urchin spermatozoa, metabolize nutrients in the surrounding medium to maintain their physiological functions. Under anaerobic conditions they maintain their motility by the glycolytic breakdown of fructose (present in the seminal plasma of most species), or glucose if available (for example, in the secretions of the female tract); in the presence of molecular oxygen a number of extracellular substrates can be metabolized. Even without exogenous oxidizable material mammalian spermatozoa can respire actively and maintain their motility for an appreciable length of time. Lardy and Phillips (1941, 1945) have attributed this to oxidation of intracellular phospholipids, and Rothschild and Cleland (1952) have found evidence that sea urchin spermatozoa obtain energy for motility by a similar mechanism. Mammalian spermatozoa are known to contain the enzymes involved in the Embden-Meyerhof glycolytic system and the Krebs cycle as well as a complete cytochrome system (see Mann, 1954; Tyler, 1955); these systems are evidently located within the spermatozoon tail since headless spermatozoa can swim actively (Redenz, 1924, 1925, 1926; Moench and Holt, 1929; Hancock and Rollinson, 1949; Bishop, 1955).

Within the female genital tract spermatozoa probably obtain energy for motility through both the glycolytic and respiratory systems, but while the importance of the former is widely appreciated that of the latter has received little recognition. Campbell (1932) has shown that the oxygen tension of the rabbit uterus is comparable to that in many other tissues of the body $(20-45 \mathrm{~mm}$. $\mathrm{Hg}$ ), and in view of the known affinity of the cytochrome system for oxygen this should be ample for aerobic metabolism. Oxidative metabolism is ten to fourteen times more productive of energy than glycolytic metabolism (Fruton and Simmonds, 1953), and there is evidence that the motility of mammalian spermatozoa is more closely related to oxygen uptake than to fructolysis 
(Bishop, Campbell, Hancock, and Walton, 1954; Bishop and Hancock, 1955; Bishop, 1955). The observation that fluoride inhibits both fructolysis and motility under aerobic conditions (Lardy and Phillips, 1943) does not invalidate the value of respiratory metabolism for motility, because of the nonspecific nature of fluoride inhibition. It is unlikely that the aerobic inhibition of spermatozoon motility by hydrogen peroxide formation, observed under certain conditions in vitro (McLeod, 1946; Tosic and Walton, 1950) will occur within the female tract, owing to the presence of catalase in the mucosa.

The importance of glycolytic metabolism is likely to be greatest when the spermatozoa exist together in dense suspension and consequently reduce the local oxygen tension. This will occur at the site of deposition of the semen, and it is of course precisely at this point that the spermatozoa are most under the influence of the seminal plasma. The semen of the dog and cat, however, contains no fructose (Mann, 1954).

As already noted, high dilution of spermatozoa occurs in the female genital tract. A well-known result of dilution in vitro is spontaneous head agglutination-it is shown notably by rat, mouse, and guinea pig spermatozoa upon suspension in physiological saline, but occurs less readily with bull or ram spermatozoa. This suggests the presence of surface charges on the heads of the spermatozoon and indeed Milovanov and Selivanova (1932) have reported that unagglutinated spermatozoa do carry a negative charge and migrate to the anode in an electric field. When the charge is neutralized by electrolytes in the medium, head agglutination occurs and the spermatozoa are not moved by the current. Schröder (1940) went further, claiming that she had separated by electrophoresis the spermatozoa bearing the $\mathrm{X}$ chromsome, which migrated to the anode, from those bearing the Y chromsome, which migrated to the cathode. This work still awaits confirmation. The surface charge carried by spermatozoa is held to be associated with the lipoid capsule (Milovanov, 1934a,b), which, as mentioned earlier, is readily removed by electrolytes. In the semen or within the female tract, however, head agglutination is not a feature of spermatozoa, presumably 
owing in part to the protective action of nonelectrolytes. There is evidence, too, of a specific protective agent. Lindahl and his associates claim to have isolated a highly potent antagglutin from the semen of several mammals and to have demonstrated its presence also in the secretions of the vagina, cervix, and Fallopian tubes and in the ovarian follicle (Lindahl and Kihlström, 1954a,b; Lindahl and Nilsson, 1954; Furuhjelm, Nilsson, Lindahl, and Ingleman-Sundberg, 1954; Lindahl and Edlund, 1955). The antagglutin appears to be a mucoprotein; it is nondialyzable and can be reversibly oxidized. It is evidently produced in the prostate gland and becomes attached, while in the reduced form, to the spermatozoa thus preventing head agglutination, in which function it exhibits no species specificity. On oxidation, the antagglutin is inactivated and is detached from the spermatozoa, whereupon head agglutination takes place. The active agent is apparently stabilized in semen by the presence of reducing substances such as ergothionine and ascorbic acid. Such an antagglutin would have an important function in the seminal plasma and throughout the female genital tract in maintaining the spermatozoa in a suitable state for reaching and penetrating the eggs.

A protective action of vaginal mucus in the rabbit against the specific tail agglutination induced by appropriate antisera has been demonstrated by Smith (1949a).

Maintenance in the female tract therefore involves both supply of metabolites to spermatozoa and protection against the adverse effects of the inevitable high dilution that spermatozoa undergo.

\section{Capacitation}

An important function of the female genital tract is the part it plays in the process of capacitation, whereby the spermatozoon gains the ability to pass through the zona pellucida and thus to enter the egg ( see Austin, 1955b). That spermatozoa are required to spend a period of a few hours in the female tract before they are able to penetrate eggs was shown by introducing suspensions of spermatozoa into the periovarian sac of the rat or into the Fallopian tube of the rabbit shortly after ovulation (Austin, 1951; 
Chang, 1951a, 1955a,b). In the rat penetration did not occur until four or more hours later. In the rabbit few or no eggs were fertilized, although control tests, in which spermatozoa were introduced before ovulation, yielded a high incidence of fertilization. The failure of fertilization in the rabbit was explained on the grounds that the eggs became impenetrable, through the deposition of the mucoprotein layer, before the spermatozoa had completed capacitation. Spermatozoa obtained from the uterus of an inseminated rabbit showed the ability to penetrate eggs after a shorter interval of time. Noyes (1953) found, by insemination into the uterus, that rat uterine spermatozoa penetrated eggs after a shorter time than did epididymal spermatozoa. It appeared, therefore, that, while capacitation could take place entirely in the tubes, it could also occur, to some extent at least, in the uterus. The possibility that the effects observed had been due in part to the operative procedures employed was ruled out by the demonstration of a delay between the arrival of the spermatozoa at the site of fertilization and the penetration of the eggs in intact rats and rabbits when coitus occurred after ovulation (Austin, 1952; Austin and Braden, 1954a). It is uncertain what capacitation involves, but it seems to take at least two hours in the rat and four hours in the rabbit. Capacitation is not simply the separation of the spermatozoa from the male accessory secretions, for epididymal spermatozoa must also spend a period within the female tract. It is not associated with any obvious change in the structure of the spermatozoa. The most likely explanation seems to be that capacitation involves the activation of an enzyme system; this may possibly be effected by interaction with something originating in the follicular secretions.

\section{The Chances of Fertilization}

It is common experience that, when eggs are recovered from animals such as rats and mice early in the day following coitus, few or no spermatozoa can be seen in the cumulus mass or in the free surrounding fluid, and yet all the eggs are found to have been penetrated. The circumstances certainly suggest the existence of chemotaxis between egg and spermatozoon. Chemotaxis 
seems to occur in ferms, mosses, and seaweeds (Rothschild, 1951a), but so far no unequivocal evidence of attraction between animal gametes has been brought forward; this was pointed out many years ago by Buller (1903) and it is apparently still true today (Tyler, 1955). Certain other features may favor the chances of fertilization: the large cumulus mass about many mammalian eggs may help by providing a larger target for the spermatozoa, and the radially arranged cumulus cells, particularly in the near vicinity of the egg, may aid by orientating the spermatozoon toward the egg (Austin and Braden, 1952).

The chances of fertilization are, however, chiefly related to the concentration of spermatozoa about the eggs, and this will depend both on the total number of spermatozoa present and on the space through which these are distributed, that is, on the size of the site of fertilization. Many more spermatozoa were found at the site of fertilization in the sheep and rabbit than in the rat and mouse (as noted earlier), but the site of fertilization in the former two animals is much larger than in the latter two. The egg itself, the ultimate target for the spermatozoon, also differs in size in these species: sheep and rabbit eggs have approximately four times the surface area of rat and mouse eggs. When all these variables are taken into account, the collision frequency between eggs and spermatozoa is found to be of the same order in all four species (Braden and Austin, 1954a). These considerations relate particularly to the chances of penetration of individual eggs; data on the chances of penetration of the eggs as a group, in any one animal or Fallopian tube, have been reported by Chang (1946b,c). He found that, when superovulation was induced in rabbits by hormone administration, a higher proportion of eggs was fertilized than in untreated rabbits inseminated with the same numbers of spermatozoa. Evidently either the increased numbers of eggs or the effect of hormone treatment in some way improved the chances of successful fertilization and more than compensated for the need for the penetration of an abnormally large number of eggs. Estrogen administration in mice has also been found to increase the incidence of fertilization, presumably by stimulating uterine and tubal movements and thus increasing 
the number of spermatozoa available for fertilization (Austin and Bruce, 1956). In rats a highly significant association was shown to exist between the number of spermatozoa at the site of fertilization and the incidence of extra spermatozoa within eggs (Braden and Austin, 1954a). The data indicate, therefore, that the collision frequency between eggs and spermatozoa is conditioned by the mechanical and physical attributes of the female tract in such a way as normally to provide all eggs with good chances of fertilization without too great a risk of penetration by excessive numbers of spermatozoa.

However, the eggs themselves also have mechanisms for protection against penetration by extra spermatozoa, namely the zona reaction and the vitelline block to polyspermy, and these devices will be discussed later. For the present it is sufficient to note that in general the entry of extra spermatozoa into the eggs of marsupial and placental mammals must be considered abnormal although probably not disadvantageous to the embryo, provided they remain within the perivitelline space. Kushner (1954), indeed, reports that Russian workers have observed improved fertility in livestock following insemination with the mixed semen of several sires. The effect was believed to be due in part to the entry into the egg of several spermatozoa originating from more than one male. The rabbit egg can certainly tolerate the presence of numerous spermatozoa in the perivitelline space (20, Van Beneden, 1875; up to 50, Hensen, 1876; a mean of 37, Moricard and Bossu, 1949; a mean of 17, Chang, 1951b; a mean of 72, Braden, Austin, and David, 1954; up to 20, Adams, 1955). Even in the rabbit egg, however, there is a limit to the invasion: at about 6 hours after ovulation a layer of mucoprotein begins to accumulate on the surface of the zona (Braden, 1952, 1953), and this layer is impenetrable to spermatozoa (Pincus, 1930; Hammond, 1934). Occasionally, more than one spermatozoon enters the vitellus of the mammalian eggs and more than one male pronucleus is formed. This constitutes the state of polyspermy which is accepted as being pathological in eutherian mammals, although it is apparently normal in several other species, notably among the insects, elasmobranchs, amphibians, reptiles, birds, and pos- 
sibly monotremes. In mammals it almost certainly gives rise to polyploidy in the embryo (Austin and Braden, 1953b), and polyploid embryos seldom go to term (Beatty, 1951).

\section{Mechanisms of Spermatozoon Penetration}

Passage of spermatozoa through the cumulus oophorus is presumably effected with the aid of the hyaluronidase that they are known to carry (McClean and Rowlands, 1942; Fekete and Duran-Reynals, 1943; Swyer, 1947a,b). Complete breakdown of the cumulus mass is not a necessary preliminary to spermatozoon penetration and normally does not occur until some time after penetration. The function of hyaluronidase in fertilization, therefore, appears to be merely that of enabling the individual spermatozoa to make paths for themselves through the matrix of the cumulus (Lewis and Wright, 1935; Leonard, Perlman, and Kurzrok, 1947; Austin, 1948a; Austin and Smiles, 1948; Blandau and Odor, 1949; Bowman, 1951). Subsequent denudation of the egg by hyaluronidase, however, may be important in allowing the eggs to start their journey through the tubes and in permitting a ready gaseous exchange and elimination of metabolites by removing the numerous actively metabolizing follicle cells.

Fertilization in rabbits has been prevented by treating the semen used for insemination with hyaluronidase inhibitors or by injecting the inhibitors into the vagina before insemination (Pincus, Pirie, and Chang, 1948; Parkes, 1953; Chang and Pincus, 1953; Parkes, Rogers, and Spensley, 1954). The results, however, are inconclusive as all the hyaluronidase carried by the spermatozoa may not have been inhibited and to some extent the failure of fertilization may have been due to the inhibition of other enzymes, including those involved in the metabolism of the spermatozoa.

The next step, the passage through the zona pellucida, is even less well understood. In vitro, spermatozoa readily become attached to the surface of the zona, particularly of rabbit eggs, and this ability may be important in vivo in ensuring against escape of the spermatozoon and in maintaining close application of the spermatozoon head to permit the action of a possible lytic agent 
upon the zona. Adherence of the spermatozoon to the zona provides a parallel in these respects to the trapping of invertebrate spermatozoa in the jelly coat by the fertilizin-antifertilizin reaction (Tyler, 1948). It has indeed been shown that there is evidence for this reaction in mammals: spermatozoa of the rabbit, mouse, and bull were found to undergo agglutination in vitro in the presence of homologous eggs but showed little effect in the presence of eggs of the other species (Tyler, 1954; Bishop and Tyler, 1956). These authors believe that a fertilizin analogous to that of sea urchin eggs exists in the zona pellucida and that this reacts with antifertilizin on the spermatozoon head so as to bring about both the attachment of the spermatozoon to the zona and its passage through the membrane. On the other hand, adherence of the spermatozoon to the zona may well depend upon the same mechanism as head agglutination. If this is so, the antagglutin described by Lindahl and his associates would oppose spermatozoon penetration and there would need to be something present about the egg or at the site of fertilization with the property of counteracting the antagglutin.

Following attachment to the zona pellucida, the fertilizing spermatozoon passes through this membrane leaving a small slit that can be recognized many hours after penetration in the eggs of rats (Austin, 1951) and some other rodents. Passage through the zona is evidently rapid, at least in rats, mice, and hamsters, for fertilizing spermatozoa are rarely seen with their heads still within the thickness of the zona (Austin and Braden, 1956). The possession by the spermatozoon of an agent capable of exerting a lytic action upon the substance of the zona is a reasonable supposition, but so far no direct evidence of such an agent has been advanced. As already noted, spermatozoa require to spend a period in the female genital tract in order to undergo capacitation, which may therefore involve either the addition to the spermatozoon of a lytic agent produced in the female tract or the activation in the tract of a lytic agent carried by the spermatozoon in an inactive form. A priori, the latter alternative seems preferable (Austin, 1951).

In varying forms, mammalian spermatozoa possess a structure 
on or near the leading surface of the head with which the supposed zona lysin could be associated (Bowen, 1924; Green, 1940), for example, the "vesicle" on the head of the rat spermatozoon (Austin and Sapsford, 1952). It is of interest, too, that a hereditary deformity of the "acrosome" in bull spermatozoa has been found to be associated with sterility (Hancock, 1949, 1953). The extraction of a lytic agent from the anterior end of the head of Discoglossus (toad) spermatozoa has been reported (Parat, 1933) and similar observations have been made with Megathura (keyhole limpet) spermatozoa (Tyler, 1949) and Mytilus (mussel) spermatozoa (Wada, Collier, and Dan, 1956).

After passing through the zona pellucida the fertilizing spermatozoon projects into the perivitelline space and because this is small the spermatozoon head soon makes contact with the vitellus or cytoplasmic part of the egg. Contact appears to evoke a reaction in the vitellus so that attachment is formed between the spermatozoon head and the surface of the vitellus (Austin and Braden, 1956). The final phase of spermatozoon penetration, the entry into the egg cytoplasm, takes place in a manner suggesting that it is chiefly a function of the vitellus (Austin, 1951). The spermatozoon is absorbed much as a food particle is absorbed by an amoeba, or, as Loeb (1917) pointed out, in a manner resembling phagocytosis. Compared with penetration through the zona, entry into the vitellus is comparatively slow, the spermatozoon head being attached to the vitelline surface but essentially within the perivitelline space for about half an hour in the rat, mouse, and hamster (Austin and Braden, 1954a; Austin, 1956c). Thereafter, part of the spermatozoon midpiece or tail may still be seen in the perivitelline space or protruding through the hole in the zona at times up to several hours after the entry of the head.

Attachment of the spermatozoon head to the vitelline surface appears to be an essential preliminary to entry into the vitellus. Supplementary spermatozoa remain free within the perivitelline space. Probably anything altering the normal state of either spermatozoon or vitellus may prevent attachment from taking place. It has been reported that unfertilized rabbit eggs with a spermatozoon still in the perivitelline space, well after the normal time 
of penetration, were seen much more commonly when the semen used for insemination had been treated with a nonspecific hyaluronidase inhibitor (Parkes, Rogers, and Spensley, 1954). In mice subjected to hyperthermia, eggs with spermatozoa only in the perivitelline space were chiefly those showing early induced parthenogenesis (Austin and Braden, 1956). Evidently, artificial activation of mouse eggs is apt to prevent attachment of spermatozoon to vitellus.

In brief, the passage of the spermatozoon through the cumulus and zona pellucida is presumed to be made possible by enzymes that it carries, whereas entry into the cytoplasm of the egg appears largely to be an active function of the vitellus. Attachment of the spermatozoon to the zona and then to the vitellus must evidently precede penetration of these membranes.

\section{Immediate Reactions of the Egg to Spermatozoon Penetration}

In most mammals - a notable exception being the rabbit-the zona pellucida undergoes a change after the entry of the first spermatozoon, with the result that further spermatozoa tend to be excluded (Braden, Austin, and David, 1954; earlier observations on the incidence of supplementary spermatozoa in mammalian eggs are reviewed in this paper). This is known as the "zona reaction," and the rate at which it occurs varies between species so that a few extra spermatozoa are often seen in the eggs of the rat, mouse, guinea pig, cat, and ferret, but rarely if ever in those of the dog, sheep, and hamster. In the rat the reaction takes between 10 minutes and 2 hours to reach completion. Smithberg (1953) reported that, in mice, the zona pellucida is removed by proteolytic enzymes more rapidly from unfertilized than from fertilized eggs. This supports the idea that the zona reaction renders the substance of the zona refractory to the action of the supposed zona lysin. The change appears to be induced by an agent released from the vitellus following attachment of a spermatozoon to its surface (Austin and Braden, 1956). The release of the agent is evidently propagated through the cortex of the egg from the point of attachment of the spermatozoon head, and 
consequently the zona reaction commences at or near the site of penetration and progressively involves the rest of the zona.

In the hamster the vitellus of the unpenetrated egg displays a large number of cortical granules that disappear when the head of the fertilizing spermatozoon makes contact with the surface (Austin, 1956b). Light scatter by the vitelline surface also diminishes after spermatozoon contact. There is good evidence that a vitelline block to polyspermy does not operate in hamster eggs (Austin, 1956c) so that the cortical changes seen are very likely associated with the zona reaction which is well developed in hamster eggs.

In certain respects the responses shown by mammalian eggs are similar to processes involved in membrane elevation in echinoderm eggs. The fertilization membrane is considered to be the vitelline membrane modified by the products of a change propagated through the cortex from the point of spermatozoon contact. The numerous cortical granules, which "explode" when the spermatozoon enters the egg, evidently play a part in the modification of the vitelline membrane (Moser, 1939; Motomura, 1941; Rumnström, Monné, and Wicklund, 1944, 1946; Runnström and Wicklund, 1950; Endo, 1952). Changes in the light-scattering property of the cortex have also been described, although there is disagreement on the direction of the change and on its possible association with the disappearance of cortical granules or the formation of the block to polyspermy (Moser, 1939; Rothschild and Swann, 1949).

The zona reaction and the vitelline block to polyspermy are complementary in function. In some species, such as rats and mice, both are operative. In others, such as the hamster, sheep, and dog, protection appears to be vested exclusively in the zona reaction. In others again, such as the rabbit and perhaps the mole and the pocket gopher, the zona reaction is slow or absent and the block to polyspermy seems to be unusually well developed (Braden, Austin, and David, 1954).

The block to polyspermy evidently involves a change in the vitelline surface such that attachment will no longer be formed with the head of a contacting spermatozoon (Austin and Braden, 
1956). The rate of its development appears to decrease as the egg ages after ovulation (Austin and Braden, 1953a,b; Braden and Austin, 1954c), and this effect is promoted by local heat (Austin and Braden, 1954b) and by hyperthermia (Austin, 1955a, 1956a; Austin and Braden, 1956). Both aging and heat have long been known to increase the incidence of polyspermy in invertebrate eggs (Wilson, 1928). It has not yet been found possible to express quantitatively the normal rate of development of the block in mammals, but estimates have been derived for sea urchin eggs. There is, it seems, a fast partial block covering the egg in less than two seconds and a slower complete component taking about one minute (Rothschild and Swann, 1952; Rothschild, 1954).

An early reaction to the penetrating spermatozoon shown by certain invertebrate eggs consists in the formation of a fertilization cone. Many years ago Asterias (starfish) eggs were observed to develop a filament that moved out to make contact with the nearest spermatozoon and appeared to assist its entry into the egg (Fol, 1877, 1879; see also Colwin and Colwin, this volume). Since then other forms of fertilization cones have been described in different species; in some animals the projection persists after spermatozoon entry, and in others it is withdrawn before this event (Chambers, 1933). Recent observations on rat, mouse, and hamster eggs show that an analogous elevation develops in the mammalian egg as the spermatozoon head is absorbed through the vitelline surface; it persists for a short time thereafter (Austin and Braden, 1956).

It may be seen, therefore, that two of the earliest reactions shown by the mammalian egg to spermatozoon penetration tend to prevent the entry of other spermatozoa. Both reactions are apparently evoked by contact of the spermatozoon head with the vitelline surface, but their relative importance varies between species in a complementary manner.

\section{Conclusions}

The evolution of internal fertilization brought with it numerous advantages arising from the complete avoidance of the external 
environment and its vagaries. With internal fertilization there is a much greater likelihood of success, which is achieved through the deposition of the gametes into a highly specialized internal environment. The success of fertilization in this environment, as with the outcome of many other biological situations, is determined by the results of interaction between opposing functions: between those responsible for activating the spermatozoa and those responsible for protection against overactivation, between those favoring rapid transport of spermatozoa and those hindering transport, between those promoting spermatozoon penetration of egg membranes and those preventing excessive penetration. The most important variables appear to be the number of spermatozoa reaching the site of fertilization and their time of arrival. The many integrated processes and reactions that constitute the environment of fertilization in mammals have the function of ensuring the meeting of the gametes in the most appropriate numerical relations and at the optimal phase of their life cycle. In no two species, however, is the mechanism quite the same, so that the preliminaries to fertilization among different species exhibit wide variations in the degree of development of the constituent complementary processes.

There may also be disadvantages to internal fertilization which stem from the fact that biological systems are often highly specific within the individual, but they tend to differ between individuals. In particular the immunological processes behave in this way. Spermatozoa are known to show a variety of antigenic properties (Smith, 1949a,b), including the possession of blood group antigens appropriate to the male producing them (Docton, Ferguson, Lazear, and Ely, 1952). Owing to antigenic diversity between individuals, spermatozoa within the female tract may, to varying degree, be regarded as foreign bodies. According to the "self-not-self" concept, it is a fundamental property of adult organisms that foreign material can be recognized as such and rejected (Burnet and Fenner, 1949; Burnet, 1954). A mechanism of this nature may underlie the failure of heterologous spermatozoa in many abortive attempts at hybridization. It is possible, also, that antigenic incompatibility between the spermatozoa and 
the female genital tract or between spermatozoon and egg, within the same species, may prejudice the chances of fertilization.

\section{REFERENCES}

Adams, C. E. 1955. The frequency of occurrence of supernumerary spermatozoa in rabbit ova. Proc. Soc. Study Fertility, 7, 130-38.

Adams, C. E. 1956. Rate of sperm transport in the female reproductive tract of the rabbit. J. Endocrinol., 13, xxi-xxii (proc.).

Alden, R. A. 1943. The utero-tubal junction in the albino rat. Anat. Record, 85, 290-91.

Andersen, D. 1928. Comparative anatomy of the tubo-uterine junction. Histology and physiology in the sow. Am. J. Anat., 42, 255-305. Anderson, J. 1945. The Semen of Animals and Its Use for Artificial Insemination. Imperial Bureau of Animal Breeding and Genetics, Edinburgh.

Austin, C. R. 1948a. Function of hyaluronidase in fertilization. Nature, $162,63$.

Austin, C. R. 1948b. Number of sperms required for fertilization. Nature, 162, 534 .

Austin, C. R. 1949. Fertilization and the transport of gametes in the pseudopregnant rabbit. J. Endocrinol., 6, 63-70.

Austin, C. R. 1951. Observations on the penetration of the sperm into the mammalian egg. Australian J. Sci. Rescarch, B4, 581-96.

Austin, C. R. 1952. The "capacitation" of the mammalian sperm. Nature, $170,326$.

Austin, C. R. 1955a. Polyspermy after induced hyperthermia in rats. Nature, 175, 1038.

Austin, C. R. 1955b. Acquisition de la capacité fertilisatrice des spermatozoides ("capacitation") dans les voies génitales femelles. In La Fonction Tubaire et ses Troubles. Masson et Cie., Paris. Pages 22-27.

Austin, C. R. 1956a. Effects of hypothermia and hyperthermia on fertilization in rat eggs. J. Exptl. Biol., 33, 348-57.

Austin, C. R. 1956b. Cortical granules in hamster eggs. Exptl. Cell Research, 10, 533-40.

Austin, C. R. 1956c. Ovulation, fertilization and early cleavage in the hamster (Mesocricetus auratus). J. Roy. Microscop. Soc., 75, 141-54. 
Austin, C. R., and A. IV. H. Braden. 1952. Passage of the sperm and the penetration of the egg in mammals. Nature, 170, 919-21.

Austin, C. R., and A. W. H. Braden. 1953a. Polyspermy in mammals. Nature, 172, 82.

Austin, C. R., and A. W. H. Braden. 1953b. An investigation of polyspermy in the rat and rabbit. Australian J. Biol. Sci., 6, 674-92.

Austin, C. R., and A. W. H. Braden. 1954a. Time relations and their significance in the ovulation and penetration of eggs in rats and rabbits. Australian J. Biol. Sci., 7, 179-94.

Austin, C. R., and A. W. H. Braden. 1954b. Induction and inhibition of the second polar division in the rat egg and subsequent fertilization. Australian J. Biol. Sci., 7, 195-210.

Austin, C. R., and A. W. H. Braden. 1956. Early reactions of the rodent egg to spermatozoon penetration. J. Exptl. Biol., 33, 358-65.

Austin, C. R., and H. M. Bruce. 1956. Effect of continuous oestrogen administration on oestrus, ovulation and fertilization in rats and mice. J. Endocrinol., 13, 376-\$3.

Austin, C. R., and C. S. Sapsford. 1952. The development of the rat spermatid. J. Roy. Microscop. Soc., 71, 397-406.

Austin, C. R., and J. Smiles. 1948. Phase-contrast microscopy in the study of fertilization and early development of the rat egg. J. Roy. Microscop. Soc., 68, 13-19.

Beatty, R. A. 1951. Heteroploidy in mammals. Animal Breeding Abstracts, 19, 283-92.

Bishop, D. W., and H. Matthews. 1952. The significance of intravas $\mathrm{pH}$ in relation to sperm motility. Science, 115, 209-11.

Bishop, D. W., and A. Tyler. 1956. Fertilizin of mammalian eggs. $J$. Exptl. Zool., 132, 575-601.

Bishop, M. W. H. 1954. Some aspects of the dilution effect in bovine spermatozoa. Proc. Soc. Study Fertility, 6, 81-95.

Bishop, M. W. H. 1955. Inter-relationships of semen characteristics. Proc. Soc. Study Fertility, 7, 48-65.

Bishop, M. W. H., R. C. Campbell, J. L. Hancock, and A. Walton. 1954. Semen characteristics and fertility in the bull. J. Agr. Sci., 44, 227-48.

Bishop, M. W. H., and J. L. Hancock. 1955. The evaluation of bull semen. Vet. Record, 67, 363-72.

Bishop, M. W. H., and G. W. Salisbury. 1955a. Effect of sperm concentration on the oxygen uptake of bull semen. Am. J. Physiol., 180, 107-12. 
Bishop, M. W. H., and G. W. Salisbury. 1955b. Effect of dilution with saline and phosphate solutions on oxygen uptake of bull semen. Am. J. Physiol., 181, 114-18.

Blandau, R. J. 1952. The female factor in fertility and infertility. I. Effects of delayed fertilization on the development of the pronuclei in rat ova. Fert. \& Ster., 3, 349-65.

Blandau, R. J., and E. S. Jordan. 1941. The efect of delayed fertilization on the development of the rat ovum. Am. J. Anat., 68, 275-S7. Blandau, R. J., and W. L. Money. 1944. Observations on the rate of transport of spermatozoa in the female genital tract of the rat. Anat. Record, 90, 255-60.

Blandau, R. J., and D. L. Odor. 1948. The number of spermatozoa reaching various segments of the oviduct of the rat, 12, 24 and 36 hr. after mating. Anat. Record, 100, 733 (proc.).

Blandau, R. J., and D. L. Odor. 1949. The total number of spermatozoa reaching various segments of the reproductive tract in the female albino rat at intervals after insemination. Anat. Record, 103, 93-110.

Blandau, R. J., and IV. C. Young. 1939. The effects of delayed fertilization on the development of the guinea-pig ovum. Am. J. Anat., 64, 303-29.

Bluntschli, H. 1938. Le développement primaire et l'implantation chez un centetiné (Hemicentetes). Compt. rend. assoc. anat., Bâle, 1, 39.

Bowen, R. H. 1924. On the acrosome of the animal sperm. Anat. Record, 28, 1-13.

Bowman, R. H. 1951. Fertilization of undenuded rat ova. Proc. Soc. Exptl. Biol. Med., 76, 129-30.

Boyarsky, L. H., H. Baylies, L. E. Casida, and R. K. Meyer. 1947. Influence of progesterone upon the fertility of gonadotrophin-treated female rabbits. Endocrinology, 41, 312-21.

Braden, A. W. H. 1952. Properties of the membranes of rat and rabbit eggs. Australian J. Sci. Research, B5, 460-71.

Braden, A. W. H. 1953. Distribution of sperms in the genital tract of the female rabbit after coitus. Australian J. Biol. Sci., 6, 693-705.

Braden, A. W. H., and C. R. Austin. 1954a. The number of sperms about the eggs in mammals and its significance for normal fertilization. Australian J. Biol. Sci., 7, 543-51.

Braden, A. W. H., and C. R. Austin. 1954b. Fertilization of the mouse egg and the effect of delayed coitus and of hot-shock treatment. Australian J. Biol. Sci., 7, 552-65. 
Braden, A. W. H., and C. R. Austin. 1954c. The fertile life of mouse and rat eggs. Science, 120, 361-62.

Braden, A. W. H., C. R. Austin, and H. A. David. 1954. The reaction of the zona pellucida to sperm penetration. Australian J. Biol. Sci., 7, 391-409.

Buller, A. H. R. 1903. Is chemotaxis a factor in the fertilization of the eggs of animals? Quart. J. Microscop. Sci., 46, 145-76.

Burnet, F. M. 1954. The new approach to immunity in its bearing on medicine and biology. Brit. Med. J., ii, 189-93.

Burnet, F. M., and F. Fenner. 1949. The Production of Antibodies. Macmillan \& Co., Melbourne.

Campbell, J. A. 1932. Normal gas tensions in the mucous membrane of the rabbit's uterus. J. Physiol., 76, 13P-14P.

Canivenc, R., C. Drouvillé, and G. Mayer. 1953. Développement simultané d'embryons d'âge différent chez la rate réalisation expérimentale. Compt. rend., 237, 1036-38.

Chambers, R. 1933. The manner of sperm entry in various marine ova. J. Exptl. Biol., 10, 130-41.

Chang, M. C. 1946a. Effect of dilution on fertilizing capacity of rabbit spermatozoa. Science, 104, 361-62.

Chang, M. C. 1946b. Fertilizing capacity of rabbit spermatozoa. In The Problem of Fertility, E. T. Engle, editor. Princeton Univ. Press, Princeton, N. J. Pages 169-81.

Chang, M. C. 1946c. Number of spermatozoa required for the fertilization of super-ovulated eggs in the rabbit. Federation Proc., 5, 16.

Chang, M. C. 195la. Fertilizing capacity of spermatozoa deposited into the Fallopian tubes. Nature, 168, 697.

Chang, M. C. 1951b. Fertilization in relation to the number of spermatozoa in the Fallopian tubes of rabbits. Ann. ostet. ginecol. Milano, 73, 918-25.

Chang, M. C. 1952a. Fertilizability of rabbit ova and the effects of temperature in vitro on their subsequent fertilization and activation in vivo. J. Exptl. Zool., 121, 351-81.

Chang, M. C. 1952b. Effects of delayed fertilization on segmenting ova, blastocysts and fetuses in rabbit. Federation Proc., 11, 24.

Chang, M. C. 1955a. Développement de la capacité fertilisatrice des spermatozoïdes du'lapin a l'intérieur du tractus génital femelle et fécondabilité des oeufs de lapine. In La Fonction Tubaire et ses Troubles. Masson et Cie., Paris. Pages 40-52. 
Chang, M. C. 1955b. Development of fertilizing capacity of rabbit spermatozoa in the uterus. Nature, 175, 1036-37.

Chang, M. C., and G. Pincus. 1953. Does phosphorylated hesperidin affect fertility? Science, 117, 274-76.

Cheng, P. L., L. E. Casida, and G. R. Barrett. 1949. The effects of dilution on motility of bull spermatozoa and the relation between motility in high dilution and fertility. J. Animal Sci., 8, 81-88.

Crew, F. A. E. 1926. On fertility in the domestic fowl. Proc. Roy. Soc. (Edinburgh ), 46, 230-38.

Cupps, P. F., and S. A. Asdell. 1944. Changes in the physiology and pharmacology of the uterine muscle of the cow in relation to the estrous cycle. J. Animal Sci., 3, 351-59.

Dallam, R. D., and L. E. Thomas. 1952. Chemical composition of mammalian sperm. Nature, 170, 377.

Dharmarajan, M. 1950. Effect on the embryo of staleness of the sperm at the time of fertilization in the domestic hen. Nature, 165, 398.

Docton, F. L., L. C. Ferguson, E. J. Lazear, and F. Ely. 1952. The antigenicity of bovine spermatozoa. J. Dairy Sci., 35, 706-9.

Emmens, C. W., and G. I. M. Sivyer. 1948. Observations on the motility of rabbit spermatozoa in dilute suspension. J. Gen. Physiol., 32, 121-38.

Endo, Y. 1952. The role of the cortical granules in the formation of the fertilization membrane in eggs from Japanese sea urchins. I. Exptl. Cell Research, 3, 406-1S.

Evans, E. I. 1933. The transport of spermatozoa in the dog. Am. J. Physiol., 105, 287-93.

Evans, E. I., and F. W. Miller. 1936. Uterine motility in the cow. Am. J. Physiol., 116, 44-45.

Fekete, E., and F. Duran-Reynals. 1943. Hyaluronidase in the fertilization of mammalian ova. Proc. Soc. Exptl. Biol. Med., 52, 119-21.

Florey, H., and A. Walton. 1932. Uterine fistula used to determine the mechanism of ascent of the spermatozoon in the female genital tract. J. Physiol., 74, 5P-6P.

Fol, H. 1877. Sur le premier développement d'une Etoile de Mer. Compt. rend., 84, 357-60.

Fol, H. 1879. Recherches sur la fécondation et la commencement de l'hénogénie chez divers animaux. Mém. Soc. Phys. d'hist. nat. Genève, 26, 89-397.

Fruton, J. S., and S. Simmonds. 1953. General Biochemistry. John Wiley \& Sons, New York, N. Y. 
Fujii, T., S. Utida, and T. Mizuno. 1955. Reaction of starfish spermatozoa to histidine and certain other substances considered in relation to zinc. Nature, 176, 1068-69.

Furuhjelm, M., A. Nilsson, P. E. Lindahl, and A. Ingleman-Sundberg. 1954. Studier över spermieantagglutinets förekomst hos kvinnan under den normala menstruation-cykeln och vid sterilitet. Förhandlingar vid Nordisk förenings för obstet. och gynekol. kongress $i$ Göteborg, 8, 76-84.

Glover, F. A., and G. W. Scott Blair. 1953. Flow properties of cervical secretions in the cow as related to certain physiological conditions. J. Endocrinol., 9, 160-69.

Gray, A. P. 1954. Mammalian Hybrids. Commonwealth Agricultural Bureau, Farnham Royal, Bucks., England.

Gray, J. 1928. The effect of dilution on the activity of spermatozoa. J. Exptl. Biol., 5, 337-44.

Green, W. W. 1940. The chemistry and cytology of the sperm membrane of sheep. Anat. Record, 76, 455-73.

Green, W. W., and L. M. Winters. 1935. Studies on the physiology of reproduction in the sheep. III. The time of ovulation and the rate of sperm travel. Anat. Record, 61, 457-67.

Gunn, R. M. C. 1936. Fertility in sheep. Artificial production of seminal ejaculation and the characters of the spermatozoa contained therein. Bull. Council Sci. Ind. Research, Australia. No. 94.

Hammond, J. 1930. The effect of temperature on the survival of rabbit spermatozoa obtained from the vagina. J. Exptl. Biol., 7, 175-95. Hammond, J. 1934. The fertilization of rabbit ova in relation to time. A method of controlling the litter size, the duration of pregnancy and the weight of the young at birth. J. Exptl. Biol., 11, 140-61.

Hancock, J. L. 1949. Evidence of an inherited seminal character associated with infertility of Fresian bulls. Vet. Record, 61, 308-9.

Hancock, J. L. 1953. The spermatozoa of sterile bulls. J. Exptl. Biol., $30,50-56$.

Hancock, J. L., and D. H. L. Rollinson. 1949. A seminal defect associated with sterility of Guernsey bulls. Vet. Record, 61, 742-43.

Hartman, C. G. 1939. Ovulation, fertilization and the transport and viability of eggs and spermatozoa. In Sex and Internal Secretions, 2nd ed., E. Allen, 'editor. Bailliere, Tindall and Cox, London, pp. 630-719.

Hays, R. L., and N. L. Van Demark. 1952. Effect of hormones on 
uterine motility and sperm transport in the perfused genital tract of the cow. J. Dairy Sci., 35, 499-500.

Heape, W. 1898. On the artificial insemination of mares. Veterinarian, $71,202$.

Heape, W. 1905. Ovulation and degeneration of ova in the rabbit. Proc. Roy. Soc. (London), B76, 260-68.

Hensen, V. 1876. Beobachtungen über die Befruchtung und Entwicklung des Kaninchens und Meerschweinchens. Z. Anat. Entwicklungsgeschichte, 1, 213-73.

Huggins, C., and W. Neal. 1942. Coagulation and liquefaction of semen. Proteolytic enzymes and citrate in prostatic fluid. J. Exptl. Med., 76, 527-41.

Huggins, C., and V. C. Vail. 1943. Plasma coagulation and fibrinogenolysis by prostatic fluid and trypsin. Am. J. Physiol., 139, 12934.

Ivanov, E. 1926. Durée de conservation de la propriété fécondatrice des spermatozoïdes des mammifères dans l'epididyme separé de l'organisme. Compt. rend., 183, 456-58.

Kampschmidt, R. F., D. T. Mayer, and H. A. Herman. 1953. Viability of bull spermatozoa as influenced by various sugars and electrolytes in the storage medium. Missouri Agr. Expt. Sta. Research Bull. No. 519.

Kok, J. C. N. 1953. Some factors influencing the longevity of bull sperm cells in vitro. In Mammalian Germ Cells, G. E. W. Wolstenholme, M. P. Cameron, and J. S. Freeman, editors. J. \& A. Churchill Ltd., London. Pages 82-90.

Krehbiel, R. H., and H. P. Carstens. 1939. Roentgen studies of the mechanism involved in sperm transportation in the female rabbit. Am. J. Physiol., 125, 571-77.

Kushner, K. F. 1954. The effect of heterospermic insemination in animals and its biological nature (Trans. title). Izvest. Akad. Nauk S.S.S.R., Ser. B, No. 1, 32.

Lardy, H. A. 1953. Factors controlling rates of metabolism in mammalian spermatozoa. In Mammalian Germ Cells, G. E. W. Wolstenholme, M. P. Cameron, and J. S. Freeman, editors. J. \& A. Churchill Ltd, London. Pages 59-70.

Lardy, H. A., and D. Ghosh. 1952. Comparative metabolic behaviour of epididymal and ejaculated spermatozoa. Ann. N. Y. Acad. Sci., 55, 594-96. 
Lardy, H. A., D. Ghosh, and G. W. E. Plaut. 1949. A metabolic regulator in mammalian spermatozoa. Science, 109, 365-67.

Lardy, H. A., and P. H. Phillips. 1941. Phospholipids as a source of energy for motility of bull spermatozoa. Am. J. Physiol., 134, 542-48.

Lardy, H. A., and P. H. Phillips. 1943. Inhibition of sperm glycolysis and reversibility of the effects of metabolic inhibitors. J. Biol. Chem., 148, 343-47.

Lardy, H. A., and P. H. Phillips. 1945. Studies of fat and carbohydrate oxidation in mammalian spermatozoa. Arch. Biochem., 6, 53-61.

Leonard, S. L., and P. L. Perlman. 1949. Conditions affecting the passage of spermatozoa through the utero-tubal junction of the rat. Anat. Record, 104, 89-102.

Leonard, S. L., P. L. Perlman, and R. Kurzrok. 1947. Relation between time of fertilization and follicle cell dispersal in rat ova. Proc. Soc. Exptl. Biol. Med., 66, 517-18.

Lewis, L. L. 1911. The viability of reproductive cells. Oklahoma Agr. Expt. Sta. Bull., No. 96.

Lewis, W. H., and E. S. Wright. 1935. On the early development of the mouse egg. Carnegie Inst. Wash. Contribs. Embryol., 25, 113-44.

Lindahl, P. E., and B. Edlund. 1955. On the antigenicity of male sperm antagglutin. Exptl. Cell Research, Suppl., 3, 241-43.

Lindahl, P. E., and J. E. Kihlström. 1954a. An antiagglutinic factor in mammalian sperm plasm. Fert.-Ster., 5, 241-55.

Lindahl, P. E., and J. E. Kihlström. 1954b. A constituent of male sperm antagglutin related to vitamin E. Nature, 174, 600.

Lindahl, P. E., and A. Nilsson. 1954. On the occurrence of sperm antagglutin in the female rabbit. Arch. Zool., 7, 223-26.

Loeb, J. 1917. Fécondation et phagocytose. Ann. inst. Pasteur, 31, $437-41$.

Lovelock, J. E. 1954. Physical instability and thermal shock in red cells. Nature, 173, 659.

Lovelock, J. E. 1955. The physical instability of human red blood cells. Biochem. J., 60, 692-96.

Mahfouz, N. P. 1949. Atlas of Mahfouz's Obstetric and Gynecological Museum. John Sharrat \& Son, Altrincham, England.

Mann, T. 1954. The Biochemistry of Semen. Methuen \& Co. Ltd., London.

McClean, D., and I. W. Rowlands. 1942. The role of hyaluronidase in fertilization. Nature, 150, 627-28 
McLeod, J. 1946. Metabolism and motility of human spermatozoa. In The Problem of Fertility, E. T. Engle, editor. Princeton Univ. Press, Princeton, N. J. Pages 154-68.

Millar, R. 1952. Forces observed during coitus in thoroughbreds. Australian Vet. J., 28, 127-28.

Milovanov, V. K. 1934a. Iskusstvennoe osemenenie s.-L. zivotnyh. State Publishing House, Moscow-Leningrad. Cited by Anderson, 1945.

Milovanov, V. K. 1934b. Osnovy iskusstvennogo osemenija. State Publishing House, Moscow-Leningrad. Cited by Anderson, 1945.

Milovanov, V. K., and O. A. Selivanova. 1932. Problemy Zhivotnovodatva, No. 2, 75. In Animal Breeding Abstracts, 1933, 1, 153.

Moench, G. L., and H. Holt. 1929. Mikrochirurgische Experimente mit menchlichen Spermatozoen. Zentr. Gynäkol., 21, 1300.

Moricard, R., and J. Bossu. 1949. Numération des spermatozoïdes au voisinage de l'ovocyte de lapine. Inexistence d'un essain de spermatozoïdes provoquant l'éffritement des cellules granuleuses au moment de la fécondation. Bull. assoc. gynécol ct obstét. langue franç., 1,30 .

Moser, F. 1939. Studies on a cortical layer response to stimulating agents in the Arbacia egg. 1. Response to insemination. J. Exptl. Zool., 80, 423-45.

Motomura, I. 1941. Materials of the fertilization membrane in the eggs of echinoderms. Tôhoku Imp. Univ. Sci. Repts., Ser. 4, 16, 345-63.

Murphree, R. L., E. J. Warwick, L. E. Casida, and W. H. McShan. 1947. Influence of reproductive stage upon the fertility of gonadotrophin-treated female rabbits. Endocrinology, 41, 308-11.

Nalbandov, A. V., and L. E. Card. 1943. Effect of stale sperms on fertility of chick eggs. Poultry Sci., 22, 216-26.

Noyes, R. W. 1953. The fertilizing capacity of spermatozoa. Western J. Surg. Obstet. Gynecol., 61, 342-49.

Parat, M. 1933. Nomenclature, genèse, structure et fonction de quelques éléments cytoplasmique des cellules sexuelles males. Compt. rend., 112, 1131-34.

Parker, G. H. 1931. The passage of sperms and eggs through the oviduct in terrestrial vertebrates. Philos. Trans. Roy. Soc. (London), 219, 381-419.

Parkes, A. S. 1953. Prevention of fertilization by a hyaluronidase inhibitor. Lancet, 265, 1285-87. 
Parkes, A. S., H. J. Rogers, and P. C. Spensley. 1954. Biological and biochemical aspects of the prevention of fertilization by enzyme inhibitors. Proc. Soc. Study Fertility, 6, 65-80.

Phillips, R. W., and F. IV. Andrews. 1937. The speed of travel of ram spermatozoa. Anat. Record, 68, 127-31.

Pincus, G. 1930. Observations on the living eggs of the rabbit. Proc. Roy. Soc. (London), B107, 132-67.

Pincus, G., N. W. Pirie, and M. C. Chang. 1948. The effects of hyaluronidase inhibitors on fertilization in the rabbit. Arch. Biochem., 19, 388-96.

Pommerenke, W. T., and E. Viergiver. 1946. Cervical mucus and the menstrual cycle. In The Problem of Fertility, E. T. Engle, editor. Princeton Univ. Press, Princeton, N. J. Pages 102-118.

Quinlan, J., G. S. Mare, and L. L. Roux. 1932. The vitality of the spermatozoa in the genital tract of the Merino ewe, with special reference to its practical application in breeding. 18th Rept. Dir. Vet. Serv. Animal Industry Union of S. Africa. Pages 831-870.

Quinlan, J., G. S. Mare, and L. L. Roux. 1933. A study of the duration of motility of spermatozoa in the different divisions of the reproductive tract of the Merino eve. Onderstepoort J. Vet. Sci. Animal Industry, 1, 135-45.

Redenz, E. 1924. Versuche eine biologischen Morphologie des Nebenhodens. Arch. Entwicklungsmechanik, 103, 591.

Redenz, E. 1925. Versuche eine biologischen Morphologie des Nebenhodens. II. Die Bedeutung elektrolytarmer Losungen für de Bewvegung der Spermien. Arch. Entwicklungsmechanik, 106, 290.

Redenz, E. 1926. Nebenhoden und Spermienbewegung. Wïrzburger Abhandl. Gesamt. Med., 4, 5.

Redenz, E. 1929. Das Verhalten der Säugetierspermatozoen zwvischen Begattung und Befruchtung. Z. Zellforsch. mikroskop. Anat., 9, 73449.

Reynolds, S. R. M. 1930. Studies on the uterus. I. A method for recording uterine activity in chronic experiments on unanesthetized animals. Am. J. Physiol., 92, 420-29.

Reynolds, S. R. M. 1949. Physiology of the Uterus, Hoeber, New York, N. Y.

Rothschild, Lord. 1948. The physiology of sea-urchin spermatozoa: lack of movement in semen. J. Exptl. Biol., 25, 344-52.

Rothschild, Lord. 1951a. Sperm-egg interacting substances and meta- 
bolic changes associated with fertilization. Biochem. Soc. Symposia (Cambridge, Engl.) 7, 40-51.

Rothschild, Lord. 1951b. Sea-urchin spermatozoa. Biol. Revs. Cambridge Phil. Soc., 26, 1-27.

Rothschild, Lord. 1954. Polyspermy. Quart. Rev. Biol., 29, 332-42.

Rothschild, Lord, and K. W. Cleland. 1952. The physiology of seaurchin spermatozoa. The nature and location of the endogenous substrate. J. Exptl. Biol., 29, 66-71.

Rothschild, Lord, and M. M. Swann. 1949. The fertilization reaction in the sea-urchin egg. A propagated response to sperm attachment. J. Exptl. Biol., 26, 164-176.

Rothschild, Lord, and M. M. Swann. 1952. The fertilization reaction in the sea-urchin. The block to polyspermy. J. Exptl. Biol., 29, 46983.

Rowson, L. E. 1955. The movement of radio-opaque material in t'se bovine uterine tract. Brit. Vet. J., 111, 334-42.

Roy, A., and M. W. H. Bishop. 1954. Effect of glycine on the survival of bull spermatozoa in vitro. Nature, 174, 746.

Runnström, J., L. Monné, and E. Wicklund. 1944. Mechanism of formation of the fertilization membrane in the sea-urchin egg. Nature, 153, 313-14.

Runnström, J., L. Monné, and E. Wicklund. 1946. Studies on the surface layers and the formation of the fertilization membrane in seaurchin eggs. J. Colloid Sci., 1, 421-52.

Runnström, J., and E. Wicklund. 1950. Formation mechanism of the fertilization membrane in the sea-urchin egg. Arch. Zool., 1, (2) 179-94.

Salisbury, G. W., G. H. Beck, P. T. Cupps, and I. Elliott. 1943. The effect of dilution rate on the livability and fertility of bull spermatozoa used for artificial insemination. J. Dairy Sci., 26, 1057-69.

Salisbury, G. W., R. W. Bratton, and R. H. Foote. 1952. The effect of time and other factors on the non-return to service estimate of fertility level in artificial insemination of cattle. J. Dairy Sci., 35, 256-60.

Schott, R. G., and R. W. Phillips. 1941. Rate of sperm travel and time of ovulation in sheep. Anat. Record, 79, 531-40.

Schröder, V. 1940. Uber die kunstliche Geschlechtsregulation bei den Säugetieren mittels der Elektrophorese und deren biologische Kontrolle. Compt. rend. acad. sci. U.R.S.S., 26, 687-91. 
Smith, A. U. 1949a. Some antigenic properties of mammalian spermatozoa. Proc. Roy. Soc. (London). B136, 46-66.

Smith, A. U. 1949b. The antigenic relationship of some mammalian spermatozoa. Proc. Roy. Soc. (London), B136, 472-79.

Smithberg, M. 1953. The effect of different proteolytic enzymes on the zona pellucida of mouse ova. Anat. Record, 117, 554 (proc.) (abstract).

Soderwall, A. L., and R. J. Blandau. 1941. The duration of the fertilizing capacity of spermatozoa in the female genital tract of the rat. J. Exptl. Zool., 88, 55-64.

Starke, N. C. 1949. The sperm picture of rams of different breeds as an indication of their fertility. II. The rate of sperm travel in the genital tract of the ewe. Onderstepoort J. Vet. Sci. Animal Industry, $22,415-525$.

Strauss, F. 1938. Die Befruchtung und der Vorgang der Ovulation bei Ericulus aus der Familie der Centetiden. Bio-Morphosis, 1, 281-312.

Strauss, F. 1950. Ripe follicles without antra and fertilization within the follicle; a normal situation in a mammal. Anat. Record, 106, 251-52 (proc.).

Swyer, G. I. M. 1947a. The hyaluronidase content of semen. Biochem. J., 41, 409-13.

Swyer, G. I. M. 1947b. The release of hyaluronidase from spermatozoa. Biochem. J., 41, 413-17.

Tosic, J., and A. Walton. 1950. Metabolism of spermatozoa. The formation and elimination of hydrogen peroxide by spermatozoa and effects on motility and survival. Biochem. J., 47, 199-212.

Trimberger, G. W. 1948. Breeding efficiency in dairy cattle from artificial insemination at various intervals before and after ovulation. Research Bull. Neb. Agr. Expt. Sta., No. 153, 26 pp.

Tyler, A. 1948. Fertilization and immunity. Physiol. Revs., 28, 180219.

Tyler, A. 1949. Properties of fertilizin and related substances of eggs and sperm of marine animals. Amer. Nat., 83, 795-219.

Tyler, A. 1953. Prolongation of life span of sea-urchin spermatozoa, and improvement of the fertilization-reaction by treatment of spermatozoa and eggs with metal-chelating agents (amino acids, versene, DEDTC, oxine, cupron). Biol. Bull., 104, 224-39.

Tyler, A. 1954. Fertilization and antibodies. Sci. American, 190, 70-75.

Tyler, A. 1955. Gametogenesis, fertilization and parthenogenesis. In 
Analysis of Development, B. H. Willier, P. A. Weiss, and V. Hamburger, editors. W. B. Saunders Company, Philadelphia, Pa. Pages 170-212.

Tyler, A., and Lord Rothschild. 1951. Metabolism of sea-urchin spermatozoa and induced anaerobic motility in solutions of amino acids. Proc. Soc. Exptl. Biol. Med., 76, 52-58.

Van Beneden, E. 1875. La maturation de l'oeuf, la fécondation, et les premières phases du developpement embryonnaire des mammifères d'après des recherches faites chez le lapin. Bull. acad. roy. Sci. Belg., 40, 686-736.

Van Demark, N. L., and R. L. Hays. 1951. The effect of oxytocin, adrenalin, breeding techniques, and milking on uterine motility in the cow. J. Animal Sci., 10, 1083-84.

Van Demark, N. L., and R. L. Hays. 1952. Uterine motility responses to mating. Am. J. Physiol., 170, 518-21.

Van Demark, N. L., and R. L. Hays. 1953. Motility patterns in the female reproductive tract. Iowa State Coll. J. Sci., 28, 107-18.

Van Demark, N. L., and A. N. Moeller. 1951. Speed of spermatozoan transport in reproductive tract of estrous cow. Am. J. Physiol., 165, 674-79.

Van Drimmelen, G. C. 1949. Structure of the sperm-nests in the oviduct of the domestic hen. Nature, 163, 950-51.

Van Drimmelen, G. C. 1951. Artificial insemination of birds by the intraperitoneal route. A study in sex physiology of pigeons and fowls with reports upon a modified technique of semen collection, and a new technique of insemination, and observations on the spermatozoa in the genital organs of the fowl hen. Onderstepoort J. Vet. Research, Suppl. No. 1, 200 pp.

Van Drimmelen, G. C., and A. G. Oettlé. 1949. Changes in sperm quality. Proc. Soc. Study Fertility, 1, 5-10.

Wada, S. K., J. R. Collier, and J. C. Dan. 1956. Studies on the acrosome V. An egg-membrane lysin from the acrosomes of Mytilis edulis spermatozoa. Exptl. Cell Research, 10, 168-80.

Walton, A. 1930. The effect of temperature on the survival in vitro of rabbit spermatozoa obtained from the vas deferens. Brit. J. Exptl. Biol., 7, 201-19.

Warbritton, V., F. F. McKenzie, V. Berliner, and F. N. Andrews. 1937. Sperm survival in the genital tract of the eve. Proc. Am. Soc. Animal Prod., 30, 142-45. 
Warren, M. R. 1938. Observations on the uterine fluid of the rat. Am. J. Physiol., 122, 602-8.

Westman, A. A. 1926. Beiträge zur Kenntnis des Mechanismus des Eitransportes bei Kaninchen. Vorläufige Mittg. Acta Obstet. Gynecol., Scand., 5, Suppl. No. 3, 1-104.

Willett, E. L. 1953. Decline in fertility of bull semen with increase in storage time as influenced by dilution rate. J. Dairy Sci., 35, 1182. Wilson, E. B. 1928. The Cell in Development and Heredity. The Macmillan Co., New York, N. Y.

Wimsatt, W. A. 1942. Sperm survival in the female bat. Anat. Record, 83, 299-307.

Wimsatt, W. A. 1944. Further studies on the survival of spermatozoa in the female reproductive tract of the bat. Anat. Record, 88, 193204.

Wislocki, G. B., and A. F. Guttmacher. 1924. Spontaneous peristalsis of the excised whole uterus and Fallopian tubes of the sow with reference to the ovulation cycle. Bull. Johns Hopkins Hosp., 35, 246-52.

Wislocki, G. B., and F. F. Snyder. 1931. On the experimental production of superfoetation. Bull. Johns Hopkins Hosp., 49, 103-5.

Wislocki, G. B., and F. F. Snyder. 1933. The experimental acceleration of the rate of transport of ova through the Fallopian tube. Bull. Johns Hopkins Hosp., 52, 379-86.

Young, W. G. 1931. A study of the functions of the epididymis. III. Functional changes undergone by spermatozoa during their passage through the epididymis and vas deferens in the guinea-pig. J. Exptl. Biol., 8, 151-62. 



\title{
SOME ASPECTS OF MAMMALIAN
}

\section{FERTILIZATION}

\author{
M. C. CHANG: WORCESTER FOUNDATION FOR EXPERIMENTAL \\ BIOLOGY, SHREWSBURY, MASSACHUSETTS, AND DEPARTAENT OF \\ BIOLOGY, BOSTON UNIVERSITY
}

Brief and concise historical accounts of the study of fertilization have been written by Lillie (1923) and Austin (1953). The study of fertilization is a classical subject but lower organisms, especially marine species, were used by early investigators and by most active workers at the present time. In the lower forms, fertilization takes place externally, thus modern physiological, immunological, biochemical, and biophysical techniques can be employed experimentally without much difficulty. In the higher animals, fertilization occurs internally, i.e., in the Fallopian tubes. This makes the experimental analysis of the basic mechanisms of mammalian fertilization very difficult. Moreover, it seems that in the higher animals, owing perhaps to their fertilization in vivo, the process of fertilization is predominantly controlled by internal factors. During the past fifty years, a great deal has been learned about the preparation for fertilization in the mammalian species, such as the growth, maturation, release, and transportation of gametes before fertilization and the morphology and physiology of zygotes after fertilization, but very little is known about the process of fertilization, per se, or the fertilization reaction in mammals and the basic mechanisms involved. This is due mainly to the fact that there is no simple procedure for fertilizing mammalian eggs in vitro. I shall review here certain facts and some problems involved in the study of mammalian fertilization. The preliminaries to fertilization are reviewed by Austin and Bishop in this volume. 


\section{Fertilization of Mammalian Eggs in vitro}

The literature on the fertilization of mammalian eggs in vitro has been reviewed in detail by Chang and Pincus (1951), Smith (1951), and Austin (1951c). The general procedures employed by various workers were to obtain eggs from the follicles or Fallopian tubes and to mix them with sperm collected from the epididymis or ejaculate in a physiological solution for certain lengths of time. Then the eggs were either cultured in various ways or transferred into recipient animals. From their reviews it seems that until 1951, except, perhaps, for certain experiments of Pincus (1930), there were scarcely any reports that can be credited as definitive, repeatable experiments demonstrating the successful fertilization of mammalian eggs in vitro although such attempts have been made since Schenk (1878). Reported successes were ascribed to artificial activation or to parthenogenetic cleavage of eggs and other accidental artifacts. Because of the frequency of degenerative fragmentation and of parthenogenetic development and the possibility of gynogenetic development, Smith (1951) suggested that the only certain proof of in vitro fertilization would be to observe and photograph the spermatozoon penetrating the vitellus and the subsequent formation and fusion of male and female pronuclei. Because of technical and optical difficulties, it would be too strict a requirement to ascertain the moment of sperm entry. However, the presence of sperm in the perivitelline space and the formation of a second polar body and a male pronucleus would be a good indication of fertilization.

Smith (1951) reported that in the presence of Fallopian tube mucosa a spermatozoon penetrated into the ooplasm of 11 of 35 rabbit eggs under a coverslip sealed preparation. Evidence for such penetration was the presence of sperm head within the vitellus, the formation of a male or female pronucleus, or the segmentation of one egg after culture for a longer time. She admitted that sperm penetration was not observed owing to the density of the surrounding corona radiata, and therefore the development might possibly have been parthenogenetic or gynogenetic. It is quite true that when recently shed rabbit eggs are examined under a 
compound microscope a spermatozoon on the top of the zona pellucida can be taken as being in the vitellus and that the presence of a nucleus in the ooplasm may not be a true male pronucleus. Venge (1953) reported his fertilization of rabbit eggs in a glass tube under partially anaerobic conditions. Although two litters of young were produced when the treated eggs were transferred into recipient rabbits, he concluded that the development was due to chance and not to controlled processes. Very recently, Shettles (1955) reported the development of a human egg into a morula after the treatment of an ovarian egg with sperm and tubal mucosa in vitro. He neither excluded the possibility of artificial activation of the egg in his procedure nor mentioned the probability of parthenogenetic cleavage in his paper.

Moricard (1950) reported the penetration of a spermatozoon into the ooplasm of 5 out of 21 rabbit eggs (24\%) in vitro under relatively anaerobic conditions obtained by enclosing the eggs in a piece of Fallopian tube placed under petroleum jelly. He stated that the second polar body was not formed and that segmentation was not observed during $7 \frac{1}{2}$ hours culture. Since the formation of the second polar body occurs very soon after the penetration of the spermatozoon into the vitellus, and since the transformation of the sperm head into the male pronucleus is also very fast (Pincus and Enzmann, 1932; Chang, 1951a), it is rather peculiar that Moricard's photomicrograph (1950) shows an intact sperm head and no second polar body after $7 \frac{1}{2}$ hours in culture. Later Moricard (1954) stated that about $30 \%$ of rabbit tubal eggs are fertilizable in the utero-tubal secretion containing spermatozoa. Since $24 \%$ of the eggs can be penetrated in vitro under anaerobic conditions by sperm obtained from the vagina (?), it is not clear whether the $30 \%$ of fertilized eggs were due to anaerobic conditions or due to the employment of uterine sperm.

After the demonstration that ejaculated sperm require a certain length of time in the female tract to develop their fertilizing capacity (Chang, 1951b; Austin, 1951c), Dauzier et al. (1954) reported that fertilization of rabbit eggs in vitro can be achieved by using sperm recovered from the genital tract of rabbits 12 
hours after mating. After the publications by Chang (1951b), Moricard (1954), and Dauzier et al. (1954), attempts were made to fertilize rabbit eggs in vitro by uterine or tubal sperm under anaerobic or aerobic conditions, and in the presence or absence of the Fallopian tube. Unfortunately no fertilization was observed (Chang, unpublished). Dr. C. R. Austin told the writer on December 1, 1955, that he was unable to fertilize eggs in vitro with uterine or tubal sperm. It seems that there are still other factors involved beside the "capacitation" of spermatozoa in the female tract.

From the above account, it seems that up till now we still do not have a repeatable procedure to fertilize mammalian eggs in vitro. This is not necessarily due to the requirement of an anaerobic condition because the Fallopian tubes are very vascular (Plate I, 1). Neither can it be due to temperature change or eggs being rendered unfertilizable once removed from the tube, because freshly shed rabbit eggs can be stored at $10^{\circ}$ or $0^{\circ} \mathrm{C}$. for 1 day without losing their fertilizability when transferred into the tubes of mated animals (Chang, 1953). Although the physical and chemical environment of the Fallopian tube is important for fertilization, it is not the only place that fertilization can take place because freshly shed rabbit eggs can be fertilized when transferred into the uterus of mated rabbits, but degeneration occurs quickly (Chang, 1955c). It seems that the motility of the Fallopian tube and unknown enzyme systems present in the tube which interact with sperm and eggs may play a role in mammalian fertilization.

Lillie (1923) stated that "the conditions to be fulfilled in fertilization involve, not only penetration of the spermatozoon, or some part of it, into the egg but also reaction between the two." He therefore speaks of "a fertilization reaction when the behavior of both partners indicates that the process is proceeding normally." In this respect, the fertilization reaction in the mammalian species may involve a third partner, that is, the Fallopian tube. Parkes (1951) mentioned that "the biochemical changes involved in penetration, activation and syngamy are almost completely unknown in mammals, and are likely to remain so until fertilization 

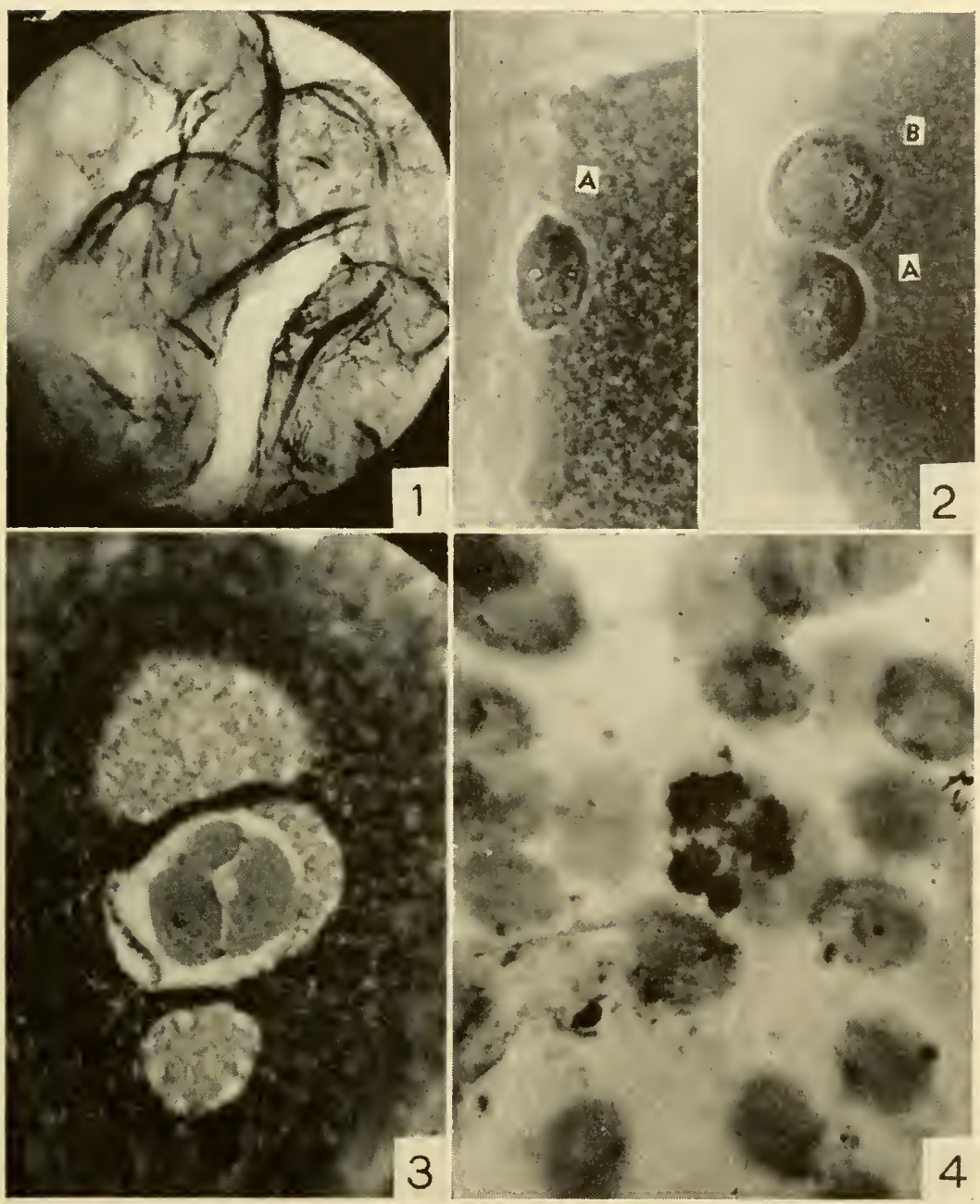

Plate I. 1, A portion of a rabbit Fallopian tube showing the blood vessels. 2, The first polar body (A) of an unfertilized rabbit egg and the first polar body (A) and the second polar body (B) of a fertilized rabbit egg. 3, A section of a rat ovary, showing the cleavage of a follicular egg and the thick granulosa cells of the follicle. 4, A tripolar spindle of a rabbit blastocyst. 
in vitro can be accomplished as a routine experimental procedure." Thus in dealing with mammalian fertilization, the fertilization reaction as elucidated in the marine species by Hartmann (1949), Runnström (1952), and Tyler (1955) is completely obscure.

\section{Activation and Parthenogenetic Development of Mammalian Eggs}

In the eggs of mammals, as in those of marine species, the immediate consequences of sperm penetration include the development of a block to prevent polyspermy, the shrinkage of the vitellus, and the resumption of the second maturation division leading to the formation of the second polar body. These processes indicate the activation of the egg from a passive state to an active one. However, activation of eggs even to parthenogenetic development can be achieved by artificial means. Discussions of parthenogenesis include the treatises of Rostand (1950) and Beatty (1957) and brief reviews of the literature by Tyler (1941), Thibault (1949), Chang and Pincus (1951), Smith (1951), and Austin and Braden (1954b).

The elevation of the fertilization membrane in the egg of lower organisms after sperm penetration is one of the earliest criteria of activation, but a fertilization membrane has not been described in mammalian eggs except, perhaps, for one possible instance in the hamster egg (Venable, 1946). Since the mammalian egg at the time of fertilization is enclosed not only with a thick zona pellucida but also with the corona radiata and cumulus oophorus, the observation of any change of the vitelline membrane in a living egg is extremely difficult.

The shrinkage of the vitellus after activation either by sperm penetration or by artificial means is not a reliable criterion. The tonicity of suspending medium and the method as well as the time interval of preparation of eggs for examination are possible causes of shrinkage. In the vitellus of the rat egg, a $14 \%$ reduction in volume occurred in the fertilized tubal eggs (Gilchrist and Pincus, 1932). This is confirmed by Austin and Braden (1954b), who reported also that shrinkage of the vitellus was not consist- 
ently observed after artificial activation by cold shock treatment. In rabbit eggs, shrinkage of the vitellus after sperm penetration (Pincus and Enzmann, 1932) or after artificial activation (Thibault, 1949) has also been reported.

The formation of the second polar body may be a good criterion of activation by sperm, but one must be sure it is the second polar body, not the cleavage of the first polar body or a fragment of the ooplasm. In the rabbit egg, it is fairly easy to distinguish between the first and second polar body. The chromosomes of the first one are a group of rods and dots spread in the whole cytoplasm whereas those of the second one are clumped together in a light circular zone (Plate I, 2). The fragment of ooplasm usually has no chromatin.

In eggs of many species of marine invertebrates, it is practically only the eggs that fail to extrude polar bodies upon artificial activation that are able to cleave and develop (Tyler, 1941). In the rat egg, the formation of the second polar body is regularly observed after artificial activation by cold treatment (Thibault, 1949). This is also confirmed by Austin and Braden (1954a) based on their observation that the first polar body persisted only in $1.3 \%$ of untreated eggs. In the rabbit egg, the second polar body is rarely, if ever, observed after cold treatment in vivo or in vitro (Thibault, 1949; Chang, 1954).

According to Thibault (1949) eggs were rendered unfertilizable following artificial activation. In the rat egg, Austin and Braden (1954b) reported that sperm can readily penetrate the eggs that have emitted the second polar body after artificial activation, and they came to the conclusion that "the development of the block to polyspermy, the shrinkage of the vitellus, and the emission of the second polar body are seen as independent processes, capable of being evoked separately. Only the block to polyspermy appears to be a specific response to sperm penetration." Gynogenetic development comparable to that of frog eggs treated with x-irradiated spermatozoa (Hertwig, 1913; Rugh, 1939) was not observed in rabbit eggs (Amoroso and Parkes, 1947).

Cleavage of eggs in the ovary of guinea pigs to blastocyst stage 
(Courrier, 1923; Bacsich and Wyburn, 1945) and in the ovary of human to the four-cell stage (Krafka, 1939) has been reported. It is probably induced by some abnormal growth or degenerative changes as shown by the thickening of the granulosa layer of the follicles (Plate I, 3). The cleavage of unfertilized tubal eggs has been reported in the mouse (Charlton, 1917), the rat (Mann, 1924; Austin, 1949), and the ferret (Chang, 1950a). In the rabbit egg, it has been observed on rare occasions a long time after ovulation (Chang, 1950a). It may be a manifestation of abnormal cytoplasmic or nuclear activity under certain conditions before degeneration. An ovarian rabbit egg cultivated in vitro by Champy (1923) cleaved into 8 regular blastomeres in the absence of sperm or any other obvious stimulation. Pincus (1930) reported $63 \%$ of unfertilized rabbit eggs divided in a regular way and were indistinguishable from the behavior of fertilized eggs.

As in the case of artificial activation of eggs in the lower organisms, hyper- or hypotonic solutions, butyric acid, or heat were successfully employed to activate rabbit eggs (Pincus and Enzmann, 1936; Pincus, 1939). Although anesthesia of the females can also induce the activation of rat eggs, probably owing to the lowering of body temperature (Thibault, 1949) or to the production of cellular anoxia (Austin and Braden, 1954b), it was found that application of cold either in vivo or in vitro is most effective (Pincus and Shapiro, 1940; Thibault, 1949; Austin and Braden, 1954b; Chang, 1954).

The cleavage of eggs to a few blastomeres is quite common after artificial activation. Cleavage up to morula and blastocyst is rare. One 12-celled egg and two blastocysts were obtained by Pincus (1939) when unfertilized eggs were treated with hypertonic solution and then transferred into the Fallopian tubes. One collapsed blastocyst was photographed (Pincus and Shapiro, 1940), and one morula and three blastocysts (Thibault, 1949) were found in the rabbit when the Fallopian tubes were previously cooled. However, Chang (1954) has shown that by storage of unfertilized rabbit eggs at $10^{\circ} \mathrm{C}$. for one day, $18.6 \%$ of 145 eggs developed into blastocysts when transferred into the Fal- 
lopian tubes of recipient rabbits, but no implantation was observed after the transfer of 230 treated eggs. According to Chang (1954), the transformation of the whole group of chromosomes in the second maturation spindle into a "pronucleus" and the resumption of mitotic division were also observed. The chromosomes of these blastocysts were determined to be diploid due to the failure of abstriction of the second polar body.

Although only a small number of artificially activated eggs developed into blastocysts, three definitely parthenogenetic young rabbits were obtained by Pincus (1939) when 615 eggs were subjected to various treatments and then transferred to recipient does and "one egg in some 200 developed into a living parthenogenetic rabbit" when freshly ovulated eggs were treated in situ with ice water for 2 to 20 minutes (Pincus and Shapiro, 1940).

From the above account, it is quite clear that the activation or parthenogenetic cleavage of mammalian eggs without the penetration of sperm is a widely spread phenomenon in vivo as well as in vitro. Since most of the unfertilized eggs do not cleave without the penetration of a spermatozoon, it must be assumed that the cleavage of the unfertilized egg is only induced under certain conditions. This is true also in the artificial activation when eggs were subjected to an adverse environment for a short time. In an abnormal environment, certain systems may be injured or enhanced. As F. R. Lillie (1911) stated, "the nature of the inhibition that causes the need of fertilization is a most funclamental problem." In this respect, the artificial activation of eggs may be a release of the inhibition under certain circumstances.

In his review of the general features of artificial parthenogenesis, Tyler (1955) stated that "in general the percentage of normal development is quite low even when a particular treatment initiates development in all of the eggs in a manner indistinguishable from that induced by sperm." This is attributable by him to various factors, such as irregularities in distribution of chromosomes, haploidy, lack of a proper division mechanism and, in some instances, to faihure to establish a plane of bilateral symmetry. This does not explain why the activated eggs may 
divide, develop, and differentiate to an early stage and fail later. Probably the contribution of the male element is more important for more advanced development, differentiation, and adaptation.

\section{Sperm Penetration}

The sperm penetration of the rabbit egg has been observed by Pincus (1930), who was under the impression that there was a slight bulging of the ooplasm at the point of sperm entry. The penetration of the rat egg was studied recently by means of phasecontrast microscopy. According to Austin (1951a), the penetration of the rat egg is a very rapid process, taking no more than a few minutes at most for the head to pass through the zona pellucida. When the spermatozoon passes through the zona of the rat egg it leaves a slit or potential hole. The entry of the spermatozoon into the ooplasm has been observed on several occasions. The spermatozoon may pass straight through the zona into the ooplasm or it may remain for a variable period in the perivitelline space. The head sinks into the vitellus and, the rest of the spermatozoon, being motionless, is gradually taken in. According to Austin (1951a) the penetration into the vitellus appears to be a function of the vitellus itself, and there must be some property of the head that results in its being absorbed into the vitellus. In a study of the sperm penetration of the rat egg, Blandau and Odor (1952) did not mention the slit in the zona pellucida, but they stated that the forward progression of the fertilizing suermatozoon into the ooplasm is discontinuous and is dependent upon a particular type of undulating movement of the tail which forces the head forward a distance of 10 to 20 microns at a time. They have also observed accessory spermatozoa penetrating into the ooplasm in which the fertilizing spermatozoon has already assumed its final position. The forward movement of accessory sperm, however, is much more continuous and uninterrupted and on one occasion, an accessory spermatozoon was seen to enter and leave the ooplasm a number of times without visible sions of decreased activity. But in no instance was the retention of the 
accessory spermatozoon within the ooplasm observed. This is an extraordinary phenomenon, if these ova are not degenerating, and it needs to be confirmed.

The modified fertilization cone described by Pincus in the rabbit egg has not been observed in the rat egg, and the small bit of clear cytoplasm enclosing the fertilizing sperm head in certain rat eggs is considered not a fertilization cone but a result of shrinkage of the vitellus (Blandau and Odor, 1952).

Austin and Blandau and Odor agree that several spermatozoa penetrate into the zona pellucida of the rat eggs, 23 in one of Austin's eggs, but they are in disagreement on the manner of sperm entry into the ooplasm. According to the writer's experience with fixed rabbit eggs, the fertilizing spermatozoon is on the very edge of the ooplasm before it changes its shape. If this is true in the rat egg, it is hard to distinguish whether the sperm is absorbed by the vitellus or pushed into the vitellus; maybe both play a part especially considering the viscous nature of the ooplasm.

One point of interest is that Austin and Blandau and Odor have observed the penetration of spermatozoa into the vitellus of rat eggs in vitro, but as yet no one has observed penetration through the zona pellucida. Since spermatozoa were never seen entering more than halfway through the zona pellucida during a study of fertilization of rabbit eggs in vitro (Chang, unpublished), it seems that the penetration of spermatozoa through the zona pellucida is more dependent upon the participation of the Fallopian tube than is the penetration of ooplasm.

The problem of polyspermy has been reviewed by Rothschild (1954). In many species of animals there is a rapid block at the egg surface after the entry of the fertilizing spermatozoon. In others (birds, salamanders, etc.) many sperm may enter but there is an inhibition of supernumerary sperm nuclei to prevent their uniting with the female pronucleus. After a review of the literature on polyspermy in mammalian eggs, Austin and Braden (1953) report that when fertilization is delayed after ovulation, polyspermy occurs in the rabbit and rat eggs. Poly- 
spermy induced after hyperthermia in rats has also been reported (Austin, 1955). Several pronuclei and sperm tails were shown in rat eggs, but only male pronuclei were shown in rabbit eggs (Austin and Braden, 1953). Whether this is due to a division of the female pronucleus as the egg is fertilized at late stages in the case of rabbit egg was not mentioned. Since the male pronuclei in the rat egg "all take part in the formation of first cleavage spindle," the second inhibition mechanism mentioned by Rothschild is not applicable in the rat egg. As for the tripolar spindle observed in the rat egg (Austin and Braden, 1953, Fig. 9), it is difficult to claim definitely it is a product of polyspermy because a tripolar spindle among normal metaphase plates in a rabbit blastocyst has been observed (Plate I, 4).

In mammalian eggs, there is probably another mechanism to prevent polyspermy, i.e., the reaction of the zona pellucida to sperm penetration as reported by Braden et al. (1954). According to their observation, the penetrability of the zona pellucida by sperm is not influenced by the entry of the first spermatozoon into the rabbit egg, thus 62 sperms were found in the perivitelline space of an egg. The number decreases after the entry of the first sperm in the rat and mouse eggs, for the number of eggs that contained more than one spermatozoon was of a lower frequency than expected. The zona pellucida of sheep and dog eggs precludes further penetration of sperm after the entry of the first one because no extra sperms were detected in the perivitelline space of fertilized eggs. Evidence of a change in the zona pellucida has been reported by Smithberg (1953), who observed that the zona pellucida of unfertilized mouse eggs was invariably removed by several proteolytic enzymes in less time than that of fertilized eggs. Braden et al. ( 1954) also reviewed the published reports on the number of spermatozoa within the eggs of various mammals. It seems that the zona reaction to the sperm penetration in the eggs of various species falls into the three categories previously mentioned. The zona reaction to sperm penetration is one of the important observations made in this field in recent years. Further study to elucidate this mechanism would be of great interest. 


\section{Pronuclear Behavior during Fertilization}

Cytological studies of fertilization in the mouse (Sobotta, 1895; Lams and Doorme, 1908; Gresson, 1941), in the rat (Tafani, 1889; Sobotta and Burckhard, 1911), in the guinea pig (Rubaschkin, 1905; Lams, 1913), in the bat (Van der Stricht, 1910), in the rabbit (Rein, 1883; Pincus, 1939), and in the ferret (Mainland, 1930 ) are well known. The cytochemistry of mammalian eggs has been investigated recently by Dalcq (1954) and by Ishida (1954).

In the rabbit egg, the second polar body is formed about 45 minutes after sperm penetration and is succeeded by the formation of both pronuclei (Pincus and Enzmamn, 1932). The pronuclear behavior and the correlation between male and female elements at fertilization in the living rat egg were studied by means of phase-contrast microscopy by Austin (1951b,c). He described the change of the sperm head within 10 minutes after penetration into the vitellus, the occurrence of the second maturation division before any alteration of the sperm head, the movement and the rotation of the second maturation spindle at telophase, the change of the sperm head and that of the female chromosomes into male and female pronucleus, and the three stages of growth and coalescence of the nucleoli of both pronuclei. In supporting the theory of protein synthesis put forward by Caspersson (1947), he suggested that the substance produced by the nucleolus associated chromatin, after appropriate modification by gene action and storage in the nucleoli, passes into the cytoplasm during the terminal reduction of the pronuclei.

As the whole process cannot be observed in vitro under the same preparation, Austin (1951a) admitted that "it has been necessary to depend upon eggs recovered from rats killed at successively later times" in order to build up a picture of pronuclear growth. To what extent these processes, especially the coalescence and division of nucleoli, are due to a degenerative process is difficult to estimate. In the rabbit, eggs recovered at various times after ovulation were stained with vital dyes and 
studied under a phase microscope. No obvious coalescence of nucleoli was noted (Chang, umpublished), but a change of the appearance of the cortex at the time of pronucleus formation was observed (Chang, 1955b).

Mark (1881) observed that the pronuclei of Limax eggs come together but do not fuse to form a first cleavage nucleus and stated that "the first cleavage nucleus does not have a morphological existence." In the rabbit egg, Pincus (1939) stated that "the stage intermediate between pronucleus juxtaposition and spindle formation is rare and must therefore be gone through speedily." In the rabbit eggs recovered at various times after mating the membrane of two pronuclei is clearly seen especially with acetic alcohol fixation but no nuclear membrane was observed before the formation of the cleavage spindle (Chang, unpublished). In Austin's beautiful photomicrographs (1951a), the close contact of pronuclei and the metaphase and anaphase chromosomes are well shown but a clear region without nuclear membrane interpreted as the prophase chromosomes is not convincing. Since the maturation of pronuclei takes about 10 hours while metaphase, anaphase, telophase, and first cleavage take about 1 to 2 hours in the rabbit egg (Chang, 1955b), it seems that the growth or maturation of pronuclei corresponds to the prophase of an ordinary cell division. A separate prophase stage after the conjugation of two pronuclei is still uncertain. Thus the point raised by Mark still requires clarification in mammals.

Since Boveri (1888) it has been known that in eggs of most species of animals an important organ of cell division, the centrosome, is lacking or inactive, and it is generally introduced by the spermatozoon for the initiation of cell division. There is little understanding of the centrosome in mammalian fertilization although the acrosome of the spermatozoon in the rat egg has been discussed (Blandau and Odor, 1950; Austin, 1951a). However, if the centrosome contributed by the sperm is the organ for cleavage, parthenogenetic division may be explained, as Tyler (1941) has done for the invertebrates and lower vertebrates. 


\section{Hyaluronidase and Antihyaluronidase in Mammalian Fertilization}

Hyaluronidase in relation to mammalian fertilization has been reviewed by Chang (1950b) and Swyer (1951). According to Mann (1954), the term hyaluronidase, in its widest sense, designates the mucolytic enzyme, or rather a group of enzymes which bring about the depolymerization and hydrolysis of hyaluronic acid. The mammalian testes and sperm are the richest animal sources of hyaluronidase. It is known that the hyaluronidase content in the semen is dependent on the concentration of sperm. Swyer (1951) found that the hyaluronidase contents per 100 million spermatozoa per milliliter of semen of rabbit, bull, man, and boar were approximately 20,7, 0.4, and 0.2 units, respectively, but only a very small amount of hyaluronidase, irrespective of the concentration of spermatozoa, could be detected in dog semen.

The recently ovulated rat or rabbit eggs are surrounded by a viscous cumulus oophoris. Yamane (1935), Pincus and Enzmamn (1935) brought to light the fact that sperm suspensions or extracts of rabbit sperm could disperse the follicular cells of the cumulus. McClean and Rowlands (1942) discovered that hyaluronidase obtained from testes, spermatozoa, snake venom, or bacteria can act as a cumulus-dispersing factor by liquefying the viscous gel which cements the follicular cells around freshly ovulated rat eggs. Since the follicular cells surrounding the eggs form an obvious barrier for the penetration of the spermatozoon into the egg, the role of hyaluronidase in mammalian fertilization was very much stressed about ten years ago. Thus, addition of hyaluronidase to rabbit sperm suspension was claimed to increase the fertilizing capacity (Rowlands, 1944), and the application of hyaluronidase for the treatment of human sterility was advocated (Kurzrok et al., 1946; Kurzrok, 1950).

It is known that a high concentration of hyaluronidase (McClean and Rowlands, 1942) or a very high concentration of spermatozoa, 20,000 per cubic millimeter (Pincus and Enzmann, 1936), is needed for the dispersal of follicular cells. This is not in 
accordance with mammalian fertilization in the Fallopian tube where only a few spermatozoa are present, about 100 in the rat (Blandau and Odor, 1949), about 1000 to 5000 in the rabbit (Austin, 1948b; Chang, 1951c). It also has been shown that the dispersal of follicular cells is not a prerequisite of sperm penetration because fertilized eggs of the mouse (Lewis and Wright, 1935), of the rat (Austin, 1948a), and of the rabbit (Chang, 1951a) are still surrounded by follicular cells. The apparent increase of fertilizing capacity of rabbit sperm by addition of seminal hyaluronidase reported by Rowlands (1944) was due not to hyaluronidase per se but to the beneficial effect of seminal plasma (Chang, 1947b).

This observation, however, does not necessarily exclude the possibility that hyaluronidase present in the individual spermatozoon will facilitate its passage through the viscous cumulus oophorus, the cements of corona radiata cells, and the mucoprotein (Braden, 1952) of the zona pellucida. This postulation, however, cannot reconcile the fact that dog sperm which contains no hyaluronidase is still able to fertilize the dog egg which is not devoid of corona radiata and zona pellucida.

It has been suggested that the egg membrane lysin of Tyler (1939) present in the spermatozoa of marine species, which helps the sperm to penetrate the jelly coat, is a mucopolysaccharase similar, but not identical, with hyaluronidase. This suggestion, according to Mann (1954), is in need of experimental support. Thus the physiological role of hyaluronidase is far from clear. It may be related to the spermiogenetic function as suggested by Mann, or it may function to prevent the spermatozoa from sticking together at the end of spermatogenesis in the testes. It may be associated with the activity of the Fallopian tubes which denudate (dispersal of corona radiata) the rabbit eggs (Swyer, 1947). because in the absence of sperm the denudation of rabbit eggs takes longer than in the presence of sperm (Pincus, 1930; Chang, 1951a).

A hyaluronidase inhibitor, nitrated hyaluronic acid, was reported to effect the fertilization of rabbit eggs (Pincus et al., 1948). Another hyaluronidase inhibitor, phosphorylated hesperi- 
din, was advocated as an oral antifertility agent (Martin and Beiler, 1952; Sieve, 1952), but when phosphorylated hesperidin was fed to rats or deposited in the Fallopian tubes of rabbits at the time of fertilization, no antifertilization effects were observed (Chang and Pincus, 1953). Prevention of fertilization by another hyaluronidase inhibitor, trigestistic acid, was examined by Parkes (1953), who concluded that although this compound has no effect orally, when added to the sperm-suspension for insemination, "the spermatozoon is incapacitated by it in some way, or other than, or additional to the neutralization of hyaluronidase." According to Parkes (1955), after the treatment of sperm with hyaluronidase inhibitor, there is evidence that spermatozoa are lodged in the perivitelline space of an egg in which no spermatozoon has penetrated the vitellus. If this is a fact and not an accidental observation, the inhibition of sperm hyaluronidase may result in the inability of sperm to penetrate vitellus. However, it is not known whether the vitelline membrane contains hyaluronic acid.

\section{Agglutination of Spermatozoa and Fertilization}

"Egg water" is enriched with some substances derived from sea urchin eggs and capable of inducing the activity and agglutination of homologous spermatozoa. This sperm-agglutinating agent was called "fertilizin" by Lillie (1923). Agglutination of horse or rabbit sperm occurs at lower (3-6.3) or at higher (8.3) $\mathrm{pH}$, and also occurs in blood serum, in the secretions of the vagina or uterus, or in body fluid (Kato, 1938). It occurs in tissue extracts (Chang, 1947a) and in saline containing Congo red or Chicago blue (Chang, unpublished). According to Parkes et al. (1954) sperm heads coated with a negatively charged substance are agglutinated in the presence of positively charged substances. It seems therefore that the agglutination of mammalian spermatozoa is not a specific reaction but a very general one. It follows then that any condition that induces agglutination may or may not at the same time impair the fertilizing capacity of mammalian spermatozoa. As for the sperm agglutination in relation to fertilization reaction of marine species as elaborated by Tyler (1948) 
in immunological terms, it is a different subject matter. It has been claimed that agglutinated sperm are unable to fertilize (Anderson, 1945; Lindahl and Kihlström, 1954), but contradictory evidences are available. For instance, intensively agglutinated sperm were recovered from the rabbit vagina, but young rabbits were obtained (Kato, 1938). Agglutinated rabbit sperm is invariably recovered from the uterus, and yet fertilization occurs after the deposition of uterine sperm into the Fallopian tube (Chang, 1955a).

Lindahl and Kihlström (1952) reported that mammalian spermatozoa agglutinate when semen is stored for some time undiluted or diluted with saline. They interpreted this to be due to a spontaneous inactivation of "sperm antagglutin" produced in the prostate gland. Lindahl and Nilsson (1954) further reported the finding of a "female sperm antagglutin" present in the follicular fluid and in the Fallopian tube of estrous rabbit. Since the mammalian egg is suspended in the follicular fluid, if there is a "fertilizin" diffused from eggs to activate and to agglutinate sperm, as in the case of the sea urchin, follicular fluid should induce the activity of sperm as reported by Kurzrok et al. (1953) rather than induce the disappearance of agglutination as reported by Lindahl and Nilsson (1954). This important finding of "antagglutin" in the male and female tract of mammals may have other implications for mammalian fertilization which need further elucidation.

\section{Conclusions}

The understanding of physiological changes at sperm penetration, activation, and syngamy is very limited. This is mainly due to the fact that there is no simple and repeatable procedure to fertilize mammalian eggs in vitro. The reaction substances present in sperm and eggs at fertilization as elucidated in the fertilization of marine species may not be transferred to mammalian fertilization at present.

The Fallopian tube may play a very important role in mammalian fertilization, especially at the time of sperm penetration through the intercellular spaces of the corona radiata and the 
zona pellucida, but our knowledge of the physiology of the Fallopian tube, the corona radiata, the zona pellucida, and the vitelline membrane is very elementary.

The activation or cleavage of eggs in vivo and in vitro without the stimulation of sperm is fairly common, but its mechanism is not known. Although parthenogenetic development to the blastocyst stage or to newborn can be achieved by subnormal temperature treatment of eggs, there may be still more effective methods to be discovered. The physiological difference between artificial activation and fertilization should be further investigated.

Sperm penetration of the vitellus, the formation of male and female pronuclei, and the maturation and conjugation of pronuclei have been observed, but their physiological properties and their interactions are completely unknown. Even the morphology of conjugated pronuclei and their subsequent division are far from clear.

The fertilizability of eggs and its physical basis, the blockage of polyspermy and its chemical nature, and the possibility of the artificial induction of polyspermy and its subsequent events are all obscure.

In view of the possibility of a complex of enzymic reactions at fertilization, the role of sperm hyaluronidase at fertilization has been erroneously interpreted. At present, we have certain knowledge about what hyaluronidase or hyaluronidase inhibitor may not do, but we do not know the actual function of sperm hyaluronidase.

It seems that agglutination of mammalian spermatozoa is not a specific reaction to eggs but rather a general reaction. The agglutination of sperm in relation to the fertilizing capacity of sperm is uncertain and its relation to the fertilization reaction of mammalian eggs is far from understood.

\section{REFERENCES}

Amoroso, E. C., and A. S. Parkes. 1947. Effects on embryonic development of $x$-irradiation of rabbit spermatozoa in vitro. Proc. Roy. Soc. (London), B134, 57-78. 
Anderson, J. 1945. The Semen of Animals and Its Use for Artificial Insemination. Imperial Bureau Animal Breeding and Genetics, Edinburgh.

Austin, C. R. 1948a. Function of hyaluronidase in fertilization. Nature, $162,63-64$.

Austin, C. R. 1948b. Number of sperms required for fertilization. Nature, 162, 534-35.

Austin, C. R. 1949. The fragmentation of eggs following induced ovulation in immature rats. J. Endocrinol., 6, 104-10.

Austin, C. R. 1951a. The formation, growth, and conjugation of the pronuclei in the rat egg. J. Roy. Microscop. Soc. 71, 295-306.

Austin, C. R. 1951b. Activation and the correlation between male and female elements in fertilization. Nature, 168, 558-59.

Austin, C. R. 1951c. Observations on the penetration of the sperm into the mammalian egg. Australian J. Sci. Research, B4, 531-96.

Austin, C. R. 1953. The growth of knowledge on mammalian fertilization. Australian Vet. J., 29, 191-98.

Austin, C. R. 1955. Polyspermy after induced hyperthermia in rats. Nature, 175, 1038.

Austin, C. R., and A. W. H. Braclen, 1953. An investigation of polyspermy in the rat and rabbit. Australian J. Biol. Sci., 6, 674-92.

Austin, C. R., and A. W. H. Braden, 1954a. Nucleus formation and cleavage induced in unfertilized rat eggs. Nature, 173, 999-1000. Austin, C. R., and A. W. H. Braden, 1954b. Induction and inhibition of the second polar division in the rat egg and subsequent fertilization. Australian J. Biol. Sci., 7, 195-210.

Bacsich, P., and G. M. Wyburn, 1945. Parthenogenesis of atretic ovary in the rodent ovary. J. Anat., 79, 177-1S0.

Beatty, R. A. 1957. Parthenogenesis and Polyploidy in Mammalian Development. Cambridge University Press.

Blandau, R. J., and D. L. Odor, 1949. The total number of spermatozoa reaching various segments of the reproductive tract in the female albino rat at intervals after insemination. Anat. Record, 103, 93-110. Blandau, R. J., and D. L. Odor, 1950. Observations on fertilization of rat ova. Anat. Rec. (Proc.), 106, 177.

Blandau, R. J., and D. L. Odor, 1952. Observations on sperm penetration into the oöplasm and changes in the cytoplasmic components of fertilizing spermatozoon in rat ova. Fert. \& Ster., 3, 13-26.

Boveri, T. 1888. Zellen-Studien. Jena. Z. Naturw., 25, 685-882. 
Braden, A. W. H. 1952. Properties of the membranes of rat and rabbit eggs. Australian J. Sci. Research, B5, 460-471.

Braden, A. W. H., C. R. Austin, and H. A. David, 1954. The reaction of the zona pellucida to sperm penetration. Australian J. Biol. Sci., 7, 391-409.

Caspersson, T. 1947. The relation between nucleic acid and protein synthesis. Symposia Soc. Exptl. Biol., 1, 127-51.

Champy, C. 1923. Parthénogénèse expérimentale chez le lapin. Compt. rend. soc. biol., 96, 1108-11.

Chang, M. C. 1947a. The effects of serum on spermatozoa. J. Gen. Physiol., 30, 321-35.

Chang, M. C. 1947b. Effects of testis hyaluronidase and seminal fluid on the fertilizing capacity of rabbit spermatozoa. Proc. Soc. Exptl. Biol. Med., 66, 51-54.

Chang, M. C. 1950a. Cleavage of unfertilized ova in immature ferrets. Anat. Record, 108, 31-44.

Chang, M. C. 1950b. Fertilization, male infertility, and hyaluronidase. Ann. N. Y. Acad. Sci., 52, 1192-95.

Chang, M. C. 1951a. Fertility and sterility as revealed in the study of fertilization and development of rabbit eggs. Fert. \& Ster., 2, 205-22.

Chang, M. C. 1951b. Fertilizing capacity of spermatozoa deposited into the Fallopian tubes. Nature, 168, 697.

Chang, M. C. 1951c. Fertilization in relation to the number of spermatozoa in the Fallopian tubes of rabbits. Ann. ost. $e$ gin. Milan, No. $73,918-25$.

Chang, M. C. 1953. Storage of unfertilized rabbit ova: Subsequent fertilization and the probability of normal development. Nature, $172,353$.

Chang, M. C. 1954. Development of parthenogenetic rabbit blastocysts induced by low temperature storage of unfertilized ova. J. Exptl. Zool., 125, 127-50.

Chang, M. C. 1955a. Development of fertilizing capacity of rabbit spermatozoa in the uterus. Nature, 175, 1036-37.

Chang, M. C. 1955b. Vital stain of rabbit eggs in vitro during fertilization. Anat. Record (Proc.), 121, 427.

Chang, M. C. 1955c. Développement de la capacité fertilisatrice des spermatozoides du lapin a l'intérieur du tractus génital femelle et fécondabilité des oeufs de lapine. La Fonction Tubaire et ses Troubles. Masson et Cie., Paris. Pages 40-52. 
Chang, M. C., and G. Pincus, 1951. Physiology of fertilization in manmals. Physiol. Revs., 31, 1-26.

Chang, M. C., and G. Pincus, 1953. Does phosphorylated hesperidin affect fertility? Science, 117, 274-76.

Charlton, H. H. 1917. The fate of the unfertilized egg in the white mouse. Biol. Bull., 33, 321-38.

Courrier, R. 1923. Vésicule blastodermique parthénogénetique dans un ovaire de cobaye impubère. Arch. Anat. Histol. et Embryol., 2, 455-59.

Dalcq, A. M. 1954. Fonctions cellulaires et cytochimie structurale dans l'oeuf de quelques rongeurs. Compt. rend. soc. biol., 148, 1332-73.

Dauzier, L., C. Thibault, and S. Wintenberger, 1954. La fécondation in vitro de l'oeuf de la lapine. Compt. rend., 238, 844-45.

Gilchrist, F., and G. Pincus, 1932. Living rat eggs. Anat. Record, 54, $275-85$.

Gresson, R. A. R. 1941. A study of the cytoplasmic inclusions during maturation, fertilization and the first cleavage division of the egg of the mouse. Quart. J. Microscop. Sci., 83, 34-59.

Hartmann, M. 1949. Untersuchungen über die Gamone von Metazoen. Union intern. sci. biol., B, No. 3, 26-39.

Hertwig, G. 1913. Parthenogenesis bei Wirbeltieren, hervorgerufen durch artfremden radiumbestrahlten Samen. Arch. mikroskop. Anat., 81, 87-127.

Ishida, K. 1954. Cytochemical studies of tubal ova. Tôhoku J. Agr. Research, 5, 1-11.

Kato, K. 1938. Experimental studies on the agglutination of mammalian spermatozoa with special reference to its bearing upon fertilization. Mem. Fac. Sci. \& Agr. Taihohu Imp. Univ., 19, 1-73.

Krafka, J. 1939. Parthenogenetic cleavage in the human ovary. Anat. Record, 75, 19-21.

Kurzrok, R. 1950. Further observations of the value of hyaluronidase in the treatment of human infertility. Ann. N. Y. Acad. Sci., 52, $1180-85$.

Kurzrok, R., S. L. Leonard, and H. Conrad, 1946. Role of hyaluronidase in human infertility. Am. J. Med., 1, 491-506.

Kurzrok, R., L. Wilson, and C. Bimberg, 1953. Follicular fluid. Its possible role in human fertility and infertility. Fert. \& Ster., 4, 479-94. Lams, H. 1913. Etude de loeuf de cobaye aux premiers stades de l'embryogenèse. Arch. Biol., 28, 229-323.

Lams, H., and J. Doorme, 1908. Nouvelles recherches sur la matura- 
tion et la fécondation de l'oeuf des mammifères. Arch. Biol., 22, 259-365.

Lewis, W. H., and E. S. Wright. 19:35. On the early development of the mouse egg. Carnegie Inst. Wash. Contribs. to Embryol., 25, 11344.

Lillie, F. R. 1911. Studies of fertilization on Nereis. I. The cortical changes in the egg. II. Partial fertilization. J. Morphol., 22, 361-9.3.

Lillie, F. R. 1923. Problems of Fertilization. The University of Chicago Press, Chicago, Ill.

Lindahl, P. E., and J. E. Kihlström, 1952. On ripening and agglutination in bull spermatozoa. Report of II Intern. Congr. Physiol. Path. Animal Reproduction and Art. Insem., 1, 70-75.

Lindahl, P. E., and J. E. Kihlström, 1954. A constituent of male sperm antagglutin related to vitamin E. Nature, 174, 600.

Lindahl, P. E., and A. Nilsson, 1954. On the occurrence of sperm antagglutin in the female rabbit. Arch. Zool. 7, 223- 2 .

Mainland, D., 1930. The early development of t'se ferret: the pronuclei. J. Anat., 64, 262-87.

Mann, M. C. 1924. Cytological changes in unfertilized tubal eggs of the rat. Biol. Bull., 46, 316-27.

Mann, T. 1954. The Biochemistry of Semen. Methuen \& Co. Ltd., London.

Mark, E. L. 1881. Maturation, fecundation and segmentation of Limax campestris. Bull. Museum Comp. Zool. Harvard Univ., 6, 173-625.

Martin, G. J., and J. M. Beiler, 1952. Effect of phosphorylated hesperidin, a hyaluronidase inhibitor, on fertility in the rat. Science, 115, 402.

McClean, D., and I. IV. Rowlands, 1942. The role of hyaluronidase in fertilization. Nature, 150, 627-2S.

Moricard, R. 1950. Penetration of the spermatozoon in vitro into the mammalian ovum oxydo potential level. Nature, 165, 763.

Moricard, R. 1954. Observation of in vitro fertilization in the rabbit. Nature, 173, 1140.

Parkes, A. S. 1951. Introduction. In The Biochemistry of Fertilization and the Gametes, R. T. Williams, editor. Biochem. Soc. Symposia (Cambridge, Engl.), 7, 1-3.

Parkes, A. S. 1953. Prevention of fertilization by a hyaluronidase inhibitor. Lancet, 265, 1285-87.

Parkes, A. S. 1955. Research into biological methods of eontrolling fertility. 5th Intern. Conf. on Planned Parenthood, Tokyo. 
Parkes, A. S., H. J. Rogers, and P. C. Spensley. 1954. Studies of fertility. Proc. Soc. Study Fertility, 6, 65-80.

Pincus, G. 1930. Observations on the living eggs of the rabbit. Proc. Roy. Soc. (London), B107, 132-67.

Pincus, G. 1939. The comparative behavior of mammalian eggs in vivo and in vitro. $1 \mathrm{~V}$. The development of fertilized and artificially activated rabbit eggs. J. Exptl. Zool., 82, 85-129.

Pincus, G., and E. V. Enzmann. 1932. Fertilisation in the rabbit. J. Exptl. Biol., 9, 403-8.

Pincus, G., and E. V. Enzmann. 1935. The comparative behavior of mammalian eggs in vivo and in vitro. I. The activation of ovarian eggs. J. Exptl. Med., 62, 665-77.

Pincus, G., and E. V. Enzmann. 1936. The comparative behavior of mammalian eggs in vivo and in vitro. II. The activation of tubal eggs of the rabbit. J. Exptl. Zool., 73, 195-208.

Pincus, G., and H. Shapiro. 1940. The comparative behavior of mammalian eggs in vivo and in vitro. VII. Further studies on the activation of rabbit eggs. Proc. Am. Phil. Soc., 83, 631-44.

Pincus, G., N. W. Pirie, and M. C. Chang. 1948. The effects of hyaluronidase inhibitors on fertilization in the rabbit. Arch. Biochem., 19, 388-96.

Rein, G. 1883. Beiträge zur Kentniss der Reifungserscheinungen und Befruchtungsvorgänge am Säugethierei. Arch. mikroskop. Anat., 22, 233-70.

Rostand, J. 1950. La Parthénogenènese Animale. Presses Universitaires de France, Paris.

Rothschild, L. 1954. Polyspermy. Quart. Rev. Bio!., 29, 332-42.

Rowlands, I. W. 1944. Capacity of hyaluronidase to increase the fertilizing power of sperm. Nature, 154, 332-33.

Rubaschkin, W. 1905. Ueber die Reifungs- und Befruchtungprozesse des Meerschweincheneies. Anat. Hefte, 29, 507-53.

Rugh, R. 1939. Developmental effects resulting from exposure to x-rays. I. Effect on the embryo of irradiation of frog sperm. Proc. Am. Phil. Soc., 81, 447-71.

Runnström, J. 1952. The problems of fertilization as elucidated by work on sea urchins. Harvey Lectures, Ser. 46. Charles C Thomas, Springfield, Ill. Pages 116-53.

Schenk, S. L. 1878. Das Säugethierei künstlich befruchtet ausserhalb des mutterleibes. Mitt. embryol. Inst. Univ. Wien, 2, 107-18. 
Shettles, L. B. 1955. A morula stage of human ovum developed in vitro. Fert. \& Ster., 6, 287-89.

Sieve, B. F. 1952. A new antifertility factor. Science, 116, 373-85.

Smith, A. U. 1951. Fertilization in vitro of the mammalian egg. In The Biochemistry of Fertilization and the Ganetes, R. T. Williams, editor. Biochem. Soc. Symposia (Cambridge, Engl.), 7, 3-11.

Smithberg, M. 1953. The effect of different proteolytic enzymes on the zona pellucicla of mouse ova. Anat. Record, 117, 554 (abstract).

Sobotta, J. 1895. Die Befruchtung und Furchung des Eies der Maus. Arch. mikroskop. Anat., 45, 15-93.

Sobotta, J., and G. Burkhard. 1911. Reifung und Befruchtung des Eies der weissen Ratte. Anat. Hefte, 42, 433-97.

Swyer, G. I. M. 1947. A tubal factor concerned in the denudation of rabbit ova. Nature, 159, 873-74.

Swyer, G. I. M. 1951. Hyaluronidase and fertilization. In The Biochemistry of Fertilization and the Gametes, R. T. Williams, editor. Biochem. Soc. Symposia (Cambridge, Engl.), 7, 34-40.

Tafani, A. 1889. La fécondation et la segmentation etudiées dans les oeufs des rats. Arch. ital. biol., 11, 112-17.

Thibault, C. 1949. L'oeuf des mammifères. Son dévelopment parthénogénétique. Ann. sci. nat. Zool., 11, 136-219.

Tyler, A. 1939. Extraction of an egg membrane-lysin from sperm of giant keyhole limpet (Megathura crenulata). Proc. Natl. Acad. Sci. U. S., 25, 317-23.

Tyler, A. 1941. Artificial parthenogenesis. Biol. Revs., 16, 291-336.

Tyler, A. 1948. Fertilization and immunity. Physiol. Revs., 28, 180-219.

Tyler, A. 1955. Gametogenesis, fertilization and parthenogenesis. In Analysis of Development, B. H. Willier, P. A. Weiss, and V. Hamburger, editors. W. B. Saunders Co., Philadelphia, Pa. Pages 170212.

Van der Stricht, O. 1910. La structure de l'oeuf des mammifères (chauve-souris), vesperugo noctula. $3^{e}$ part. L'oocyte à la fin du stade d'accroissement, au stade de la maturation, au stade de la fécondation et au début de la segregation. Mém. acad. roy. med. Belgique, 2, 1-176.

Venable, T. H. 1946. Pre-implantation stages in golden hamster ( $\mathrm{Cri}$ cetus auratus). Anat. Record, 94, 105-19.

Venge, O. 1953. Experiments on fertilization of rabbit ova in vitro with subsequent transfer to alien does. In Mammalian Germ Cells, G. E. W. Wolstenholme, editor. Churchill Ltd,, London. 
Yamane, J. 19:5. Kausal-analytische Studien über die Befruchtung des Kanincheneies. I. Die Dispersion der Follikelzellen und die Ablösung der Zellen der Corona radiata des Eies durch Spermatozoen. Cytologia (Tokyo), 6, 233-55. 


\title{
MORPHOLOGY OF FERTILIZATION: \\ ACROSOME FILAMENT FORMATION \\ AND SPERM ENTRY
}

\author{
ARTHUR L. COLWIN AND LAURA HUNTER COLWIN: \\ QUEENS COLLEGE, FLUSHING, NEW YORK
}

\section{Some Aspects of Sperm Morphology}

The older studies of spermatozoa by Retzius (1904, 1905, 1910 ) and others revealed that there are wide morphological variations among the spermatozoa of different species. Contemporary investigations of sperm morphology are in part directed toward a detailed analysis of structure by means of electron microscopy as in the studies of Dan $(1952,1954)$ and of Burgos and Fawcett (1955, 1956), and in part toward a cytochemical characterization as in the studies of Clermont, Glegg, and Leblond (1955). Phase contrast microscopy is facilitating observation of the living spermatozoon. The present paper will deal chiefly with the acrosomal region, especially with reference to certain changes occurring in this and other regions at fertilization or under other conditions some of which may obtain at fertilization.

The acrosomal region can be seen as a structural entity in spermatozoa of many species. Often it projects beyond the nucleus in an apical or near apical position. Some investigators have used the terms "acrosome" and "perforatorium" synonymously to indicate the entire acrosomal region. Others have used these same terms to distinguish two specific structures within the acrosomal region. It is to be expected that the confusing terminology which exists in the literature concerning the acrosomal region will soon be clarified (vide Burgos and Fawcett, 1955, 1956).

Dan and Wada (1955) have described three differentiated 


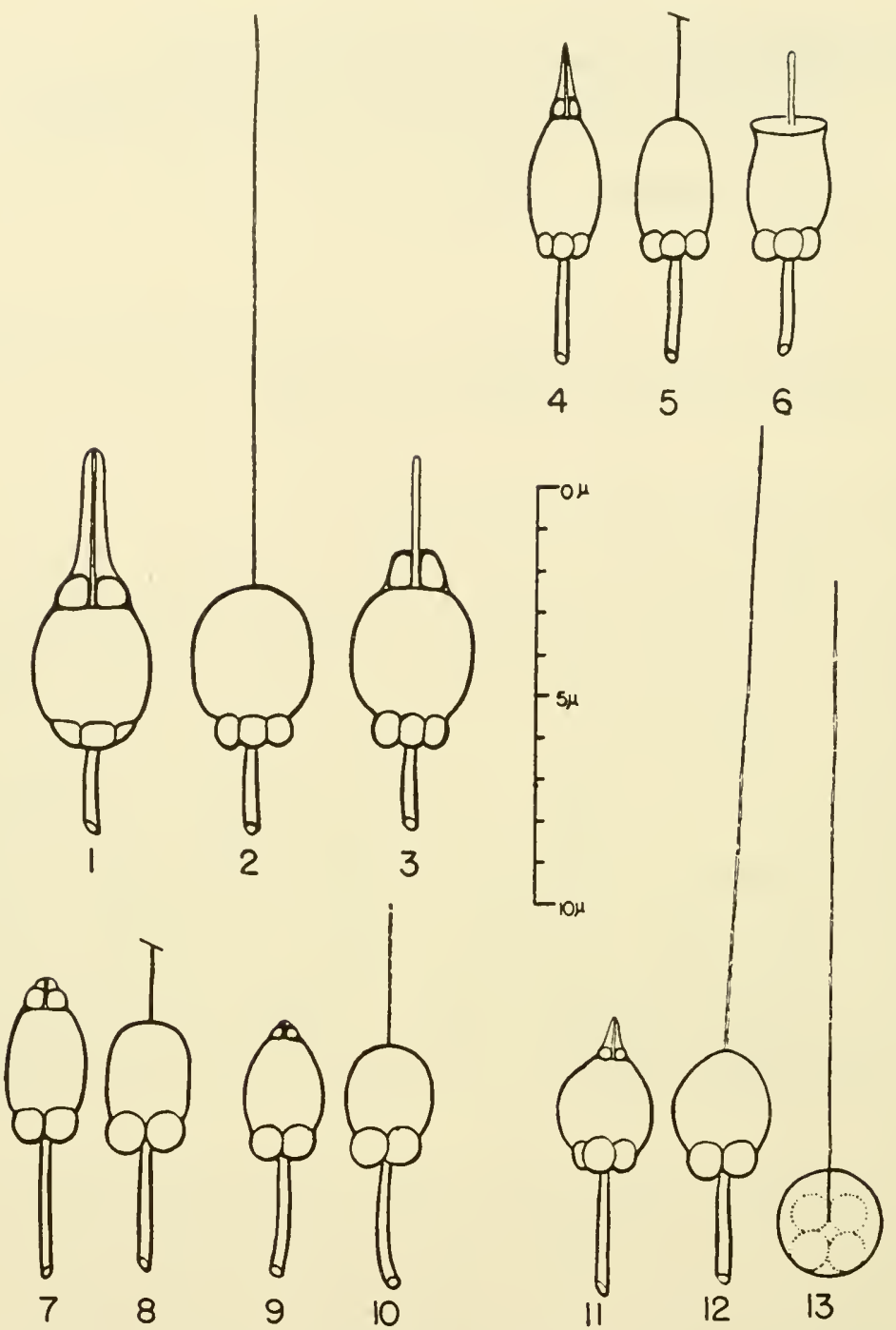

Figs. 1-13. Spermatozoa of bivalve molluse species to show morphological changes resulting from the acrosome reaction. (From Dan and Wada, Biol. Bull., 1955.) 1, Mytilus edulis spermatozoon in sea water. 2, Mytilus spermatozoon after egg water treatment. 3, Mytilus spermatozoon showing partial reaction. 4, Petricola japonica spermatozoon before reaction. 5, Reacted Petricola spermatozoon in vicinity of egg. 6, Partially reacted Petricola spermatozoon. 7, Mactra sulcataria spermatozoon. 8, M. sulcataria supernumerary spermatozoon. 9, Mactra veneriformis spermatozoon. 10, $M$. veneriformis spermatozoon after egg water treatment. 11, Spondylus cruentus spermatozoon. 12, Spondylus spermatozoon reacted in egg water (side view). 13, Reacted Spondylus spermatozoon as found affixed to under side of coverglass. 
parts of the "acrosome" in spermatozoa of several species of bivalve molluscs (Figs. 1, 4, 7, 11): a distal section containing what these authors believe to be an egg-membrane lysin, an axial structure possibly related to the precursor of a filament, and a basal structure which may be concerned with the extrusion of the filament. The axial structure described in these acrosomal regions would seem to resemble the "stéréocil" reported in the spermatozoa of some prosobranch molluses and in Lumbricus (Grassé and Tuzet, 1933; Tuzet, 1950).
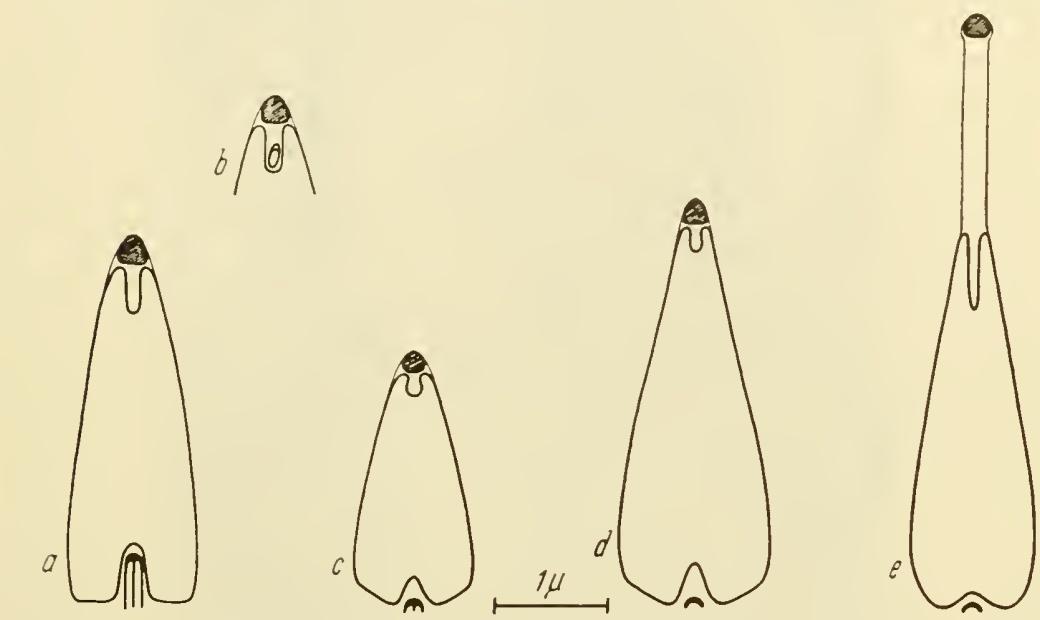

Fig. 14. Profiles of heads of sea urchin spermatozoa. (From Afzelius, Z. Zellforsch., 1955.) a-b, Strongylocentrotus droebachiensis; c, Psammechinus miliaris; d, Echinus esculentus; e, Echinocardium cordatum.

Afzelius (1955) has made electron microscope studies of thin sections of spermatozoa of four species of sea urchin. They reveal that a rather dense acrosomal particle lies in the tip of the acrosomal region. Beneath this particle the nucleus shows a depression or "cave" filled with material less osmiophilic than that of the particle (Figs. 14-15). In one species, Echinocardium cordatum, the acrosomal region is elongated in a manner unusual for sea urchins (Figs. 14e and 15B). Nevertheless, the acrosomal particle occupies the apical position. Beneath the particle a long stalk is apparently filled with material like that of the "cave" in 
the nucleus. In all four species there is some eviclence that the material filling the "cave" is oriented as fibers. These structures of the acrosomal region, as well as all other parts of the sperma-

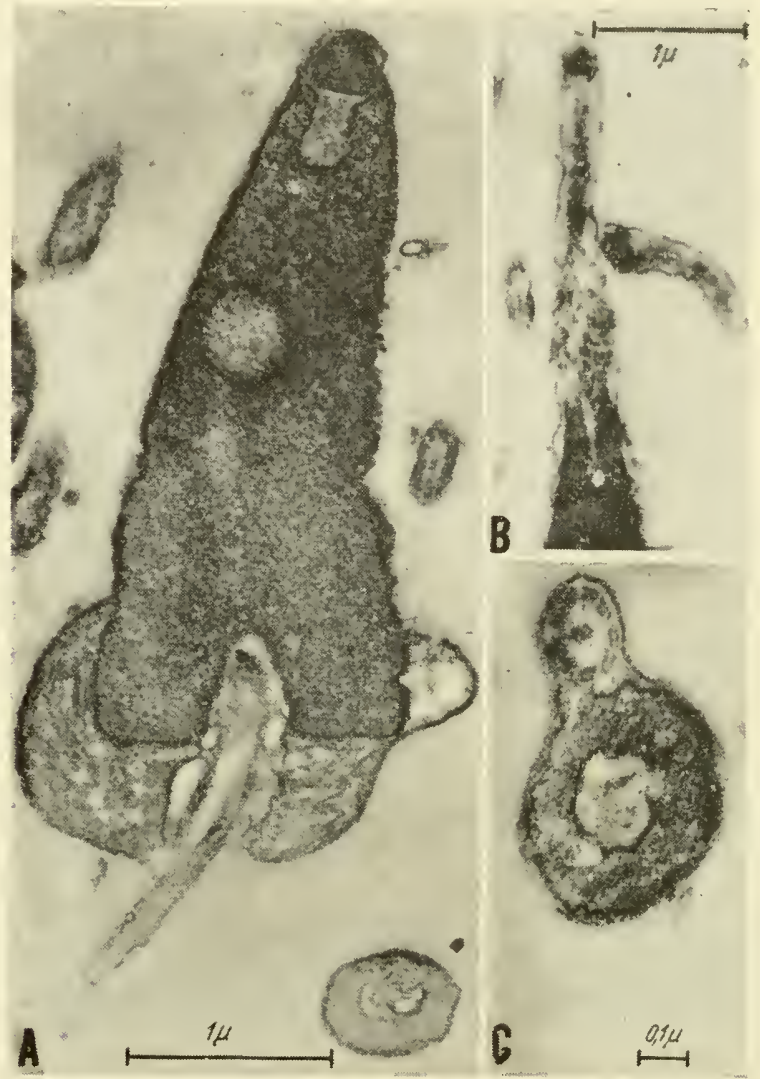

Fig. 15. Electron micrographs of thin sections of sea urchin spermatozoa. (From Afzelius, Z. Zellforsch., 1955.) Longitudinal sections, A, through head of Strongylocentrotus drocbachiensis and B, through two acrosomal regions of Echinocardium cordatum.

tozoon, are completely enclosed within a cell membrane. Afzelius suggests a comparison between the acrosomal particle he observed and the particle observed by Dan (1952) in living spermatozoa of other species of sea urchin. 


\section{Response of Spermatozoon to Certain Stimuli}

Although there have been numerous studies on the morphological changes which the individual egg undergoes during fertilization or parthenogenetic activation, there have been few investigations of the also important morphological changes which the individual spermatozoon undergoes at the critical time when it becomes associated with the egg, or under conditions which may be supposed to obtain at such a time. Yet theories of fertilization must be in accord with the morphological features observed during sperm-egg association and sperm penetration into the egg. Most of the early studies were based chiefly on fixed material. A few are of particular interest. Kupelweiser (1909) and Mèves (1915) studied fixed material of the mollusc Mytilus edulis; both noted the complete disappearance of the "perforatorium" by the time the spermatozoon had entered the egg, and Mèves further noted that the perforatorium had disappeared even from spermatozoa in process of entering the egg. Lillie (1912b) pointed out that in Nereis the perforatorium of the fixed spermatozoon is a rather straight filament, but he called attention to the fact that in the living spermatozoon the perforatorium is shaped more like "the spike of a helmet" and is shorter.

Popa (1927) studied Arbacia spermatozoa suspended in egg water with the expectation that any changes observed would resemble those preliminary to fertilization. He reported that the treatment caused the appearance of a small granule of sticky substance which he thought was eliminated through the pointed apex of the spermatozoon. Other changes in sperm morphology also were noted. While Popa's observations are difficult to assess, his experiments were at least an attempt at observation of the individual living spermatozoon.

Dan (1952, 1954; Dan and Wada, 1955) first demonstrated clearly that on suitable stimulation the spermatozoa of a number of species can undergo rather consistent profound morphological changes. These changes affect the acrosomal region and, to some extent, the middle piece and flagellum. This reaction was termed 
the "acrosome reaction" and spermatozoa which showed the changed appearance were called "reacted" spermatozoa. In most species, egg water and/or the presence of unfertilized eggs were effective stimuli. Although these conditions might be supposed to approach those encountered at fertilization, it was found also that the changes could be evoked in other ways, such as by treatment with alkaline sea water, or by "contact" with solid surfaces (e.g., glass slides, collodion membranes). It was not demonstrated whether the causal agent was contact per se or some other as yet undetermined factors associated with the handling of the preparations. Dan's studies included two species of sea urchin (Pseudocentrotus depressus and Strongylocentrotus pulcherrimus), three species of starfish (Asterina pectinifera, Asterias amurensis, and Astropecten scoparius), and twelve species of bivalve mollusc.

Sea Urchins. In studies of living spermatozoa by phase contrast microscopy and of whole formalin-fixed spermatozoa by electron microscopy, Dan (1952) found that suspension in egg water would induce the acrosome reaction. The reaction was interpreted as a breakdown of the acrosomal membrane so that the contained acrosomal material was exposed. Part of the exposed material was dispersed rapidly. There remained a central core or fiber which Dan (1954) termed the "acrosome filament" (Fig. 16; cf. with the untreated spermatozoon, Fig. 18). The length of the filament was about one micron, short as compared with the length of the sperm head. A similar reaction occurred when sea urchin sperm suspensions were placed in alkaline sea water of pH 9.2. Frequently the reacted spermatozoon (Fig. 17) showed the middle piece displaced to a lateral position while the flagellum appeared to emerge from the head at an angle instead of lying in the long axis of the body. Reacted spermatozoa with acrosome filaments were found also in untreated control suspensions. Dan interpreted these to be the result of "contact" stimulation with a solid surface.

Rothschild and Tyler (1955) studied sea water sperm suspensions from two other species of sea urchin. In Echinocardium cordatum they found two forms of the spermatozoon and con- 

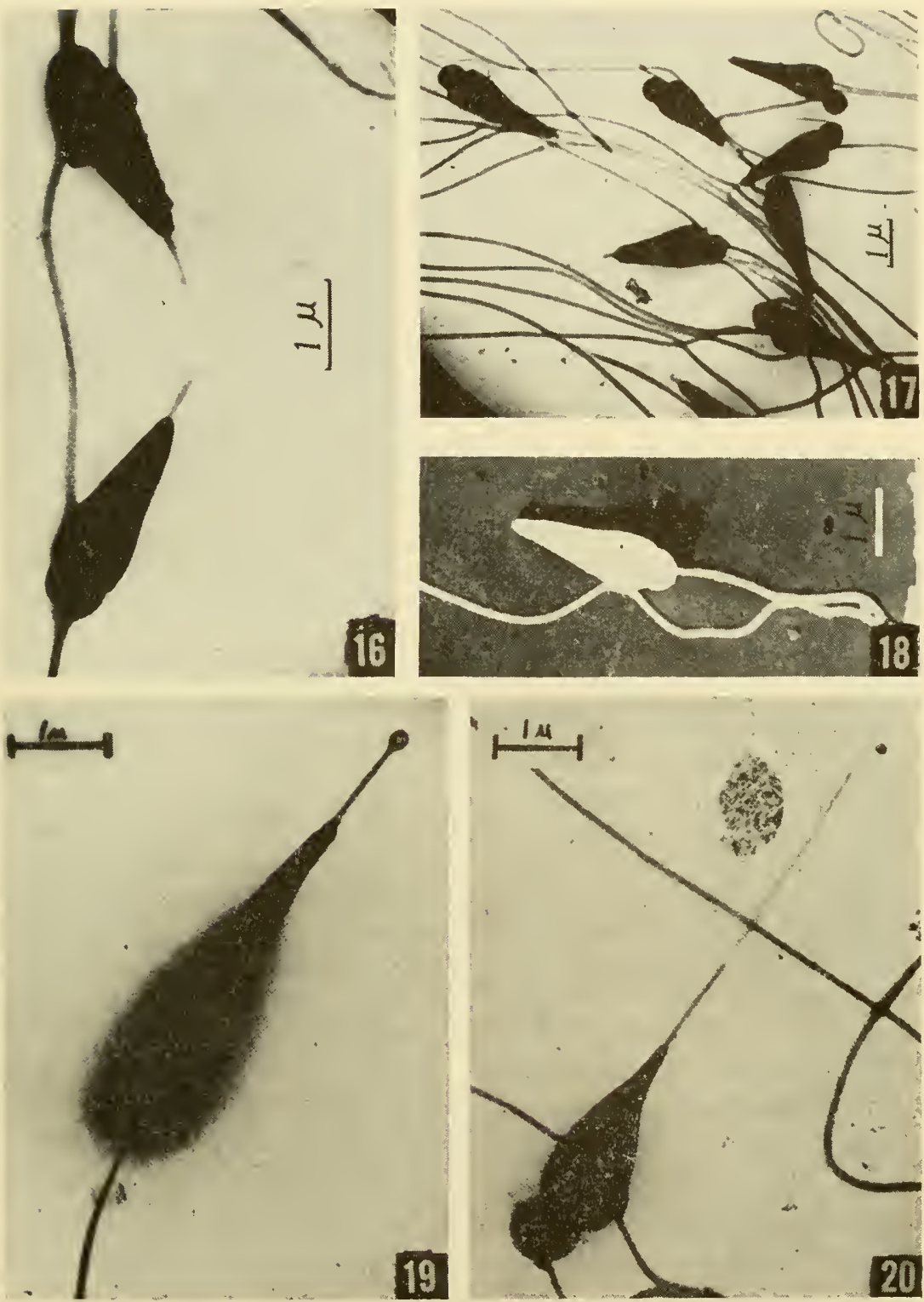

Figs. 16-18. Electron micrographs of spermatozoa of the sea urchin, Strongylocentrotus pulcherrimus. (From Dan, Biol. Bull., 1952.) 16, after agglutination with egg'water. 17 , after treatment with alkaline sea water. 18 , in sea water (control).

Figs. 19-20. Electron micrographs of spermatozoa of Echinocardium cordatum. (From Rothschild and Tyler, Exptl. Cell Research, 1955.) 
sidered the possibility that either form might be the precursor of the other. In one type of spermatozoon (Fig. 19), found in both living and fixed preparations, the acrosomal region appeared as a short stalk terminating in an apical knob. This is the type of spermatozoon illustrated by Vasseur (1947) in darkfield studies and, apparently, by Afzelius ( 195.5) in electron microscope studies of thin sections (Figs. 14e and 15B). The other type of spermatozoon (Fig. 20), found only in fixed preparations, has a profoundly different appearance. Extending from the apex of the sperm head is a slender filament which is much longer than the acrosomal region of the first type. There is no terminal knob, the middle piece lies in a postero-lateral position, and the flagellum and acrosome filament lie nearly at right angles to each other. All these characteristics are typical of the reacted sea urchin spermatozoon as shown by Dan. It seems probable that Fig. 20 represents a reacted spermatozoon. Tyler's (1952) electron microscope studies of fertilizin-treated sea urchin spermatozoa would seem to support this view. After reversal of agglutination, these spermatozoa too showed the middle piece postero-laterally displaced from its normal location at the base of the head. Since Rothschild and Tyler found spermatozoa with long acrosomal filaments only in fixed preparations, the possibility exists that the fixative itself or some feature of the process en route to fixation may have stimulated the acrosomal regions to produce these filaments (vide supra, living vs fixed spermatozoa of Nereis; for a more detailed discussion see Colwin and Colwin, 1956).

Starfishes. A more striking example of the acrosome reaction with formation of an acrosome filament was found in several starfish species by Dan (1954). When sperm suspensions were made in sea water plus egg albumin (Metz, 1945) to which was then added homologous egg water, irreversible agglutination occurred. Both phase contrast (Fig. 21) and electron microscope studies (Fig. 23) showed that within such preparations there were spermatozoa with long slender acrosome filaments of considerabie rigidity. The filament extended from the apex of the acrosomal region for about 25 microns. In the reacted spermatozoon (Fig. 22A) the middle picce was more nearly spherical 


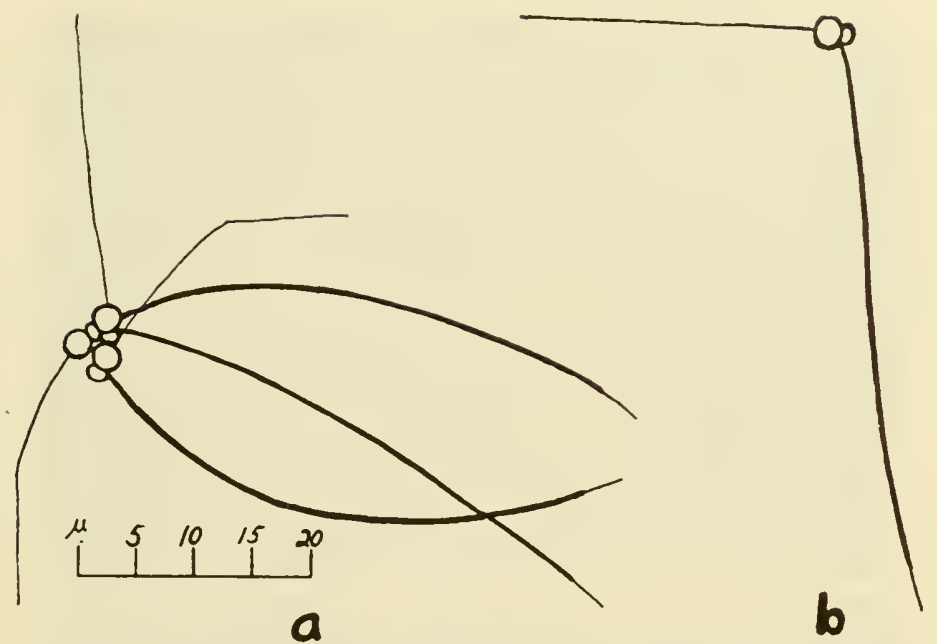

Fig. 21. Reacted spermatozoa of Asterina pectinifera showing acrosome filaments after suspension in egg water. (From Dan, Biol. Bull., 1954.) a, small cluster of agglutinated spermatozoa; b, single reacted spermatozoon.

than in the unreacted spermatozoon (Fig. 22B), and the base of the flagellum and the acrosome filament lay nearly at right angles to each other.

Molluscs. In some of the species of bivalve molluse studied by Dan and Wada (1955), the acrosome reaction was elicited by the species egg water and/or by "contact" with glass surfaces. However, in all the species studied, the spermatozoa produced acrosome filaments when placed in the presence of unfertilized

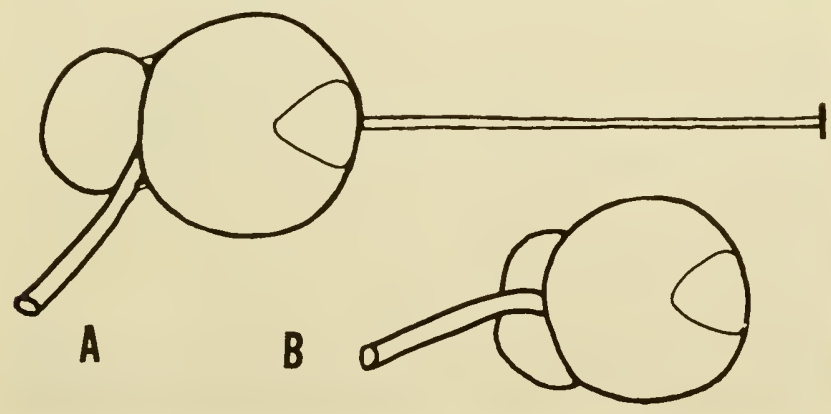

Fig. 22. Head ends of spermatozoa of starfish. (After Dan, Biol. Bull., 1954.) A, reacted, showing the acrosome filament; B, unreacted. 
MORPHOLOGY OF FERTILIZATION
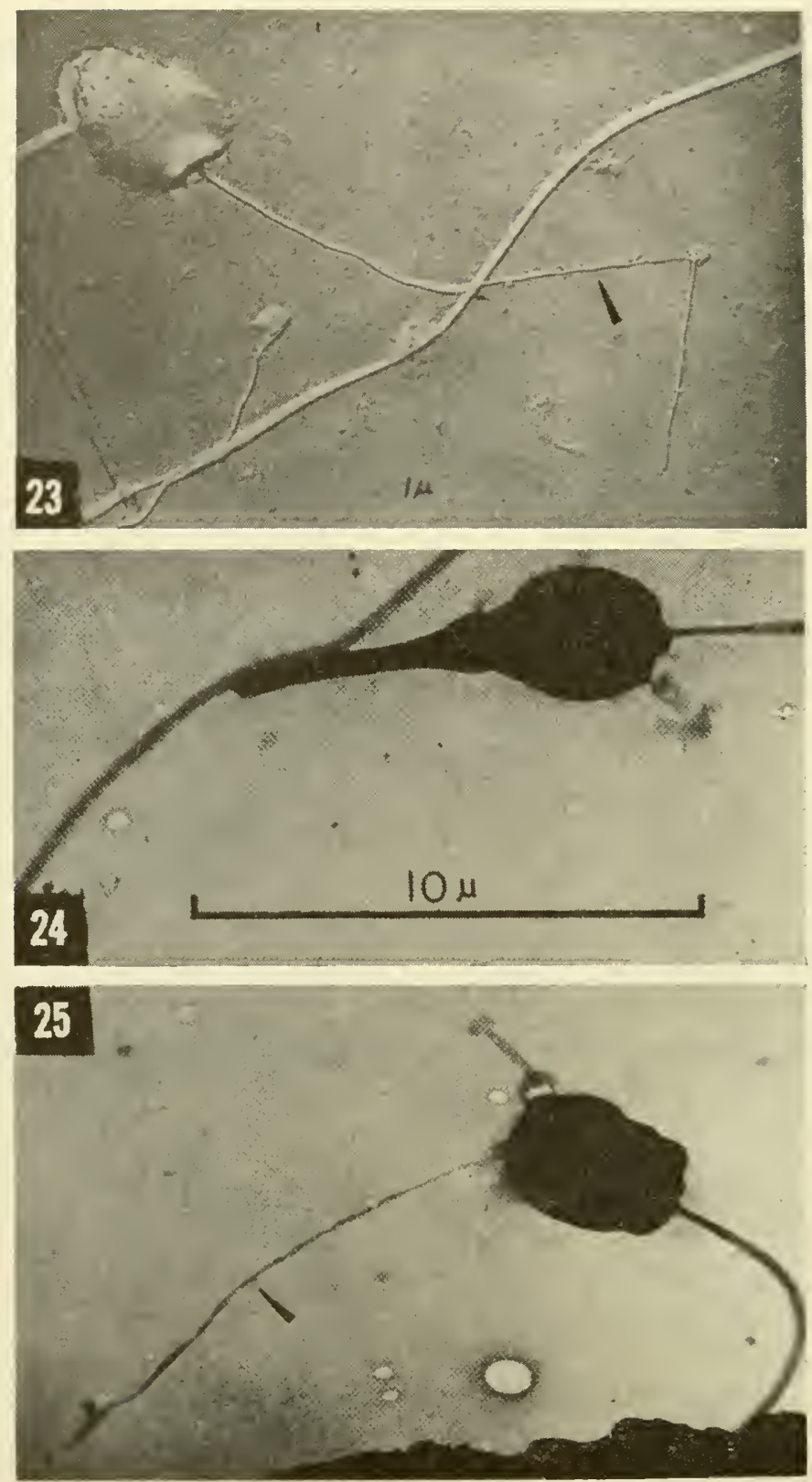
eggs of the same species (Figs. 1-13 and cf. Figs. 1 and 2 with Figs. 24 and 25). In all species the reaction resulted in the complete disappearance of the original acrosome and the production of a slender rigid filament. The length of the filament varied with the species, being in each case about three times the length of the sperm head. The longest filament measured about 15 microns. In the reacted spermatozoa the middle piece spherules appear to have become less tightly affixed to the base of the sperm head.

In some species the reacted condition was observed also in "supernumerary" spermatozoa, that is, in spermatozoa which were associated with the egg (Figs. 5 and 8 ) but did not subsequently enter it. In some species spermatozoa were found in which the acrosome had undergone only a "partial reaction" (Figs. 3 and 6), supposedly because of subnormal condition of the spermatozoa or suboptimal stimulation. In these spermatozoa the filament was always about the length of the original unreacted acrosome.

Rothschild and Tyler (1955) have reported that fixed spermatozoa of the chiton Lepidochitona cinerea, seen with the electron microscope, have an "acrosomal filament" or "anterior process" about twice as long as the rest of the head, whereas in living spermatozoa, seen with the light microscope, "the proximal portion of the process is the only part visible." Until a comparison is made between fixed and living spermatozoa under one kind of microscope, a different interpretation cannot be excluded, namely, that the two different relative lengths of the process might represent reacted and unreacted conditions in fixed and living spermatozoa, respectively. Some factor in the initial phase of fixation might have stimulated the acrosome reaction.

Dan's important observation that spermatozoa undergo an acrosome reaction in response to various stimuli has been con-

Fig. 23. Electron micrograph of a reacted (egg water treated) spermatozoon of Asterias amurensis; black arrow points to acrosome filament. (From Dan, Biol. Bull., 1954.)

Figs. 24-25. Electron micrographs of formalin-fixed spermatozoa of Mytilus edulis. (From Dan and Wada, Biol. Bull., 1955.) 24, in sea water (control). 25, reacted (egg water treated); black arrow points to acrosome filament. 
firmed in living material in other species of starfish and in the holothurians, Holothuria atra and Thyone briareus (Colwin and Colwin, 1955a,c, 1956). Quantitative data for the acrosome reaction have been obtained in Thyone.

TABle I. Acrosome Reaction of Spermatozoa of Thyone briareus as Olsserved in Living Preparations. Production of Aerosome Filaments Evoked by Addling Sea Water Sperm Suspensions to Egg Water or to Sea Water Marle Alkaline

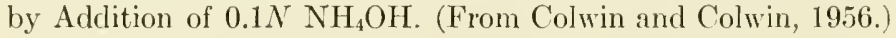

\begin{tabular}{|c|c|c|c|c|}
\hline Experiment No. & $\begin{array}{l}\text { Number } \\
\text { spermatozoa } \\
\text { counted }\end{array}$ & $\begin{array}{l}\text { Per cent } \\
\text { with } \\
\text { filaments }\end{array}$ & $\begin{array}{l}\text { Number } \\
\text { spermatozoa } \\
\text { counted }\end{array}$ & $\begin{array}{l}\text { Per cent } \\
\text { with } \\
\text { filaments }\end{array}$ \\
\hline & \multicolumn{2}{|c|}{ Egg water } & \multicolumn{2}{|c|}{ Sea water control } \\
\hline $\mathrm{EG}, \mathrm{NN}-1^{a}$ & 100 & 21 & 100 & 2 \\
\hline $\mathrm{EG}, \mathrm{SN}-2$ & 52 & 21 & $>100$ & 0 \\
\hline $\mathrm{EG}, \mathrm{SG}-3$ & 100 & 18 & 100 & 3 \\
\hline $\mathrm{EG}, \mathrm{SN}-4$ & 104 & 12.6 & 100 & 1 \\
\hline $\mathrm{EG}, \mathrm{SG}-5$ & 73 & 6.8 & 100 & 0 \\
\hline $\mathrm{EG}, \mathrm{SG}-6(\mathrm{a})$ & 111 & 1.8 & sweep $^{b}$ & 0 \\
\hline \multirow[t]{2}{*}{$\mathrm{EG}, \mathrm{SG}-7(\mathrm{a})$} & 100 & 0 & sweep & $<1$ \\
\hline & \multicolumn{2}{|c|}{ Alkaline sea water } & \multicolumn{2}{|c|}{ Seat water control } \\
\hline $\mathrm{EG}, \mathrm{SG}-6(\mathrm{~b})$ & sweep & $>90^{c}$ & sweep & 0 \\
\hline $\mathrm{EG}, \mathrm{SG}-7(\mathrm{~b})$ & sweep & $>99^{c}$ & sweep & $<1$ \\
\hline $\mathrm{EG}, \mathrm{SG}-7(\mathrm{c})$ & 97 & $92^{d}$ & sweep & $<1$ \\
\hline $\mathrm{EG}, \mathrm{SG}-8$ & sweep & $>90^{d}$ & sweep & 0 \\
\hline
\end{tabular}

Note. Experiments bearing the same number were made simultaneously from the same sperm suspension and have the same control.

${ }^{a} \mathrm{E}$ eggs; $\mathrm{S}$ sperm; $\mathrm{N}$ naturally shed; $\mathrm{G}$ obtained by removal from gonad.

${ }^{b}$ Sweep Extensive examination of area of coverslip by back and forth movement with a mechanical stage.

${ }^{c} \mathrm{pH}$ of alkaline sea water to which sperm suspension was arded was slightly higher than $9.2-9.4$

${ }^{d} \mathrm{pH}$ of alkaline sea water to which sperm suspension was added was 9.2-9.4.

Thyone briareus. In this species acrosome filaments were formed when sperm suspensions were treated either with egg water or with alkaline (ammoniated) sea water (Table I). Within the concentrations used, the latter was found to be the 
more effective stimulant. Thus as shown in experiment 7 of Table I, with samples from the same original sperm suspension egg water was ineffective whereas alkaline sea water caused at least $92 \%$ of the spermatozoa to produce acrosome filaments. Since untreated (control) sperm suspensions sometimes show a very low percentage of spermatozoa with acrosome filaments, it

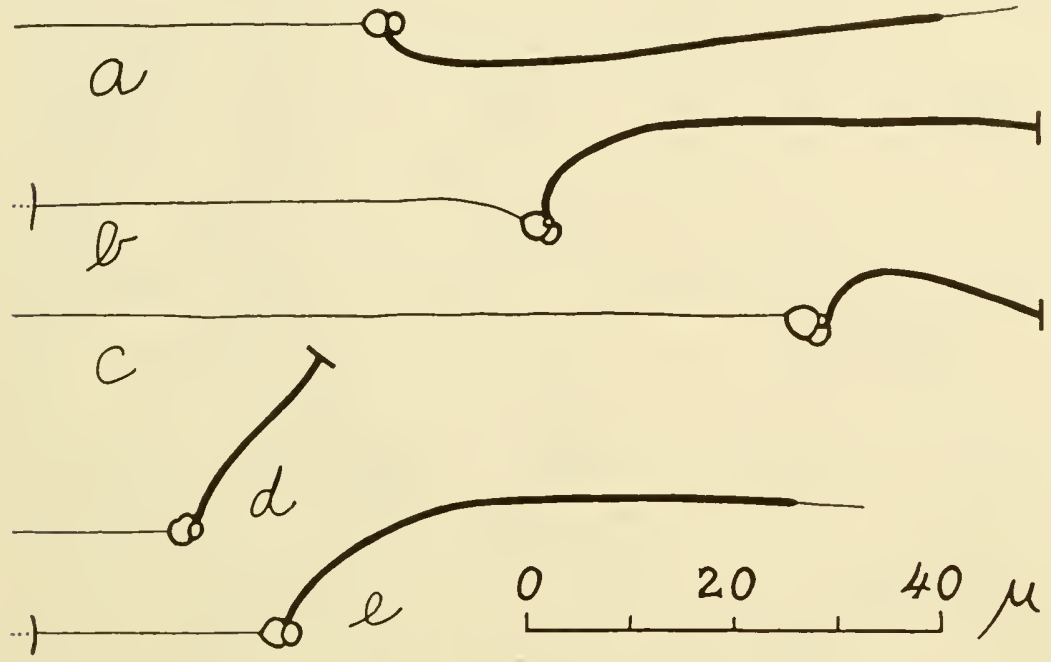

Fig. 26. Reacted spermatozoa showing acrosome filament, from photographs of living specimens. (From Colwin and Colwin, Biol. Bull., 1956.) a-c, Thyone briareus; d-e, Asterias forbesii. a, in egg water (35 microns); b, at egg surface ( 48 microns); c, in alkaline sea water ( 75 microns) (position of distal part of flagellum modified for reasons of space); $d$, in inseminated culture but directed away from egg ( 15 microns); e, at egg surface (22 microns).

would seem possible that other factors, as yet unknown, may also evoke the acrosome reaction.

The changes which the spermatozoa undergo when suitably stimulated are seen readily in living preparations. Figure 28 shows an unreacted spermatozoon for comparison with others which have reacted to treatment with alkaline sea water (Figs. 26c, 29 and 30) or with egg water (Figs. 26a and 31). Reacted spermatozoa may be found also in preparations of inseminated eggs. The sperm head is connected with the egg surface by a 
long acrosome filament (Figs. 26b and 32). Typically, the reacted spermatozoa show the middle piece rounded in outline, while the filament and the base of the flagellum lie nearly at right angles to each other. This appearance resembles that of reacted starfish spermatozoa (Dan, 1954).

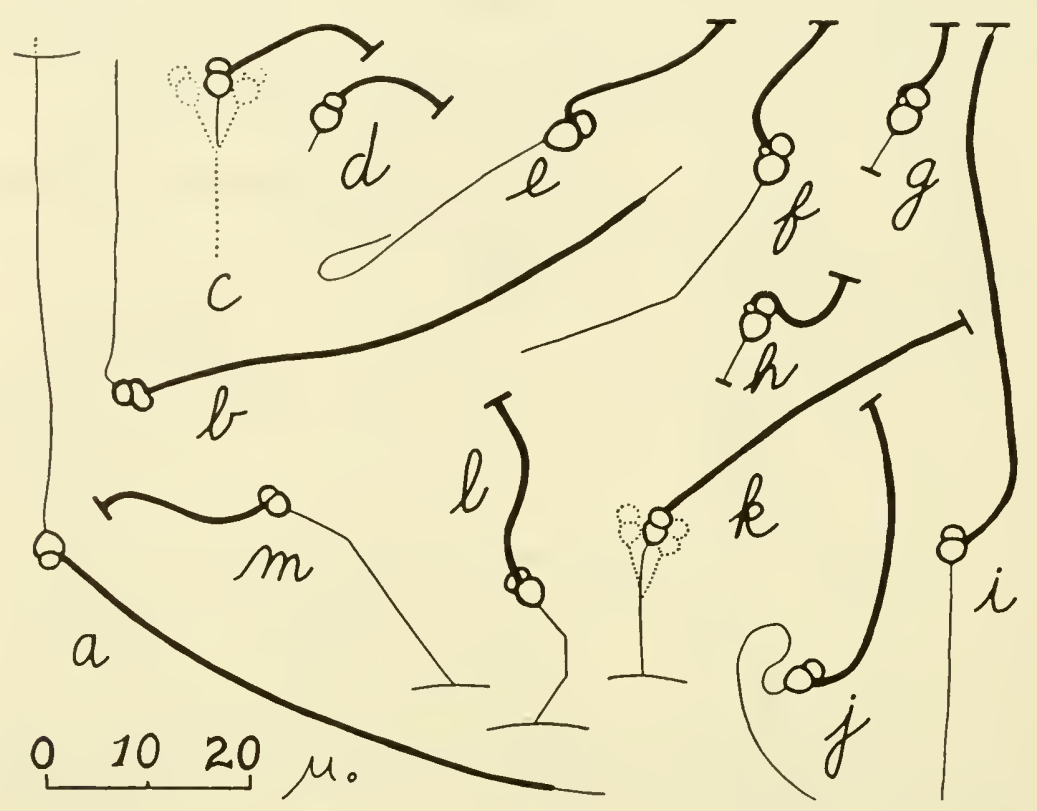

Fig. 27. Reacted spermatozoa; bending and curving of acrosome filament, from sketches and photographs of living specimens. (From Colwin and Colwin, Biol. Bull., 1956.) a-h, Thyone briareus; i-l, Asterias forbesii; $\mathrm{m}$, A. vulgaris (presumed distal part of acrosome filament dotted). a and $\mathrm{k}-\mathrm{m}$, at egg surface; others, unassociated with egg. b, in egg water; $\mathrm{c}-\mathrm{h}$, in alkaline sea water ( $d$, same specimen as $c$, after separating from fixed point); $\mathrm{i}-\mathrm{j}$, successive views of one specimen, in inseminated culture but not associated with an egg.

A striking feature of the acrosome filament of Thyone is its great length. Whereas the longest acrosome filament previously reported attained a maximum length of 22 to 28 microns (in starfishes, Dan, 1954), the filament of Thyone occasionally is as long as 75 microns (Fig. 29), and in one case it measured 90 microns. For comparison, the length of the flagellum is usually 
about 60 microns, and the depth of the jelly hull, through which the acrosome filament must penetrate in order to reach the egg surface, is approximately 55 microns. The spermatozoa of Thyone do not swim through this jelly hull.

Other Species. In Holothuria atra (Colwin and Colwin, $1955 \mathrm{a}$ ), acrosome filaments were found on spermatozoa suspended in egg water (with egg albumin as an adjuvant) and on spermatozoa associated with the egg surface (Fig. 38). In starfishes (Colwin and Colwin, 1955a,d, 1956) the acrosome filament has been found on spermatozoa in association with the egg in Asterias amurensis (Fig. 35), A. vulgaris (Fig. 27m) and A. forbesii (Figs. 27k,l and 33 and 34 ). In all four species spermatozoa with acrosome filaments were found also in the surrounding medium but not directly associated with any egg. There is also evidence of acrosome filament formation in spermatozoa of the annelid Sabellaria vulgaris (Colwin and Colwin, 1955b).

Metz and Morrill (1955) have demonstrated that fertilizin treatment of spermatozoa of Asterias forbesii and the annelid Nereis limbata results in the production of acrosome filaments. In Nereis the acrosome membrane breaks down and a rod-like filament is exposed (or arises); the overall length of the sperm head remains unchanged. This material was fixed in formalin and examined with the electron microscope.

From the foregoing evidence it is quite clear that in many species, representing several phyla, the spermatozoa undergo rather profound changes when suitably stimulated. The most striking change is the production of the more or less straight, relatively rigid acrosome filament. In some species the reaction has been elicited by egg water, in some by alkaline sea water or by surface "contact," but in others it has been seen thus far only when the spermatozoa are in the vicinity of, or in contact with, unfertilized species eggs (some molluscs). As is well known, a number of stimuli other than the normal one (that is, association with the opposite gamete) may cause parthenogenetic activation of the egg. It is not surprising, then, that the spermatozoon too may be activated by other than normal stimuli.

It is suggested that the term "acrosome filament" be reserved, 


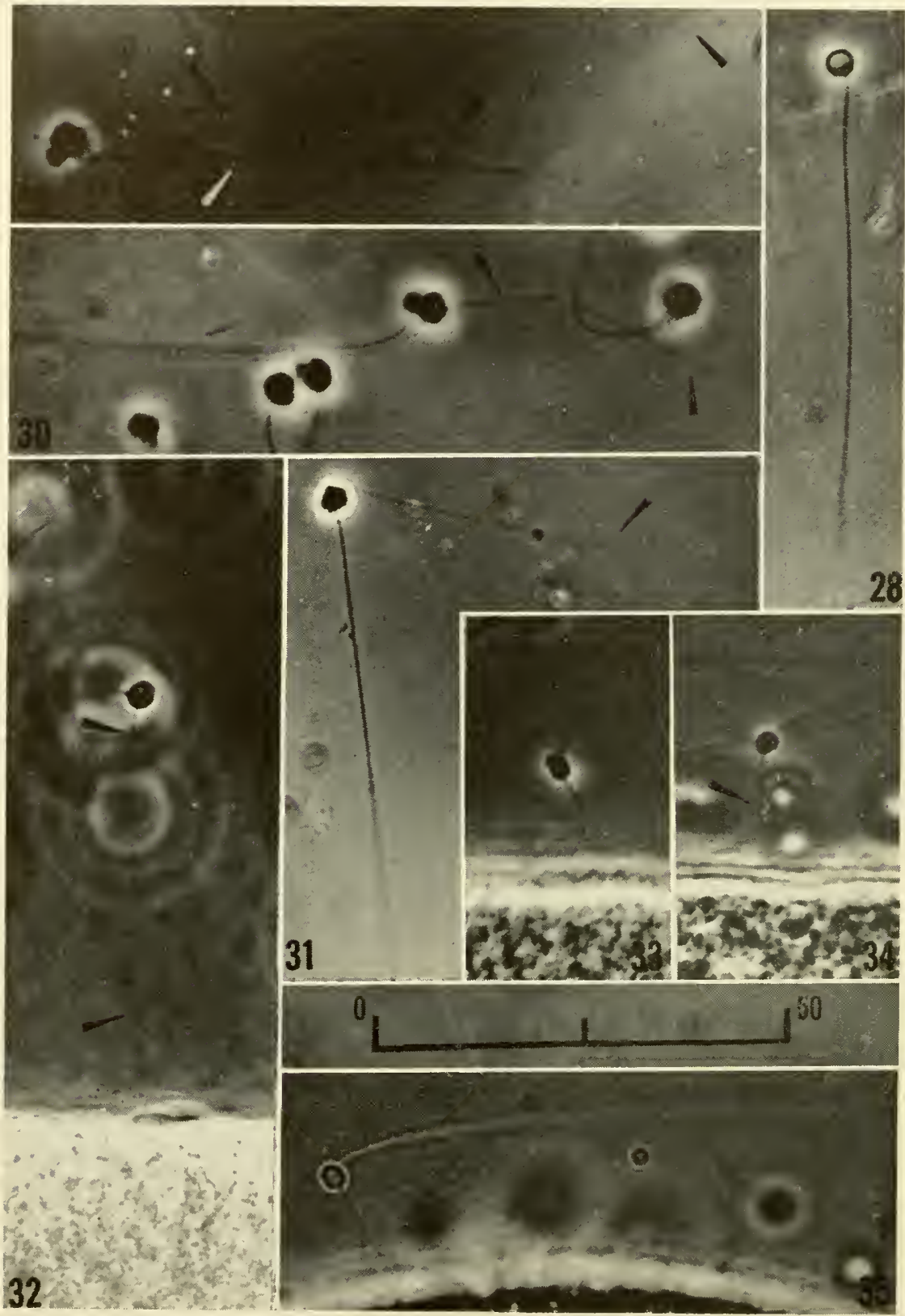


expressly for the filamentous structure or projection which occurs in the acrosomal region when the spermatozoon undergoes the acrosome reaction and that the term be avoided when referring to the unreacted acrosomal region whatever its length may be.

\section{Some Physical Properties of the Acrosome Filament}

Shape. The threadlike acrosome filament is generally rather straight although this is not invariably the case. The filament may curve gently, or sharply, or even bend (cf. various examples in Figs. 26-35). Although it appears to have considerable rigidity, it is nevertheless somewhat flexible. This was shown by Dan for certain starfishes (Fig. 21), and it has been found so for other starfishes and also for Thyone (Fig. 27). In some cases the acrosome filament was observed to break. Occasionally spermatozoa were seen in which it appeared that the head had reacted but the acrosome filament was much shorter than usual, or simply not present. Possibly breakage may account for these exceptional specimens.

Length. Dan and Wada (1955) have indicated that there does not seem to be a simple taxonomic relationship between species and length of acrosome filament. However, it is evident that a positive correlation exists between the length of the filament and the depth of the barrier through which the spermatozoon must pass in order to meet the egg proper. For example, in a number of sea urchins the jelly hull offers little or no barrier and the spermatozoon readily swims through it to the egg; in these the acrosome filament is very short. In contrast, the egg jellies of various starfishes and holothurians offer effective bar-

Figs. 28-35. Unretouched photographs of living preparations. (From Colwin and Colwin, Biol. Bull., 1956.) Black arrow points to acrosome filament, white arrow to flagellum. The scale is in microns and applies only to Figs. 28-34. 28-31, spermatozoa of Thyone briareus: 28, unreacted spermatozoon; 29-30, long acrosome filaments on reacted spermatozoa in alkaline sea water; 31 , egg water treated spermatozoon with acrosome filament; 32 , reacted spermatozoon with acrosome filament in contact with egg surface (no cone formed). 33-34, reacted spermatozoa of Asterias forbesii showing acrosome filament in contact with the egg surface (no cone formed). 35, reacted spermatozoon of Asterias amurensis showing the acrosome filament in contact with the egg surface (no cone formed). 
riers through which their respective spermatozoa do not swim. In these species the acrosome filament is quite long. In the extreme case of Thyone the depth of the barrier approximates 55 microns and the length of the filament is sometimes even greater than this. It has been suggested for some species (Colwin and Colwin, 1954b; Dan, 1954) that the egg reacts only after the filament of the spermatozoon makes physical contact with the true egg surface or with the protoplasm immediately beneath

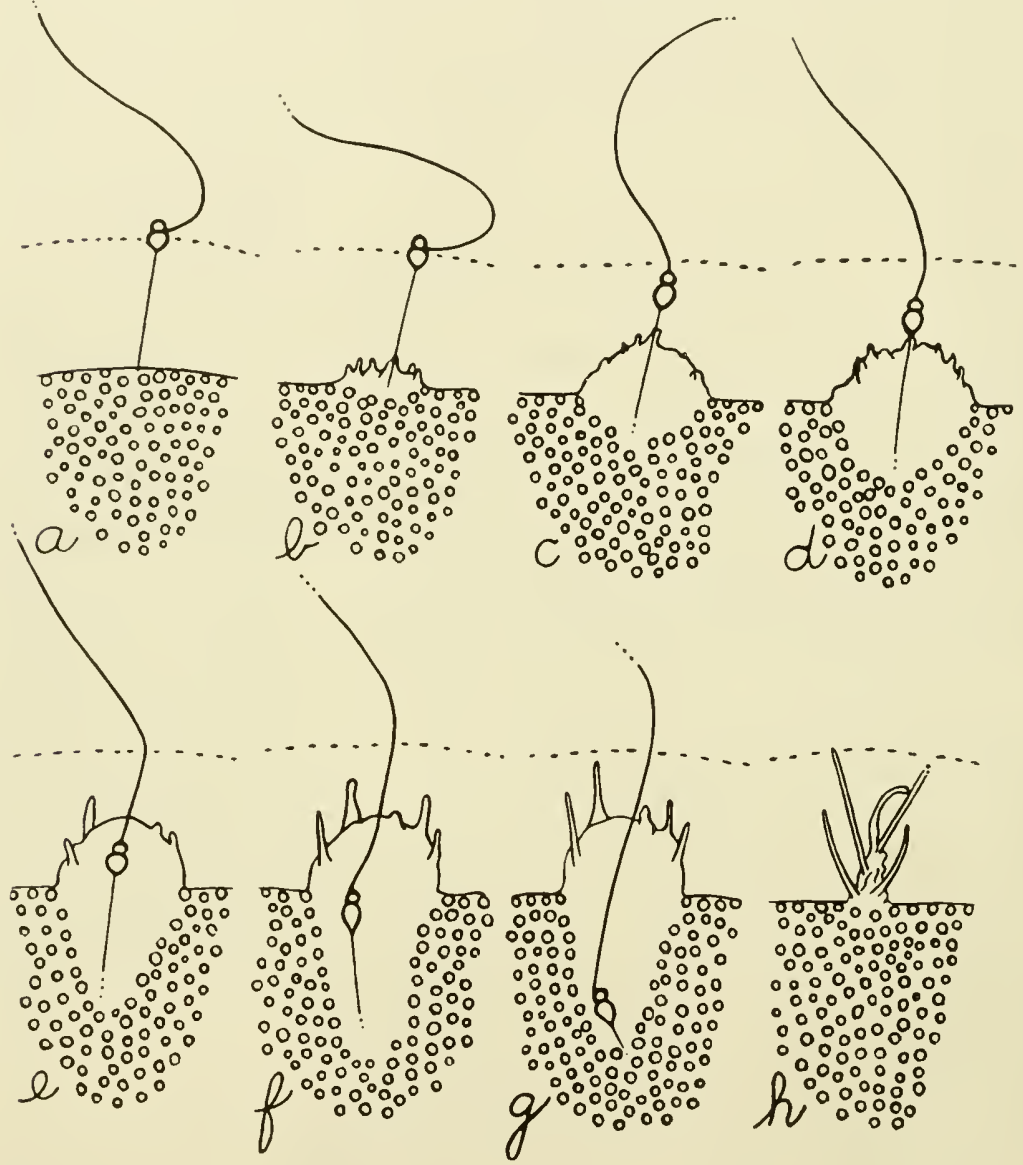

Fig. 36. Diagrammatic representation of successive stages of sperm entry as seen in the living egg of Holothuria atra. (From Colwin and Colwin, J. Morphol., 1955a.) 
the surface. Subsequently, this suggestion has received strong support from observations on sperm entry in several other species (Colwin and Colwin, 1955a, 1956). From the above considerations it seems likely that the acrosome filament of a species would have to be at least as long as the depth of the barrier which separates the approaching sperm head from the reactive egg surface in that species. Within a given preparation (e.g., in Thyone) spermatozoa may be found with acrosome filaments of different lengths. Some filaments are shorter than the depth of the barrier around the species egg. It has been observed frequently that the first spermatozoon, or even the first several spermatozoa, to reach a ripe egg may not succeed in fertilizing it. Inadequate length of the filament might account for such failure.

\section{Sperm-Egg Association and Sperm Entry}

The acrosome filament now may be examined in relation to the egg during sperm entry. The following descriptions are based exclusively on living material.

Holothuria atra. The exceptional clarity of the entrance cone in this species made it possible to observe many details readily (Colwin and Colwin, 1955a). The eggs were removed from the gonads. Most were in the germinal vesicle stage when used. Although all were moderately polyspermic and failed to cleave, they were considered (op. cit.) to be close to physiological maturity and to reflect the essentials of the normal entry pattern of the species.

The egg is surrounded by a jelly hull (Fig. 37) through which the spermatozoon does not swim. The chief events of sperm entry are shown diagrammatically in Fig. 36, and representative stages are shown in photographs in Figs. 39 to 44 . At the earliest observation an incipient cone was already present, and the acrosome filament extended to the cone through the jelly hull. The main points to be noted are as follows. (1) The cone rises around the acrosome filament. Often one projection of the cone creeps up the filament in advance of the main body of the cone (Figs. 3940 ). For a time at least, the apex of the cone moves outward while the spermatozoon moves inward. Indeed, the cone may 


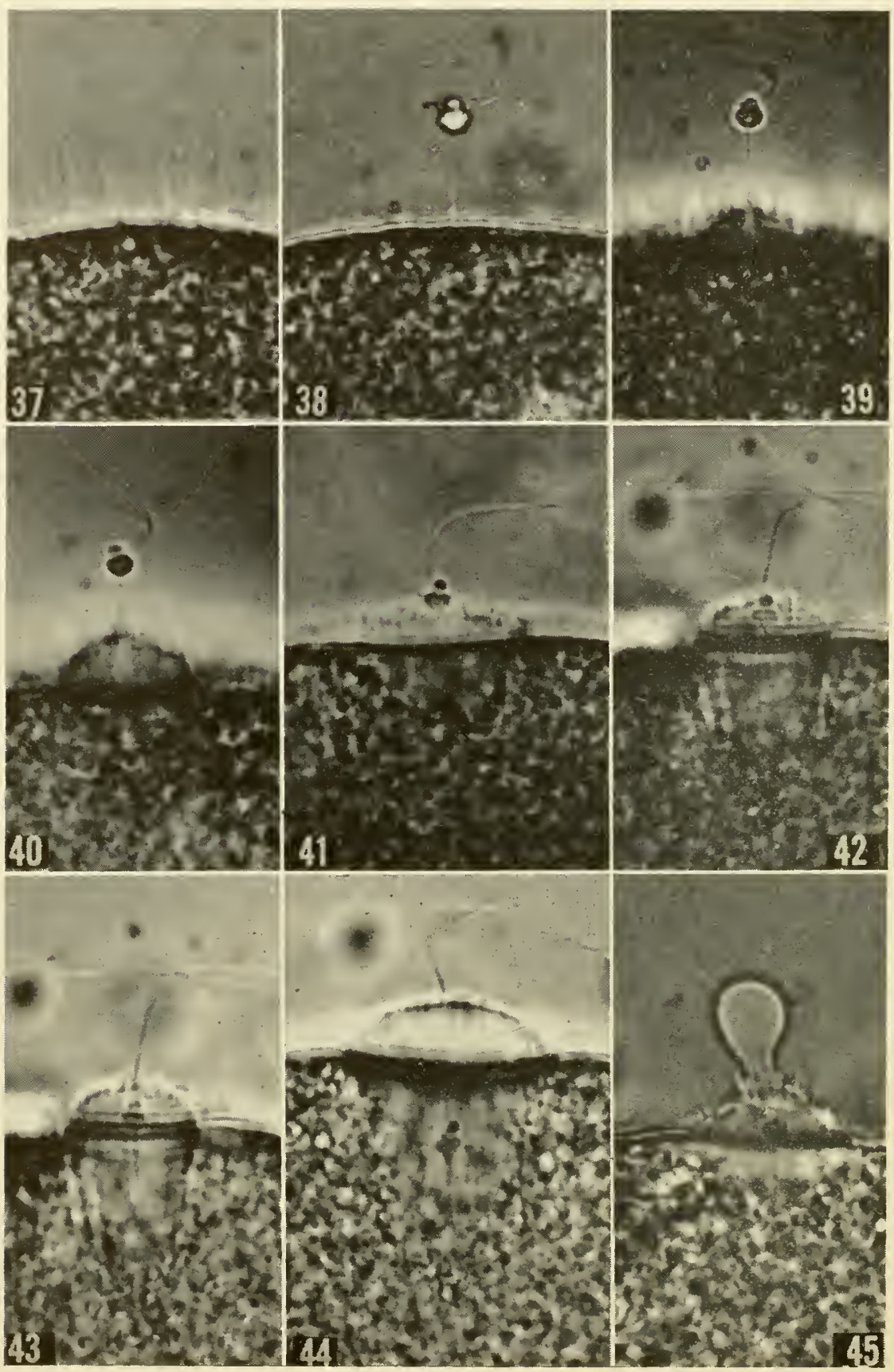


continue to enlarge even after the sperm head and its acrosome filament are well within the egg proper. The cones are always broad. (2) The acrosome filament enters the egg intact as the most anterior part of the sperm head and remains essentially unaltered in diameter and length until at least well into the egg. With less favorable material one might erroneously have concluded that the filament connected the sperm head with the apex of the cone and that the filament contracted during sperm entry. (3) At no time was there any basis for confusion between the straight rodlike acrosome filament and the numerous coarse raclial striations which occur in the jelly hull (cf. Fig. 37 with Figs. 38-39).

Thyone briareus. The process of sperm entry and cone formation in this holothurian is similar to that of $H$. atra in many respects, but it differs in certain significant details (Colwin and Colwin, 1956). The observations were made on eggs removed from the gonads and also on naturally shed normal eggs. Eggs from both sources were polyspermic in coverslip preparations. Control cultures of artificially obtained eggs did not cleave, but the control cultures of the naturally shed eggs gave 98-99\% cleavage and more than $90 \%$ active larvae. The chief differences between the entry phenomena in eggs from the two sources were that in the artificially obtained eggs sperm entry was slower and the cone rose higher around the acrosome filament than in the naturally shed eggs.

The egg is surrounded by a jelly hull of about 55 microns in thickness. Through this jelly rum radial striations which are

Figs. 37-45. Unretouched photographs of living preparations showing sperm entry in Holothuria atra. (From Colwin and Colwin, J. Morphol. 1955a.)

Fig. 37. Portion of uninseminated egg showing jelly hull with filamentous radial projections from the egg surface.

Fig. 38. A reacted spermatozoon with the acrosome filament in contact with the egg surface (no cone formed); spermatozoon did not enter egg.

Figs. 39-44. Successive stages of sperm entry into the egg (taken from several eggs); note the entry of the intact acrosome filament into the egg proper as the most anterior part of the sperm head.

Fig. 45. Compressed cone with exudate emerging from ruptured region; spermatozoon in cone appeared unaffected. 
readily distinguishable from the acrosome filament (Fig. 49). The exceedingly long and tenuous acrosome filament spans the jelly and reaches the egg surface. Presumably in response to a stimulus from this filament, the egg forms a hyaline fertilization cone. Figure 46 shows a scheme of the sperm entry process, and Fig.

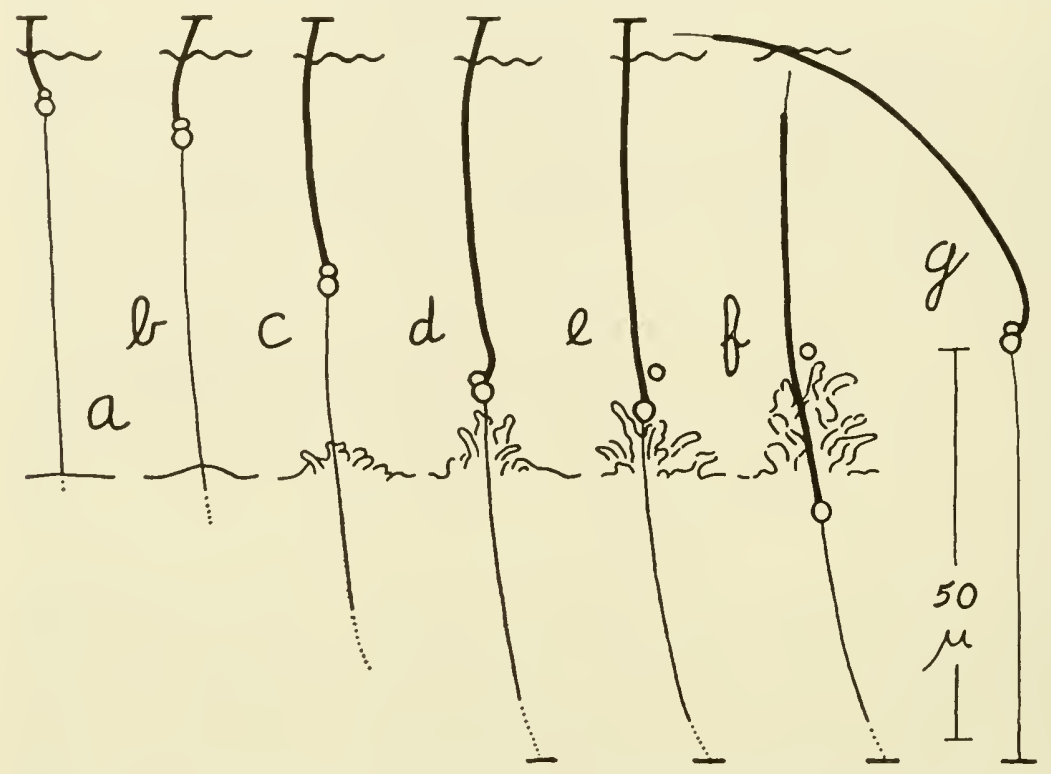

Fig. 46. a-f, scheme of sperm entry process in Thyone briareus. (From Colwin and Colwin, Biol. Bull., 1956.) Part shown in dotted line represents minimum additional length of acrosome filament presumed but not actually seen to enter egg. g, reacted spermatozoon from alkaline sea water suspension for comparison of length of acrosome filament. a, presumed very early stage, based on spermatozoon which failed subsequently to enter; b, low broad incipient cone rises as acrosome filament proceeds into egg proper; $\mathrm{c}-\mathrm{f}$, successive stages of sperm entry; acrosome filament enters egg proper as most anterior part of spermatozoon (middle piece, left outside in this case, frequently enters egg). In subsequent stages, entire flagellum passes into egg proper.

47 illustrates successive stages in one egg. Figure 48a-e and Figs. 49 to 51 show stages in several other living eggs. The main points to be noted are as follows. (1) The cone rises around the acrosome filament to varying heights and surrounds it like a sleeve. In some eggs (Fig. 46) the cone rises around the fila- 
ment for only a short distance. In others (Figs. 47, 49, 50) one projection from a rather broad based cone rises around the filament as a fairly narrow process. In still other eggs (Figs. 48a and e, and 51) a very slender projection creeps up the acrosome filament for some distance and surrounds it in a sleeve of proto-
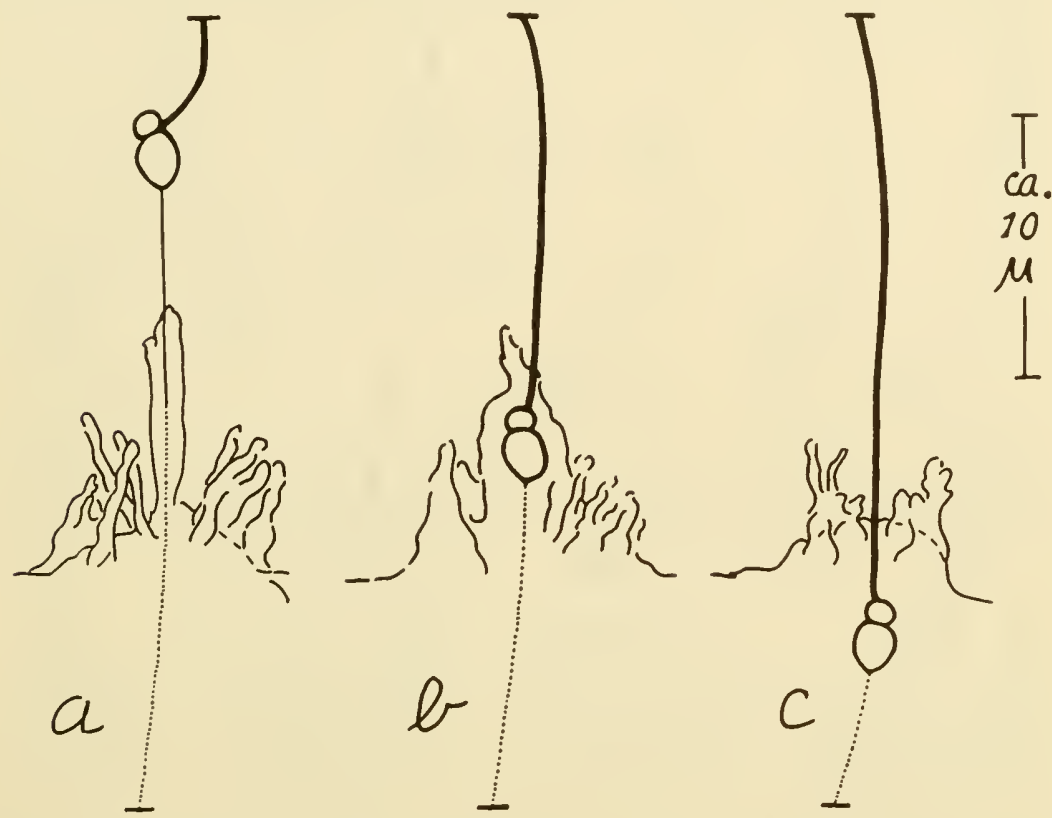

Fig. 47. Successive stages of sperm entry in Thyone briareus, from sketches of a living specimen. (From Colwin and Colwin, Biol. Bull., 1956.) A broad cone with filose projections elevated one moderately slender sleeve of protoplasm around the inmoving acrosome filament. Acrosome filament seen in outer part of cone: solid line. Presumed further course of filament: dotted line.

plasm so narrow as to make this portion of the cone itself seem like a filament. (2) The acrosome filament can sometimes be seen within the hyaline cone (Figs. 48a-e and 49-51). Failure at other times to see the filament within the cone was attributed to optical conditions since often the even much thicker flagellum could not be seen within the cone. (3) While areas beneath the egg surface were very difficult to observe, nevertheless in a few 
cases the acrosome filament was seen to extend into the egg proper for some distance (Figs. 46-48). In a few other cases the filament could not be identified as such, but a long narrow disturbance in the arrangement of the yolk granules extended to a depth approximating that to which the filament could be presumed to have entered, as judged by the position of the head.

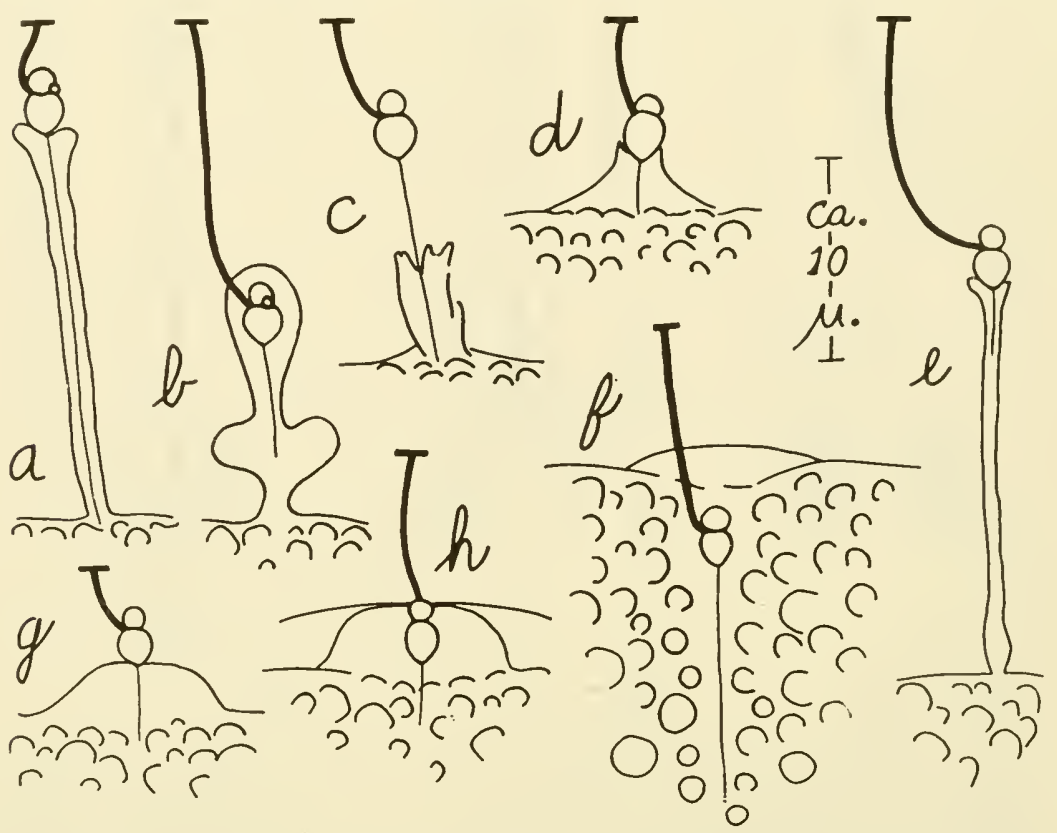

Fig. 48. Variations in sperm entry, from sketches of living specimens. (From Colwin and Colwin, Biol. Bull., 1956.) a-f, Thyone briareus; g-h, Asterias forbesii. Acrosome filaments shown only to depth actually seen. $a-b$ and $c-d$, successive views of two specimens, respectively; e, very slender cone embracing acrosome filament; $f$, acrosome filament within egg proper; $\mathrm{g}-\mathrm{h}$, from two specimens of A. forbesii, successive stages which preceded stages closely resembling that shown in $\mathrm{f}$.

The overall picture of sperm entry in Thyone, then, agrees with the main observations in H. atra. From the very earliest stage of cone formation the acrosome filament is already in contact with the egg surface and becomes encased by the elevating cone. As part of the sperm head, the acrosome filament enters into the protoplasm of the egg proper. The entire filament enters in $H$. 
atra and there is at least partial entry in $T$. briareus. There is collateral evidence for this picture of sperm entry in the following species as well.

Asterias. In A. amurensis (Colwin and Colwin, 1955a) the acrosome filament was seen within the cone. In A. forbesii (Colwin and Colwin, 1956) the filament was sometimes seen to be within the cone and to extend a short distance into the egg proper (Figs. 48g-h). Rarely it was observed to be well within the egg proper, as in Thyone (cf. Fig. 48f).

Saccoglossus kowalevskii. In this enteropneust, too, similar events appear to occur during sperm-egg association and sperm entry (Colwin and Colwin, 1954b). The egg is not surrounded by a jelly hull. Instead there are two membranes, an outer and an inner one, Membranes I and II, respectively (Colwin and Colwin, 1954a). From the earliest observation spermatozoon and egg are connected by a filament. As the cone develops it surrounds a portion of the filament. In some cases an advance projection from the broader base of the cone creeps up the filament. This was observed both in polyspermic and in normal eggs (Figs. 5254).

After Dan's original (1952) publication on the acrosome reaction it was "conjectured that in the egg of S. kowalevskii a similar acrosomal breakdown, occurring when the spermatozoon reaches the outside of Membrane I, might discharge a threadlike projection through the outer and the vitelline [II] membranes and that this structure or substance, on reaching the true egg surface, might elicit the reaction of the fertilization cone" (Colwin and Colwin, 1954b). The observations on Holothuria atra and Thyone briareus, as well as the collateral evidence from other species, tend to support this view that cone formation is a response by the egg to stimulation by the acrosome fialment. This view was expressed also by Dan (1954).

\section{A Reinterpretation of Earlier Descriptions of Sperm Entry in Echinoderms}

Fol (1878-79) noted that in Asterias glacialis a slender tapering cone arose from the egg surface and grew toward the sperma- 


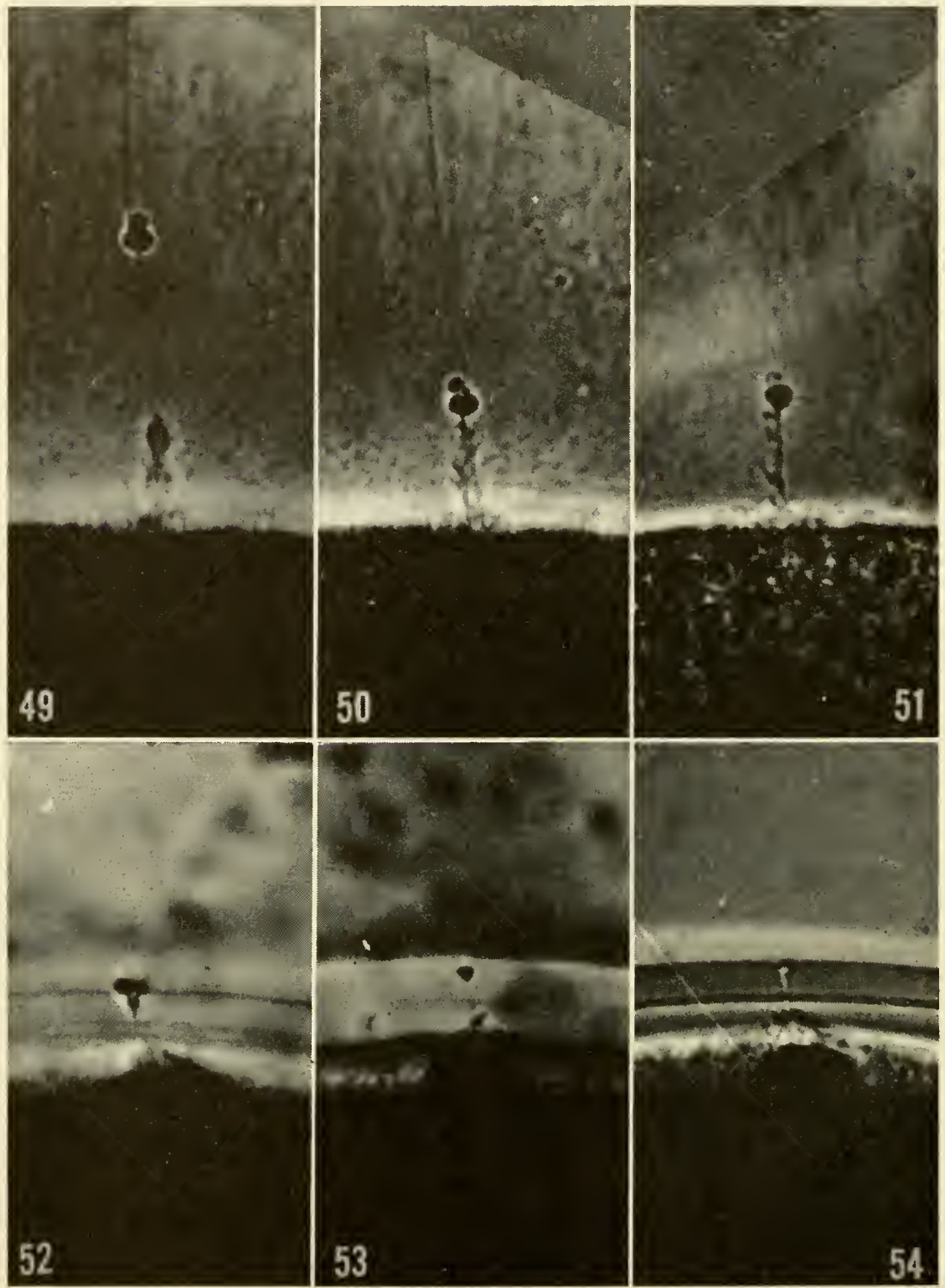


tozoon even though part of the jelly hull appeared physically to separate the spermatozoon from the egg. He conchuded that the egg must send an "attraction cone" to meet the spermatozoon. However, before reaching this conclusion Fol speculated that some connecting filament might arise from the sperm head and extend to the egg surface. He discarded this view because he could not see such a filament. It is now clear that the hypothesis rejected by $\mathrm{Fol}$ for $A$. glacialis is satisfied in Holothuria atra and Thyone briareus by the demonstration that the spermatozoon does make contact with the egg surface by means of the acrosome filament and that the cone subsequently rises around the filament. It is therefore suggested that what Fol (1877) described as a fine thread of protoplasm growing from the cone to establish communication with the spermatozoon was, in fact, a projection of the cone growing up around the acrosome filament which had already established the initial communication.

Chambers (1923, 1930), working with Asterias (forbesii?), adopted essentially the view of Fol. According to Chambers, a long straight "insemination filament" grew out from the cone to make contact with the sperm head and then contracted, dragging the sperm head through the jelly toward the cone. In fresh mature eggs, however, no cone was seen which was not already connected with the sperm head by means of a filament. It is now suggested that the filament described by Chambers in the fresh eggs was the acrosome filament and that the insemination filament which appeared to grow out to meet the sperm head in other cases was, in fact, a very slender projection of the cone

Figs. 49-54. 49-51, unretouched photographs of sperm cntry as seen in living specimens of Thyone briarens. (From Colwin and Colwin, Biol. Bull., 1956.) (Figures have had nonrelevant pieces spliced into upper portions.) Scale of Figs. 28-34 applies. Cones of slender type. Note acrosome filament within cone. 49-50, successive views of one specimen. 52-54, unretouched photographs of sperm entry in living material of Saccoglossus kowalevskii. (From Colwin and Colwin, J. Morphol. 1954b.) 52, a polyspermic egg showing a filament extending from sperm head to and into a very early cone (the heads of two nonentering spermatozoa lie outside the egg membrane). 53, a normal egg with a filament between sperm head and early cone; a narrow projection of the cone extends up the filament. 54, a normal egg with filament from sperm head apparently extending into hyaline portion of cone. 
rising around a more delicate but already established acrosome filament, as occurs in Thyone. In two of Chambers' (1930) cases there is actually evidence that an acrosome filament remains intact within the cone. In one case (his Fig. 10) the insemination filament appeared to shorten progressively until the sperm head finally reached the apex of the cone. But the head was rejected and came to lie somewhat removed from the egg surface. At that time a filament of some length extended from the tip of the sperm head. In the second case (his Fig. 19) the egg had been denuded of its jelly hull. No insemination filament was seen. However, the sperm head which entered the cone was later expelled, and after expulsion a filament extended from the tip of the head (cf. the acrosome filament within the cone of Asterias in Fig. 48g-h).

Hörstadius described long narrow cones in the egg of the starfish Astropecten aranciacus (1939a) and of the holothurian Holothuria poli (1939b). These cones were said to traverse the jelly hull and "take possession of" the spermatozoon. His sketch of the cone in this holothurian (as well as in the starfish) gives the impression that a thin filament connects the sperm head to the cone. It is now suggested that in both these cases what is portrayed is a slender cone which has risen around an acrosome filament already present as in Thyone (cf. Figs. 48a,e and Figs. 4951).

Reinterpreted thus the descriptions by Fol, Chambers, and Hörstadius fall into harmony with the general picture of spermegg association and sperm entry as they occur in Holothuria atra and Thyone briareus. The acrosome filament arises from the sperm head and projects through the jelly to the egg surface; the egg is stimulated and responds by cone formation. Depending on the species and perhaps too on the degree of maturity of the egg, the cone may vary from broad to very narrow, rise quickly or slowly and to various heights, and may or may not form advance projections. Whatever these variations may be, the cone surrounds the already established acrosome filament like a sleeve, and the filament (in some cases at least ) enters the egg proper as an essentially intact structure. 


\section{Mechanism of Sperm Entry into Egg}

Little is known of the mechanism by which the movement of the spermatozoon into the egg is effected once the acrosome filament has made its initial association with the egg. It is clear that the mechanism is not direct contraction of the acrosome filament per se, nor recession of the external part of the cone. Lillie's (1912a and 1912b) description of sperm entry in Nereis offers some indication of what the mechanism may be. As mentioned previously, Lillie noted that the "perforatorium" had the form of "the spike of a helmet" in living spermatozoa but that in fixed spermatozoa, whether free or attached to an egg, the perforatorium was a straight filament-like structure. Metz and Morrill (1955) have found that a comparable change in the acrosomal region was induced by fertilizin treatment of Nereis spermatozoa. It seems reasonable to consider, then, that Lillie's account of the behavior of the spermatozoon and its perforatorium during sperm entry is in reality an account of the behavior of the reacted spermatozoon and its acrosome filament during sperm entry. In Lillie's description based on fixed material, the "fertilization cone" becomes converted into a "specialized cell organ" identifiable by its staining reaction. The sperm head becomes "anchored" in this organ by the tip of its perforatorium (i.e., acrosome filament). This complex, consisting of sperm head and cone, moves slowly from the egg surface and penetrates more deeply into the egg. About 64 minutes after insemination the sperm head becomes separated from this cell organ. The further history of this "cone" is unknown.

Lillie's centrifuge experiments with inseminated eggs of Nereis indicate that once the sperm head is associated with the substance of the cone the relationship is a firm one. There is some evidence for such a firm relationship between the spermatozoon and the substance of the cone in Holothuria atra; in a few cases it was found that if enough pressure were applied to the coverslip to cause the cone to rupture and form an exudate, the spermatozoon within the cone was not expelled (Fig. 45). Moreover, in similar preparations in Thyone briareus, the spermatozoon 
even continued to progress inward. If, as Lillie described it, the "fertilization cone" is a cell organ which moves a considerable clistance into the egg, then one might speculate that the mechanism which effects the passage of the sperm head through the surface of the egg is the same one which effects the continued movement of the sperm head once it has entered the egg.

Lillie (1912b) considered the fertilization cone of Nereis to be quite different from the fertilization cone of echinoderms since in the latter "its significance has been, apparently, merely temporary and local, a reaction of the ovum to the spermatozoon with no definable function of its own." In the light of present knowledge this view certainly merits reconsideration. There is no doubt that the formation of an outwardly projecting fertilization cone is a normal phenomenon at least in the eggs of some species. In these the cone is not simply a result of pressure or other conditions introduced by placing eggs on a slicke and covering them with a coverslip. In Saccoglossus kowalevskii, for example, the relatively large fertilization cone may be seen with the dissecting microscope in eggs inseminated and left in ample water in open syracuse or stendor dishes. Such eggs develop normally to larval stages (Colwin and Colwin, 1953). Moreover, in at least three echinoderms, $T$. briareus, $H$. atra, and A. forbesii, the acrosome filament which initially may be seen within the outwardly projecting part of the cone subsequently moves into the egg proper. Further study of these species may reveal a mechanism similar to the one clescribed for Nereis. The great difference in time required for sperm penetration in Nereis as compared with other species may not reflect any fundamental difference in mechanism.

\section{Summary}

1. From the evidence reviewed it is clear that in certain echinoderms, molluscs, annelids, and probably an enteropneust, spermatozoa undergo a profound reaction when suitably stimulated. The most striking feature of the reaction is the production of a fairly straight, relatively rigid filament, the acrosome filament of Dan. Egg water, alkaline sea water, and the presence of unferti- 
lized eggs elicit this reaction in spermatozoa of one or more of the species studied. In some species the reaction is also elicited by "contact" with a surface and, presumably, other factors as yet unknown. Both quantitative and descriptive data are presented for the acrosome reaction as observed in living spermatozoa of Thyone briareus.

2. The length of the acrosome filament varies from species to species, ranging from about 1 micron in some sea urchins to 75 microns or more in Thyone in which it sometimes exceeds the length of the flagellum. It is suggested that in any species the length of the filament of a successful spermatozoon can never be less than the depth of the barrier which effectively separates the sperm head from the reactive egg protoplasm. The jelly hull acts as a barrier in the starfishes and holothurians studied but not in the sea urchins.

3. At the very earliest stage of sperm-egg association observed in Holothuria atra and Thyone, an acrosome filament is already present and extends through the jelly hull to an incipient cone. The cone rises around the acrosome filament to varying heights, surrounding all or part of the filament in a sleeve of protoplasm. In some cases the sleeve is so narrow as to make this portion of the cone itself seem like a filament. The acrosome filament enters the egg intact as the most anterior part of the sperm head and remains essentially unaltered in cliameter and length until well into the egg proper, at least in H. atra and probably also in Thyone. Partial evidence suggests essentially the same course of events in several starishes and an enteropneust.

4. Some of the earlier descriptions of sperm entry in echinoderms are reinterpreted as follows. The filament seen between sperm head and cone (Fol, Chambers) is not of egg origin but is the acrosome filament of the spermatozoon; the narrow cone which appears to rise from the egg to meet the spermatozoon (Hörstadius) is simply rising around the acrosome filament which has already established contact with the egg proper.

5. Little is known of the mechanism which effects the movement of the spermatozoon into the egg, but this mechanism is not direct contraction of the acrosome filament nor recession of the external part of the cone. 


\section{REFERENCES}

Afzelius, B. A. 1955. The fine structure of the sea urchin spermatozoa as revealed by the electron microscope. Z. Zellforsch., 42, 134-48. Burgos, M. H., and D. W. Fawcett. 1955. Studies on the fine structure of the mammalian testis. I. Differentiation of the spermatids in the cat (Felis domestica). J. Biophys. Biochem. Cyt., 1, 287-300.

Burgos, M. H., and D. W. Fawcett. 1956. An electron microscope study of spermatid differentiation in the toad, Bufo arenarum Hensel. J. Biophys. Biochem. Cyt., 2, 223-40.

Chambers, R. 1923. The mechanism of sperm entrance into the starfish egg. J. Gen. Physiol., 5, 821-29.

Chambers, R. 1930. The manner of sperm entry in the starfish egg. Biol. Bull., 58, 344-69.

Clermont, Y., R. E. Glegg, and C. P. Leblond. 1955. Presence of carbohydrates in the acrosome of the guinea pig spermatozoon. Exptl. Cell Research, 8, 453-58.

Colwin, A. L., and L. H. Colwin. 1953. The normal embryology of Saccoglossus kowalevskii (Enteropneusta). J. Morphol., 92, 401-54. Colwin, A. L., and L. H. Colwin. 1955a. Sperm entry and the acrosome filament (Holothuria atra and Asterias amurensis). J. Morphol., 97, 543-68.

Colwin, A. L., and L. H. Colwin. 1955b. Concerning the spermatozoon and fertilization in the egg of Sabellaria vulgaris. Biol. Bull., $109,357$.

Colwin, L. H., and A. L. Colwin. 1954a. Fertilization changes in the membranes and cortical granular layer of the egg of Saccoglossus kowalevskii (Enteropneusta). J. Morphol., 95, 1-46.

Colwin, L. H., and A. L. Colwin. 1954b. Sperm penetration and the fertilization cone in the egg of Saccoglossus kowalevskii (Enteropneusta). J. Morphol., 95, 351-72.

Colwin, L. H., and A. L. Colwin. 1955c. The spermatozoon and sperm entry in the egg of the holothurian, Thyone briareus. Biol. Bull., $109,357$.

Colwin, L. H., and A. L. Colwin. 1955d. Some factors related to sperm entry in two species of Asterias. Biol. Bull., 109, 357.

Colwin, L. H., and A. L. Colwin. 1956. The acrosome filament and 
sperm entry in Thyone briareus (Holothuria) and Asterias. Biol. Bull., 110, 243-55.

Dan, J. C. 1952. Studies on the acrosome. I. Reaction to egg-water and other stimuli. Biol. Bull., 103, 54-66.

Dan, J. C. 1954. Studies on the acrosome. II. Acrosome reaction in starfish spermatozoa. Biol. Bull., 107, 203-1S.

Dan, J. C., and S. K. Wada. 1955. Studies on the acrosome. IV. The acrosome reaction in some bivalve spermatozoa. Biol. Bull., 109, 4055.

Fol, H. 1877. Sur le commencement de l'hénogénie chez divers animaux. Arch. $\approx o o l$. exptl. et gén., 6, 145-69.

Fol, H. 1878-1879. Recherches sur la fécondation et le commencement de l'hénogénie chez divers animaux. Mém. soc. phys. et hist. nat. Genève, 26, 89-397.

Grassé, P. P., and O. Tuzet. 1933. Sur la structure du spermatozoide des metazoaires. Compt. rend. soc. biol., 113, 44-46.

Hörstadius, S. 1939a. Über die Entwicklung von Astropecten aranciacus L. Publ. staz. zool. Napoli, 17, 221-312.

Hörstadius, S. 1939b. Über die larve von Holothuria poli delle Chiaje. Arkiv Zool., 31A, No. 14.

Kupelweiser, H. 1909. Entwicklungserregung bei Seeigeleiern durch Molluscasperma. Arch. Entwicklungsmech. 27, 434-62.

Lillie, F. R. 1912a. Studies of fertilization in Nereis. I. The cortical changes in the egg. II. Partial fertilization. J. Morphol, 22, 361-93.

Lillie, F. R. 1912b. Studies of fertilization in Nereis. III. The morphology of the normal fertilization of Nereis. IV. The fertilizing powers of portions of the spermatozoon. J. Exptl. Zool., 12, 413-78.

Metz, C. B. 1945. The agglutination of Starfish sperm by fertilizin. Biol. Bull., 89, 84-94.

Metz, C. B., and J. B. Morrill. 1955. Formation of acrosome filaments in response to treatment of sperm with fertilizin in Asterias and Nereis. Biol. Bull., 109, 349.

Mèves, F. 1915. Ueber den Befruchtungsvorgang bei der Meismuschel (Mytilus edulis L.). Arch. mikroskop. Anat., 87, Abt. 2, 47-62.

Popa, G. 1927. The distribution of substances in the spermatozoon (Arbacia and Nereis). Biol. Bull., 52, 238-57.

Retzius, G. 1904. Biologische Untersuchungen. N. F. 11. G. Fischer, Jena.

Retzius, G. 1905. Biologische Untersuchungen. N. F. 12. G. Fischer, Jena. 
Retzius, G. 1910. Biologische Untersuchungen. N. F. 15. G. Fischer, Jena.

Rothschild, Lord, and A. Tyler. 1955. Acrosomal filaments in spermatozoa. Exptl. Cell Research, Supp. 3, 304-11.

Tuzet, O. 1950. Le spermatozoide dans la série animale. Rev. suisse zool., 57, 433-51.

Tyler, A. 1952. Further investigations on fertilizins of eggs of seaurchins. Anat. Record, 113, 525.

Vasseur, E. 1947. The spermatozoon of the sea urchin Echinocardium cordatum (Pennant). Arkiv Zool., 40B, No. 3. 


\title{
STUDIES OF PROTEINS OF SEA URCHIN EGG AND OF THEIR CHANGES FOLLOWING FERTILIZATION
}

\author{
ALBERTO MONROY: LABORATORY OF COMPARATIVE \\ ANATOMY, THE UNIVERSITY OF PALERMO, ITALY
}

The activation of the egg consists fundamentally in the release of the metabolic reactions which are responsible for the initiation of morphogenesis. To learn how this is accomplished is the aim of the investigations of the physiological and biochemical basis of morphogenesis.

It therefore appears important to investigate the kind of changes that take place in the various systems of the egg upon fertilization since such analysis may help a great deal in understanding the basic mechanisms of the activation. The study of the changes occurring in the proteins of the egg is obviously one of the most interesting to pursue since it is at the protein level that differentiation takes place and therefore it is hoped that it may eventually help to uncover the basic events of differentiation.

This study, although still at an early stage, inclicates that immediately following fertilization a process of rearrangement of the whole protein pattern of the egg is started. On the other hand, different lines of investigation give consistent evidence that protein synthesis is started much later in development (Perlmann and Gustafson, 1948; Perlmann, 1953; Hobermann, Metz, and Graff, 1952; Hultin, 1953).

The starting point for the study of the changes of the egg proteins following fertilization was the observation of Mirsky (1936) that in the sea urchin eggs a conspicuous decrease of solubility of a protein fraction takes place during the first ten minutes after fertilization. Mirsky showed, in fact, a $12 \%$ de- 
crease of the proteins soluble in $1 M \mathrm{KCl}$, and he was also able to trace this fraction in the extracts of unfertilized eggs as the one that is precipitated by $50 \%$ saturation with ammonium sulfate.

Later the present writer and his co-workers undertook a systematic investigation of the changes taking place in the proteins of the egg upon fertilization. The results of these investigations are summarized here.

Water extracts of sea urchin eggs were submitted to electrophoretic analysis, and it was shown that a few minutes after fertilization a small new component appears. However, this component is no longer detectable thirty minutes after fertilization.

The extracts were then fractionated with ammonium sulfate, and the fractions were studied electrophoretically. The following facts were established: $(a)$ a decrease in solubility of one component immediately after fertilization and $(b)$ a splitting of a component present in the unfertilized eggs, thus giving rise to a new component (Monroy, 1950). Further changes of solubility were also shown to take place, but on the whole these were somewhat irregular and hence difficult to interpret (Monroy and Monroy-Oddo, 1951).

In the first investigations of Mirsky and in those of the present writer, lyophilized eggs were used. This introduces the possibility of artifacts. Hence in subsequent work only fresh material has been used, and special precautions have also been taken to avoid secondary alterations during preparation (Giardina and Monroy, 1955; Ceas, Impellizzeri, and Monroy, 1955). In the latter investigations attention was focused on a fraction which is precipitated by $50 \%$ saturation with ammonium sulfate. Three components are indicated in this fraction by the electrophoretic analysis. Upon treatment with trypsin the fraction prepared from unfertilized eggs is split into five components, whereas the one prepared from fertilized eggs is split into four components (Fig. 1) (D’Amelio, 1955). Comparable results were obtained when the action of trypsin on these proteins was followed by chemical determinations (Fig. 2) (Giardina and Monroy, 1955). Proteins from unfertilized and fertilized eggs also behave differently in 
respect to heat denaturation. To distinguish between denatured and nondenatured proteins the solubility in an acid buffer of high molarity was used. This buffer has been shown to induce precipitation of denatured lactoglobulin and serum albumin, whereas when they are in the native condition these proteins stay in solution (Christensen, 1952). In the case of the sea urchin egg extracts, a large proportion of the extracted proteins is precipitated by the buffer without any previous denaturing treatment, and the amount of precipitate is greater in the case of the unfertilized eggs. Although this result does not allow one to draw any conclusion as to the condition that makes such proteins susceptible to the salt buffer, it is nevertheless indicative of a differ-

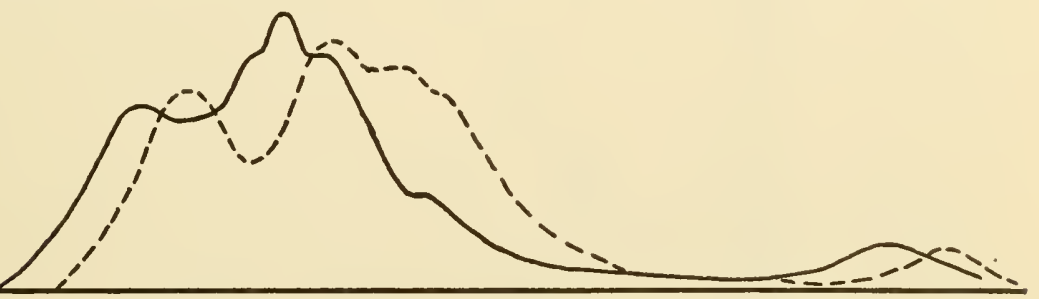

Fig. 1. Electrophoretic patterns after trypsin digestion of the fraction precipitated at $50 \%$ saturation of ammonium sulfate from an extract of unfertilized (solid line) and fertilized (dotted line) eggs. (Redrawn from an experiment of D'Amelio.)

ence between the proteins of the unfertilized and of the newly fertilized eggs. A difference between the two is also shown by mere inspection of the precipitate which is flocculent and rapidly settling in the former, whereas in the latter it is finely dispersed, takes some time to appear, and settles only very slowly. The total amount of precipitable proteins upon heating between $50^{\circ}$ and $60^{\circ} \mathrm{C}$. followed by addition of the buffer is significantly greater in the extracts of unfertilized than in those of fertilized eggs. The same result has been obtained with the fraction precipitated by $50 \%$ saturation with ammonium sulfate (Giardina and Monroy, 1955). Two alternative explanations were presented to account for these results, i.e., either a change occurred in the molecular configuration of some proteins or a splitting of a large complex present in the unfertilized egg took place. It was shown 
that the intrinsic viscosity of the protein fraction isolated by precipitation by $50 \%$ saturation with ammonium sulfate does not vary upon fertilization, thus inclicating that no appreciable changes of shape and or hydration of these protein molecules occurs at fertilization. However, the increase of viscosity induced by urea was considerably greater in the fraction extracted from fertilized than in the one from unfertilized eggs, and a greater

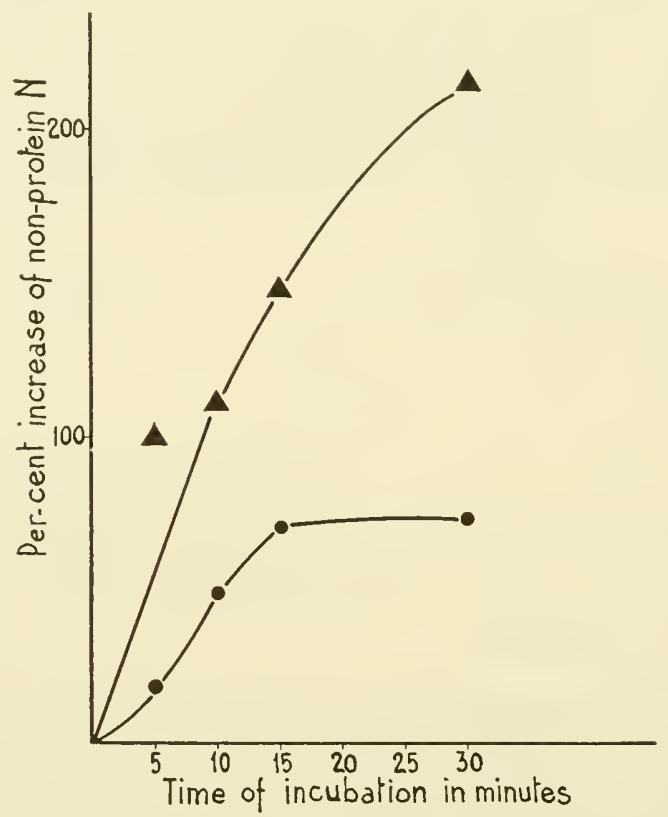

Fig. 2. Release of nomprotein $\mathrm{N}$ from the fraction precipitated at $50 \%$ saturation of ammonium sulfate from an extract of unfertilized ( $\mathbf{A}$ ) and fertilized (-) eggs of Arbacia lixula during trypsin digestion. (Calculated from the data of Giardina and Monroy.)

amount of phenolic groups was exposed in the former than in the latter as a result of this treatment (Ceas, Impellizzeri, and Monroy, 1955 ).

These experiments give evidence that, although no changes in the molecular configuration of the proteins of our fraction after fertilization has been demonstrated thus far, these molecules seem to undergo some sort of internal rearrangement. The ex- 
periments with urea suggest that in these molecules H-bonds may be more exposed after fertilization. The new configuration appears to render them less susceptible to the attack of trypsin and less easily denatured by heat.

A question of considerable importance is whether as a part of this process, end groups, viz., peptides or amino acids, are split off. Some years ago Örström (1941) gave evidence of a slight but statistically significant increase of the nonprotein $\mathrm{N}$ during the first ten minutes following fertilization. A reinvestigation of this problem is now in progress in our laboratory. A positive answer to it would make one consider the interesting analogy between activation of the egg at the level of the protein molecules and the activation of some enzymes (e.g., pepsin) in which it is known that the transition from the pro- to the active enzyme is accompanied by the splitting off of a terminal peptide. One could then speak of an activation of the egg proteins upon fertilization. It is interesting to recall here that Hultin (1950) found a considerable acceleration of the turnover of the egg proteins after fertilization.

On the basis of some model experiments, a working hypothesis has been presented concerning the nature of the cortical reaction in the activation of the sea urchin egg (Maggio and Monroy, 1955; Monroy, 1956). It has been suggested that the key reaction of the activation of the egg is the release, followed by the inactivation, of a lysophosphatide-like substance in the cortex of the egg as a result of the reaction with the fertilizing sperm or of any activating treatment. It has also been shown (Tyler, Monroy, Kao, and Grundfest, 1956) that coincident with fertilization a change of the membrane potential of the egg occurs. However, how this group of early phenomena can possibly be linked to the changes in the proteins of the egg is at present obscure.

\section{REFERENCES}

Ceas, M. P., M. A. Impellizzeri, and A. Monroy. 1955. The action of urea on some proteins of the unfertilized and fertilized sea urchin egg. Exptl. Cell Research, 9, 366-69.

Christensen, L. K. 1952. Denaturation and enzymatic hydrolysis of 
lactoglobulin. Compt. rend. trav. lab. Carlsberg, Sér. chim., 28, 37169.

D'Amelio, V. 1955. Trypsin sensitivity of some proteins of the sea urchin egg before and after fertilization. An electrophoretic analysis. Experientia, 11, 443.

Giardina, G., and A. Monroy. 1955. Changes in the proteins of the sea urchin egg at fertilization. Exptl. Cell Research, 8, 466-73.

Hobermann, H. D., C. B. Metz, and J. Graff. 1952. Uptake of deuterium into proteins of fertilized and unfertilized Arbacia eggs suspended in heavy water. J. Gen. Physiol., 35, 639-43.

Hultin, T. 1950. The protein metabolism of sea urchin eggs during early development studied by means of $\mathrm{N}^{15}$-labeled ammonia. Exptl. Cell Research, 1, 599-602.

Hultin, T. 1953. Metabolism and determination. Proc. Symposium on the Biochemical and Structural Basis of Morphogenesis in Arch. néerl. zool., 10 (Suppl.), 76-91.

Maggio, R., and A. Monroy. 1955. Some experiments pertaining to the chemical mechanisms of the cortical reaction in fertilization of sea urchin egg. Exptl. Cell Research, 8, 240-44.

Mirsky, A. 1936. Protein coagulation as a result of fertilization. Science, 84, 333-34.

Monroy, A. 1950. A preliminary electrophoretic analysis of proteins and protein fractions in sea urchin eggs and their changes on fertilization. Exptl. Cell Research, 1, 92-104.

Monroy, A., and A. Monroy-Oddo. 1951. Solubility changes of proteins in sea urchin eggs upon fertilization. J. Gen. Physiol., 35, 245-53.

Monroy, A. 1956. Some experiments concerning the chemical mechanisms of the activation of the sea urchin egg. Exptl. Cell Research, 10, 320-23.

Örström, A. 1941. Über die Stickstoffraktionen im Ei von Paracentrotus lividus vor und nach der Entwicklungserregung und ïber ihre Bedeutung für den osmotischen Druck und Stoffwechsel. Arkiv Kemi, Mineral. Geol., 15A, No. 1.

Perlmann, P., and T. Gustafson. 1948. Antigens in the egg and early developmental stages of the sea urchin. Experientia, 4, 481-83.

Perlmann, P. 1953. Soluble antigens in sea urchin gametes and developmental stages. Exptl. Cell Research, 5, 394-99.

Tyler, A., A. Monroy, C. Y. Kao, and H. Grundfest. 1956. Membrane potential and resistance of the starfish egg before and after fertilization. Biol. Bull., 111, 153-75. 


\title{
NUCLEOCYTOPLASMIC RELATIONS \\ IN EARLY INSECT DEVELOPMENT*
}

\author{
R. C. VON BORSTEL: BIOLOGY DIVISION, OAK RIDGE \\ NATIONAL LABORATORY, OAK RIDGE, TENNESSEE
}

Experimental study of interaction between the nucleus and cytoplasm in development had its origin in the analyses of Boveri (1907) on sea urchins, which showed that alteration of the chromosome complement disrupted development. The role of the cytoplasm has been heavily emphasized by such studies as the classical research of Conklin on ascidian embryos (1931). Fankhauser $(1952,1955)$ has comprehensively reviewed nucleocytoplasmic relations in development of animals other than insects. Since certain aspects of development are revealed with greatest clarity in the insect embryo, and since the genetic background is so well known in certain species, it would seem that information of general interest would be derived from an experimental study of insect development. The work described here is confined for the most part to the parasitic wasp Habrobracon; the results are used wherever possible to illustrate general principles of development. The embryology of the young system is presented primarily from cytogenetic and cytochemical points of view. Some of the conclusions drawn from the work described depend on a study of gynandromorphs and genetic mosaics, and most of the remainder rely on interpretations of the action of radiation.

In insects as in other animals, the first mitotic divisions are rapid and result in many nuclei within many cells, which constitute a pool utilized during tissue formation. As in all animals, much depends on the particular code within the genome at the outset of embryogeny, by which a wild-type Drosophila can be mutated into a mottled peach, a Mormoniella into an oyster, or

* Work performed under USAEC contract No. W-7405-eng-26. 
a Habrobracon into a black dahlia. Superficially, it would appear that the interaction of cells and cellular components that occurs in embryogenesis has its basis in this coded information contained in the genetic nucleus. The simplest model would be an evolving system in which the yolk acts as a nutrient medium and the cytoplasm as a transport system that funnels nourishment to the nucleus and utilizes information from it. Inasmuch as development of such systems as legs, eyes, wings, antennae, the thorax, and abdomen are under control of the genetic nucleus, by the doctrine of obvious hypothesis, the entire differentiation system has its basis in the genetic nucleus as well. That this model is too simple, however, is apparent upon consideration of determinate development in which egg regions are predestined prior to the existence of nuclei in these regions. The egg cytoplasm guides the totipotent nuclei into specified but not completely fixed channels of development. The final fixation is a nuclear function. The cytoplasm in determinate eggs therefore must be a repository for a different order of informational organization from that of the nucleus. Since regulative and mosaic development are essentially alike (Penners, 1924; Tyler, 1930), a general model for illustrating development should include a directive action of fixed extent in the cytoplasm.

We are interested in the early development of the egg and embryo because the potential exists here for the differentiated, fully developed organism. Before an egg can be activated, its development must be inhibited; prior to embryonic differentiation, the potentialities must exist. By analyzing several components of the predifferentiation system, perhaps the entire embryonic organism will be more clearly understood. As the provisional model, the young embryo will be considered as a substrate pool for an itinerant nucleus with reproduction as its sole activity until diverted by a determined cytoplasm.

\section{General Considerations}

The experimental animal most often referred to is Habrobracon juglandis (Ashmead), a small Braconid wasp that parasitizes the larva of the Mediterranean flour moth Ephestia kïhniella Zeller. 
The females of Habrobracon are diploid and the males are haploid-unfertilized eggs become haploid males, females originate from fertilized eggs. When eggs are fertilized by sperm containing the same sex alleles as the egg pronuclei, diploid males result (P. W. Whiting, 1943b). This sex determination mechanism appears to occur also in the honey bee, Apis mellifera L. (Mackensen, 1951, 1955).

The morphology of meiosis and early embryogeny of Habrobracon has been studied in detail by Torvik-Greb (1935), Henschen (1928), and Speicher (1936). The description given in this review is, for the most part, summarized from the analysis of Speicher. Oogenesis in most insects differs from this form only in details (Wilson, 1928; Sonnenblick, 1950); the description here is restricted to Habrobracon. The female has four ovarioles, each with a uterine sac where mature eggs are stored prior to oviposition (Fig. 1). "One ovariole with attached uterine sac is shown in Fig. 2. The egg arises from a nest of 32 oogonia, 31 of which become nurse cells. (Henschen, 1928, reported a nest of 16 oogonia, but as is apparent from the number of heavily staining nuclei in Fig. 3, more than 15 nurse cells normally exist.) During oocyte growth the nurse cells grow too. While the oocyte becomes larger the oocyte nucleus proceeds through the long first meiotic prophase, and the nurse cell nuclei go through several cycles of polysomatic enlargement; the nuclei in nurse cells next to the oocyte are somewhat larger than the nurse cell nuclei farthest from the oocyte. Just prior to entrance of the egg into the uterine sac from the ovariole, the nuclei of the nurse cells disintegrate and are injected into or are engulfed by the egg (Fig. 4). It has been suggested (Painter, 1940; Zeuthen, 1951) that this broken down deoxyribonucleic acid is incorporated into nuclei during the ensuing rapid mitoses. The point might be raised that some of the genetic structure could be passed intact from the deoxyribonucleic acid of the mother to the nuclei of the embryo. This would be equivalent to transformation (Hotchkiss, 1955) and has not been observed. Most of the deoxyribo-

- The photomicrographs (Figs. 1-4) were made by Henry H. Jones, of the Carnegie Institution of Washington, Cold Spring Harbor, N. Y. 

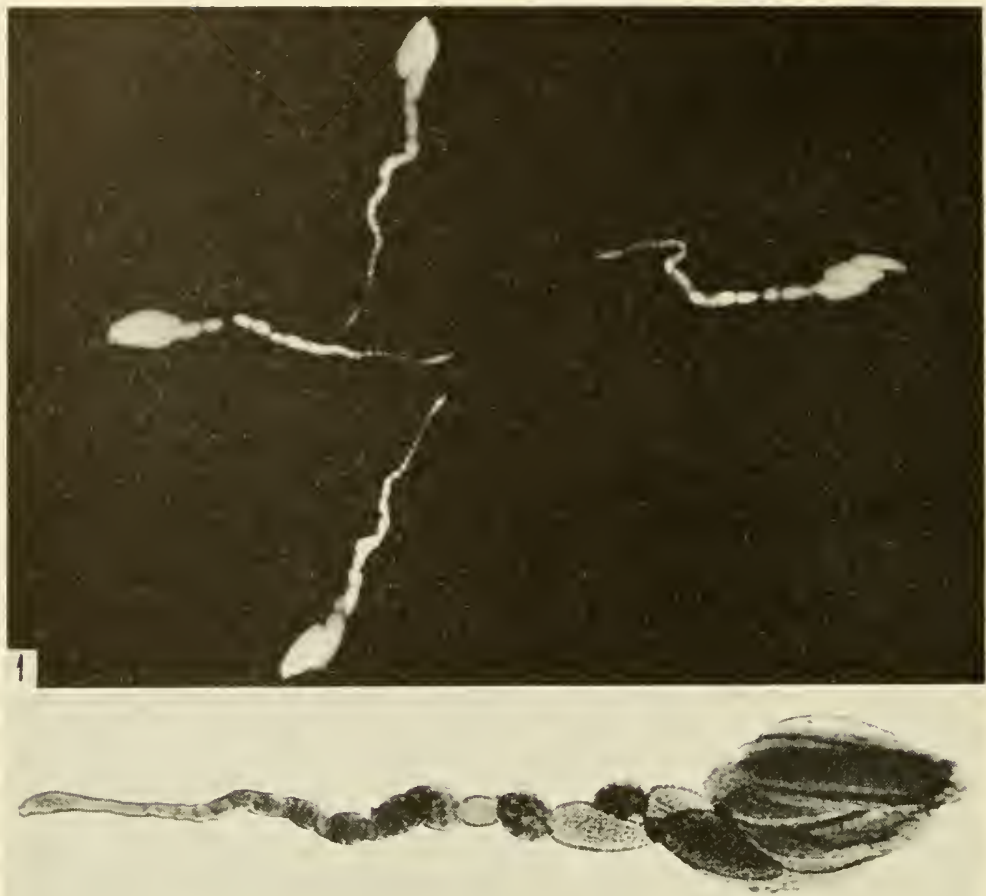

2

3

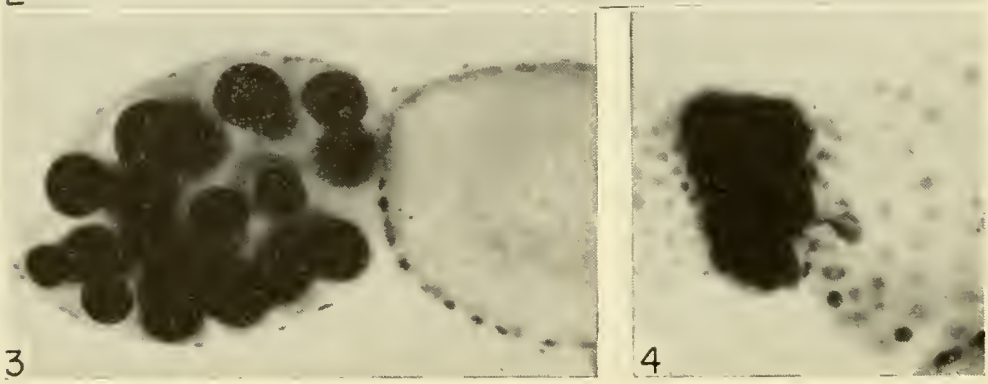

Fig. 1. The four ovarioles from a Habrobracon female immediately after removal from abdomen. $\times 10$

Fig. 2. Ovariole from a well-fed Habrobracon female showing stages in development of eggs. Mature eggs in uterine sac at right. $\times 40$

Fig. 3. Posterior end of developing egg with nurse cells attached. Nuclear stain employed. $\times 250$

Fig. 4. Disintegrating nurse cell nuclei being engulfed into developing egg; smaller stained bodies are follicle cell nuclei on egg periphery. $\times 250$ 
nucleic acid from the nurse cells has broken down into units soluble in hot acid. This implies that it is in the form of mononucleotides or oligonucleotides of low order. Since most of the deoxyribonucleic acid is probably in small units, this could account for failure to find transformation, which would be a predictable consequence of incorporation of large blocks of deoxyribonucleic acid from nurse cells. Also, except under unusual circumstances, nuclear mutation reflected in the phenotype can be only of an order that is not reparable by cytoplasmic deoxyribonucleic acid. After nurse cell incorporation, the mature egg
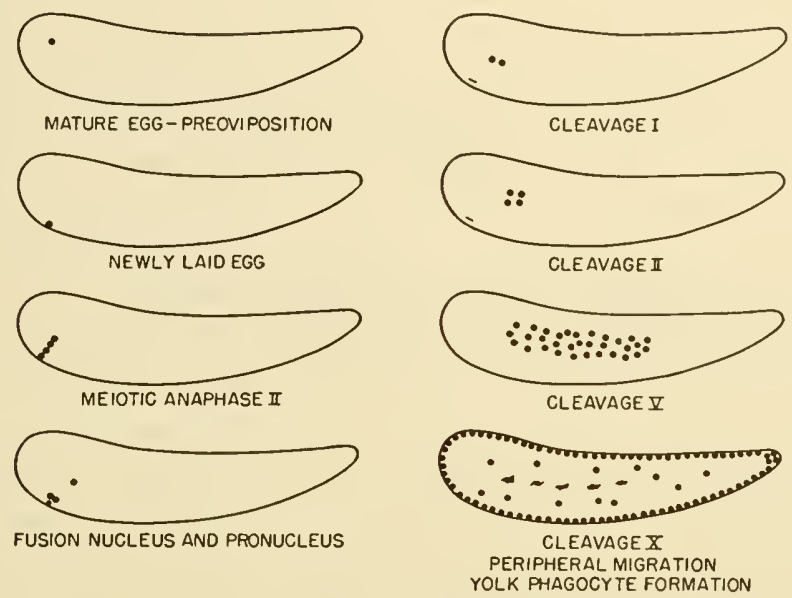

Fig. 5. Diagrammatic representation of nuclear activities during meiosis, nuclear cleavage, and peripheral migration in the Habrobracon egg.

now resides in the uterine sac, and the oocyte nucleus proceeds through diakinesis and metaphase. Meiosis is blocked at late metaphase or early anaphase of the first meiotic division, and the egg is ready to be oviposited.

The egg is 600 microns long and 150 microns across at its widest place. It is concave-convex in shape and the anterior end of the embryo is the widest. The egg is positioned at least partially in accordance with the orientation law of Hallez (1886), that is, with the anterior end of the future embryo pointing toward the anterior end of the mother while residing in the uterine 
sac. This seems more a fortuitous circumstance than an actual requirement, however, since eggs will occasionally emerge anterior end first; several have been closely observed and all developed normally. Much of the cytoplasm is distributed in a layer 5 to 10 microns thick around the egg periphery, and the rest is threaded through the yolk that constitutes the major portion of the egg. The nucleus of the unlaid egg lies in the egg interior at the anterior end (see Fig. 5). When oviposition takes place, the egg is tightly squeezed through the ovipositor and emerges with the nucleus now lying against the convex (ventral) surface at the anterior end. It has been suggested that the act of squeezing displaces the nucleus and activates the egg into resumption of normal development. The egg obviously is not activated by sperm since fertilization is not necessary for normal development. The mechanical interpretation of egg activation is merely a recording of observed events in sequence. It would seem that until eggs can be removed from uterine sacs and artificially activated the activation process will not be fully understood.

After oviposition the first meiotic division begins and the chromosomes go through a brief interphase, which is quickly followed by the second division. The divisions leave the four meiotic nuclei in a linear quartet perpendicular to the egg surface, all within the egg. The outer polar nucleus quickly disintegrates, the two middle polar nuclei fuse and form an abortive metaphase plate, and the inner nucleus becomes the functional pronucleus. At $30^{\circ}$, meiosis is completed in thirty minutes after oviposition.

The pronucleus migrates into the egg interior, and nuclear cleavages quickly begin. If the egg is fertilized, the sperm nucleus comes to lie beside the egg nucleus and forms a double metaphase plate, a characteristic not observed in later cleavages. Nuclear cleavage is a rapid, orderly, and at first completely synchronous process. During later cleavages, nuclei in the anterior end divide somewhat sooner than nuclei in the posterior end. This partial asynchrony is not an artifact, since it is observed whether fixation is done at $50^{\circ}, 2^{\circ}$, or $-83^{\circ}$, or whether either end is punctured before fixation. At the tenth cleavage, when 
approximately 1024 nuclei are present, the first signs of blastulation appear. Some cleavage nuclei remain in the egg interior while the great majority migrate to the periphery. The nuclei in the interior stain more intensely and, as cells, are known as yolk phagocytes or vitellophags (see Sonnenblick, 1950, for review). The nuclei at the periphery undergo several more synchronous divisions, cell membrane formation takes place, and tissue differentiation begins.

Several questions can be asked about relations between the nucleus and cytoplasm. Our work with Habrobracon and studies done in other laboratories on other insects have provided answers for some of these questions.

1. The four meiotic nuclei are apparently all genetically equipotent. Since all four remain inside the egg, why does only one take part in further development?

2. Is there any condition by which accessory sperm can take an active part in development?

3. Can the young embryonic system be regarded as a pool in which mitosis freely occurs (the "pure culture of mitoses" of Zeuthen, 1951) until blastulation, or do critical periods exist during the cleavage stages?

4. What component of the cytoplasm is the agent of determinate development?

5. Is there any general method by which one can distinguish between action of the nucleus and the cytoplasm in bringing about an embryonic event?

\section{Genetic Control of the Meiotic Block}

Genetic Mosaics. During a routine testing following an irradiation experiment, a curious mutant was discovered. When this mutant stock was inbred, a relatively high incidence of mosaicism resulted. These are mosaics in the genetic rather than the embryological sense. In this stock, a virgin female heterozygous for a semidominant body color gene (designated as "lemon lethal"), which is a pupal lethal when homozygous, will occasionally produce haploid male offspring that are made up of nuclei carrying the normal allele and nuclei carrying the mutant 
allele. Sometimes half the animal bilaterally is lemon lethal, and the other half wild type, each region being autonomous. At other times, certain portions of the body or head are lemon lethal with the rest wild type; or the inverse occurs where only a small patch of wild-type tissue is present on the adult animal. The lethal effect of the gene is nonautonomous, and a male will eclose if only a small patch of wild-type tissue is present. The hereditary background necessary for production of the mosaics is not fully understood at present; not all females of the lemon lethal stock produce mosaics, but when one female is a mosaic producer she
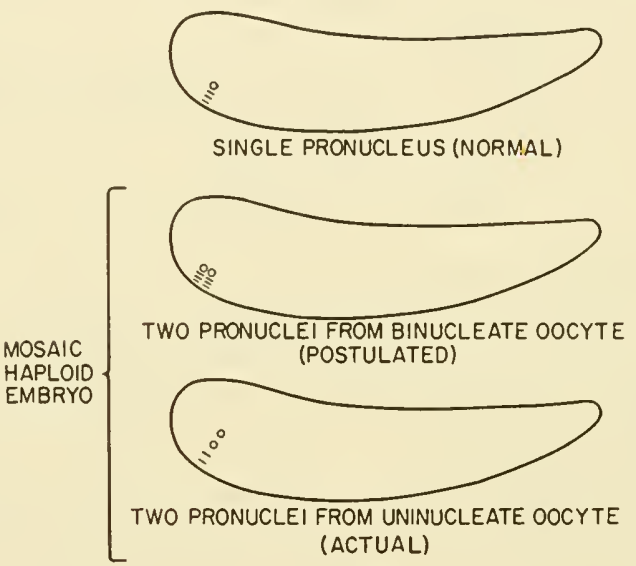

Fig. 6. Representation of normal meiosis, meiosis in a binucleate oocyte, and meiosis in which two meiotic products become pronuclei.

tends to produce others. Gynandromorphs from virgins are rare, but they also occur.

In any event, the occurrence of a haploid mosaic male means that the egg from which it originated was binucleate. In which sense is it binucleate-two oocyte nuclei undergoing meiosis side by side, or two meiotic products from one oocyte nucleus becoming cleavage nuclei (Fig. 6)? In a cytological investigation of oocytes from females that produced mosaic males, no more than one nucleus was observed in any developing oocyte; however, in several cases, eggs were observed which were not blocked at the first meiotic metaphase. Meiosis was continuing 
past metaphase $\mathrm{I}$ in eggs still in the uterine sacs, a condition never observed in females from other stocks. Meiosis in these cases was observed to be continuing in the interior of the anterior portion of the egg, where the blocked metaphase nucleus usually lies. The phenomenon of uninhibited meiosis would seem to be as rare an occurrence as mosaic production. Since in our study only those females that show uninhibited meiosis also produce mosaics, and vice versa, it seems justifiable to correlate continuation of meiosis in the egg interior with mosaic production and to conclude that the faulty meiotic block is in some way responsible for incluction of mosaics. In agreement with this conclusion, P. W. Whiting (1932) found a wasp that was mosaic for reciprocal crossover types, indicating two pronuclei from the products of a single meiosis. It is conceivable that, if meiosis does not occur at the egg surface, cleavage nuclei of two meiotic nuclei or more (P. W. Whiting, 1934) might survive destruction. Furthermore, this indicates that in normal eggs some agent present in the cortical cytoplasm must be responsible for disintegration of the most peripheral polar nucleus and inhibition of further division of the fusion nucleus. The chromosome set that will become the pronucleus pushes farther into the interior at each meiotic division and escapes destruction. The simplest explanation then is that, in mosaics, two or more meiotic nuclei must have escaped destruction by some agent in the egg cortex.

That the egg cytoplasm can be incompatible to foreign nuclei has been shown by the interesting cytological analysis of Tchou-Su (1931). Working with amphibian eggs, he has shown that foreign sperm can be destroyed by cytoplasm in a number of different ways before fusion of the egg pronucleus and the foreign sperm nucleus can take place. Namney (1953), by centrifuging Tetrahymena undergoing conjugation, was able to demonstrate that the position of the meiotic products in the cytoplasm determined the later behavior of the nuclei. The cytoplasm in this case certainly has a critical role in directing nuclear events.

The most famous mosaics are the Eugster gynandromorph honey bees, which were discovered in the middle of the nineteenth century and were puzzled over for the next seventy years. 
Boveri (1915) studied them and concluded that the male parts were inherited from the mother and the female parts from both parents. He suggested that the sperm had not united with the egg pronucleus but with one of the cleavage nuclei (Fig. 7). The discovery by P. W. Whiting (1924) of a haploid mosaic male, mosaic in traits inherited from a heterozygous mother, prompted the hypothesis that two products of meiosis had survived and the eggs were binucleate. In 1932, P. W. Whiting discovered a Habrobracon gynandromorph in which the female part came from the sperm and one set of the heterozygous mother's markers

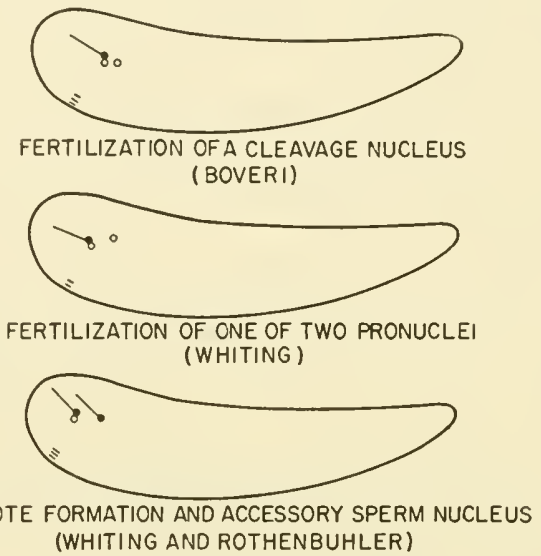

Fig. 7. Diagrammatic representation of three possible mechanisms for gynandromorph formation in Hymenoptera.

whereas the male portion came from the other set of the mother's markers. This gave strong support to the hypothesis that gynandromorphs resulted from fertilization of one of the meiotic products of a binucleate egg (Fig. 7). This is an acceptable alternative to Boveri's hypothesis of fertilization of the cleavage nuclei, and, in explaining the origin of this Habrobracon gynandromorph, Boveri's hypothesis fails.

Meiotic Block. The meiotic block in Habrobracon must be under genetic control, since lack of control is inherited in the lemon lethal stock. Other than this, little is known. Is the block intrinsic? Is there some agent in the egg cytoplasm which inhibits 
meiosis or does there exist some extrinsic factor produced by the female such as that described by Humphries (1955) in frogs? Humphries' discovery that a low frequency of the frog eggs prevented from going down a tied-off oviduct would pass through meiosis uninhibited suggests that a substance secreted by the oviduct causes the block. The altemative hypothesis is still possible although it is less likely that inhibition is intrinsic and does occur; something in the coelom then activates the frog eggs. The possibility that the inhibiting mechanism in the case of the Habrobracon egg is built into the egg is more attractive than extrinsic control, but no evidence that can help in solving this problem is yet available.

\section{Karyokinesis}

In the consideration of the stage of development between one nucleus prepared for cleavage and several thousand nuclei, three items will be examined briefly: (1) prevention of cleavage of accessory sperm, (2) mitosis in broken eggs and egg exudates, and (3) feulgen-negative nuclei in irradiated eggs.

In embryogeny proper, of utmost interest is the problem of nondivision of accessory sperm. Rothschild (1954) has briefly considered prevention of polyandrous syngamy (Type II Inhibition of Polyspermy) in marine eggs and vertebrates, but he had very little to say about insects. The accessory sperm in insects do not cleave independently of the zygote nucleus. That sperm nuclei are capable of cleavage, however, has been demonstrated in Habrobracon by A. R. Whiting (1948), who obtained androgenetic male offspring from fertilization of heavily irradiated eggs. In these embryos, the egg pronucleus was held back by chromosome bridges and was unable to fuse with the sperm nucleus; the sperm nucleus cleaved normally. Polyspermy is unusual but not rare in Habrobracon. It occurs in approximately $1 \%$ of the eggs (Speicher, 1936). Gynandromorphs are much less frequent than would be expected if all nuclei in dispermic eggs normally developed. P. W. Whiting (1943a) discovered a strain of Habrobracon that normally produced gynandromorphs with androgenetic parts; Rothenbuhler et al. (1952) discovered a simi- 
lar mutant in the honey bee Apis mellifera. The implications are obvious. An accessory sperm nucleus cannot, in general, undergo cleavage as readily as a zygote nucleus, but some genetic difference in Whiting's and Rothenbuhler's stocks allows both the accessory sperm nucleus and zygote nucleus to enter cleavage (Fig. 7). Rothenbuhler (1955) has found that the genetic factor for allowing sperm nuclei to be equipotent with zygote nuclei in their ability to enter cleavage has as its basis a modified form of cytoplasmic inheritance. Oddly enough, the influence can be built up in other stocks after several generations of matings by males from the gynandromorph-producing strain (Rothenbuhler, 1955; Rothenbubler and Gowen, 1955). This is indeed very interesting and, as an ideal nucleocytoplasmic interaction, no better example can be found. Normally, an influence must exist in the egg cytoplasm which prevents excess sperm nuclei from dividing as soon as a zygote nucleus forms; this indicates that a substance diffuses with extreme rapidity from zygote nucleus to cytoplasm to sperm. It appears that the mutant honey bee lacks the ability to produce the diffusible agent. Fankhauser (1925) demonstrated the existence of a similar condition in amphibian eggs by a series of elegant experiments in which he separated by constriction an accessory sperm nucleus from the activated zygote nucleus.

Several experiments have been carried out by the author in which organization of the Habrobracon egg has been radically disrupted by breaking the egg and forcing the egg nucleus into the exudate. Of utmost interest is that mitosis under such conditions can occur at all. A typical experiment begins when timed eggs have just finished meiosis. Each egg was torn from one end to the other and quickly covered with mineral oil to prevent evaporation. After being incubated for 1 hour longer, the eggs were fixed and stained. In most cases, the nuclei were in the exudate and freely dividing when fixed. Extended experiments have been performed on eggs that were broken and in which cleavage was allowed to continue within the broken membranes (Table I). When newly oviposited eggs were broken widely at their posterior ends and covered with mineral oil to prevent 
dehydration, 47 of $63(74.6 \%)$ of the eggs were capable of further development. Thirty-three of $47(70.2 \%)$ of the eggs examined proceeded as far as the sixth or seventh cleavage stage. Nineteen of $36(52.8 \%)$ of the eggs reach the blastula stage. Of those that develop at all but still die before blastulation, most die

TABle I. Development in Habrobracon Eggs Broken at Completion of Meiosis (30 minutes after oviposition at $30^{\circ}$ )

\begin{tabular}{|c|c|c|c|c|c|}
\hline & \multicolumn{5}{|c|}{ Time when development interrupted, hr. } \\
\hline & 1 & 1.5 & 2 & 3 & 4 \\
\hline Stage of control & $\begin{array}{c}2 \mathrm{nd} \\
\text { cleavage }\end{array}$ & $\begin{array}{c}4 \text { th } \\
\text { cleavage }\end{array}$ & $\begin{array}{c}\text { 6th } \\
\text { eleavage }\end{array}$ & $\begin{array}{l}\text { 1-cell } \\
\text { layered } \\
\text { blastula }\end{array}$ & $\begin{array}{c}2 \text {-cell } \\
\text { layered } \\
\text { blastula }\end{array}$ \\
\hline $\begin{array}{l}\text { Total broken embryos } \\
\text { Total of embryos } \\
\text { stopped at differ- } \\
\text { ent nuclear cleav- } \\
\text { age stages }\end{array}$ & 9 & 7 & 11 & 15 & 21 \\
\hline 1 st & 1 & 3 & 2 & 6 & 4 \\
\hline 4 th & - & - & 0 & 1 & 1 \\
\hline 6 th & - & - & - & 1 & 3 \\
\hline 7th & - & - & - & 0 & 1 \\
\hline $\begin{array}{l}\text { Broken eggs showing } \\
\text { normal develop- } \\
\text { ment }\end{array}$ & 8 & 4 & 9 & 7 & 12 \\
\hline $\begin{array}{l}\text { Percentage normal de- } \\
\text { velopment }\end{array}$ & 88.9 & 57.2 & 81.8 & 46.7 & 57.2 \\
\hline
\end{tabular}

between the fourth and eighth cleavage stages. It would appear from these limited data that the stages around the sixth cleavage are partially critical for nuclei in rapid division.

Another characteristic of the sixth or seventh cleavage stage that indicates a critical period of embryogeny is illustrated by a specific action of radiation or nitrogen mustard on eggs or sperm manifested at that time (von Borstel, 1952, 1953b, 1955). When metaphase I eggs are irradiated with $10,000 \mathrm{r}$, a dose below that which is injurious to cytoplasm as indicated by induced androgenesis (A. R. Whiting, 1955), nearly all the embryos die at the same stage, the sixth or seventh cleavage. The 
conditions of death are unusual. After irradiation of the females, the eggs are oviposited, and meiosis proceeds at the usual rate. Mitosis slowly takes place through two to four cleavages and then nuclear division is blocked for several hours. At approximately the seventh or eighth hour after oviposition, feulgen-negative nuclei are seen here and there in the egg interior. When the total number of nuclei reaches approximately 64 or 128 per egg - the sixth or seventh cleavage-division is blocked completely. The nuclei immediately begin to enlarge, occasionally reaching a size 200 times their normal volume. The nuclei contain protein, but deoxyribonucleic acid, as shown by the feulgen reaction and other methods, is lacking (von Borstel, 1953a, 1955).

This answers the third question, which refers to critical periods during the cleavage stages. When the egg is placed under stress from radiation or breaking, some condition present at the sixth cleavage appears to be some sort of barrier to further development. Furthermore, it is of interest to note that, in those embryos that get past this cleavage stage (for radiation effects, lower doses are used), development will proceed to the blastula stage at least. Critical periods during cleavage occur normally in Sciara (Du Bois, 1933; Metz, 1938) where the "limited" chromosomes are eliminated at the fifth or sixth cleavage and the sex chromosomes are eliminated at the seventh or eighth cleavage. That critical periods exist during rapid cleavage is apparent; the mechanisms involved are unknown. It is clear from study of the broken IIabrobracon eggs that the organization of non-nuclear elements is vital; it is apparent from the radiation experiment that the nucleus is also involved. It seems possible that some basic interaction between the nucleus and cytoplasm or some switch in nuclear and cytoplasmic function occurs at this stage of development in Habrobracon.

\section{The Nucleus and Cytoplasm in Determinate Development}

Depending on the insect, the age of the embryo, and the type of experiment, early insect development has been shown to be completely regulative, completely determined, or somewhere in between. Seidel and his school (see Seidel et al., 1940, for review) 
laid the groundwork for experimental study of insects; their methods and interpretations have been used on examples from a variety of insect orders. Differentiation in insects has been considered by Bodenstein (1955) in a short but comprehensive review, and no attempt will be made here to reevaluate the tremendous amount of work that has been done in the field of insect morphogenesis. Suffice it to say that in general the Diptera are considered as being completely determined embryologically and Hymenoptera partially so. Of insects that have been studied genetically, Drosophila embryos have been fairly well analyzed by the methods available (Geigy, 1932; Howland and Child, 1935; Howland and Sonnenblick, 1936; Howland, 1941); Habrobracon embryos have not. The available experimental data on Habrobracon embryos indicate that development is largely predetermined. The few eggs that have been tied in half have not hatched, and ultraviolet-irradiated eggs (with the nucleus shielded) raised to imago have had distorted tergites which were not the result of gene mutations. Bodenstein thoroughly considers the characteristics of insect eggs with determinative development. These have the various structures of the future embryo localized in their peripheral cytoplasm. He points out that experiments on determinate eggs show quite conclusively that peripheral cytoplasm is a differentiated continuum in which localized differentials exert specific influences on totipotent cleavage nuclei, leading them toward special assignments. "One has to assume that the cytoplasmic regions possess their specific qualities only when in normal topographic relationship to the cortical cytoplasmic layers as a whole. Their influence must be regarded as of a general directive nature in that they set up differentials in cleavage nuclei, thereby creating a different pattern within the framework of the blastoderm, which forms the basis of the ensuing developmental events." That is to say, if any organ-forming region of cytoplasm on the egg surface is injured, no amount of totipotent nuclei coming into that region can repair or redirect the cytoplasm. The information for development is locked in the peripheral cytoplasm, and invading nuclei are guided in their destiny by this cytoplasm. The work of Brauer and Taylor (1936) is of especial 
interest since they were able to demonstrate progressive differentiation in the cortical cytoplasm before nuclei had migrated into these regions.

Of specific interest are the components of the cytoplasm that contain the information necessary for direction of further devel-

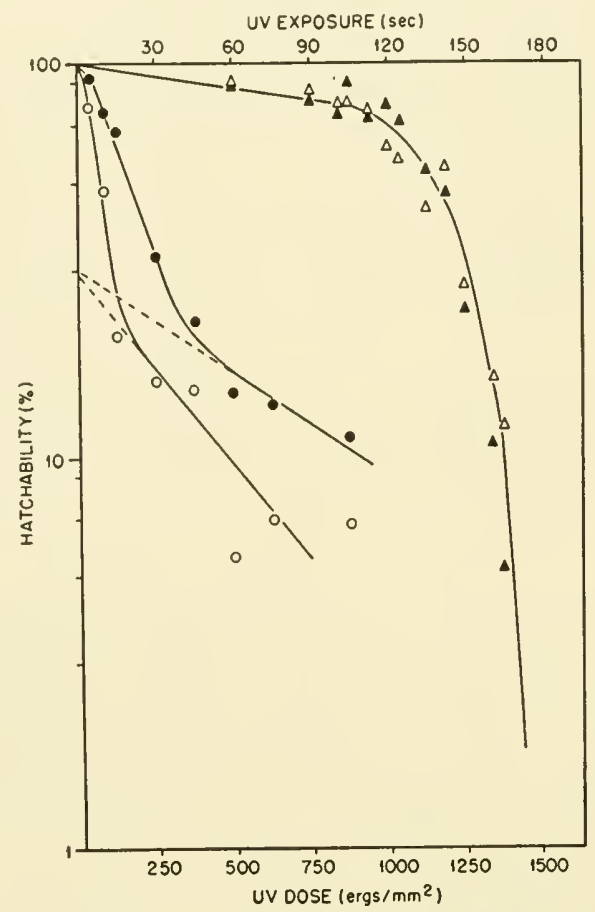

Fig. 8. Dose-hatchability curves for Habrobracon eggs irradiated on their convex (nuclear) surfaces $(O$, ultraviolet; $\bullet$, ultraviolet plus photoreactivating light) or concave (non-nuclear) surfaces $(\triangle$, ultraviolet;

ultraviolet plus photoreactivating light). From von Borstel and Wolff, 1955. Proc. Natl. Acad. Sci. U. S., by permission of the University of Chicago Press.

opment. We assume ultraviolet radiation can destroy the ability for progressive differentiation of regions on the periphery of determinate eggs.

The Habrobracon egg is unique inasmuch as ultraviolet irradiation of the convex side of the egg kills the egg by damage to the nucleus, whereas irradiation of any other place on the egg surface 
kills the egg by damage to non-nuclear elements. The survival curve is exponential for nuclear killing and sigmoid with respect to cytoplasmic killing (Fig. 8). Nuclear killing was discussed previously; damage to the cytoplasm, resulting in death, has certain characteristics that make it highly instructive. (1) Eggs killed by irradiation of cytoplasm die late in development-hatching time is longer in many of those that do hatch, and of those that die, most are characterized by having hemiated gut or fragile endoderm or ectoderm tissues (Amy and von Borstel, 1955). (2) Surviving embryos at high doses to cytoplasm have as adults irregular tergites as at least one nonlethal developmental abnormality. (For a similar effect in Drosophila following x-irradiation, see Ulrich, 1951, 1953.) These are gross defects indicating interference with normal determination and synthesis. (3) The survival curve is steeply sigmoid (von Borstel and Moser, 1956; Ulrich, 1955a,b,c). (4) The action spectrum for cytoplasmic killing indicates that the energy is absorbed by nucleic acid or nucleoprotein (Amy and von Borstel, 1955). (See Loofbourow, 1948, for assumptions and limitations in action spectrum analysis.)

While this work was being done on Habrobracon, an independent study of ultraviolet radiation effects on Drosophila eggs was carried out at Yale by Goldman and Setlow (1956). The research can be considered as mutually confirmatory in most respects, since Goldman and Setlow also observed gut herniation and an action spectrum which they interpreted as indicating energy absorption in nucleic acid when the egg is irradiated.

It has been calculated (see Bachem and Reed, 1931) that in normal tissues ca. $80 \%$ of the energy of ultraviolet radiation is expended in the first 30 microns. Most of the cytoplasm in Habrobracon eggs is located in a 5- to 10-micron peripheral layer; therefore, it appears reasonable to assume that the cytoplasm comprises the substance sensitive to ultraviolet radiation. Cytochemical methods show that peripheral cytoplasm is rich in nucleic acid. This is consistent with action spectrum analysis.

The steeply sigmoid shape of the dose-action curve for cytoplasm suggests a multihit survival curve of high order (von Borstel and Moser, 1956). The shape of the curve appears to be 
consistent with the hypothesis that the egg cytoplasm is a multiunit system, with one hit able to inactivate a unit and not all units having to be hit in order to inactivate the system. This is an extension of Atwood and Norman's theory (1949) of multihit survival curves (see also Kimball, 1953). It is noteworthy that a great deal of the cytoplasmic pentose nucleic acid appears to be located in particles on the periphery. It should be pointed out that a possible alternative explanation to that of unit inactivation by ultraviolet radiation is that of production of toxic substances. Wilbur, Bernheim, and their collaborators (see Bernheim et al., 1952; Fisher and Wilbur, 1954) have described fatty acids oxidized by ultraviolet radiation as being such substances. It would be interesting to see if irradiated fatty acids can kill eggs and yield results identical to that of direct irradiation of the eggs. However, since the action spectrum for killing indicates that nucleic acid or nucleoprotein absorbs the energy, it appears more profitable at present to explore the consequences of inactivation of cytoplasmic particles in the egg.

The developmental events that follow irradiation of the cytoplasm suggest that normal synthesis is hampered. This, if true, is of extreme importance. Overly fragile or badly constructed tissues and disoriented tergites in surviving adults suggest a dislocation of synthesis of structural proteins which may be the consequence of inactivation of cytoplasmic pentose nucleic acid. The work of Geigy (1932) on Drosophila indicated that fewer defects in adults resulted when the egg was irradiated early than when irradiated cluring differentiation processes. The tergite of the adult is far removed both in time and space from the egg; since the stages between them have not been worked out in Habrobracon, any conclusions at present must be considered as tentative.

When eggs were irradiated at shorter wavelengths, around $2300 \mathrm{~A}$ or less, it was found (Amy and von Borstel, umpublished) that eggs killed by irradiating the cytoplasm have unusual characteristics. They die at a much earlier stage of development and the embryos have very little recognizable form. At these wavelengths, the proteins usually absorb more of the incident energy 
than nucleic acids. Indeed, Goldman and Setlow (1956) have found a similar circumstance in Drosophila eggs and they explain the effect as being caused by protein denaturation. This phenomenon deserves careful analysis because it may reveal a great deal about information content of cytoplasmic elements in determinate eggs. Immediately apparent is the possibility that cytoplasmic protein is used in the determination of egg regions for the first steps in differentiation and the nucleic acid utilized for direction of later development. Alternatively, this phenomenon may be an important clue in deciding between production of toxic substances and inactivation of cytoplasmic particles as a cause of death in these eggs.

\section{Photoreactivation}

Now, is there any general method by which one can distinguish between action of the nucleus and action of the cytoplasm in bringing about an embryonic event?

It has already been pointed out that one can distinguish between eggs killed by ultraviolet radiation when the nucleus and cytoplasm are separately exposed. In 1949, Kelner and Dulbecco, working on fungi and viruses respectively, independently discovered the phenomenon of photoreactivation. This is the counteraction of ultraviolet radiation damage (ca, 2600 A) by radiation of a longer wavelength (ca. $3600 \mathrm{~A}$ ). Photoreactivation is possible after ultraviolet irradiation of a wide variety of living material from protozoa to vertebrates, from viruses and bacteria to the cells of higher plants (see Dulbecco for review, 1955). After ultraviolet irradiation of the nucleus or cytoplasm of the Habrobracon egg, eggs were subjected to reactivating light (von Borstel and Wolff, 1954, 1955). The results were striking. Injured nuclei can be repaired by light of a longer wavelength, but injured cytoplasm cannot (Fig. 8). In both the photorecoverable nucleus and the nonphotorecoverable cytoplasm the energy is absorbed into nucleic acid or nucleoprotein (Amy and von Borstel, 1955).

A similar situation has been reported in Paramecium, where ciliary immobilization from ultraviolet radiation is adjudged to 
be a non-nuclear effect and the action of the radiation is nonphotorecoverable (Brandt and Giese, 1956). The action spectrum for ciliary immobilization indicates that the ultraviolet radiation inducing this effect is absorbed by protein. Blum, Cook, and Loos (1954) have found four nonphotorecoverable effects in ultraviolet-irradiated sea urchin eggs. They have suggested that these effects are non-nuclear rather than being indirect effects following irracliation of the egg nucleus.

We postulate that this effect of ultraviolet radiation is a general one: Only injury to the mucleus from ultraviolet radiation can be repaired by reactivating light; the cytoplasm is a nonphotorecoverable system. If such a reaction system is truly a general one, it would seem that the system could be profitably employed to follow the interplay of the nucleus and cytoplasm during embryonic development. Miss Skreb, working on enucleate amoebae in Brachet's laboratory, has results which indicate that hastening of cleath by ultraviolet radiation can be delayed by photoreactivating light (M. Errera, personal communication). Whether her system or ours is the exceptional one still remains to be determined.

\section{Conclusion and Summary}

Several questions have been asked that are concerned with relations between the nucleus and cytoplasm.

1. The four meiotic nuclei are apparently all genetically equipotent. Since all four remain inside the egg, why does only one take part in further development? By a cytological analysis of oocytes from females that produced a high frequency of haploid mosaic adults, it appears that meiosis occurring at the egg periphery leaves three of the four meiotic nuclei susceptible to destruction by some agent in the egg cortex.

2. Is there any condition by which accessory sperm can take an active part in development? In certain genetic strains of Habrobracon and the honey bee, occurrence of partial androgenesis indicates that normally a zygote nucleus reacts with the cytoplasm in such a way that the cytoplasm can block further development of accessory sperm. The reaction system is incom- 
plete in certain genetic strains of the wasp Habrobracon and the honey bee.

3. Can the young embryonic system be regarded as a pool in which mitosis freely occurs until blastulation, or do critical periods exist during the cleavage stages? By observing development taking place in punctured eggs and by irradiating and damaging the nuclei of otherwise normal eggs, it was found that the sixth or seventh cleavage is such a critical period in Habrobracon.

4. What component of the cytoplasm is the agent of determinate development? By studying the consequences of ultraviolet irradiation of the egg cytoplasm, it appears that nucleic acid or nucleoprotein, perhaps in a particulate system, contains the information necessary for determinate development in the insect egg.

5. Is there any general method by which one can distinguish between action of the nucleus and action of the cytoplasm in bringing about an embryonic event? We suggest that photoreactivation of ultraviolet radiation damage may be such a method. When Habrobracon egg cytoplasm is irradiated, dose-reduction by photoreactivation does not occur, but photoreactivation can occur after irradiation of the nucleus.

\section{REFERENCES}

Amy, R. L., and R. C. von Borstel. 1955. Inactivation of the Habrobracon egg with different wavelengths of ultraviolet radiation. Presented at Annual meeting of American Association for the Advancement of Science, Atlanta, December 1955.

Atwood, K. C., and A. Norman. 1949. On the interpretation of multihit survival curves. Proc. Natl. Acad. Sci., U. S., 35, 696-709.

Bachem, A., and C. I. Reed. 1931. The penetration of light through human skin. Am. J. Physiol., 97, S6-96.

Bernheim, F., K. M. Wilbur, and C. B. Kenaston. 1952. The effect of oxidizing fatty acids on the activity of certain oxidative enzymes. Arch. Biochem. and Biophys., 38, 177-84.

Blum, H. F., J. S. Cook, and G. M. Loos. 1954. A comparison of five effects of ultraviolet light on the Arbacia egg. J. Gen. Physiol., 37, $313-24$.

Bodenstein, D. 1955. Insects. In Analysis of Development, B. H. 
Willier, P. A. Weiss, and V. Hamburger, editors. W. B. Saunders Company, Philadelphia, Pa. Pages 337-45.

von Borstel, R. C. 1952. Effects of nitrogen mustard on nuclei during meiosis and cleavage of Habrobracon eggs (Abstr.). Genetics, 37, 567.

von Borstel, R. C. 1953a. Cytochemical studies of mutagenesis in the wasp Habrobracon. Carnegie Inst. Wash. Year Book, 52, 244-46.

von Borstel, R. C. 1953b. Some aspects of chemical mutagenesis in

Habrobracon juglandis Ashmead and Sciara coprophila Lintner.

Dissertation, University of Pennsylvania, Philadelphia, Pa.

von Borstel, R. C. 1955. Feulgen-negative nuclear division in Habrobracon eggs after lethal exposure to $\mathrm{X}$-rays or nitrogen mustard. Nature, 175, 342.

von Borstel, R. C., and H. Moser. 1956. Differential ultraviolet irradiation of the Habrobracon egg nucleus and cytoplasm. In Progress in Radiobiology, J. S. Mitchell, B. E. Holmes, and C. L. Smith, editors. Oliver and Boyd, Ltd., Edinburgh. Pages 211-15.

von Borstel, R. C., and S. Wolff. 1954. Photoreactivation of the Habrobracon egg. (Abstr.) Radiation Rescarch, 1, 565-66.

von Borstel, R. C., and S. Wolff. 195.5. Photoreactivation experiments on the nucleus and cytoplasm of the Habrobracon egg. Proc. Natl. Acad. Sci. U. S., 41, 1004-9.

Boveri, T. 1907. Zellenstudien. VI. Die Entwicklung dispermer Seeigeleier. Ein Beitrag zur Befruchtungslehre und zur Theorie des Kerns. Jena. Z. Naturw., 43, 1-292.

Boveri, T. 1915. Über die Entstehung der Eugsterschen Zwitterbienen. Wilhelm Roux' Arch. Entwicklungsmech. Organ., 41, 264-311.

Brandt, C. L., and A. C. Giese. 1956. Photoreversal of nuclear and cytoplasmic effects of short ultraviolet radiation on Paramecium candatum. J. Gen. Physiol., 39, 735-51.

Brauer, A., and A. C. Taylor. 1936. Experiments to determine the time and method of organization in bruchid (Coleoptera) eggs. J. Exptl. Zool., 73, 127-48.

Conklin, E. G. 1931. The development of centrifuged eggs of ascidians. J. Exptl. Zool., 60, 1-119.

Du Bois, A. M. 1933. Chromosome behavior during cleavage in the eggs of Sciara coprophila (Diptera) in the relation to the problem of sex determination. Zellforsch. mikroskop. Anat., 19, 595-614.

Dulbecco, R. 1949. Reactivation of ultraviolet-inactivated bacteriophage by visible light. Nature, 163, 949-50. 
Dulbecco, R. 1955. Photoreactivation. In Radiation Biology, Vol. II, A. Hollaender, eclitor. McGraw-Hill Book Co., New York. Pages $455-86$.

Fankhauser, G. 1925. Analyse der physiologischen Polyspermie des Triton-Eies auf Grund von Schnürungsexperimenten. Wilhelm Roux' Arch. Entuicklungsmech. Organ., 105, 501-80.

Fankhauser, G. 1952. Nucleo-cytoplasmic relations in amphibian development. Intern. Rev. Cytol., 1, 165-93.

Fankhauser, G. 1955. The role of nucleus and cytoplasm. In Analysis of Development, B. H. Willier, P. A. Weiss, and V. Hamburger, editors. IV. B. Saunders Company, Philadelphia, Pa. Pages 126-50.

Fisher, IV. D., and K. M. WVilbur. 1954. Depolymerization of desoxyribonucleic acid preparations by oxidized methyl lineolate. (Abstr.) J. Elisha Mitchell Sci. Soc., 70, 124-25.

Geigy, R. 1932. Erzergung rein imaginaler Defekte durch ultraviolette Eibestrahlung bei Drosophila melanogaster. Wilhelm Roux' Arch. Entwicklungsmech. Organ., 125, 406-47.

Goldman, A. S., and R. B. Setlow. 1956. An action spectrum analysis of the effects of ultraviolet irradiation on morphogenesis in Drosophila. Exptl. Cell Research, 11, 146-59.

Hallez, P. 1SS6. Loi de l'orientation de l'embryon chez les Insectes. Compt. rend., 103, 606-S.

Henschen, W. 1928. Über die Entwicklung der Geschlechtdrüsen von Habrobracon juglandis Ash. Z. wiss. Biol., 13, 141-78.

Hotchkiss, R. D. 1955. Bacterial transformation. J. Cellular Comp. Physiol., 45 (Suppl. 2), 1-23.

Howland, R. B. 1941. Structure and development of centrifuged eggs and early embryos of Drosophila melanogaster. Proc. Am. Pliil. Soc., 84, 605-16.

Howland, R. B., and B. P. Child. 1935. Experimental studies on development in Drosophila melanogaster. I. Removal of protoplasmic materials during late cleavage and early embryonic stages. J. Exptl. Zool., 70, 415-24.

Howland, R. B., and B. P. Sonnenblick. 1936. Experimental studies on development in Drosophila melanogaster. II. Regulation in the early egg. J. Exptl. Zool., 73, 109-25.

Humphries, A. A. 1955. Experimental removal of metaphase II inhibition in ova of the newt Triturus viridescens. (Abstr.) A. S. B. Bull., 2,7 .

Kelner, A. 1949. Effect of visible light on the recovery of Streptomyces 
griseus conidia from ultraviolet irradiation injury. Proc. Natl. Acad. Sci. U. S., 35, 73-79.

Kimball, A. W. 1953. The fitting of multi-hit survival curves. Biometrics, 9, 201-21.

Loofbourow, J. R. 1948. Effects of ultraviolet radiation on eells. Growth, 12 (Suppl.), 77-149.

Mackensen, O. 1951. Viability and sex determination in the honey bee (Apis mellifera L.). Genetics, 36, 500-9.

Mackensen, O. 1955. Further studies on a lethal series in the honey bee. J. Heredity, 46, 72-74.

Metz, C. W. 1938. Chromosome behavior, inheritance and sex determination in Seiara. Am. Naturalist, 72, 485-520.

Nanney, D. L. 1953. Nueleo-eytoplasmic interaction during conjugation in Tetrahymena. Biol. Bull., 105, 133-48.

Painter, T. S. 1940. On the synthesis of cleavage chromosomes. Proc. Natl. Acad. Sci. U. S., 26, 95-100.

Penners, A. 1924. Experimentelle Untersuehungen zum Determinationsproblem am Keim von Tubifex rivulorum Lam. I. Die Duplicitas eruciata und organbildende Keimbezirke. Arch. mikroskop. Anat., u. Entucicklungsmech., 102, 51-100.

Rothenbuhler, WV. C., J. W. Gowen, and O. W. Park. 1952. Androgenesis with zygogenesis in gynandromorphic honey bees (Apis mellifera L.). Science, 115, 637-38.

Rothenbuhler, W. C. 1955. Hereditary aspects of gynandromorph occurrence in honey bees (Apis mellifera L.). ( $\mathrm{Ph} . \mathrm{D}$. Thesis abstr.) Iowa State Coll. J. Sci., 29, 487-88.

Rothenbuhler, W. C., and J. W. Gowen. 1955. Chromosomal localization of hereditary basis for gynandromorph production in honey bees (Apis mellifera L.). (Abstr.) Genetics, 40, 593-94.

Rothschild, Lord. 1954. Polyspermy. Quart. Rev. Biol., 29, 332-42.

Seidel, F., E. Bock, and G. Krause. 1940. Die Organisation des Insekteneies (Reaktionsablauf, Induktionsvorgänge, Eitypen). Naturwissenschaften, 28, 433-46.

Somnenblick, B. P. 1950. The early embryology of Drosophila melanogaster. In Biology of Drosophila, M. Demeree, editor. John Wiley \& Sons, New York. Pages 62-167.

Speicher, B. R. 1936. Oogenesis, fertilization and early cleavage in Habrobracon. J. Morphol., 59, 401-21.

Tchou-Su. 1931. Étude cytologique sur l'hybridation chez les anoures. Arch. anat. microscop., 27, 1-105. 
Torvik-Greb, M. 1935. Chromosome numbers in Habrobracon. Am. Naturalist, 68, 25-34.

Tyler, A. 1930. Experimental production of double embryos in annelids and molluses. J. Exptl. Zool., 57, 347-407.

Ulrich, H. 1951. Sensitive periods and egg-regions in production of the modification "abnormal abdomen" by x-raying eggs of D. melanogaster. Dros. Inf. Serv., 25, 131.

Uhich, H. 1953. Induction of "abnormal abdomen" by partial x-raying of Drosophila eggs. Dros. Inf. Serv., 27, 116-17.

Ulrich, H. 1955a. Die Bedeutung von Kern und Plasma bei der Abtötung des Drosophila-Eies durch Röntgenstrahlen. Naturwissenschaften, 42,468 .

Ulrich, H. 1955b. Comparative studies on the lethal action of $x$-rays on nucleus and cytoplasm of Drosophila eggs before cleavage. Dros. Inf. Serv., 29, 170-71.

Ulrich, H. 1955c. Ein Vergleich der Röntgenstrahlenwirkung auf Kern und Plasma des Drosophila-Eies. Biol. Zentr., 74, 498-515.

Whiting, A. R. 1948. Incidence and origin of androgenetic males in x-rayed Habrobracon eggs. Biol. Bull., 95, 354-60.

Whiting, A. R. 1955. Androgenesis as evidence for the nature of x-rayinduced injury. Radiation Research, 2, 71-78.

Whiting, P. W. 1924. Some anomalies in Habrobracon and their bearing on maturation, fertilization, and cleavage. (Abstr.) Anat. Record, 29, 146.

Whiting, P. W. 1932. Modification of traits in mosaics from bimcleate eggs of Habrobracon. Biol. Bull., 63, 296-309.

Whiting, P. W. 1934. Egg-trinuclearity in Habrobracon. Biol. Bull., 46, 145-51.

Whiting, P. W. 1943a. Androgenesis in the parasitic wasp Habrobracon. J. Heredity, 34, 355-66.

Whiting, P. W. 1943b. Multiple alleles in complementary sex determination of Habrobracon. Genetics, 28, 365-\$2.

Wilson, E. B. 1928. The Cell in Development and Heredity. The Macmillan Company, New York.

Zeuthen, E. 1951. Segmentation, nuclear growth and cytoplasmic storage in eggs of echinoderms and amphibia. Pubbl. staz zool. Napoli, 23 (Suppl.), 47-69. 



\title{
NUCLEAR TRANSPLANTATION,
}

\section{A TOOL FOR THE STUDY OF \\ NUCLEAR DIFFERENTIATION}

\author{
H. E. LEHMAN: DEPARTMENT OF ZOOLOGY, \\ UNIVERSITY OF NORTH CAROLINA, \\ CHAPEL HILL, NORTH CAROLINA
}

The problems of embryonic determination and differentiation are concerned primarily with the mechanisms whereby a limited part of the total capacity of the genome is selected for phenotypic expression in different somatic cells of the developing organism. A substantial body of information derived from numerous studies on isolated blastomeres, induction systems, physiological gradients, etc. indicates that the selective mechanism in determination is extranuclear in origin and is dependent primarily upon local cytoplasmic differences. This view is in agreement with the conventional opinion which accepts the concept of "constancy of chromosome number" of Hertwig (1916) and assumes that nuclei are quantitatively and qualitatively equivalent throughout the somatic cells of the body. The theory of Weismann $(1885,1892)$ which postulated fractional allocation of nuclear materials to different blastomeres as the primary mechanism for somatic differentiation has generally been abandoned since the equivalence of blastomere nuclei has been repeatedly demonstrated on representative eggs of most major phyla. Normal development can still take place after the cleavage nuclei are shifted to various "unnatural" positions by compression, centrifugation, or constriction of the egg (see reviews by Wilson, 1925; Morgan, 1927; Spemann, 1938). A host of regeneration studies on vertebrates, invertebrates, and plants have supplied evidence which, although inconclusive, has been interpreted as an indication that nuclei of 
differentiated cells also retain a large measure of their totipotency (see reviews by Schotté, 1939; Child, 1941; Needham, 1952). In the light of this pressure of evidence it is not surprising that the question of nuclear differentiation has received little attention in most experimental studies of development.

It should be realized that, although the prevailing consensus accepts the concept of nuclear uniformity in somatic tissues, the possibility of nuclear differentiation has never been conclusively eliminated with regard to the cells of late embryonic or adult tissues. During recent years the need for reconsideration of this question has been expressed with increasing frequency (e.g., Huskins, 1947, 1952; Huskins and Steinitz, 1948a,b; Schultz, 1952; Stern, 1955). In this connection it is noteworthy that the embryonic evidence for nuclear uniformity is primarily based upon studies of nuclei in early cleavage stages only, the most striking demonstration being that supplied by the constriction experiments on eggs of Triton in which total development resulted in fragments that received only one of the 2-, 4-, or 8-cell stage blastomere nuclei (Spemann, 1914, 1928; Fankhauser, $1925,1930)$. When single nuclei from 16- and 32-cell stages entered non-nucleated egg fragments, partial development of the fragment resulted. This failure to complete development has generally been attributed to irreversible cytoplasmic changes that resulted from prolonged isolation from a nucleus. Although this may be true, these observations also admit the seldom considered alternative, namely, loss of nuclear totipotency which is nuclear specialization.

These and related experiments (see review by Spemann, 1938) have demonstrated conclusively the equivalence of early cleavage nuclei, but they throw no light on the nuclear character of older cells. Predictions from these data that all somatic nuclei remain equivalent during development are particularly insecure in view of the extensive body of information which indicates that for the most part the cytoplasm appears to be almost completely autonomous during cleavage and blastulation and very few nucleusdependent functions have been demonstrated during this early phase of development. For example, enucleated eggs and egg 
fragments of echinoderms and amphibians have the capacity to cleave and form "blastulae," but none has given any evidence of gastrulating (see reviews by Fankhauser, 1955; J. A. Moore, 1955). The rate and pattern of cleavage until the onset of gastrulation in hybrids, and particularly in hybrid andromerogons, proceeds strictly according to the genetic character of the egg cytoplasm and gives no indication of sperm nucleus influence until gastrula and postgastrula stages (see reviews by Needham, 1950; Fankhauser, 1955; J. A. Moore, 1955). Physiological and biochemical studies indicate that, although there is a continuous rise in the metabolic rate during cleavage, the most conspicuous accelerations in respiration and specific syntheses follow the onset of gastrulation (see reviews by Barth and Jaeger, 1947; Brachet, 1947, 1952; Gregg, 1948; Ebert, 1954; Fankhauser, 1954). These observations suggest that, if nuclei become differentiated during development, such changes should be sought, not in early development when the nuclear influence is slight but, rather, in gastrula and older tissues when nuclear function can be clearly demonstrated.

In examining the possibility of nuclear differentiation, the first question which must be answered relates to whether or not there is sufficient evidence to indicate that cytoplasmic differentiation is accompanied by tissue-specific nuclear change. Until this is settled, it is premature to speculate on secondary questions relating to mechanics of nuclear differentiation, or labile versus irreversible determination, or functions of differentiated nuclei in histogenesis and tissue syntheses. Present information does not allow one to generalize in answering the primary question; however, certain evidence unequivocally shows that at least some differentiated somatic cells possess nuclei which vary in a tissuespecific manner from other nuclei in the organism.

\section{Evidence for Nuclear Differentiation in Somatic Tissues}

The nuclei of differentiated tissues possess distinctive variations in size, shape, density, and composition which are histologically diagnostic for specific tissues. Many of these differences show a constant relation to functional activity of the cells con- 
taining them; for example, large nuclei and nucleoli are generally indicative of rapid cytoplasmic synthesis associated with growth or secretion. In addition, numerous cytochemical assays of nuclear composition show that nuclei of different tissues of the same organism vary both quantitatively and qualitatively (within the sensitivity range of the tests employed) in content and synthesis of special enzymes, proteins, protein precursors, nucleic acids, glycogen, lipoprotein, etc. (see reviews by Boivin, Vendreley, and Vendreley, 1948; Mirsky and Ris, 1949; Brachet, 1950, 1952, 1955; Caspersson, 1950; Caspersson and Schultz, 1951; Novikoff, 1952; Stern et al., 1952; B. C. Moore, 1952; Pollister, 1952, 1954; Fankhauser, 1954).

In addition to evidences of chemical variation, unequal chromosome composition has been reported in the cells of a number of plants and animals. Of these, the earliest and still one of the most striking examples is found in the work of Boveri and others (see review by Tyler, 1955) on chromatin diminution. This occurs during the early cleavage divisions of the somatic cells of Ascaris, whereas the primordial germ cell retains the full chromatin complement. Somewhat comparable differences are found in the somatic and germ cells of certain insects, e.g., the fungus fly, Sciara (Metz, 1938; Berry, 1941), and gall midges, Cecidomidae (White, 1946, 1947, 1948). Of greater interest for present purposes, however, are evidences of nuclear differences in histologically distinct somatic tissues. Comprehensive reviews of the occurrence of normal polyploidy in specific tissues of otherwise diploid animals and plants are given by Berger (1941), Geitler (1941), Huskins (1947, 1952), Schultz (1952), and Fankhauser (1954). Polyploid nuclei have been reported in vascular bundles and epidermal structures of plants, in nematode muscle cells, in ganglion cells of snails, and in various arthropod tissues. Similar cases of somatic polyploidy have been reported in the kidney, liver, and epidermis of amphibia, as well as in liver, vascular, and tumor tissues in mammals. Tissue-specific haploidity is claimed for the tail mesenchyme of frog larvae (Green, 1953) and for the mesenchyme-forming micromeres of the sea urchin in which 
reduction from diploid to haploid is described as occurring between the 16- and 32-cell stage (Lindahl, 1953; however, contested by Makino and Alfert, 1954); the remaining tissues in these embryos retain the normal $2-\mathrm{N}$ count.

Without question the most striking examples of tissue-specific chromosomal variation are to be found in insects where many tissues possess specific multiples of the basic diploid number characteristic for the species. The most detailed study is provided by the work of Geitler $(1934,1941)$ on chromosome numbers in various tissues of the "pond skater," Gerris lateralis. This species is particularly favorable for study owing to the presence of distinctive heterochromatic regions on the sex chromosomes, which permit them to be identified and to ascertain ploidy during interphase. By this means Geitler found the chromosome number in salivary gland nuclei to be 2048-ploid; Malpighian tubules were from 32- to 64-ploids; and mid-gut epithelium and testicular septa were octaploid. He further demonstrated that the nuclei achieved their various polyploid states by endomitosis during the development of germinal diploid cells, the individual chromosomes undergoing recognizable pro-, meta-, and anaphase changes within the intact nuclear membrane. Somewhat comparable results have been reported for the grasshopper, Romalea (Mickey, 1945); the mosquito, Culex (Berger, 1938, 1941; Grell, 1946a,b); the fungus fly, Sciara (White, 1946, 1947, 1948); and Drosophila (Painter and Reindorp, 1939). The number of such cases probably could be extended considerably if it were certain that multistrand (polytene) chromosomes represent a preliminary step in the establishment of endopolyploidy. Berger $(1939,1941)$ and Grell (1946a,b), for example, have found that the diploid cells of the mosquito intestine increase in size but do not divide during larval development. During this period the chromosomes duplicate themselves and form bundles of closely associated chromonemata (equivalent to 8-, 12-, 32-, or 64-ploid), which later separate into individual chromosomes when division is resumed at metamorphosis. If each strand in a polytene chromosome indeed represents internal chromosomal duplication, variations in 
polyteny in different cells might also be taken as evidence of quantitative multiplication of whole sets of the basic genetic units in the nuclei containing them.

The constant relation of definite polytene and polyploid numbers to certain insect tissues strongly suggests that they are related to differentiation or special functions in these cells. White (1945, pp. 33-34) expresses the opinion of a number of cytologists in attributing developmental significance to these nuclear tissue-specific relationships when he suggests that "The whole process of histological differentiation in insects seems to be intimately bound up with this phenomenon of endopolyploidy, each organ and each tissue having its own characteristic degree of ploidy, some being entirely composed of one type of cell while others are mosaics of cells with different multiples of the fundamental diploid number. To what extent endopolyploidy occurs outside the Insecta is not known at present, but there are indications that it is fairly widespread in many groups of animals." For a critical evaluation of this possibility, one is also referred to Huskins (1947).

In addition to the presence of quantitative differences in the number of complete sets of chromosomes in different somatic cells, there is also evidence for tissue-specific variation in the siructure of individual chromosomes. Kosswig and Shengün (1947) and Beermann (1952) working with Chironomus larvae have made detailed cytological studies of similar regions on homologous chromosomes obtained from salivary glands, Malpighian tubules, mid-gut, and rectum. They found major tissue-specific differences in polyteny, in overall size of comparable regions and, most noteworthy, differences in the thickness and number of homologous dises at specific loci on the chromosomes. Moreover, these variations showed modification with developmental age with some distinctive structural features appearing or disappearing at various times during differentiation. These observations are contrary to the less extensive, but somewhat comparable, study of Berger (1940) on salivary and mid-gut chromosomes of Sciara in which similar regions of homologous chromosomes from the two tissues were described as having similar structure. The work of Kosswig 
and Shengün and of Beermann indicates, in Chironomus larvae at least, that in addition to other more easily recognized nuclear variations there are also clear-cut tissue-specific differences in the fine structure of chromosomes. These authors consider the possibility that these differences in structure and staining properties of comparable bands on homologous chromosomes may be evidence of activity or inactivity of different specific genes in the respective tissues. A similar suggestion has been made in connection with the possible functional significance of the "lamp brush" chromosomal structure of amphibian oocyte nuclei; the localized enlargement of certain loci on the chromosomes may indicate multiplication of specific regions of the chromosome associated with special syntheses in the developing germ cell (see Duryee, 1950; Gall, 1952).

A final category of cytological evidence for nuclear differentiation is associated with variability in heterochromatic material demonstrable in interphase nuclei at a time when the nucleus is physiologically most active (Berrill and Huskins, 1936; Huskins and Steinitz, 1948a). In a number of instances interphase heterochromatin can be traced to specific chromosomes during mitosis and has been useful in determining ploidy in interphase nuclei (Geitler, 1934, 1941; Huskins and Steinitz, 1948b). Heterochromatin is considered to be for the most part genetically inert (as, for example, in the $\mathrm{X}$ and $\mathrm{Y}$ chromosomes of Drosophila and in the eliminated chromatin in somatic cells of Ascaris and Sciara); nevertheless, duplications, deletions, and translocations of heterochromatin are known to produce sterility and a variety of "position effects." There has been much speculation concerning the possibility that variations in heterochromatic content might be evidence of differential gene action as was suggested by Muller and Gershenson (1935; see also Schultz, 1939, 1947, 1952; Brachet, 1947; Huskins, 1947; Lewis, 1950; Hannah, 1951; Caspersson, 1950; Caspersson and Schultz, 1951; Gall, 1952). As an example of one of the present trends of thought, Schultz (1952, p. 38) suggested that only the specific genes required for function in a particular type of cell are in an active state; the others are in the "heterochromatic" state and could be dispensed with with- 
out endangering the life of the cell. He points out that this hypothesis resembles that of Weismann but differs "in that the experiments which discredited the Weismannian point of view (nuclear differentiation at the cleavages) are not relevant to it. It is closer to the hypothesis of changes in the centers of activity of the genes during differentiation of the tissues" which was earlier suggested by Morgan (1934) as a possible mechanism whereby determined cytoplasm selectively affects genes which in turn maintain the differentiation of the cytoplasm in a reciprocal interaction between these two basic cell components. Until additional information is available concerning the dynamic properties of heterochromatin in interphase nuclei, it is not possible to assay its significance in cell function and differentiation.

The essential fact from the foregoing summary of visible differences in somatic cell nuclei is that there are now numerous "exceptions" to the concept of quantitative and qualitative nuclear uniformity in somatic tissues. As Huskins (1947) has intimated, additional studies, unbiased by the preconception of nuclear uniformity, would undoubtedly add materially to the growing body of data that points toward nuclear specialization as a general, rather than an exceptional, aspect of histogenesis. In collecting these data, however, the fact still remains that the cytological evidence of nuclear differentiation in cells of embryos most suitable for experimental study are meager. It is hoped that additional cytogenetic and cytochemical studies will concentrate attention on species favorable for developmental analysis so that the varied techniques from these disciplines can jointly be brought to bear on this morphogenetic problem. One relatively new embryological method, namely, nuclear transplantation, has recently been applied to the question of nuclear differentiation. With more extensive application, it should constitute an important supplement to the cytological and biochemical information now available on this subject.

\section{Technique and Results of Nuclear Transplantation}

The simplest and most direct manner in which information could be obtained concerning irreversible nuclear determination 
during development would be by transplantation of a nucleus from a determined cell into one that was labile or totipotent prior to removal of its own nucleus, as, for example, in an enucleated mature egg. Then, as Briggs and King (1952, p. 356) suggest, "the nature of the ensuing development should reveal the character of the transplanted nucleus-complete differentiation would indicate that irreversible nuclear differentiation had not occurred, while limited differentiation would indicate that it had." Accordingly, when the methods are finally perfected, nuclear transplantation gives promise of being one of the most significant technical advances that has been made in recent years for the study of causal relationships between nucleus and cytoplasm and may well rank in importance with hybridization and merogony as an embryological tool for protoplasmic recombination. Nuclear transplantation has the unique advantage, heretofore impossible, of permitting one to unite a nucleus and cytoplasm of radically different age and prospective fate in a manner comparable to that practiced in the standard transplantation of embryonic tissue fragments.

The first demonstration that nuclear transplantation could be successfully carried out was reported by Comandon and deFonbrune (1939) working with Amoeba sphaeronucleus. A blunt microdissection needle was used to force the nucleus of an intact animal through the cell membrane into an enucleated fragment lying adjacent to the donor animal. The fragment with the transplanted nucleus, although not regaining its total former metabolic capacity, nevertheless gave evidence of "rejuvenation" after the transfer. Lorch and Danielli (1950) and Danielli (1952, 1955) extended the study with homo- and heterospecific nuclear transfers between Amoeba proteus and A. discoides. Mass, single clone cultures were very readily obtained from homospecific transfers but were only obtained in about $1 \%$ of the nucleocytoplasmic hybrids. Species differences in the parent clones involved nuclear size, body form, mode of locomotion, and specific antigenic characters. The nuclear size in hybrids was intermediate between that of the parent clones, indicating that the cytoplasm exerts some influence in determining this character. The general shape and 
action of the hybrids was at first intermediate between that characteristic of the parent strains; however, after a few divisions the nucleocytoplasmic hybrids assumed and maintained for over 400 cell generations the characteristics of the host cytoplasm, thereby showing that morphological form and locomotion are almost entirely independent of the nucleus. When hybrid antigenic characters were tested they were found to be predominantly of the type characteristic for the species contributing the nucleus. Danielli (1955) suggested that these data may be interpreted as evidence that the nucleus is the controlling agent in synthesis of specific macromolecules, but that the cytoplasm is relatively autonomous with regard to supramolecular organization of these molecules within the cell. If this interpretation be valid, one is faced with a most interesting problem concerning the material basis for this cytoplasmic control of growth products which are apparently largely nucleus-dependent in origin.

As illuminating as these studies are, protozoan material is nevertheless inherently incapable of throwing much light on the question of tissue differentiation. For this question metazoan material must be used. No successful nuclear transfers have been reported for other invertebrates although Danielli (195.5) stated that preliminary attempts have been made on sea urchin and ascidian eggs. All remaining studies reported to date have dealt with amphibian eggs and, of these, by far the most extensive and successful experiments have been carried out by Briggs and King working with the frog, Rana pipiens (Briggs and King, 1952, 1953, 1955; King and Briggs, 1953, 1954a,b, 1955).

In brief, their transplantation technique involved activation of eggs with a clean glass needle; this is sufficient to cause the egg to rotate and initiate the second maturation division. A few abortive furrows may appear, but no true cleavage or blastulation takes place (Briggs, Green, and King, 1951). Guyer (1907) showed that, in the absence of tissue fluid contaminants, pricking alone is not sufficient to stimulate parthenogenetic development in the frog egg. The egg nucleus was removed by the method of Porter (1939) in which a needle is inserted under the egg nucleus and drawn upward, causing an exovate of egg cytoplasm which, 
when properly executed, contains the egg nucleus. In the hands of Briggs and King, enucleation by this means was approximately 99\% successful. Diploid donor cells were isolated from normal blastulae, gastrulae, neurulae, and tail-bud embryos by microdissection, or better, by the trypsin-versene method for dissociating embryonic cells (King and Briggs, 1955). Single cells were drawn into fine micropipets in such a manner as to cause the cell membrane to rupture without diluting the cell contents with the operating medium. With the aid of an Emerson micromanipulator, the whole cell was then injected into an activated and enucleated host egg. No attempt was made to exclude the donor cytoplasm which, however, constituted only a very minute fraction (1:20,000 to $1: 600,000$ ) of the total egg volume. It is significant in connection with the results reported that differentiated cytoplasm lacking nucleus never stimulated any development when injected into enucleated host eggs (Briggs and King, 1953).

The transplantation technique was first tested to determine whether or not the various manipulations damaged either the egg cytoplasm or the transplanted nucleus. Initial experiments (Briggs and King, 1952) employed only undetermined prospective ectodermal cells of normal diploid blastulae. Approximately one-third of the cases gastrulated and, of these, nearly half formed embryos which were quite normal in appearance and capable of developing into swimming larvae, and the remainder underwent somewhat abnormal postgastrula development. Determinations of ploidy in these embryos, based on nuclear size and nucleolar number, revealed that all were either diploid or polyploid (haploids would generally be expected if these cases represented failures in enucleation of the egg followed by parthenogenetic development; however, spontaneous regulation to diploidy can occur in parthenogenetic frog eggs as Parmenter, 1952, and others have shown). Although the percentage of successful cases was somewhat lower, essentially similar results were obtained when undetermined prospective neuro-epidermal cells of early gastrulae were used as a source of donor nuclei (Briggs and King, 1953; King and Briggs, 1954a, 1955). It thus seems certain that these diploid nuclei from blastulae and early gastrulae were not 
irreversibly determined at the time of transplantation since they were capable of replacing the zygote nucleus and of participating in total normal development.

With the foregoing demonstration of the feasibility of this operative technique, Briggs and King have proceeded to improve the method and to test the possibility of nuclear differentiation in determined embryonic cells by using gastrulae, neurulae, and tail-bud embryos as sources of donor nuclei. In general it can be said that the older the donor nucleus, the lower is the percentage of successful cases which show cleavage, gastrulation, and postgastrula development. As yet, no cases involving neurula or tail-bud nuclear transplants have been reported which gastrulated normally, although a small number have undergone normal cleavage (King and Briggs, 1954a). This may be due to technical difficulties encountered in handling the smaller cells. It is also possible that this developmental failure may be associated with a restriction in the capacity of older nuclei to participate in total development. The strongest evidence in support of the latter possibility is supplied by transplantation of nuclei from determined cells of late gastrulae (Briggs and King, 1953; King and Briggs, 1954a, and, particularly, 1955).

The results from transplanting nuclei from recently induced neural ectoderm from late gastrulae into enucleated eggs showed that cases reaching the blastula stage could develop into entirely normal tadpoles (King and Briggs, 1954a). Although the donor nucleus came from a cell determined to form neural tissue, it is apparent that if any tissue-specific nuclear differentiation existed at the time of transfer, it was completely reversible. Briggs and King (1955) pointed out that these results should be viewed in context with the observations of Grobstein (1952) and Grobstein and Zwilling (1953) who have found that, although large masses of explanted mouse or chick neural plate will form nervous tissue, small fragments fail to differentiate. This indicates that the neural plate may be irreversibly determined as a whole while its component cells remain labile and incapable of self-differentiation. If the same situation were to obtain in Amphibia, the possibility 
exists that recently determined neural cells of the frog may possess nuclei in a labile state of differentiation.

When late gastrula "chorda-mesoderm" nuclei were injected into enucleated eggs, a few cases developed into entirely normal larvae, one of which was carried to metamorphosis (King and Briggs, 1954a). However, in a great majority of the cases, development was arrested by the late neurula stage (King and Briggs, 1955). Histological sections of the abnormal postneurulae revealed that brain, spinal cord, notochord, gut, pronephric tubules, heart, blood vessels, somites, and sense organs developed (King and Briggs, 1954a). Neural differentiation was generally reduced or entirely absent. It was suggested that the donor "chorda-mesoderm" nucleus, although capable in some instances of giving rise to total normal development, might be partially deficient in its control of the ectodermal response to neural induction (King and Briggs, 1955). However, on the basis of the best cases obtained, it would appear that these nuclei, at most, are determined in an entirely labile manner at the late gastrula stage.

The most decisive evidence of nuclear specialization during development was obtained when determined mid-gut endoderm nuclei of late gastrulae were injected into enucleated eggs (King and Briggs, 1955). In $40 \%$ of the attempts, complete blastulae were obtained. All failed to develop normally in gastrula and postgastrula stages. The most advanced experimental embryos exhibited a consistent combination of anomalies not observed in other embryos. These included epidermal disorganization involving localized deficiencies and unequal thickness, poor neural development with cytological evidence of nuclear degeneration, well-developed notochord, differentiated somites of abnormal form, and a gut "developed as well as the general condition of the embryo allows" (King and Briggs, 1955, p. 324). Endodermal cytoplasm alone did not produce this result when injected into normally fertilized eggs. On the basis of these clata, King and Briggs seemed justified in revising their earlier and more conservative interpretations (King and Briggs, 1954a; Briggs and King, 1955) and in concluding that "it now appears definite that 
nuclei undergo certain changes during differentiation ... experiments not reported here reveal that at later developmental stages there is a loss of the capacity of these nuclei to enter into cleavage of egg cytoplasm. All together, this suggests a progressive specialization of nuclear function during cell differentiation" (King and Briggs, 1955, p. 324).

The writer is aware of only one attempt to repeat the studies of Briggs and King on eggs of $R$. pipiens. This consists of an unpublished study by Dr. C. L. Markert who has generously given permission to have his data summarized here. The enucleation and transplantation technique was essentially similar to that used by Briggs and King and the results outlined in a written communication are of sufficient interest and corroborative value to be quoted in full:

"In the initial series of experiments [performed in collaboration with Arthur Freedman] a total of 256 nuclei were transplanted. Of the eggs receiving these transplanted nuclei, 117 showed no signs of development; 34 underwent abortive cleavage; 40 showed extensive cleavage; 32 developed to blastula; 20 gastrulated (generally abnormal); 9 became well developed neurula, and 4 developed into larvae. One of the larvae was tetraploid. I cite these data as illustrative of the discouragingly low level of success that we achieved. Later I resumed this work with a higher percentage of success but the general picture remained essentially unchanged. A variety of cell types was used as a source of nuclei in these experiments. Nearly all of the successful transplants involved nuclei from cells of blastula or early gastrula embryos. One of the neurulae-an abnormal one-developed after transplantation of a nucleus from an endoderm cell taken from the floor of the archenteron in the late neurula stage of development. This was the most advanced stage of development induced by nuclei taken from post-gastrulae. However, cleavage was induced occasionally even with nuclei from larvae old enough to show muscular responses" (C. L. Markert, umpublished experiments).

These results are in agreement with those of Briggs and King which indicate that normal development is less frequently obtained as the age of the donor nucleus increases. The concluding 
statement of Markert is of particular interest in giving promise of success in transplanting nuclei from histologically differentiated cells with further refinement of the operative technique.

In evaluating the results of late gastrular nuclear transplants, it can be said with certainty that irreversible nuclear specialization does not take place at a uniform rate throughout the embryo. Apparently none has occurred by this time in prospective ectoderm derivatives; chorda-mesoderm nuclei may illustrate an intermediate condition, whereas endoderm nuclei are clearly specialized. The data from "mid-gut embryos" probably should be interpreted as evidence of quantitative, rather than qualitative, modification in nuclear fumction since, in the most advanced cases at least, all tissue types were represented to a greater or lesser degree. Even ectoderm, although poorly developed, showed a slight capacity for neural development. An alternative interpretation admits the possibility of tissue-specific (i.e., qualitative) nuclear differentiation. For example, current evidence does not permit one to decide whether the limited neural capacity in "mid-gut embryos" stemmed from the transplanted nucleus (as is assumed above), or is the expression of a residual effect of the egg nucleus dating from the period of oogenesis. The latter possibility should not be overlooked, since the well-known studies of Hämmerling (1934, 1953) on regeneration in Acetabularia, and of Hadorn (1936) on andromerogonic Triton hybrids [T. palmatus ( $q$ ) x T. cristatus $\hat{0}$ ] have shown that species-specific characters of nuclear origin can be maintained in the cytoplasm of enucleated cells and in the presence of a foreign nucleus for extended periods of time (several months in Acetabularia; until postmetamorphosis in Triton hybrid merogon tissues when transplanted to diploid hosts). This second possibility gains some support from the cytological condition of the epidermal nuclei in "mid-gut embryos" which showed abnormal degenerative structure that suggests an incompatibility between irreversibly determined cytoplasm and nuclei. This question, along with those relating to the influence of donor cytoplasm injected with the transplanted nuclei, and the possible effects of nuclear damage in operative manipulation (in particular the trypsin-versene method of isolating donor cells) 
cannot be answered in the light of present knowledge. It will be particularly interesting in these connections to learn of the results being obtained with improved techniques for transplantation of postgastrula nuclei which King and Briggs (1955) indicate are in progress. To complete the picture, it would also be desirable to learn the developmental capacities of blastula and young gastrula endoderm nuclei to discover when nuclear specialization in these cells is first demonstrable.

Blastula and gastrula nuclei from $R$. pipiens $q \times R$. catesbeiana $\hat{o}$ diploid hybrids and from $R$. pipiens ( $q$ ) x $R$. catesbeiana $\hat{o}$ andromerogonic haploid hybrids have also been transplanted into enucleated R. pipiens eggs (Briggs and King, 1952; King and Briggs, 1953). These experiments were designed to analyze the role of the nucleus in the well-known lethality which occurs during gastrulation in $R$. pipiens of $\mathrm{x} R$. catesbeiana $\hat{o}$ crosses (see review by J. A. Moore, 1955). Since this subject is aside the major line of interest here and is treated in a separate section of this volume (see J. R. Gregg), it will suffice to say that potentially lethal hybrid nuclei from undetermined blastula and gastrula cells could be transferred into enucleated eggs and would participate in normal cleavage and blastulation, but they would not permit complete gastrulation. This was true provided that the donor nucleus had not advanced to the stage when irreversible degenerative changes take place which anticipate lethality in the donor hybrids. The hybrid donor nuclei therefore gave evidence of being able to survive long after they would have died had they remained in the donor embryos. These results also show that lathality in this cross is not due to autonomous nuclear change, but it is the result of failure on the part of $R$. catesbeiana nuclear material and $R$. pipiens cytoplasm to cooperate in postgastrula development. Related to this study is a brief report (Briggs and King, 1955) of transplanting nuclei from blastulae of the anuran, Triturus pyrrhogaster, into enucleated $R$. pipiens eggs. Partial cleavage and blastulae were obtained in the best cases. Cytological study showed that the pyrrhogaster cell probably supplied a centrosome which was capable of quite normal function as a cleavage center in pipiens cytoplasm. The foreign nu- 
cleus, although incapable of maintaining its integrity during interphase and mitosis, was nevertheless able to increase in chromatin volume, presumably by utilization of nonspecific protein precursors in the pipiens cytoplasm.

The remaining studies on nuclear transplantation that have been reported were carried out on eggs of the salamander, Triturus (Triton) palmatus (Waddington and Pantelouris, 1953; Lehman, 1955). These attempts have been entirely unsuccessful so far as obtaining postblastula is concerned, and no information relative to progressive nuclear differentiation has been obtained from these experiments. Waddington and Pantelouris injected nuclei from diploid blastula, gastrula, and neurula donor cells into non-nucleate halves of normally fertilized eggs. Cleavages were obtained with all types of donor cells. When blastula and gastrula donor cells were used, some of the cases developed into abnormal arrested blastula with a reduced blastocoele filled with loose cells. It was not clear from these results whether the arrest in development at the blastula stage was occasioned by nuclear specialization, or by operative damage, or by lack of totipotency on the part of the host egg fragment.

In view of these uncertainties, an attempt was made to repeat these experiments on whole eggs of T. palmatus (Lehman, 1955). Unfortunately, Triton eggs cannot be parthenogenetically activated by pricking, nor was it possible to stimulate development by the injection of blastula nuclei alone. This difficulty was partly circumvented by using Rugh's (1939) technique of x-irradiating sperm at 50,000 $\mathrm{r}$ to inactivate the chromatin without destroying the fertilizing capacity of the sperm. Although haploid embryos were consistently obtained from normal eggs fertilized by such sperm, the technique cannot be considered entirely satisfactory since minute disorganized chromatin fragments, probably of sperm origin, were frequently observed in smear preparations. These fragments, if of sperm origin, had undoubtedly undergone some multiplication during development even though they were not intimately associated with the clivision figure. The possibility of some developmental effect of these degenerating "sperm chromatin fragments" cannot be ignored. After fertilization with 
irradiated sperm, host eggs were pricked and the egg nucleus was sucked out in the manner described by Curry (1931, 1936); in my experience, this enucleation technique was successful in only about $50 \%$ of the attempts (as determined by the incidence of haploids developing from "enucleated" eggs fertilized by normal sperm). Normal diploid blastula ectoderm and endoderm cells were used for injection and they gave similar results. About $65 \%$ of the injected eggs cleaved and, of these, about one-third developed into blastulae which externally appeared to be quite normal; however, internally they were invariably atypical and at best had a reduced blastocoele. Most of the cases were sacrificed at the blastula stage for cytological study but, of those permitted to continue development, none progressed beyond the earliest crescent blastopore stage. Since half of these embryos probably retained the egg nucleus after unsuccessful attempts at enucleation and should develop as typical hybrids, these results suggest that the Triton cytoplasm is less able to recover from the injury of injection than is the cytoplasm of $R$. pipiens.

The interpretation of evidence from nuclear transplantation in Triton (Waddington and Pantelouris, 1953; Lehman, 1955) is extremely problematical since no development was obtained in these embryos which cannot be duplicated in totally enucleate eggs of this species (Fankhauser, 1929, 1934). The injected nuclei from undetermined or determined cells from blastula to neurula stages are probably capable of at least limited participation in cleavage and blastulation, but there is no direct evidence that these Triton nuclei can take part in postblastula development. Whether this is due to operative damage or nuclear specialization is not known. Similar types of arrested blastulae have been described in various salamander hybrids (e.g., Baltzer et al., 1939; Baltzer and Schönmann, 1951), and in certain instances the individual tissues have been shown to be completely viable when transplanted to normal diploid hosts. The application of this method to the arrested "injection blastulae" of Triton is the most promising approach available at present for assaying the developmental capacities of transplanted nuclei of different age and de- 
velopmental history. Although the eggs of Triton appear to be relatively unfavorable for nuclear transplantations, it is hoped that techniques for activation, enucleation, and injection can be improved so that decisive evidence can be obtained concerning nuclear differentiation in this classic form for embryonic study. Other species of Triturus (Triton) may be more amenable to nuclear transplantation than $T$. palmatus, and the search for such a species is particularly desirable in view of the favorable cytological properties of this material.

The cytological analysis of "nuclear transplant embryos" is deserving of more thorough study. Nothing is known concerning the actual behavior of the injected nuclei during the initial cleavage stages, and this subject has considerable intrinsic interest entirely apart from the question of determination. Secondly, it is apparent that the major evidence of successful egg enucleation followed by injection of a diploid donor cell is based on the presence of diploid nuclei in tissues of the experimental embryo; haploidity is indicative of failure in enucleation of the egg. In the studies by Briggs and King, ploidy in "nuclear transplant" embryos that developed to late neurulae and tadpole stages was determined by nuclear size and, wherever possible, by nucleolar number (for method, see Briggs, 1947). Of 67 cases reported (Briggs and King, 1952; King and Briggs, 1954a), only one embryo gave evidence of failure in enucleation; this was a haploiddiploid mosaic which had been injected with a young gastrula cell. It probably indicates that both the egg and injected nucleus cooperated in development. The remaining 66 cases represent successful enucleation and transplantation; 34 were diploid and 32 were polyploid (probably tetraploid). Briggs and King (1952) suggested that the high incidence of polyploidy may result from doubling and division of donor chromosomes before the egg cytoplasm is capable of cleaving. This is probably true, but it does not relieve the necessity of considering the possible developmental significance of polyploidy in the experimental animals. This is particularly important when one examines the data given below and finds that the incidence of polyploid individuals in- 
creases with the age and differentiation of the donor nuclei and therefore parallels the evidence interpreted as an indication of nuclear differentiation.

Origin of Donor Cells

Blastula ectoderm

Young gastrula ectoderm

Late gastrula neural ectoderm

and chorda-mesoderm
Ploidy in "Nuclear

Transplant" Embryos

\section{Diploid Polyploid}

$\begin{array}{rrl}21 & 9 & \text { (Briggs \& King, 1952) } \\ 10 & 7 & \text { (King \& Briggs, 1954a) } \\ 3 & 16 & \text { (King \& Briggs, 1954a) }\end{array}$

Note: No data on ploidy were included with the most recent and convincing evidence of nuclear differentiation in late gastrula mid-gut cells reported by Briggs and King (1955).

It is well known that, so long as complete sets of chromosomes are duplicated, a moderate increase in ploidy is compatible with normal development (see review by Fankhauser, 1955). The results of Briggs and King have shown that polyploidy in "nuclear transplant" embryos bear this out in that some of their best and most long-lived cases were polyploids. However, when chromosome duplication involves only part of the chromosome complement (aneuploidy) viability is greatly impaired and differentiation is usually abnormal (see reviews by Fankhauser, 1945, 1952, 1955). The latter fact should be considered along with the evidence from chromosome counts on "nuclear transplant embryos" of Triton which revealed a high incidence of hyperdiploids and diploid-hyperdiploid mosaics (Lehman, 1955). This alone could be a significant factor contributing to the generally poor development that was obtained with Triton eggs. The technique for determining ploidy used by Briggs and King (namely, nuclear size and nucleolar number) cannot yield precise information concerning degrees of aneuploidy.

Considerable caution should be exercised in deducing positive evidence for nuclear differentiation from arrested or atypical "nuclear transplant embryos" unless there is a cytological basis for demonstrating euploidy and/or a consistent syndrome in the anomaly obtained with a given type of determined donor cell nucleus. The latter condition has been satisfactorily met in the 
case of mid-gut nuclei from late gastrulae of $R$. pipiens (King and Briggs, 1955), and this example stands as the only positive evidence of nuclear differentiation yet obtained from nuclear injection experiments. As such, it represents a real advance in the understanding of this problem. However, even this example does not express its nuclear specialization in cytoplasmic responses that are limited to the tissue-specific determination of the injected mid-gut donor cells. It is therefore apparent that nuclear and cytoplasmic determinations do not proceed at the same pace since it is well known from the work of Holtfreter (1938a,b) that as early as the late blastula stage the endoderm consists of an almost rigid mosaic of organ-specific irreversibly determined cells. The nucleus of a determined cell may well remain in a labile state of differentiation and/or retain a wider range of histogenic potentialities than the cytoplasm surrounding it. An answer to questions concerning the possibility of tissue-specific nuclear specialization and labile versus irreversible nuclear determination must await additional information from transplantations of more advanced nuclei, preferably from cells showing histological or biochemical differentiation as well as determination. It is probably not until quantitative and qualitative differences in the macromolecular composition of the embryonic tissues is distinct that one should expect to find nuclei restricted to tissue-specific functions.

\section{Conclusion}

Evidence from biochemical, cytological, and nuclear transplantation studies has been reviewed which indicates that in certain instances at least tissue-specific differences can be demonstrated in the nuclei of histologically determined cells within embryos and adult organisms. These examples stand at present as exceptions to the generally held concept of quantitative and qualitative nuclear uniformity in somatic cells, a concept which to a large measure is based on evidence obtained from the demonstration of nuclear totipotency in early cleavage cells and regenerating tissue. Nuclear transplantation studies suggest that embryonic nuclei are totipotent until gastrulation and may retain the capacity 
for participating in total development even after the cells containing them are histologically determined. However, with advancing age and progressive differentiation there is an indication that embryonic nuclei become restricted in their developmental capacities. These data would indicate that nuclear determination and differentiation, if they do indeed regularly occur during histogenesis, do not take place concurrently with the initial determination of the cell as a whole. One is led to suspect that determination is gradually imposed on the nucleus by its surrounding cytoplasm. There is no information available at present to clarify the question of labile versus irreversible nuclear differentiation; nor is it possible in the light of current knowledge to decide whether or not cytoplasmic differentiation accompanied by nuclear differentiation is a general or an exceptional aspect of histogenesis.

In concluding this summary of evidences for nuclear differentiation it is safe to say that even the most guarded and conservative evaluation must admit the possibility of progressive nuclear differentiation in development. Stern (1955) has pointed out that this hypothesis is not required to account for local developmental differences, but the possibility is compatible with the general array of facts provided by genetics, physiology, and embryology. Additional examples of restriction in nuclear function correlated with cytoplasmic differentiation are needed from older tissues and other species before it will be possible to say with any degree of certainty that nuclear differentiation does indeed characterize histogenesis generally. If this primary question is answered affirmatively by new data, it will be appropriate to consider secondary questions beyond the scope of this paper relative to the manner in which determined cytoplasm "induces" nuclear change, as well as the nature of the reciprocal influence of the nucleus in maintaining cytoplasmic function (for theories already advanced relating to these questions, see reviews on: auto-antibodies, Tyler, 1946; Weiss, 1950, 1955; Ebert, 1954; Woerdeman, 1955; plasmagenes, Mather, 1948; Schultz, 1950, Sonneborn, 1951; Stern, 1955; en₹yme adaptation, Monod, 1947; Spiegelman, 1948; Stanier, 1954). With regard to these latter questions one of 
the most promising modifications of the nuclear transplantation technique could involve experimental attempts to "determine" labile blastula cell nuclei by pretreatment with various agents including organ-specific extracts before testing their capacities for differentiation. The method of nuclear transplantation has so far only been used as a means of studying nuclear differentiation but this technique, when explored more fully, may find a considerably wider application in the study of other aspects of cell function including synthesis of gene-controlled materials in the cytoplasm and, as Briggs and King (1952) have suggested, in the study of the division process itself.

\section{REFERENCES}

Baltzer, F. 1952. The behavior of nuclei and cytoplasm in amphibian interspecific crosses. Symposia Soc. Exptl. Biol., 6, 230-42.

Baltzer, F., and H. Schönmann. 1951. Ueber die Letalität des Bastards Triton palmatus of x Salamandra atra of. Rev. suisse zool., 58, 495502.

Baltzer, F., H. Schönmann, H. Lüthi, and F. Boehringer. 1939. Analyse der nucleären Letalität bei Urodelenbastarden. Arch. exptl. Zellforsch., 22, 276-81.

Barth, L. G., and L. Jaeger. 1947. Phosphorylation in the frog's egg. Physiol. Zool., 20, 133-46.

Beermann, W. 1952. Chromomerenkonstanz und spezifische Modifikationen der Chromosomenstruktur in der Entwicklung und Organdifferenzierung von Chironomus tentans. Chromosoma, 5, 139-98.

Berger, C. A. 1938. Multiplication and reduction of somatic chromosome groups as a regular developmental process in the mosquito, Culex pipiens. Carnegie Inst. Wash. Publ., 496, 209-32.

Berger, C. A. 1940. The uniformity of the gene complex in the nuclei of different tissues. J. Heredity, 31, 3-4.

Berger, C. A. 1941. Multiple chromosome complexes in animals and polysomaty in plants. Cold Spring Harbor Symposia Quant. Biol., 9, 19-21.

Berrill, N. J., and C. L. Huskins. 1936. The "resting" nucleus. Am. Naturalist, 70, 257-61.

Berry, R. O. 1941. Chromosome behavior in the germ cells and devel- 
opment of the gonads in Sciara ocellaris. J. Morphol., 68, 547-83. Boivin, A., R. Vendreley, and C. Vendreley. 1948. L’acide désoxyribonucléique du noyau cellulaire, dépositaire des charactères héréditaires; arguments d'ordre analytique. Compt. rend., 226, 1061-63. Brachet, J. 1947. Biochemical and physiological interrelations between nucleus and cytoplasm during early development. Growth (7th Growth Symposium), 11, 309-24.

Brachet, J. 1950. Chemical Embryology. Interscience Publishers, New York-London.

Brachet, J. 1952. The role of the nucleus and the cytoplasm in synthesis and morphogenesis. Symposia Soc. Exptl. Biol., 6, 173-200.

Brachet, J. 1955. Recherches sur les interactions biochemiques entre le noyau et le cytoplasme chez les organisms unicellulaires. I. Amocba proteus. Biochem. Biophys. Acta, 18, 247-68.

Briggs, R. 1947. The experimental production and development of triploid frog embryos. J. Exptl. Zool., 106, 237-66.

Briggs, R., E. U. Green, and T. J. King. 1951. An investigation of the capacity for cleavage and differentiation in Rana pipiens eggs lacking "functional" chromosomes. J. Exptl. Zool., 116, 455-500.

Briggs, R., and T. J. King. 1952. Transplantation of living nuclei from blastula cells into enucleated frogs' eggs. Proc. Natl. Acad. Sci. U. S., 38, 455-63.

Briggs, R., and T. J. King. 1953. Factors affecting the transplantability of nuclei of frog embryonic cells. J. Exptl. Zool., 122, 485-506.

Briggs, R., and T. J. King. 1955. Specificity of nuclear function in embryonic development. Biological Specificity and Growth (12th Growth Symposium). Princeton Univ. Press, Princeton, N. J. Pages 207-28.

Caspersson, T. 1950. Cell Grouth and Cell Function. Norton, New York.

Caspersson, T., and J. Schultz. 1951. Cytochemical measurements in the study of the gene. Genetics in the 20th Century. The Macmillan Company, New York. Pages 155-71.

Child, C. M. 1941. Patterns and Problems of Development. Chicago Univ. Press, Chicago, Ill.

Comandon, J., and P. deFonbrune. 1939. Greffe nucléaire totale, simple ou multiple, chez une Amibe. Compt. rend. soc. biol., 130, 74448.

Curry, H. A. 1931. Methode zur Entefernung des Eikerns bei normal- 
befruchteten und bastardbefruchteten Triton-Eiern durch Anstich. Rev. suisse $\approx 0 o l .$, 38, 401-3.

Curry, H. A. 1936. Über die Entkernung des Tritoneies durch Absaugen des Eifleckes und die Entwicklung des Tritonmerogons Triton alpestris ( Organ., 134, 694-715.

Danielli, J. F. 1952. Separate nuclear and cytoplasmic actions of drugs. Nature, 170, 1042-44.

Danielli, J. F. 1955. The transfer of nuclei from cell to cell as a method of studying differentiation. Exptl. Cell Research, Suppl. 3, 98-101.

Duryee, W. R. 1950. Chromosomal physiology in relation to nuclear structure. Ann. N. Y. Acad. Sci., 50, 920-53.

Ebert, J. D. 1954. Some aspects of protein biosynthesis in development. Aspects of Synthesis and Order in Growth (13th Growth Symposium). Princeton Univ. Press, Princeton, N. J. Pages 69-112.

Fankhauser, G. 1925. Analyse der physiologischen Polyspermie des Triton-eies auf Grund von Schnürungsexperimenten. Arch. Entwicklungsmech. Organ., 105, 501-80.

Fankhauser, G. 1929. Über die Beteiligung kernloser Strahlungen (Cytaster) an der Furchung geschnürter Triton-Eier. Rev. suisse zool., 36, 179-87.

Fankhauser, G. 1930. Zytologische Untersuchungen an geschnürten Triton-Eiern. I. Arch. Entwicklungsmech. Organ., 122, 117-39.

Fankhauser, G. 1934. Cytological studies on egg fragments of the salamander Triton. V. Chromosome number and chromosome individuality in the cleavage mitoses of merogonic fragments. J. Exptl. Zool., 68, 1-57.

Fankhauser, G. 1945. The effects of changes in chromosome number on amphibian development. Quart. Rev. Biol., 20, 20-78.

Fankhauser, G. 1952. Nucleo-cytoplasmic relations in amphibian development. Intern. Rev. Cytology, 1, 165-94.

Fankhauser, G. 1954. Interaction of nucleus and cytoplasm in cell growth. Dynamics of Growth Processes (11th Growth Symposium). Princeton Univ. Press, Princeton, N. J. Pages 68-94.

Fankhauser, G. 1955. The role of the nucleus and cytoplasm. In Analysis of Development. Saunders, Philadelphia, Pa. Pages 126-50.

Gall, J. G. 1952. The lampbrush chromosomes of Triturus viridescens. Exptl. Cell Research, Suppl. 2, 95-102.

Geitler, L. 1934. Grundriss der Cytologie. Borntraeger, Berlin. 
Geitler, L. 1941. Das Wachstums des Zellkerns in tierischen und pflanzlichen Geweben. Ergeb. Biol., 18, 1-54.

Green, E. U. 1953. Regular occurrence of the haploid number of chromosomes in mesenchymal cells of the tail tip of Rana pipiens tadpoles. Nature, 172, 766-67.

Gregg, J. R. 1948. Carbohydrate metabolism of normal and of hybrid amphibian embryos. J. Exptl. Zool., 109, 119-34.

Grell, M. 1946a. Cytological studies in Culex. I. Somatic reduction divisions. Genetics, 31, 60-76.

Grell, M. 1946b. Cytological studies in Culex. II. Diploid and meiotic divisions. Genetics, 31, 77-94.

Grobstein, C. 1952. Effect of fragmentation of mouse embryonic shields on their differentiative behavior after culturing. J. Exptl. Zool., 120, 437-56.

Grobstein, C., and E. Zwilling. 1953. Modification of growth and differentiation of chorioallantoic grafts of chick blastoderm pieces after cultivation at a glass-clot interface. J. Exptl. Zool., 122, 259-84.

Guyer, M. F. 1907. The development of unfertilized frog eggs injected with blood. Science, 25, 910-11.

Hadorn, E. 1936. Übertragung von Artmerkmalen durch das entkernte Eiplasma beim merogonischen Tritonbastard, palmatus-Plasma $\mathrm{x}$ cristatus-Kern. Verhandl. deut. zool. Ges. (Freiburg), 38, 97-104. Hämmerling, J. 1934. Über genomwirkungen und Formbildungsfähigkeit bei Acetabularia. Arch. Entwicklungsmech. Organ., 132, 42462.

Hämmerling, J. 1953. Nucleo-cytoplasmic relationships in the development of Acetabularia. Inter. Rev. Cytology, 2, 475-98.

Hannah, A. 1951. Localization and function of heterochromatin in Drosophila melanogaster. Advances in Genetics, 4, 87-126.

Hertwig, O. 1916. Das Werden der Organismen. G. Fischer, Jena.

Holtfreter, J. 1938a. Differenzierungspotenzen isolierter Teile der Urodelengastrula. Arch. Entwicklungsmech. Organ., 138, 522-56.

Holtfreter, J. 1938b. Differenzierungspotenzen isolierter Teile der Anurengastrula. Arch. Entwicklungsmech. Organ., 138, 657-738.

Huskins, C. L. 1947. The subdivision of the chromosomes and their multiplication in non-dividing tissues: Possible interpretations in terms of gene structure and gene action. Am. Naturalist, 81, 401-34.

Huskins, C. L. 1952. Nuclear reproduction. Intern. Rev. Cytology, 1, 9-26.

Huskins, C. L., and L. M. Steinitz. 1948a. The nucleus in differentia- 
tion and development. I. Heterochromatic bodies in energic nuclei of Rhoeo roots. J. Heredity, 39, 35-43.

Huskins, C. L., and L. M. Steinitz. 1948b. The nucleus in differentiation and development. II. Induced mitoses in differentiated tissues of Rhoeo roots. J. Heredity, 39, 67-77.

King, T. J., and R. Briggs. 1953. The transplantability of nuclei of arrested hybrid blastulae ( $R$. pipiens o $\times R$. catesbeiana ô). J. Exptl. Zool., 123, 61-78.

King, T. J., and R. Briggs. 1954a. Transplantation of living nuclei of late gastrulae into enucleated eggs of Rana pipiens. J. Embryol. Exptl. Morphol., 2, 73-80.

King, T. J., and R. Briggs. 1954b. Nuclear changes in differentiating endoderm cells as revealed by nuclear transplantation (abstract). Anat. Record, 120, 723-24.

King, T. J., and R. Briggs. 1955. Changes in the nuclei of differentiating gastrula cells, as demonstrated by nuclear transplantation. Proc. Natl. Acad. Sci., 41, 321-25.

Kosswig, C., and A. Shengün. 1947. Intraindividual variability of chromosome IV of Chironomus. J. Heredity, 38, 235-39.

Lehman, H. E. 1955. On the development of enucleated Triton eggs with an injected blastula nucleus. Biol. Bull., 108, 138-50.

Lewis, E. B. 1950. The phenomenon of position effect. Advances in Genetics, 3, 73-116.

Lindahl, P. E. 1953. Somatic reduction division in the development of the sea urchin. Nature, 171, 437-38.

Lorch, I. J., and J. F. Danielli. 1950. Transplantation of nuclei from cell to cell. Nature, 166, 329-30.

Makino, S., and M. Alfert. 1954. Disputandum: To the question of somatic reduction divisions in sea urchin micromeres. Experientia, 10, 489-90.

Markert, C. L. 1955. Unpublished experiments.

Mather, K. 1948. Nucleus and cytoplasm in differentiation. Symposia Soc. Exptl. Biol., 2, 196-216.

Metz, C. W. 1938. Chromosome behavior, inheritance and sex determination in Sciara. Am. Naturalist, 72, 485-520.

Mickey, G. H. 1945. Additional polyploid and mixoploid tissues in nymphs of the Louisiana lubber grasshopper, Romalca microptera (Beauv.). Proc. Louisiana Acad. Sci., 9, 39-56.

Mirsky, A. E., and H. Ris. 1949. Variable and constant components of chromosomes. Nature, 163, 666-67. 
Monod, J. 1947. The phenomenon of enzymatic adaptation and its bearings on problems of genetics and cellular differentiation. Growth (7th Growth Symposium), 11, 223-89.

Moore, B. C. 1952. Desoxyribose nucleic acid in embryonic diploid and haploid tissues. Chromosoma, 4, 563-76.

Moore, J. A. 1955. Abnormal combinations of nuclear and cytoplasmic systems in frogs and toads. Advances in Genctics, 7, 139-82.

Morgan, T. H. 1927. Experimental Embryology. Columbia Univ. Press, New York.

Morgan, T. H. 1934. Embryology and Genetics. Columbia Univ. Press, New York.

Muller, H. J., and S. M. Gershenson. 1935. Inert regions of chromosomes as the temporary products of individual genes. Proc. Natl. Acad. Sci. U. S., 21, 69-75.

Needham, A. E. 1952. Regeneration and Wound-healing. Methuen Monographs, London.

Needham, J. 1950. Biochemistry and Morphogenesis, 2nd ed., Univ. Press, Cambridge, England.

Novikoff, A. B. 1952. Histochemical demonstration of nuclear enzymes. Exptl. Cell Research, Suppl. 2, 123-40.

Painter, T. S., and E. C. Reindorp. 1939. Endomitosis in the nurse cells of the ovary of Drosophila melanogaster. Chromosoma, 1, 276-83.

Parmenter, C. L. 1952. Diploid virgin frog eggs; a possible origin of diploid parthenogenetically developed frog larvae without delay in cleavage and of triploid larvae developed from fertilized eggs. $J$. Morphol., 90, 243-61.

Pollister, A. W. 1952. Nucleoproteins of the nucleus. Exptl. Cell Research, Suppl. 2, 59-70.

Pollister, A. W. 1954. Cytochemical aspects of protein synthesis. Dynamics of Growth Processes (11th Growth Symposium). Princeton Univ. Press, Princeton, N. J. Pages 33-67.

Porter, K. R. 1939. Androgenetic development of the egg of Rana pipiens. Biol. Bull., 77, 233-57.

Rugh, R. 1939. Developmental effects resulting from exposure to X-rays. I. Effect on the embryo of irradiation of frog sperm. Proc. Am. Phil. Soc., 81, 447-71.

Schotté, O. E. 1939. The origin and morphogenetic potencies of regenerates. Growth, Suppl. 1, 59-76. 
Schultz, J. 19:39. The function of heterochromatin. Proc. 7 th Intern. Genetics Congr., pp. 257-262.

Schultz, J. 1947. The nature of heterochromatin. Cold Spring Harbor Symposia Quant. Biol., 12, 179-91.

Schultz, J. 1950. The question of plasmagenes. Science, 111, 403-7.

Schultz, J. 1952. Interrelations between nucleus and cytoplasm: problems at the biological level. Exptl. Cell Research, Suppl. 2, 17-42. Sonneborn, T. M. 1951. The role of the genes in cytoplasmic inheritance. Genetics in the 20th Century. The Macmillan Company, New York. Pages 291-314.

Spemann, H. 1914. Über verzögerte Kernversorgung von Keimteilen. Verhandl. deut. zool. Ges. (Freiburg), 24, 216-21.

Spemann, H. 1928. Die Entwicklung seitlicher und dorso-ventraler Keimhälften bei verzögerter Kerversorgung. Z. wiss. Zool., 132, 10534.

Spemann, H. 1938. Embryonic Development and Induction. Yale Univ. Press, New Haven, Conn.

Spiegelman, S. 1948. Differentiation as the controlled production of unique enzymatic patterns. Symposia Soc. Exptl. Biol., 2, 286-325.

Stanier, R. Y. 1954. The plasticity of enzymatic patterns in microbial cells. Aspects of Synthesis and Order in Growth (13th Growth Symposium). Princeton Univ. Press, Princeton, N. J. Pages 43-68.

Stern, C. 1955. Gene action. In Analysis of Development. Saunders. Philadelphia, Pa. Pages 151-69.

Stern, H., V. Allfrey, A. E. Mirsky, and H. Saetren. 1952. Some enzymes of isolated nuclei. J. Gen. Physiol., 35, 559-78.

Tyler, A. 1946. An auto-antibody concept of cell structure, growth and differentiation. Growth (6th Growth Symposium), 10, 7-19.

Tyler, A. 1955. Gametogenesis, fertilization and parthenogenesis. In Analysis of Development. Saunders, Philadelphia, Pa. Pages 170212.

Waddington, C. H., and E. M. Pantelouris. 1953. Transplantation of nuclei in newt's eggs. Nature, 172, 1050-51.

Weismann, A. 1855. Die Kontinuität des Keimplasmas als Grundlage der Vererbung. Jena.

Weismann, A. 1892. Das Keimplasma. Eine Theorie der Vererbung. Jena.

Weiss, P. 1950. Perspectives in the field of morphogenesis. Quart. Rev. Biol., 25, 177-98. 
Weiss, P. 1955. Specificity in growth control. Biological Specificity and Growth (12th Growth Symposium). Princeton Univ. Press, Princeton, N. J. Pages 195-206.

White, M. J. D. 1945. Animal Cytology and Evolution. Univ. Press, Cambridge, England.

White, M. J. D. 1946. The cytology of the Cecidomyidae (Diptera). II. The chromosome cycle and anomalous spermatogenesis of Miastor. J. Morphol., 79, 323-70.

White, M. J. D. 1947. The cytology of the Cecidomyidae (Diptera). III. The spermatogenesis of Taxomyia taxi. J. Morphol., 80, 1-24.

White, M. J. D. 1948. The cytology of the Cecidomyidae (Diptera). IV. The salivary-gland chromosomes of several species. J. Morphol, $82,53-80$.

Wilson, E. B. 1925. The Cell in Development and Heredity. The Macmillan Company, New York.

Woerdeman, M. W. 1955. Immunobiological approach to some problems of induction and differentiation. Biological Specificity and Growth (12th Growth Symposium). Princeton Univ. Press, Princeton, N. J. Pages 33-54. 


\section{MORPHOGENESIS AND METABOLISM OF \\ GASTRULA-ARRESTED EMBRYOS \\ IN THE HYBRID}

Rana pipiens \& $x$ Rana sylvatica ô

JOHN R. GREGG: zOOLOGY DEPARTMENT, COLUMBIA UNIVERSITY, NEW YORK

The purpose of the account following is to provide a fairly critical and detailed summary of some recent descriptive and experimental work on embryos belonging to the hybrid Rana pipiens $\&$ x Rana syluatica $\hat{b}$. Embryos of this type become gastrula-arrested; that is to say, when they are of gastrula age the morphogenetic movements exhibited by their tissues are not correlated in the normal (R. pipiens) pattern, and to casual observation they appear to live out their lives in a state no more developmentally advanced than that of very young $R$. pipiens gastrula.

The fact that such embryos are hybrids, each developing from a zygote formed by the union of an ovum from a member of $R$. pipiens with a spermatozoon from a member of $R$. sylvatica, is not yet of much explanatory value in accounting for their defections as developmental systems. Embryos in the two parental species are morphologically similar to a very marked degree. They are of about the same size, they are telolecithal to about the same moderate degree, they cleave totally and in the same pattern, their cells are believed to contain the same number of chromosomes $(\mathrm{N}=13)$, and, in general, the sequences of developmental transformations they exhibit are alike to such an extent that Shumway's (1940) normal table for R. pipiens and that of Pol- 


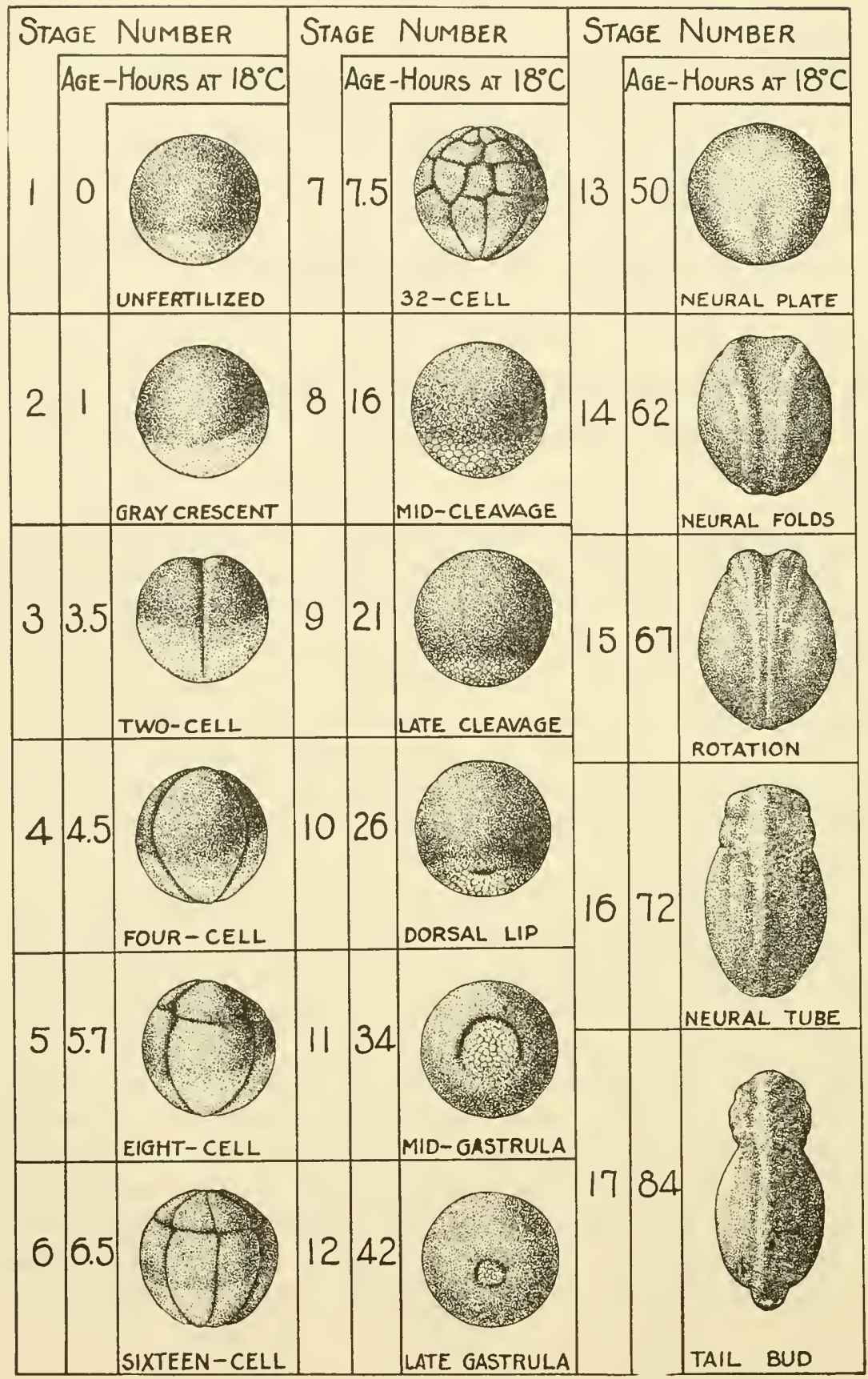

Fig. 1. Normal stages in the development of embryos in the species Rana pipiens. (From Shumway, 1940.) 


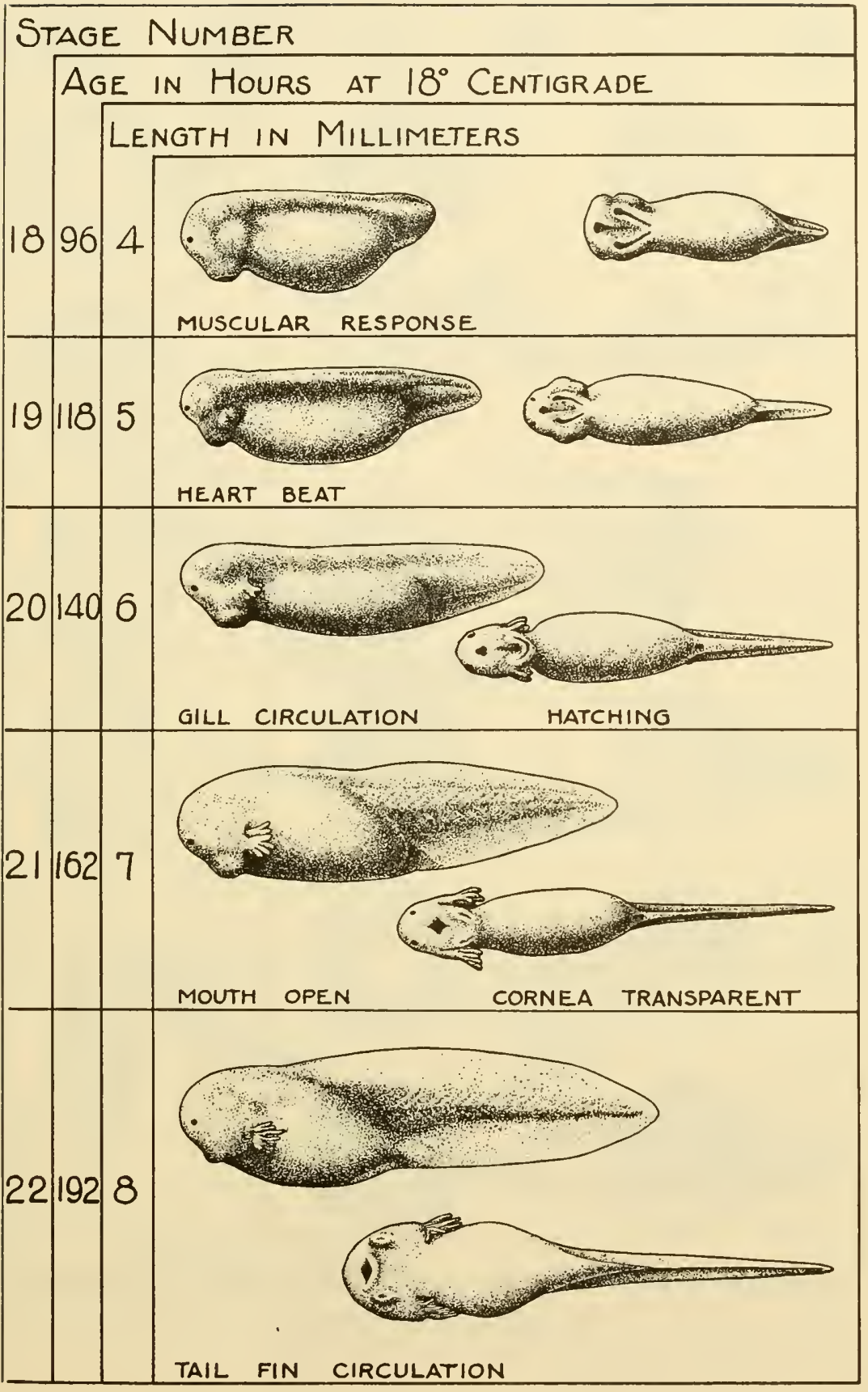

Fig. 1. (Continued.) 


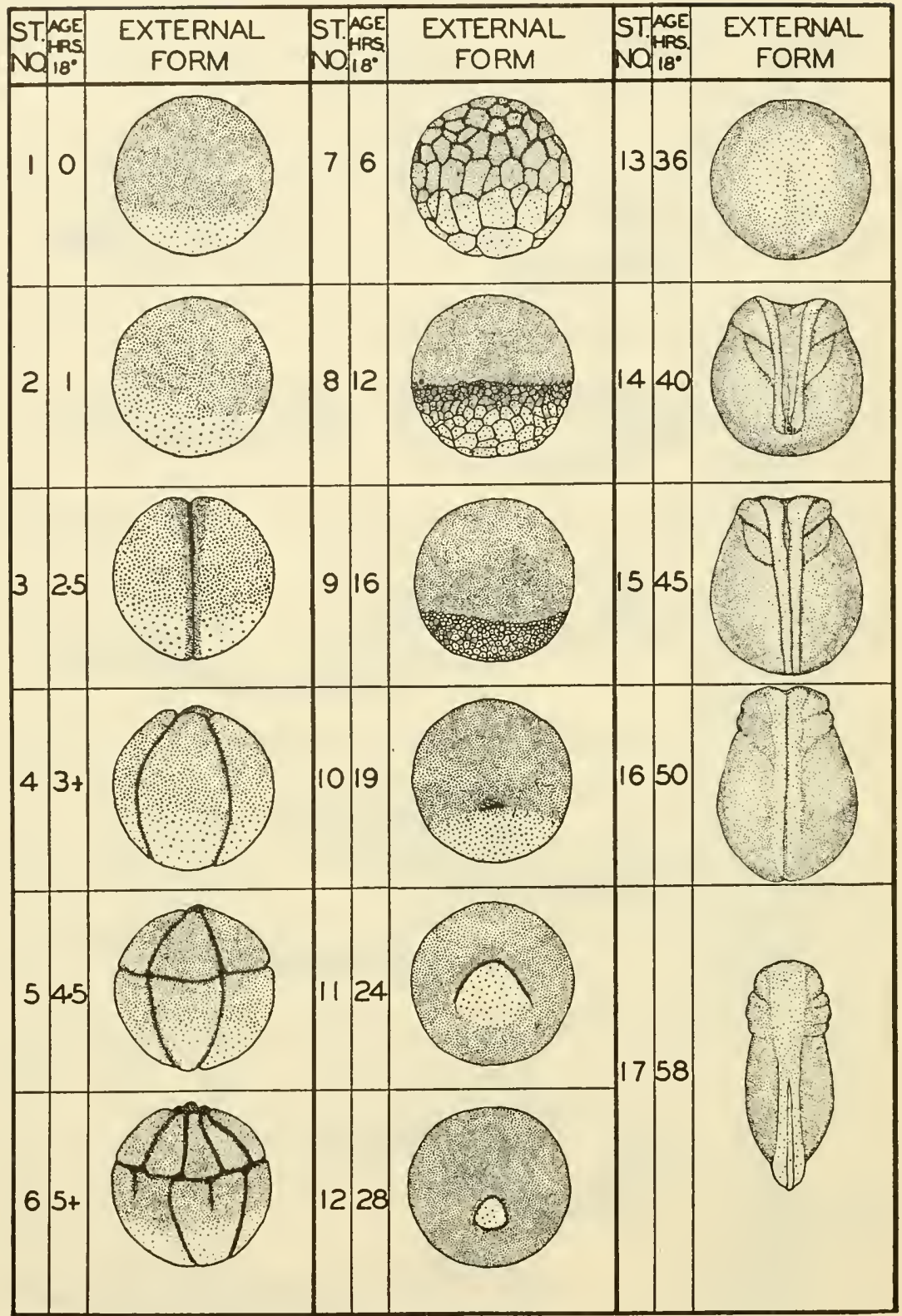

Fig. 2. Normal stages in the development of embryos in the species Rana sylvatica. (From Pollister and Moore, 1937.) 


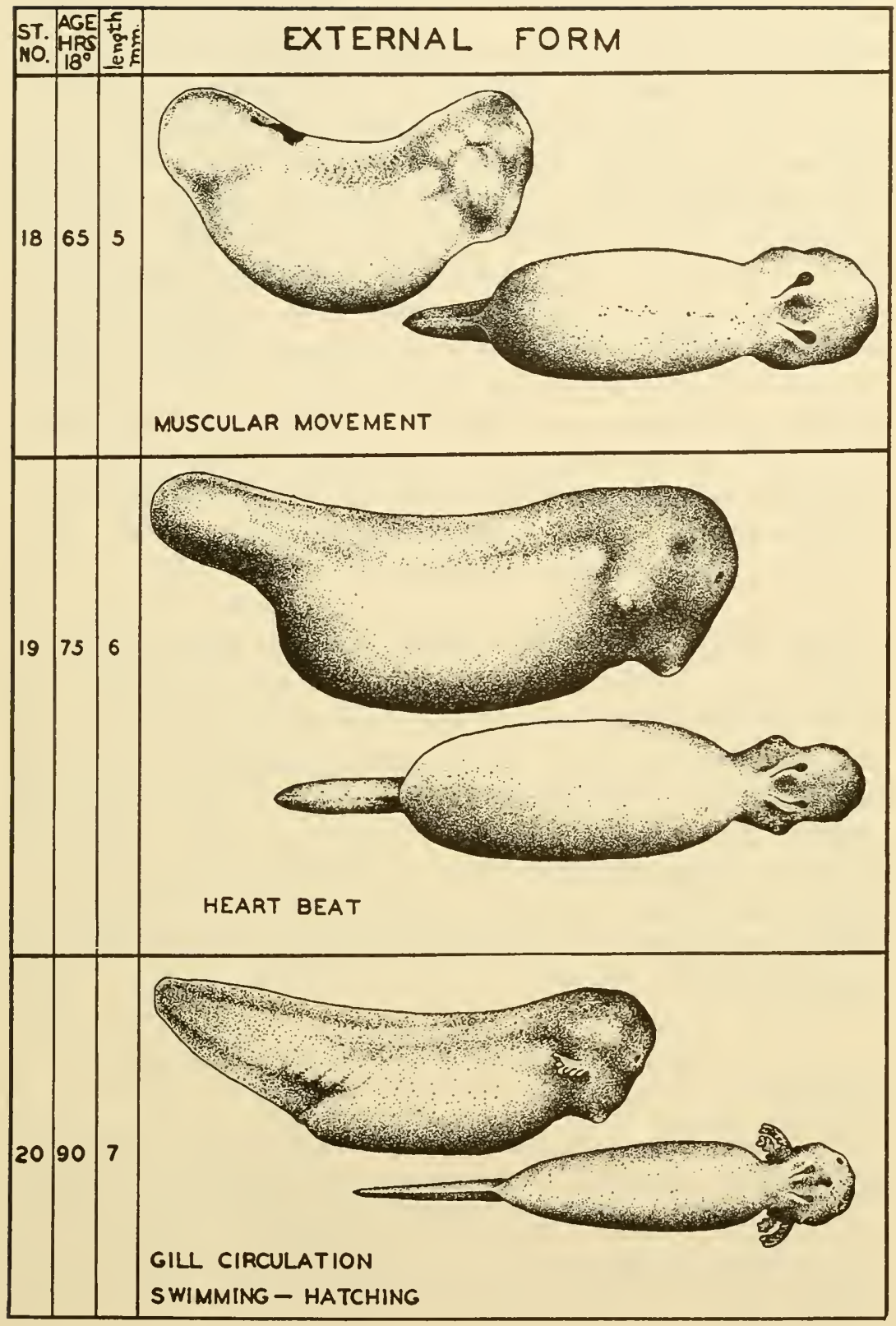

Fig. 2. (Continued.) 
lister and Moore (1937) for R. sylvatica are usable interchangeably (Figs. 1 and 2). Of course, they are not alike in all respects. For example, their blastopores are shaped differently, and as larvae they are lordotic to different degrees. Under precisely similar environmental conditions, furthermore, they may undergo corresponding changes at different rates. A $R$. pipiens zygote, for instance, will develop into an early gastrula in about 26 hours at $18^{\circ} \mathrm{C}$, whereas a $R$. sylvatica zygote will do the same thing in only 19 hours. Also, the temperature ranges within which they develop normally are not the same (Moore, 1939): $R$. pipiens embryos tolerate any temperature between $6^{\circ} \mathrm{C}$ and $28^{\circ} \mathrm{C}$; R. sylvatica embryos any temperature between $2^{\circ} \mathrm{C}$ and $24^{\circ} \mathrm{C}$. But, generally speaking, our knowledge of the phenotypes of members of the parental species does not suggest explicit hypotheses about their genotypes which are presently useful in explaining why hybrids develop improperly.

The basis of present ideas about these hybrids is Moore's careful descriptive study (1946) together with the experimental work stimulated by it. The latter includes Moore's own analyses of the capacities of hybrid tissues to induce secondary embryonic structures in normal embryos (1948) and to respond to normal embryonic inductors (1947), but the subjects of these particular papers fall outside our scope. In addition, Moore (1955) has published a general review of recent work on anuran hybridization, in one section of which the interested reader will find briefly summarized most of the findings that will now be presented in greater detail.

\section{General}

\section{Morphogenesis of Hybrid Embryos}

The following statements are intended to characterize the chief, easily observable characteristics of developing hybrids. *

1. Hybrid embryos cleave and blastulate in the same pattern as

"By "hybrid" or "hybrid embryo" we shall mean any embryo whose female parent is a member of $R$. pipiens and whose male parent is a member of $R$. sylvatica. 
and synchronously with control embryos." Small differences between advanced blastulae, however, might be difficult to detect.

2. Hybrid embryos do not begin to gastrulate until controls are in Shumway Stage $10^{+}-11^{-}$. We shall express this by saying that hybrids begin to gastrulate only when they are in stage $\mathrm{H} 10^{+}-\mathrm{H} 11^{-}$. $f$ At $18^{\circ} \mathrm{C}$ this represents a developmental delay of about 3 to 4 hours; but, in appearance, hybrids at this stage are exactly like controls in Stage 10.

3. Once formed, the blastopore of a hybrid embryo does not enlarge appreciably. (Some rare exceptions to this rule are described in Moore's (1946) paper.) This should not be read as stating that all gastrular movements cease at this stage, for this is not true, as we shall see.

4. When hybrids are in Stage H17 they develop functional external cilia, which rotate them slowly within their tighter-thannormal vitelline membranes. Control embryos develop cilia when they are in Stage 15.

5. By the time they are in Stage H20-H21, hybrid embryos have swollen until their diameters are some $20 \%$ greater than their diameters at Stage H10, and their animal hemispheres have become curiously pitted. Possible mechanisms of swelling were discussed by Moore and also by Gregg (1948), but none of their suggestions (all of which postulated hypernormal intrablastocoelic hydrostatic pressure) has yet been put to test.

6. When hybrid embryos are in Stage H20-H21, their blastocoel roofs usually rupture, possibly as the result of intolerable internal pressure, and they shrink to their original sizes, approximately.

7. Most hybrids die by progressive cytolysis when they are in Stage H21 (about 160 hours after fertilization, at $18^{\circ} \mathrm{C}$ ). It

"We shall use "control" or "control embryo" in accordance with the rule that $x$ is a control for $y$ provided that the following conditions are satisfied: (i) $x$ is a member of R. pipiens; (ii) $y$ is a hybrid; (iii) $x$ and $y$ have the same female parent, and have developed under similar environmental conditions for the same length of time.

f In general, we shall say that hybrids are in Stage $\mathrm{H} s$ if their controls are in Shumway Stage $s$. 
should be noted that not all gastrula-arrested anuran hybrids survive this long. Embryos belonging to the hybrid Rana sylvatica $\&$ x Rana pipiens $\hat{o}$, for example, cytolyze relatively soon after the onset of gastrulation, when their controls are in Stage 13. Therefore, hybrids of the sort with which we are concerned in this report are exceptionally favorable experimental material.

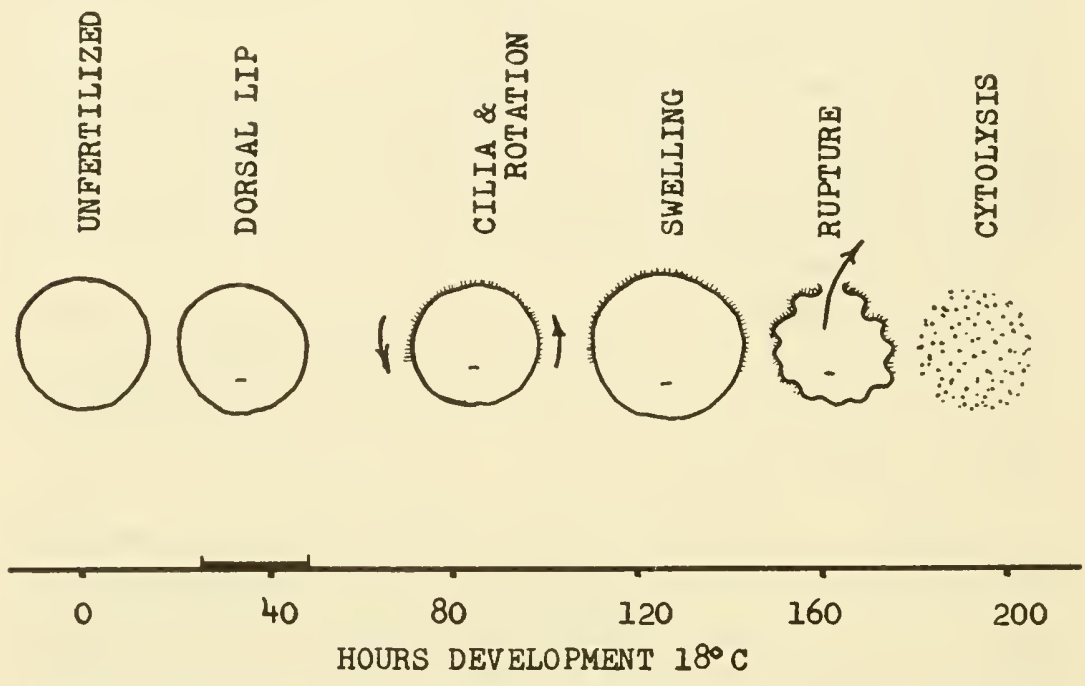

Fig. 3. Development of embryos in the hybrid Rana pipicus $\& \times$ Rana sylvatica $\hat{o}$. (Reconstructed from data of Moore, 1946.)

Figure 3 is a schematic representation of the developmental events just outlined.

\section{Morphogenetic Movements}

Unfortunately, we are not in possession of an adequate general theory of amphibian gastrulation in terms of which we can explain hybrid developmental patterns. Nor, for that matter, do we have precise ways even of describing various tissue movements that occur when embryos gastrulate. Nevertheless, gastrulating amphibians all exhibit movements belonging to some roughly identifiable types. The classification following is useful for our present purpose. A more exhaustive one is given by $\mathrm{Nel}$ son (1953). 
Dorsal Lip Formation. The first clearly visible external sign that an embryo is beginning to gastrulate is the appearance of a small pigmented streak to one side of the vegetal hemisphere. If median sagittal sections are made of an embryo in this stage, it is easy to see that the pigmented streak consists of the outermost constricted ends of cells attached to the surface coat and bulging at their free ends inward and upward toward the blastocoel. Vogt (1929) has some exceptionally clear figures of such cells, which we shall call "flask cells." The pigmented streak thus constituted indents in the surface of the embryo, the cells just dorsal

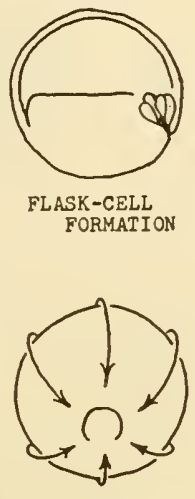

EPIBOLY
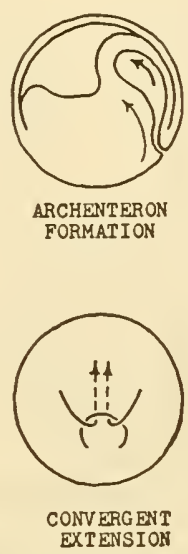

Fig. 4. Morphogenetic movements in amphibian gastrulation.

to it forming the early dorsal lip. Figure 4 contains a highly schematized representation of this process.

Since each hybrid embryo finally, if belatedly, develops a normal-looking early dorsal lip, it is not surprising that Moore found no irregularities of histological structure when he examined median sagittal sections of Stage $\mathrm{H} 0^{+}$hybrid embryos. Flask cells were present in normal fashion, attached at their outer ends to the indented and pigmented area adjacent to the forming dorsal lip. It is unlikely, therefore, that incapacity to execute the correct preliminaries to early dorsal lip formation is instrumental in bringing hybrid gastrulae to a developmental impasse. Experiments with explant systems reinforce this view. Holtfreter 
(1944) showed that a bit of normal head endoderm (rider) suitably mounted upon the surface of a yolk endoderm substratum (base) would in due course embed itself in the latter; and he was able to demonstrate that cells of the rider transformed into flask cells as they infiltrated the cells of the base. Applying this method to hybrids, Gregg and Klein (1955) found that presumptive head endoderm riders from hybrid embryos embed in yolk endoderm bases with as much dispatch as those from normal embryos. Their systems were not studied histologically, but as far as

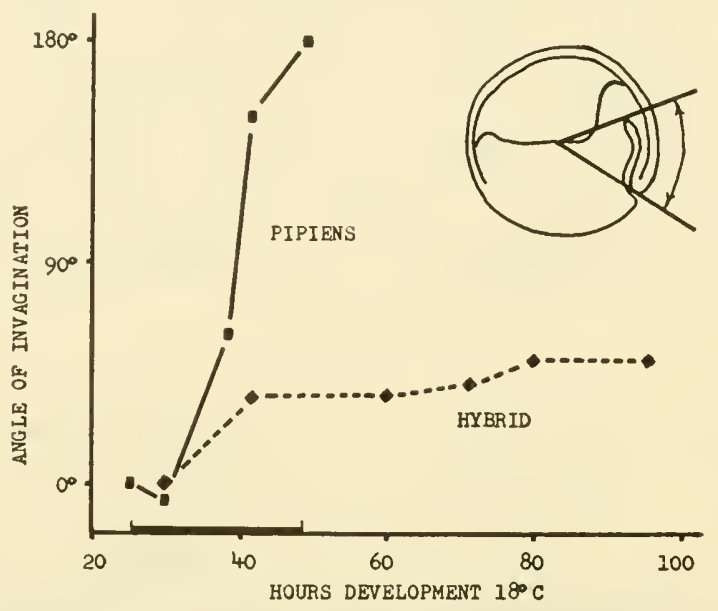

Fig. 5. The angle of invagination in developing Rana pipiens and hybrid embryos. (Reconstructed from data of Moore, 1946.)

their evidence goes, it sustains the belief that hybrid dorsal lip endoderm is capable of normal morphogenetic behavior.

Archenteron Formation and Enlargement. Continued invagination of the pigmented streak just vegetal to the earliest dorsal lip soon results in the formation of a cavity, the archenteron, which in normal amphibian embryos enlarges continuously while gastrulation proceeds (Fig. 4). Moore has devised a method for obtaining a measure of the rate and extent of archenteron formation. It consists in obtaining the value of the angle subtended by two lines in the median sagittal plane, both originating at a point on the center of the blastocoel floor, and tangent respectively 
to the innermost tip of the archenteron and the edge of the dorsal lip (Fig. 5). It is easily seen that elongation of the archenteron will be accompanied by increases in the value of this angle, which Moore calls the angle of invagination.

Figure 5 shows that the value of the invagination-angle of an $R$. pipiens embryo increases sharply throughout the period during which the embryo is gastrulating; for a hybrid, this value increases almost as rapidly at first, but thereafter remains nearly constant. Thus, in hybrid embryos, formation of the archenteron

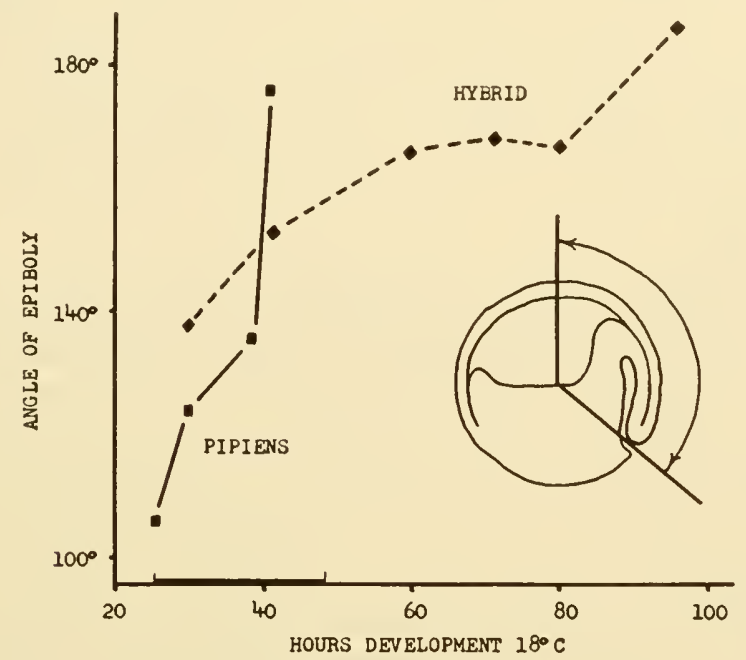

Fig. 6. The angle of epiboly in developing Rana pipiens and hybrid embryos. (Reconstructed from data of Moore, 1946.)

gets under way, but is brought to a halt when it is only onequarter complete.

Epiboly. As an amphibian embryo gastrulates, its stock of internal tissues is increased by draughts upon that of its external endoderm and mesoderm. The inward transfer is made possible in several ways, but at least partly by epiboly, a thoroughgoing meridional extension of presumptive ectoderm and mesoderm (Fig. 4). Mesodermal tissues are turned inward over the blastoporal lip; ectodermal ones will eventually constitute the entire external surface. 
Moore has attempted to provide us with a measure of epiboly. He exploited the fact that the dorsal lip of an embryo stands in a determinate geometrical relationship to the plane of its blastocoel floor. This relationship can be expressed by citing the value of an angle which Moore calls the angle of epiboly: it is the angle subtended by two lines, both in the median sagittal plane and both originating from the center of the blastocoel floor, one being perpendicular to the plane of the blastocoel floor and the other tangent to the edge of the dorsal lip (Fig. 6). The value of this angle for $R$. pipiens embryos just commencing to gastrulate is about $106^{\circ}$, and by the time they are in middle Stage 12 its value has increased to $176^{\circ}$ at a steady rate. For hybrid embryos the initial value is $138^{\circ}$; with time, the values climb more slowly than normal, and at a decreasing rate, but they finally reach a level of about $168^{\circ}$.

The problem now is to interpret those results. Moore believes that the rate and amount of change in this angle are measures of the rate and amount of epiboly. If this interpretation is correct, then Fig. 6 yields the following information: $(a)$ epiboly occurs in hybrid embryos at a rate somewhat slower than normal but to almost the same final extent, and $(b)$ the appearance of a dorsal lip in hybrid embryos is preceded by a considerable amount of epiboly. In connection with $(b)$, it should be remembered that the dorsal lips of hybrid embryos do not appear until the latter are in Stage $\mathrm{HIO}^{+}-\mathrm{H}_{1}{ }^{-}$. However, it may be that Moore's interpretation is correct only by chance, for although it is true that the progress of epiboly will increase the value of the epiboly angle, it is by no means true that an increase in the value of this angle can always be construed as indicating that epiboly has progressed. Any change, whether or not it is accompanied by epiboly, that results in tilting the blastocoel floor away from the dorsal lip will entail an increase in the value of the epiboly angle. One such change that needs to be considered is the streaming anteriorly along the archenteron floor of cells originally from the vegetal pole area, for this normally occurring movement might be expected to alter the plane of the blastocoel floor in such a way as to cause an increase in the value of the angle of 
epiboly. Should this actually happen, this value would be a measure not of epiboly alone but of a complex of morphogenetic movements having more than one component. It may not happen in hybrid embryos, for Moore says that "the tip of the archenteron maintains essentially the same position relative to the blastocoel floor throughout. ..." the length of time required for controls to gastrulate; but it may happen in normal gastrulae. But Moore's interpretation of change in the value of the angle of epiboly is supported by considerable evidence. First, on his interpretation, the final value of this angle for normal embryos is that which would have been predicted from the knowledge that, when they have finished gastrulating, the descendants of their animal pole cells lie about $180^{\circ}$ from their blastopores. Second, one would expect epiboly to wrinkle the animal hemispheres of hybrid embryos (since little slack is taken up by invagination), and this is exactly what happens. Third, there is evidence from experiments with explant systems that hybrid ectoderm is capable of normal epibolic spreading. Holtfreter (1944) showed that a piece of ventral ectoderm from an amphibian gastrula, when suitably mounted on an endodermal substratum, will spread in all directions over the latter. Gregg and Klein (1955) applied this technique to hybrid embryos and were able to show that hybrid ventral ectoderm will spread normally upon an endodermal base. All this is consistent with Moore's interpretation and is just what would be expected from his results.

From our discussion, it is evident that appropriate ectodermal tissues of hybrid gastrulae are capable of epiboly and, in all likelihood, exhibit it in situ. Thus we must search elsewhere for factors contributory to hybrid juvenile delinquency.

Convergent Extension. As they stream toward the blastopore, the presumptive notochordal cells of gastrulating amphibians converge sharply toward the median sagittal plane, and after invaginating they migrate cephalad parallel to or convergent to this plane. At the close of gastrulation, therefore, the notochordal cells form a narrow elongated rod of tissue lying centered in the median sagittal plane (Fig. 4).

By studying models, Holtfreter (1944) showed that normal 
amphibian presumptive notochord is self-differentiating with respect to the morphogenetic movement of convergent extension, for notochordal explants from a young gastrula will elongate in the proper axis within a reasonable time, and so will similar explants mounted suitably upon an endodermal substrate.

On the other hand, hybrid presumptive notochord explants behave abnormally (Gregg and Klein, 1955); instead of elongating, they merely round up into balls of tissue and remain that way as long as they are cultured. Now, if autonomous convergent extension of notochordal tissue is a necessary concomitant of normal gastrulation, its failure to occur constitutes a sufficient condition for the nonoccurrence of normal gastrulation. Thus, in its failure, we have a partial explanation for the peculiar course of post-blastula hybrid development. But we also have a generation of further puzzles. It will be recalled that the initial value of the epiboly angle for hybrid embryos $\left(138^{\circ}\right)$ is much greater than that for $R$. pipiens embryos $\left(106^{\circ}\right)$. Moore, as we have seen, regards this as evidence that considerable epiboly precedes dorsal lip formation in hybrid embryos. But that epiboly is one component (extension) of convergent extension. If the latter is not autonomous in hybrid embryos, then the question arises, how is the initial pre-invagination epiboly accomplished? At present, there is no clear-cut answer.

It is evident, from Moore's description, that a hybrid invaginates enough to move its presumptive head endoderm in underneath its presumptive chordamesoderm. When this relationship is mimicked in vitro by mounting a bit of hybrid chordamesoderm on an endodermal substratum, the chordamesoderm not only fails to elongate normally, it also spreads upon the substratum, in all directions, like ectoderm (Gregg and Klein, 1955). If this sort of thing happens in situ, then it is easy to see why the notochordal convergence necessary for normal gastrulation does not occur, and why invagination is brought to a sudden halt.

Thus, by considering the behavior of explant systems in relation to known features of hybrid development, we can construct a fragmentary explanation in morphological terms for some of the peculiarities of that development. We turn now to consider some 
attempts to analyze hybrid morphogenesis from a physiological or biochemical point of view.

\section{Respiration}

\section{Metabolism of Hybrid Embryos}

Oxygen Uptake. Barth (1946) has made a special study to compare the respiratory rates of hybrid and control embryos. His results are summarized in Fig. 7. The rate at which $R$. pipiens

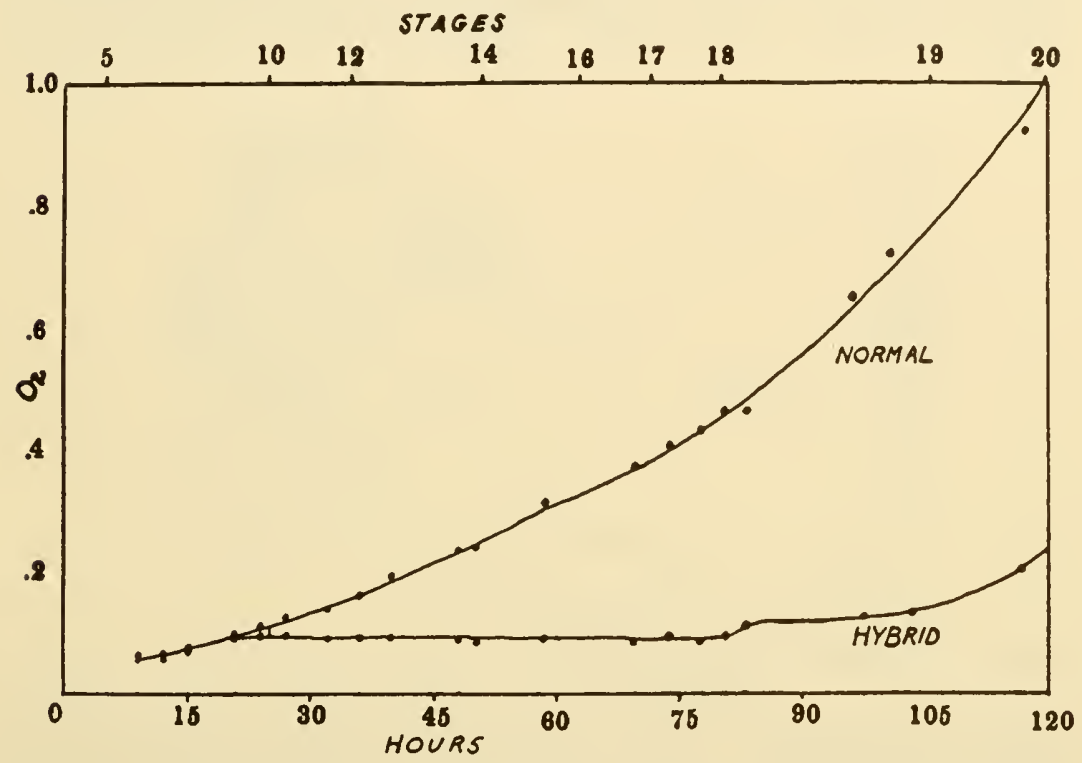

Fig. 7. Respiration (cu $\mathrm{mm} \mathrm{O}_{2}$ /hour embryo) of developing Rana pipiens and hybrid embryos. (From Barth, 1946.)

embryos utilize environmental oxygen increases with time, roughly in exponential fashion. Hybrid embryos at first respire oxygen at the same rate as $R$. pipiens control embryos, but when they are late blastulae their respiratory rate becomes constant and remains so until they are in Stage H18, when a small, abrupt increase in respiratory rate (not clearly associated with any morphological change, external cilia, for example, begin to function at about Stage 17, according to Moore) initiates a very slow ex- 
ponential rise (possibly associated with the onset of cytolysis) that continues to Stage H20, beyond which respiratory rates have not been measured. It is easy to see that, from late Stage $\mathrm{H} 9$ on, hybrid embryos are characterized by increasingly subnormal respiratory rates.

Respiratory depression seems to be a feature of all parts of hybrid gastrulae. Sze (1953) has compared the respiration of four different regions of the animal hemisphere of hybrid embryos in early Stage H11 with that of corresponding regions of control embryos. From the graph of his results (Fig. 8), it can

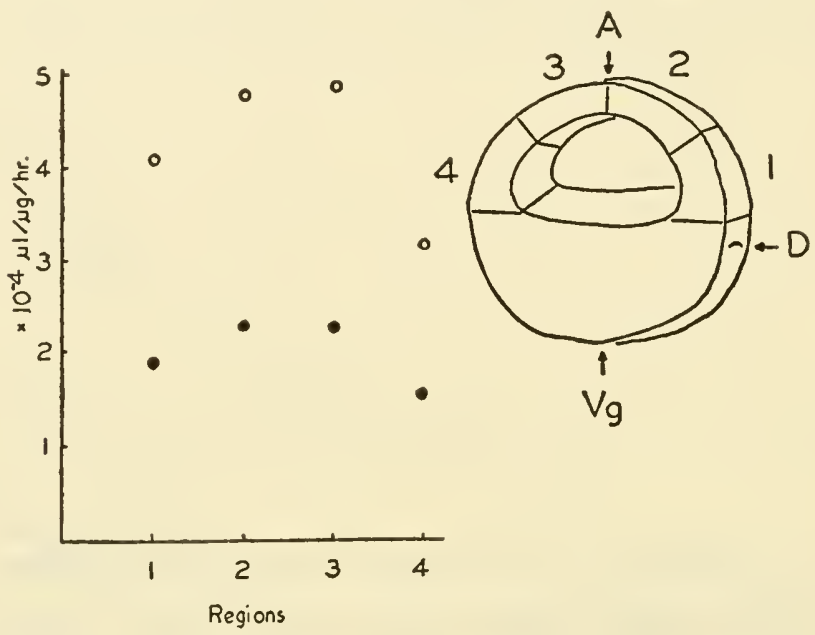

Fig. 8. Respiration of parts of Rana pipiens and hybrid gastrulae. Hollow circles, Rana pipiens; solid circles, hybrid. (Adapted from Sze, 1953.)

be seen that the rate of respiration of hybrid tissues from embryos in the stage mentioned is everywhere about half that of the corresponding $R$. pipiens tissues. The difference is a little greater than might be expected if Barth's results on whole embryos are taken as standard, but, pending evidence to the contrary, Sze's results must be interpreted as warranting the supposition that there is no tissue-localized block to respiration in hybrid embryos.

Respiratory Quotient. In the work cited above, Barth also 
compared the respiratory quotients $\left(\mathrm{R} . \mathrm{Q} .=\mathrm{CO}_{2}\right.$ produced per $\mathrm{O}_{2}$ consumed) of hybrid and $R$. pipiens embryos (Fig. 9). The respiratory quotients of hybrid embryos in all stages between Stage $\mathrm{H1}$ and Stage H12 are not significantly different from those of R. pipiens control embryos. Beginning at Stage H12, however, the respiratory quotients of hybrid embryos become increasingly larger than those of controls. Aging hybrid embryos are thus characterized by hypernormal $\mathrm{CO}_{2}$ production, relative to their oxygen consumption. We have no knowledge at present about the R.Q.'s associated with various parts of hybrid gastrulae. Barth notes that his results are consistent with the view that up to Stage

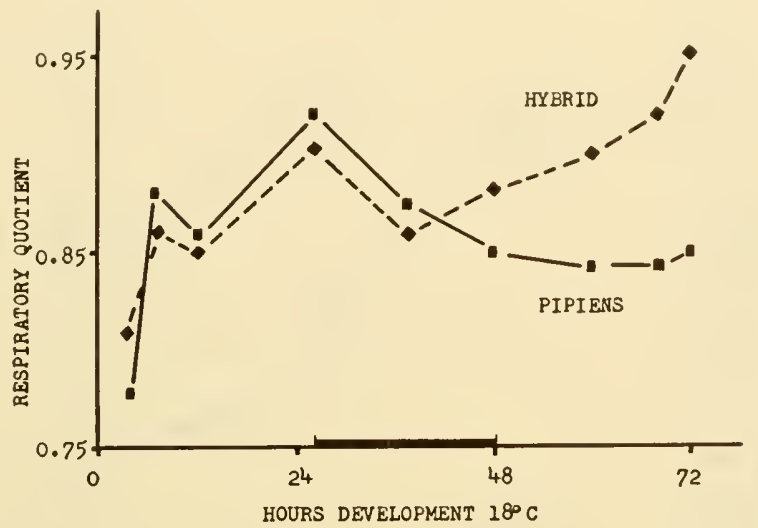

Fig. 9. Respiratory quotients of developing Rana pipiens and hybrid embryos. (Reconstructed from data of Barth, 1946.)

H12, hybrid embryos are oxidizing substrates of the same kind as control embryos, and that not until thereafter do they oxidize substrates of different kinds. Therefore, to the extent that R.Q. measurements warrant such statements, we are deprived of support for the hypothesis that hybrids fail to gastrulate because they do not oxidize substrates providing the normal types of necessary metabolic intermediates. But because of technical difficulties involved in the determination of respiratory quotients, especially on pre-gastrula embryos, Barth urges that the absolute values of the R.Q.'s obtained should not be construed as evidence for any hypothesis stating what substrates embryos are oxidizing. 
Evidence relevant to this last point is meager, indeed; but there is at least some.

\section{Utilization of Endogenous Carbohydrate}

In 1948, Gregg made a comparative study of carbohydrate utilization by developing hybrid and $R$. pipiens embryos. Normal

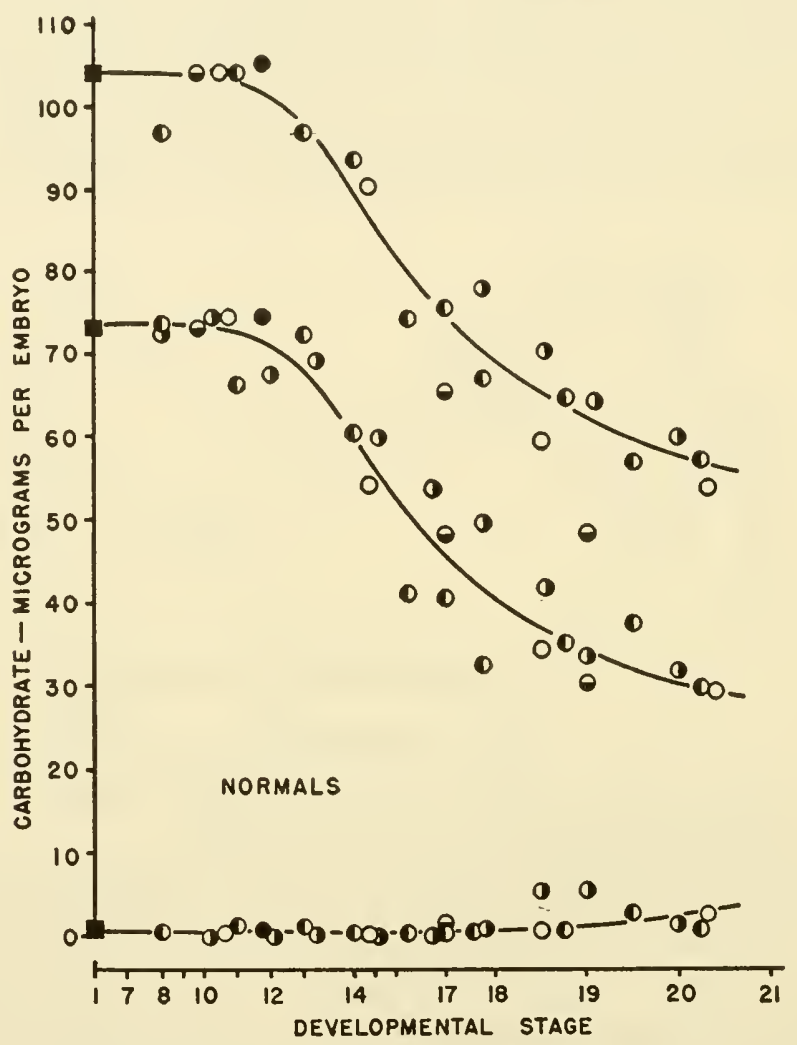

Fig. 10. Endogenous carbohydrate of developing Rana pipiens embryos. Upper curve, total carbohydrate; middle curve, glycogen; lower curve, free carbohydrate. (From Gregg, 1948.)

embryos (Fig. 10) are characterized by the fact that they begin to oxidize their carbohydrate store not later than the onset of gastrulation and continue thereafter to do so to such an extent that, by the time they are hatched larvae, they have little more 
than half of it left; while hybrid embryos (Fig. 11) seem to utilize their carbohydrates at a slow, almost constant rate throughout their development from Stage $\mathrm{H} 1$ to Stage H21. The fact that embryos of both types use their glycogen and their total carbo-

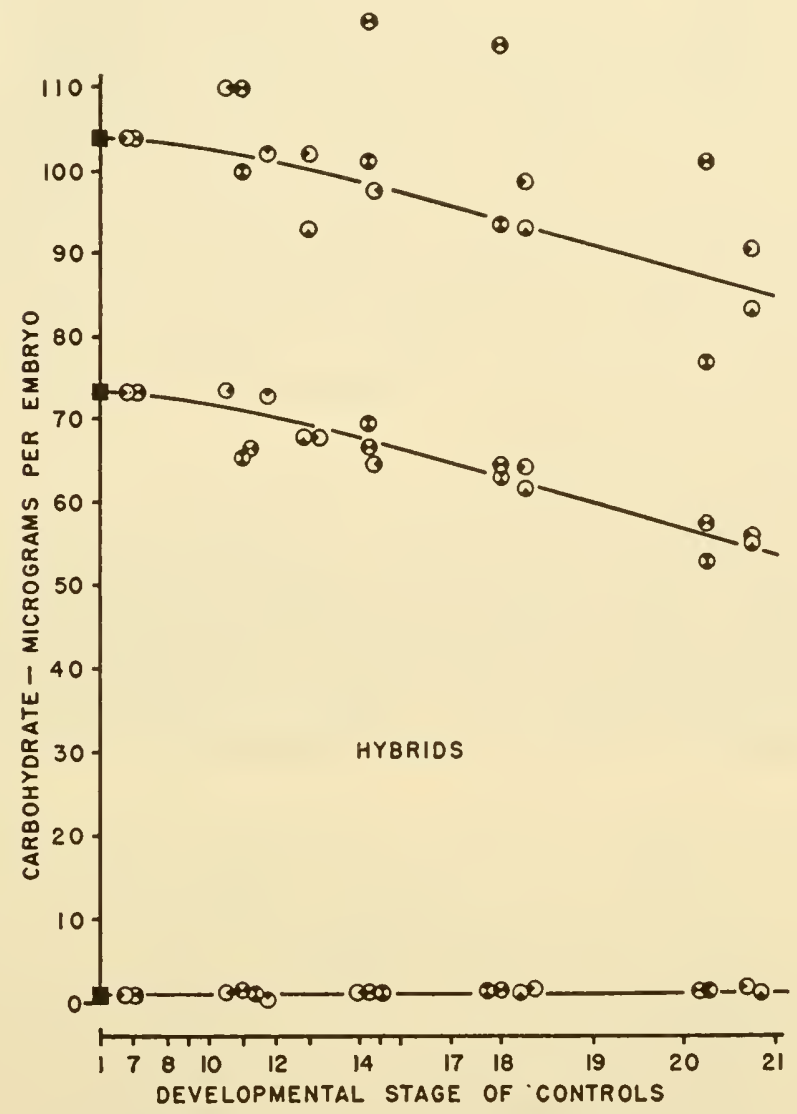

Fig. 11. Endogenous carbohydrate of developing hybrid embryos. Upper curve, total carbohydrate; middle curve, glycogen; lower curve, free carbohydrate. (From Gregg, 1948.)

hydrate at similar rates suggests two things: $(a)$ that glycogen is the only stored carbohydrate oxidized in any great amount throughout embryonic development, and $(b)$ that there is no conversion of glycogen into any other stored carbohydrate-a 
conclusion supported also by the absence from both types of embryo of significant amounts of free carbohydrate at any stage in embryogenesis. Glycogen, indeed, seems to be the chief energy source drawn upon by young frog embryos, for we know (Barth and Barth, 1954) that relatively little protein or fat is burned by normal embryos until late in development. Protein and fat metabolism of hybrid embryos has not yet been studied.

It is not known whether the parts of hybrid gastrulae utilize glycogen at different rates. The work of Jaeger (1945) suggests that they do not, for she found that dorsal tissues of Stage H10 and Stage H12 hybrid embryos did not differ in their glycogen contents, and neither did analogous ventral tissues. It seems probable that there is a general depression of glycolysis common to all hybrid cells, corresponding to the general lowering of the respiratory rate discovered by Sze.

\section{Lactic Acid Production}

In his paper on the respiratory metabolism of hybrid embryos, Barth (1946) also reported some measurements of their aerobic and anaerobic lactic acid production. Under strictly aerobic conditions, neither $R$. pipiens nor hybrid embryos produce appreciable amounts of lactic acid; although embryos allowed to sit

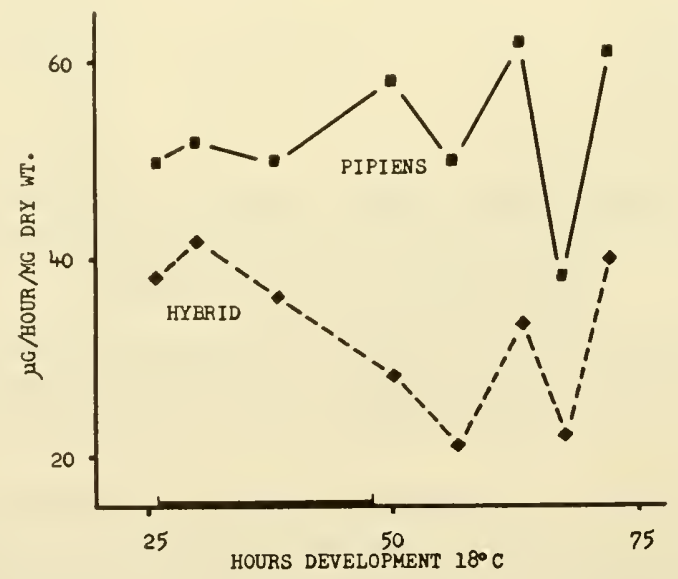

Fig. 12. Anaerobic lactic acid production of Rana pipiens and hybrid embryos. (Reconstructed from data of Barth, 1946.) 
close together in a dish of aerated culture medium may excrete considerable amounts of lactic acid, possibly because crowding limits the rate at which environmental oxygen is supplied to them. In nitrogen, both sorts of embryos accumulate large amounts of lactic acid, hybrids to a lesser extent than $R$. pipiens controls (Fig. 12). Thus, under anaerobic conditions, hybrid embryos produce subnormal amounts of lactic acid.

\section{Localization of Metabolic Blocks in Hybrids}

From the foregoing sections, it is clear that hybrid gastrulae exhibit subnormal oxygen uptakes, subnormal endogenous carbohydrate utilization, and subnormal anaerobic lactic acid production. In discussing these results we shall make the following assumptions about the intermediary carbohydrate metabolism of hybrid gastrulae:

1. Glycogen, in the presence of ATP (adenosine triphosphate) and inorganic phosphate, is enzymatically oxidized to pyruvic acid, with the production of hydrogen ions and ATP.

2. Under anaerobic conditions, pyruvic acid is enzymatically reduced by hydrogen ions and is converted to lactic acid.

3. Under aerobic conditions, pyruvic acid is enzymatically oxidized to carbon dioxide, with the production of ATP and hydrogen ions.

4. Under aerobic conditions, hydrogen ions enzymatically reduce respiratory oxygen, with the formation of water.

The exact mechanisms by which these events occur will not be critical for the present discussion, but there is no reason to suppose that they are unorthodox. Cohen (1954) has recently presented convincing evidence that glycolysis in $R$. pipiens embryos is of the usual Embden-Meyerhof type, which, in the absence of oxygen, terminates in lactic acid. Hydrogen transport and the oxidative degradation of pyruvate have not been systematically studied in $R$. pipiens or other amphibian embryos, but there is a comparatively large scattered literature whose review is beyond the scope of this contribution but which is consistent with the hypothesis that hydrogen transport in amphibian embryos is carried out in the classic Warburg-Keilin manner and that pyruvate 
is oxidized by a system of intermediate steps of the type usually called a Krebs cycle.

Let us imagine, then, that events of the types diagrammed in Fig. 13 occur both in R. pipiens and in hybrid embryos. Furthermore, for simplicity, let us make the possibly counterfactual assumption that glycogen is the sole endogenous energy source of pipiens and hybrid gastrulae, and on this basis let us try to localize reactions whose subnormal rates may account for the biochemical deficiencies just reviewed. From Fig. 13 it will be seen that there are four major places, 1, 2, 3, and 4, at which partial blocks may or may not occur. If $S_{i}$ is a blocked reaction at place $i$ and $\bar{S}_{i}$ is a nonblocked reaction at place $i$, then we shall have $2^{4}$ $=16$ possible situations that may be the state of affairs in hybrid gastrulae:
(1) $\mathrm{S}_{1} \quad \mathrm{~S}_{2} \mathrm{~S}_{3} \mathrm{~S}_{4}$
(9) $\quad \mathrm{S}_{1} \quad \mathrm{~S}_{2} \mathrm{~S}_{3} \overline{\mathrm{S}_{4}}$
(2) $\overline{\mathrm{S}_{1}} \mathrm{~S}_{2} \mathrm{~S}_{3} \mathrm{~S}_{4}$
(10) $\overline{S_{1}} S_{2} S_{3} \quad \overline{S_{4}}$
(3) $\mathrm{S}_{1} \overline{\mathrm{S}_{2}} \mathrm{~S}_{3} \mathrm{~S}_{4}$
(11) $\mathrm{S}_{1} \overline{\mathrm{S}_{2}} \mathrm{~S}_{3} \overline{\mathrm{S}_{4}}$
(4) $\overline{S_{1}} \overline{S_{2}} S_{3} S_{4}$
(12) $\overline{S_{1}} \overline{S_{2}} S_{3} \overline{S_{4}}$
(5) $\mathrm{S}_{1} \mathrm{~S}_{2} \overline{\mathrm{S}_{3}} \mathrm{~S}_{4}$
(13) $S_{1} \quad S_{2} \overline{S_{3}} \overline{S_{4}}$
(6) $\overline{\mathrm{S}_{1}} \quad \mathrm{~S}_{2} \overline{\mathrm{S}_{3}} \mathrm{~S}_{4}$
(14) $\overline{\mathrm{S}_{1}} \mathrm{~S}_{2} \overline{\mathrm{S}_{3}} \overline{\mathrm{S}_{4}}$
(7) $\mathrm{S}_{1} \overline{\mathrm{S}_{2}} \overline{\mathrm{S}_{3}} \mathrm{~S}_{4}$
(8) $\overline{S_{1}} \overline{S_{2}} \overline{S_{3}} S_{4}$
(16) $\overline{S_{1}} \overline{S_{2}} \overline{S_{3}} \overline{S_{4}}$

Of these possibilities, only five are clearly disconfirmed by the available data: (4) and (8), because if they were true, then the anaerobic lactic acid production of hybrid gastrulae ought to be, but is not, rate-normal; (12), because if it were true, hybrid anaerobic lactic acid production ought to be, but is not, rate-normal, whereas aerobic lactic acid production ought to proceed at an abnormally high rate, but does not; (14), because if it were true, then the oxygen consumption of hybrid gastrulae ought to be, but is not, normal in rate; and (16), because differences between hybrid and normal embryos in respect to $\mathrm{O}_{2}$ uptake, lactate production and glycogen utilization should not be, but are, observed.

Several other possibilities- (1), (2), (3), (5), (7), (9), (10), and (11)-are neither confirmed nor disconfirmed by existing 
data. To evaluate these cases we shall need additional information. In particular we shall have to know which of the blocked reactions, if any, become rate-limiting for the entire system, and the degrees to which oxygen and pyruvic acid can compete successfully for hydrogen ions under each of the postulated conditions. Consider case (1), for example, where there is imagined a partial block at all four sites. Under these conditions we should

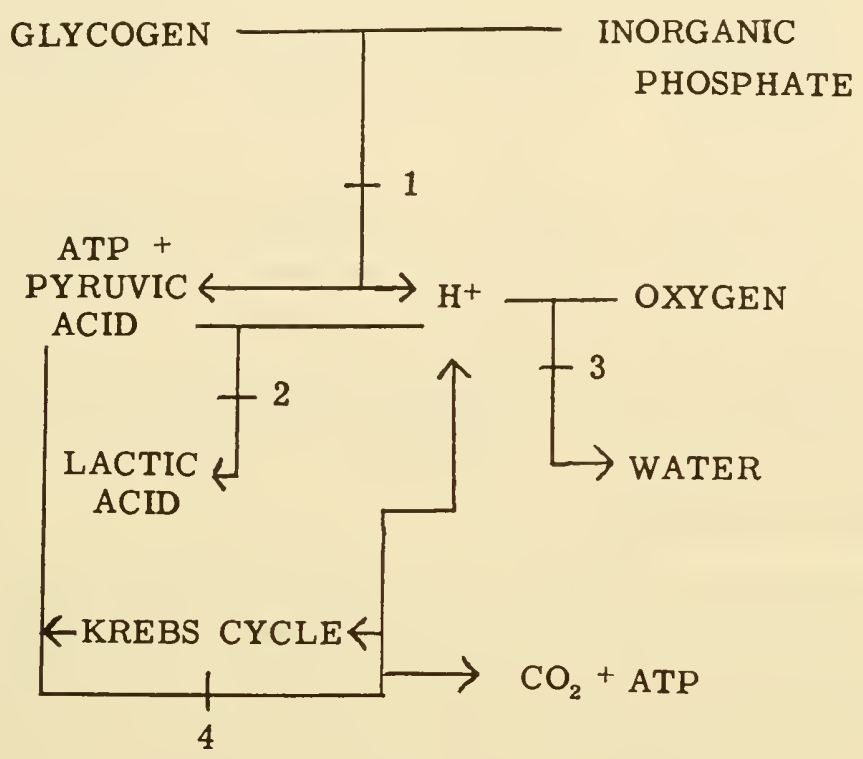

Fig. 13. Carbohydrate metabolism schema.

expect to find, and do find, that hybrids respire and utilize glycogen at a subnormal rate and produce lactic acid anaerobically at a subnormal rate. But we cannot predict how hybrid and $R$. pipiens gastrulae will compare in respect to aerobic lactic acid production, for this would depend, among other things, upon knowing (as we do not) which of $S_{1}, S_{2}, S_{3}$, and $S_{4}$ are rate-limiting so that we would know which intermediates accumulate, and how well under these restrictions pyruvate and oxygen compete for hydrogen ions. Therefore, the fact that we actually do find the hybrids aerobically producing lactic acid at a normal, negligible rate is 
neither for nor against this postulate. Analogous considerations can be advanced for the other indeterminate cases. The best we can say is that all these cases remain consistent with the data now on hand.

The remaining cases-(6), (13), and (15)-are supported indiscriminately by information that we now have. That is to say, if any of these is the state of affairs in hybrid embryos, then we should expect the hybricts to exhibit subnormal rates of oxygen uptake, glycogen utilization, and anaerobic lactate production, and to produce little or no aerobic lactic acid, and this, in fact, is just what they do.

In summary, there are eleven mutually exclusive general possibilities for blocks in hybrid carbohydrate metabolism which must be investigated further before we can decide which of them, if any, actually occur. And this leaves entirely out of consideration all other sorts of biochemical deficiencies not directly involved with the schema just discussed, not to mention the details of the system that schema represents.

\section{Phosphorus Metabolism}

Hybrid embryos, clearly, are somewhat deficient energy producers. For this reason, they ought perhaps to find it difficult to maintain their stores of esterified phosphorus, especially when put under stress by being made to develop under conditions where energy production is even further curtailed. In 1947, Barth and Jaeger made some measurements designed to answer the question whether hybrids are as well able as $R$. pipiens embryos to meet the stresses imposed by anaerobiosis. Their results (Table I) are summarized below:

1. Aerobic hybrid embryos have been shown not to exhibit a probably significant difference from $R$. pipiens controls in respect of inorganic phosphorus (I) or ATP-ADP phosphorus $\left(\mathrm{E}_{7}\right)$.

2. Under anaerobiosis: (a) R. pipiens gastrulae exhibit a probably significant elevation of $\mathrm{I}$, but no significant change in $\mathrm{E}_{\mathbf{7}}$ is indicated; while $(b)$ hybrid gastrulae exhibit a significant increase in $I$ and also a probably significant decrease in $E_{\overline{7}}$. The 
TABle I. Phosphorus Metabolism of R. pipiens and Hybrid Embryos

\begin{tabular}{|c|c|c|c|c|c|}
\hline & & $\begin{array}{l}\text { Aerobic } \\
\bar{x} \pm s\end{array}$ & $\begin{array}{c}\text { Anaerobic } \\
\bar{x} \pm s\end{array}$ & $\begin{array}{l}\text { Diff. } \\
\bar{x} \pm s\end{array}$ & $P^{\prime}$ \\
\hline Total & $\begin{array}{l}R . \text { pipiens } \\
\text { Hybrid } \\
\text { Diff. } \\
\text { P }\end{array}$ & $\begin{array}{c}43.0 \pm 9.4 \\
38.7 \pm 6.7 \\
4.3 \pm 1.7 \\
<0.05\end{array}$ & $\begin{array}{c}48.8 \pm 4.7 \\
46.1 \pm 6.3 \\
2.7 \pm 1.8 \\
>0.05\end{array}$ & $\begin{array}{l}5.8 \pm 7.7 \\
7.4 \pm 2.0\end{array}$ & $\begin{array}{l}>0.0 .5 \\
<0.01\end{array}$ \\
\hline I & $\begin{array}{l}\text { R. pipiens } \\
\text { Hybrid } \\
\text { Diff. } \\
\text { P }\end{array}$ & $\begin{array}{c}19.3 \pm 2.4 \\
17.3 \pm 1.9 \\
2.0 \pm 3.4 \\
>0.05\end{array}$ & $\begin{array}{c}29.9 \pm 4.4 \\
30.2 \pm 1.0 \\
0.3 \pm 3.2 \\
>0.05\end{array}$ & $\begin{array}{c}10.6 \pm 4.8 \\
12.9 \pm 0.9 \\
2.3 \pm 5.6 \\
>0.05\end{array}$ & $\begin{array}{l}<0.05 \\
<0.01\end{array}$ \\
\hline $\mathrm{E}_{7}$ & $\begin{array}{l}\text { R. pipiens } \\
\text { Hybrid } \\
\text { Diff. } \\
\text { P }\end{array}$ & $\begin{array}{c}23.7 \pm 8.3 \\
21.4 \pm 4.9 \\
2.3 \pm 4.2 \\
>0.05\end{array}$ & $\begin{array}{c}18.9 \pm 2.8 \\
15.9 \pm 5.3 \\
3.0 \pm 4.4 \\
>0.05\end{array}$ & $\begin{array}{l}4.8 \pm 7.4 \\
5.5 \pm 2.3\end{array}$ & $\begin{array}{l}>0.05 \\
<0.05\end{array}$ \\
\hline
\end{tabular}

Source: Reeonstrueted from Barth and Jaeger, 1947, Table 7 , together with original data kindly supplied by these authors.

Embryos were allowed to develop 10-22 hr. in aerated or nitrogenated medium, beginning at Stage 10, after which phosphorus fractions were measured.

Total This is essentially the total inorganic phosphorus in a trichloracetic

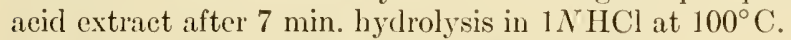

I This is essentially the total inorganic phosphorus in a trichloracetic acid extract before acid hydrolysis.

$\mathrm{E}_{7}=$ Total $-\mathrm{I}$, and is interpreted to be mostly inorganic phosphorus liberated by aeid hydrolysis from ATP and ADP. Values are in micrograms per 100 embryos.

$$
s=\text { standard deviation }=\sqrt{\frac{\Sigma d \bar{x}^{2}}{n-1}}
$$

Probabilities of differences determined by $t$-test for small samples, where

Throughout, $n=4$.

$$
t=\frac{\bar{x}-m_{0}}{s / \sqrt{n}}
$$

hybrid increase in I is shown not to be significantly different from that of $R$. pipiens embryos, but is in excess of that which might be expected to occur as the result of the liberation of I from breakdown of $\mathrm{E}_{7}$.

Thus, if inorganic phosphorus is a reliable indicator, anaerobic 
hybricls do not expend esterified phosphorus more than $R$. pipiens controls. Since they do not expend enough $\mathrm{E}_{\overline{7}}$ anaerobically to account for the increase in I, it appears that they draw upon some as yet unidentified store of esterified phosphorus for the excess I. Whether $R$. pipiens embryos do also remains to be established.

The evidence thus warrants the conchusion that hybrids meet relatively short anaerobic demands for energy about as well as $R$. pipiens controls, whatever the actual mechanism, but whether

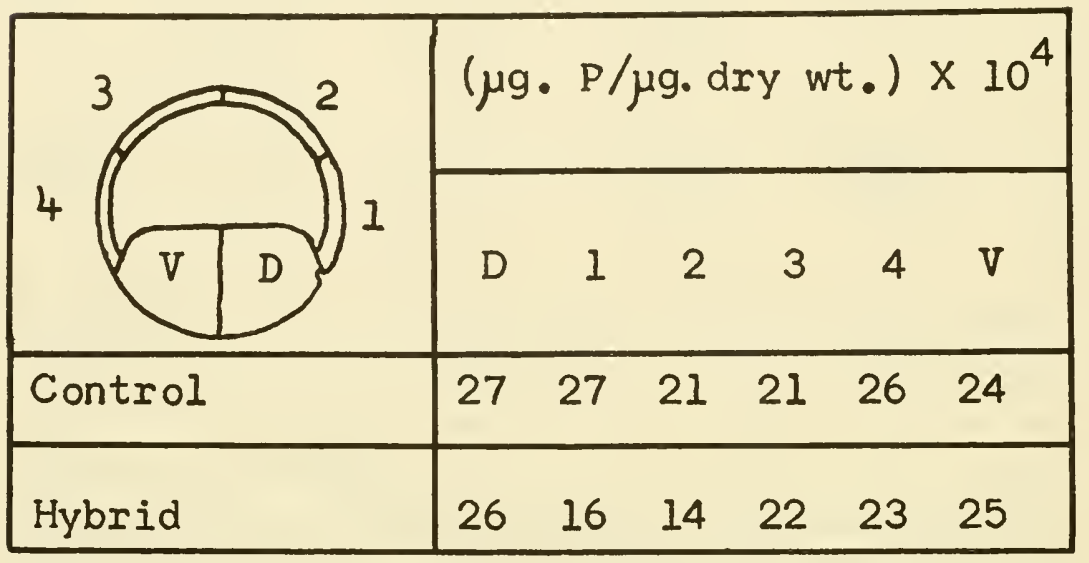

Fig. 14. Liberation of inorganic phosphate by acid breis of Rana pipiens and hybrid gastrula tissues. (Reconstructed from data of MezgerFreed, 1953.)

they preserve their entire store of phosphate bond energy as well as controls is open to further inquiry.

Additional information about the phosphorus metabolism of hybrid embryos has been obtained by Mezger-Freed (1953). This author measured the inorganic phosphorus liberated by acid breis of embryos in various stages of development and also by acid breis of explanted gastrula parts. In this respect, she discovered little that would distinguish hybrids from controls, except that breis of dorsal tissues from the animal hemispheres of hybrid gastrulae liberate much less inorganic phosphate than those of corresponding parts of controls (Fig. 14). She regards her results as evidence for the existence of a phosphatase catalyzing the lib- 
eration of inorganic phosphorus from phosphoprotein, but otherwise their significance in relation to hybrid developmental failure is not clear.

\section{Deoxyribosenucleic Acid Synthesis}

It is plausible to suppose that hybrid embryos may fail to develop properly because they cannot synthesize substances neces-

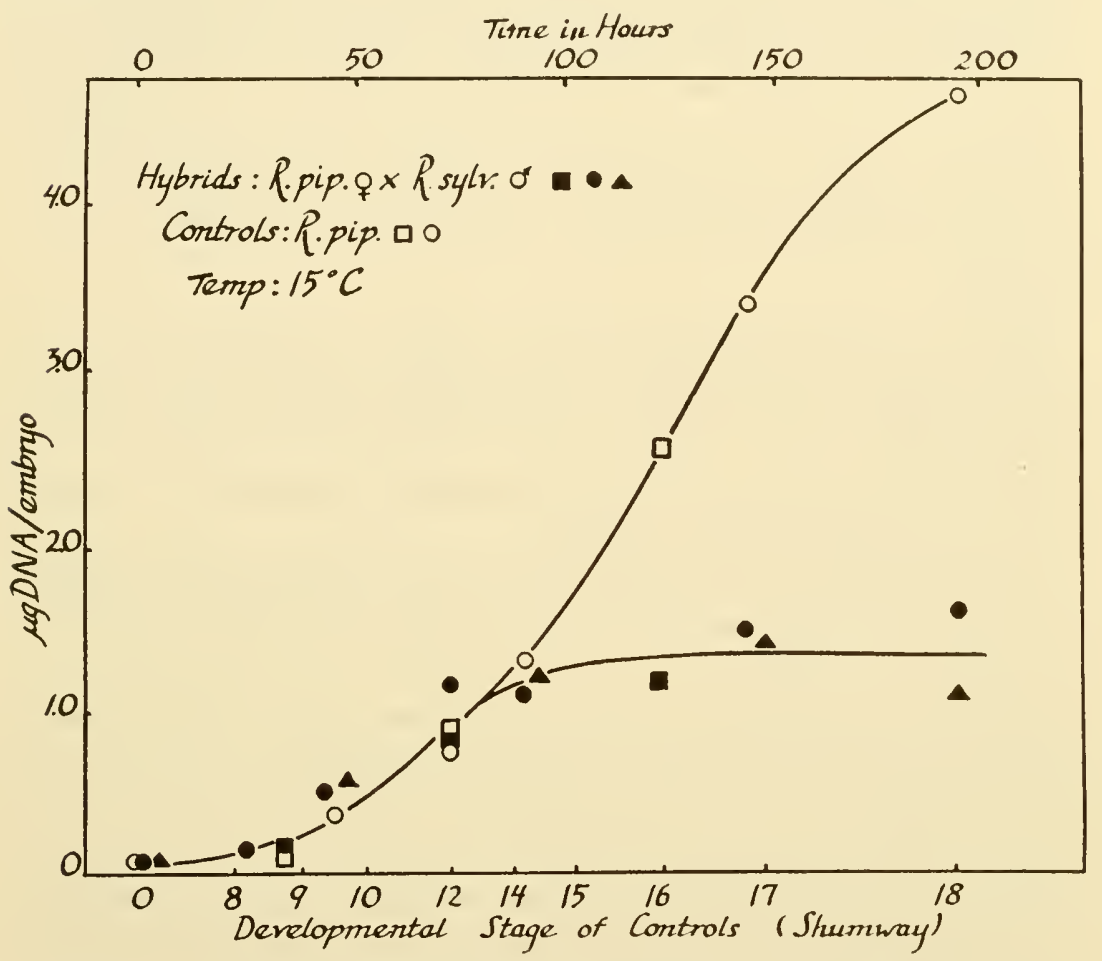

Fig. 15. Deoxyribosenucleic acid in developing Rana pipiens and hybrid embryos. (From Gregg and Løvtrup, 1955.)

sary for continued normal morphogenesis. Unfortunately, we have practically no information about the synthetic capacities of hybrid embryos of the type under consideration. The sole published investigation of this question is that of Gregg and L $\varnothing v$ trup (1955), who claim to have shown that deoxyribosenucleic acid (DNA) is synthesized by hybrids at a normal rate until Stage 
H14, after which no further synthesis occurs (Fig. 15). Therefore, according to them, the failure of hybrids to gastrulate is not a consequence of subnormal synthesis of DNA. But it should be noted that the analytical method employed by Gregg and L $\varnothing v-$ trup did not distinguish between free deoxyribosides and those incorporated in nucleic acids. For this reason, it may be best to regard their data as showing only that the total deoxyriboside content of hybrid embryos is not lower than that of controls until after Stage H14. Whether hybrid DNA synthesis is normal still remains to be demonstrated. In this connection, A. B. C. Moore is in possession of microspectrophotometric data (unpublished) which she regards as showing that as long as hybrid embryos are alive their nuclei each contains a normal amount of DNA.

\section{Summary}

The general picture of hybrid development emerging from the work we have reviewed may now be summarized and commented upon briefly.

1. At all stages precedent to Stage H10, hybrid embryos exhibit no developmental abnormalities.

2. Hybrid embryos are tardy in forming a dorsal lip, but finally do so in the normal manner at late Stage H10 or early Stage H11. Epiboly seems to begin at the normal time and progresses to almost the normal final extent, but at a subnormal rate. Archenteron formation gets underway at a slightly lower than normal speed, but is brought to a standstill while it is only one-quarter complete. Chordamesodermal convergent extension does not occur in hybrids. Instead, the chordamesoderm spreads on the substratum provided it by invaginated head endoderm, thus effectively putting a stop to further mesodermal invagination.

3. Hybrid embryos, still looking like early gastrulae, cytolyze when they are in Stage H21-H22.

4. On the biochemical side, post Stage H10 hybrid embryos are characterized by subnormal rates of oxygen uptake, endogenous carbohydrate utilization, and anaerobic lactic acid production. At all stages up to Stage H12, however, their respiratory quotients are normal; only thereafter are they increasingly hypernormal. It 
is not known whether, under the stress of anaerobiosis, hybrid gastrulae are less able than $R$. pipiens controls to maintain their total stores of esterified phosphorus, but they do not appear to expend more phosphate bond energy under anaerobiosis than do $R$. pipiens controls. Their only known tissue-localized metabolic difference from normal embryos is the deficient rate at which acid breis of their dorsal tissues will liberate inorganic phosphorus. They probably synthesize deoxyribosenucleic acid at the normal rate until they are in Stage H14, after which there is a fixation of the steady-state level at which this compound is maintained.

Unfortunately, it is difficult at the present time to relate the biochemical features of hybrid embryos to their developmental peculiarities. It is tempting to suppose that the lowered rates at which they liberate energy from glycolytic processes is causally connected with their delay in beginning to gastrulate, with the slowness with which epiboly proceeds, or even with the complete morphogenetic failure of mesoderm which so effectively disorganizes gastrular movements. For it is plausible, at least, to suppose that morphogenetic processes-tissue movements, cellshape changes, and the rest-are endergonic processes, and that when an unimpaired supply of energy is not forthcoming such processes must necessarily slow down or fail altogether. But it is also possible that the morphogenetic peculiarities of hybrid embryos and their metabolic ones are jointly caused. We do not know what alterations of fine structure may occur in a hybrid as a result of its unusual parentage. It is easy to imagine, however, that they are of such a kind that neither morphogenetic changes nor metabolic processes can occur normally, even in the presence of a normal energetic coupling between the latter and the former. Clarification of these questions must await further thought and investigation.

\section{REFERENCES}

Barth, L. G. 1946. Studies on the metabolism of development. J. Exptl. Zool., 103, 463-86. 
Barth, L. G., and L. J. Barth. 1954. The energetics of development. Columbia University Press, New York.

Barth, L. G., and L. Jaeger. 1947. Phosphorylation in the frog's egg. Physiol. Zool., 20, 133-46.

Cohen, A. I. 1954. Studies on glycolysis during the early development of the Rana pipiens embryo. Physiol. Zool., 27, 128-41.

Gregg, J. R. 1948. Carbohydrate metabolism of normal and of hybrid amphibian embryos. J. Exptl. Zool., 109, 119-34.

Gregg. J. R., and D. Klein. 1955. Morphogenetic movements of normal and gastrula-arrested hybrid amphibian tissues. Biol. Bull., 109, 26570.

Gregg, J. R., and S. Løvtrup. 1955. Synthesis of desoxyribonucleic acid in lethal amphibian hybrids. Biol. Bull., 108, 29-34.

Holtfreter, J. 1944. A study of the mechanics of gastrulation. Part II. J. Exptl. Zool., 95, 171-212.

Jaeger, L. 1945. Glycogen utilization by the amphibian gastrula in relation to invagination and induction. J. Cellular Comp. Physiol., 25, 97-120.

Mezger-Freed, L. 1953. Phosphoprotein phosphatase activity in normal, haploid and hybrid amphibian development. J. Cellular Comp. Physiol., 41, 493-518.

Moore, J. A. 1939. Temperature tolerance and rates of development in the eggs of amphibia. Ecology, 20, 459-78.

Moore, J. A. 1946. Studies in the development of frog hybrids. I. Embryonic development in the cross Rana pipiens of $\mathrm{x}$ Rana sylvatica o. J. Exptl. Zool., 101, 173-220.

Moore, J. A. 1947. Studies in the development of frog hybrids. II. Competence of the gastrula ectoderm of Rana pipiens $q \times$ Rana sylvatica ô hybrids. J. Exptl. Zool., 105, 349-70.

Moore, J. A. 1948. Studies in the development of frog hybrids. III. Inductive ability of the dorsal lip region of Rana pipiens of $\mathrm{x}$ Rana sylvatica of hybrids. J. Exptl. Zool., 108, 127-54.

Moore, J. A. 1955. Abnormal combinations of nuclear and cytoplasmic systems in frogs and toads. Advances in Genetics, 7, 139-82.

Nelsen, O. E. 1953. Comparative embryology of the vertebrates. The Blakiston Company, New York.

Pollister, A. W., and J. A. Moore. 1937. Tables for the normal development of Rana sylvatica. Anat. Record, 68, 489-96.

Shumway, W. 1940. Normal stages in the development of Rana pipiens. Anat. Record, 78, 139-49. 
Sze, L. C. 1953. Respiration of the parts of the hybrid gastrula Rana pipiens x Rana sylvatica. Science, 117, 479-80.

Vogt, W. 1929. Gestaltungs analyse am Amphibienkeim mit örtlicher Vitalfärbung. II. Teil. Gastrulation und Mesodermbildung bei Urodelen und Anuren. Wilhelm Roux' Arch. Entwicklungsmech. Organ. 120, 384-706. 



\section{SOME OBSERVATIONS ON CYTOPLASMIC PARTICLES IN EARLY ECHINODERM DEVELOPMENT}

JOHN R. SHAVER: " KERCKHOFF LABORATORIES OF BIOLOGY, CALIFORNIA INSTITUTE OF TECHNOLOGY, PASADENA, CALIFORNIA

An embryonic system could be defined within the framework of our present concepts of cellular metabolism as one which, in addition to the demands of growth and maintenance, has to meet the unique exigencies of differentiation (cf. recent discussions of Steinbach and Moog, 1955, and Boell, 1955). Our understanding of the ways in which differentiated cells of metazoan organisms carry on such vital functions as energy transfer and protein synthesis has been enormously extended in recent years by studies on the structure and function of various kinds of cytoplasmic formed elements. It does not seem surprising, therefore, that numerous suggestions have come from embryologists concerning the role of these subcellular entities in embryonic differentiation (for recent reviews see Brachet, 1950, 1952; Gustafson, 1954).

But the information about the interrelationships of cytoplasmic particles and other cell constituents in the life of the cell is still largely descriptive, especially as they concern the intact cell (cf. Porter, 1955). To assign a dominant, if not a unique, place to one or another of the granule populations of protoplasm in the series of transformations leading to specific cell types necessitates an identification of visible structures with causality which still seems very far from being able to be made.

* Special Research Fellow, National Cancer Institute, United States Public Health Service. Present address: Department of Zoology, Michigan State University, East Lansing, Michigan. 
The purpose of this brief review is to attempt an examination of current information concerning patterns and gradients of cytoplasmic particles in echinoderm embryos and to assess some of the recent hypotheses concerning their functions in early differentiation.

\section{Cytoplasmic Particles and Initial Stages of Development}

As Tyler remarks (1955): “An understanding of the factors that endow egg and sperm with the ability to unite and produce a new individual may be expected to depend largely on knowledge of the manner of formation of the gametes." An extensive literature exists describing the results of various cyto- and histochemical tests performed on cells in various stages of gametogenesis (for a review of earlier literature, see Brachet, 1950). Although there is information on the origin of ribonucleoproteins in the gonial cells of several invertebrate species (Arvy, 1950; Nigon and Delavault, 1952; Fauré-Fremiet et al., 1950; FautrezFirlefyn, 1951; Panijel, 1951) and a great deal of discussion about the possible participation of these substances in yolk formation (cf. Wittek, 1952; Urbani, 1955), there seems to be no evidence that ribonucleic acid, demonstrable by the usual cytochemical tests, is associated for the most part with sedimentable fractions of oocytes or unfertilized eggs. Brachet and Chantrenne (1942) have reported about $20 \%$ to $40 \%$ of the ribonucleic acid to be associated with granules in amphibian egg homogenates, but the granule-free fragments of sea urchin eggs obtained by centrifugation were reported to be rich in ribonucleic acid (Harvey and Lavin, 1944).

It has long been known, however, that gonial cells and mature gametes contain cytoplasmic elements identical with those found in adult cells (Wilson, 1928). Recent observations with phase contrast and electron microscopy confirm the existence of "typical" mitochondria and/or Golgi bodies in the protoplasm of unfertilized sea urchin eggs (Shaver, 1955), of germ cells of Helix aspersa (Beams and Tahmisian, 1953), and of frog eggs (Nath and Malhotra, 1954). The flow of these particulate elements from nurse cells into the maturing egg has been described (Wilson, 
1928; Agarawal, 1949), but the distribution of various granular constituents along axes, or into "organ-forming" areas, of eggs is, as has been pointed out on numerous occasions (Wilson, 1928; Watterson, 1955), a result, rather than a cause, of the polarity of the egg. Summarizing the earlier literature on the subject of cytoplasmic inclusions of egg cells, Wilson (1928) states: "It is important to bear in mind the rapid increase of chondriosomes (and of Golgi bodies?) that takes place during the growth of the egg. Only a part of them are used up in the production of other formed elements. The greater number persist, possibly to play some role in the fertilization of the egg, in any case to be handed on to the embryonic cells by cleavage. Perhaps we catch here a glimpse of a mechanism concerned not merely with yolk formation but with the general processes of determination, localization and heredity."

But it is precisely the significance for mechanisms of determination and localization of the cytoplasmic inclusions of egg cells (not to mention the still problematical nature of inclusions transported into some egg cells by the sperm) that still eludes us. It has been the universal result of centrifuging egg cells of both mosaic and regulatory types, that the disarrangement of visible cell inclusions, either slightly or quite drastically, does not appear markedly to alter the development of the embryo. The extreme case of this type of experiment is the well-known one of Harvey (1946), whereby fragments of Arbacia eggs, presumably devoid of any gramular inclusions, developed into normal embryos after fertilization.

Two points may be mentioned in connection with this experiment:

1. Harvey states (1946) that mitochondria displaced from the most centripetal egg fragment are replaced during development by de novo formation of these particles, since the phuteus larva developing from it can be seen to have mitochondria. Harvey, however, described in the clear quarter-egg and the "white" halves, a fine line of granules, which sometimes included small fibers, which were thought to be microsomes (see Fig. 1). The identification of mitochondria in the various fragments of centri- 


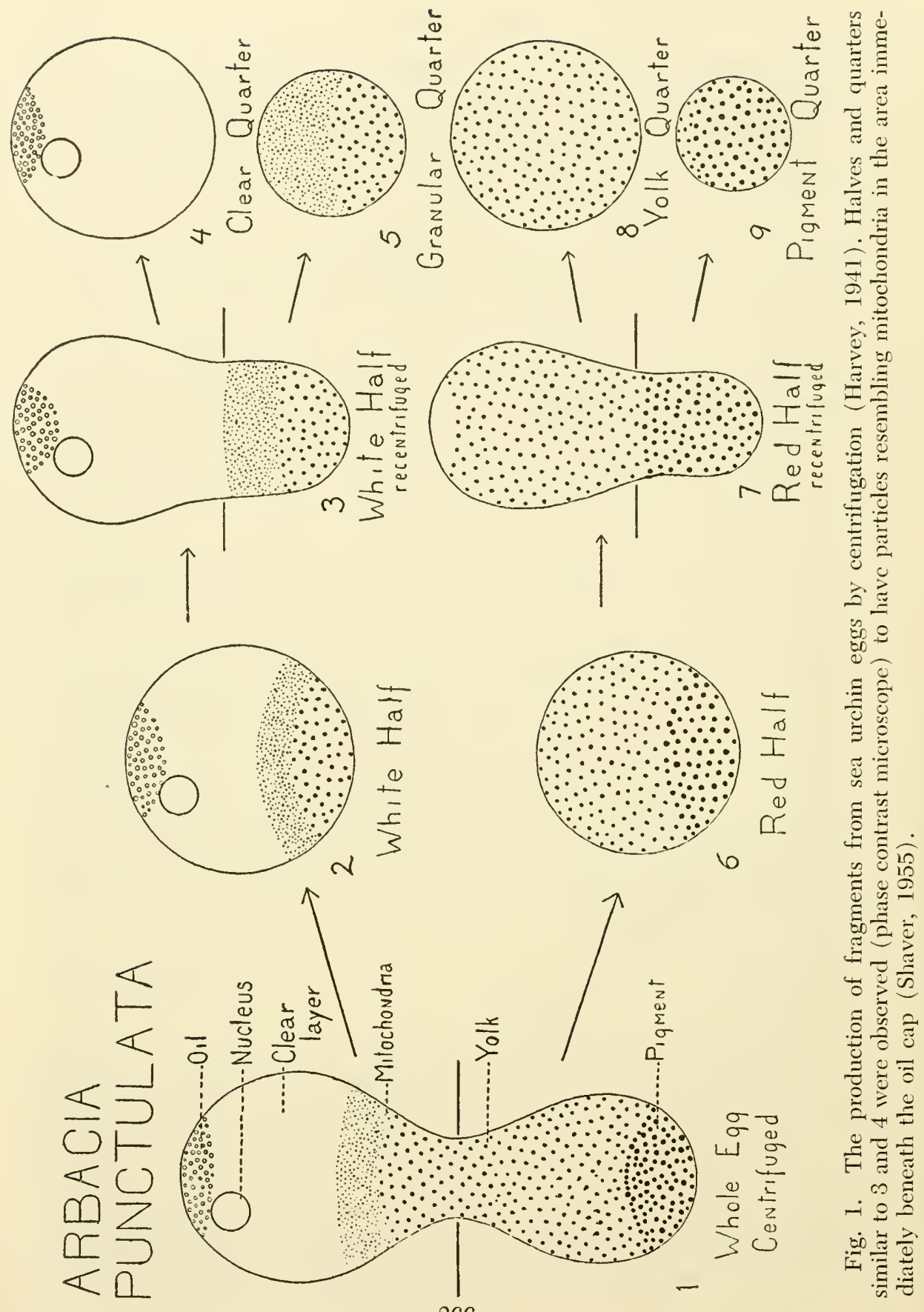


fuged eggs was made by Harvey by means of staining with methyl green which she considers "just as specific" as Janus green. Shaver (unpublished observations) centrifuged Lytechinus pictus unfertilized eggs into "light" and "heavy" halves, and the former into "clear" and "granular" quarters, with the same force of gravity employed by Harvey. These fragments were observed with phase contrast microscope, unstained, or after staining with Janus green or methyl green. The fine line of granules seen in the clear quarters under oil immersion dark phase objective appears to be a mixture of elements. The largest were spheres or spheroids of from 0.5 to 1.0 micron diameter. Harvey (1946) gives the dimensions of mitochondria seen in granular quarters and heavy halves as $0.6-1.0$ micron. In some of these particles observed by Shaver, the bipartite structure seen frequently in mitochondria of sea urchin embryonic cells, as well as in adult tissue cells of mammals (Harman, 1950), was unmistakable. The other elements of the fine line of granules (just at the limit of visibility at $1400 \times$ magnification) consisted of very much smaller granules and very small rods. The latter appeared to be closer to the oil cap, and in some fragments formed a boundary between it and the granular stratum just below.

The results of staining with Janus green or methyl green were not very definitive. The former stain has not proved satisfactory for mitochondria in the intact cells of sea urchin embryos (Shaver, 1955). In fragments of centrifuged eggs, granular elements corresponding to mitochondria (in the sense used by Harvey, 1946), as well as the elements of the "fine" layer of granules in the clear quarter, and a portion of the yolk layer, all took on a bluish-green to purple color in the presence of the dye; phase contrast observation of stained fragments also indicated that there was a physical change in the granular elements after dye penetration, a tendency to clumping being seen, especially in the granular quarters. Methyl green proved unsatisfactory as a specific stain for mitochondria since, under the conditions in which it was used, most of the granular elements in all quarters, or halves, stained a bluish purple.

The clear quarters were unfortunately not followed after ferti- 
lization to see if any indications of de novo formation of mitochondria could be seen in later stages.

2. The second point concerning the granule-free nature of the clear fragments of centrifuged sea urchin eggs concerns the observation by Lansing and Hillier (1954) that, in electron micrographs of stratified Arbacia eggs, two distinct layers of mitochondria could be seen, one of higher density than the other. It was pointed out (Palade, 1954) that the light mitochondria might have been trapped just below the lipid layer. The observations of Shaver concerning the close proximity to the oil cap of the small fibrils and the light mitochondria seem to agree with this suggestion.

Admittedly, it is very difficult to be certain that the exact conditions of Harvey's experiments are being duplicated in attempts to repeat them, but the report by Harvey of granular elements in the clear quarters, together with the observations noted above, suggest that a reinvestigation of the development of clear fragments might be profitable.

But aside from the question of the presence or absence of cytoplasmic particles in egg fragments which produce normal embryos (which is of obvious physiological interest), it is evident that there are no patterns of distribution of mitochondria and/or microsomes in the unfertilized sea urchin egg which have determinative significance. It is equally evident, from the results of micrurgical operations made in various planes of eggs and early embryos of both mosaic and regulatory eggs, that determinative patterns are established at various times before fertilization, or shortly thereafter ( these experiments). The ground substance or the cortex, or both, have been suggested as the site of such a localization, the latter having attracted especial interest because of the presence in it of granular structures, in sea urchin eggs, which undergo striking changes at fertilization (Harvey, 1910; Moser, 1939).

In the experiments by Harvey (1946), it was observed that cortical granules in Arbacia were not displaced by the gravitational forces used. Motomura (1949), using much higher forces, reported that the axis of differentiation in eggs of two sea urchin 
species could be shifted in accordance with a centripetal shifting of the cortical cytoplasm. Invagination started at the point where the cortical cytoplasm was thickest. This observation seems to agree with the earlier ones of Runnström (1928b) who described an area in the cortex of the vegetal half of sea urchin eggs which, when followed by dark field illumination, became localized in cells which were invaginated to form the archenteric walls of the embryo.

Later studies (Motomura, 1941; Runnström, 1949; Endo, 1952) relate the release of cortical granules to the formation of the fertilization membrane. Release of material to the cell interior may well play an important part in activating preexisting patterns for differentiation in the egg (Rumnström, 1952). Suggestions as to the nature of this mechanism have been made by Heilbrumn (1952), who emphasizes the colloidal changes produced in the cell interior by the release of calcium from the cortex. Perhaps a more specific type of mechanism that could be set in motion by the release of materials inward from cortical granules (or other cortical areas) at fertilization is one suggested by Tyler (1947), whereby differentiation is envisaged as the result of interactions of substances similar to antigen-antibody reactions. As Tyler remarks (1947): “To account for these differences in location and amount (of specific antigens of the organism) we must again fall back on initial regional differences in the cytoplasm of the uncleaved egg." The application of newer techniques for preparing cytoplasmic fractions of greater homogeneity (cf. Hogeboom and Kuff, 1955) than heretofore, against which antisera could be made for testing developmental effects, might be a profitable means of testing this interesting idea.

Although not related directly to the differentiation of the embryo, some studies on the effects of granular fractions of embryonic and adult tissues of vertebrates and of sea urchins, on the fertilization and cleavage processes, are of physiological interest. Runnström et al. (1954) have observed the effect of an extract of a granular fraction, and of a supernatant fluid, prepared from sea urchin eggs, on the fertilization of eggs of Arbacia lixula. All the control eggs apparently were of the tight membrane type, and 
the principal effect of the granule extract was to enable normal membranes to be elevated at fertilization. A later effect of this fraction was to counteract the tendency toward radialization seen in the control larvae. The authors imply that the normal balance between ventral and dorsal tendencies in sea urchin development might be maintained by substances released from granules within the egg. The supernatant fluid contained a jelly-precipitating factor which is compared in its physiological role with egg antifertilizin (Tyler, 1940).

Shaver (1953) studied the effects of various fractions of embryonic and adult tissues of the frog in initiating cleavage when injected into unfertilized frog eggs. Large granule fractions appeared to be the most effective in this regard. Active fractions were not obtained until just before gastrulation commenced. It was suggested that a possible mechanism of action of the granules in initiating cleavage might be connected with a protoplasmic clotting system similar to the one postulated by Heilbrunn (1952).

These studies, as well as others made in the period before the importance of the homogenization medium for the preservation of structure of intracellular cytoplasmic particulates was realized, would appear to suffer from lack of homogeneity of the fractions being tested. Runnström et al. (1954) used isotonic sodium chloride (or in some cases sodium and calcium chloride) as the homogenization medium, and Shaver (1953) employed a dilute phosphate buffer. It has been pointed out (Schmeider and Hogeboom, 1950) that the use of electrolyte solutions for homogenization of tissues results in changes of the particles that may grossly alter the distribution of substances in the fractions subsequently isolated from the homogenate by centrifugation.

\section{Gradients and Cytoplasmic Particles in Early Sea Urchin Differentiation}

Atomistic theories were certainly among the first and appear to be among the most recurrent of attempts to explain cell and tissue differentiation. From the invisible "pangens" of deVries to the "plasmagenes" of more recent hypotheses, the intervention of cytoplasmic particles or centers of one kind or another has often 
been invoked to explain the appearance of specific morphological properties in cells. As Wilson (1928, p. 1085) states: "More accessible to investigation (than theories of invisible 'pangens') are hypotheses which assume differentiation to be effected by the transformation of visible cytoplasmic granules or other definite bodies, arising either by migration from the nucleus, or independently in the cytosome. ...."

Equally influential has been the concept of differentiation which expresses regional determination of the embryo in terms of gradients of types or intensity of metabolism, or of specific substances. The manifestations of this idea, as applied to various embryonic or adult differentiating tissues, are protean. The reviews of Lindahl (1942), Brachet (1950), Horstadius (1949), and Child (1941) present the evidence for and criticisms of gradient concepts as applied to the differentiation of echinoderms.

More recently, a theory of differentiation for the sea urchin has been advanced by Gustafson (1954), which embodies features of both the above mentioned concepts. It incorporates within the double-gradient theory of Runnström (1928a) and Horstadius (1949), the idea that cytoplasmic particles, specifically the mitochondria, act as primary agents in establishing the basic embryonic shape. Gustafson assumes that mitochondria in actively differentiating regions produce fibrous structure proteins, which are responsible for such transformations as cell stretching and the appearance of the apical tuft.

The principal observations and experiments on which Gustafson's concept is based are:

1. Mitochondria in the egg and early stages are represented mainly as "precursors," described as "small granules," which are sensitive to the action of lithium during a certain period.

2. The number of mitochondria per se in early stages is low. Gustafson and Lenicque (1955) have described a small increase in mitochondria during cleavage and blastula stages, which is followed by a rapid and large increase in the number of these particles at the mesenchyme blastula stage.

3. Counts of the mitochondria in mesenchyme blastulae and young gastrulae, along the animal-vegetal axis, indicate, accord- 
ing to Gustafson and Lenicque (1952), that these particles are arranged in a gradient, decreasing toward the vegetal pole.

4. One of the features of the original double gradient concept of differentiation in the sea urchin is the postulation of animal and vegetal substances, the concentrations of which are highest at the respective poles, decreasing toward the opposite pole. According to Gustafson (1954), agents producing animalization of the embryo act by suppressing a mitochondrial inhibitor in the vegetal region, producing larvae with a uniform distribution of mitochondria. Conversely, vegetalizing agents suppress the animal substance which favors mitochondrial production; hence the number of mitochondria in vegetalized larvie is lower than in normal ones.

5. The primary mitochondrial gradient in mesenchyme blastulae is soon succeeded, however, by a series of localized waves of mitochondrial production in actively differentiating regions, which in turn produce substances inhibitory to mitochondrial production in immediately adjacent regions. When the effect of these inhibitors declines, succeeding waves of mitochondrial production occur in the next regions to differentiate. Gustafson and Lenicque (1952) state: “. . . the localized development of mitochondrial populations appears to be controlled by inhibitors, produced in regions of high mitochondrial activity."

It has been noted in the preceding section that the distribution of cytoplasmic inclusions along gradients in unfertilized, or just fertilized, eggs, can have no direct connection with the differentiation potentialities of the regions along the presumptive embryonic axis, since the disarrangement of particles by centrifugation appears not to affect the subsequent formation of the embryo. But Harvey (1946) reports mitochondria present in the plutei developed from clear egg quarters in Arbacia, although she states that they were not found in day-old blastulae. In view of the importance for primary differentiation attributed by Gustafson to a gradient pattern of cells in mesenchyme blastulae and young gastrulae, with reference to their mitochondrial content, a brief consideration of the results of other investigators on this subject seems of interest. 
It is apparent that there is no discernible gradient in the distribution of ribonucleoprotein in the development of sea urchins so far studied. Brachet (1950) using toluidine blue and ribonuclease to indicate the localizations of these substances, followed the distribution of both deoxyribonucleic acid and ribonucleic acid in sea urchin embryos. Although there was an overall decrease in cytoplasmic basophilia, interpreted as a decrease in ribonucleic acid, there was no evidence of a gradient-like clistribution of this substance. The micromeres were especially rich in ribonucleic acid, but, as Brachet states (1950, p. 451): “. . . we are still simply dealing with a local accumulation of the ribonucleoproteins, which do not show a true gradient visible under the microscope. Of course, one cannot a priori reject the idea that particular ribonucleoproteins bound to granules, for example, are distributed in gradient fashion, but this supposition is gratuitous at present."

Shaver (unpublished results) has obtained essentially the same picture of the ribonucleic acid distribution in developmental stages of two sea urchin species. Toluidine blue or methyl green pyronine were used after fixation of whole embryos on coverslips with Zenker's fluid (without acetic acid) or Altman's fluid. There did not appear to be any evidence of a gradient of dye absorption in any of the stages observed.

Cytochemical and biochemical evidence has been increasing concerning the association of ribonucleic acid with protein synthesis in the cell (Brachet, 1952; Pollister, 1954). The fact that a larger part of the ribonucleic acid of adult cells is associated with the microsome fraction (cf. Lindberg and Ernster, 1954), emphasizes the importance of these particles in protein synthesis. There seems relatively little information, however, about the concentra. tions of ribonucleic acid in the particulate fractions of sea urchin embryonic cells. If the assumption is made that ribonucleic acid is progressively bound to microsomes in the cells of the sea urchin embryo, there appears to be no gradient in the distribution of these particles.

Unlike microsomes, mitochondria stain relatively weakly with basophilic dyes (see, however, Lindberg and Ernster, 1954, for a 
discussion of mitochondrial basophila attributed to perimitochondrial aggregation of microsomes). This may be connected with the fact that these particles contain proportionately much less ribonucleic acid than microsomes (Schneider and Hogeboom, 1950), at least in adult mammalian cells, but it may also be due to the lipid sheath which surrounds a mitochondrion.

Shaver (1955) undertook an examination of the question of mitochondrial gradients in sea urchin embryos of two species, Lytechinus pictus and Strongylocentrotus purpuratus. The technique described by Gustafson and Lenicque (1952) was followed as closely as possible, and other methods recommended for the visualization of mitochondria were also used. The most satisfactory fixatives employed were Altman's fluid or $1 \%$ osmium tetroxide; the stain which yielded best results was fast green and safranin. All preparations were of embryos fixed and flattened on coverslips. Concurrent studies were also made with the phase contrast microscope of both intact embryos and of homogenates.

Details of the results cannot be given here, but certain points relating to the question of mitochondrial gradients may be noted.

1. The method employed by Gustafson and Lenicque (1952) for the identification of mitochondria appears to be unsatisfactory. The technique used by these investigators consists of vitally staining embryos with Nile blue sulfate, flattening them under coverslips, and counting particles (as mitochondria) within an area marked off by a reticule oriented (in mesenchyme blastulae or later stages) along the animal-vegetal axis.

Some preliminary observations by Shaver of eggs stratified at $10,000 \mathrm{~g}$ and stained with Nile blue sulfate indicated that the dye is absorbed by most of the particulate elements of the cytoplasm, by some of the elements of interphase nuclei, and, to a lesser degree, by the hyaloplasm. In intact cells, it appeared very uncertain which elements were mitochondrial on the basis of coloring by Nile blue sulfate.

2. Mitochondria in various types of cells have been described as being of different sizes. The usual range given for these particles from adult tissue cells is from 0.5-2.0 microns in diameter, and up to 7.0 microns in length. Observations of mitochondria 
from sea urchin embryonic cells, studied with the phase contrast microscope in homogenates, indicated a size range of from 0.5 to 2.5 microns, with a majority of spherical or oval forms being about 1.5-2.0 microns in diameter (Shaver, unpublished observations; see Fig. 2a). Electron micrographs of mitochondria in homogenates of sea urchin embryos have provided additional information on the size range of these particles in this material (Fig. 2b). Gustafson and Lenicque $(1952,1955)$ have not given any dimensions for the particles identified by them as mitochondria. Agrell (1955), however, observing sea urchin embryonic cells under
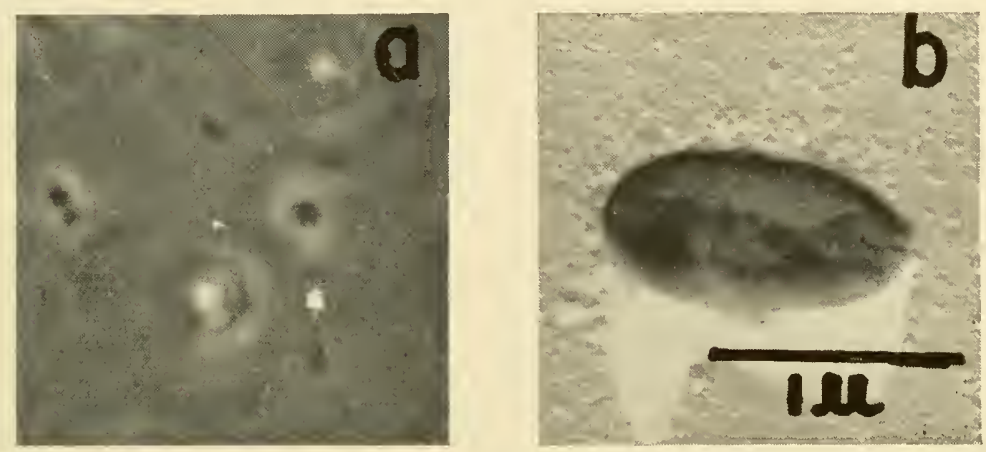

Fig. 2. (a) Homogenate of unfertilized eggs, Lytechinus pictus, showing typical forms and sizes of mitochondria. Dark $M$ phase contrast oil immersion objective, $1455 \times$. (b) Electron micrograph of mitochondrion from homogenate of $L$. pictus gastrulae ( 24 hours; $17^{\circ} \mathrm{C}$ ); dialyzed on collodion membrane, fixed with buffered $2 \%$ osmium tetroxide; air dried; chrome shadowed. Original magnification, 16,000×.

conditions similar to those employed by Gustafson and Lenicque (1952), states that mitochondria are "dark, round granules, 0.2 micron in diameter, very often double granules, or sometimes clustered together in larger aggregates, staining clearly with Janus green." The tendency of small particles in the cytoplasm of cells, vitally stained with Janus green or Nile blue sulfate, to aggregate has also been noticed by Shaver (umpublished observations). It is conceivable that the development of mitochondria from "very small blue units" (Gustafson and Lenicque, 1952) may in part be due to such a phenomenon. 
3. Since Gustafson and Lenicque (1952) report mitochondrial counts made only within the area of a reticulum, the process of flattening embryos for observation might have affected particle distribution within this area. Shaver (1955) has observed embryos during the flattening process and has noted differences in resistance to pressure of cells in animal and vegetal regions, which result in distortion of cell shape and of the distribution of particles within the cytoplasm.

4. In the fixed and stained preparations, in which mitochondria are much more easily identified than in vitally stained cells, careful observation under oil immersion lens revealed no consistent differences in the number of particles in cells along the length of the animal-vegetal axis, in mesenchyme blastulae, or young gastrulae. Quantitative counts of the particles were not replicable from one embryo to another, however (Shaver, 1955).

The inability to distinguish a gradient of distribution of mitochondrial by Shaver (1955) inclicates either that there are species differences among sea urchins in this respect or that more accurate methods of determining the localization of mitochondria should be utilized. Results of electron microscopy of ultra-thin sections of both plant and animal tissues have pointed to a basic similarity of structure of mitochondria from diverse sources $\mathrm{Pa}$ lade, 1952). An application of these techniques to sea urchin embryonic material would seem to be a promising approach to the clarification of the problem of particle localization.

Some other observations by Shaver (1955) confirm and extend Gustafson and Lenicque's (1952) findings. An examination of early blastula cells, which develop ciliated borders, revealed larger numbers of particles in peripheral regions than in more internal ones. This orientation of particles in ciliated cells was also noted in later larvae stages, when the ciliated bands make their appearance. As development continues (gastrula and prism larvae), there is a pronounced increase on the number of mitochondria in the cells of the developing gut structures. In the pluteus, there are larger numbers of mitochondria in the cells of the developing arms, while the cells of the body wall show a relative decrease in this respect. 
In addition to the conflicting cytological evidence concerning the existence of mitochondrial gradients in sea urchin embryos, a few other points may be noted which seem to present some objections to Gustafson's hypothesis.

1. Although the initial phases of development (fertilization and cleavage ) may go on in the absence of mitochondria and/or microsomes (Harvey, 1946), it does not follow that these particles are not utilized in normal development. Alternate pathways may exist in the cell which could accomplish the same ends. It is possible that soluble factors from mitochondria may remain in the fragments after the removal of the granules (assuming that all mitochondria are removed), which, in conjunction with the microsomes of Harvey (1946), present in the fine line of granules, might substitute for the missing mitochondria for a limited period. In any case, the cytological evidence that the mitochondria in the embryo before differentiation are present mainly as precursors is conflicting.

2. The use of the phrase "primary differentiation" can be misleading if it is meant to imply that nothing has occurred in the embryo up to gastrulation but the passive distribution of materials during cleavage. Sea urchin embryos, for example, are, in a sense, free-living organisms for some time after hatching before primary differentiation commences. The elaboration of cilia, for locomotion, is a form of differentiation which presumably requires at least some of the processes of transformation involved in any specialization of cell type. If it is accepted that mitochondria per se do not begin to function in differentiation until gastrulation in the sea urchin, it must be admitted that other systems not requiring mitochondria can also function in such cellular transformations.

3. The elaboration of proteins, either structural or metabolic, has been postulated by many cytologists to result directly from the activity of cytoplasmic particles ( see Wilson, 1928, for a review of older literature; Holtfreter, 1948, for a recent application of this idea to shape changes in embryonic cells), but it has been pointed out that we as yet know little about the synthesis of proteins in vivo (Fruton, 1954). Biochemical information indicates 
(Siekevitz, 1952) that protein synthesis in vitro by microsomes is facilitated by the presence of mitochondria or by a soluble factor from them. It does not so far seem to have been suggested, on the biochemical level, that mitochondria directly produce proteins. Gustafson (195.5) has observed bundles of fibers in sea urchin eggs which have differentiated without cleavage, but an association of fibrous structures with mitochondria in normal embryos has not been reported.

4. Although there is evidence that enzymes may increase or decrease in activity during development and that the differentiation of specific organs and tissues may be accompanied by the appearance (or activation) of a particular enzyme or enzymes, there is no evidence so far that "the development of an enzyme is in any way causally linked with the differentiation process with which it appears to be associated" (Boell, 1955). Gustafson and Hasselberg (1951) showed that several enzymes increase in activity at the mesenchyme blastula stage in the sea urchin, while others maintain a constant level. It was not directly shown that these enzymes are structurally associated with mitochondria in the sea urchin, and the assumption that they are so bound has been based on a comparison of curves for enzyme activities with the curves of relative mitochondrial densities observed by Gustafson and Lenicque (1952). But the assumption that there is an accumulation of enzymes in mitochondria at a particular period of development does not seem to justify placing a causal interpretation on the event.

5. Gradient theories of differentiation have suffered generally from the criticism that it is difficult to decide whether the patterns of metabolic activity or cellular structures are the cause or the, result of the determination of a region (Brachet, 1950; Holtfreter and Hamburger, 1955). Gustafson's hypothesis does not seem to avoid this difficulty, and presents some additional problems in connection with physiological gradients in the sea urchin egg.

No difference in the respiration of animal and vegetal halves of sea urchin eggs or embryos has been detected (Lindahl and Holter, 1940). Horstadius $(1953,1955)$ reexamined the question 
of gradients of intensity of dye reduction in animal and vegetal halves of sea urchin embryos and concluded that the activity of the fragments in this respect is not equivalent to that of the whole egg. But it has been pointed out (Brachet, 1950) that the technique of anaerobic dye reduction is qualitative and that the investigators who have used it on sea urchin embryos are not unanimous about the existence of such gradients.

There is a further difficulty in reconciling reported metabolic gradients with the mitochondrial gradients described by Gustafson and Lenicque (1952). It will be recalled that, according to these investigators, mitochondrial numbers are higher in the cells of the animal hemisphere in mesenchyme blastulae and young gastrulae. If it is supposed that enzymes are incorporated into mitochondria at this time, it would seem reasonable to expect that the areas in which they occur in higher numbers would be characterized by higher metabolic activity. It would also follow, from Gustafson's theory, that these areas would be the locale of highest differentiation potential. But the reverse situation seems to exist, according to the results of Child (1941) and Horstadius (1952). These investigators found a vegetal-animal gradient of dye reduction at the beginning of gastrulation, which Child thought was independent of respiratory activity. Thus, a gradient, opposing the animal-vegetal gradient, whose highest point coincides with the point where primary differentiation is ordinarily understood to begin in the sea urchin embryo, apparently requires no mitochondria to function.

Clearly, many points remain to be clarified before we can understand how the many complex interactions which must be involved in the morphogenetic gradients of the sea urchin embryo operate in differentiation.

\section{Quantitative Aspects of Mitochondrial}

\section{Populations in Development}

There is a fairly extensive older literature concerning the duplication and distribution of cytoplasmic particles during development and the corollary problem of the differentiation of mitochondria into fibrillar structures, secretory granules, etc. 
These investigations are reviewed in Wilson (1928); more recent hypotheses are summarized in Lindberg and Ernster's recent review (1954).

The earlier results included most of the logical possibilities that can be imagined for the duplication and segregation of cytoplasmic particles in a developing system, but the consensus seems to have been that there is a decrease in mitochondria during cleavage and differentiation, sometimes correlated with the parallel increase of secretory granules, plastids, etc. (Meves, 1908; Guillermond, 1912). However, some observations of an increase in mitochondria during development were made (Romeis, 1913). A study of bat development by Levi (1915) showed a constant decrease in number of mitochondria during cleavage, with an accompanying increase in size, until a point was reached where the number of particles remained constant.

The problem of self-duplication of particles in cells has attracted wide interest recently, especially in connection with speculations on "plasmagenes" and the role of the cytoplasm in genetic continuity of cell types. Evidence seems to point to the origin of mitochondria from microsomes (Brachet, 1952; Zollinger, 1950; Eichenberger, 1953), but not all investigators have agreed that this is the only possibility (Jeener, 1952). As Lindberg and Ernster (1954) pointed out, the essential problem seems to be whether self-duplication of particles is necessary for genetic continuity.

Gustafson and Lenicque (1952, 1955) stated that, in the sea urchin species studied by them, the number of mitochondria is low during early cleavage stages, rises to a level which is maintained for some hours, and then sharply rises again in mesenchyme blastulae and young gastrulae. Mitochondria are said by these investigators to arise from smaller particles by gradual aggregation. They interpreted these results to mean that mitochondria cannot develop during periods of rapid cleavage, since the nucleus, which controls synthetic processes in interphase, is at this time concerned with processes of self-reorganization. A similar conclusion was reached by Agrell $(1954,1955)$ who made mitotic counts in sea urchin embryos and found a gradient of 
mitoses opposed to that of the mitochondria. This investigator also claimed that there is a "plasmatic rhythm" in the production of mitochondria, which consists of a disappearance of particles during division phases and a reappearance when the nucleus is reconstituted.

It may be remarked that the figures given by Gustafson and Lenicque $(1952,1955)$ for overall numbers of mitochondria are based on the relative mitochondrial densities of sample embryonic sectors.

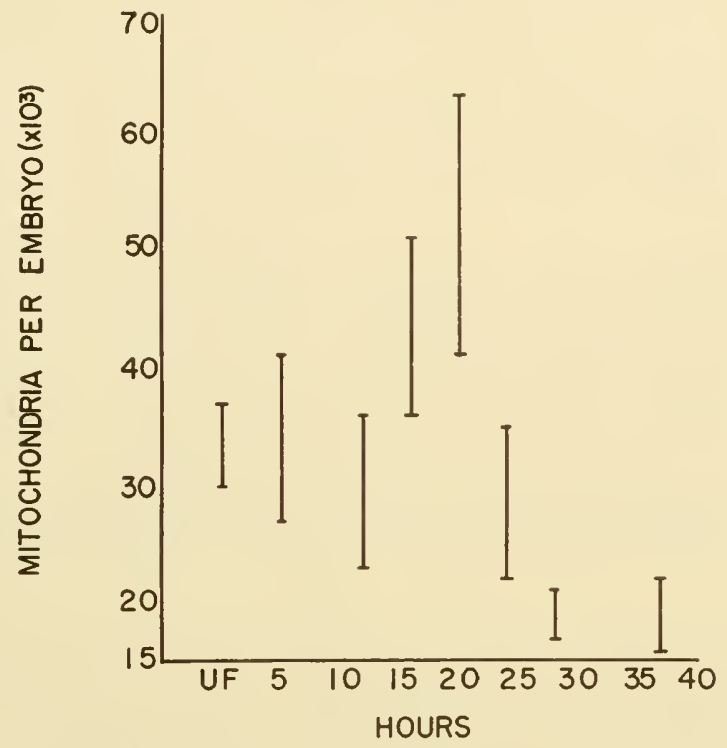

Fig. 3. Lytechinus pictus, cultured at $19.5^{\circ} \mathrm{C}$. Numbers of mitochondria per embryo at different times in early development.

Shaver $(1955,1956)$ has attempted to estimate the numbers of mitochondria at different stages in sea urchin development, with a modification of quantitative technique clescribed by Shelton et al. (1953) for counting mitochondria in liver homogenates.

Preliminary studies were made to ascertain optimum conditions of homogenization medium for the preservation of mitochondria (1.1M sucrose made up in $0.0005 M$ phosphate buffer at $\mathrm{pH} 7.4$ 7.6), method of homogenization (breaking of eggs or embryos by means of a mechanically operated syringe and No. 20 canula), 
dilution of sample for counting, etc. Counts were made in a Petroff-Hauser bacterial counting chamber, at a magnification of $1400 \times$, with a dark $M$ phase contrast oil immersion objective. The criteria used for identification of the mitochondria in homogenates included size, structure, intensity of contrast, behavior in media of different osmotic concentrations, and the ability to undergo changes in shape (cf. Harman, 1950).

The results are presented in Figs. 3 and 4. They are plotted as confidence intervals calculated from the raw data at the $90 \%$

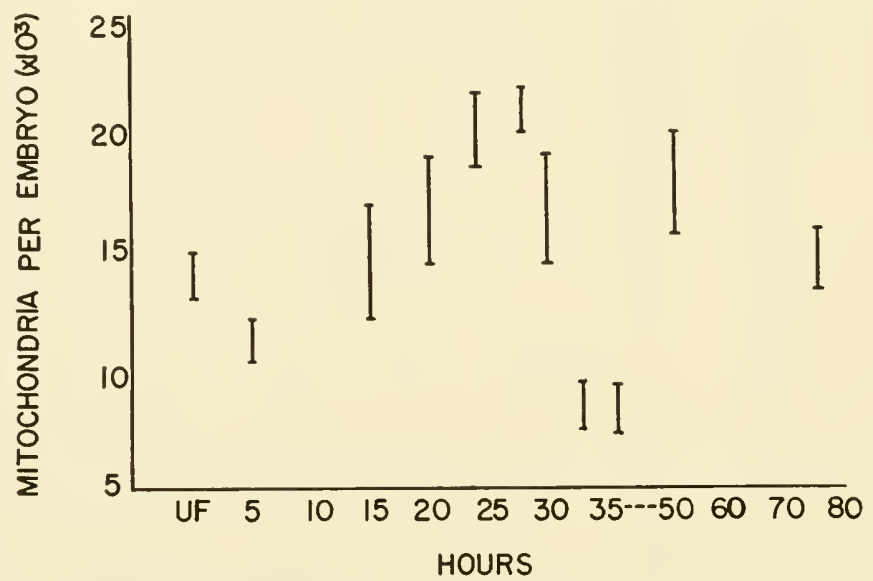

Fig. 4. Strongylocentrotus purpuratus, cultured at $17^{\circ} \mathrm{C}$. Numbers of mitochondria per embryo at different times in early development.

level, with a statistical treatment the details of which will be published elsewhere.

Several points may be briefly noted in connection with these results:

1. In both species studied, the number of mitochondria remains constant during the first twelve or fifteen hours of development (temperature of culturing and rates of development were different for each species). This result indicates that mitochondria do not multiply during cleavage, but are apportioned among the dividing cells. If equal distribution of the particles is assumed, 
the number per cell would be approximately halved at each division, but the total number of mitochondria per embryo would remain the same. The obvious alternative to this interpretation is that mitochondria are destroyed and produced at about the same rates during this period as Agrell (1955) suggested, but at present there seems to be no way of deciding between the two possibilities.

2. In the advanced blastula stage, just prior to the beginning of migration of the primary mesenchyme cells ( 16 hours for $L$. pictus, 20 hours for $S$. purpuratus), there is a sharp increase in mitochondrial number. This increase in number is consistent with the suggestion (Gustafson and Lenicque, 1955) that mitochondria do not increase markedly during cleavage, but there is no evidence from this study that mitochondria result from an aggregation of smaller precursors.

3. The level of mitochondria reached at the mesenchyme blastula stage is maintained for some hours. At the time when gut differentiation is progressing (about 28 hours in L. pictus, 33 hours in S. purpuratus) there is a sharp decrease in mitochondria, reaching a level below that of the uncleaved egg.

4. In S. purpuratus, where later developmental stages were studied, mitochondria in pluteus stages have regained the level of the uncleaved egg.

The figures presented afford only a rough estimate of mitochondrial numbers during sea urchin development. The method used, however, appears to be more reliable for quantitative purposes than techniques which depend on the identification of particles in intact cells. If it is assumed that the estimations approximate reality, a few questions raised by such fluctuations of mitochondrial populations in sea urchin development may be noted:

1. If the numbers of mitochondria do, in fact, remain approximately constant during the cleavage period, what does this mean in relation to the energy-requiring processes occurring at this time? Are we dealing with a situation in which the uncleaved egg has stored enough material, not only to provide for the syntheses which go on during cell division but also to provide for the energy 
demands of the system? Or, as has been suggested, are mitochondria destroyed and produced at a rate corresponding to a plasmatic rhythm (Agrell, 1955)?

2. Does the apparent increase in mitochondria in the mesenchyme blastula reflect new demands of the embryonic system in preparation for, or coincident with, the beginning of primary differentiation? This question is loaded with imponderables, since we as yet seem to be quite unaware of any specific distinctions that can be made among the demands of the embryonic cell for growth, maintenance, or transformation. To ask whether or not the increase in mitochondria reflects the requirements of the embryo at this time for new protein types seems merely to be rephrasing the question.

3. What is the meaning of the decrease in mitochondrial number, shortly after the peak reached at the beginning of gastrulation? It has been reported by Gustafson and Lenicque (1952) and Shaver (1955) that, in intact stained embryos, after gut differentiation has progressed to some extent, there is a diminution in mitochondrial number in the cells of the body wall and a concentration of particles in the cells of gut structures and of ciliated bands. An obvious guess as to the nature of the decrease in particles at this time is that synthetic processes or physiological activity, or both, have become restricted to a smaller area of the embryo, producing an overall diminution in mitochondria.

4. In addition to questions raised by changes in total numbers of mitochondria, the problem arises of changes in classes of mitochondria during early development. Recent studies by Paigen (1954) and Novikoff et al. (1953), and others, of mitochondrial heterogeneity, indicate that in adult mammalian cells the chemical structure (and function?) of mitochondria varies with their size. Considering the range of dimensions of the particles counted in this study, it is possible that transitions occur from one size class to another which would be revealed only by differential counts. Although no quantitative data are available, the impression was gained by Shaver (1955) that the larger spherical or oval forms seen in the uncleaved egg and earlier stages were ex- 
ceeded in numbers by smaller rod-shaped forms in the gastrula and later stages.

Caspari (1955) suggested that genetically controlled differences exist in mitochondria of the cells of the same tissues in different strains of mice. From his study there was also some evidence of tissue differences in mitochondria in the same animal. The idea is advanced that the composition of particle types in a particular kind of cell is an expression of its developmental and physiological activities. It would be interesting to test this hypothesis by studying mitochondrial heterogeneity in the cells of developing embryos, but echinoderm material evidently would not be appropriate, owing to the lack of genetic information about this group of animals.

\section{Summary}

A brief review is given of observations and experiments dealing with cytoplasmic particles in development. Some hypotheses concerning their role in differentiation are discussed. The results of some current work by the author on changes in number and distribution of mitochondria during development of the sea urchin are presented. Marked changes in number and, possibly, kinds of mitochondria are evident during development. Especially noticeable is an increase in numbers of the particles in mesenchyme blastulae and gastrulae, followed by a sharp decrease in immediately subsequent stages. A gradual return to the earlier level of mitochondrial density was observed in one of the two species studied. The author has failed to find, in the material studied by him, that mitochondria are distributed along a gradient in mesenchyme blastulae and gastrulae, as has been reported in another sea urchin species. This result, therefore, does not support hypotheses of differentiation based on such a distribution pattern of these particles. Technical details are given concerning the identification of mitochondria in intact sea urchin embryos, in living and fixed condition, as well as in homogenates. 


\section{REFERENCES}

Agarawal, S. C. 1949. The phenomenon of infiltration of Golgi bodies and mitochondria from the egg membranes into the egg. U. Allahabad Zool. Sect., pp. 1-7.

Agrell, I. 1954. A mitotic gradient in the sea-urchin embryo during gastrulation. Arkiv Zool., 6, 213-17.

Agrell, I. 1955. A mitotic rhythm in the appearance of mitochondria during the early cleavages of the sea-urchin egg. Exptl. Cell Research, 8, 232-34.

Arvy, L. 1950. Données histologiques sur l'ovogénèse chez Dentalium entale Deshayes. Arch. Biol., 61, 187-96.

Beams, H. W., and T. Tahmisian. 1953. Phase contrast and electron microscope studies on Golgi bodies and mitochondria of germ cells of Helix aspersa. Cytologia, 18, 157-66.

Boell, E. J. 1955. Energy exchange and enzyme development during embryogenesis. In Analysis of Development, B. H. Willier, P. A. Weiss, and V. Hamburger, editors. W. B. Saunders Company, Philadelphia, Pa. Pages 520-55.

Brachet, J. 1950. Chemical Embryology. Interscience Publishers, New York-London.

Brachet, J. 1952. Le rôle des acides nucléiques dans la vie de la cellule et de l'embryon. Actualités biochimiques, No. 16. Éclitions Desoer. Liège.

Brachet, J., and H. Chantrenne. 1942. Nucleoprotéides libres et combinés sous forme des granules chez l'oeuf d'Amphibiens. Acta Biol. Belgica, 2, 451-53.

Caspari, E. 1955. The role of genes and cytoplasmic particles in differentiation. Ann. N. Y. Acad. Sci., 60, 1026-37.

Child, C. M. 1941. Patterns and Problems of Development. University of Chicago Press, Chicago, Ill.

Eichenberger, M. 1953. Elektronmikroskopische Beobachtungen über die Entstehung des Mitochondrien aus Mikrosomen. Exptl. Cell Research, 4, 275-82.

Endo, Y. 1952. The role of the cortical granules in the formation of the fertilization membrane in eggs from Japanese sea-urchins. I. Exptl. Cell Rescarch, 3, 406-18.

Fauré-Fremiet, E., A. Courtines, and F. Mugard. 1950. Double origine 
des ribonucléoproteines cytoplasmiques dans l'oöcyte de Glomeris. Exptl. Cell Research, 1, 253-63.

Fautrez-Firlefyn, N. 1951. Cytochemical studies of nucleic acids during gametogenesis in Artemia. Arch. Biol., 62, 391-438.

Fruton, J. S. 1954. The biosynthesis of proteins and pepticles. In Aspects of Grouth and Order. 13th Symposium Soc. for Study of Dev. and Growth, D. Rudnick, editor. Princeton University Press, Princeton, N. J. Pages 15-42.

Guillermond, A. 1912. Sur les mitochondries des organes sexuels des végètaux. Compt rend., 154, CLIV. (Cited in Wilson, 1928, p. 711.)

Gustafson, T. 1954. Enzymatic aspects of embryonic differentiation. In International Review of Cytology, Vol. 3, G. H. Bourne and J. F. Danielli, editors. Pages 272-328.

Gustafson, T. 1955. Observations on differentiation with inhibited cleavage in the sea-urchin egg. Exptl. Cell Research, 8, 118-20.

Gustafson, T., and I. Hasselberg. 1951. Studies on enzymes of developing sea-urchin egg. Exptl. Cell Research, 2, 642-72.

Gustafson, T., and P. Lenicque. 1952. Studies on mitochondria in the developing sea-urchin egg. Exptl. Cell Research, 3, 251-74.

Gustafson, T., and P. Lenicque. 1955. Studies on mitochondria in early cleavage stages of the sea-urchin egg. Exptl. Cell Research, 8, 114-17.

Harman, J. W. 1950. Studies on mitochondria. I. The association of cyclophorase with mitochondria. II. Structure of mitochondria. Exptl. Cell Research, 1, 382-93, 394-402.

Harvey, E. B. 1941. Vital staining of the centrifuged Arbacia egg. Biol. Bull., 81, 114-18.

Harvey, E. B. 1946. Structure and development of the clear quarter of the Arbacia punctulata egg. J. Exptl. Zool., 102, 253-76.

Harvey, E. B., and G. I. Lavin. 1944. The chromatin in the living Arbacia punctulata egg and the cytoplasm of the centrifuged egg as photographed by ultra-violet light. Biol. Bull., 86, 163-68.

Harvey, E. N. 1910. The mechanism of membrane formation and other early stages in developing sea urchin's egg as bearing on the problem of artificial parthenogenesis. J. Exptl. Zool., 8, 354-76.

Heilbrunn, L. V. 1952. An Outline of General Physiology. 3rd ed. W. B. Saunders Company, Philadelphia, Pa.

Hogeboom, G. H., and E. Kuff. 1955. Relationship between cell structure and cell chemistry. Federation Proc., 14, 633-38.

Holtfreter, J. 1948. Concepts on the mechanism of embryonic induc- 
tion and its relation to parthenogenesis and malignancy. Symposia Soc. Exptl. Biol., 2, 17-49.

Holtfreter, J., and V. Hamburger. 1955. Progressive differentiation: Amphibians. In Analysis of Development, B. H. Willier, P. A. Weiss, and V. Hamburger, editors. W. B. Saunders Company, Philadelphia, Pa. Pages 230-96.

Horstadius, S. 1949. Experimental researches on the developmental physiology of the sea-urchin. Pubbl. staz. zool. Napoli, 21, 131-72.

Horstadius, S. 1952. Induction and inhibition of reduction gradients by the micromeres in the sea-urchin egg. J. Exptl. Zool., 120, 421-36. Horstadius, S. 1953. Influence of implanted micromeres on reduction gradients and mitochondrial distribution in developing sea urchin eggs. J. Embryol. Exptl. Morphol., 1, 257-59.

Horstadius, S. 1955. Reduction gradients in animalized and vegetalized sea-urchin eggs. J. Exptl. Zool., 129, 249-56.

Jeener, R. 1952. Studies on the evolution of nucleoprotein fractions of the cytoplasm during the growth of a culture of Polytomella coeca. Biochem. et Biophys. Acta, 8, 270-82.

Lansing, A., and R. Hillier. 1954. Cited in, J. Histo- and Cytochemistry, 1, 265.

Levi, G. 1915. Il comportimento dei condrosomi durante i pui precoci periodi, etc., Arch. Zellforsch., 19. (Cited in Wilson, 1928, p. 711.) Lindahl, P. E. 1942. Contributions to the physiology of form generation in the development of the sea urchin. Quart. Rev. Biol., 17, 213-27.

Lindahl, P. E., and H. Holter. 1940. Beitrage zur Enzymatischen Histochimie. XXXIII. Die atmung Animaler und Vegetativer Keimhalften von Paracentrotus lividus. Compt. rend. trav. lab. Carlsberg, Ser. Chim., 23, 249-87.

Lindberg, O., and L. Ernster. 1954. Chemistry and physiology of mitochondria. Protoplasmatologia, Vol. III. Lange, Maxwell and Springer, London-New York.

Meves, F. 1908. Die Chondriosomen als Trager erblicher Anlagen. Arch. mikroskop. Anat., 72. (Cited in Wilson, 1928, p. 711.)

Moser, F. 1939. Studies on a cortical layer response to stimulating agents in the Arbacia egg. I. Response to insemination. J. Exptl. Zool., 80, 423-46.

Motomura, I. 1941. Materials of the fertilization membrane in the eggs of Echinoderms. Sci. Rept., Tôhoku Imp. Univ., Ser. 4, 16, 345-63. Motomura, I. 1949. Artificial alteration of the embryonic axis in the 
centrifuged eggs of sea-urchins. Sci. Repts., Tôhoku Imp. Univ., Ser. 4, 18, 117-25.

Nath, V., and S. K. Malhotra. 1954. Microphotographs demonstrating the vacuome, Golgi bodies and nucleolar extrusions in fresh eggs of the frog as studied under phase contrast microscopy. Rescarch Bull. East Panjab Univ. Zool., 59/60, 149.

Nigon, V., et Delavault, R. 1952. L'évolution des acides nucléiques dans les cellules réprodutives d'un Nematode pseudogame. Arch. Biol. 63, 393-409.

Novikoff, A., E. Podber, J. Ryan, and J. Noe. 1953. Biochemical heterogeneity of the cytoplasmic particles isolated from rat liver homogenates. J. Histo- and Cytochem., 1, 27-46.

Paigen, K. 1954. The occurrence of several biochemically different types of mitochondria in rat liver. J. Biol. Chem., 206, 945-58.

Palade, G. 1952. Fine structure of mitochondria. Anat. Record, 113, 539-40.

Palade, G. 1954. Cited in J. Histo- and Cytochem., 1, 265.

Panijel, J. 1951. Evolution des granules cytoplasmiques et conditions de synthése des ribonucléoprotéides. Experientia, 7, 100-2.

Pollister, A. W. 1954. Cytochenical aspects of protein synthesis. In Dynamics of Grouth Processes, E. J. Boell, editor. Univ. Princeton Press, Princeton, N. J. Pages 33-67.

Porter, K. R. 1955. The fine structure of cells. Federation Proc., 14, 673-82.

Romeis, B. 1913. Beobachtungen uber die Plastosomen von Ascaris. Arch. Anat., 81. (Cited in Wilson, 1928, p. 711.)

Runnström, J. 192Sa. Zur experimentellen analyse der Wirkung des Lithiums auf den Seeigelkeim. Acta Zool., 9, 365-424.

Runnström, J. 1928b. Plasmabau und Determination bei den Ei von Paracentrotus lividus Lk. Arch. Entwicklungsmech., 113, 556-81.

Runnström, J. 1949. The mechanism of fertilization in Metazoa. Advances in Enzymol., 9, 241-327.

Runnström, J. 1952. The cytoplasm, its structure and role in metabolism, growth and differentiation. In Modern Trends in Physiology and Biochemistry, E. S. Guzman-Barron, editor. Academic Press, New York. Pages 47-76.

Runnström, J., E. Wicklund, and R. Löw. 1954. Fertilization and development of the sea-urchin egg, Arbacia lixula, under the influence of fractions of egg homogenates. Exptl. Cell Research, 6, 459-78.

Schneider, W. C., and G. H. Hogeboom. 1950. Cytochemical Studies 
of Mammalian Tissues. The isolation of cell components by differential centrifugation. A review. Cancer Research, 11, 1-22.

Shaver, J. R. 1953. Studies on the initiation of cleavage in the frog egg. J. Exptl. Zool., 122, 169-92.

Shaver, J. R. 1955. The distribution of mitochondria in sea-urchin eggs. Experientia, 11, 351-53.

Shaver, J. R. 1956. Mitochondrial populations during development of the sea urchin. Exptl. Cell Research, 11, 549-59.

Shelton, E., W. C. Schneider, and M. J. Striebich. 1953. A method for counting mitochondria in tissue homogenates. Exptl. Cell Research, 4, 32-41.

Siekevitz, P. 1952. Uptake of radioactive alanine in vitro into proteins of rat liver fractions. J. Biol. Chem., 195, 549-65.

Steinbach, H. B., and F. Moog. 1955. Cellular Metabolism. In Analysis of Development. B. H. Willier, P. A. Weiss, and IV. Hamburger, editors. W. B. Saunders Company, Philadelphia, Pa. Pages 70-90.

Tyler, A. 1940. Agglutination of sea urchin eggs by means of a substance extracted from the eggs. Proc. Natl. Acad. Sci. U. S., 26, 24956.

Tyler, A. 1947. An auto-antibody concept of cell structure, growth and differentiation. 6th Growth Symposium, pp. 7-19.

Tyler, A. 1955. Gametogenesis, fertilization and parthenogenesis. In Analysis of Development. B. H. Willier, P. A. Weiss, and V. Hamburger. W. B. Saunders Company, Philadelphia, Pa. Pages 170-212. Urbani, E. 1955. Studi comparativi sulla vitellogenesi e sui nuclei vitellini. Pubbl. zool. staz. Napol., 26, 63-109.

Watterson, R. L. 1955. Progressive differentiation; selected invertebrates. In Analysis of Development. B. H. Willier, P. A. Weiss, and V. Hamburger. W. B. Saunders Company, Philadelphia, Pa. Pages 315-36.

Wilson, E. B. 1928. The Cell in Development and Heredity. 3rd Ed. The Macmillan Company, New York.

Wittek, M. 1952. La vitellogénèse chez les Amphibiens. Arch. Biol., 63, 133-97.

Zollinger, H. 1950. Les mitochondries (leur étude à l’aide du microscope à contraste de phases). Rev. d'Hematologie, 5, 696-745. 


\title{
EARLY DETERMINATION IN DEVELOPMENT UNDER NORMAL AND EXPERIMENTAL CONDITIONS
}

\author{
SILVIO RANZI: ZOOLOGICAL DEPARTMENT, \\ THE UNIVERSITY OF MILAN, ITALY
}

\section{Development Alterations and How They Are Obtained}

Working on sea urchin embryos, Runnström (1954) and his group showed that there are certain substances such as $\mathrm{LiCl}$ that inhibit organ development at the animal half of the embryo by
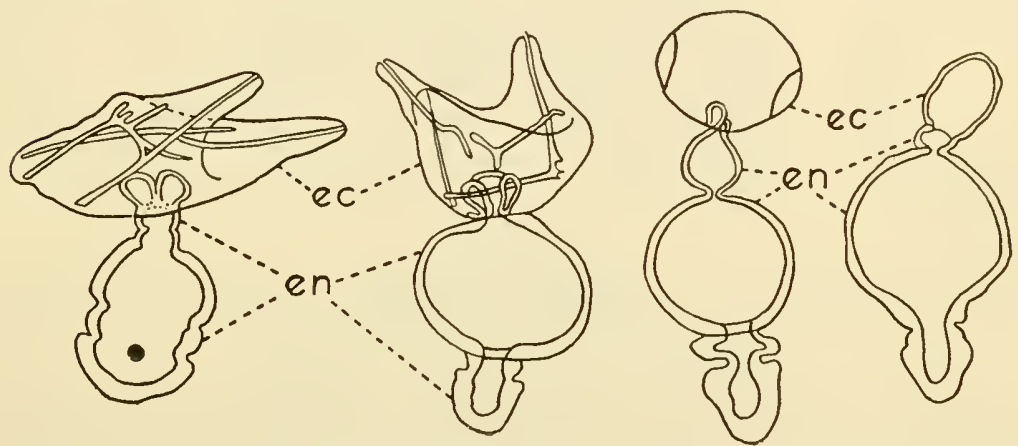

Fig. 1. Vegetalized sea urchin embryos. (From Lindahl and Ohman, 1938.)

inducing a developmental increase in the organs formed at the vegetal half (vegetalized larvae) (Fig. 1). On the other hand, other substances such as iodosobenzoate and NaSCN inhibit the organs formed at the vegetal half and favor the development of rudiments which appear at the animal half (animalized larvae) (Fig. 2). The morphology of the two above mentioned larvae was analyzed by Runnström (1928), Lindahl (1936), and Gustafson 
(1954): vegetalized embryos show a smaller ciliar tuft at the animal pole than the controls; these embryos develop into larvae in which the ectoderm is reduced whereas the entoderm is hyperdeveloped and in certain instances it protrudes (exogastrulae). The animalized embryos develop with a very large ciliar tuft; in these embryos entoderm and mesenchyme are reduced.

Vertebrate cyclopic embryos, obtained by Stockard (1907) in Fundulus and by Cotronei (1922) in amphibians through the action of $\mathrm{MgCl}_{2}$ and $\mathrm{LiCl}$, may be considered as originated from the same causes which induce vegetalized larvae in sea urchins. Adelmann (1934) and Lehmann (1937) showed that LiCl induces an inhibition of prechordal plate and of the notochord in
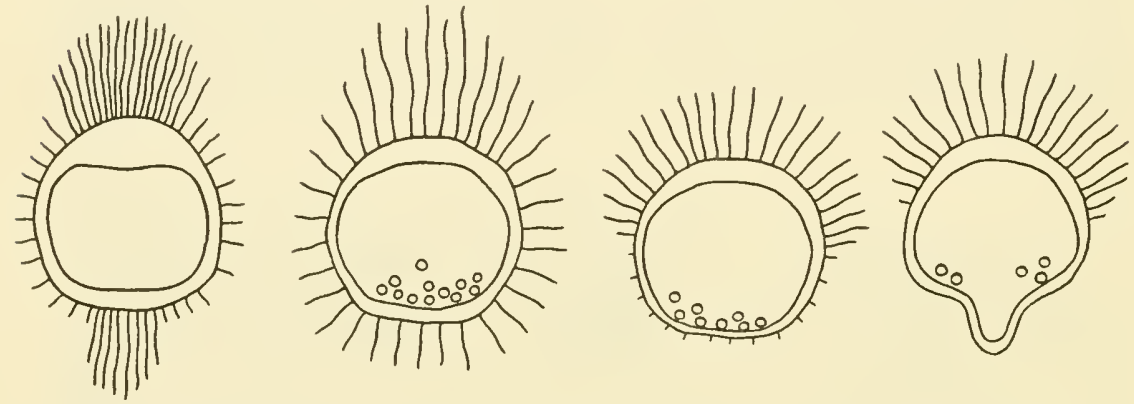

Fig. 2. Animalized sea urchin embryos. (From LindahI, 1936; Tamini, 1941; Bäckström, 1953.)

amphibians (Fig. 3). Therefore the cyclopy originates from a disturbance in the induction process, and the hypodevelopment of the notochord and of the prechordal plate corresponds to the sea urchin vegetalization. Later Bäckström (1953) showed a reduction in organ development and in the animal half of the Xenopus embryo (therefore small embryo). So far we are unable to state whether this phenomenon can be observed in other amphibians.

An increase of notochord in the amphibians is induced by NaSCN (Ranzi et al., 1946) (Fig. 4). Statistical research carried out by Corti at Milan on Rana esculenta embryos in the tailbud stage showed the following average number of notochordal cell 
nuclei: $1107 \pm 24$ in the control embryos; $1233 \pm 28$ in NaSCN embryos; difference in the means is 126; standard error of difference is \pm 37 , i.e., a significant difference. Furthermore SCN ${ }^{-}$induces chordal differentiation from cells of other organ rudiments (Corti, 1950; Badínez et al., 1954). These authors obtained larvae which, beside the normal notochord, had more or less extended

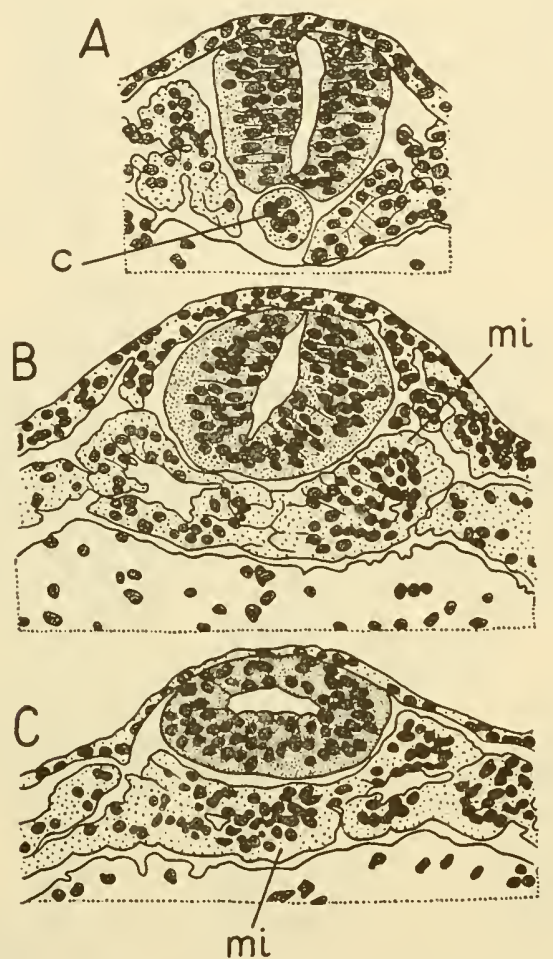

Fig. 3. Cross sections of Triton embryos: A, control embryo; B, C, Litreated embryos; c, notochord; mi, somites. (From Lehmann, 1937.)

sections of notochord, lateral or dorsal to the brain. Generally, animalizing substances induce notochord formation from cells of other presumptive rudiments; this is also shown by Lallier (1955). He showed that sodium thiomalate, an animalizing agent in the sea urchin, induces the formation of notochord in the ventral explants of young amphibian gastrulae in which, therefore, the 


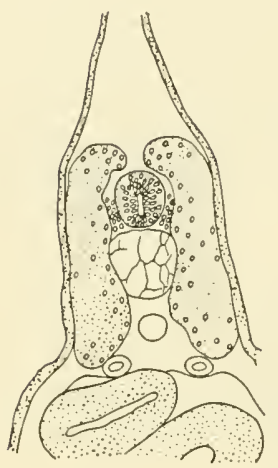

A
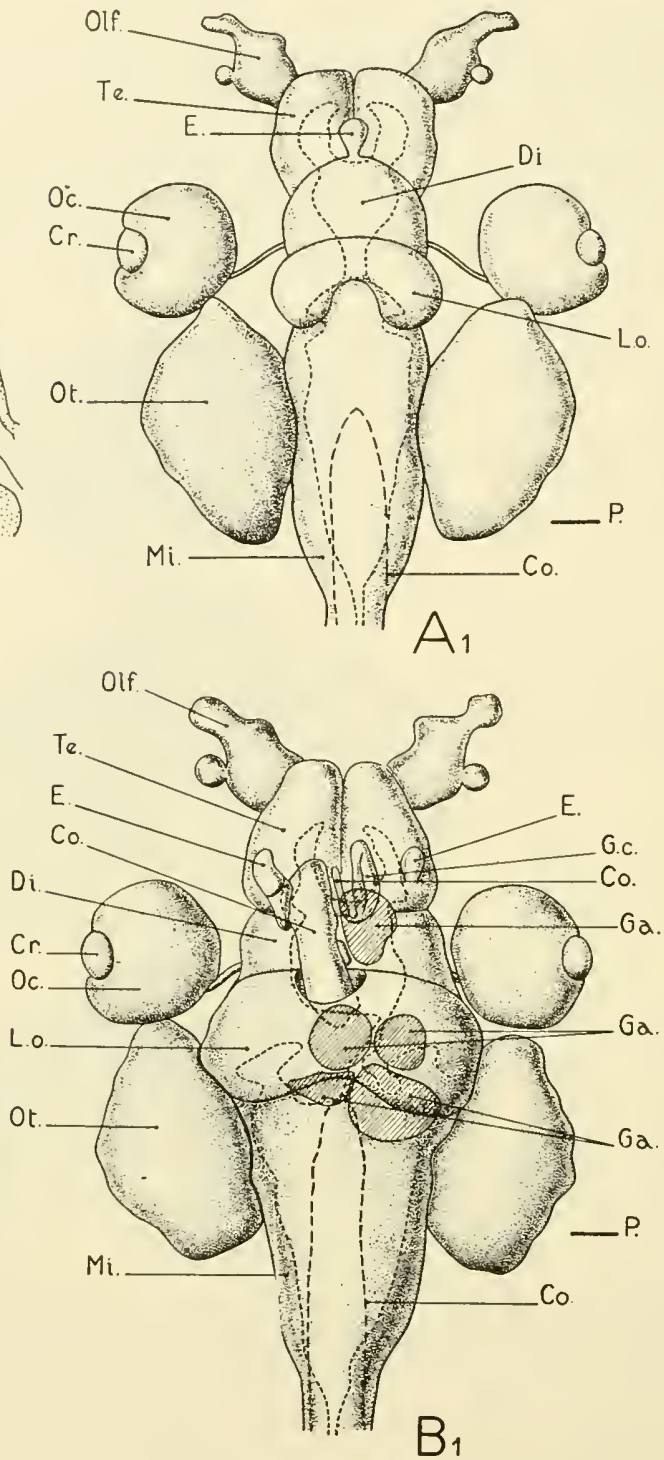

Fig. 4. Cross sections of amphibian tadpoles: A, control tadpole; B, NaSCN-treated tadpole. Dorsal view of brain and sense organs reconstruction: $\mathrm{A}_{1}$, normal tadpole; $\mathrm{B}_{1}$, NaSCN-treated tadpole; Co, notochord; $\mathrm{Cr}$, lens; Di, diencephalon; E, epiphysis; Ga, ganglion; G.c, notochord sheath; L.o., optic lobes; Mi, myelencephalon; Oc, optic cup: Olf., olfactory pit; Ot., otocyst; P., first cross section passing through the pronephros; Te., telencephalon. Short dotted line indicates ependymal cavities. Long dotted line indicates notochord. (From Ranzi, 1954.) 
presumptive rudiment of the notochord is not present. The same phenomena, although with small notochord sections (Fig. 5), were observed by Leone working with urea, when it was recognized that proteins are denatured by animalizing substances. On the other hand, notochordal sections appear in the whole embryo treated with urea (Jenkinson, 1906; Fautrez, 1951; Leone, 1953). Leone recognized in these embryos the same developmental alterations which are induced by $\mathrm{SCN}^{-}$and $\mathrm{I}^{-}$. The alterations shown by older embryos with larger notochords are described by Ranzi et al. (1946). These alterations (Fig. 4) are: an increase in hindbrain dimensions, the formation of ganglia from the roof of

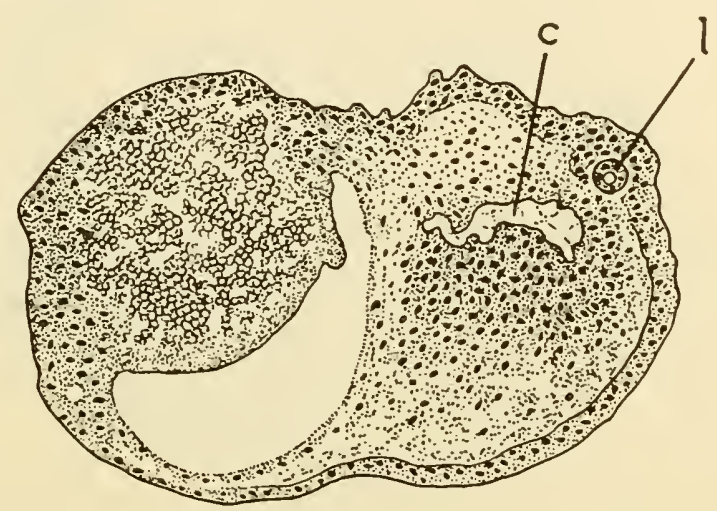

Fig. 5. Section through ventral explantate of Rana esculenta gastrula treated with urea: c, notochord; 1, lentoid. (From Leone, 1952.)

the hindbrain, the epiphysis duplication, the hyperdevelopment of lateral line organs, the formation of epithelial vesicles from the epidermis, the abnormal proliferation of epidermis. Rana esculenta embryos treated with iodosobenzoate show the same kind of alterations (umpublished research).

Whether the alterations in the nervous system are induced by the enlargement of the notochord or by an excess of active evocating substances is a problem which seems to be solved by the presence of nervous rudiments in axolotl ventral explants treated with NaSCN (Ranzi and Tamini, 1941). In this instance the notochordal rudiment is absent and evocating substances must 
originate from materials other than the normal material. The paper by Holtfreter (1944), showing that action of several chemical and physical agents bring about the same results, supports the interpretation of the liberation of evocating substances from abnormal materials.
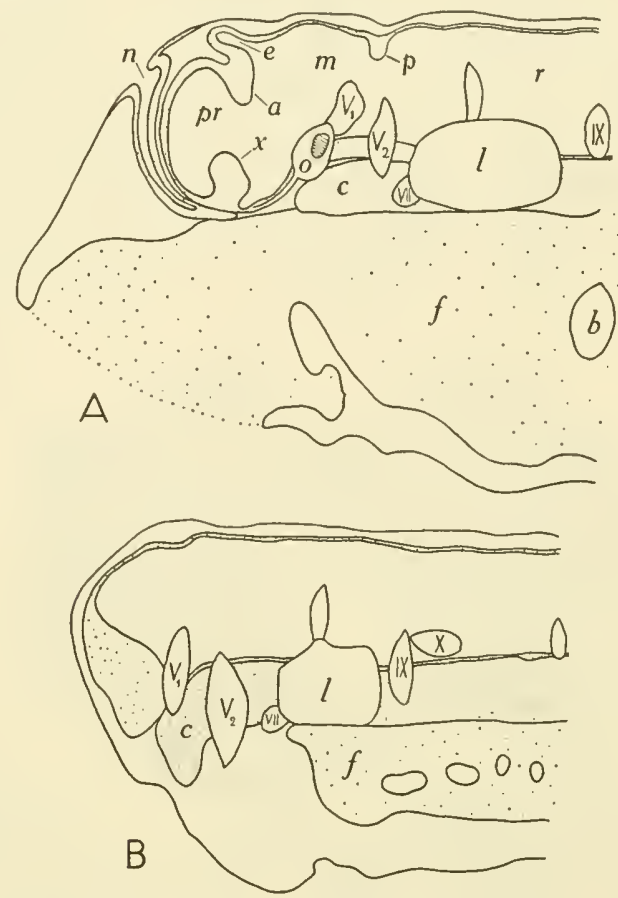

Fig. 6. Petromyzon larvae, head reconstruction: A, control; $\mathrm{B}, \mathrm{Li}^{+}$treated larva; a habenular ganglia; b, first branchial pouch; c, notochord; e, epiphysis; $f$, pharynx; 1 , otocyst; $m$, midbrain; $n$, olfactory organ; $p$, plica rhombo-mesencephalica; pr, forebrain; $\mathrm{r}$, hindbrain; $\mathrm{x}$, protuberance of chiasma; $V_{1}$, first trigeminal ganglion; $V_{2}$, second trigeminal ganglion; VII, facialis; IX, glossopharyngeus; X, vagus. (From Ranzi and Janeselli, 1941.)

The Petromyzon embryos seem to react to $\mathrm{Li}^{+}$and $\mathrm{SCN}^{-}$just as the amphibians. LiCl-treated embryos are described by Ranzi and Janeselli (1941) (Fig. 6). NaSCN-treated embryos showed large notochord and hind-brain enlargements (Ranzi, 1945). This field is open to further research.

The lithium chloride-treated embryos of an ascidian (Ciona 
intestinalis) may develop into exogastrulae (Ranzi and Ferreri, 1945 ) (Fig. 7). In some of these larvae the notochordal cells do not differentiate. In some other larvae notochordal cells may appear with little difference from entodermal cells. It is concluded, therefore, that there is an entodermization of notochordal cells induced by $\mathrm{LiCl}$. NaSCN-treated embryos show a larger neural plate. In Ascidia malaca embryos, treated with LiCl, Nieuwkoop

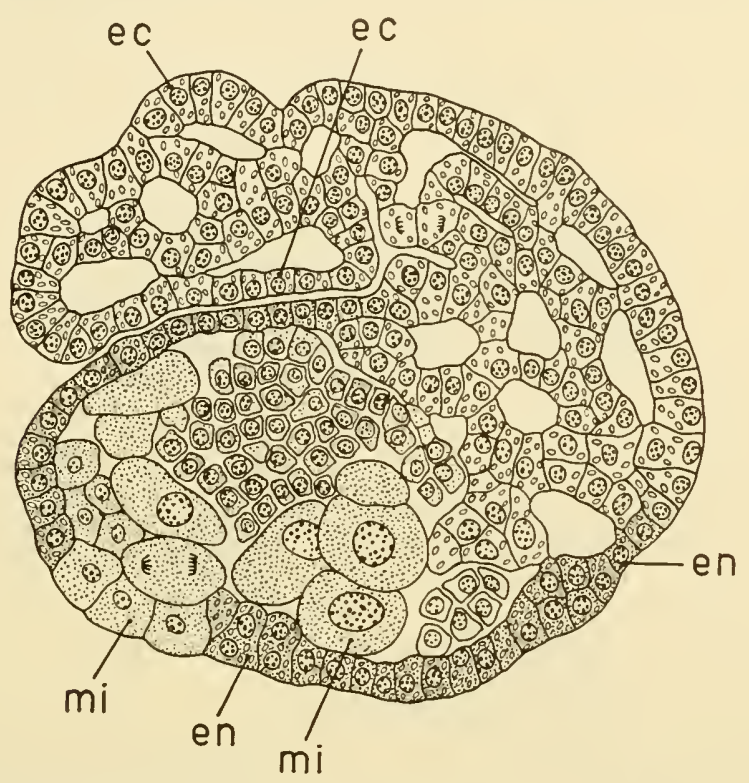

Fig. 7. Exogastrula from $\mathrm{Li}^{+}$-treated embryo of Ciona: ec, ectoderm; en, entoderm; mi, myoblasts.

(1953) found only exogastrulae of the second type." I did not have the opportunity to study the material further, because I deemed it sufficient to find certain malformations in asciclians corresponding to those of vertebrates.

- Nieuwkoop (1953) interprets the organization of exogastrulae without notochord by admitting that intrinsic differentiation tendencies, extrinsic realization factors, and tissue affinities are required for embryonic differentiation, and that realization factors are blocked by LiCl. Perhaps Nieuwkoop's realization factors represent the demolition of preexisting protein structures inhibited by $\mathrm{LiCl}$, as discussed below. 
Vegetalizing and animalizing agents act on molluscs. Working with LiCl and other salts, Ranzi (1928) obtained a series of monsters of Loligo vulgaris (cephalopod) ranging from convergent eyes, to cyclopy, cyclopy with a small eye and anophthalmia (Fig. 8). SCN-treated embryos developed a large stomodaeum (stomodaeum rudiment is between eye rudiments) (Ranzi, 1944). Studying embryos with duplicitas cruciata, Ranzi (1931) reached the conchusion that in cephalopod embryos it is most

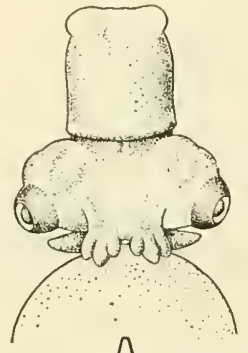

A

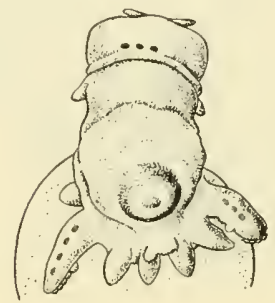

C
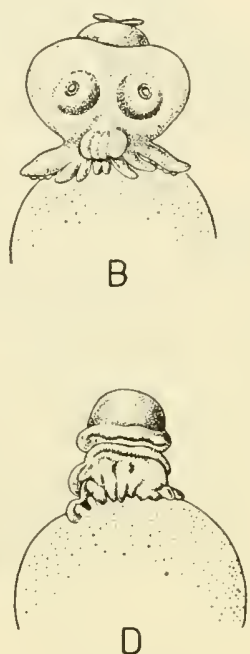

D

Fig. 8. $\mathrm{Li}+$ effects on Loligo embryos: A, control; B, convergent eyes; C, cyclopy; D, anophthalmy. (From Ranzi, 1928.)

likely that an evocator is acting (entoderm?). I think that possibly in cephalopods a rudiment hyperdeveloped by $\mathrm{SCN}^{-}$and reduced by $\mathrm{LiCl}$, as occurs for amphibian notochord, is involved. However, I have never carried out direct research to study this point nor have other authors investigated this problem. Thus today we cannot state positively whether an organizer exists in cephalopod embryos. Experimental embryology of cephalopods must be reconsidered. A great deal of material is available and may be handled quite easily. 
Raven ( 1952 ) carried out extensive research on Limnaea stagnalis (gasteropod). LiCl-treated embryos develop as exogastrulae (Fig. 9) in which, as in those of ascidians, no entodermization occurs, but the animal pole organs are reduced just as the ciliar tuft of the sea urchin. Monsters with convergent eyes, cyclopy, and anophthalmia have been described. Arendsen de Wolff-Exalto (1947) did not notice any change in determination due to NaSCN action.

A comparison between the alterations noted in the two molluses has not been made. However, an outstanding fact is the
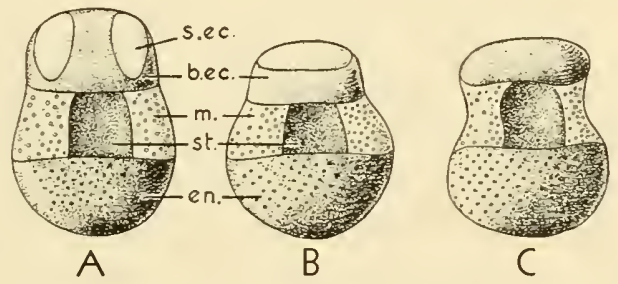

Fig. 9. Topographical relationship in Limmaea exogastrulae: A, normally developed organ rudiments; B,C, reduced organ rudiments at the animal pole; b.ec., large-celled ectoderm; en., entoderm; m., marginal zone; s. ect. small-celled ectoderm; st, stomodaeum. (From Raven, 1952.)

identity of the series of cyclopic monsters induced by $\mathrm{LiCl}$ in both.

It is difficult to carry out a comparative analysis based on egg organization. LiCl inhibits rudiment development at the animal half in sea urchins and Limmaea. This does not occur in amphibians and in Ciona in which $\mathrm{LiCl}$ affects the notochord that is a rudiment on the equatorial level of the egg. As a result, an interpretation on the basis of comparative morphology does not seem possible.

\section{Differences in Proteins from Embryos Showing Different Malformations}

Research carried out in our laboratory many years ago showed that ions inducing colloid precipitation also induce vegetalization in sea urchins (Tamini, 1943b) and cyclopic monsters in Amphibia (Tamini, 1943a). Conversely "swelling" ions induce sea 
urchin animalization and the enlargement of the amphibian notochord (Ranzi, 1942). By arranging the various ions in the order of their activity, it appears that they follow the lyotropic series of Hofmeister. The greater the aciivity in inducing cyclopy (or vegetalization) the greater the activity in precipitating the colloids. On the other hand, ions with more swelling activity are more active in inducing notochord enlargements (or animalization) (Ranzi, 1943). This conclusion brings forth the supposition of a direct action of substances that change embryonic determination on protoplasmic ultrastructures.

An attempt to examine this point directly was made by Abruzzese Sgarlata (1947). Unfertilized eggs of Arbacia were treated either with NaSCN or with $\mathrm{LiCl}$ and then centrifuged. In NaSCNtreated eggs stratification was faster than in controls; in LiCltreated eggs stratification was slower than in controls. This research was confirmed and extended to fertilized eggs by Lallier (1955).

In order to study the differences between normal, vegetalized and animalized frog embryos, we (Ranzi and Citterio, 1955a,b) have studied the possibilities of extracting the proteins from lyophilized embryos and of precipitating them by using the "salting out" method of Derrien et al. (1952). With this method we started to study the changes in proteins during normal embryonic development. At first, during fertilization, and later, during the cleavage stages, the amount of protein extracted decreases. Furthermore, extracted proteins precipitate at a lower concentration of ammonium sulfate. Myosin and actin antigen appear during gastrulation. After this stage a gradual process of protein differentiation occurs. New proteins with different characteristics of precipitation appear. Plasma and red cell antigens appear during neurulation.

On the basis of these data the following experiment is possible. Frog embryos are treated with $\mathrm{LiCl}$ or $\mathrm{NaSCN}$ at the sensitive stage and then, after a thorough washing in fresh water, are freed from jelly and are lyophilized. The fractions precipitating at different concentrations of ammonium sulfate are determined quantitatively (Fig. 10). In the young gastrulae, after a six-hour treat- 


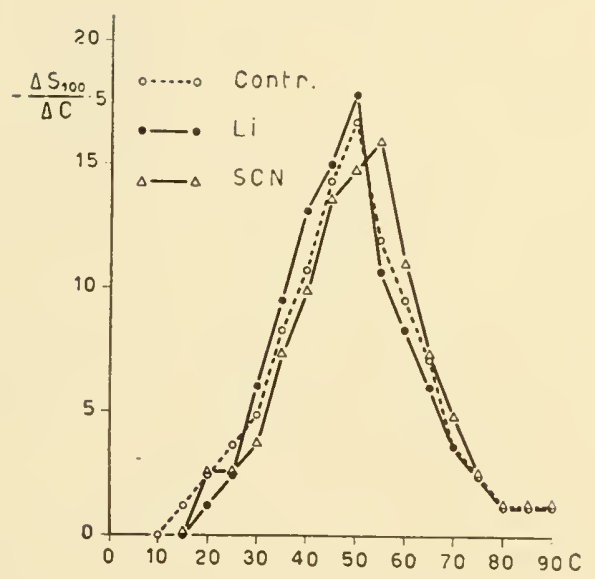

Fig. 10. Graphs of salting out plotted following Derrien et al. for frog embryos at stage 10\% left for 6 hours in Holtfreter solution (control), or NaSCN, or LiCl. (From Ranzi and Citterio, 1955.)

ment with LiCl, a higher amount of fractions precipitating at a lower concentration of ammonium sulfate ( 30 to $50 \%$ saturation) appears. In the embryos treated with NaSCN, a greater amount of proteins precipitate at a higher concentration of ammonium sulfate ( 55 to $60 \%$ saturation).

Embryos after a one-day treatment with NaSCN develop with large notochords and have a far greater quantity of proteins precipitating at higher concentrations of ammonium sulfate (Ranzi and Citterio, 1955a) (Fig. 11).

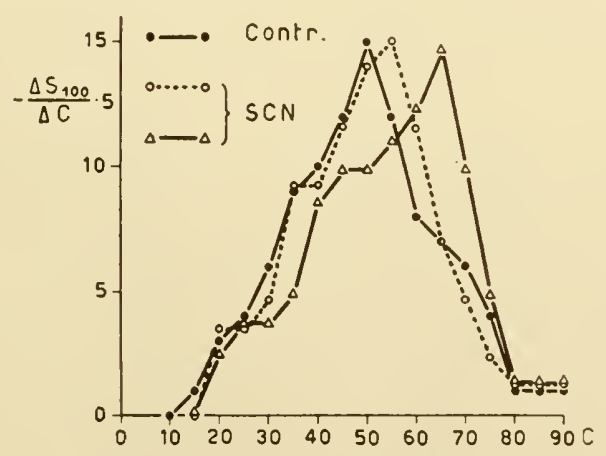

Fig. 11. Graphs of salting out like those of Fig. 10 showing NaSCN action. Controls at stage 12. (From Ranzi and Citterio, 1955.) 
It is necessary to discuss the nature of different conditions of protein precipitation of embryos treated with $\mathrm{LiCl}$ or $\mathrm{NaSCN}$. There may be a difference in physicochemical properties of some proteins or there may be a synthesis of some new proteins. In order to check this point we extracted, following Lawrence et al. (1944), euglobulin $a+b^{*}$ from frog eggs. By adding $1: 1 \quad 1 M$ KSCN or $1 M \mathrm{LiCl}$ and storing for one night in a cold room, we plotted the salting out graph. $\mathrm{Li}^{+}$incluces precipitation at a lower concentration of ammonium sulfate; $\mathrm{SCN}^{-}$induces precipitation at a higher concentration of ammonium sulfate (Fig. 12). That is to say that the fibrillar proteins treated in vivo and in vitro with NaSCN or LiCl show the same transformations. Therefore we conclude that the difference in the salting out graph of embryos treated with $\mathrm{NaSCN}$ or LiCl originates most likely from the physicochemical conditions of their proteins and not from the synthesis of new proteins.

Moreover, it is possible to show that animalizing agents induce a decrease in viscosity of solutions of protein particles which under viscosimetric analysis appear fibrillar. The vegetalizing agents induce instead an increase in viscosity of the same protein solutions (Fig. 13). These changes in viscosity are related to the shape of the particles in solution because they appear only in solutions containing fibrillar proteins and not in solutions of globular proteins (Citterio and Ranzi, 1947). Moreover, both animalizing and vegetalizing agents induce an increase in viscosity of the globular protein solutions. The observation of the different actions of animalizing and vegetalizing substances on fibrillar

- It is possible to extract euglobulin $\mathrm{a}+\mathrm{b}$ from lyophilized eggs with $1 M \mathrm{KCl}$. After delipidation with ether, if the solution is diluted to $0.3 \mathrm{M}$, euglobulin $\mathrm{a}+\mathrm{b}$ precipitate and can be dissolved in $1 \mathrm{MKCl}$. This protein does not show flow birefringence but appears highly anisodiametric in the viscosimeter. Its axial ratio, taken with the viscosimeter, seems to increase with dilution; moreover, starting from 0.50 reduced viscosity figures one may reach values exceeding 1.00 (that is, an axial ratio of over 35.1). After Lawrence et al. (1944), I termed this protein fibrillar folded by assuming that its globular-shaped particles may unfold and are unfolded along the walls of the viscosimeter while they appear folded in the axis of the channel where flow birefringence is read. For discussion on other possibilities see Ranzi (1955). 


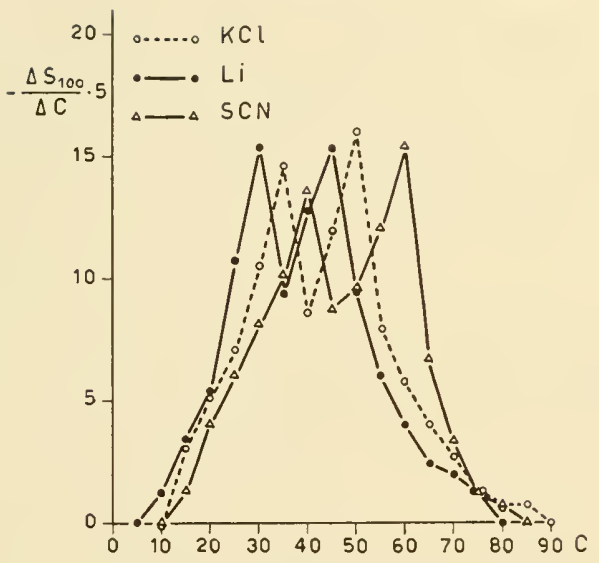

Fig. 12. Salting out graphs plotted as in Fig. 11 for euglobulin $\mathrm{a}+\mathrm{b}$ diluted $1: 1$ with $1 M \mathrm{KCl}$ (control) or with $1 M \mathrm{KCl}+1 M \mathrm{LiCl}(1: 1)$ or with $1 M \mathrm{KSCN}$. As in Fig. 10, LiCl-treated proteins precipitate at lower ammonium sulfate concentrations, KSCN-treated proteins precipitate at higher ammonium sulfate concentrations. (From Ranzi, 1955.)

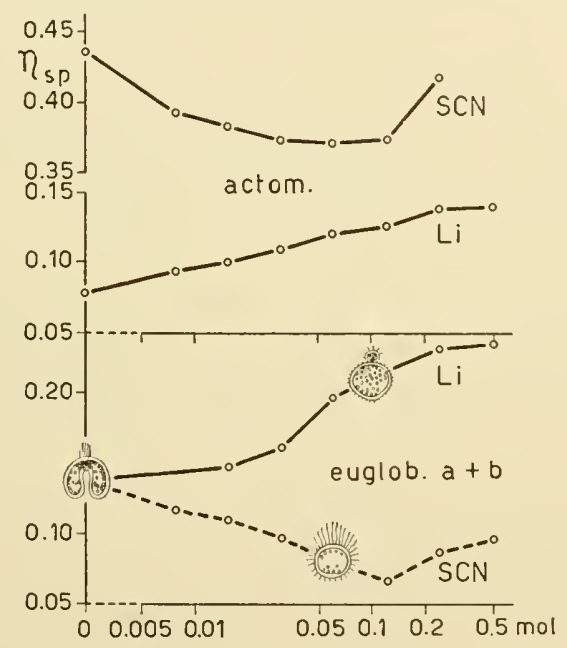

Fig. 13. Specific viscosity of rabbit actomyosin (actom.) solutions and of euglobulin $\mathrm{a}+\mathrm{b}$. On the abscissa is plotted the final molar concentration of the added salts ( $\mathrm{LiCl}$ or $\mathrm{KSCN}$ ). Ionic strength is $\mathrm{I}=1.0 \mathrm{in}$ all samples. $\mathrm{LiCl}$ induces an increase in viscosity, KSCN induces a decrease in viscosity. The sketches of the embryos (normal, vegetalized, and animalized) are located according to the active concentration in modifying the development. (From Ranzi, 1955.) 
proteins has seemed important since the early stages of this research (Arosio et al., 1946). The embryonic differentiation is a cytoplasmic phenomenon and some protein fractions which are anisodiametric to viscosimetric analysis and which show in some instances flow birefringence can be extracted from the cytoplasm (Cigada et al., 1954). These fractions can be purified. Therefore, when animalizing and vegetalizing agents induce their opposite effects on the development, those proteins which may be extracted in a fibrillar shape from cytoplasm are involved.

\section{Proteins Are Denatured by Animalizing Agents}

Viscosimetric data of the action of animalizing agents on globular protein solutions (increasing viscosity) and on fibrillar protein solutions (decreasing viscosity) suggest protein denaturation. This denaturation by breaking some bonds increases the volume of globular particles and induces a reduction in the anisotropy of the fibrillar particles. This phenomenon was observed with the electron microscope on actomyosin treated with $\mathrm{SCN}^{-}$and $\mathrm{I}^{-}$(Ranzi, 1947). The research carried out with the Signer apparatus of flow birefringence shows that actomyosin and myosin particles decrease in length after treatment with animalizing substances (Rocca, unpublished research).

Also the study of chemically detectable free groups favors the conclusion that there is a denaturation process. It is possible to show a greater amount of $\mathrm{OH}$ groups and of phenolic groups in actomyosin treated with animalizing substances (Arosio and Bossi, 1954). The same occurs in denaturation processes induced by urea or heat.

The ATPase activity of myosin is considerably reduced by the action of animalizing substances.

The precipitin test was used to study the action of $\mathrm{SCN}^{-}$and $\mathrm{I}^{-}$on actomyosin solutions. $\mathrm{SCN}^{-}$and $\mathrm{I}^{-}$induce changes in the antigens and the immunological properties of the changed antigens are similar in both cases. The changes indicate a denaturation process (Arosio, 1953).

That a denaturation process is the basis of the action of animalizing substances is shown (as mentioned before) by the fact 
that Leone $(1952,1953)$ found an enlargement of the notochord in amphibians to be induced by urea, a well-known denaturing agent. The formation of notochord and neural rudiments in explanted ventral pieces of young gastrulae can be induced by urea.

\section{Action of Vegetalizing Agents}

Vegetalizing substances do not change considerably the aforementioned properties of proteins; the flow birefringence is not altered; the intensity of $\mathrm{OH}$ and phenolic group reaction is not increased (Arosio and Bossi, 1954).

The action of vegetalizing substances becomes evident from another type of experiment. We take into consideration the action of a strong denaturing agent such as urea on proteins treated with animalizing or vegetalizing substances. Two samples are prepared of a solution of euglobulin $a+b$ from sea urchin eggs (Fig. 14). A certain quantity of an animalizing or vegetalizing substance sufficient to induce an alteration in the embryonic development is added to one sample. For example, by using $\mathrm{LiCl}$ as a vegetalizing agent, 86 parts of $1 M \mathrm{KCl}$ plus 14 of $1 M \mathrm{LiCl}$ are added to 100 parts of the first sample (tube 2). To the other sample the same amount of $1 M \mathrm{KCl}$ is added (tube 1). After overnight storage in a cold room we assume that the sample treated with $\mathrm{LiCl}$ is vegetalized. The proteins of the second sample are assumed to be proteins of the normal embryo. From both samples we prepare two samples of $5 \mathrm{ml}$ each. Then $0.6 \mathrm{ml}$ of $1 \mathrm{M} \mathrm{KCl}$ are added to one sample (tubes 3,5) and $0.6 \mathrm{ml}$ of $30 \%$ urea is added to the other sample (tubes 4,6 ). The viscosity readings are taken after four hours immersion in the viscosimeter bath. The treatment with vegetalizing substances, as mentioned before, induces an increase in viscosity. Now it is possible to show another fact. The viscosity decreases in the sample with urea and the rate of decrease in proteins treated with vegetalizing agents is lower than in the controls. On the other hand, the rate of decrease in viscosity of proteins treated with animalizing agents is much higher than in the controls (Ranzi and Citterio, 1954). These data (in Fig. 14) show the greater resistance of 


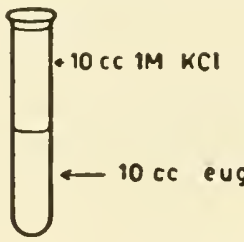

(1)

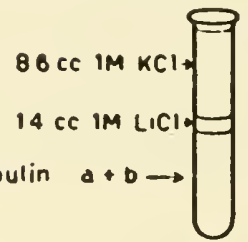

(2)

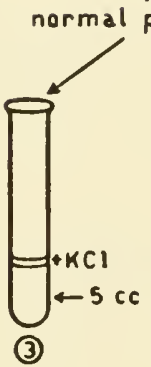

protein

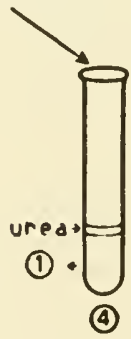

vegetalized protein

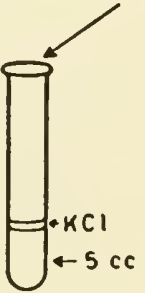

(5)

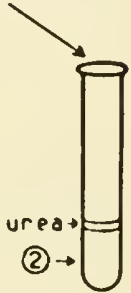

(6)

4 hours of maturation
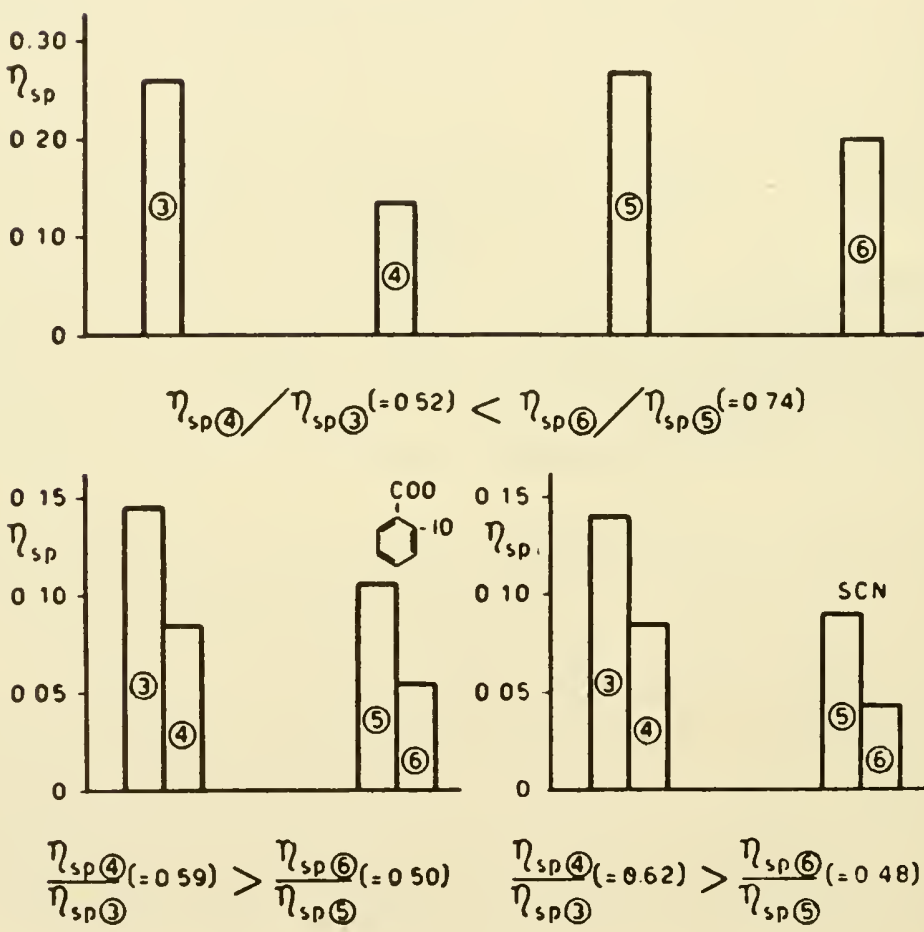

Fig. 14 . 
proteins treated with vegetalizing substances and the lower resistance of proteins treated with animalizing substances.

The denaturation induced by animalizing substances leads to an additional denaturation induced by urea. The action of vegetalizing substances is, however, a stabilizing action that opposes the demolition by urea.

In the experiment just described all vegetalizing substances exert the same action of protecting from denaturation. All animalizing agents denature and predispose to denaturation (Table I).

\section{Differences in Resistance to Demolition of Proteins from Embryos Showing Different Malformations}

It is obvious that if the above phenomena are important in the changes of embryonic determination, something must be observable in the embryo itself after treatment with vegetalizing or animalizing substances. To examine this point we carried out the following experiment.

Fig. 14. Scheme of the experiments. Into tubes (1) and (2), $10 \mathrm{ml}$ of euglobulin $\mathrm{a}+\mathrm{b}$ solution was poured. To tube (1), $10 \mathrm{ml}$ of $1 \mathrm{M} \mathrm{KCl}$ and to tube (2), $10 \mathrm{ml}$ of fluid $(1.4 \mathrm{ml} 1 M \mathrm{LiCl}+8.6 \mathrm{ml} 1 M \mathrm{KCl})$ were added and then stored one night in cold room; $5 \mathrm{ml}$ of mixture (1) were taken and put into tube (3), together with $0.6 \mathrm{ml}$ of $1 M \mathrm{KCl} ; 5 \mathrm{ml}$ of mixture (1) plus $0.6 \mathrm{ml} 30 \%$ urea represent the sample in tube (4). The same procedures were followed for the mixture of tube (2) (vegetalized proteins) and samples (5) and (6) were obtained. After 4 hours of maturation, the viscosity was read by Ostwald viscosimeter at $14^{\circ} \mathrm{C}$. Values of readings are plotted on the column diagram under their respective tubes. The lower column diagrams represent values obtained using iodosobenzoate (left) and thiocyanate (right). In the iodosobenzoate experiment, tube (1) contained the proteins dissolved in Weber and Edsall fluid plus $10 \mathrm{ml}$ of Weber and Edsall fluid; tube (2) contained the proteins plus $10 \mathrm{ml}$ of $0.001 M$ iodosobenzoic acid dissolved in Weber and Edsall fluid (the last retained a constant $\mathrm{pH}$ in spite of the addition of iodosobenzoic acid). In the thiocyanate experiment, the mixture of tube (1) was the same as the $\mathrm{Li}$ experiments, while $1 \mathrm{ml}$ of $1 M \mathrm{KSCN}$ and $9 \mathrm{ml}$ of $1 M \mathrm{KCl}$ were added to tube (2). It is evident that, with $\mathrm{Li}$, the decrease in viscosity of tube (6) mixture compared with tube (5) was less marked than the controls. With iodosobenzoate and KSCN, the contrary is true. [Decrease of viscosity of tube (6) in comparison with (5) is stronger than the decrease of (4) as compared with (3).] (From Ranzi and Citterio, 1954.) 
TABle I. Action of Different Agents on Embryonic Development and on Proteins in Solution

\begin{tabular}{|c|c|c|c|c|c|c|}
\hline \multirow[b]{2}{*}{ Agent } & \multicolumn{2}{|c|}{ Sea urchin } & \multicolumn{2}{|c|}{ Amphibian } & \multicolumn{2}{|c|}{ Protein } \\
\hline & $\begin{array}{c}\text { Ani- } \\
\text { malizes }\end{array}$ & $\begin{array}{l}\text { Vege- } \\
\text { talizes }\end{array}$ & $\begin{array}{l}\text { Large } \\
\text { noto- } \\
\text { chord }\end{array}$ & $\begin{array}{l}\text { Cyclopic } \\
\text { monsters }\end{array}$ & $\begin{array}{c}\text { De- } \\
\text { natures }\end{array}$ & Stabilizes \\
\hline $\mathrm{KCl}$ & & + & & & & + \\
\hline $\mathrm{LiCl}$ & & + & & + & & + \\
\hline $\mathrm{MgCl}_{2}$ & & + & & + & & + \\
\hline $\mathrm{NaCl}$ & & + & & + & & + \\
\hline $\mathrm{NaI}$ & + & & + & & + & \\
\hline $\begin{array}{l}\mathrm{NaN}_{3} \\
\mathrm{NaSCN}\end{array}$ & + & + & & & & + \\
\hline $\begin{array}{l}\mathrm{NaSCN} \\
\mathrm{Na}_{2} \mathrm{SO}_{4}\end{array}$ & $\begin{array}{l}+ \\
+\end{array}$ & + & + & + & $\begin{array}{l}+ \\
+\end{array}$ & + \\
\hline Chymotrypsin & + & & & & + & \\
\hline Citrate & & + & + & & + & + \\
\hline Colchicine & & + & & + & & + \\
\hline Ethanol & & + & & + & & + \\
\hline Ficin & + & & & & + & \\
\hline Glucose & + & & & & + & \\
\hline Glyceraldehyde & & + & & & & + \\
\hline Iodosobenzoate & + & & $t$ & & + & \\
\hline Lactate & $(+)$ & & & & + & \\
\hline Leucine & & $(+)$ & & & & + \\
\hline Lisine & $(+)$ & & & & + & \\
\hline Maleinate & + & & & & + & \\
\hline Methylene blue & + & & + & & + & \\
\hline Paranitrophenol & + & & + & & + & \\
\hline Pyocyanine & + & & + & & + & \\
\hline Pyruvate & + & + & & + & + & + \\
\hline Tartrate & + & + & & + & + & + \\
\hline Thiomalate & + & & $(+)$ & & + & \\
\hline Thionine & + & & & & + & \\
\hline Thiourea & & + & & & & + \\
\hline Trypan blue & & & & + & & + \\
\hline Trypsin & + & & & & + & \\
\hline Urea & + & & + & & + & \\
\hline Valine & & $(+)$ & & & & + \\
\hline High $\mathrm{pH}$ & & & $(+)$ & & + & \\
\hline
\end{tabular}

Note: The crosses in parentheses show for sea urchins action on animal halves, for the amphibians the notochordal formation in ventral explants (from Ranzi, 1955). 
Three groups of frog embryos at the stage of late blastula, (stage 9) were allowed to develop in fresh water or in $0.05 \mathrm{M}$ $\mathrm{NaSCN}$ or $0.07 \mathrm{M} \mathrm{LiCl}$. At the stage of young gastrula (stage 10), after 6 hours treatment, the embryos were carefully washed, liberated from jelly, washed again in Holtfreter fluid, and then lyophilized. The powder was extracted overnight in $1 M \mathrm{KCl}$. Euglobulin $\mathrm{a}+\mathrm{b}$ was taken in a solution of $1 M \mathrm{KCl}$ and the three solutions, $(a)$ euglobulin of control embryos, $(b)$ euglobulin of vegetalized embryos, and $(c)$ euglobulin of animalized embryos,

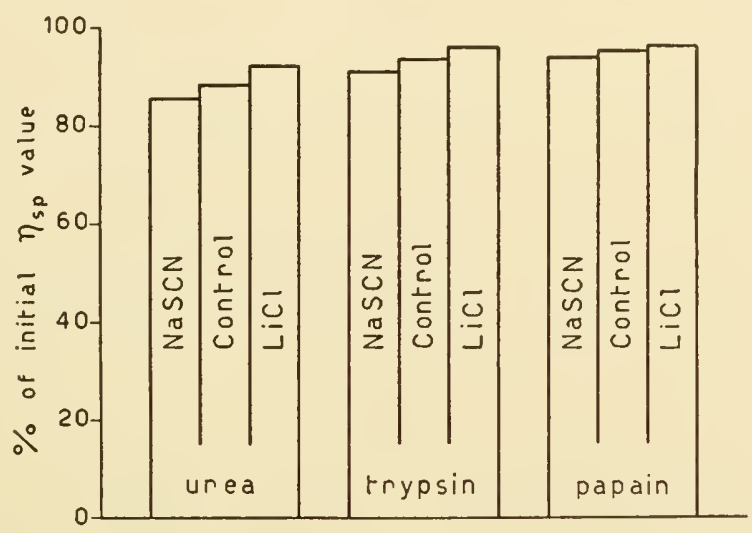

Fig. 15. The diagram shows the decrease per cent of viscosity induced by urea ( $15 \%$ final concentration), trypsin $(0.5 \%$ final concentration $\mathrm{pH}$ 7.9), and papain in the euglobulin $a+b$ extracted from embryos: $i$, controls; ii, developed in NaSCN solution; iii, developed in $\mathrm{LiCl}$ solution. (The embryos used were taken from the same cultures as those used for the graphs Fig. 10.) (From Ranzi, 1955.)

were diluted in such a way as to reach the same optical density at 275 millimicrons in the Beckman spectrophotometer. With each solution the following samples were prepared: $(a)$ euglobulin $\mathrm{a}+\mathrm{b}$ diluted $1: 1$ with the solvent ( $1 M \mathrm{KC1})$; $(b)$ euglobulin $\mathrm{a}+\mathrm{b}$ diluted $1: 1$ with $30 \%$ urea; $(c)$ euglobulin $\mathrm{a}+\mathrm{b}$ diluted 1:1 with trypsin (Merck) dissolved in $1 \mathrm{M} \mathrm{KCl} \mathrm{kept} \mathrm{at} \mathrm{pH} 7.9$ with Weber and Edsall fluid; $(d)$ euglobulin $\mathrm{a}+\mathrm{b}$ diluted 1:1 with papain in $1 M \mathrm{NaCl}$. After four hours incubation in the viscosimeter bath, the viscosity readings were taken (Fig. 15), the 
viscosity of proteins diluted in $1 \mathrm{M} \mathrm{KCl}$ being 100 . The values show that the proteins from embryos treated with $\mathrm{LiCl}$ are much more resistant to the action of urea and to proteolytic enzymes such as trypsin and papain than are control proteins; the proteins of embryos treated with NaSCN are less resistant to urea and proteolytic enzymes.

Another experiment was performed with these materials. The

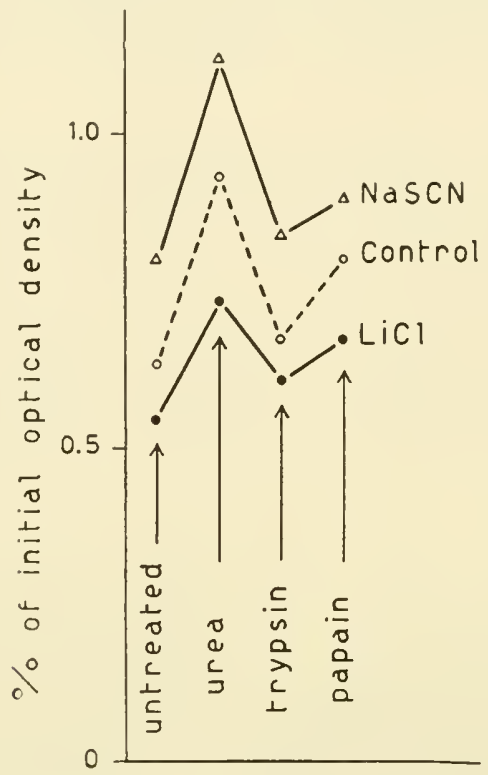

Fig. 16. The optical densities (at 275 millimicrons) of the solutions of Fig. 15 are assumed to be 100 . After the readings, the proteins were precipitated with trichloracetic acid. The optical density after precipitation is plotted on the ordinates. (From Ranzi, 1955.)

solutions used for the viscosimetric test mentioned above were precipitated by diluting 1:1 with $10 \%$ trichloracetic acid. The optical density of the supernatant fluid was read at 275 millimicrons in the Beckman spectrophotometer (Fig. 16). The data show that, in the protein solutions of embryos treated with NaSCN, a greater quantity of material remains in solution than in the controls. In the solutions of embryos treated with $\mathrm{LiCl}$ a 
lower quantity of material than in the controls remains in solution. Also with this experiment it can be shown that $\mathrm{LiCl}$, by acting on the embryos, inhibits demolition while NaSCN makes demolition easier.

\section{Predisposition and Inhibition to Demolition of Protoplasmic Structures}

The action of animalizing agents which predisposes to demolition and of vegetalizing agents which inhibits demolition has been shown also on some cell structures. Orlandi (1953) showed that NaI, NaSCN, urea, iodosobenzoate, and high $\mathrm{pH}$, disintegrate the isolated chromosomes, whereas $\mathrm{LiCl}$ preserves them. L. Cigada (1954) showed that NaI, NaSCN, methylene blue, and high $\mathrm{pH}$ disintegrate the isolated yolk granules whereas $\mathrm{LiCl}$ and thiourea preserve them. Brioschi (1955) working on glycerinated muscle fibers showed that while in the presence of vegetalizing substances they regularly contract because of ATP, this property is lost or reduced when animalizing agents are present.

The demolishing action induced by animalizing agents and the resistance to demolition induced by vegetalizing agents are therefore phenomena which concern not only embryonic proteins but also structures in the cell.

\section{The Nature of Denaturation Induced by Animalizing Agents}

Another problem is the nature of the denaturation induced by animalizing agents on these proteins. In the past I have put forward the hypothesis that smaller units could be liberated by the action of animalizing agents. Viscosimetric readings taken this year give an intrinsic viscosity of 0.16 for these subunits (that is, an axial ratio slightly above 11 , by admitting a prolate ellipsoid).

From all the above data it seems today that the predisposition to the demolition phenomenon (of which the formation of these subunits represents only one part of the process) is the aspect of greatest importance of embryonic determination. 


\section{Above-Mentioned Conclusions and Data from Experimental Embryology}

The action of animalizing substances is shown as a demolition of preexisting proteic structures and the action of vegetalizing substances as a resistance to demolition. Does this agree with the findings of experimental embryology?

All the authors who, in their studies on vertebrates, speak of developmental inhibition induced by $\mathrm{LiCl}$ have encountered the resistance to demolition of proteic ultrastructures at a microscopic level. The delay in synthesis due to $\mathrm{Li}^{+}$is in agreement with the smaller increase of many enzymes in the LiCl-treated embryos studied by the Stockholm group (Gustafson, 1954), by Lallier (1955) and by others.

On the other hand, the animalization seems in fact to correspond to a demolition of preexisting proteic structures. Proteolytic enzymes (chymotrypsin, ficin, trypsin) are animalizing agents (Hörstadius, 1949, 1953; Moore, 1952). The observation made by Lindahl et al. (1951) in this field is highly significant: that from a population of more easily animalizable eggs it is possible to extract in $0.6 M \mathrm{KI}$ a greater amount of $\mathrm{N}$; that is, they contain a lower ratio of insoluble $\mathrm{N}$.

Animalization at times may be induced under the same conditions of protein denaturation. Hörstadius (1949) found that animalization occurs more easily at a low temperature, Jacobsen et al. (1948) found that denaturation, induced by urea, is easier to obtain at lower temperatures. Animalization induced by $\mathrm{Na}$ SCN occurs more easily in calcium-free sea water; $\mathrm{Ca}^{++}$prevents many proteins from undergoing denaturation (Gorini, 1950).

From a comparative viewpoint, the regions overdeveloped by the action of animalizing agents and inhibited by vegetalizing agents show a higher oxydoreduction potential. [See the research by Child (1936a,b, 1943), by Ranzi (1939), and by Hörstadius (1955) ]. I think that this may be interpreted as an indication of a much more active protein breakdown. It is possible to follow the formation of the ciliar tuft and of the mitochondria in the cells of the animal pole of the sea urchin embryo (Gustafson, 1954; 
Shaver, 1955) which shows a higher oxydoreduction potential. On the other hand, the analyses carried out directly demonstrate the protein breakdown. In the frog blastoporal dorsal lip, that is, the notochordal rudiment at the time at which it is sensitive to animalizing and vegetalizing agents, Deuchar (1955) found a higher quantity of free amino acids than in other areas of the embryo.

The findings of Kavanau (1954) also seem important. He found that the highest quantity of free amino acids in sea urchin embryos occurs exactly during the stage which Bäckström and Gustafson (1953) found more sensitive to the action of $\mathrm{LiCl}$.

\section{Conclusion}

The above indicates that animalization and vegetalization originate from the enlargement or inhibition of the areas in which a process of protein demolition, necessary for new protein synthesis, is acting. The following hypothesis may be formulated: It is possible to represent the unfertilized sea urchin egg with much more reactive protoplasm at the animal pole. Fertilization, by activating certain enzymatic systems according to the conception of Runnström (1949), activates a higher metabolism in the animal pole. If we bear in mind the fact evidenced by the Stockholm School that several metabolites are animalizing substances, the activation of enzymes and the following formation of metabolites, occurring at the animal pole, seem to lead to the development of the animal pole, while the vegetative pole is stabilized because of failure to form these metabolites.

\section{AdDendun}

A new train of research was performed in this field by the Milan group during the last year (Ranzi et al., 1957). The salting out diagrams of proteins extracted from the sea urchin, Arbacia lixula L., were studied.

The animalized embryos show proteic fractions precipitating at higher ammonium sulfate concentration than those of the controls, whereas the vegetalized embryos show some fractions precipitating at lower ammonium sulfate concentration. Proteins from embryos animalized by iodosobenzoic acid treatment show salting out diagrams identical to those of the NaSCN animalized embryos. In immunological experiments the two kinds of animalized embryos are identical and both show some differences with the 
control. Digestion experiments (as shown in Figs. 15 and 16) were repeated on the proteins of the sea urchin embryos with identical results.

The salting out diagrams show that the proteins of the lethal cross Bufo viridis of $\mathrm{x}$ Bufo bufo of appear to be like vegetalized proteins, if compared with the parent species Bufo viridis and Bufo bufo. The digestion experiments corroborate this conclusion.

\section{REFERENCES}

Abruzzese Sgarlata, S. 1947. Variazioni di viscosità delle uova di riccio di mare per effetto di sostanze chimiche. Ricerca sci. e ricostruz, 17, 437-38.

Adelmann, H. B. 1934. A study of cyclopia of Amblystoma punctatum, with special reference to the mesoderm. J. Exptl. Zool., 67, 217-28. Arendsen de Wolff-Exalto, E. 1947. Some investigations on the embryonic development of Limnaea stagnalis L. Konink. Ned. Akad. Wetenschap., Proc, 50, 315-22.

Arosio, R. 1953. Ricerche sierologiche sullazione di solfocianuro e ioduro su macromolecole. Rend. ist. lombardo sci., 86, 873-78.

Arosio, R., and J. Bossi. 1954. Gruppi chimicamente attivi dell'actomiosina dopo trattamento con sostanze animalizzanti e vegetalizzanti. Rend. ist. lombardo sci., 87, 445-51.

Arosio, R., P. Citterio, P. Menotti, S. Ranzi, and F. Semenza. 1946. Sostanze modificanti lo sviluppo embrionale e viscosità di proteine estratte da embrioni. Riv. biol. (Perugia), 38, 153-62.

Badínez, O. S., E. C. Carrasco, and C. M. Manríquez. 1954. Rol de los iones litio y sulfocianuro sobre la morfogenesis del anfibios chilenos. Contribucion a la teratologia experimental. Biologica (Santiago de Chile) 18/19, 53-83.

Bäckström, S. 1953. Studies on the animalizing action of iodosobenzoic acid in the sea urchin development. Arkiv Zool. (2), 4, 485-91.

Bäckström, S. 1954. Morphogenetic effects of lithium on the embryonic development of Xenopus. Arkiv Zool. (2), 6, 527-36.

Bäckström, S., and T. Gustafson. 1953. Lithium sensivity in the sea urchin in relation to the stage of development. Arkiv Zool. (2), 6, $185-88$.

Brioschi, G. 1955. Sullazione di alcune sostanze sulla possibilità di contrarsi di fibre muscolari glicerinate. Rend. ist. lombardo sci., 88, 169-72.

Child, C. M. 1936a. Differential reduction of vital dyes in the early 
development of echinoderms. Wilhelm Roux' Arch. Entwicklungsmech. Organ., 135, 426-56.

Child, C. M. 1936b. A contribution to the physiology of exogastrulation in echinoderms. Wilhelm Roux' Arch. Entwicklungsmech. Organ. 135, 457-93.

Child, C. M. 1943. Differential dye reduction and reoxidation in Triturus development. Physiol. Zool., 16, 61-76.

Cigada, L. 1954. Sulla stabilità dei granuli del tuorlo del pollo. Boll. soc. ital. biol. sper., 30, 104-6.

Cigada, M., C. Lanzi, and G. Brioschi. 1954. Ricerche sul citoplasma. Rend. ist. lombardo, sci., 87, 365-78.

Citterio, P., and S. Ranzi. 1947. Sostanze modificanti lo sviluppo embrionale e viscosità di soluzioni contenenti macromolecole. Rend. accad. naz. Lincei (Sci. fis.) (8), 3, 150-55.

Corti, C. 1950. Ricerche sull'ipersviluppo della corda e iperinduzione negli Anfibi. Riv. Biol. (Perugia), 42, 443-60.

Cotronei, G. 1922. Correlations et differentiations. Essai de morphologie causale sur la tête des Amphibiens. Arch. ital. biol., 71, 83.

Derrien, Y., E. P. Steyn-Parvé, M. Cotte, and G. Laurent. 1952. Studies on proteins by means of salting-out curves, II. Biochim. et Biophys. Acta, 9, 49-55 (1952).

Deuchar, E. M. 1955. Distribution of free amino-acid in embryos of Xenopus laevis. Nature, 176, 258.

Fautrez, J. 1951. L'action de l'urée sur le developpment embryonnaire de Rana temporaria. Arch. biol. (Liége), 62, 195-307.

Gorini, L. 1950. Le rôle du calcium dans lactivité et la stabilité de quelques protéinases bactériennes. Biochim. et Biopliys. Acta, 6, 237-55.

Gustafson, T. 1954. Enzymatic aspects of embryonic differentiation. Intern. Rev. Cytol., 3, 277-327.

Hörstadius, S. 1949. Experimental researches on the developmental physiology of the sea urchin. Pubbl. staz. zool. Napoli, 21 suppl., 131-72.

Hörstadius, S. 1953. Vegetalization of the sea-urchin egg by dinitrophenol and animalization by trypsin and ficin. J. Embryol. exptl. Morphol., 1, 327-48.

Hörstadius, S. 1955. Reduction gradients in animalized and vegetalized sea urchin eggs. J. Exptl. Zool., 129, 249-56.

Holtfreter, J. 1944. Neural differentiation of ectoderm through exposure to saline solution. J. Exptl. Zool., 95, 307-40. 
Jacobsen, C. F., and L. Korsgaard Christensen. 1948. Influence of the temperature on the urea denaturation of $\beta$-lactoglobulin. $\mathrm{Na}$ ture, 161, 30-31.

Jenkinson, J. W. 1906. On the effect of certain solutions upon the development of the frog's egg. Arch. Entwicklungsmech. Organ., 21, $367-460$.

Kavanau, J. L. 1954. Amino acid metabolism in the early development of the sea urchin Paracentrotus lividus. Exptl. Cell Research, 7, $530-57$.

Lallier, R. 1955. Recherches sur le problème de la determination embryonnaire chez les Amphibiens et les Echinodermes. Arch. Biol. (Liége) , 66, 223-402.

Lawrence, A. S. C., M. Miall, J. Needham, and S.-C. Shen. 1944. Studies on the anomalous viscosity and flow birefringence of protein solutions. II. On dilute solutions of proteins from embryonic and other tissues. J. Gen. Physiol., 27, 233-71.

Lehmann, F. 1937. Mesodermisierung des präsuntiven Chordamaterials durch Einwirkung von Lithiumchlorid auf die Gastrula von Tryton alpestris. Wilhelm Roux' Arch. Entwicklungsmech. Organ., $136,112-46$.

Leone, V. 1952. Effetti di trattamento con urea su espianti ventrali di gastrula di Rana esculenta L. Rend. accad. naz. Lincei (Sci. fis.) (8), 12, 195-99 (1952).

Leone, V. 1953. Sull'azione dell'urea sullo sviluppo embrionale di Anfibi. Rend. ist. lombardo sci., 86, 351-66.

Lindahl, P. E. 1936. Zur Kenntnis der physiologischen Grundlagen der Determination im Seeigelkeim. Acta Zool., 17, 179-365.

Lindahl, P. E., and L. O. Öhman. 1938. Weitere Studien über Stoffwechsel und Determination im Seeigelkeim. Biol. Zentr., 58, 179218.

Lindahl, P. E., B. Swedmark, and J. Lundin. 1951. Some new observations on the animalization of the unfertilized sea urchin egg. Exptl. Cell Research, 2, 39-46.

Moore, A. R. 1952. The process of gastrulation in trypsin embryos of Dendraster excentricus. J. Exptl. Zool., 119, 37-46.

Moore, A. R. 1952. An animalizing effect of trypsin and its inhibition by lithium in the developing eggs of Strongylocentrotus droebachiensis. J. Exptl. Zool., 121, 99-104.

Nieuwkoop, P. D. 1953. The influence of the Li ion on the development of the egg of Ascidia malaca. Pubbl. staz. zool. Napoli, 24, 101-61. 
Orlandi, A. 1953. Sulla struttura submicroscopica dei cromosomi isolati. Rend. ist. lombardo sci., 86, 855-72.

Ranzi, S. 1928. Suscettibilità differenziale nello sviluppo dei Cefalopodi. Pubbl. staz. zool. Napoli, 9, 81-159.

Ranzi, S. 1931. Duplicitas cruciata in embrioni di Cefalopodi. Pubbl. staz. zool. Napoli, 11, 86-103.

Ranzi, S. 1939. Ricerche sulle basi fisiologiche della determinazione degli embrioni degli Echinodermi II. Arch. zool. ital., 26, 427-40.

Ranzi, S. 1942. Analogie zwischen der Wirkung von Vitalfarbstoffen und NaSCN in Phänomena der Embryonalentwicklung. Naturwissenschaften, 30, 329-30.

Ranzi, S. 1943. Azione di sostanze chimiche sullo sviluppo embrionale di Anfibi ed Echinodermi. Boll. soc. ital. biol. sper., 18, 314-15.

Ranzi, S. 1944. Effetto di KSCN sullo sviluppo embrionale di Cefalopodi. Boll. soc. ital. biol. sper., 19, 68-70.

Ranzi, S. 1945. Effects of sodium thiocyanate on the development of Amphibia. Nature, 155, 578.

Ranzi, S. 1947. Electron microscope investigation on the action of salt solutions on myosin. Nature, 160, 712.

Ranzi, S. 1955. Le macromolecole nella determinazione embrionale. Rend. ist. lombardo sci., 89, 200-23.

Ranzi, S., and P. Citterio. 1954. Sul meccanismo di azione degli ioni che inducono cambiamenti nella precoce determinazione embrionale. Pubbl. sta $\approx$. $\approx o o l$. Napoli, 25, 201-40.

Ranzi, S., and P. Citterio. 1955a. The proteins in the Rana esculenta embryo in normal development and in experimental conditions. Exptl. Cell Research, Suppl. 3, 287-93.

Ranzi, S., and P. Citterio. 1955b. Le comportment des différentes fractions protéiques au cours du developpement embryonnaire de Rana esculenta. Rev. suisse zool., 62, 275-81.

Ranzi, S., P. Citterio, M. V. Copes, and C. Samuelli. 1957. Proteine e determinazione embrionale nella rana, nel riccio di mare e negli incroci dei rospi. Acta embryol. morphol. exptl., 1, 78-98.

Ranzi, S., and G. Ferreri. 1945. Evocazione nello sviluppo embrionale delle Ascidie. Boll. soc. ital. biol. sper., 20, 153-56.

Ranzi, S., and L. Janeselli. 1941. Effetto di LiCl sullo sviluppo dei Ciclostomi. Rend. ist. lombardo sci., 74, 403-36.

Ranzi, S., and E. Tamini. 1941. Azione di NaSCN sullo sviluppo di embrioni di Anfibi II. Rend. ist. lombardo sci., 73, 525-44.

Ranzi, S., E. Tamini, and Offer E. Storari. 1946. Alterazioni dello 
sviluppo embrionale di Anfibi prodotte da solfocianato e da altre sostanze. Rend. ist. lombardo sci., 79, 161-97.

Raven, C. P. 1952. Morphogenesis in Limnaea stagnalis and its disturbance by lithium. J. Exptl. Zool., 121, 1-77.

Runnström, J. 1928. Zur experimentellen analyse der Wirkung des Lithiums auf den Seeigelkeim. Acta Zool. 9, 365-424.

Runnström, J. 1949. The mechanism of fertilization in Metazoa. Advances in Enzymol., 9, 241-327.

Runnström, J. 1954. Die analyse der primären Differenzierungsvorgänge in Seeigelkeim. Ver. deut. zool. Ges. Tübingen, 32-68.

Shaver, J. R. 1955. The distribution of mitochondria in sea urchin embryos. Experientia, 9, 351-55.

Stockard, C. R. 1907. The artificial production of a single median cyclopean eye in the fish embryo by means of sea water solution of magnesium chloride. Arch. Entwicklungsmechan. Organ., 23, 249-58.

Tamini, E. 1941. Ricerche sulla animalizzazione nello sviluppo dei ricci di mare. Monit. zool. ital., 52, 81-92.

Tamini, E. 1943a. Ricerche sulle cause che determinano la ciclopia degli Anfibi. Wilhelm Roux' Arch. Entwicklungsmech. Organ., 142, 455-89.

Tamini, E. 1943b. Ricerche sulla vegetatilizzazione nello sviluppo dei ricci di mare. Rend. ist. lombardo sci., 76, 363-92. 


\title{
THE ROLE OF SOME ENZYMES IN THE DEVELOPMENT OF ASCIDIANS
}

\author{
G. REVERBERI: ZOOLOGICAL INSTITUTE, \\ UNIVERSITY, PALERMO, ITALY
}

The cytologists of the past century, closing their research and their discussion on mitochondria, could not suspect that a new brilliant mitochondrial era would be opened in the next century by the work of the biochemists. In any scientific movement it is always difficult to fix exactly the starting point; but perhaps we are not much mistaken in ascribing the begimning of the new golden age of mitochondria to the fundamental discovery of Green et al. (1948), by which it was established that the complete oxidation of pyruvate and the connected oxidative phosphorylation are carried out by a group of enzymes and coenzymes that are situated in the particulate elements of the cytoplasm. In the years that followed other important discoveries were made, particularly in the past five years, and enzymology became in a short time one of the most prosperous branches of biology.

Morphologists, physiologists, and even the embryologists could not remain indifferent to these new discoveries; they immediately felt that a reconsideration of some of the old, dismissed problems would be very profitable.

The morphologists were much helped in such reconsideration by the electron microscope which disclosed, in the mitochondria, unsuspected features. In fact, the electron microscope revealed a mitochondrial structure with transversal bands or "cristae mitochondriales," as they were named. The problem arose as to their meaning, and of course that problem led to many other problems.

The physiologists, for their part, were particularly affected by the new discoveries, as they shed new light on the problems of 
muscular contraction, cellular secretion, and synthesis of biological substances.

The embryologists, always in search of that "something" responsible for cellular and organic differentiation, felt immediately that they would be greatly helped by the new biochemical research: the factors responsible for differentiation and induction must have a chemical basis! Particularly interesting to them was the fact that the mitochondria contain clozens or hundreds of enzymes. These are not distributed at random but, on the contrary, are assembled in a fixed pattern, that is, locally disposed, spatially connected, and in determined quantities.

It is a well-established fact in genetics that the chromosomes also possess a preordered and constant pattern, and there are valid cases in which results have sufficiently demonstrated that genes are enzymes, or at least produce enzymes. Another consideration associates in the mind of an embryologist the mitochondria and the chromosomes: the fact that, as in the case of the chromosomes, the mitochondria can be separated, with respect to their form and functions, into many different classes. Generally it is assumed that every mitochondrion possesses the power of operating the Krebs cycle, the transfer of electrons to molecular oxygen and the oxidative phosphorylation; but other functions are typical of certain classes of mitochondria. There have been described (Lenicque, 1953) two kinds of mitochondria in the muscles of amphibians, one devoted to the lipidic metabolism, the other implicated in the energetics of contraction. In the liver, too, there are known to exist two kinds of mitochondria which provide two different functions, the synthesis of citrulline and the detoxication of aromatic substances. The brain mitochondria are not able to catalyze the reactions of fat metabolism, and the maximum of differentiation and specialization is represented by the mitochondria of the secretory cells, which perform the most diverse functions. Very often one speaks of "ectodermic" or "entodermic" mitochondria to indicate their principal role. The former would carry out the synthesis of some proteins, and the latter the synthesis of pigments and other substances. In the 
plants, the chloroplasts are mitochondria that have acquired new functions.

It is obvious that all these different functions are based on a peculiar enzymatic constitution, from whence possibly derive the different forms of the mitochondria. Electron microscope research shows that the "cristae mitochondriales" are more numerous in the mitochondria that have a high enzymatic content. One of the principal tasks in the future will be to describe where and how the different groups of enzymes are disposed in a mitochondrion. Probably it will be very useful in the future to compare the localization of the enzymes in the mitochondria and the localization of the genes in the chromosomes. If the mitochondria are ultimately responsible for the form, the length, and other characteristics of a cell, it would be useful to establish what sort of dependence exists between the mitochondria and the genes.

Of course it is not intended here to compare the importance of chromosomes with that of mitochondria. It would be sufficient to compare only the ways of their reproduction. Mitochondria grow in length, divide transversely, and are spread at random in the originating cells, because they do not possess that very elaborate mechanism which is peculiar to the chromosomes, that is, the "achromatic spindle." Apparently the mitochondria do not possess the very complicated chromosomal structure!

\section{Mitochondria of the Ascidian Egg}

The assumption that the mitochondria are distributed at random during the mitotic process must be corrected if the cell which divides is a fertilized egg. We shall see, on the contrary, that in some kinds of eggs there is a sort of mechanism, which is rather accurate and which segregates the mitochondria only in certain cells. Probably that segregation is not only quantitative but also qualitative.

The importance of this fact is very evident from the embryological point of view, as every cell, while possessing a complete set of genes, does not always have at its disposal the enzymes by which, in consequence of the action of the genes, are initiated 

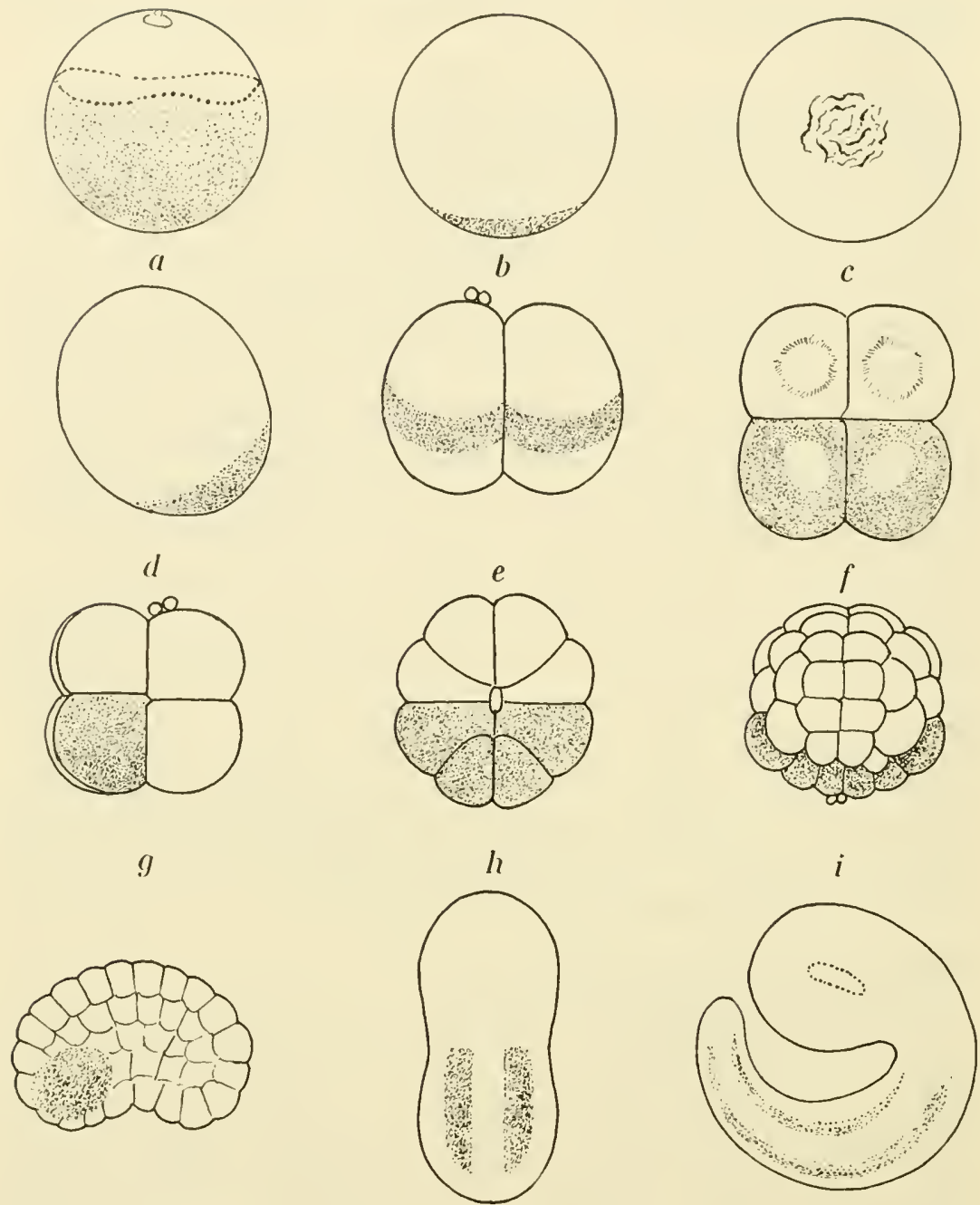

j

k:

l

Fig. 1. Phallusia eggs and embryos at different stages of development, after staining of the unfertilized egg with Janus green. See the text (Reverberi, 1956a). 
those chemical chain reactions that bring about the processes of differentiation.

One of the best examples of differential segregation of the mitochondria in certain cells of the developing embryo is offered by the ascidian egg (Reverberi, 1956a). Janus green staining reveals in this egg the presence of a large quantity of mitochondria. In the unfertilized egg they are spread everywhere in the cytoplasm, except at the animal pole, where there is the nuclear sap of the collapsed nuclear vesicle. Between the two zones runs a circular, sinuous line of large granules of an intense green (Fig. 1, a). Upon centrifuging the unfertilized green egg, the colored mitochondria gather between the animal hyaline cap and the large mass of deutoplasm and pigments.

The local segregation of the mitochondria starts at fertilization. The uniformly colored egg in a few minutes becomes clear-only the vegetal pole, to which migrates the mass of green-colored mitochondria, becomes green (Fig. $1, b, c$, and $d$ ). With a new migration the mitochondrial mass reaches the dorsal part of the egg, where normally the yellow crescent is found (Fig. 1,e). The first three segmentations of the egg segregate the mitochondria in the two posterior vegetal blastomeres (Fig. 1, $f$ and $g$ ). These blastomeres are the representatives of the mesodermic organs. With the next egg divisions the mitochondria are segregated only in the cells of the muscular line (Fig. $1, h, i, i$, and $k$ ). The tadpoles originating from eggs treated with the Janus green at the beginning of development have green colored tails; more exactly, the green coloration is localized in the muscular cells of the tail (Fig. 1, l).

The very impressive movements of migration and segregation of the mitochondria just described and the apparent existence of an accurate mechanism controlling these movements raise the question of the meaning of such processes.

It is necessary, however, to remove at once the idea, possibly raised by the above described processes, that the other blastomeres of the developing embryo are deprived of mitochondria. First of all, in the ascidian egg there are probably at least two kinds of mitochondría. Meves (1913), Duesberg (1926), Conklin 
(1931), Ries (1939), and Tung et al. (1941) described granules which are not stained by the Janus green. They are osmophilic and are brought by centrifugation to the centripetal pole. They are also rich in yellow pigment from which derives the typical "yellow crescent" described by Conklin. Such granules are supposed to be mitochondria because they behave like them when treated with ordinary lipidic solvents or with osmic acid. On the other hand, we have described rodlike mitochondria, which take the coloration with the Janus green and which gather, by centrifugation, above the equator of the egg, between the hyaline cap and the pigmented zone. Secondly, we have also noticed, especially at the time of their segmentation, that the non-muscleforming blastomeres of the embryo possess, although in small number, typical mitochondria.

\section{Enzymes of the Ascidian Mitochondria}

The present knowledge on the quality, quantity, and localization of the enzymes in the mitochondria is generally very poor, because only a few histochemical techniques are at our disposal. Ries (1937) was the first to indicate the presence and localization in the cells of the developing ascidian egg of "inclophenoloxidase," "benzidinperoxidase," and "oxidoreductase." These enzymes were segregated in the cells of the muscle line. Reverberi and Pitotti (1939) confirmed these points and showed that the pattern of the enzymatic distribution is very different in the unfertilized and in the fertilized egg.

Ries supposed that these enzymes are not localized in the mitochondria but in the plasm. He attributed a paramount importance to them in relation to the differentiation of the musculature, and he stated that only when the plasm containing these enzymes is displaced by centrifugation, larvae arise which are very deficient in musculature. The displacement of the mitochondria is, according to Ries, of no consequence to morphogenesis.

Our recent research has shown that the indophenoloxidase of Ries is inhibited by sodium azide; thus, it must be identified as a cytochrome oxidase; also it is localized not in the plasm but in the mitochondria. In fact, the mitochondrial zone of the centrifuged 
egg gives a very intensive reaction to the Nadi reagent. This reaction is negative if the egg was treated before by sodium azide. It also seems likely that the benzidinperoxidase and the oxidoreductase are localized in the mitochondria.

Another enzyme which is also supposed to be localized in the mitochondria is the "succinodehydrogenase" which has been studied in the ascidian egg by Mancuso (1952). Mancuso showed that this enzyme presents the same pattern of distribution and segregation that is typical for the cytochrome oxidase. We propose to check all these data on cell-free mitochondria. We plan to investigate also the localization of these enzymes in the mitochondrion and their relative quantity. At the moment we can only say, judging from the intensity and rapidity of the Nadi reaction, that the quantity of cytochrome oxidase is very high.

\section{Inhibition of Mitochondrial Enzymes in the Ascidian Egg}

It is well known that the activity of an enzyme can be specifically inhibited by the use of appropriate chemical substances. In some conditions the inhibition can be reversed. Much research has been done by the biochemists on enzyme inhibition; but the methods and the conclusions deduced from their studies cannot be used without reservation for the mitochondria inside the cells. In fact, strong chemical solutions could not be used in the developing eggs without seriously impairing development. Also specific substances acting only on one enzyme and not on other cellular components are scarcely known. In other words, great care must be employed when using inhibitors on living and developing eggs.

A specific inhibitor of cytochrome oxidase (C.O.) is sodium azide. At appropriate concentrations in vitro it inhibits $80 \%$ of the enzyme activity. The sodium azide is not absolutely specific; in fact, it influences also the phosphorylating system. In the ascidian egg the inhibition of the C.O. can be easily and at any moment checked by the Nadi reaction, which is negative or retarded. Solutions of sodium azide at $0.1 M$ inhibit the enzyme in fifteen minutes, but at that concentration the fertilized egg does not develop, polocytes are not emitted, and the egg does not 
divide. The same concentration used on the eggs at 2-, 4-, and 8-cell stages produces a similar result; that is, the eggs are blocked. Solutions at $0.01 \mathrm{M}$ inhibit the enzyme partially; at this concentration development is also impossible. Only at $0.001 \mathrm{M}$ or $2 \times 10^{-3}$ and $3 \times 10^{-3} M$ is some development possible. Stronger solutions $(0.2$ or $0.1 M)$ can be used only with the unfertilized egg without any consequent damage to development. After treatment, even prolonged for 12 hours, it can be fertilized in normal sea water and start development. Under such conditions the C.O. is inhibited, as shown by the Nadi, and the inhibition lasts longer (Reverberi, 1956b).

Sodium malonate and selenite are considered good inhibitors of succinodehydrogenase. The inhibition can be checked histochemically by tetrazolium salts. In our experiments with ascidian eggs solutions $5 \times 10^{-2}$ to $1 \times 10^{-1} M$ and $6 \times 10^{-4}$ to $1 \times 10^{-3}$ $M$, respectively for malonate and for selenite, are effective. At these concentrations, however, the inhibition of the enzyme is only partial, as revealed by the positive histochemical reaction. Malonate and selenite do not inhibit the activity of the C.O.

\section{Development of the Ascidian Egg with Blocked Enzymes}

The central problem of our research was to establish whether the ascidian egg with one or more blocked enzymes develops into a normal larva or into a larva with specific and constant abnormalities. Eggs at different stages of development were submitted to the action of sodium azide, malonate, or selenite, or sodium azide plus malonate (or selenite).

Treatment with Sodium Azide. Unfertilized eggs can be treated at length and at high concentrations $(0.1$ to $0.01 M)$. In such solutions the C.O. is completely inhibited, fertilization and development are possible in normal sea water or in diluted azide solutions, and the inhibition of the enzyme persists. The segmentations of the eggs are normal and synchronous with the controls. Tadpoles develop which have a normal "head" but an abnormal tail which is distorted and physiologically impotent. The tadpoles move poorly and very irregularly, and they are easily exhausted (Fig. $2 b)$. 


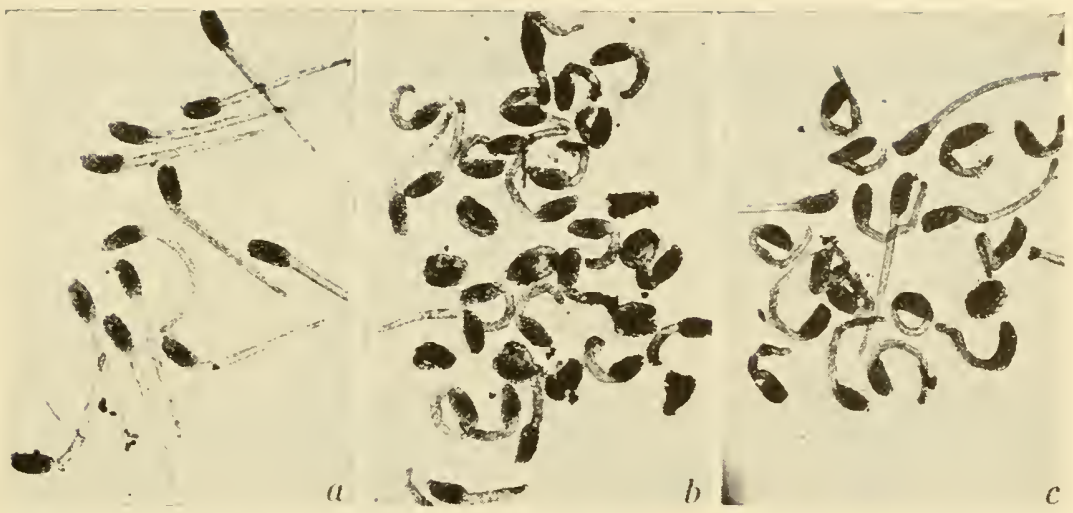

Fig. 2. Phallusia tadpoles. $a$, controls; $b$, treatment with $0.1 .1 /$ sodium azide for 3 hours before fertilization, and development in $0.001 \mathrm{M}$ azide; $c$, treatment as in $b$, interrupted at neurula stage.

Fertilized eggs can develop only in dilute solutions (from $2 \times$ $\left.10^{-3} M\right)$; the C.O. is only partially inhibited. The developed tadpoles possess normal "head" with brain, sensorial spots, and palps, but very abnormal tails (Fig. 3 ). The same results are also obtained when the treatment was interrupted before the differentiation of the musculature, that is, at the neurula stage (Fig. 2c).

Treatment with Malonate. Development is affected only at concentrations about $5 \times 10^{-2} M$ or stronger. In Fig. 4 are pre-

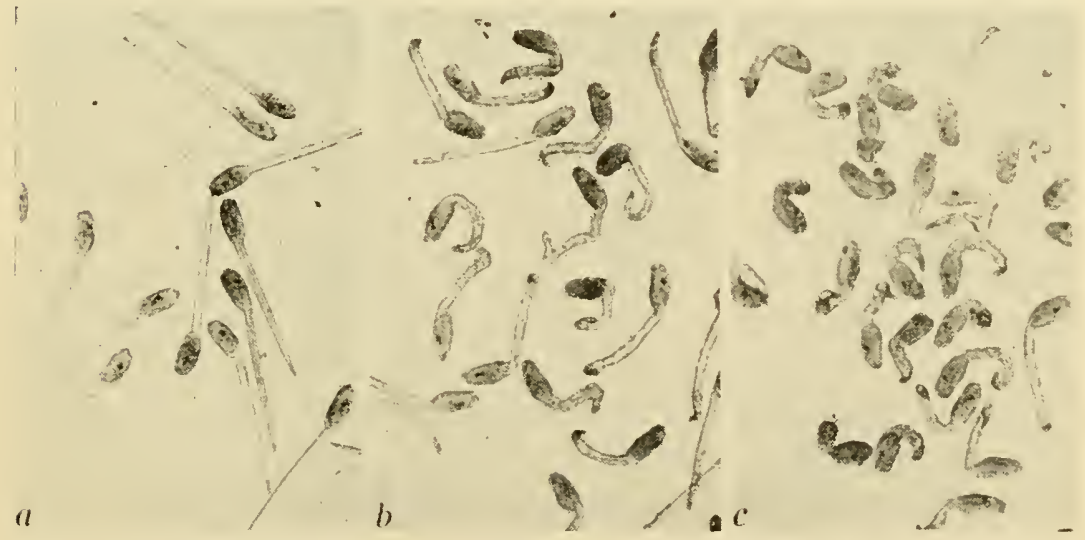

Fig. 3. Phallusia tadpoles. $a$, controls; $b$, development in $2 \times 10^{-3} \mathrm{M}$ sodium azide; $c$, development in $3 \times 10^{-3} M$ azide. 

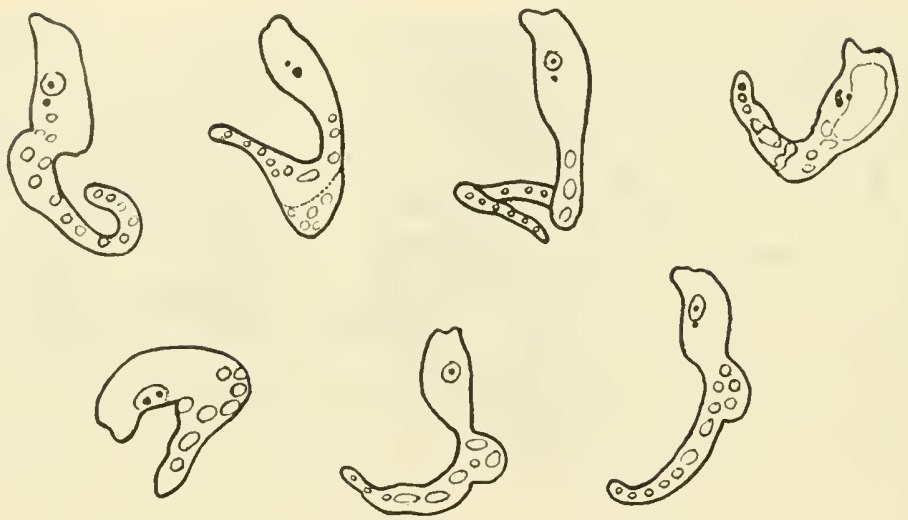

Fig. 4. Phallusia tadpoles. $a$, development in $0.1 M$ sodium malonate; $b$, development in $6 \times 10^{-2} M$ malonate.

sented some larvae which developed after the treatment. They have almost normal "heads," but the tails are very abnormalatrophic, distorted, and poorly functional, with the chordal cells partially fused and randomly disposed, apparently as a consequence of the disturbed differentiation of the muscle-cells. The above results were obtained also when the treatment was interrupted at neurula stage.

Treatment with Selenite. Eggs at the 2-cell stage reared in selenite solutions at $1 \times 10^{-3}$ to $4 \times 10^{-3} M$ can develop into larvae (Fig. $5 a$ ). The larvae from a $1 \times 10^{-3} M$ solution cannot, however, get out of the membranes, their tails are poorly devel-
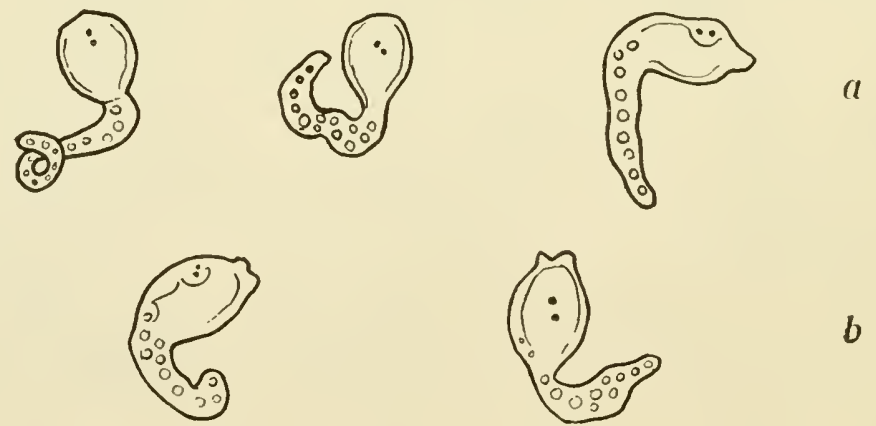

$b$

Fig. 5. Phallusia tadpoles. $a$, development in $1 \times 10^{-3} M$ sodium selenite; $b$, development in $6 \times 10^{-3} M$ selenite, until the neurula stage. 
oped, without any movement or contraction. The larvae seem to be dead. That they are living is however shown by the fact that they enter metamorphosis. The immobility of the larvae is not due to paralysis, because they do not reacquire motility if they are immersed in normal sea water and are allowed to remain in it for a length of time. Normal larvae, if placed in $1 \times 10^{-3} M$ selenite solution, do not lose their active movement even after a long period.

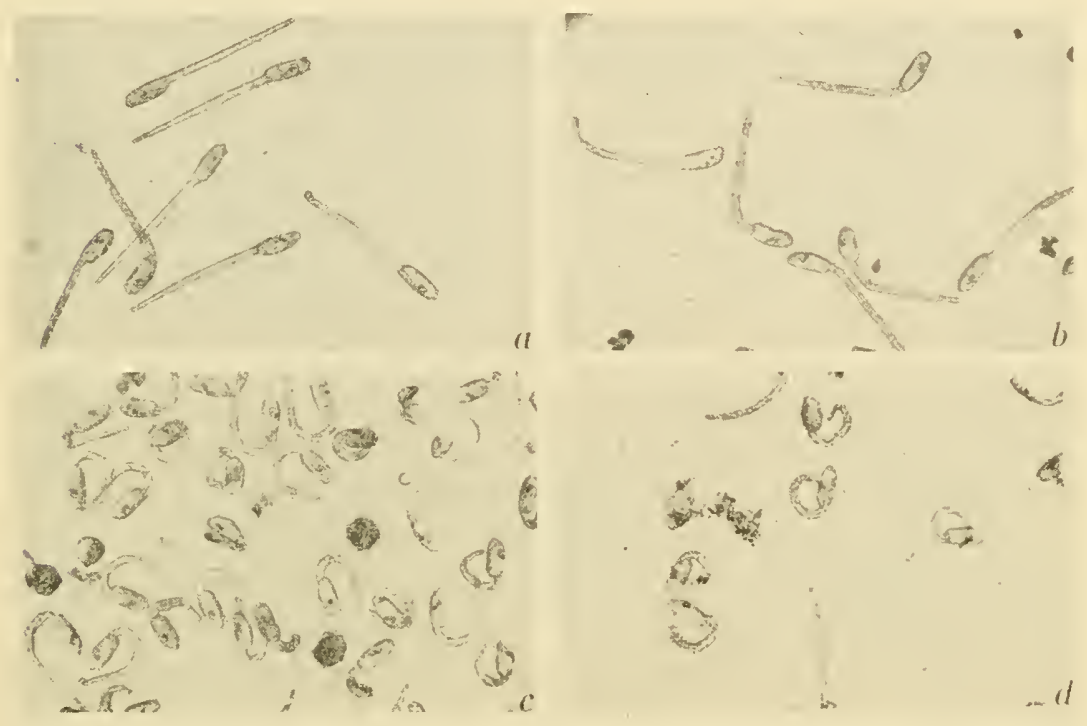

Fig. 6. Phallusia tadpoles. $a$, controls; $b$, development in $1 \times 10^{-3} M$ sodium azide. $c$, development in $5 \times 10^{-2} M$ sodium malonate; $d$, development in $1 \times 10^{-3} M$ azide plus $5 \times 10^{-2} M$ malonate.

Eggs in weaker solutions $\left(6 \times 10^{-4} M\right)$ develop into membrane-free larvae, which, however, have distorted tails and are incapable of any movement. Their "heads" are normal. Their condition does not improve in normal sea water.

If the treatment is interrupted at the neurula stage (solutions $6 \times 10^{-3}$ or $4 \times 10^{-3} \mathrm{M}$ ) before any muscular differentiation begins, larvae arise which also have abnormal tails and are deprived of movement (Fig. $5 \mathrm{~b}$ ). They do not recover if immersed in normal sea water. 
Treatment with Sodium Azide Plus Malonate or Plus Selenite. These experiments by which two kinds of mitochondrial enzymes were simultaneously inactivated (C.O. and succinodehydrogenase) were designed to ascertain whether the larvae produced presented more marked caudal abnormalities. The results obtained show that, while azide or malonate alone (respectively azide or selenite) do not produce at low concentrations any abnormality in the larvae, they produce marked tail abnormalities if used together (Fig. 6).

\section{Topographical Distribution of Mitochondria}

In "Mosaic" Eggs. The above described differential segregation of the mitochondria in particular cells of the developing embryo is not an exceptional case. In mosaic eggs other interesting cases have been described. The most notable is that of the Tubifex egg. It must be recalled that first Lehmann (1941) and later Carrano and Palazzo (1955) demonstrated the presence in this egg, at the opposite poles, of a peculiar plasm rich in indophenol oxidase or cytochrome oxidase, the "polplasma" (Fig. 7). During development the polplasma is differentially distributed in the $2 \mathrm{~d}$ and $4 \mathrm{~d}$ cells. Other research has shown that the polplasma is particularly rich in mitochondria, which are differentially segregated, with it, in the $2 \mathrm{~d}$ and $4 \mathrm{~d}$ cells. A more accurate analysis (Lehmann, 1950), confirmed by the use of electron and phase contrast microscope (Lehmann and Wahli, 1954), has shown that larger particles or mitochondria are distributed into the $4 \mathrm{~d}$ cells, whereas the smaller ones or microsomes, and only few mitochondria, are segregated into the $2 \mathrm{~d}$ cells.

Other equally clear examples of mitochondrial segregation in certain cells of the developing egg are not known, but we have many indications that lead us to believe that such a process is more frequent in "mosaic" eggs than one would suppose.

It has been stated (Attardo, 1955a) that the Nadi reaction is positive only in the animal pole of the uncleaved egg of Bithynia. In the following stages of development the Nadi reaction is positive only in the quartets of micromeres which will give rise to the ectoderm (Fig. 8). As in this case the Nadi reaction is pre- 


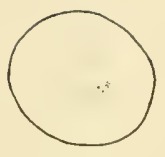

$a$

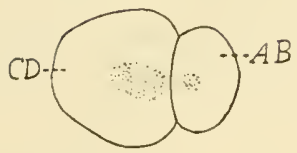

$d$

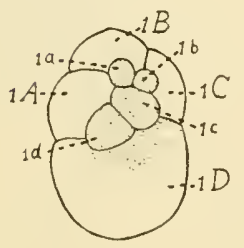

g

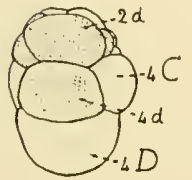

j

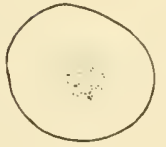

$b$

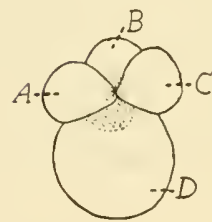

$e$

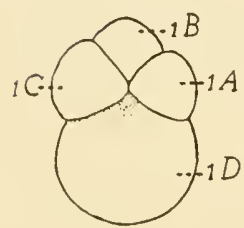

$h$

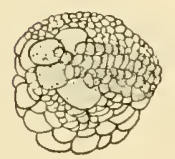

$k$

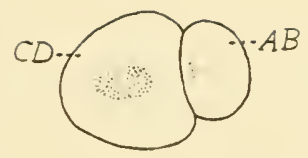

C

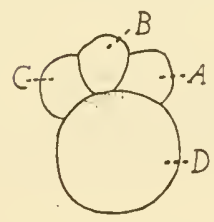

$f$

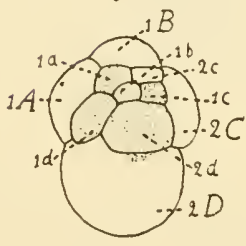

i

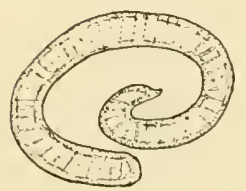

l

Fig. 7. Nadi reaction (dotted) in developing eggs of Tubifex. $a, c, e$, $g$, $i$, from the animal pole; $b, d, f, h, i$, from the vegetal pole; $k$, blastula from the animal pole; $l$, hatched worm (Carrano and Palazzo, 1955).

vented by the azide treatment, one can affirm that the zones of the egg which are Nadi positive possess cytochrome oxidase. If this enzyme is localized in the mitochondria, these would ultimately be segregated only in the ectodermic blastomeres. Similar results have also been obtained by Mancuso (1955a) in Physa. Mitochondria segregated in the animal pole of the egg have been actually observed by Ries and Gersch (1936) in Aplysia. However, these authors were not able to follow their destiny in the following development. They supposed, probably founded on 
some observations, that they were "quantitativ ungleich verteilt" in the blastomeres.

Other indications of a differential distribution of mitochondria in some blastomeres of a developing embryo are found in the eggs of Nereis, Eucharis, and probably of Myzostoma (Reverberi and Pitotti, 1940; Pitotti, 1947). In these eggs the Nadi reaction showed definite localization of a certain substance. Confirmation that such a substance is cytochrome oxidase, as we suppose, is however lacking. We hope that coloration of the eggs with Janus

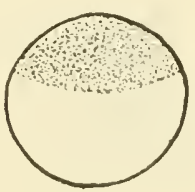

a

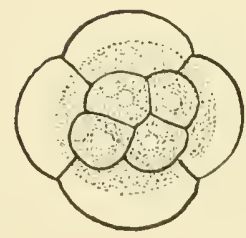

$d$

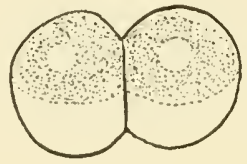

$b$

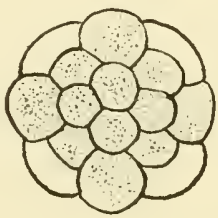

$e$

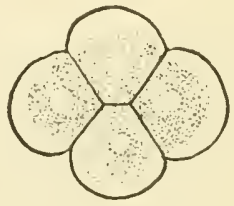

$c$

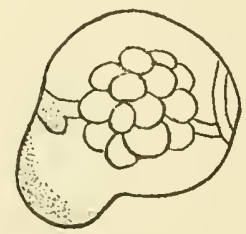

f

Fig. 8. Nadi reaction (dotted) in developing egg of Bithynia (Attardo, 1955a).

green will give more information. It is important to note for the moment that, as in the ascidians and in Tubifex, the Nadi reaction is positive only in those blastomeres that will give rise to the larval organs of movement.

In the "Regulative" Eggs. In the sea urchin egg the topographical distribution of the mitochondria has been studied by Gustafson and Lenicque $(1952 ; 1955)$. In the unfertilized egg and in the first stages of development there was a small quantity of mitochondria. Their number suddenly increased at the begin- 
ning of the migration of the mesenchyme cells into the blastocoelic cavity. Counts of mitochondria in the early gastrula show that they are more abundant at the animal pole; their number decreases toward the vegetal pole along a gradient. There has been doubt, however, about such mitochrondrial distribution (Shaver, 1955; see also Shaver, this volume).

In the amphibian eggs and in other regulative eggs no topographical segregation of mitochondria in particular cells of the developing embryo seems to have been described. Of some interest is the work of Shaver (1953) concerning the differentiation or maturation of mitochondria. In fact, while the mitochondria of the young development stages are not able to stimulate a parthenogenetic development, this property is possessed by the mitochondria from late blastula or gastrula.

\section{Inactivation of Enzymes and Morphogenesis}

In the "Mosaic" Eggs. We have reported above some results which follow the blocking of the cytochrome oxidase or the succinodehydrogenase in ascidian development. Do we have other examples which can confirm such results in the "mosaic" eggs? This can be answered in the affirmative.

First we want to recall some results obtained by Raven and Spronk (1952) in the Limnaea egg. The topographical distribution of the alkaline phosphatase in the developing embryo of Limnaea has been described by Minganti (1950) who, by histochemical methods, showed that it is localized at early stages of development in the stomodaeum, protonephridium, and shell gland. Beryllium is considered a strong inhibitor of the alkaline phosphatase. Raven and Spronk exposed the eggs of Limnaea to beryllium salts. The embryos which developed from these treated eggs showed very marked abnormalities in the stomodaeum, protonephridium, and shell gland. Similar results have been obtained by some of my collaborators in this laboratory.

The research of Lehmann (1941) and Carrano and Palazzo (1955) on the localization of the cytochrome oxidase in the developing eggs of Tubifex has been mentioned above. The C.O. is abundant in the mitochondria, particularly in the $4 \mathrm{~d}$ cell, that 

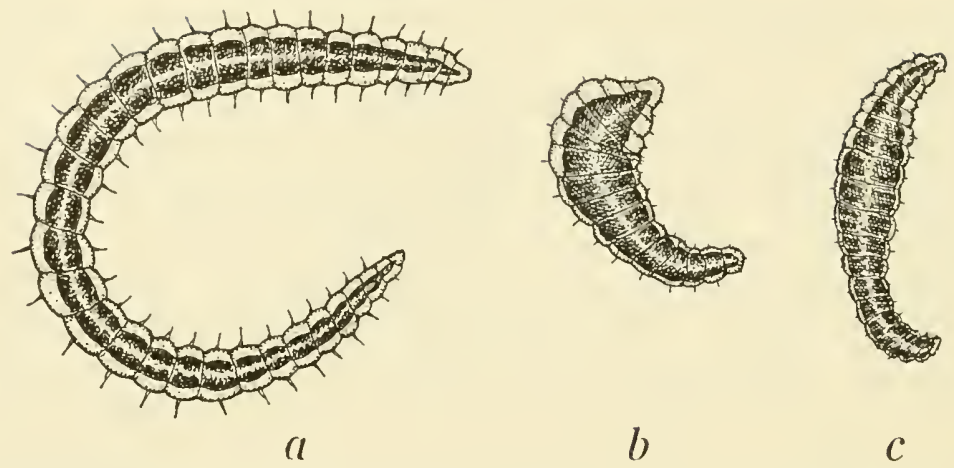

C

Fig. 9. Hatched Tubifex worms. $a$, control; $b$, $c$, after treatment with $1 \times 10^{-3} M$ sodium azide (Palazzo, 1955).

is, the mesodermic cell. Palazzo (1955) partially blocked the C.O. with sodium azide in the first stages of development. She obtained worms with relevant deficiencies in the muscular system and in the circulatory system, both of which are mesodermic derivates (Fig. 9).

In the eggs of Bithynia (Attardo, 1955a) and Physa (Mancuso, 1955a), however, the C.O. appears localized in the ectodermic blastomeres. Now the blocking of the enzyme by sodium azide (Figs. 10 and 11) produces animals which are abnormal for the ectodermic derivates, i.e., the brain, the eyes, and the tentacles (Attardo, 1955b; Mancuso, 1955b).

Another example of relations between the enzymes and morphogenesis is offered by the Physa egg. Mancuso (1955a) showed

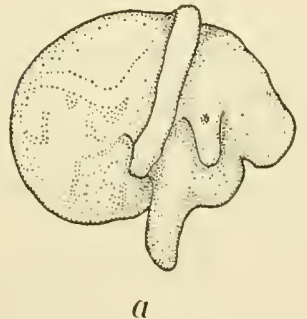

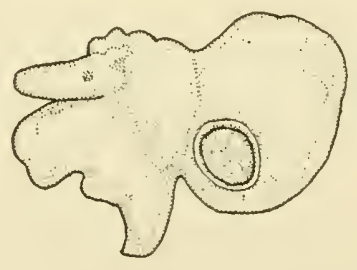

b

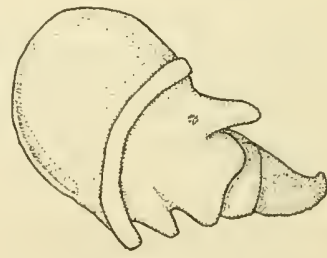

c

Fig. 10. Larvae of Bithynia. $a$, control; $b, c$, after treatment with $7 \times$ $10^{-2} M$ sodium azide for 4 hours, at the earliest stages of development (Attardo, 1955b). 
that the embryos of this mollusc possess in the mantle and in the shell gland a KCN-sensitive oxidase, probably a M-Nadi oxidase. The treatment of the eggs with KCN, which blocks the enzyme, gives rise to embryos with defective or rudimentary mantles and shells (Fig. 12) (Mancuso, 1955c).

However, we can add more evidence to the above results in the ascidian egg. This evidence comes from experiments on the

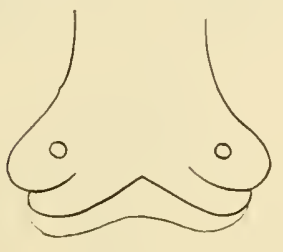

$a$

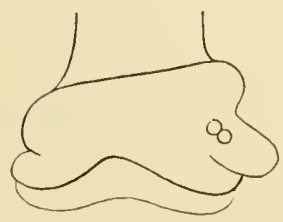

$d$

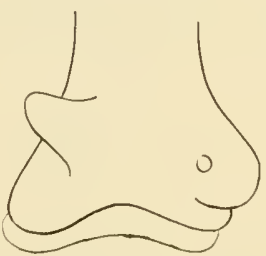

$b$

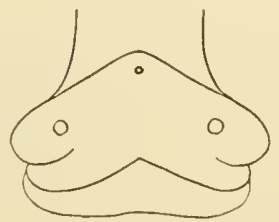

$e$

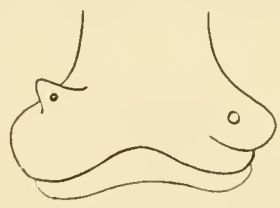

c

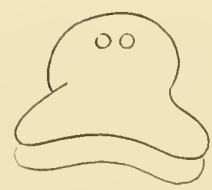

$f$

Fig. 11. Larvae of Physa (schematic representation of the heads). $a$, control; $b$ to $f$, after treatment with $0.5 \%$ sodium azide for 4 hours (Mancuso, $1955 \mathrm{~b}$ ).

development in anaerobiosis (De Vincentiis, unpublished). In a partially oxygen-deprived atmosphere, that is, in conditions in which the cytochrome oxidase is poorly active, larvae develop which again are abnormal for the tail but normal for the "head," as in the case of the azide-treated larvae.

Finally, to remove any objection to the specificity of this result and of the ones reported above, we shall mention some data obtained by Farinella-Ferruzza (1955) in ascidian eggs after 
treatment with a lithium salt. The larvae which developed after such treatment had normal tails, but were without brains, sensorial organs, and palps.

In the "Regulative" Eggs. The effects of the enzymatic blocking on organogenesis have been particularly studied in the sea urchin egg. Many papers on this subject have been published by Rulon (1949, 1950, 1951, 1952, 1955), who organized a wellplanned and systematic research. Rulon dedicated most of his attention to the blocking of cytochrome oxidase, succinodehy-

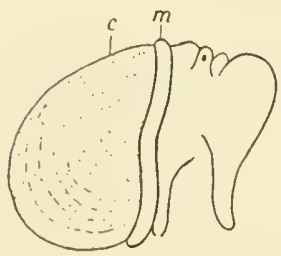

$a$

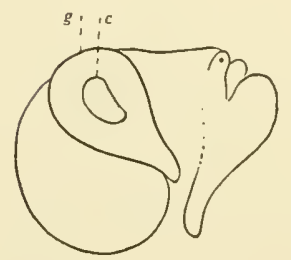

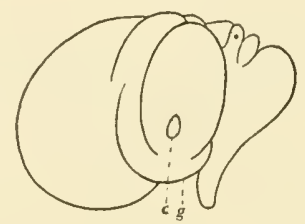

$b$

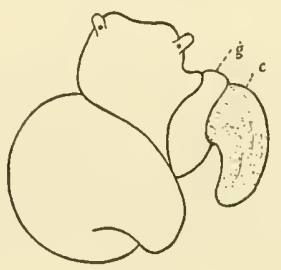

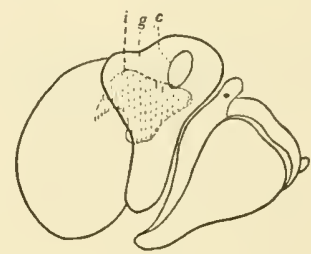

c

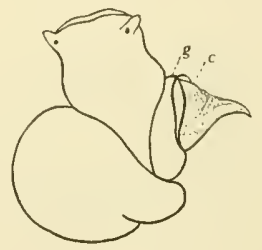

Fig. 12. Larvae of Physa. $a$, control; $b$ to $f$, after treatment with $0.005 \%$ potassium cyanide (Mancuso, $1955 \mathrm{c}$ ).

drogenase, peroxidase, phosphorylases, and enzymes with sulfhydrylic radicals. He used, respectively, sodium azide, sodium malonate, or maleic acid, sodium selenite, thiourea, glucose, and zinc chloride. He obtained rather generalized abnormalities in the larvae, which also can be produced with other treatments and in that sense are not specific. For example, malonate does not produce the abnormalities that are produced by sodium azide. Both glucose and azide inhibit the phosphorylations, but their effects on development are very different. The results obtained by Rulon are certainly suggestive. However, one would like to know something about the local distribution of these enzymes in the 
egg and on this point histochemical research is still largely wanting.

Other research on the effects of the blocking of the $\alpha$-ketoglutarase or the aconitase by $p$-pyruvate or fluoroacetate in the sea urchin egg has been recently published by Montgomery and Bamberger (1955). The inhibitors used do not produce any effect on the first stages of development. The embryos arrest at the blastula or early gastrula stages and do not differentiate-the effects of the inhibitors seem to be of rather general character.

In the regulative eggs extensive research has been conducted on the amphibians. The eggs have been treated with many enzymatic inhibitors, for example, KCN, sodium azide, and anaerobiosis, but as far as we know no localized, specific effects have been observed. The blocking of cholinesterase, which is largely present in the nervous system, was not followed by any abnormality in that system (Boell, 1946).

\section{Conclusions}

It seems, from the above reported data, that one can affirm with reasonable probability that some enzymes, at least, play a role in morphogenesis. This conclusion emerges more clearly for the mosaic eggs than for the regulative ones. In the latter, as has been mentioned, the inactivation of the enzymes induces abnormalities of general rather than of specific character, as in mosaic eggs.

The question arises concerning the mechanism by which the enzymes influence morphogenesis. I suppose that no one can pretend at the present stage of the biological sciences to give a plausible answer to that question. However, on the basis of the data presented above, we would like to offer the following interpretation. As we know, every morphogenetic character is under the control of the genes. Where then does the morphogenetic effect of the mitochondrial enzymes enter the picture? As Brachet $(1952,1954)$ pointed out in several of his papers, the nucleus is the site where nucleotides, either "nucleic acids or coenzymes" (Brachet, 1954, p. 96) are synthesized. It is quite possible that some of these coenzymes activate some mitochondrial enzymes. 
Thus the long chain of chemical reactions leading to differentiation and organogenesis would be initiated.

\section{REFERENCES}

Attardo, C. 1955a. Localizzazione della citocromo-ossidasi e dei lipidi nell'novo di Bithynia codiella. Ricerca sci., 25, 2797-2800.

Attardo, C. 1955b. Effetti dell'azide sodico sulle uova di Bithynia codiella. Atti accad. Naz. Lincei, Rend., Ser. \$, 19, 83-84.

Boell, E. J. 1946. The effect of di-isopropyl fluorophosphate on the development of behavior and cholinesterase in Amblystoma punctatum. Anat. Record (Suppl.), 96, 4-5.

Brachet, J. 1952. Le rôle du noyau cellulaire dans les oxydations et les phosphorylations. Biochim. et Biophys. Acta, 4, 221.

Brachet, J. 1954. Nuclear control of enzymatic activities. Colston Papers, 7, 91-102.

Carrano, F., and F. Palazzo. 1955. Localizzazione precoce di alcuni enzimi nello sviluppo dell'uovo di Tubifex rivulorum. Riv. biol. (Perugia), 47, 193-202.

Conklin, E. G. 1931. The development of centrifuged eggs of ascidians. J. Exptl. Zool., 60, 1-20.

Duesberg, J. 1926. Etude cytologique des oeufs centrifugés de Ciona intestinalis. Arch. biol. (Liége), 36, 489.

Farinella-Ferruzza, N. 1955. Lo sviluppo embrionale delle Ascidie dopo trattamento con LiCl. Pubbl. staz. zool. Napoli, 26, 42-54.

Green, D. E., W. F. Loomis, and V. H. Auerbach. 194S. Studies on the cyclophorase system. I. The complete oxidation of pyruvic acid to carbon dioxide and water. J. Biol. Chem., 172, 359-403.

Gustafson, T., and P. Lenicque. 1952. Studies on mitochondria in the developing sea-urchin egg. Exptl. Cell Research, 3, 251-74.

Gustafson, T., and P. Lenicque. 1955. Studies on mitochondria in early cleavage stages of the sea urchin egg. Exptl. Cell Rescarch, 8, 11417.

Lehmann, F. E. 1941. Die Lagerung der Polplasmen des Tubifexeies in ihrer Abhängigkeit von der Eirinde. Naturwissenschaften, 29, 101.

Lehmann, F. E. 1950. Elektronenmikroskopische Untersuchungen an den Polplasmen von Tubifex und den Mikromeren von Paracentrotus. Arch. Klaus-Stiftg., 25, 611-14. 
Lehmann, F. E., and H. R. Wahli. 1954. Histochemische und elektronenmikroskopische Unterschiede im Cytoplasma den beiden Somatoblasten des Tubifexkeimes. Z. Zellforsch. u. mikroskop. Anat., 39, 618-29.

Lenicque, P. 1953. Étude sur l'évolution du chondriome au cours de la génèse du tissu musculaire et de sa dégénérescence provoquée par la colchicine. Arkiv Zool., 5, 289-96.

Mancuso, V. 1952. Ricerche istochimiche nell'uovo di Ascidie. II. Distribuzione delle ossidasi, perossidasi e della succinodeidrogenasi. Rend. ist. super. sanità, 15, 265-69.

Mancuso, V. 1955a. Sostanze Nadi-positive nello sviluppo di Physa rivularis. Ricerca sci., 25, 2843-44.

Mancuso, V. 1955b. L'azione dell'azide sodico sullo sviluppo dell'uovo di Physa rivularis Ph. Riv. biol. (Perugia), 47, 203-7.

Mancuso, V. 1955c. Azione del cianuro di potassio sullo sviluppo di Physa rivularis. Rend. accad. naz. Lincei, ser. 8, 19, 71-73.

Meves, Fr. 1913. Über des Verhaltenes plastosomatischen Bestandteiles des Spermiums bei der Befruchtung des Eies von Phallusia mamillata. Arch. mikroskop. Anat., 82, 215.

Minganti, A. 1950. Acidi nucleici e fosfatasi nello sviluppo della Limnaea. Riv. biol. (Perugia), 42, 295.

Montgomery, C. M., and J. IV. Bamberger. 1955. Action of parapyruvate on early development of Strongylocentrotus purpuratus. Science, 122, 967-68.

Palazzo, F. 1955. Effetti dell'azide sodico sullnovo di Tubifex rivulorum. Ricerca sci., 25, 2873-76.

Pitotti, M. 1947. La distribuzione delle ossidasi e perossidasi nelle uova di Myzostoma, Beroe e Nereis. Pubbl. staz. zool. Napoli, 21, 93-100.

Raven, Chr. P., and N. Spronk. 1952. The action of beryllium on the development of Limnaea stagnalis. Koninkl. Ned. Akad. Wetenschap., 55, 541-53.

Reverberi, G. 1956a. Experientia, in press.

Reverberi, G. 1956b. Pubbl. staz zool. Napoli, in press.

Reverberi, G., and M. Pitotti. 1939. Differenziazioni fisiologiche dell'uovo delle Ascidie. Commens. Pont. Acad. Sci., 3, 469-88.

Reverberi, G., and M. Pitotti. 1940. Ricerche sulla distribuzione delle ossidasi e perossidasi lungo il "cell-lineage" di nova a mosaico. Pubbl. staz. zool. Napoli, 18, 250-63.

Ries, E. 1937. Die Verteilung von Vitamin C, Glutathion, Benzidin- 
Peroxydase, Phenolase und Leukomethylenblau-Oxydoreducase während der frühen Embryonalentwicklung verschiedener wirbelloser Tiere. Pubbl. staz. zool. Napoli, 16, 363-401.

Ries, E. 1939. Versuche über die Bedeutung des Substanzmosaiks für die embryonale Gewebedifferenzierung bei Ascidien. Arch. Exptl. Zellforsch., 23, 95-121.

Ries, E., and M. Gersch. 1936. Die Zelldifferenzierung und Zellspezialisierung während der Embryonalentwicklung von Aplysia limacina L. Zugleich ein Beitrag zu Problemen der vitalen Färbung. Pubbl. staz. zool. Napoli, 15, 223-27.

Rulon, O. 1949. The modification of developmental patterns in the sand dollar with maleic acid. Physiol. Zool., 22, 247-61.

Rulon, O. 1950. The modification of developmental patterns in the sand dollar with sodium azide. Physiol. Zool., 23, 236-47.

Rulon, O. 1951. The modification of developmental patterns in the sand dollar by malonic acid. Physiol. Zool., 24, 85-92.

Rulon, O. 1952. The modification of developmental patterns in the sand dollar by sodium selenite. Physiol. Zool., 25, 333-46.

Rulon, O. 1955. Developmental modifications in the sand dollar caused by zinc chloride and prevented by glutathione. Biol. Bull., $109,316-27$.

Shaver, J. R. 1953. Studies on the initiation of cleavage in the frog egg. J. Exptl. Zool., 122, 169-92.

Shaver, J. R. 1955. The distribution of mitochondria in sea urchin eggs. Experientia, 11, 351.

Tung, T. C., S. H. Ku, and F. Y. F. Tung. 1941. The development of the Ascidian egg centrifuged before fertilization. Biol. Bull., 80, 153-69. 


\title{
IMMUNOLOGICAL STUDIES OF
}

\section{EARLY DEVELOPMENT}

\author{
ALBERT TYLER: KERCKHOFF LABORATORIES OF BIOLOGY, \\ CALIFORNIA INSTITUTE OF TECHNOLOGY, \\ PASADENA, CALIFORNIA*
}

During recent years there has been increasing interest in the application of immunological methods and concepts to the analysis of problems of the formation and early development of the embryo. The subject was reviewed a short while ago by the author (Tyler, 1955b). In this paper some of the newer developments in this field are presented along with pertinent background of earlier work. The material to be considered concerns the origin of adult antigens and of antibody-forming capacity, effects of antibodies on development, and a concept of natural auto-antibodies. A brief account is also included of some current experiments of the author on inhibition of cleavage by antisera.

Immunologically produced antibodies possess the capacity to react selectively with the specific substances (antigens) employed to induce their formation and with substances possessing certain related structural features. The classical experiments of Landsteiner (1917-1946) showed that determinants of antigenic specificity may be represented by relatively small chemical groups on a large complex molecule rather than by the structure of the molecule as a whole. This is illustrated in experiments in which a small molecular substance of known structure, such as arsanilic acid, is conjugated with proteins, such as those of horse serum. When this antigen is injected into a rabbit the antiserum that is

- Preparation of this article and original investigations of the author reported herein were supported by a research grant (No. C-2302) from the National Cancer Institute, of the National Institutes of Health, Public Health Service. 
produced reacts not only with the original antigen but also with other proteins, such as those of chicken serum, that have been coupled with arsanilic acid. The antiserum reacts also with ordinary horse serum, with arsanilic acid alone (no visible precipitate) and with "haptens" structurally similar to the arsanilic acid, but not with chicken serum; nor does an antiserum against horse serum react with chicken serum. From the many experiments of this type with which the immunological literature abounds it is now clear that relatively small parts of a large complex molecule can act as determinants of the specificity of antigens and antibodies.

Immunochemical research has not, as yet, provided very much information as to the size, number, and diversity of structure of the determinant groups of various native proteins and other large molecular substances of interest to biologists. Landsteiner (1942) showed that products of the hydrolysis of silk protein with molecular weight of about 600 possessed such activity. Another example of investigations in this clirection that may be mentioned is the current work of Kabat and Leskowitz (1955; ef. Watkins and Morgan, 1955) showing that certain simple sugars possessed the ability to react specifically with antibodies against human blood group substance. They suggest that the determinant structures of the blood group mucopolysaccharidic antigens are probably no larger than tri- to penta- or hexasaccharides.

One of the aims of embryologists in applying immunological methods is the determination of the time of appearance of specific constituents of the adult organs. However, this approach is beset with various difficulties, which have not apparently been appreciated by all the workers in the field. The prime difficulty is in knowing what is being detected by the antiserum that is used as the test reagent. As indicated above antibodies can detect certain specific structures of a large molecule. A particular protein may possess a number of such structures and they may be of several sorts, each of which may induce the formation of distinct antibodies in the serum, as is illustrated in the recent work of Francis et al. (1955) with "multi-haptenic" antigens. If some of the determinant groups are common to different proteins of an 
organism, as illustrated in Fig. 1, or if there are similarities in structure, cross reactions are to be expected. Cross-reacting antisera are also obtained if the preparation of immunizing antigen contains other active substances as impurities. However, it is not easy to decide in different cases to what extent cross reactions are due to impurities in the original immunizing antigen and to what extent these are due to similarities in determinant groups. Even with highly purified proteins used as antigens, such as the proteins

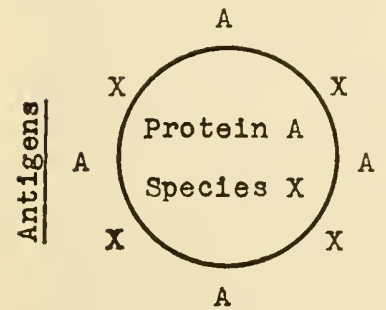

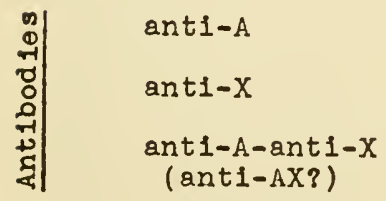

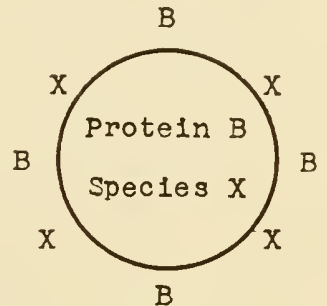

ant $1-B$

ant $1-X$

ant1-B-ant $1-X$ (ant1-BX?)
A

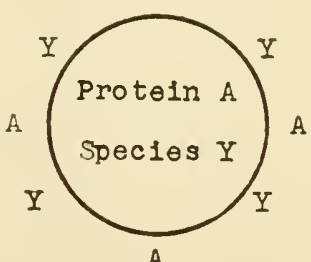

$\operatorname{ant} 1-A$

ant $1-Y$

ant1-A-ant1-Y (ant1-AY?)

Fig. 1. Illustration of the assumption that a particular protein may possess two (or more) kinds of determinant groups, one of which (X) may be present also on other proteins of the same species of organism and the other of which (A) may be present on the same type of protein in a different species. The types of antibodies that may be expected upon immunization are listed below each antigen. See text for discussion in relation to cross reactions.

of chicken egg-white studied by Cohn, Wetter, and Deutsch (1949), cross-reacting antibodies are obtained.

Absorption techniques eliminate to some extent certain of these difficulties. However, it is perhaps important to emphasize that in the use of an antiserum as a test reagent, one does not detect a specific protein or other large molecular substance but rather specific determinant groups. These do not necessarily characterize one particular (chemically defined) protein, and it is also possible that during embryonic development they may not remain continuously with the same protein. The term antigen is, therefore, 
used in this discussion primarily with reference to the determinant groups.

If extracts of various tissues and organs of the adult contained solely or primarily antigens characteristic of the tissue or organ, problems of detection of these antigens in the developing embryo could be rather directly approached. Examples of such organspecific preparations can be found in the immunological literature, but they are not as numerous or clear-cut as might be desired. The classical example is that of lens protein, first described many years ago by Uhlenhuth (1903). Antisera against salinesoluble proteins of the lens of the vertebrate eye do not crossreact with other proteins of the same organism. On the other hand, they are largely lacking in species specificity since they cross-react quite generally with lens extracts from various vertebrates from fish to man. Alcoholic extracts of vertebrate brain have also been shown to possess such organ-specific antigenicity although in this case there are cross reactions with testis (see Witebsky, 1929; Lewis, 1933). Another example is thyroglobulin, recently studied by Witebsky et al. (1955). References to other work on this subject may be found in various texts such as those of Landsteiner (1947), Loeb (1945), and Raffel (1953). In most cases the antibodies against various organ or tissue extracts show rather broad cross reactivity. Selective absorption procedures must therefore generally be used to demonstrate distinct antigenic constituents in various organs, but this suffers from technical limitations when most of the antibodies in an antiserum against a particular preparation are directed against antigens common to various tissues and organs.

\section{Relation of Embryonic to Adult Antigens}

At one time it was thought that eggs and developing embryos possessed no antigens similar to those of the adult, or even that their proteins were of such "general" nature as to lack antigenic properties. The work of many recent investigators has abundantly demonstrated in many species of animals that the eggs and developing embryos possess antigenically active materials, that many of the antigens are similar to certain adult antigens, and that 
changes occur in extractable and cellular antigens during development. For reference to investigations in this field during the past decade may be cited the work on frogs by Cooper (1946, 1948, 1950), Ten Cate and Van Dooremmaalen (1950), Flickinger and Nace (1952), and Spar (1953); on salamanders by Woerdeman (1950, 1953a,b) and Clayton (1953); on birds by Schechtman (1947, 1948, 1952, 1955), Nace and Schechtman (1948), Briles, McGibbon, and Irwin (1948; cf. Irwin, 1949, 1951), Schechtman and Nace (1950), Ten Cate and Van Doorenmaalen (1950), Schechtman and Hoffman (1952), Ebert (1950, 1951, 1952, 1953, 1954, 1955), Miller (1953), and Nace (1953); on mammals by Maculla (1948), Yčas (1949), Chernoff (1953), and Goodman and Campbell (1953); on sea urchins by Perlmann and Gustafson (1948), Perlmann (1953), and Harding, Harding, and Perlmann (1954); and on silkworms by Telfer and Williams (1953) and Telfer (1954). Most of this work has been recently reviewed (see Ebert, 1955; Nace, 1955; Tyler, 1955b) and the present discussion will be limited to a brief consideration of certain special features.

One must recognize in the first place that technically it is not possible at present to prove the complete absence of an antigen; that failure to detect an antigen does not prove its absence. Thus Ten Cate and Van Doorenmaalen (1950) detected lens antigen at earlier stages of development than had Burke et al. (1944). They attribute this to the use of more sensitive procedures. This suggests that the antigen might be detected at still earlier stages of development if further technical sensitivity were achieved. The concentration of lens antigen evidently decreases the earlier the embryonic stage tested, but there is no clear justification for the assumption that it extrapolates to zero. The same considerations apply to the interpretation of the various experiments cited above that deal with other organ-specific antigens, such as those of brain, spleen, kidney, and heart. In general, then, the question of preformation in embryonic development is raised again, but in a manner that does not permit easy resolution. Many antigens, such as those of vertebrate red cells that characterize blood groups and blood types, are known to be gene determined. It is 
reasonable to assume that the specific structure of any antigen is represented by some special feature of a corresponding gene. For example, this feature can be considered a structure complementary to that of the antigen (see p. 365). In this sense all antigens would be regarded as preformed in the fertilized egg. At the same time, the actual appearance of the antigen would be epigenetic, dependent upon the time and extent of action of the particular gene. It is also possible that all antigens are present, but some in undetectable amounts, along with their determinant genes (or other self-reproducing cytoplasmic body) at the start of development. In either case the processes involved in the determination and differentiation of the various tissues and organs would be assumed to entail concomitant activity of specific genes, determining also the formation of characteristic antigens of the tissue or organ.

Despite the inability to prove complete absence of an antigen one may, nevertheless, raise the question of whether or not specific "organ" antigens can be detected before the time of visible differentiation. The evidence in the above-cited investigations, although rather incomplete, would answer this in the affirmative. For example, specific antigens of lens, brain, spleen, and heart have been detected at stages well in advance of the differentiation of the particular organ. It has also been reported (Voercleman, 1953a,b, 1955) that lens antigen can be induced to appear in extracts of presumptive lens ectoderm by incubating in the presence of extracts of optic vesicle.

A large fraction of the antigens of adult tissue are detectable in the uncleaved egg and even in the oocyte. This appears to be especially true for antigens of adult serum or serum-like antigens of adult organs as Cooper (1946) showed in the first work to give real impetus to the current investigations on soluble antigens. The extent to which egg and adult serum have antigens in common is illustrated in the work of Schechtman and Hoffman (1952) and of Nace (1953). In this work antisera that were produced against whole chicken serum or the separate albumin and globulin fractions were found to cross-react quite strongly with egg yolk. Absorption with yolk greatly reduced the reactivity of these antisera 
with the serum fractions. For example, an antiserum against whole serum which gave a titer of 0.0004 , in terms of milligrams of protein in the highest reacting dilution of the antigen, gave a titer of 0.029 , a seventy-fold decrease, after absorption with yolk ( see Nace, 1953, Table 1, p. 430). With the oiher antisera against the various separated serum proteins (albumin, $\alpha, \beta$-globulin, $\gamma$-globulin) there was similar loss in reactivity with original antigen upon absorption with yolk or with heterologous serum proteins. As noted by these authors contamination of the yolk, preparations with serum can be ruled out as an explanation of the results. They suggest (Nace, 1953, p. 440) that the yolk proteins may be a direct transudate from the maternal serum, or that there is a mechanism for resynthesis of antigens very similar to serum from degradation products of serum that pass into the yolk. However, since these experiments and those of others show that some reactivity for serum constituents remains after absorption with yolk, it is evident that neither explanation is satisfactory unless it is further assumed that there is a selectivity as to which serum proteins transudate or as to which antigens are resynthesized. The same sort of difficulty arises in connection with the presence of serum-like antigens in other tissues of the adult and the developing embryo.

An alternative explanation would be based on the suggestion, presented at the beginning of this paper, that many of the chemically different proteins, or other large molecular substances, of an organism may each have identical or similar antigenic determinant groups along with others that are characteristic of the particular substance. On this basis the reaction of yolk proteins with an antiserum against serum proteins would be attributed to the similarity or identity of one or more of the determinant groups. The great reduction in reactivity of the antiserum with serum proteins after absorption with yolk indicates that most of the antibodies are directed against these common antigenic structures. The remaining activity after such absorption is due to antibodies directed against determinants characteristic of the particular serum proteins. However, it should be emphasized again that even such absorbed sera do not necessarily detect the particular 
protein against which they were originally produced but rather certain determinant groups. Thus statements as to the time of detection of various proteins during development must be qualified to the effect that the substance is not necessarily chemically the same as that in the aclult, since the antisera identify only certain parts of the molecule. The cited experiments on the serum proteins of the chick show that the determinant groups of serum albumin are present in sufficient quantity to be detected, by the absorbed antisera employed, at about the fifth day of incubation; those of $\alpha, \beta$-globulin at about the sixth day, and those of $\gamma$-globulin at the ninth to twelfth day.

The only other detailed immuno-embryological experiments with highly purified proteins that have been so far reported are those of Ebert $(1953,1955)$ on myosin and actin. By the use of antisera made specific for cardiac myosin by absorption with skeletal myosin he has detected determinant groups of cardiac myosin in chick blastoderms in the mid-primitive streak stage, but not earlier. Tests with various portions of the blastoderm at various stages indicated that the determinant groups are detected throughout the blastoderm (perhaps confined to the epiblast) at the mid-streak stage, but become restricted in the head process and head fold stages to two lateral areas corresponding roughly to the location of potential heart-forming areas (Rawles, 1943). The determinant groups of cardiac actin (or at least one antigenic component thereof) were first detected in the head-process stage, with localization similar to that of the myosin.

There is, then, evidence that at least the determinant groups of certain proteins (if not the proteins themselves) characteristic of adult tissues or organs appear in detectable amounts prior to differentiation of the particular tissue or organ, and that their distribution may coincide with the corresponding "organ-forming" areas of the early embryo. This suggests possible causal connection with processes of determination and differentiation of various organs and tissues in the embryo, since the general features of the results obtained with lens, heart, serum proteins, etc., can be assumed to be representative of what may be found for other tissues and organs. 
In addition to the studies with purified proteins there have been a number (e.g., Flickinger and Nace, 1952; Spar, 1953; Clayton, 1953) in which antisera produced against saline extracts of early embryos have been used, after appropriate absorptions, to detect changes in antigenic composition during early development. Different stages of development and even different embryonic germ layers have thus been shown to provide extracts in which a different assortment of antigens is detectable, new antigens becoming detectable at certain stages of development and some apparently disappearing. In these, as well as in the experiments with antisera against highly purified adult substances tested against saline extracts of early embryo, there is the uncertainty as to whether or not a particular antigenic structure remains associated with a saline-soluble constituent, and as to whether or not it is available for reaction in specific absorption procedures. In studies with cellular antigens, such as those of the red blood cells (e.g., Briles et al., 1948; Miller, 1953; Yčas, 1949; cf. Irwin, 1949, 1951; Levine, 1948), the analogous question is to what extent the change in surface antigen that is detected cluring development represents a change in location rather than new synthesis.

For the immediate future the main utility of studies of the type discussed above would appear to be that they illustrate how immumological procedures may be employed to demonstrate specific chemical changes in an embryonic tissue prior to its actual differentiation. Further studies of this type, it may be hoped, will shed some light on the question of whether or not this approach will provide pertinent chemical information of some primary change occurring in embryonic tissues during the otherwise invisible process of "determination."

\section{Antibody Formation}

Many early investigators have demonstrated that the early embryo, the fetus, and even the newborn animal lack the capacity to produce antibodies (detectable.in the serum) in response to the injection of a foreign antigen ( see reviews by Needham, 1942; Beveridge and Burnet, 1946; Burnet and Fenner, 1949; 
Topley and Wilson, 1946). Even natural antibodies, such as the isoagglutinins of the human blood groups do not appear in the serum until some time after birth (see Wiener, 1943). Antibodies that are found in the newborn can be attributed to transfer from the mother through the placenta, in the case of manimals, or to the egg in the case of birds. The discovery by Levine et al. (1939, 1941) of isoimmunization of the mother by fetal cells demonstrated at the same time, dramatically, the transfer of maternal antibodies to the fetus. Experiments on immunization of the fetus in mammals would be complicated by uncertainties as to whether or not the antigen reached the maternal circulation and antibodies produced there passed back into the fetus. However, even the newborn mammal evidently lacks antibody-forming capacity as shown, for example, in experiments by Freund (1930) on rabbits. In chickens various experiments (cited by Tyler, 1955b) have shown no antibody formation before the fifteenth day of incubation and very weak if any activity at the time of hatching (cf. Wolfe and Dilks, 1948).

Correlated with this apparent lack of antibody-forming capacity is the ability of foreign tissue grafts to establish themselves in the embryo whereas they consistently fail in the adult. Lack of antibody-forming capacity has also been assumed to account for the ready growth of various viruses on membranes and tissues of chick and mammalian embryos.

It has been previously suggested (Tyler, 1955b) that the various experiments need not be interpreted as indicating inability of cells of the developing embryo to manufacture antibodies. Quite possibly the embryonic cells do produce antibodies, in response to foreign antigens, without releasing them into the fluids that are customarily tested. Since the embryo, fetus, and newborn are in a process of rapid growth it is quite conceivable that such antibodies as they might produce would remain a part of the structural proteins of the cell. Thus they would not appear in serum, or even be available for tissue-incompatibility reactions. This is consistent with experiments on cells grown in tissue culture where, for example, it has been shown that rat and mouse tissues exhibit no incompatibility in mixed cultures (Harris, 
1943), even when one of the animals has been previously immunized against tissues of the other (Grobstein and Youngner, 1949).

As far as phagocytic ability is concerned, tests have shown that this is present in the cells of all three germ layers of early (2-day) chick embryos and becomes progressively delimited to the familiar sites of the mature organism (Heine, 1936; Steinmiiller, 1937).

Not only do homoplastic and heteroplastic grafts succeed well in embryos but the foreign cells may also persist well into the adult, as illustrated in the experiments of Willier and Rawles (1940, 1944) on neural crest tissue. The same sort of persistence of foreign cells is evident in the observations of Owen (1945) on erythrocyte mosaicism of cattle twins, which can be attributed to a transfer of erythropoietic tissue from one twin to the other through the conjoined placentas, a phenomenon also recently reported to occur in human twins (Dunsford et al., 1953). Such persistence implies that the adult has become incapable of forming antibodies, or a destructive amount of antibody, against the foreign antigen introduced in the embryonic stage.

The recent remarkable experiments of Billingham, Brent, and Medawar (1953, 1955a,b, 1956) have now demonstrated such failure to react immunologically against specific antigens on the part of adult animals that had been injected with the antigen during fetal life. In particular they showed that adult mice of $C B A$ strain that had been injected in utero with tissue (chopped-up adult testis, kidney, and spleen) of $A$ strain can tolerate A strain skin grafts, whereas without such injection the typical incompatibility reaction would ensue. In chickens they accomplished the same thing by transfusing blood between embryos of different strains. They termed this phenomenon "actively acquired tolerance" to skin grafts, but it is quite clear from the earlier analyses of the incompatibility reaction that this relates to specific antibody-forming ability. They showed also that the adult lacks only ability to respond to the specific antigens that it received in fetal life, its ability to form antibodies against other antigens being unimpaired. Furthermore, if lymph nodes from a normal animal are transplanted to a tolerant animal, the latter 
can now react to a tolerated skin graft. Evidently the host's own antibody-forming cells do not respond to the antigen received in fetal life, but antibody-forming cells received from another animal (same strain) can react to antigens in the graft or elsewhere in the body.

This work has now been extended to a number of other systems. In rats it has been reported (Woodruff and Simpson, 1955) that the tolerance to skin grafts can be induced by injection with cells of the prospective donor at the day of birth. In experiments with tumor transplants, mouse Crocker sarcoma S 180 has been found to grow to large size, but not indefinitely, when implanted into rats that had been injected during fetal life with mouse tissue (Bollag, 1955). An ascites tumor of mice (6C3HED lymphosarcoma) has been gotten to grow in strains of mice in which it would ordinarily regress by injection of the 16- to 17-day fetuses with donor strain blood or tumor cells (Koprowski, 1955). In the latter experiments the tumor cells undergo a change in antigenic specificity upon growth on the tolerant, foreign strain, mouse. A great many earlier experiments particularly by Snell, Kaliss, and their co-workers (see Snell, 1952; Kaliss, 1955) have demonstrated a "conditioning the host" to tumor homografts by preinjection with various tissue (normal or tumor) homogenates or extracts. This appears to be related to the acquired tolerance phenomenon, although the effect is produced by injection of adult animals immediately prior to tumor grafting and can be produced also by injection of antisera (prepared in mice or rabbits) to donor strain mouse tissues.

Acquired tolerance is also indicated in experiments in which chick embryos have been injected with killed Salmonella pullorem and the hatched chickens later found to show marked decrease in ability to form antibodies against this antigen (Buxton, 1954). Similarly the antibody response of cattle to Trichomonas fortus (freeze-dried or acetone-dried) has been inhibited (Kerr and Robertson, 1954) by injection of this antigen into newborn calves. Specific inhibition of antibody-forming capacity has also been demonstrated by use of simpler protein antigens, such as bovine serum albumin and human serum albumin injected into rabbits 
during the first days after birth (Hanan and Oyama, 1954; Dixon and Maurer, 1955; Cinader and Dubert, 1955). The unresponsiveness persists long after the antigen becomes undetectable in the serum, although possibly persistent in the tissues, and does not affect the ability of the animal to respond to an unrelated antigen.

Billingham et al. (1955a,b, 1956) suggest that the immunological paralysis induced by large doses of pneumococcal polysaccharide (Felton, 1949) might be related to the "actively acquired tolerance." However, this seems to involve neutralization of antibody, as it is formed, by the pneumococcal polysaccharide antigen fixed in the tissues (cf. Dixon and Maurer, 1955), rather than a "central derangement of the antibody-forming capacity" as Billingham et al. describe their results. One possibility that has been suggested (Tyler, 1955b) to account for such a central derangement is that the host cells concerned in antibody formation undergo a "type-transformation" of the sort exhibited by microorganisms in response to specific DNA. The experiments with antigens such as serum albumin would rule out a direct action of specific nucleic acid, in the sense of genetic alteration of antibody-forming cells by DNA. Alternatively one might assume (as suggested on p. 350) that the embryo or newborn manufactures antibodies against foreign antigens but retains them as an integral part of the cell. As such these fixed antibodies might serve as templates (see "The Concept of Natural Auto-Antibodies," below) for the formation of antigenic structures of the type originally introduced. If cells of the adult organism have thus acquired a particular antigenic specificity they would not be expected to respond to the same antigen. Other possible interpretations have been discussed by the cited investigators in this field. Since it is still uncertain as to whether or not all the reported experiments represent the same kind of acquired tolerance and since the field is being actively explored, one may expect that current research will soon provide some of the answers.

In connection with the above-cited work it is of interest to recall some early experiments of Murphy (1914a,b). He showed that tumor tissue of a rat could grow readily in the avian embryo, but when the foreign implants were made at the time of hatch- 
ing, they were quickly destroyed. In tissue culture in chicken plasma, rat sarcoma cells grew well in the presence of adult chicken connective tissue, kidney, or liver. However, pieces of adult chicken spleen caused practically total inhibition of growth of the rat sarcoma cells. Chicken bone marrow caused a definite retardation but not so marked an inhibition as that brought about by spleen. When the combinations were made in vivo by implantation on the outer membrane of the seven-day chick embryo the results were similar, the grafted adult chicken spleen causing a rapid regression of the rat sarcoma tissue. Murphy also demonstrated that pretreatment of adult rats with sublethal total body $\mathrm{x}$-irradiation rendered the animals tolerant to implantation of mouse sarcoma. Recently Lindsley et al. (1955) have shown that a functional implant of erythropoietic cells can be established in $\mathrm{x}$-irradiated rats by injection of homologous bone marrow carrying an immunogenetic marker, and Makinodan (1956) has found that when lethally irradiated mice are injected with rat bone marrow, being thus protected from the 30-day irradiation death, the mouse red cells can be completely replaced by those of the rat.

\section{Effects of Antibodies on Development}

It is well known that antibodies produced against various kinds of cells and tissues can have a destructive action on the homologous material. Reviews of such cytotoxic activity may be found in various immunological texts (e.g., Raffel, 1953). Of more special interest would be examples of antibody action that were not necessarily lethal and led to specific alterations in development. There have been reports of stimulating effects of antisera, but these have largely lacked substantiation. One of the most noted of these is the reticulo-endothelial immune serum of Bogomolets (1943), which has been described as a veritable cure-all. While cytotoxic or inhibiting in high concentration, the serum has been claimed to be highly stimulating to cellular growth and activity in low doses. Experiments by Pomerat (1945, 1946, 1949) and others have failed to confirm the claims. A relative stimulation of growth of homologous organs was reported by Weiss (1947) in experiments in which antisera against cytolyzed adult liver or 
kidney were injected into hen's eggs at $2 \frac{1}{2}$ to 8 days of incubation. However, Weiss (1953b, 1955) more recently considered this to be due to hemorrhage caused by vascular damage rather than to specific stimulation of growth by the antisera.

Apart from the above-mentioned work, experiments on the effects of antisera on development deal with inhibitory effects. Much of the current work in this field has been summarized by Nace (1955). In most cases the antisera have been prepared against rather complex extracts, and the various inhibitory effects are not readily interpretable in specific terms. Perhaps the best examples of specific action of antisera on embryonic tissues stem from the discovery that destruction of fetal blood cells in human cases of hemolytic disease of the newborn was due to the action of an antibody produced in the mother in response to isoimmunization with fetal antigen (Levine and Stetson, 1939; Levine et al., 1941). This discovery has led to the identification of a large number of human blood cell antigens (see Levine, 1954) in addition to the now well-known Rh factor (Landsteiner and Wiener, 1940) and its variants that were concerned in the original observations. The action of the antisera is evidently specifically on the fetal red cells, other clinical and pathological features of the disease being referable to blood cell destruction (Levine et al., 1941). This is, then, a selective action of an antiserum on a tissue of the developing organism and one in which much is known, at least genetically, about the particular antigens involved. Unfortunately embryological studies in this field have not kept pace with the genetic, ethnological, and technical advances. This is understandable by virtue of the relative inaccessibility of the material. The Rh factor has been demonstrated in a 5-cm fetus (Stratton, 1943; cf. Levine, 1948). However, the effects of isoimmunization appear to be exerted on the almost fully developed fetus or on the newborn infant. There is, of course, uncertainty as to just when the antibodies are produced and reach the fetus in effective concentration. Experiments with lower mammals in which similar isoimmunization has been reported (see Coombs, 1949; Kellner and Hedal, 1953) may be expected to provide more information of embryological significance. 
An example of a specific effect with an antiserum against a highly purified antigen is contained in the work of Ebert (1955). Antisera against cardiac actin when administered in ovo to chick embryos at 48 to 60 hours blocked further development of the heart and resulted in death of the embryo. With appropriately diluted antisera against saline extracts of adult chicken heart, brain, and spleen Ebert (1950) had earlier reported specific inhibitory effects on the development of the homologous organ. The more concentrated antisera gave nonspecific lethal and growthinhibitory effects even after absorption with heterologous organ extracts. Johnson and Leone (1955) report that anti-actomyosin inhibits morphogenesis of the heart in chick embryos, but the degree of specificity is not clear since there is also general inhibition of development. Antisera against lens protein have also been reported to produce specific lens damage in 6- to 8-day chick embryos (Burke et al., 1944). Experiments with antisera against saline extracts of amphibian embryos by Flickinger and Nace (1952) and by Clayton (1953) have given some indication of stage-specific inhibitory action, but the authors consider further tests necessary to establish the selectivity of the action. Nettleship (1953) reported that antisera againsi chicken whole embryo brei, when injected into the incubating egg, blocked development at the corresponding stage. For an unabsorbed antiserum of this type to produce a highly specific effect does seem surprising, and one wonders whether or not this might be due to fortuitous variation in the antibody content of the various antisera.

The experiments cited point to possible uses of antisera in modifying development in specific ways. As yet, however, they have been too limited in scope to provide information that can be used for further analysis of problems of induction and determination in early development.

\section{Inhibition of Cleavage in Sea Urchins by Specific Antisera}

The author has for many years prepared antisera against various constituents of the sperm, eggs, developing embryos, and adult tissues of sea urchins as part of a program of investigation 
of problems of fertilization and early development (cf. Tyler, $1955 \mathrm{a}, \mathrm{b})$. One aspect of this work, which has now been reported (Tyler and Brookbank, 1955; 1956a,b), will be presented here.

Antisera prepared against extracts of developing sea urchin eggs were found to block cleavage of the eggs. At first there appeared to be a stage-specific effect, antisera against eggs in early cleavage blocking early, those against later cleavage blocking later. However, this was found to be illusory, the time of cleavage block being dependent upon the strength of antiserum employed. Antisera against eggs in early stages would block at any specific later stage if appropriately diluted, and anti-late stage could block early if sufficiently strong.

Immunological literature abounds with experiments showing inhibition of cell division by action of antisera against cells of many kinds of organisms. In the field of cancer research this is an especially active line of investigation, the efforts being directed toward the production of antisera that act specifically on the tumor cells and not on normal tissue cells. Various types of material ranging from whole tissue homogenates to washed particulate or viral suspensions have been used as antigens, and inhibitory effects of the antisera have been described in in vitro and in vivo experiments. This work cannot be reviewed here, but for purpose of reference to some of the investigations in this field may be cited experiments and reviews by Woglom (1929), Lumsden (1937), Phelps (1937), Sigurdsson (1942), Spencer (1942), Kidd (1946), Green (1946), Dulaney and Arnesen (1949), Law and Malmgren (1951), Barrett (1952), Werder et al. (1952), Hauschka (1952), Nungester and Fisher (1954), Imagawa et al. (1954a,b), and Mountain (1955).

A new feature of the present work is that the inhibition of cell division can be obtained with an antiserum produced against a chemically rather well-defined constituent, namely the substance of the gelatinous coat of the egg, known as fertilizin.

Tests of antisera produced against the various sea urchin materials showed that the fertilizin antisera were particularly effective in blocking cell division. A summary is given in Table I of the number of rabbits that produced cleavage-blocking antisera 
TABle I. Prorluction of Antisera That Block Cleavage of Eggs of Strongylocentrotus purpuratus and Lytechinus pictus (data revised 3/14/57)

No. producing antisera that block cleavage of:

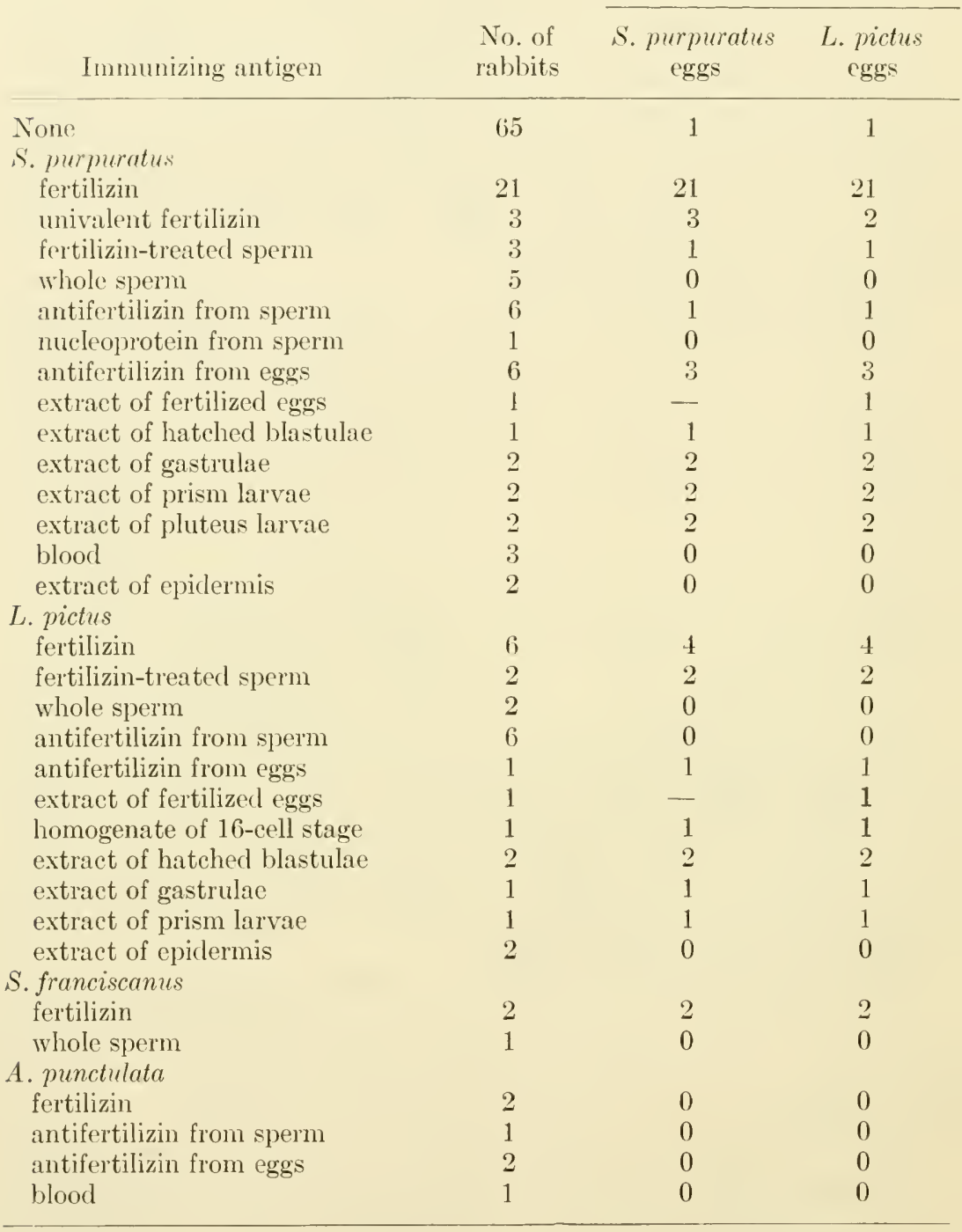


in response to immunization with various materials of four species of sea urchins. It may be noted that the fertilizin antisera are consistently effective in this respect and that they are cross reactive among three of the species used (S. purpuratus, L. pictus, and S. franciscanus), but possibly not with the fourth (A. punctulata). In control sera, cleavage and development generally proceeded normally to swimming late blastula or early gastrula stage.

Details of the results with the various antisera cannot be given here. It may be noted, however, that the listing in Table I refers to antisera that blocked cleavage effectively within the space of one division after treatment. Some of the antisera gave retardation of cleavage and cessation of development at a late cleavage stage. The majority of the nonblocking antisera permitted development to proceed apace with the controls.

The absorption with whole sperm, of blocking antisera produced against fertilizin or extracts of fertilized eggs, does not remove the cleavage-blocking effect (Table II). However, an antiserum against sperm extract (antifertilizin) that had retarding action lost this property upon absorption with whole sperm.

TABLE II. Absorption of Cleavage-Blocking Antisera

Antiserum vs.

Absorbed with

Cleavage block

S. purpuratus

fertilizin

fertilizin

fertilizin

fertilizin

L. pictus

fertilizin

fertilizin

unfertilized eggs

unfertilized eggs

unfertilized eggs

fertilized eggs

fertilized eggs

16-cell stage

16-cell stage

16-cell stage

antifertilizin

antifertilizin

S. purpuratus fertilizin

S. purpuratus sperm

L. pictus sperm

L. pictus sperm

L. pictus sperm

L. pictus fertilized eggs

L. pictus sperm

$+$

$+$

$+$

$+$

-

L. pictus 16-cell stage

S. purpuratus sperm

L. pictus sperm 
In the performance of the tests of inhibition of cleavage the gelatinous coat (fertilizin) and fertilization membrane of the egg are generally first removed before addition of the antiserum. The antisera also act, but usually much more slowly, on eggs that have not been so clenuded. It appears, then, that the surface of the denuded egg possesses antigenic groups similar to those of the fertilizin molecule. Further discussion and evidence for the fertilizin-like nature of the surface of the denuded egg is given in the report by Tyler, Monroy, and Metz (1956; see also Metz, this volume) on the refertilizability of denuded fertilized eggs.

When hatched blastulae or gastrulae are placed in antisera against fertilizin they become immediately immobilized, their further development is inhibited, and they presently cytolyze. Evidently surface antigens of the uncleaved egg persist until these stages in sufficient amount to produce cytotoxic effects upon reaction with the antisera. As noted above (p. 345), there are reports (Perlmann and Gustafson, 1948; Perlmann, 1953; Harding et al., 1954) also of new antigens being detected at the gastrula stage of sea urchins, but it is not known whether or not these are surface antigens.

Nuclear as well as cytoplasmic division is blocked by antisera against fertilizin. Division is not blocked at any particular stage of mitosis, and the amount of mitotic progress made depends on the strength of the antiserum. In the most effective antisera (vs. fertilizin) this amounts to about 15 minutes, or about one-fourth to one-sixth of the first division time for L. pictus and S. purpuratus respectively. Treatment as short as 15 to 30 minutes in strong antiserum can block cell division irreversibly. With shorter exposures the eggs can resume development. Cleavage block is effected without other visible signs of damage being at first evident, but after several hours exposure to the antiserum cytolytic changes are observed (Fig. 2). Complement is evidently not necessary for the action since heating the antisera at $56^{\circ} \mathrm{C}$ for one hour does not destroy the cleavage-blocking activity. A marked temporary rise in respiratory rate occurs in eggs treated with blocking antisera. Determinations of sodium content have been made on the supposition that the treatment may have permitted 

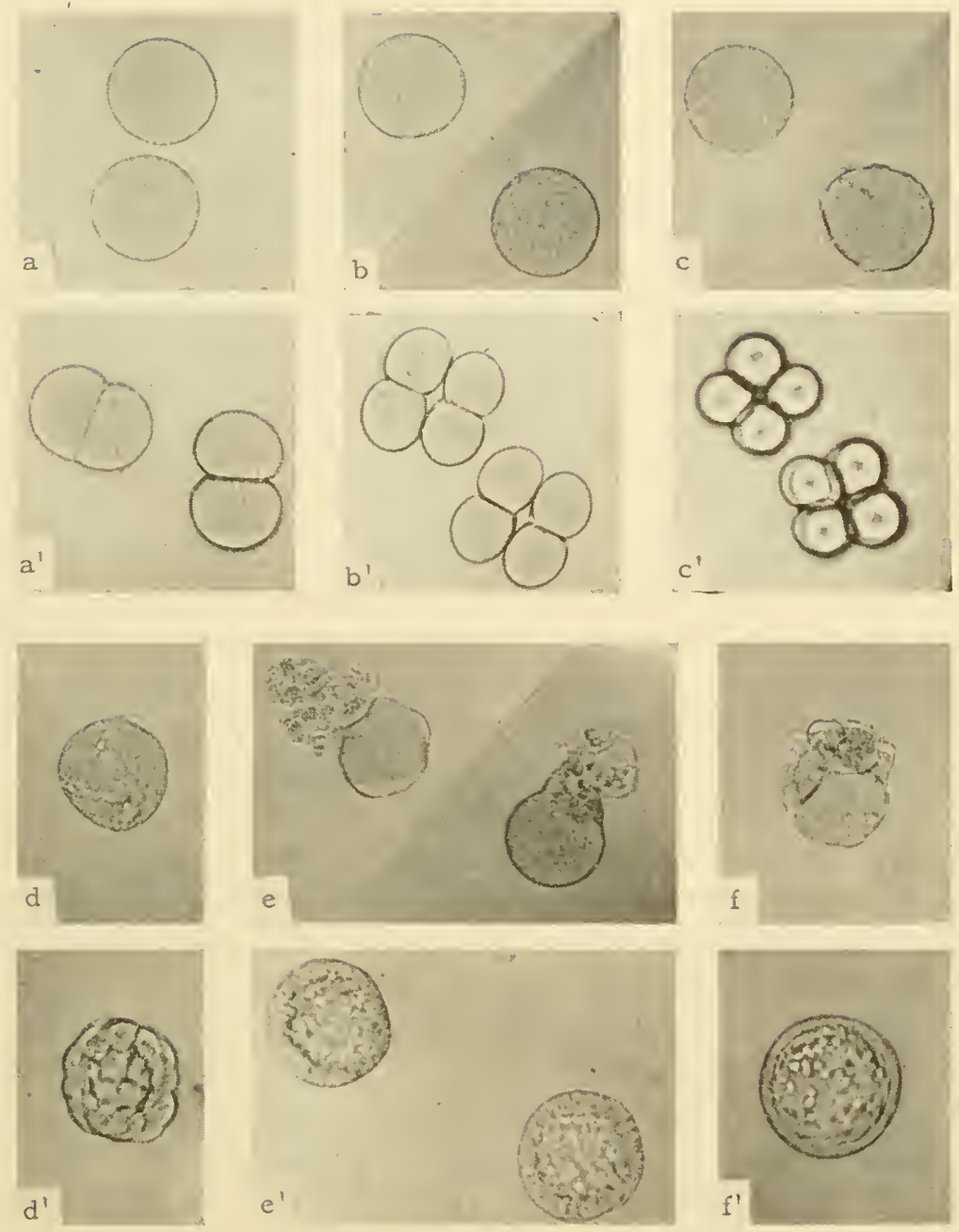

Fig. 2. Inhibition of cleavage of demembranated, fertilized eggs of the sea urchin Lytechimus pictus by treatment with a rabbit antiserum against fertilizin of Strongylocentrotus purpuratus. Figures 2a to f are of eggs in antiserum. Figures $2 a^{\prime}$ to $f^{\prime}$ are of eggs in control serum. The eggs were placed in the antiserum and control serum at $10 \mathrm{~min}$ after insemination and photographs taken at following times (at $17^{\circ} \mathrm{C}$ ) after fertilization: a, a', 2 hr; b,b', 21/2 hr; c,c', 3 hr; d,d', 41/2 hr; e,e', 6 hr; f,f', 24 hr. Magnification, $100 \times$. 
entry of this ion which is normally in very low concentration inside the cell. However, no significant increase was found. Determinations were also made of the relative tension at the surface of untreated and treated eggs, by the method of separating the egg into light and heavy halves by centrifugal force. An increase, estimated as approximately $40 \%$, was found in the treated eggs.

Of special interest in this work is the fact that highly effective antisera are produced by immunization with fertilizin, since much is known concerning the chemical and biological properties of this substance (cf. Tyler, 1948, 1949, 1955a,b, 1956b; Runnström, 1949, Vasseur, 1948, 1952). The fertilizins of sea urchins are obtainable in a form that is electrophoretically and ultracentrifugally homogeneous, and whose purity is further evidenced by the effective removal of nitrogen-containing substance upon absorption with homologous sperm. Molecular weight determination give a value of about 280,000 for the fertilizin of Arbacia punctulata, and fertilizins of other species are in the same range as judged from their sedimentation constants (Tyler, 1956b). The molecule is highly elongate (axial ratio of about 20:1, calculated as a prolate ellipsoid with 0.4 gram of water of hydration per gram ), which is consistent with its gel-forming properties. Chemically, sea urchin fertilizins belong to that class of sugar- and amino acid-containing substances termed glycoproteins or mucopolysaccharides. In several species of sea urchins that have been examined there are two kinds of sugars and 14 kinds of amino acids in the molecule, and the content of the two kinds of residues is approximately the same. Knowledge of the composition of the fertilizins should prove useful in investigation of the determinant groups that are involved in the production of the cleavage-blocking antisera.

Experiments on the biological properties of fertilizin have led to the view (cf. Tyler, 1955a; Tyler and Metz, 1955) that it represents the specific receptor substance for the union of egg and sperm in fertilization and is largely responsible for the tissue and species specificity of the process. When unfertilized eggs are treated with antisera against fertilizin, they lose their fertilizability. This, however, does not necessarily mean that the antibodies 
are directed against the particular molecular sites that are concerned in the fertilization reaction. The presence of antibody on the surface, due to reaction with determinants at neighboring sites, could suffice to prevent effective interaction between the fertilizin of the egg surface and antifertilizin of the sperm.

The fact that, in sea urchins, a cell division-blocking antiserum can be produced by immunization with a surface constituent of the cell suggests that this may be possible with various types of cells of other animals. Some recent experiments of Billingham and Sparrow (1955) may be interpreted as pointing in this direction. These investigators injected saline washings of dissociated epıdermal cells from one rabbit intradermally into another. When skin grafts were subsequently attempted from the former to the latter, the accelerated incompatibility reaction, typical of an immunized animal, was exhibited. It seems likely that the washings contained primarily, or solely, surface constituents of the cells, and that these served as the effective antigens. In the cited experiments no in vitro tests were made of possible cytotoxic action of the serum of the immunized animal on donor cells, but earlier experiments by Billingham and Sparrow (1954) showed that treatment of the dissociated cells with the serum of an animal that had been immunized by attempted skin graft can completely or partially prevent the cells from giving rise to epithelium upon grafting. They hesitate to term this cytotoxic action since no cytolytic effects were observed on the serum-treated cells. However, there was evidently a specific effect of the antibodies that rendered the cells susceptible to early disintegration upon transplantation.

It seems reasonable to expect, then, that antigens effective in engendering the production of specific cytopathogenic sera may be prepared from various kinds of tissues, normal and neoplastic, by extraction of surface constituents. Such extracts, obtained by mild extraction methods, would contain a less complex mixture of substances than obtained by the usual homogenization procedures that are employed. Possibly in some cases preparations containing a single chemical constituent could be readily obtained, as is the case with sea urchin eggs. The current trend, particularly 
in the field of cancer research, is toward the use of various sedimentable particles obtained from cell homogenates as immunizing antigens for the production of cytotoxic antisera. One would expect, however, that the likelihood of obtaining tissue-specific antisera would be greater if simpler antigenic preparations were employed. In any case the present experiments warrant an exploration of the effectiveness of mild procedures, tending to extract surface constituents, for the preparation of immunizing antigens for use in the study of problems of malignant growth as well as in problems of normal development.

\section{The Concept of Natural Auto-Antibodies}

During the earlier investigations by the author on the location of fertilizin in the egg, an antifertilizin was extracted from below the surface of the egg (Tyler, 1940), after the fertilizin had been found to be the material of the gelatinous coat of the egg. This antifertilizin behaved like antifertilizin derived from sperm, in neutralizing fertilizin, agglutinating a suspension of eggs, forming a precipitation membrane on the surface of the gelatinous coat, etc. Since the interaction of fertilizin and antifertilizin is considered analogous to that of antigen and antibody, this finding indicated that two substances capable of interacting in that manner could be extracted from a single cell. Various reports on auto-antibodies in the immumological literature could be similarly interpreted as indicating the existence of mutually complementary substances in the same cell or tissue. It was therefore proposed that this situation is a general feature of living cells and that it might provide a basis for interpretation and further investigation of specific immunological problems and of problems of growth and differentiation (Tyler, 1942, 1947, 1955b). A somewhat similar concept of mutually interacting complementary substances being involved in processes of growth and differentiation has been developed by Weiss (1947, 1949, 1950, 195.5).

The term auto-antibody concept was used to lend emphasis to the iclea that each of the various macromolecular substances of which cells are constructed bears the same sort of relation to another of these substances as do antigen and antibody, and they 
are formed by processes analogous to antibody formation. In fact, the formation of immune antibodies is considered a special variation of a process that occurs normally without the intervention of a foreign antigen (cf. Tyler, 1947, 1948, 1955b). For immune antibody formation it is now quite generally assumed, in accord with the views proposed by Breinl and Haurowitz (1930), Alexander (1932), Mudd (1932), and Pauling (1940), that foreign antigen becomes incorporated in the site of synthesis of serum globulin, so that, as molecules of the latter are formed, they will bear regional surface configurations complementary to specific structures on the antigen that serves as a template. If one considers the situation in the absence of foreign antigen, one may conclude that normal globulin is complementary in structure to whatever specific substances comprise the normal site of synthesis. The auto-antibody concept assumes in addition that this mode of origin is general for the formation of all macromolecular constituents of cells. Pauling and Delbrïck (1940, cf. Pauling, 1955 ) and Emerson (1945) have shown how this process may be involved also in gene duplication.

Examples of the extraction of antigen-antibody-like systems of mutually complementary substances from cells have been previously presented (Tyler, 1940, 1947, 1955b), but these are not as yet very numerous. Experimentally there are difficulties that may well depend upon mutual neutralization during extraction procedures, particularly where these involve destruction of the cells, and on lack of suitable testing methods in the event the substances are of the nonprecipitating ("univalent") type (cf. Tyler, 1945, Tyler, Fiset, and Coombs, 1954). There are also indications that natural auto-antibodies may have the ability of immune antibodies to act as protective agents, as illustrated by experiments on the neutralization of the venom of the Gila monster by serum of the same animal (Tyler, 1946, 1956a).

One of the suggested applications of the auto-antibody concept was to problems of the specific adhesion of cells in the formation of tissues. For these, useful experimental material was evident in the experiments on the reconstitution of sponges from dissociated cells (Wilson, 1907, 1932) and the interactions of dissociated 
cells of amphibian embryos (Holtfreter, 1943, 1948). Experiments along this line have since been performed by Spiegel (1954a,b, 1955) on sponges and frog embryos. By use of antisera he has been able to interfere with the reaggregation process in such a way as to indicate a role of specific surface antigens.

A striking recent example of specific interaction of cells is given in the experiments by Weiss and Andres (1952) who showed that presumptive melanoblasts of dissociated embryonic chick cell suspensions when injected into the blood stream of early

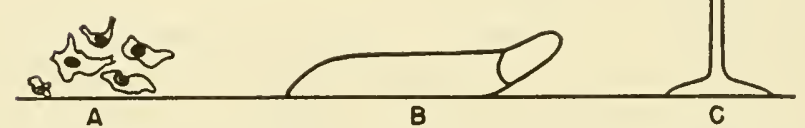

Fig. 3. Diagram illustrating the aggregation of vegetative amoebae (A) of Dictyostelium into a pseudoplasmodium (B) and transformation of the latter into the sorocarp. (From Gregg et al., 1954.)

chick embryos localized in the proper regions characteristic of the cell type and of the donor strain. Other examples may be found in experiments on type-specific reaggregation and differentiation of dissociated embryonic cells in mixed cultures, as in the experiments of Trinkaus and Groves (1955) and of Moscona (1956) on mixed mesonephric and limb-bud cells of the chick embryo, and of Townes and Holtfreter (1955) on mixed aggregates of amphibian gastrula and neurula cells.

Another kind of material, the slime mold Dictyostelium, has been investigated recently by J. H. Gregg (1956). In this organism individual amoebae aggregate to form a cell mass which undergoes further morphogenetic change (Fig. 3). With three spe- 


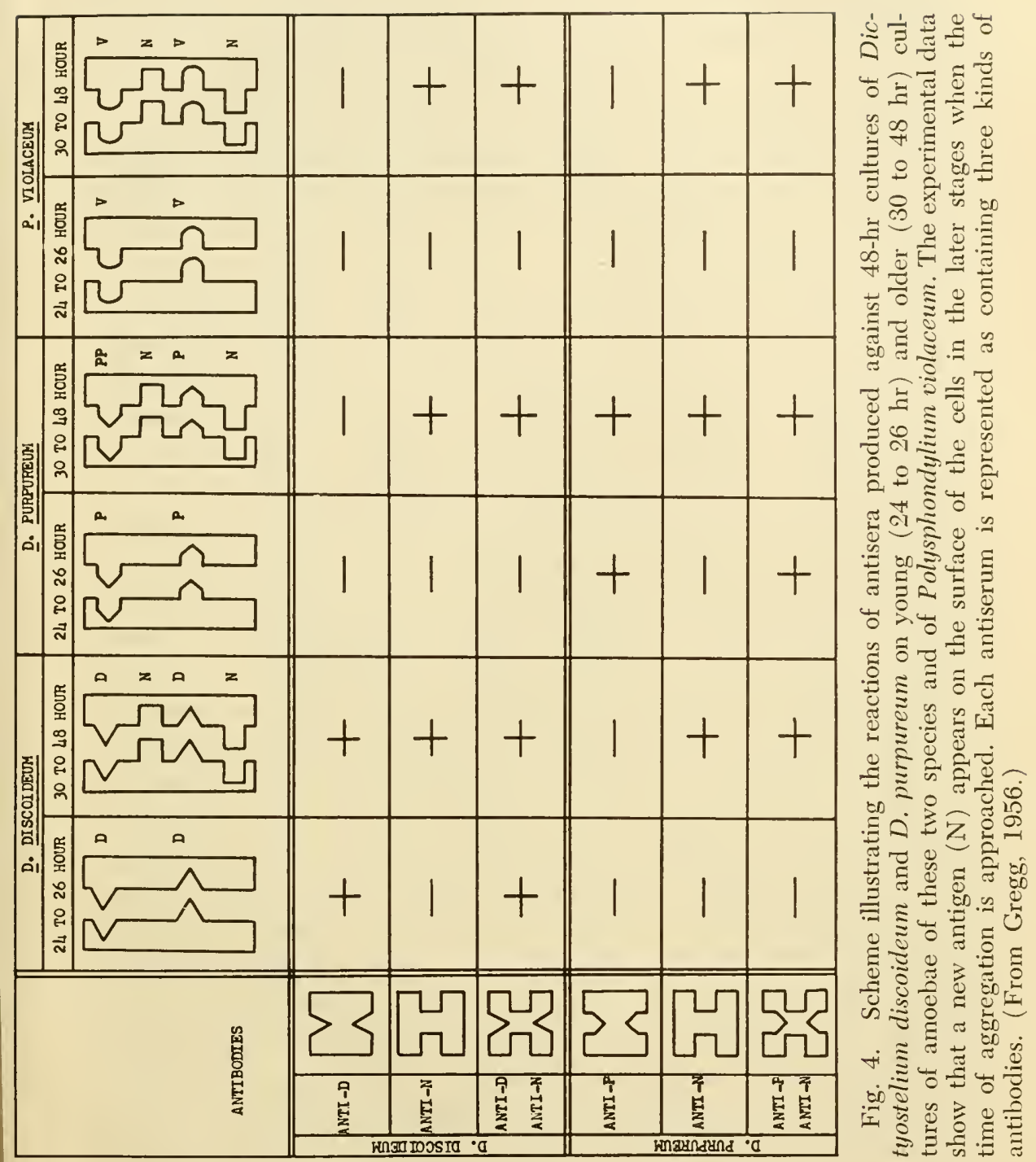


cies of slime molds Gregg showed that new surface antigens (as illustrated in Fig. 4) are detected as the time of aggregation is approached. Again one cannot conclude that the antigenic structures that are detected by the antibodies are necessarily the same as those actually concerned in the cell adhesion. However, the antisera have revealed a specific change in cell surface structure correlating with the aggregation phenomenon. It can be expected that this work will lead to extraction and characterization of the specific substances involved.

Since the previous discussion (Tyler, 1947) of the relation of the auto-antibody concept to problems of embryonic differentiation there have been a few pertinent, if not critical, experiments on the subject. Mention was made on p. 348 of work showing the detection of specific adult tissue antigens at stages prior to visible differentiation. Their time of origin (or increase to detectable amounts) correlates in some cases with the time that the embryonic tissue becomes "determined." In one particular case, lens protein, experimental induction of the antigen has been reported (Woerdeman, 1953a,b, 1955) through action of optic vesicle extract on extracts of competent ectoderm.

More particularly the question may be raised as to whether or not processes of induction and determination can be influenced in specific fashion by substances that can also be described as natural auto-antibodies, extractable from the same organism. There is, as yet, no direct experimental evidence concerning this, nor, for that matter, concerning possible specific action of immune antibodies on these processes. As noted above the work with immune antisera has, so far, related to cytotoxic or generally lethal effects in which action on specific developmental processes are not immediately evident. Changes in cell type would be one of the effects one might seek to obtain. Such changes have been frequently described in experiments with microorganisms grown in immune sera (cf. Dubos, 1946), although it is often uncertain to what extent this is due to selection of variants not inhibited by the antibodies. Selection is not involved in the experiments on Paramecium by Sonneborn (1948, 1950; cf. Beale, 1952) who showed the induction of changes in antigenicity by means of 
homologous antisera. The transformations also occur in response to certain nonspecific environmental (temperature, $\mathrm{pH}$, etc.) changes. It would be of interest to know whether or not they could be produced by specific cell extracts.

In experiments on frog embryos Rose $(1952,1955)$ reported specific inhibition (mostly temporary) of the differentiation of blood, brain, and heart by culturing the embryos in the presence of the homologous tissue or extracts thereof. On the other hand, somewhat similar experiments with chick embryos by Ebert (1955) showed no inhibition of the development of the spleen in response either to transplantation of spleen from the hatched chick or to injection of homogenates of adult spleen. Some time ago several workers (Murphy, 1916; Danchakoff, 1916, 1918; Willier, 1924) reported that chorioallantoic grafts of adult chicken spleen caused an enlargement of the spleen of the host embryo. Ebert (1951, 1952, 1954) investigated this effect in considerable cletail and employed also ingenions experiments with radioactively labeled material. He has shown that the effect is class specific and quantitatively tissue specific. The effect first appears with spleens taken from embryos of about 14 days incubation and increases with age of the donor. Although certain splenic antigens are first detected at 14 days of incubation Ebert does not consider his experiments to demonstrate that any one of these is the effective agent. With $S^{3 \pi}$-labeled spleens and kidneys he has shown a specific transfer of raclioactivity from the graft to the homologous organ, which was evidently not due to transfer and localization of cells, as might have been suspected from the experiments of Weiss and Andres (1952). From the quantities transferred and other considerations, Ebert (1955) concluded that the results favor a "building block" rather than a "template" or catalytic mechanism and that the material transferred is of the nature of whole, specific splenic, protein molecules or large fragments thereof. The experiments pertain, then, more particularly to growth rather than differentiation.

Grobstein (1955) has recently reviewed his experiments on specific inductive effects between embryonic mammalian tissues separated by filters whose porosity excludes massive cell contacts. 
He suggested that intercellular matrices may play an important part in the inductions, and (Grobstein, 1955, p. 252) that one way in which the matrices might interact is by "molecular complementariness, as has been suggested by Weiss (1947) and Tyler (1947) for cell surfaces." He emphasized, however, that there are many possible interpretations of the mechanism of the inductive effects. Again the lack of direct information as to the nature of the specific substances involved precludes further speculation with respect to the auto-antibody concept.

In general, while there are suggestions that interactions of the type envisioned in the auto-antibody concept may have a causal connection with processes of induction and determination, direct evidence of this is still lacking.

\section{Summary}

This paper is mainly a review of recent immuno-embryological studies of various investigators, dealing with the detection in the embryo of specific antigens of adult tissues, changes in antigenicity during development, development of antibody-forming capacity, and effects of antibodies on development. These topics are discussed in relation to an auto-antibody concept developed by the author. It contains also results of certain current experiments, by the author and his co-workers, in which it has been found that cell division in the early development of eggs of sea urchins can be blocked by antisera prepared against fertilizin. These experiments represent the first, to the author's knowledge, in which a block to cell division has been obtained with antisera prepared against a chemically well-defined antigen.

\section{REFERENCES}

Alexander, J. 1932. Some intracellular aspects on life and disease. Protoplasma, 14, 296-306.

Barrett, M. K. 1952. Some immunogenetic influences upon transplanted tumors. Cancer Research, 12, 535-42.

Beale, G. H. 1952. Antigen variation in Paramecium aurelia Var. 1. Genetics, 37, 62-74. 
Beveridge, W. I. B., and F. M. Burnet. 1946. The cultivation of viruses and rickettsiae in the chick embryo. Med. Research Council, Spec. Rept. Ser. No. 256, pp. 1-92. H. M. Stationery Office, London.

Billingham, R. E., L. Brent, and P. B. Medawar. 1953. "Actively acquired tolerance" of foreign cells. Nature, 172, 603-6.

Billingham, R. E., L. Brent, and P. B. Medawar. 1955a. Acquired tolerance of skin homografts. Ann. N. Y. Acad. Sci., 59, 409-16.

Billingham, R. E., L. Brent, and P. B. Medawar. 1955b. Tolerance of red cell antigens and transplantation immunity in chickens. Experientia, 11, 444.

Billingham, R. E., L. Brent, and P. B. Medawar. 1956. Quantitative studies on tissue transplantation immunity III. Actively acquired tolerance. Philosoph. Trans. Roy. Soc. (London), B239, 357-414.

Billingham, R. E., and Elizabeth M. Sparrow. 1954. Studies on the nature of immunity to homologous skin grafts, with special reference to the use of pure epidermal grafts. J. Exptl. Biol., 31, 16-39.

Billingham, R. E., and Elizabeth M. Sparrow. 1955. The effect of prior intravenous injections of dissociated epidermal cells and blood on the survival of skin homografts in rabbits. J. Embryol. Exptl. Morphol., 3, 265-85.

Bogomolets, A. A. 1943. Antireticular cytotoxic serum as a means of pathogenic therapy. Am. Rev. Soviet Med., 1, 101-12.

Bollag, W. 1955. Heterologe Transplantation von Tumoren bei Vorbehandlung der Empfängertiere mit Gewebe der Spendertiere während der Embryonalzeit. Experientia, 11, 227-77.

Breinl, F., and F. Haurowitz. 1930. Chemische Untersuchung des Praezipitates aus Hämoglobin und Anti-Hämoglobin-Serum und Bemerkungen über die Natur der Antikörper. Z. physiol. Chem., 192, $45-57$.

Briles, WV. E., W. H. McGiblon, and M. R. Irwin. 1948. Studies of the time of development of cellular antigens in the chicken. Genetics, $33,97$.

Burke, Victor, N. P. Sullivan, Helen Petersen, and Ruth Weed. 1944. Ontogenetic change in antigenic specificity of the organs of the chick. J. Infectious Diseases, 74, 225-33.

Burnet, F. M., and F. Fenner. 1949. Production of Antibodies, 2nd ed. Macmillan \& Co. Ltd., London.

Buxton, A. 1954. Antibody production in avian embryos and young chicks. J. Gen. Microbiol., 10, 398-410. 
Chernoff, A. I. 1953. Immunologic studies of hemoglobin. Blood, 8, 399-421.

Cinader, B., and J. M. Dubert. 1955. Acquired immune tolerance to human albumin and the response to subsequent injections of diazo human albumin. Brit. J. Exptl. Pathol., 36, 515-29.

Clayton, R. M. 1953. Distribution of antigens in the developing newt. J. Embryol. Exptl. Morphol., 1, 25-42.

Cohn, M., L. R. Wetter, and H. F. Deutsch. 1949. Immunological stuclies on egg white proteins. I. Precipitation of chicken-ovalbumin and conalbumin by rabbit- and horse-antisera. J. Immunol., 61, 283-96.

Coombs, R. R. A. 1949. Discussion: Haemolytic disease of the newborn. Proc. Roy. Soc. Med., 43, 347-50.

Cooper, Ruth S. 1946. Adult antigens (or specific combining groups) in the egg, embryo, and larva of the frog. J. Exptl. Zool., 101, 14372.

Cooper, Ruth S. 1948. A study of frog egg antigens with serum-like reactive groups. J. Exptl. Zool., 107, 397-438.

Cooper, Ruth S. 1950. Antigens of frog embryos and of achult frog serum studied by diffusion of antigens into agar columns containing antisera. J. Exptl. Zool., 114, 403-20.

Danchakoff, V. 1916. Equivalence of different hematopoietic anlagen (by method of stimulation of their stem cells). Am. J. Anat., 20, 255-327.

Danchakoff, V. 1918. Equivalence of different hematopoietic anlagen (by method of stimulation of their stem cells). II. Grafts of spleen on the allantois and response of the allantoic tissues. Am. J. Anat., $24,127-89$.

Dixon, F. J., and P. H. Maurer. 1955. Immunologic unresponsiveness induced by protein antigens. J. Exptl. Med., 101, 245-57.

Dubos, R. J. 1946. The Bacterial Cell. Harvard University Press, Cambridge, Mass.

Dulaney, A. D., and K. Arnesen. 1949. Cytotoxic action of antisera to cell components of normal and leukemic mouse spleens. Proc. Soc. Exptl. Biol. Med., 72, 665-68.

Dunsford, I., C. C. Bowley, Ann M. Hutchison, Joan S. Thompson, Ruth Sanger, and R. R. Race. 1953. A human blood group chimera. Brit. Med. J., $2,81$.

Ebert, J. D. 1950. An analysis of the effects of anti-organ sera on the development, in vitro, of the early chick blastoderm. J. Exptl. Zool., $115,351-78$. 
Ebert, J. D. 1951. Ontogenetic change in the antigenic specificity of the chick spleen. Physiol. Zool., 24, 20-41.

Ebert, J. D. 1952. Appearance of tissue-specific proteins during development. Arm. N. Y. Acad. Sci., 55, 67-84.

Ebert, J. D. 1953. An analysis of the synthesis and distribution of the contractile protein, myosin, in the development of the heart. Proc. Natl. Acad. Sci. U. S., 39, 333-44.

Ebert, J. D. 1954. The effects of chorio-allantoic transplants of adult chicken tissues on homologous tissues of the host chick embryos. Proc. Natl. Acad. Sci. U. S., 40, 337-47.

Ebert, J. D. 1955. Some aspects of protein biosynthesis in development. In Aspects of Synthesis and Order in Growth, D. Rudnick, editor. Princeton University Press, Princeton, N. J. Pages 69-112.

Emerson, S. 1945. Genetics as a tool for studying gene structure. Ann. Missouri Botan. Garden, 32, 243-49.

Felton, Lloyd D. 1949. The significance of antigen in animal tissues. J. Immunol., 61, 107-17.

Flickinger, R. A., and G. W. Nace. 1952. An investigation of proteins during the development of the amphibian embryo. Exptl. Cell Research, 3, 393-405.

Francis, G. E., W. Mulligan, and A. Wormall. 1955. The use of radioactive isotopes in immunological investigations. 9. The reactions of antisera to antigens containing multiple determinant groups. Biochem. J., 60, 370-79.

Freund, J. 1930. Influence of age upon antibody formation. J. Immunol., 18, 315-24.

Goodman, M., and D. H. Campbell. 1953. Differences in antigenic specificity of human normal adult, fetal and sickle cell anemia hemoglobin. Blood, 8, 422-33.

Green, R. G. 1946. Cytotoxic property of mouse cancer antiserum. Proc. Soc. Exptl. Biol. Mcd., 61, 113-14.

Gregg, J. H. 1956. Serological investigations of cell adhesion in the slime molds, Dictyostclium discoideum, Dictyostelium purpureum and Polysphondylium violaceum. J. Gen. Physiol., 39, 813-20.

Gregg, James H., A. L. Hackney, and J. O. Krivanek. 1954. Nitrogen metabolism of the slime mold Dictyostclium discoideum during growth and morphogenesis. Biol. Bull., 107, 226-35.

Grobstein, C. 1955. Tissue interaction in the morphogenesis of mouse embryonic rudiments in vitro. In Aspects of Synthesis and Order in 
Growth, D. Rudnick, editor. Princeton University Press, Princeton, N. J. Pages 233-256.

Grobstein, C., and J. S. Youngner. 1949. Combination of tissues from different species in flask cultures. Science, 110, 501-3.

Hanan, R. Q., and J. Oyama. 1954. Inhibition of antibody formation in mature rabbits by contact with the antigen at an early age. J. Immunol., 73, 49-53.

Harding, C. V., D. Harding, and P. Perlmann. 1954. Antigens in sea urchin hybrid embryos. Exptl. Cell Rescarch, 6, 202-10.

Harris, Morgan. 1943. The compatibility of rat and mouse cells in mixed tissue cultures. Anat. Record, 87, 107-17.

Hauschka, T. S. 1952. Immunologic aspects of cancer: A review. Cancer Research, 12, 615-33.

Heine, F. 1936. Phagozytoseversuche am Hühnerembryo. Arch. Entwicklungsmech. Organ., 134, 283-93.

Holtfreter, J. 1943. Properties and functions of the surface coat in amphibian embryos. J. Exptl. Zool., 93, 251-323.

Holtfreter, J. 1948. Significance of the cell membrane in embryonic processes. Amm. N. Y. Acad. Sci., 49, 709-60.

Imagava, D. T., J. T. Syverton, and J. J. Bittner. 1954a. The cytotoxicity of serum for mouse mammary cancer cells. I. The effects of admixture in vitro upon homoiotransplantability. Cancer Rescarch, $14,1-7$.

Imagawa, D. T., J. T. Syverton, and J. J. Bittner. 1954b. The cytotoxicity of serum for mouse mammary cancer cells. II. The effects upon cells in culture. Cancer Research, 14, 8-11.

Irwin, M. R. 1949. Immunological studies in embryology and genetics. Quart. Rev. Biol., 24, 109-23.

Irwin, M. R., 1951. Genetics and Immunology. In Genetics in the 20th Century. L. C. Dunn, editor. The Macmillan Company, New York.

Johnson, I. S., and C. A. Leone. 1955. The ontogeny of proteins of the adult chicken heart as revealed by serological techniques. J. Exptl. Zool., 130, 515-54.

Kabat, E. A., and S. Leskowitz. 1955. Immunochemical studies on blood groups. XVII. Structural units involved in blood group A and B specificity. J. Am. Chem. Soc., 77, 5159-64.

Kaliss, N. 1955. Induced alteration of the normal host-graft relationship in homotransplantation of mouse tumors. Ann. N. Y. Acad. Sci., 59, 385-93.

Kellner, A., and E. F. Hedal. 1953. Experimental erythroblastosis 
fetalis in rabbits. I. Characterization of a pair of allelic blood group factors and their specific immune isoantibodies. J. Exptl. Med., 97, 33-50.

Kellner, A., and E. F. Hedal. 1953. Experimental erythroblastosis fetalis in rabbits. II. The passage of blood group antigens and their specific isoantibodies across the placenta. J. Exptl. Med., 97, 51-60. Kerr, W. R., and M. Robertson. 1954. Passively and actively acquired antibodies for Trichomonas foetus in very young calves. J. Hyg., 52, 253-63.

Kidd, J. G. 1946. Suppression of growth of Brown-Pearce tumor cells by a specific antibody, with a consideration of the nature of the reacting cell constituent. J. Exptl. Med., 83, 227-50.

Koprowski, H. 1955. Actively acquired tolerance to a mouse tumor. Nature, 175, 1087-88.

Landsteiner, K. 1942. Serological reactivity of hydrolytic products from silk. J. Exptl. Med., 75, 269-76.

Landsteiner, K. 1947. The Specificity of Serological Reactions. (Rev. Ed.) Harvard University Press, Cambridge, Mass.

Landsteiner, K., and A. S. Wiener. 1940. An agglutinable factor in human blood recognized by immune sera for Rhesus blood. Proc. Soc. Exptl. Biol. Med., 43, 223.

Law, L. W., and R. A. Malmgren. 1951. Studies on the "cytotoxic" property of antiserum of the mammary tumor agent. J. Natl. Cancer Inst., 11, 1259-68.

Levine, P. 1948. The mechanism of transplacental isoimmunization. Blood, 3, 404-13.

Levine, P. 1954. The genetics of the never human blood factors. Advances in Genet., 6, 183-234.

Levine, P., E. M. Katzin, and L. Burnham. 1941. Isoimmunization in pregnancy. J. Am. Med. Assoc., 116, 825-27.

Levine, P., and R. E. Stetson. 1939. An unusual case of intra-group agglutination. J. Am. Med. Assoc., 113, 126-27.

Lewis, J. H. 1933. The immunologic specificity of brain tissue. J. Immunol., 24, 193-211.

Lindsley, D. L., T. T. Odell, and F. G. Tausche. 1955. Implantation of functional erythropoietic elements following total body irradiation. Proc. Soc. Exptl. Biol. Med., 90, 512-15.

Loeb, L. 1945. The Biological Basis of Individuality. Charles C Thomas, Springfield, Ill. 
Lumsden, T. 1937. On cytotoxins lethal to nucleated mammalian cells normal and malignant. Am. J. Cancer, 31, 430-40.

Maculla, E. S. 1948. The immunochemistry of mouse tissue components. III. A comparison of the antigenic composition of the embryonic mouse organs with that of adult mouse organs with mouse tumors. Yale J. Biol. and Med., 20, 465-72.

Makinodan, T. 1956. Circulating rat cells in lethally irradiated mice protected with rat bone marrow. Proc. Soc. Exptl. Biol. Med., 92, 174-79.

Miller, W. J. 1953. The time of appearance of species-specific antigens of Columba guinea in the embryos of back cross hybrids. Physiol. Zool., 26, 124-30.

Moscona, A. 1956. Development of heterotypic combinations of dissociated embryonic chick cells. Proc. Soc. Exptl. Biol. Med., 92, 41016.

Mountain, Isabel Morgan. 1955. Cytopathogenic effect of antiserum to human malignant epithelial cells (strain HeLa) on HeLa cell culture. J. Immunol., 75, 478-84.

Mudd, S. 1932. A hypothetical mechanism of antibody formation. J. Immunol., 23, 423-27.

Murply, J. B. 1914a. Factors of resistance to heteroplastic tissue-grafting. Studies in tissue specificity. III. J. Exptl. Med., 19, 513-22.

Murphy, J. B. 1914b. Heteroplastic tissue grafting effected through Roentgen-ray lymphoid destruction. J. Am. Med. Assoc., 62, 1459.

Murphy, J. B. 1916. The effect of adult chicken organ grafts on the chick embryo. J. Exptl. Med., 24, 1-6.

Nace, G. W. 1953. Serological studies of the blood of the developing chick embryo. J. Exptl. Zool., 122, 423-48.

Nace, G. W. 1955. Development in the presence of antibodies. Ann. N. Y. Acad. Sci., 60, 1038-55.

Nace, G. W., and A. M. Schechtman. 1948. Development of non-vitelloid substances in the blood of chick embryo. J. Exptl. Zool., 108, 217-34.

Needham, J. 1942. Biochemistry and Morphogenesis. Cambridge University Press, Cambridge, England.

Nettleship, A. 1953. Growth and mortality effects produced in the early chick embryo by antiserum. Proc. Soc. Exptl. Biol. Med., 84, 325-27.

Nungester, W. J., and H. Fisher. 1954. The inactivation in vivo of 
mouse lymphosarcoma 6C3HED by antibodies produced in a foreign host species. Cancer Research, 14, 284-88.

Owen, R. D. 1945. Immunogenetic consequences of vascular anastomoses between bovine twins. Science, 102, 400-1.

Pauling, L. 1940. A theory of the structure and process of formation of antibodies. J. Am. Chem. Soc., 62, 2643-57.

Pauling, L. 1955. The duplication of molecules. In Aspects of Synthesis and Order in Growth, D. Rudnick, editor. Princeton University Press, Princeton, N. J. Pages 3-14.

Pauling, L., and M. Delbrück. 1940. The nature of the intermolecular forces operative in biological processes. Science, 92, 77-79.

Perlmann, P. 1953. Soluble antigens in sea urchin gametes and developmental stages. Exptl. Cell Research, 5, 394-99.

Perlmann, P., and T. Gustafson. 1948. Antigens in the egg and early developmental stages of the sea-urchin. Experientia, 4, 481-82.

Phelps, H. J. 1937. A note on the non-specific action of so-called "anticancer serum." Am. J. Cancer, 31, 441-45.

Pomerat, C. M. 1945. Reticulo-endothelial immune serum (REIS). III. The effect of strong concentrations on the growth of Walker rat sarcoma 319 in vitro. Cancer Research, 5, 724-28.

Pomerat, C. M. 1946. A review of recent developments on reticuloendothelial immune serum (REIS). Quart. Phi Beta Pi, 42, 203-8.

Pomerat, C. M. 1949. Morphogenetic effects of spleen antigen and antibody administration to chick embryos. Exptl. Cell Research Suppl., 1, 578-81

Raffel, S. 1953. Immunity, Hypersensitivity, Serology. Appleton-Century-Crofts, New York.

Rawles, M. E. 1943. The heart-forming areas of the early chick blastoderm. Physiol. Zool., 16, 22-44.

Rose, S. M. 1952. A hierarchy of self-limiting reactions as the basis of cellular differentiation and growth control. Am. Naturalist, 86, 33754.

Rose, S. M. 1955. Specific inhibition during differentiation. Ann. N. Y. Acad. Sci., 60, 1136-53.

Runnström, J. 1949. The mechanism of fertilization in metazoa. Advances in Enzymol., 9, 241-327.

Schechtman, A. M. 1947. Antigens of early developmental stages of the chick. J. Exptl. Zool., 105, 329-48.

Schechtman, A. M. 1948. Organ antigen in the early chick embryo. Proc. Soc. Exptl. Biol. Med., 68, 263-66. 
Schechtman, A. M. 1952. Physical and chemical changes in the circulating blood. Ann. N. Y. Acad. Sci., 55, 85-98.

Schechtman, A. M. 1955. Ontogeny of the blood and related antigens and their significance for the theory of differentiation. In Biological Specificity and Growth, E. G. Butler, editor. Princeton University Press, Princeton, N. J. Pages 3-31.

Schechtman, A. M., and H. Hoffman. 1952. Serological studies of the origin of globulins in the serum of the chick embryo. J. Exptl. Zool., $120,375-90$.

Schechtman, A. M., and G. W. Nace. 1950. Development of serum proteins in the embryonic chick. Anat. Record, 106, 436.

Sigurdsson, B. 1942. A new method for demonstrating cyto-antibodies in vitro. Proc. Soc. Exptl. Biol. Med., 50, 62-66.

Snell, G. D. 1952. The immunogenetics of tumor transplantaton. Cancer Research, 12, 543-46.

Sonneborn, T. M. 1948. The determination of hereditary antigenic differences in genically identical Paramecium cells. Proc. Natl. Acad. Sci., 34, 413-18.

Sonneborn, T. M. 1950. The cytoplasm in heredity. Heredity, 4, 11-36. Spar, I. 1953. Antigenic differences among early developmental stages of Rana pipiens. J. Exptl. Zool., 123, 467-97.

Spencer, R. R. 1942. Tumor immunity. J. Natl. Cancer Inst., 2, 317-32. Spiegel, Melvin. 1954a. The role of specific surface antigens in cell adhesion. Part I. The reaggregation of sponge cells. Biol. Bull., 107, $130-48$.

Spiegel, Melvin. 1954b. The role of specific surface antigens in cell adhesion. Part II. Studies on embryonic amphibian cells. Biol. Bull., 107, 149-55.

Spiegel, Melvin. 1955. The reaggregation of dissociated sponge cells. Ann. N. Y. Acad. Sci., 60, 1056-76.

Steinmüller, O. 1937. Phagozytoseversuche am lebenden Hühnerembryo. Arch. Entwicklungsmech. Organ., 137, 13-24.

Stratton, F. 1943. Demonstration of the Rh-factor in the blood of a $48 \mathrm{~mm}$. embryo. Nature, 152, 449.

Telfer, W. H. 1954. Immunological studies of insect metamorphosis. II. The role of a sex-limited blood protein in egg formation by the Cecropia silkworm. J. Gen. Physiol., 37, 539-58.

Telfer, W. H., and C. M. Williams. 1953. Immunological studies of insect metamorphosis. I. Qualitative and quantitative description of 
the blood antigens of the Cecropia silkworm. J. Gen. Physiol., 36, 389-413.

Ten Cate, G., and W. J. Van Doorenmaalen. 1950. Analysis of the development of the eye-lens in chicken and frog embryos by means of the precipitin reaction. Koninkl. Ned. Akad. Wetenschap. Proc., $53,3-18$.

Topley, W. W. C., and G. S. Wilson. 1946. The Principles of Bacteriology and Immunity, 3d ed. Williams and Williams, Baltimore, Md. Townes, P. L., and J. Holtfreter. 1955. Directed movements and selective adhesion of embryonic amphibian cells. J. Exptl. Zool., 128, 53-120.

Trinkaus, J. P., and P. W. Groves. 1955. Differentiation in culture of mixed aggregates of dissociated tissue cells. Proc. Natl. Acad. Sci. U. S., 41, 787-95.

Tyler, A. 1940. Agglutination of sea-urchin eggs by means of a substance extracted from the eggs. Proc. Natl. Acad. Sci. U. S., 26, 24956.

Tyler, A. 1942. Specific interacting substances of eggs and sperm. Western J. Surg. Obstet. Gynecol., 50, 126-38.

Tyler, A. 1945. Conversion of agghutinins and precipitins into "univalent” (non-agglutinating or non-precipitating) antibodies by photo-dynamic irradiation of rabbit-antisera vs. pneumococci, sheepred-cells and sea urchin sperm. J. Immunol., 51, 157-72.

Tyler, A. 1946. On natural auto-antibodies as evidenced by anti-venin in serum and liver extract of the Gila monster. Proc. Natl. Acad. Sci. U. S., 32, 195-201.

Tyler, A. 1947. An auto-antibody concept of cell structure, growth and differentiation. Grouth, 10 (suppl.), 7-19.

Tyler, A. 1948. Fertilization and immunity. Physiol. Revs., 28, 180-219. Tyler, A. 1949. Properties of fertilizin and related substances of eggs and sperm of marine animals. Am. Naturalist, 83, 195-219.

Tyler, A. 1955a. Gametogenesis, fertilization and parthenogenesis. In Analysis of Development, B. H. Willier, P. A. Weiss, and V. Hamburger, editors. W. B. Saunders Company, Philadelphia, Pa. Pages 170-212.

Tyler, A. 1955b. Ontogeny of immunological properties. In Analysis of Development, B. H. Willier, P. A. Weiss, and V. Hamburger, editors. W. B. Saunders Company, Philadelphia, Pa. Pages 556-73.

Tyler, A. 1956a. An auto-antivenin in the Gila monster and its relation 
to a concept of natural auto-antibodies. In Venoms, E. E. Buckley and N. Porges, editors. American Association for the Advancement of Science, Washington, D. C.

Tyler, A. 1956b. Physico-chemical properties of the fertilizins of the sea-urchin Arbacia punctulata and the sand-dollar Echinarachnius parma. Exptl. Cell Research, 10, 377-86.

Tyler, A., and J. W. Brookbank. 1955. Inhibition of cell division in sea urchin eggs by specific antiserums. Science, 122, 881 .

Tyler, A., and J. W. Brookbank. 1956a. Antisera that block cell division in developing eggs of sea urchins. Proc. Natl. Acad. Sci. U. S., $42,304-8$.

Tyler, A., and J. W. Brookbank. 1956b. Inhibition of division and development of sea urchin eggs by antisera against fertilizin. Proc. Natl. Acad. Sci. U. S., 42, 308-13.

Tyler, A., M. L. Fiset, and R. R. A. Coombs. 1954. The agglutinating and sensitizing capacity of antisera to sheep red cells after varying degrees of photo-oxidation. Proc. Natl. Acad. Sci. U. S., 40, 736-40.

Tyler, A., and C. B. Metz. 1955. Effects of fertilizin-treatment of sperm and trypsin-treatment of eggs on homologous cross-fertilization in sea urchins. Pubbl. staz. zool. Napoli, 27, 128-45.

Tyler, A., A. Monroy, and C. B. Metz. 1956. Fertilization of fertilized sea-urchin eggs. Biol. Bull., 110, 184-95.

Uhlenhuth, P. 1903. Zur Lehre von der Untersuchung verschiedener Eiweissarten mit Hilfe verschiedener Sera. Festschr. Robert Koch, G. Fischer, Jena.

Vasseur, E. 1948. Chemical studies on the jelly coat of the sea urchin egg. Acta chem. Scand., 2, 900-13.

Vasseur, E. 1952. The Chemistry and Physiology of the Jelly Coat of the Sea-Urchin Egg. Wenner-Gren Institute for Experimental Biology, University of Stockholm, Stockholm, Sweden.

Watkins, W. M., and W. T. J. Morgan. 1955. Inhibition by simple sugars of enzymes which decompose the blood-group substances. Nature, 175, 676-77.

Weiss, P. 1947. The problem of specificity in growth and development. Yale J. Biol. and Med., 19, 235-78.

Weiss, P. 1949. Differential growth. In The Chemistry and Physiology of Growth, A. K. Parpart, editor. Princeton University Press, Princeton, N. J. Pages 135-86.

Weiss, P. 1950. The outlook in morphogenesis. Ann. Biol., 26 (10), 563-82. 
Weiss, P. 1953a. Some introductory remarks on the cellular basis of differentiation. J. Embryol. Exptl. Morphol., 1, 181-211.

Weiss, P. 1953b. Discussion: Serological methods in the study of morphogenesis. Arch. néerl. zool., 10 (Suppl. 1), 159-61.

Weiss, P. 1955. Specificity in growth control. In Biological Specificity and Growth, E. G. Butler, editor. Princeton University Press, Princeton, N. J. Pages 195-206.

Weiss, Paul, and G. Andres. 1952. Experiments on the fate of embryonic cells (chick) disseminated by the vascular route. J. Exptl. Zool., $121,449-88$.

Werder, A. A., A. Kirschbaum, E. C. MacPowell, and J. T. Syverton. 1952. The inactivation in vitro of transplantable myeloid and lymphoid mouse leukemic cells by antibodies produced in a foreign host species. Cancer Research, 12, 886-89.

Wiener, A. 1943. Blood Groups and Transfusion, 3rd ed. Charles C Thomas, Springfield, Ill.

Willier, B. H. 1924. The endocrine glands and the development of the chick. Am. J. Anat., 33, 67-103.

Willier, B. H., and M. E. Rawles. 1940. The control of feather color pattern of melanophores grafted from one embryo to another of a different breed of fowl. Physiol. Zool., 13, 177-99.

Willier, B. H., and M. E. Rawles. 1944. Genotypic control of feather color pattern as demonstrated by the effects of a sex-linked gene upon the melanophores. Genetics, 29, 309-30.

Wilson, H. V. 1907. On some phenomena of coalescence and regeneration in sponges. J. Exptl. Zool., 5, 245-58.

Wilson, H. V. 1932. Sponges and biology. Am. Naturalist, 66, 159-70.

Witebsky, E. 1929. Disponibilität und Spezifität alkohollöslicher Strukturen von Organen und bösartigen Geschwülsten. Immunitätsforsch., $62,35-73$.

Witebsky, E., N. R. Rose, and S. Shulman. 1955. Studies on organ specificity. I. The serological specificity of thyroid extracts. J. Immunol., 75, 269-81.

Woerdeman, M. W. 1950. Over de toepassing von serologische methods in de experimental embryologie. Proc. Acad. Sci. Amsterdam, 59, 5.

Woerdeman, M. W. 1953a. The differentiation of the crystalline lens. J. Embryol. Exptl. Morphol., 1, 301-5.

Woerdeman, M. W. 1953b. Serological methods in the study of morphogenesis. Arch. néerl. zool., 10 (Suppl. 1), 144-59.

Woerdeman, M. W. 1955. Immunobiological approach to some prob- 
lems of induction and differentiation. In Biologiral Specificity and Growth, E. G. Butler, editor. Princeton University Press, Princeton, N. J. Pages 33-53.

Woglom, W. H. 1929. Immunity to transplantable tumors. Cancer Revs., 4, 129, 214.

Wolfe, H. R., and E. Dilks. 194S. Precipitin production in chickens. III. The variation in the antibody response as correlated with the age of the animal. J. Immunol., 58, 245-50.

Woodruff, M. F. A., and L. O. Simpson. 1955. Induction of tolerance to skin homografts in rats by injection of cells from the prospective donor soon after birth. Brit. J. Exptl. Pathol., 36, 494-99.

Yčas, Mary K. W. 1949. Studies of the development of a normal antibody and of cellular antigens in the blood of sheep. J. Immunol., 61, 327-48. 


\section{INDEX}

Abruzzese Sgarlata, S., 300

Absorption, 343, 344

Accessory cells, see Nurse cells

Acetabularia, 215

Acrosome

cave, 137

and egg membrane lysin, 57

filament, 135

insemination filament, 161

in mammalian fertilization, 89, 122

particle, 137

physical properties, 151

reaction, $24,29,140$

Actin

antigens, 300

detection in chick blastoderms, 348

effects of antisera against, 356

Actively acquired tolerance, 3.51

Actomyosin, 304

effects of antisera against, 356

Adams, C. E., 76, 86

Adelmann, H. B., 292

Adenosine triphosphate, 251

Afzelius, B. A., 137, 138, 142

Agaraval, S. C., 265

Agglutination

calcium as aid to, 48

of eggs, 49

by fertilizin, 24, 28, 31

of mammalian sperm, 82, 88, 125

mechanism of, $25,31,53$

reversal of, 33

of sperm, 33

Agrell, I., 275, 280, 283, 284

Alden, R. A., 77

Alexander, J., 365

Alfert, M., 205

Altman's fluid, 274

Amoeba, 89, 194

passage of RNA in, 16

Amoeba discoides, 209

Amoeba proteus, 209
Amoeba sphaeronucleus, 209

Amoroso, E. C., 115

Amphibians, 86; see also Frogs

cyclopic embryos in, 292

dissociated cells of embryos, 366

eggs of, effect of enzyme-inhibition on, 337

embryos of, effects of antisera on, 356

oocyte growth curves of, 5

Amy, R. L., 191-193

Anaerobiosis

development in, 335

Andersen, D., 77

Anderson, J., 74, 126

Andres, G., 366, 369

Andrews, F., 77, 79

Animal halves dye recluction of, 279 respiration of, 278

Animal pole metabolism at, 313

Animal-vegetal axis differences in particles along, 276 gradient, 272, 279

Animalization, 272, 300

agents, 298, 302, 307, 311, 312

larvae, 291

Anophthalmia, 298

Anson, M. L., 35

Antagglutin

for sperm, 83, 88, 126

Antibodies, 341

cytotoxic activity of, 354

in developing chick, 350

developmental effects of, 345

by embryo, fetus, and newborn, 349

formation of, 365

inhibitory effects of, 355

natural, 350

stimulating effects of, 354

univalent, 55

Antifertility agents, 124, 125 
Antifertilizin, 270

from eggs, 49

extraction of, 364

from sperm, $31,36,44,52,88$

Antigen-antibody reactions, 31

Antigens, 341

bird, 345

determinants of specificity, 341

determination in relation to, 346

embryonic and adult, 344

frog, 345

of hybrids, 210

of mammals, 345

multi-haptenic antigens, 342

organ-specific, 345

of red blood cells, 300,349

salamander, 345

sea urchins, 345

serum-like, in eggs and embryo, 346,347

silkworm, 345

of spermatozoa, 93

Antisera

cross-reacting, 343

against saline extracts of embryos, 349

against serum albumin, 347

against serum globulin, 347

Apis mellifera, 177; see also Honey bee

Aplysia eggs

mitochondria in, 331

Arbacia, 139; see also Sea urchin entries

\section{Arbacia eggs}

fragments of, 265,272

mitochondria in, 268, 272

NaSCN or LiCl treatment of, 300

Arbacia lixula, 46, 49, 50, 172

fertilization of eggs of, 269

Arbacia punctulata, 27, 28, 30, 43, 47

fertilizin of, 359,362

Archenteron formation, 240

Arendsen de Wolff-Exalto, E., 299

Arnesen, K., 357

Arosio, R., 304, 305

Arsanilic acid, 342
Arvy, L., 264

Ascaris, 204, 207

Ascidia malaca

LiCl treatment of embryos, 297

Ascidian egg

centrifugation of, 323

development with blocked enzymes, 326

effect of anaerobiosis on, 335

mitochondria of, 321

Ascidians

enzymes in development of, 319

Asclell, S. A., 78

Asterias, 92, 162; see also Starfish entries

Asterias amurensis, 140, 145, 149 , 151,159

Asterias forbesii, 10, 29, 31, 147. $151,158,161,164$

Asterias glacialis, 159

Asterias pectinifera, 140, 143

Asterias rubens, 10

Asterias vulgaris, 148

Astropecten, 36

Astropecten aranciacus, 162

Astropecten scoparius, 140

Attardo, C., 330, 334

Attraction cone, 161; see also Entrance cone

Atwood, K. C., 192

Austin, C. R., 77-79, 83-92, 109$112,114-116,118-122,124$

Auto-antibodies, 364

determination and, 368

Azide, 325

Bachem, A., 191

Bachman, E., 27

Bäckström, S., 292, 313

Bacsich, P., 116

Badinez, O. S., 293

Baltus, E., 9, 10, 17

Baltzer, F., 218

Bamberger J. W., 337

Barrett, G. R., 74

Barrett, M. K., 357

Barth, L. G., 203, 245-247, 250

Bat, 76,80121 
Baylies, L. E., 79

Beale, G. H., 368

Beams, H. W., 264

Beatty, R. A., 87, 114

Beck, G. H., 74

Beermann, W., 206, 207

Beiler, J. M., 125

Benzidinperoxidase, 325

Berg, W. E., 57, 58

Berger, C. A., 204-206

Berliner, V., 79

Bernheim, F., 192

Berrill, N. J., 1, 207

Berry, R. O., 204

Beveridge, W. I. B., 349

Bielig, H. J., 24, 27, 37, 49

Billingham, R. E., 351, 353, 363

Birds, 86

derivation of yolk in eggs of, 2

Birky, C. W., Jr., 28, 29

Bishop, D. W., 46

Bishop, M. W. H., 73-74, 81-82, 88

Bithynia eggs

cytochrome oxidase in, 334

Nadi reaction in, 330

Blandau, R. J., 76-78, 87, 118-119, 122,124

Blastomeres

mitochondria in, 323

Blastula

effects of antisera on, 360

mitochondria in, 283

Blood

inhibition of differentiation of, 369

types, 345

Blood groups, 345

antigens in spermatozoa, 93

substances, 342

time of appearance of isoagglutinins, 350

Blum, H. F., 194

Bluntschli, H., 78

Bodenstein, D., 189

Body wall

mitochondrial number in, 284

Boell, E. J., 263, 278, 337

Bogomolets, A. A., 354

Bohus Jensen, A., 42
Boivin, A., 204

Bollag, W., 352

von Borstel, R. C., 187, 188, 19119.3

Bossi, J., 305

Bossu, J., 86

Boveri, T., 122, 175, 184, 204

Bowen, R. H., 89

Bowman, R. H., 87

Boyarsky, L. H., 79

Brachet, J., 4, 9, 17, 203 204, 207, $263,264,271,273,279,280$, 337

Braden, A. W. H., 76-79, 84-92, $114-116,119,120,124$

Brain

effects of antisera against, 356

extracts of, 344

inhibition of differentiation of, 369

Brandt, C. L., 194

Bratton, R. W., 81

Brauer, A., 189

Breinl, F., 365

Brent, L., 351

Briggs, R., 209-214, 216, 219-221, 223

Briles, W. E., 345, 349

Brioschi, G., 311

Brissopsis lyrifera, 45, 48

Brookbank, J. W., 357

Bruce, H. M., 86

Bull, 73, 82, 89, 123; see also Cow

Buller, A. H. R., 85

Burbank, A., 47

Burckhard, G., 121

Burgos, M. H., 135

Burke, V., 345, 356

Burnet, F. M., 93, 349

Buxton, A., 352

Byers, H. L., 40

Campbell, D. H., 345

Campbell, J. A., 81, 82

Canivenc, R., 79

Capacitation, 83, 84, 88, 112

Card, L. E., 80

Carrano, F., 330, 333 
Carstens, H. P., 75

Carter, G. S., 28, 30

Casida, L. E., 74, 79

Caspari, E., 285

Caspersson, T., 4, 18, 121, 204, 207

Cat, 77, 90

Ceas, M. P., 170, 172

Ceciclomidae, 204

Cecropia, 2

Cell division; see also Cleavage inlibition of by antisera, 356

Cells

accessory, see Nurse cells

adhesion of, 365

ciliated, particles in, 276

dissociated, 365

epiclermal, 363

erythropoietic, implants in $\mathrm{x}$-irradiated rats, 354

flask, 239

mesonephric, 366

phagocytic ability of cmbryonic, 351

secretory, mitochondria of, 319

Centrifugation

disarrangement of particles by, 292

effect on egg cells, 265

Centrosome in mammalian fertilization, 122

Cephalopod embryos, 298

Cerebratulus, 57

Chambers, R., 93, 161, 162, 165

Champy, C. 116

Chang, M. C., 76-78, 84-87, 110$112,114-117,119,123-126$

Chantrenne, H., 264

Chargaff, E., 11

Charlton, H. H., 116

Chelation of metals, see Metal binding

Chemotaxis of sperm, 26, 84, 85

Cheng, P. L., 74

Chernoff, A. I., 345

Chicken

dissociated cells of embryos, 366 effects of antisera on embryos, 356 egg-white, 343

serum, 346

Child, C. M., 189, 202, 271, 279, 312

Chimpanzee, 76

Chironomus, 206

Cholinesterase, 337

Chondriosomes, 265

Christiansen, L. K., 171

Chromatin diminution, 204

Chromosomes

constancy of number, 201

disintegration and preservation, 311

lampbrush, 207

limited, 188

in parthenogenesis, 117

in polar bodies, 115

separation of sperm-bearing, 82

somatic reduction of, 204

Cigada, L., 304, 311

Cinader, B., 353

Ciona intestinalis

LiCl treatment of embryos, 296 , 299

Citterio, P. 300, 301, 302, 305

Clayton, R. M., 345, 349, 356

Cleavage, 185

effects of granular fractions on, 269

of egg fragments, 202

inhibition of, by antisera, 356

mitochondria during, 280,282

protoplasmic clotting and, 270

Cleland, K. W., 81

Clermont, Y., 135

Clowes, G. H. A., 27

Cohen, A. I., 251

Cohn, M., 343

Collier, J. R., 29, 89

Colwin, A. L., 29, 92, 146, 148-159, 164

Colwin, L. H., 29, 92, 146, 148-159, 164

Comandon, J., 209

Complement cleavage-block and, 360 
Complementary substances extraction of, 365

Conklin, E. G., 175, 323, 324

Convergent extension, 243

Cook, J. S., 194

Coombs, R. R. A., 355, 365

Cooper, R. S., 345, 346

Cornman, 1., 27

Cortex, 268

changes in mammalian egg, 91

cytoplasm, 269

granules, 91, 268

release of calcium from, 269

Corti, C., 293

Costello, D. P., 41, 49

Cotronei, G., 292

Courrier, R., 116

Cowv, 73, 75-77, 79, 82, 89; see also Bull

Crew, F. A. E., 80

Cristae mitochondriales, 319, 321

Culex, 205

Cumulus oophorus, 87, 123

Cupps, P. F., 74, 78

Curry, H. A., 218

Cyclopy, 292, 298, 308

Cytochrome oxidase, 325

blocking of, 336

Cytofertilizin, 40, 52

rytoplasm

in determinate development, 188 incompatibility of, 183

irradiation of, 189

maintenance of specificity in, 17 nucleus relationship, 175

particles, 263, 319

synthesis, 7,17

Dalcq, A., 8, 121

Dallam, R. D., 74

D'Amelio, V., 170, 171

Dan, J. C., 29, 31, 33, 35, 38, 43, 48, $89,135,136,139-143,145$, $148,151,152,159,164$

Danchakoff, V., 369

Danielli, J. F., 209, 210

Dauzier, L., 111, 112

David, H. A., 86, 90, 91
DeBusk, A.G., 4, 16

Delavault, R., 264

Delbrück, M., 365

Denaturation, 304, 311, 312

Deoxyribonucleic acid (DNA), 177, $179,188,257,353$; see also Nucleic acid

Derrien, Y., 300

Determinant groups, $342,343,347$

Deuchar, E. M., 313

Deutsch, H. F., 343

Development

alterations in, 291

complementary substances in, 364

critical periods of, 195

determinate (mosaic), 189

determination in, 265, 291, 349

model of, 176

Dharmarajan, M., 80

Dictyostelium

effect of antisera against, 366

Differentiation

without cleavage, 278

complementary substances in, 364

cytoplasmic particles in, 270

enzymes and, 278

of oocyte, 1

primary, 277, 284

relation to genes and antigens, 346

Dilks, E., 350

Discoglossus pictus, 57, 89

Dixon, F. J., 353

DNA, see Deoxyribonucleic acid

Docton, F. L., 93

Dog, $75,76,90,91,120,123$

hyaluronidase in semen of, 123

Dohrn, P., 27, 28

Donovan, J. E., 33, 35, 38, 43, 48, 53

Doorme, J., 121

Dornfeld, E. J., 2, 3, 9

Dorsal lip

formation of, 239

Double-gradient theory, 271

Dounce, A. L., 4, 16

Drosophila, 175, 189, 191, 205, 207

Drouvillé, C., 79

Dubert, J. M., 353 
DuBois, A. M., 188

Dubos, R. J., 368

Duesberg, J. 323

Dulaney, A. D., 357

Dulbecco, R., 193

Dunsford, I., 351

Duplicitas cruciata, 298

Duran-Reynolds, F., 87

Duryee, W. R., 207

Dye reduction, 279

Ebert, J. D., 203, 222, 345, 348, 356,369

Echinarachnius parma, 46

Echinocardium cordatum, 45, 46, $137,138,140,141$

Echinochrome, 26, 27

Echinoderm

cytoplasmic particles in clevelopment, 263

Echimus esculentus, 30, 45, 46, 137

Echinus miliaris, 28, 30

Edlund, B., 83

Eggs

activation of, $23,59,89,114$

blood proteins and cytoplasm of, 2

collision frequency of, with sperm, 85,86

cross-reactions with yolk of, 346 ;

see also Yolk

granule-free fragments, 267

human, 111, 115

hyalin layer of, 40

lysins of membrane, $56,88,124$

mammalian, 110-114, 121

membranes, 56-59, 88-90, 124

mitochondria in fragments, 268

penetration by sperm, $56,82,87$,

118,124

reaction of, to mammalian spermatozoa, 89

ribonucleic acid in fragments, 264 unfertilized, 363

Egg water, 24, 125

agglutination of sperm and, 31

chemotaxis of sperm and, 26 motility of sperm and, 26

respiration of sperm and, 26,28

Eichenberger, M., 280

Elasmobranchs, 86

Elliott, I., 74

Elson, D., 11

Ely, F., 93

Emerson, S., 365

Emmens, C. W., 74

Endo, Y., 91, 269

Entodermization, 297

Entrance cone, 153, 155-159, 161162,165

Enucleation experiments, 17

Enzmann, E. U., 111, 115, 116, 121, 123

Enzymes

blocked, development with, 326

effect of, on development, 278, 319

genes and, 320

morphogenesis and, 333

proteolytic, $76,310,312$

Ephestia kïhniella, 176

Epiboly, 241

angle of, 242

Epigenesis, 346

Ernster, L., 273, 280

Errera, M., 19, 194

Erythrocyte mosaicism, 351

Estrous cycle sperm transport and, 79

Eucharis mitochondria in eggs, 332

Euglobin, 305, 309 extraction of, 302

Evans, E. I., 76, 78

Everett, N. B., 2

Exogastrulae, 292, 297

Explants, 239

Fallopian tube role in mammalian fertilization, $110,126,127$

spermatozoa in, 76, 124

Fankhauser, G., 175, 186, 202-204, 218, 220

Farinella-Ferruzza, N., 335 
Fatty acids

effects of ultraviolet radiation on, 192

Fauré-Fremiet, E., 264

Fautrez, J., 295

Fautrez-Firlefyn, N., 264

Fawcett, D. W., 135

Fekete, E., 87

Felix, K., 24

Felton, L. D., 353

Female tract, see Genital tract

Fenner, F., 93, 349

Ferguson, L. C., 93

Ferns, 26, 84, 85

Ferreri, G., 297

Ferret, 116, 121

Fertilization

acrosomes in, 89, 122

chances of, 84

effects of granular fractions on, 269

history, 109

of mammalian egg in vitro, 110

site in mammals, 78, 85, 93

specificity, 58

Fertilization cone, 92, 119, 164; see also Entrance cone

Fertilization membrane, 51 cortical granules and, 269

Fertilizin, 52, 55, 59, 88, 125, 149

amino acids in, 45

antisera against, 357, 362

axial ratio, 47

biological properties, 362

carbohydrate in, 45

chemistry of, 45-49, 362

effect of, on fertilization, 37-44

electrophoresis of, 45,47

irradiation of, 33,36

location, 362

molecular weight, 47

reactive groups, 47

source, 39

sperm agglutination and, 31-37

sperm morphology and, 29-30

sperm motility and, 26, 27, 56, 59

sperm respiration and, 26, 28, 29

sulfate in, $45-47$ surface of denuded egg and, 360 theory, 24

ultracentrifugation of, 45,47

univalent, $32,43,47$

Ficq, A., 12, 13

Fiset, M. L., 365

Fisher, H., 357

Fisher, W. D., 192

Flickinger, R. A., 345, 348, 356

Florey, H., 76

Flow birefringence, 304, 305

Fol, H., 92, 159, 161, 165

Foley, M. T., 53

Follicle

cells of, 3

fertilization in ovarian, 78

de Fonbrune, P., 209

Foote, R. H., 81

Fowl, 80: see also Chicken

Fox, S. W., 27, 39, 47-49

Francis, G. E., 342

Frank, J. A., 41, 52, 55

Freedman, A., 214

Freund, J., 350

Frogs; see also Amphibians

amino acids in blastoporal dorsal lip, 313

eggs, 264, 270, 302

embryos, vegetalized, 300, 809 , 369

Fruton, J. S., 81, 277

Fuchs, H. M., 43

Fujii, T., 73

Fundulus, 292

Furuhjelm, M., 83

Gall, J., 5, 207

Gamow, G., 4

Gastrulae

effects of antisera on, 360

mitochondria in, 276

Geigy, R., 189, 192

Geitler, L., 204, 205, 207

Genes, 346

enzymes and, 320

determination in relation to, 346

duplication, 365

transformation, 177, 179 
Genetic mosaics, see Mosaics

Genital tract capacitation, 83, 88, 112 muscular activity, $75,85,86$ spermatozoa transport in, 75-79, 85,86

Gcrm cell, 1

Gerris lateralis, 205

Gersch, M., 331

Gershenson, S. M., 207

Ghosh, D., 73

Giardina, G., 31, 46, 48, 54, 170

Giese, A. C., 194

Gila monster venom of, 365

Gilchrist, F., 114

Glaser, O., 33

Glegg, Y., 135

Glover, F. A., 79

Goldman, A. S., 191, 193

Goldstein, L., 4, 16

Golgi bodies, 264

Goodman, M., 345

Gopher, 91

Gorini, L., 312

Gowen, J. W., 186

Gradients, 270

Graff, J., 169

Grassé, P. P., 137

Gray, J., 28, 30

Graz, A. P., 73, 78

Green, E. U., 204, 210

Green, R. G., 357

Green, W. W., 79, 89

Greenberg, M., 28, 30

Gregg, J. H., 366-368

Gregg, J. R., 203, 216, 237, 240, $243,244,248,257,258$

Grell, M., 205

Gresson, R. A. P., 121

Grobstein, C., 212, 351, 370

Ground substance, 268

Groves, P. W., 366

Growth, see Development

Grundfest, H., 173

Guillermond, A., 280

Guinea pig, 77, S0, 82, 90, 115, 121

Gunn, R. M. C., 72, 73
Gustafson, 'T., 169, 263, 271, 272, 274-281, 283 284, 291, 312, $313,332,345,360$

Gut herniation, 191

Guttmacher, A. F., 78

Guyer, M. F., 210

Gynandromorph, 184

Habrobracon juglandis, 175-193

Hadorn, E., 215

Iagström, B., 26, 27, 43, 45, 50, 51, 56

Haliotus, 58

Hallez, P., 179

Hamburger, V., 278

Hamer, D., 54

Hämmerling, J., 17, 215

Hammond, J., 72, 77, 86

Hamster, 88-92; see also Mouse; Rats

Hanan, R. Q., 353

Hancock, J. L., 81, 82, 89

Hannah, A., 207

Hapten, 342

Harde, S., 40

Harding, C. V., 345, 360

Harding, D., 345, 360

Harman, J. IV., 267, 282

Harris, M., 350

Hartman, C. G., 80

Hartmann, M., 24, 26, 27, 31, 39, 49 $52,55,56,114$

Harvey, E. B., 264, 265, 267, 268, 272,277

Harvey, E. N., 268

Hasselberg, I., 278

Haurowitz, F., 365

Hauschka, T. S., 357

Hayashi, T., 28, 30

Hays, R. L., 75

Heape, W., 75, 76

Heart

effects of antisera against, 356

inhibition of differentiation of, 369

Hedal, E. F., 355

Heilbrumn, L. V., 269, 270

Heine, F., 351

Hillier, R., 268 
Helix aspersa, 264

Henschen, W., 177

Hensen, V., 86

Herman, H. A., 74

Hertwig, G., I15

Hertwig, O., 201

Hesperidin, phosphorylated, I24, 125

Heteroagglutinins, 55

Heterochromatin, 207

Hibbard, H., 57

Histones, 25, 53,

Hobermann, H. D., 169

Hoff-Jørgenson, E., 3

Hoffman, H., 345, 346

Hofmeister series, 300

Hogeboom, G. H., 10, 270, 274

Holothuria atria, 146, 152-155, 159165

Holothuria poli, 162

Holt, H., 81

Holter, H., 278

Holtfreter, J., 221, 239, 243, 277, 296,366

Homogenization, 281

Honey bee, 186, 194, 195 of Eugster, 183

Horse, 75, 125

Hörstadius, S., 162, 165, 271, 278, 279,312

Hotchkiss, R. D., 177

Howland, R. B., 189

Huggins, C., 76

Hultin, T., 42, 52-55, 169, 173

Humphries, A. A., 185

Huskins, C. L., 202, 204, 206-208

Hyaloplasm, 274

Hyaluronidase, 56, 87

inhibitors of, 87, 90, 123

in semen, 123

Imagawa, D. T., 357

Immers, J., 48

Impellizzeri, M. A., 170, 172

Incompatibility reaction, 351

Indophenol oxidase, 324, 330

Induction

effects in mammalian tissues, 369 intercellular matrices and, 370

natural auto-antibodies and, 368

Ingleman-Sunberg, A., 83

Insectivores, 76

Insects, 86

Insemination filament, see Acrosome, filament

Invagination

angle of, 241

Iodosobenzoate

treatment of embryos with, 295

Irwin, .1. R., 345, 349

Ishida, K., 121

Isoimmunization

fetal cells and, 350,355

Ivanov, E., 72

Jacobsen, C. F., 312

Jaeger, L., 203, 250

Janeselli, L., 296

Janus green, 275, 323

Jeener, R., 280

Jenkinson, J. W., 39, 295

Johnson, I. S., 356

Jones, R. M., 2

Jordon, E. S., 77

Just, E. E., 33, 37

Kabat, E. A., 342

Kaliss, N., 352

Kamen, M. D., 17

Kampschmidt, R. F., 74

Kao, C. Y., 173

Karyokinesis, see Cleavage

Kato, K., 125, 126

Kavinau, J. L., 313

Kelner, A., 193

Kellner, A., 355

Kerr, IV. R., 352

Kidd, J. G., 357

Kihlström, J. E., 83, 126

Kimball, A. W., 192

King, T., 209-214, 216, 219-221, 223

Klein, D., 240, 243, 244

Kok, J. C. N., 74

Koprowski, H., 352

Kosswig, C., 206 
Krafka, J., 116

Krauss, M., 28, 47, 57, 58

Krehbiel, R. H., 75

Kriszat, G., 52

Kuff, E., 270

Kuhn, R., 26, 27, 49

Kupelweiser, H., 139

Kurzrok, R., 87, 116

Kushner, K. F., 76, 86

Lallier, R., 293, 300, 312

Lams, H., 121

Landsteiner, K., 341, 342, 344, 355

Lansing, A., 268

Lardy, H. A., 73, 81, 82

Lavin, G. I., 264

Law, L, W., 357

Lazear, E. J., 93

Leblond, C. P., 135

Lehman, H. E., 217, 218, 220

Lehmann, F. F., 292, 330, 333

Lenicque, P., 271, 272, 274-276, 278-281, 283, 284, 320, 332

\section{Lens}

antigen, 345

effect of antisera against, 356

extract, lack of species specificity, 344

protein, 344,368

Leonard, S. L., 77, 87

Leone, C. A., 356

Leone, V., 295, 305

Lepidochitona cinerea, 145

Leskowitz, S., 342

Leuchtenberger, C., 3

Levi, G., 280

Levine, P., 349, 350, 355

Lewis, E. B., 207

Lewis, L. L., 76

Lewis, J. H., 344

Lewis, W. H., 87, 124

Lillie, F. R., 24, 26, 27, 31, 33, 37, $39,41,43,49,52,109,112$, $117,139,163,164$

Limax, 122

Limnaea

alkaline phosphatase in egg, 333

LiCl treatment of egg, 299
Lindahl, P. E., 39, 83, 88, 205, 271, $278,291,312$

Lindberg, O., 273, 280

Lindsley, D. L., 354

Lindvall, S., 52, 55, 56, 58

Lithium chloride effects of, 291

Liu, C. K., I

Lockingen, L. S., 4, 16

Loeb, J., 27, 33, 38, 39, 89

Loeb, L., 344

Loligo vulgaris, 298

Loofbourow, J. R., 191

Loos, G. M., 194

Lorch, I. J., 209

Lovelock, J. E., 74

Løvtrop, S., 257, 258

Löw, H., 50-52

Lumbricus, 137

Lumsden, T., 357

Lundblad, G., 52

Lymph nodes transplantation of, 351

Lysins, 56-59, 88-90, 124

Lytechinus pictus, 28-30, 36 antisera against fertilizin of, 359, 360

mitochondria in, 274, 283

Lytechinus variegatus, 28, 30

McClean, D., 87, 123

McGibbon, W. H., 345

McKenzie, F. F., 79

McLeod, J., 82

McShan, W. H., 79

Mackenson, O., 177

Mactra (Spisula) solidissima, 38, 43

Mactra sulcataria, 136

Mactra veneriformis, 136

Maculla, E. S., 345

Maggio, R., 31, 46, 48, 54, 173

Mahfouz, N. P., 78

Mainland, D., 121

Makino, S., 205

Makinodan, T., 354

Malhotra, S. K., 264

Malmgren, R. A., 357 
Malonate, 326

Mancuso, V, 325, 331, 334, 335

Mann, T., 72, 76, 81, 82

Mare, G. S., 77, 80

Mark, E. L., 122

Markert, C. L., 214, 215

Marshak, A., 3

Marshak, C., 3

Martin, G. J., 125

Mather, K., 222

Matthews, H., 73

Maurer, P. H., 353

Mayer, D. T., 74

Mayer, G., 79

Medawar, P. B., 351

von Medem, 24, 27, 37, 49, 57, 58

Megathura cremulata, 27, 28, 41, 49, $56,57,89$

Meiosis, see Oogenesis

Meiotic block, 184

Melanoblasts

localization of, 366

Mellita quinquiesperforata, 39, 43

Metabolism

carbohydrate utilization, 248

Embden-Meyerhof glycolysis, 81, 251

of hybrid embryos, 245

Krebs cycle, 81, 252

lactic acid production, 250

of phosphorus, 254

Warburg-Keilin hydrogen transport, 251

Metal binding, 28, 35, 51, 74

Metz, C. B., 24, 25, 27-29, 3I, 33, $35-40,42-44,46-48,50,53-$ $55,57,142,149,163,169,357$

Metz, C. W., 188, 204

Mèves, F., 139, 280, 323

Meyer, R. K., 79

Mezger-Freed, L., 256

Mickey, G. H., 205

Micromeres

ribonucleic acid in, 273

Microsomes, 265

distribution of, 330

ribonucleic acid and, 273

Millar, R., 75
Miller, F. W., 78

Miller, W. J., 345, 349

Milovanov, V. K., 73, 74, 82

Minganti, A., 46, 49, 333

Mirsky, A., 35, 169, 170, 204

Mitochondria, 264, 319

ascidian, enzymes of, 323

de novo formation, 265

differential segregation, 323

dimensions, 267, 274

distribution, 268, 330

ectodermic, 320

electron micrographs of, 275

entodermic, 320

enzymes, inhibition of, 325

fibrillar structure and, 279

gradients, 272

identification, 282

kinds, 285,320

origin, 280

preservation, 281

quantitative aspects, 279

reproduction, $32 \mathrm{I}$

secretory granules and, 279

staining of, 267, 273

structure, 319

time of function, 277

Mitosis, see Cleavage

Mizuno, T., 73

Moeller, A. N., 76, 77

Moench, G. L., 81

Money, W. L., 76

Monné, L., 40, 91

Monod, J., 222

Monotremes, 87

Monroy, A., 31, 40, 42, 44, 46-5I, $57,58,170-173,360$

Monroy-Oddo, A., 170

Montgomery, C. M., 337

Montgomery, T. H., 4

Moog, F., 263

Moore, A. B. C., 204, 258

Moore, A. R., 312

Moore, J. A., 203, 216, 236-245

Morgan, T. H., 26, 31, 201, 208

Morgan, W. T. J., 342

Moricard, R., 86, 111, 112

Mormoniella, 175 


\section{Morphogenesis}

enzymes and, 333

Morrill, J. B., 29, 31, 149, 163

Mosaics

eggs, 265, $3: 30$

genetic, 181, 194

Moscona, A., 366

Moser, F., 91, 268

Moser, H., 191

Moss sperm, 26, 84, 85

Motomura, I., 40, 51, 52, 54, 91, 268

Mountain, I. M., 357

Mouse, 76, 82, 84, 88, 116, 120, 124; see also Hamster; Rats

Mudd, S., 365

Muller, H. J., 207

Murphree, R. L., 79

Murphy, J. B., 353, 369

Muscle fibers, 311

Myosin, 304 detection in chick blastoderms, 348

Myosin antigen, 300

Mytilus, 89

Mytilus californianus, 58

Mytilus edulis, 56, 58, 136, 139, 145

Myzostoma

mitochondria in eggs, 332

Nace, G. W., 2 345-348, 355, 356

Nadi reaction, 325, 330

Nalbandov, A. V., 80

Nanney, D. L., 183

NaSCN

effects of, 291

explants treated with, 295

Nath, V., 264

Neal, W., 76

Needham, A. E., 202

Needham, J., 203, 349

Nelsen, O. E., 2, 238

Nereis, 139, 142, 163 mitochondria in eggs, 332

Nereis limbata, 24, 27, 31, 41, 49, 149

Nettleship, A., 356

Nieuwkoop, P. D., 297

Nigon, V., 264
Nile blue sulfate, 274

Nilsson, A., 83, 126

Norman, A., 192

Notochord

action of different agents on, 308 NaSCN effect on, 292, 301

Novikoff, A. B., 41, 204, 264

Noyes, R. W., 84

Nucleic acid, 191, 193, 195; see also Deoxyribose nuclcic acid; Ribonucleic acid

Nucleolus, 5

chemical properties, 10

duplicating machine and, 18

isolation of, 6

and mammalian pronuclei, 121

organizer region, 16

RNA in, 6-15

ultraviolet absorption of, 7

Nucleoprotein, 191, 193, 195

Nucleoside phosphorylase, 17

Nucleus

and cytoplasm, 175-195, 216

in determinate development, 188193

differentiation, 203-208

feulgen-negative, 188

irradiation of, 189-194, 217

synthesis in absence of, 17

transplantation, 208-221

Nungester, W. J., 357

Nurse cells, 3, 264 incorporation into eggs, 178

Odlor, D. L., 78, 87, 118, 119, 122, 124

Oettlé, A. G., 80

O’Melveny, K., 52, 55

Oocyte

DNA in, 3

effect of surrounding cells on, 2 growth, 5

nuclear changes, 3

RNA in, 4,8

role of nucleoli, in, 4

size relationships, 5

starfish, 5 
Oogenesis

Habrobracon, 177

Opossum, 76

Orlandi, A., 311

Örström, A., 173

Osmium tetroxide, 274

Owen, R. D., 351

Oxidoreductase, 325

Oxytocin, 75

Oyama, J., 353

$\mathrm{P}^{32}$, see Radiophosphorus

Paigen, K., 284

Painter, T. S., 4, 177, 205

Palade, G., 268, 276

Palazzo, F., 330, 333, 334

Pangens, 270

Panijel, J., 4, 8, 264

Pantelouris, E. M., 217, 218

Paracentrotus lividus, 45, 46, 49

Paralysis, immunological pneumococcal polysaccharide and, 353

Paramecium, 193, 368

Parat, M., 89

Parker, G. H., 76

Parkes, A. S., 87, 90, 112, 115, 125

Parmenter, C. L., 211

Parthenogenesis, mammalian, 90, $110,114,127$ polar bodies and, 115

Patiria miniata, 36, 38

Pauling, L. 365

Penners, A., 176

Pentose nucleic acid, see Nucleic acid

Perforatorium, 135, 139, 163

Perlman, P. L., 77

Perlnann, P., 169, 345, 360

Peroxidase blocking of, 336

Petricola japonica, 136

Petromyzon, 296

Phelps, H. J., 357

Phillips, R. W., 77, 79, 81, 82

Phosphatase inhibition by beryllium, 333
Phosphorylases blocking of, 336

Photoreactivation, 193-195

Physa eggs, 331, 334, 335

Pig, 75, 77

Pincus, G., 86, 87, 110, 111, 114$119,121-125$

Pirie, N. W., 87

Pitotti, M., 324, 332

Placenta transfer of antibodies through, 350

Plant sperm chemotaxis of, 26, 84

Plasmagenes, 270, 280

Plasmatic rhythm, 281, 284

Plaut, W., 4, 16

Plaut, G. W. E., 73

Pluteus mitochondria in, 276, 283

Polarity, 265

Pollister, A. WV., 204, 236, 273

Polplasma, 330

Polyploidy, 177, 204, 219, 220

Polyspermy, 77, 185 block to, $85,91,114,120$

Pomatoceros triquester, 57

Pomerat, C. M., 354

Pommerenke, W. T., 79

Popa, G., 31, 139

Porter, K. R., 263

Prechordal plate, 292

Preformation, 345

Prism larvae, 276

Pronuclei

in mammalian fertilization, 121

Protamines, 25, 53

Proteins, 192 action of different agents on, 305 basic, 25,53

changes following fertilization, 169

demolition, 307, 310, 313

denaturation, 304, 307

fibrillar, 304

globular, 302

in malformed embryos, 299, 307 
salting out method for, 300

synthesis, 273, 277, 313

turnover, 173

viscosity changes, 305

Psammechinus miliaris, 28, 30, 137

Pseudocentrotus depressus, 140

Pseudopregnancy, 79

Quinlan, J., 77, 78

Rabbit, 75, 81, 84, 89, 110, 115, 118, 123

Radioautography, 12

Radiophosphorus ( $\left.\mathrm{P}^{32}\right), 11$ localization, 16

Raffel, S., 344, 354

Rana

metabolic blocks in hybrids, 251

respiration in hybrids, 245

Rana catesbeiana, 216

Rana esculenta notochordal cells in, 292 treatment with jodosobenzoate, 295

Rana pipiens, 209, 219, 231, Shumway stages, 232

Rana sylvatica, 231 Pollister and Moore stages, 234

Ranzi, S., 291, 293-298, 300-310, 312,313

Rats, $75,76,82,84,88,115,118$ oocyte, growth curves of, 5

Raven, C. P., 299, 333

Rawles, M. E., 348, 351

Reaggregation, 366

Redenz, E., 80, 81

Reed, C. I., 191

Regulative eggs, 265 enzyme-inactivation in, 336 mitochondria in, 332

Rein, G., 121

Reindorp, E. C., 205

Reptiles, 86

Retzius, G., 135

Reverberi, G., 319, 322-324, 326, 332
Reynolds, S. R. M., 78

Rh factor, 355

Ribonucleic acid (RNA), 264; see also Nucleic acid

base content of, 10

in egg fragments, 264

functions of, 15

metabolism, 8

in micromeres, 273

and microsomes, 273

in nucleoli, 6

oocyte diameter and, 7

P32 incorporation into, 11

and protein synthesis, 273

radioisotope studies on, 11

in sea urchin embryos, 273

solubility of 7,15

synthesis of, 16

ultraviolet absorption of, 7

Ribonucleoproteins, 264

Rich, A., 4

Ries, E., 324, 331

Ris, H., 204

RNA, see Ribonucleic acid

Robertson, M., 352

Rodents, see Hamster; Mouse; Rats

Rogers, H. J., 87, 90

Rollinson, D. H. L., 81

Romalea, 205

Romanoff, A. L., 2

Romanoff, A. J., 2

Romeis, B., 280

Rose, S. M., 369

Rostand, J., 114

Rothenbuhler, W. C., 185, 186

Rothschild, Lord, 24, 26, 28-32, 56, $73,74,81,85,91,92,119,120$, $140-142,145,185$

Roux, L. L., 77, 80

Rowlands, I. W., 87, 123, 124

Rowson, L. E., 77, 79

Roy, A., 74

Rubaschkin, W., 121

Rugh, R., 115, 217

Rulon, O., 336

Runnström, J., 24, 30, 31, 39, 43, $44,47,49-53,55,56,58,59$, $91,114,269-271,291,313,362$ 
Sabellaria vulgaris, 149

Saccoglossus kowalevskii, 159, 161, 164

Salisbury, G. W., 73, 81

Salmon, 56, 73

Salmonella pullorem, 352

Sapsford, C. S., 89

Scharta11, O., 26, 27, 31, 39, 52, 55, 56

Schechtman, A. M., 345, 346

Schenk, S. L., 110

Schneider, WV. C., 270, 274

Schönmann, H., 218

Schott, R. G., 79

Schotté, O. E., 202

Schrader, F., 3

Schröder, V., 82

Schultz, J., 202, 204, 207, 222

Sciara, 188, 204

Scott Blair, G. W., 79

Sea urchin, 140, see also individual species

cytoplasmic particles in eggs, 270

effects of enzyme-blocking on eggs, 336

enzymes in development of, 278 euglobin from eggs, 305

fluoroacetate effect on eggs, 337

Golgi bodies in eggs, 264

gradients in eggs, 270

inhibition of cleavage in, 356

$\mathrm{LiCl}$ effect on embryos, 291

mitochondria at different stages of development, 264, 281, 332

p-pyruvate effect on eggs, 337

Seaweeds, 85

Seidel, F., 188

Selenite, 326

Selivanova, O. A., 82

Semen, 72-76, 80, 82, 83; see also Sperm

Seminal plasma, see Semen

Sera, see also Antisera cytopathogenic, 363 reticulo-endothelial immune, 354

Serum albumin, 347,352

Serum globulin, 347

Setlow, R. B., 191-193
Sex determination, 177

Sex substances, classification of, 2425

Shapiro, H., 116, 117

Shaver, J. R., 263, 264, 266-268, $270,273-276,281,284,313$, 333

Sheep, 76-79, 82, 90, 91, 120

Shelton, E., 281

Shengün, A., 206, 207

Shettles, L. B., 111

Shumway, W., 231

Siekevitz, P., 278

Sieve, B. F., 125

Sigurdsson, B., 357

Silk protein, 342

Simmonds, S., 81

Simpson, L. O., 352

Skreb, Miss, 194

Slautterback, D. B., 40

Slime mold

effect of antisera against, 366

Smellie, R. M. S., 11

Smiles, J., 87

Smith, A. U., 83, 93, 110, 114

Smithberg, M., 90, 120

Snell, G. D., 352

Snycler, F. F., 79

Sobotta, J., 121

Soderwall, A. L., 77

Sodium thiomalate, 293

Sonneborn, T. M., 222, 368

Sonnenblick, B. P., 177, 181, 189

Southwick, W. E., 55, 56

Spar, I., 345, 348

Sparrow, E. M., 363

Specificity

genetic, transfer of, 16

structural, RNA as carrier of, 19

Speicher, B. R., 177, 185

Spemann, H., 201, 202

Spencer, R. R., 357

Spensley, P. C., 87, 90

Sperm, see also Semen

antagglutin for, 83, 88, 126

mammalian, fertilizing capacity, 79,111

midpiece, 31 
penetration of egg by, $56,82,87$, 118,124

Spermatozoa, 135-165; see also $\mathrm{Ac}$ rosomes; Agglutination

accessory, 194

activation of, $72,80,93$

age and fertilizing capacity, 80

antigens of, 93

attachment to egg, 89

entry into egg, 153-159, 163

in female tract, 75-88, 111

metabolism of, 81,82

reacted, $140,142,163$

separation of chromosome-bearing, 82

storage of, 72,74

Spiegel, M., 366

Spiegelman, S., 17, 222

Spikes, I. D., 28, 30, 31

Spleen

effects of antisera against, 356

induced enlargement of, 369

$\mathrm{S}^{35}$-labeled, 369

Spondylus cruentus, 136

Sponges, 366

Spronk, N., 333

Stanier, R. Y., 222

Starfish, 33, 142; see also individual species

cytoplasm, RNA concentration of, 13

oocyte, 5

RNA metabolism in oocyte, 8

Starke, N. C., 76, 79, 80

Steinbach, H. B., 263

Steinitz, L. M., 202, 207

Steinmüller, O., 351

Stéréocil, 137

Stern, C., 202, 222

Stern, H., 204

Stetson, R. E., 355

Stockard, C. R., 292

Stratton, F., 355

Strauss, F., 78

Strongylocentrotus drocbachiensis, $45,46,137,138$

Strongylocentrotus franciscanus antisera against fertilizin of, 359
Strongylocentrotus pulcherrimus, 40, 140,141

Strongylocentrotus purpuratus

antisera against fertilizin of, 24 , $30,36,43,46,49,359,360$

mitochondria in, 274, 283

Succinodehydrogenase, 325

blocking of, 336

inhibitors of, 326

Superfetation, 79

Survival curve, see Ultraviolet radiation

Swann, M. M., 91, 92

Sivyer, G. I. M., 74, 123-124

Sze, L. C., 246, 250

Tafani, A., 121

Tahmisian, T., 264

Tamini, E., 295, 299

Taylor, A. C., 189

Taylor, A. N., 4

Taylor, J. H., 12, 16

Tchou-Su, M., 183

Telfer, W. H., 2, 345

Temnoplemrns hardewickii, 40

Ten Cate, G., 345

Tenrecs, 78

Tergites, 189, 191

Testis

cross reactions with, 344

Tetrahymena, 183

Thibault, C., 114-116

Thomas, L. E., 74

Thyone, 151, 162

Thyone briareus, 146, 155, 161, 163

Thyroglobulin, 344

Tiselius, A., 39, 47, 53, 55, 56, 58

Tissue culture, 350

Tissue grafts, 350, 351

Topley, W. W. C., 350

Torvik-Greb, M., 177

Tosi, L., 58

Tosic, J., 82

Totipotency, 202

Trichomonas foctıs, 352

Trimberger, G. W., 77

Trinkaus, J. P., 366

Triton, 202 
Triton cristatus, 215

Triton palmatus, 215, 217

Triturus palmatus, 218

Triturus pyrrhogaster, 216

Trout, 73

Tubifex eggs

cytochrome oxidase in, 333

mitochondria in, 330

Nadi reaction in, 332

Tumor transplants

induced tolerance to, 352

of rat in chick embryo, 353

Tung, T. C., 324

Tuzet, O., 137

Tyler, A., 2, 24, 26-31, 33, 37-58, $74,81,85,88,89,114,115$, $117,122,124,125,140-142$, $145,173,176,204,222,264$, $269,341,345,350,353,357$, $360,362,364,365,368,370$

Tyler, J. S., 47

Uhlenhuth, P., 344

Ulrich, H., 191

Ultraviolet radiation, 190-195

Unfertilized eggs, 363

Univalent substances, 365

Urbani, E., 264

Urea, effect on notochord, 295 resistance of proteins to, 310

Urechis caupo, 38

Utero-tubal junction, 77, 78

Uticla, S., 73

Vaginal plugs, 76

Vail, V. C., 76

Van Beneden, E., 86

Van Demark, N. L., 75-77

Van der Stricht, O., 121

Van Doorenmaalen, W. J., 345

Van Drimmelen, G. C., 80

Van Egmond, M., 8

Vasseur, E., 26-28, 30, 31, 38, 39, $44-48,52,53,55,56,142,362$

Vegetal halves, 278, 279

Vegetalized larvae, 291
Vegetalizing agents, 298, 302, 304, $305,307,311$

Vegetal pole, 313

Venable, T. H., 114

Vendreley, C., 204

Vendreley, R., 204

Venge, O., 111

Venom, 365

Versene, 35

Viergiver, E., 79

Vincent, IV. S., 1, 4, 5, 9-11, 13, 1517

Viruses, 350

Vogt, IV., 239

Wada, S. K., 29, 89, 135, 136, 139, $143,145,151$

Waddington, C. H., 217

Wahli, H. R., 330

Wallenfels, K., 27, 31, 39, 52, 55, 56

Walton, A., 72, 76, 82

Warbritton, V., 79

Warren, M. R., 76

Warwick, E. J., 79

Watkins, W. M., 342

Watson, J. D., 4

Watterson, R. L., 265, 268

Weismamn, A., 201, 208

Weiss, P., 222, 354, 355, 364, 366, 369,370

Werder, A. A., 357

Westman, A. A., 75

Wetter, L. R., 343

White, M. J. D., 204-206

Whiting, A. R., 185, 187

Whiting, P. W., 177, 183-185

Whitney, 76, see Evans (1933), p. 98

Wicklund, E., 30, 50, 51, 52, 91

Wiener, A., 350, 355

Wilbur, K. M., 192

Willett, E. L., 74

Willier, B. H., 351, 369

Wilson, E. B., 1, 92, 177, 201, 264, $265,271,277,280$

Wilson, G. S., 350

Wilson, H. V., 365

Wimsatt, W. A., 80 
Winters, L. M., 79

Wislocki, G. B., 78, 79

Witebsky, E., 344

Wittek, M., 4, 264

Woerdeman, M. IV., 222, 345, 368

Woglom, W. H., 357

Wolfe, H. R., 350

Wolff, S., 193

Woodruff, M. F. A., 352

Woodward, A. E., 33

Wright, E. S., 76, 87, 124

Wyburn, G. M., 116

Xenopus

reduction of animal half in embryo, 292

X-radiation, 217,354
Yamane, J., 123

Yčas, M. K. W., 4, 342, 349

Yellow crescent, 323

Yolk

absorption of antisera with, 346347

disintegration and preservation of granules, 311

formation of, 264

Young, IV. G., 77, 80

Youngner, J. S., 351

Zeuthen, E., 3, 177, 181

Zollinger, H., 280

Zona pellucida, 82, 87-92, 119, 124

Zwilling, E., 212 





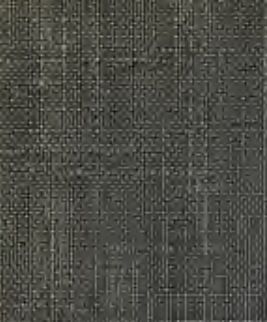

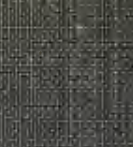

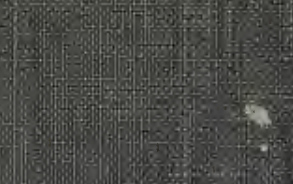

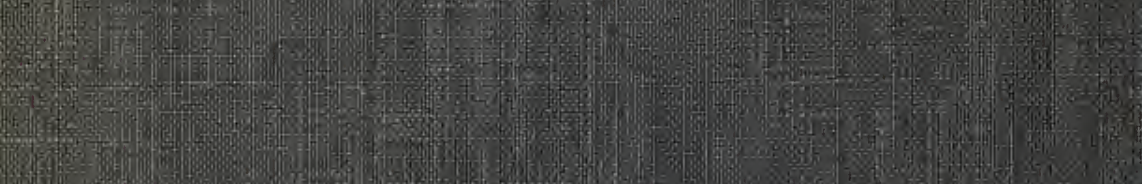

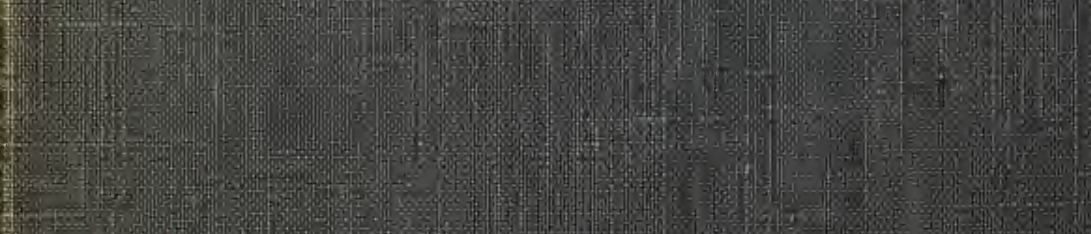

-

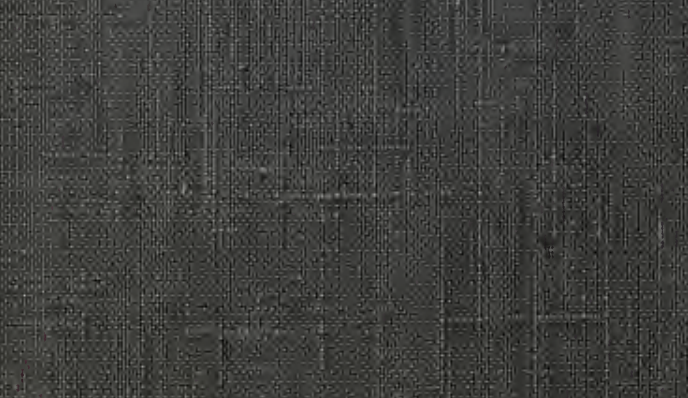

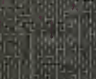

1)

$\frac{1}{4}+x$

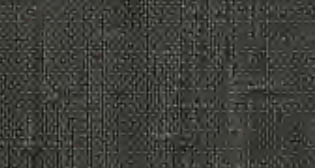

H.

- 13
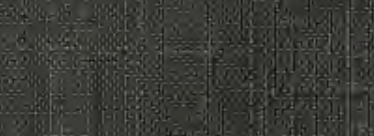

2.
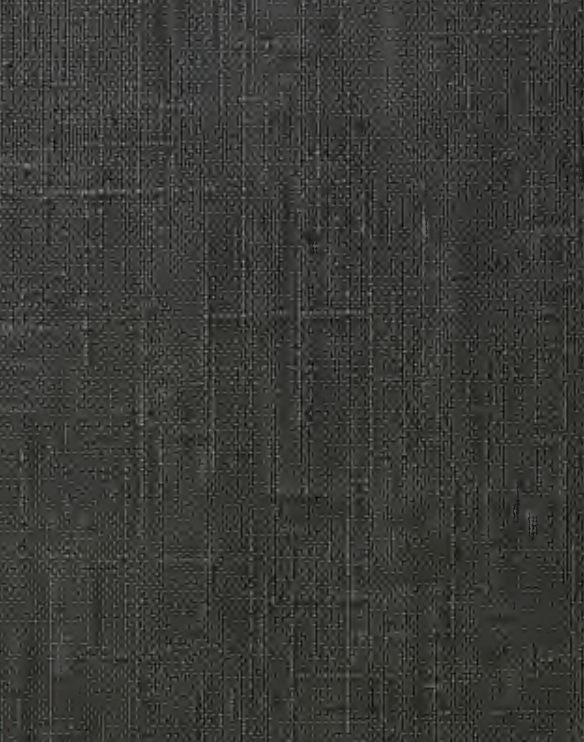

-5.

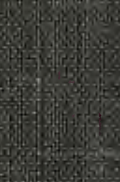

(5)

(x)
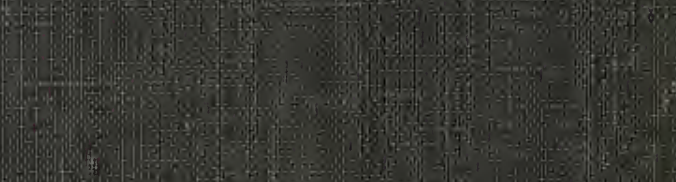

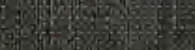

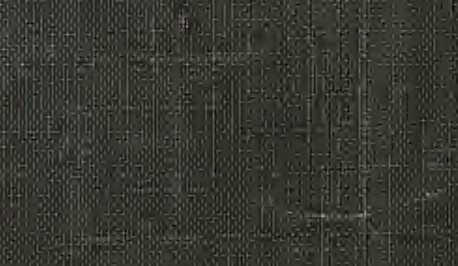

